Eötvös Loránd Tudományegyetem

Bölcsészettudományi Kar

Doctoral Dissertation

Anita Jóri

\title{
The Discourse Community of Electronic Dance Music
}

Doctoral School of Linguistics,

Dr. Gábor Tolcsvai Nagy, PhD, DSc, Head of the Doctoral School

Intercultural Linguistics Doctoral Programme,

Dr. Tamás Gecső, PhD, Associate Professor, Head of the Doctoral Programme

Members of the Committee:

Chairperson of the Committee: Dr. Mária Ladányi, PhD, DSc

Opponents: Dr. Ágnes Huszár, PhD, Dr. habil. and Dr. Zsuzsa Vladár, PhD, Dr. habil.

Other Members of the Committee: Dr. Tamás Gecsö, PhD, Associate Professor, Secretary of the Committee; Dr. Klára Falkné Bánó, PhD, Dr. habil.

Substitute Members of the Committee: Dr. Ágnes Albert, PhD, Dr. Ágnes Veszelszki, PhD

Supervisor: Dr. Csilla Ilona Dér, PhD

Budapest, 2016 


\section{ADATLAP \\ a doktori értekezés nyilvánosságra hozatalához}

\section{A doktori értekezés adatai}

A szerző neve: Jóri Anita

MTMT-azonosító: 10021253

A doktori értekezés címe és alcíme: The Discourse Community of Electronic Dance Music

DOI-azonosító: 10.15476/ELTE.2016.161

A doktori iskola neve: Nyelvtudományi Doktori Iskola

A doktori iskolán belüli doktori program neve: Interkulturális Nyelvészet Doktori Program

A témavezető neve és tudományos fokozata: Dr. Dér Csilla Ilona PhD, egyetemi docens

A témavezető munkahelye: Károli Gáspár Református Egyetem Bölcsészettudományi Kar

\section{Nyilatkozatok}

1. A doktori értekezés szerzőjeként

a) hozzájárulok, hogy a doktori fokozat megszerzését követően a doktori értekezésem és a tézisek nyilvánosságra kerüljenek az ELTE Digitális Intézményi Tudástárban. Felhatalmazom az ELTE BTK Doktori és Tudományszervezési Hivatal ügyintézőjét, Manhercz Mónikát, hogy az értekezést és a téziseket feltöltse az ELTE Digitális Intézményi Tudástárba, és ennek során kitöltse a feltöltéshez szükséges nyilatkozatokat.

b) kérem, hogy a mellékelt kérelemben részletezett szabadalmi, illetöleg oltalmi bejelentés közzétételéig a doktori értekezést ne bocsássák nyilvánosságra az Egyetemi Könyvtárban és az ELTE Digitális Intézményi Tudástárban;

c) kérem, hogy a nemzetbiztonsági okból minősített adatot tartalmazó doktori értekezést a minősítés (dátum)-ig tartó időtartama alatt ne bocsássák nyilvánosságra az Egyetemi Könyvtárban és az ELTE Digitális Intézményi Tudástárban;

d) kérem, hogy a mü kiadására vonatkozó mellékelt kiadó szerződésre tekintettel a doktori értekezést a könyv megjelenéséig ne bocsássák nyilvánosságra az Egyetemi Könyvtárban, és az ELTE Digitális Intézményi Tudástárban csak a könyv bibliográfiai adatait tegyék közzé. Ha a könyv a fokozatszerzést követőn egy évig nem jelenik meg, hozzájárulok, hogy a doktori értekezésem és a tézisek nyilvánosságra kerüljenek az Egyetemi Könyvtárban és az ELTE Digitális Intézményi Tudástárban.

2. A doktori értekezés szerzőjeként kijelentem, hogy

a) az ELTE Digitális Intézményi Tudástárba feltöltendő doktori értekezés és a tézisek saját eredeti, önálló szellemi munkám és legjobb tudomásom szerint nem sértem vele senki szerzői jogait;

b) a doktori értekezés és a tézisek nyomtatott változatai és az elektronikus adathordozón benyújtott tartalmak (szöveg és ábrák) mindenben megegyeznek. 
3. A doktori értekezés szerzőjeként hozzájárulok a doktori értekezés és a tézisek szövegének Plágiumkereső adatbázisba helyezéséhez és plágiumellenőrző vizsgálatok lefuttatásához.

Kelt: 2016. december 1.

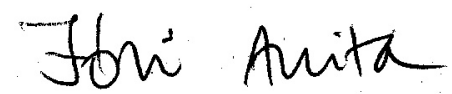

a doktori értekezés szerzőjének aláírása 


\section{TABLE OF CONTENTS}

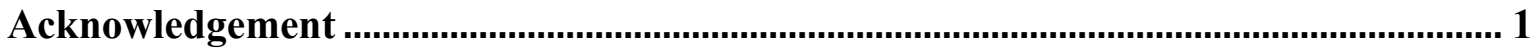

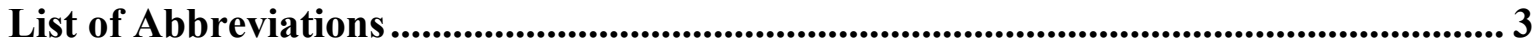

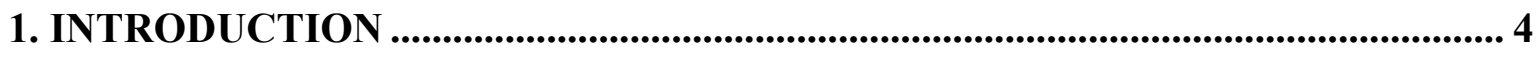

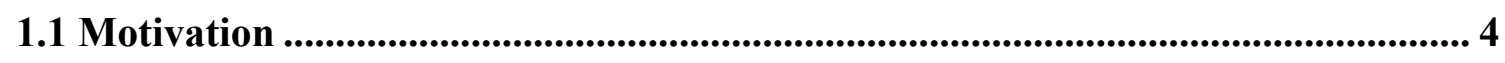

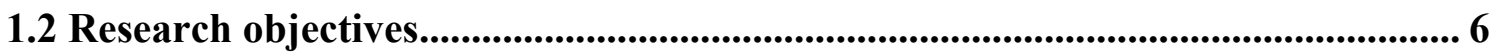

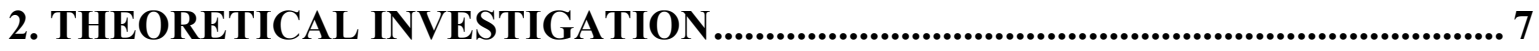

2.1 Introduction to the theoretical investigation .......................................................... 7

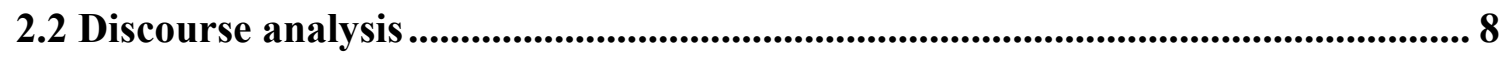

2.2.1 The notion of discourse and discourse categories ............................................ 8

2.2.2 'Discourse' and discourse analysis in social sciences

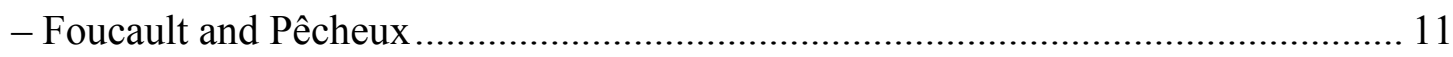

2.2.3 'Discourse' and discourse analysis (DA) in linguistics................................... 12

2.2.3.1 A short genealogy of the (applied) linguistic DA ..................................... 14

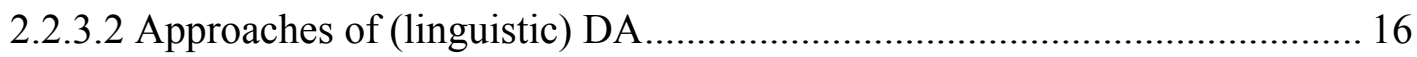

2.2.4 The main approach: Computer-Mediated Discourse Analysis (CMDA) ........... 17

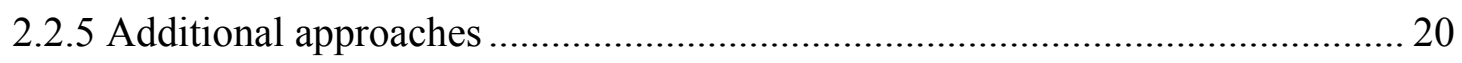

2.2.5.1 Multimodal Discourse Analysis (MMDA) ................................................ 20

2.2.5.2 Discourse Analysis and Corpus Linguistics:

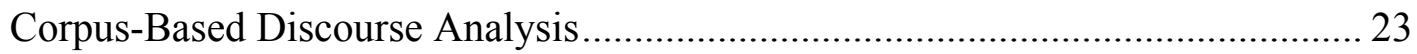

2.3 Discourse community (DC) ................................................................................................... 25

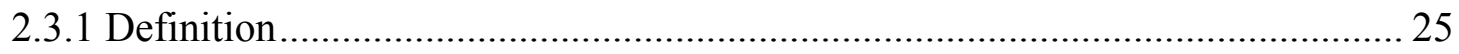

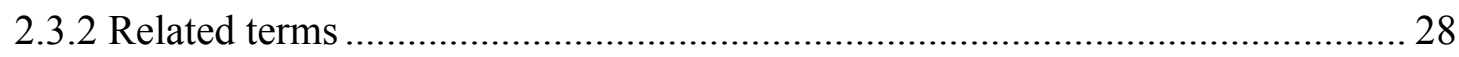

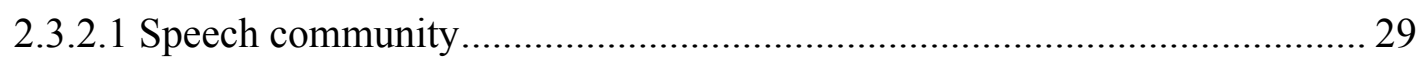

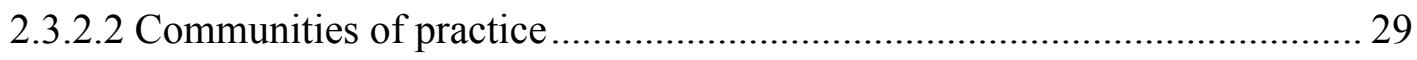

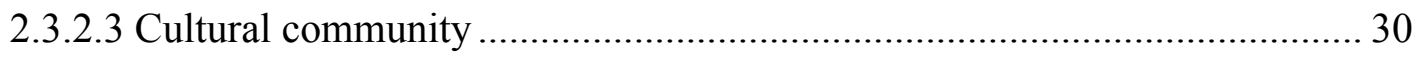

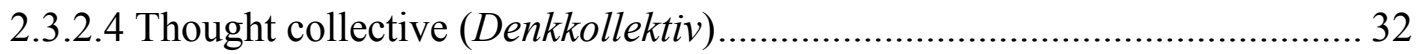

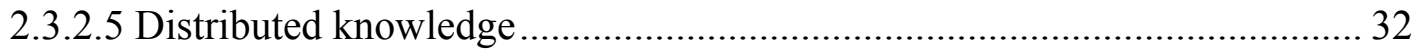

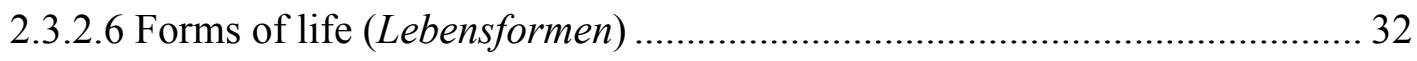

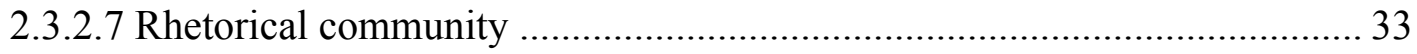


2.3.3 Discourse community feat. online/virtual community

$=$ online/virtual discourse community

2.4 Research on electronic dance music................................................................ 35

2.4.1 Struggle with definitions: electronic music vs. electronic dance music............. 35

2.4.2 A short history of electronic- and electronic dance music ............................... 38

2.4.2.1 The pre-history of electronic instruments ............................................... 38

2.4.2.2 The history of electronic music ............................................................... 39

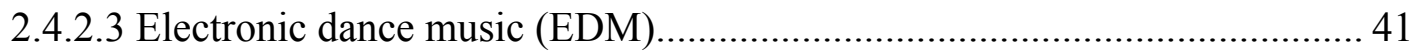

2.4.3 Research interests on Electronic Dance Music Cultures (EDMCs) .................. 44

2.4.3.1 Public health perspectives on Electronic Dance Music Cultures ................ 45

2.4.3.2 Cultural studies, youth-subcultural studies

(or post-subcultural studies), and youth studies................................................. 45

2.4.3.2.1 Cultural studies' research topics on EDMC(s) ......................... 47

2.4.3.2.2 Cultural studies' results on the rave era ................................. 47

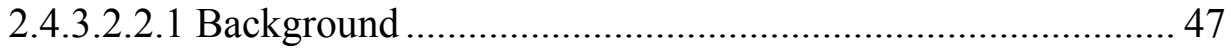

2.4.3.2.2.2 Research questions on the rave era .................................... 48

2.4.3.2.3 Cultural studies' results on club culture.................................... 50

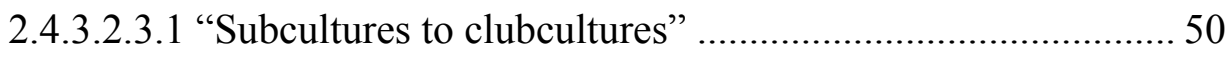

2.4.3.2.3.2 The model of scene ........................................................ 51

\subsection{Conceptualisation and characteristics of the discourse community}

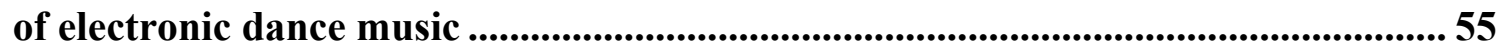

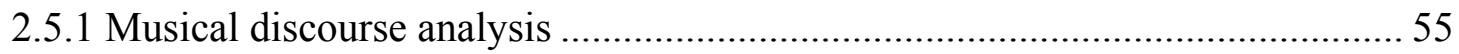

2.5.2 Parent discourse community, discourse communities

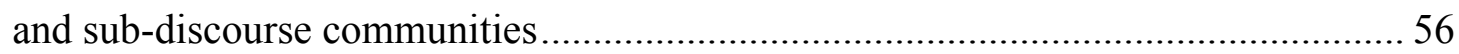

2.5.3 The discourse community of electronic dance music

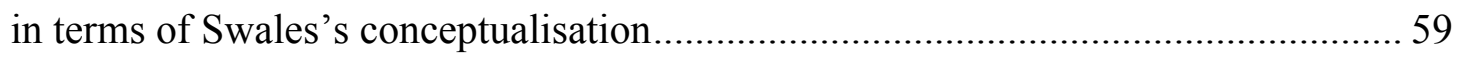

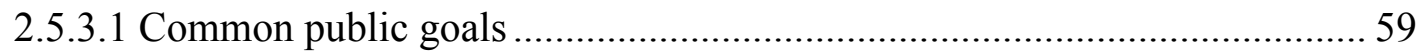

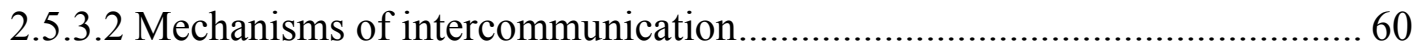

2.5.3.3 Mechanisms to provide information about electronic dance music ............ 61

2.5.3.4 Genres in the communicative furtherance ................................................ 61

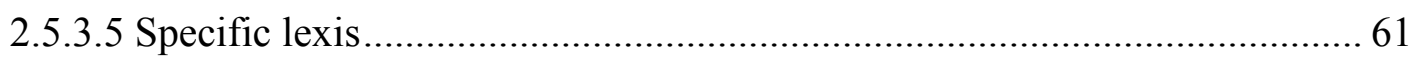

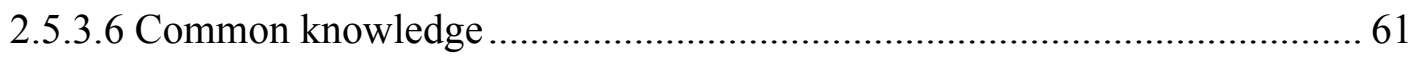

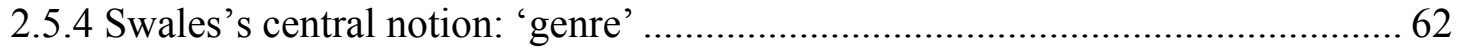

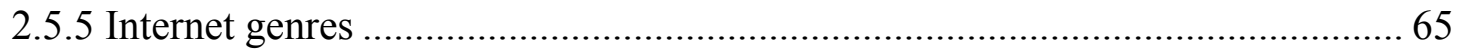


2.6 Questions of identity ....................................................................................................... 68

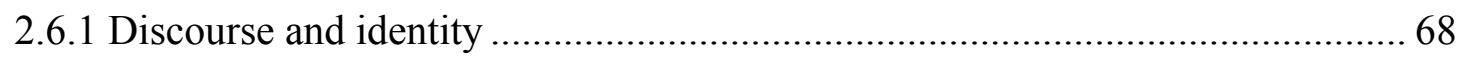

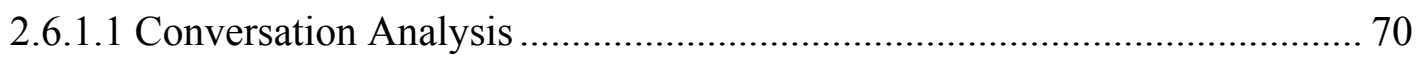

2.6.1.2 Membership Categorisation Analysis .......................................................... 71

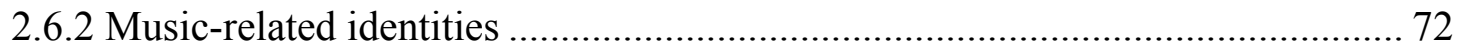

2.6.3 Music-related identities in discourse ............................................................... 73

3. RESEARCH QUESTIONS................................................................................................. 75

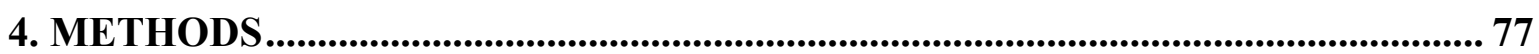

4.1 Main framework: Computer-mediated discourse analysis .................................... 77

4.2 Analytical methods on the four domains of language .............................................. 80

4.2.1 Structure and meaning .................................................................................... 80

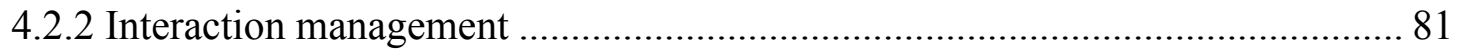

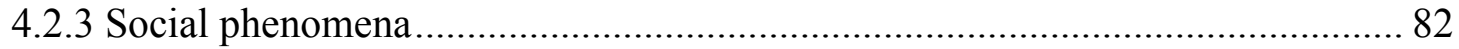

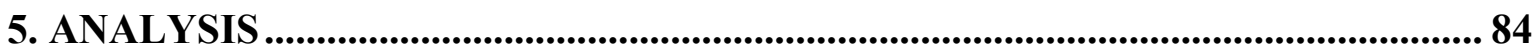

5.1 Foreword to the analysis ............................................................................................... 84

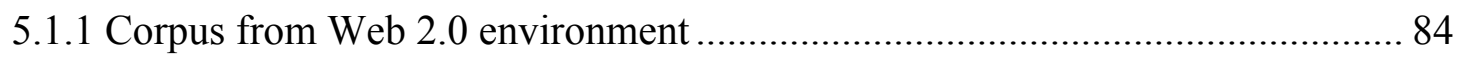

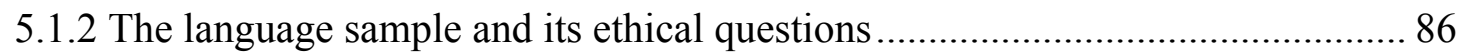

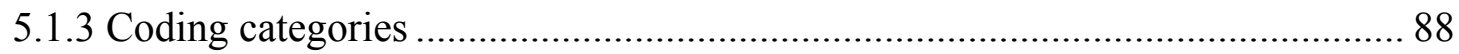

5.2 Linguistic analysis........................................................................................................ 89

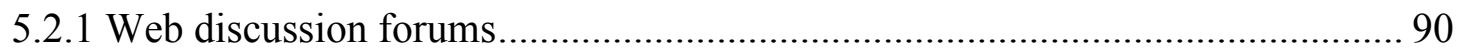

5.2.1.1 We Are The Music Makers Forum (WATMMF)........................................ 92

5.2.1.1.1 General details about WATMMF .......................................................... 92

5.2.1.1.2 WATMMF in the faceted classification scheme ..................................... 95

5.2.1.1.3 The language use of WATMMF ........................................................... 97

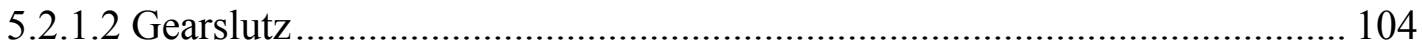

5.2.1.2.1 General details about Gearslutz.......................................................... 104

5.2.1.2.2 Gearslutz in the faceted classification scheme ..................................... 105

5.2.1.2.3 The language use of Gearslutz............................................................. 105

5.2.1.3 Summarising the web discussion forums ............................................... 110

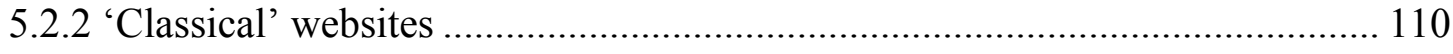

5.2.2.1 Vintage Synth Explorer ……………………………………………….. 111 
5.2.2.1.1 General details about Vintage Synth Explorer 111

5.2.2.1.2 Vintage Synth Explorer in the faceted classification scheme. 112

5.2.2.1.3 The language use of Vintage Synth Explorer. 113

5.2.2.2 Resident Advisor ..... 116

5.2.2.2.1 General details about Resident Advisor 116

5.2.2.2.2 Resident Advisor in the faceted classification scheme 117

5.2.2.2.3 The language use of Resident Advisor 117

5.2.2.3 Summarising 'classical' websites 121

5.2.3 Facebook Groups 122

5.2.3.1 TB-303 Owners Club 124

5.2.3.1.1 General details about the TB-303 Owners Club 124

5.2.3.1.2 The TB-303 Owners Club in the faceted classification scheme... 126

5.2.3.1.3 The language use of the TB-303 Owners Club 127

5.2.3.2 ITALO DISCO MANIACS 135

5.2.3.2.1 General details about ITALO DISCO MANIACS 135

5.2.3.2.2 ITALO DISCO MANIACS in the faceted classification scheme 136

5.2.3.2.3 The language use of ITALO DISCO MANIACS . 137

5.2.3.3 Summarising the analysed Facebook Groups..... 143

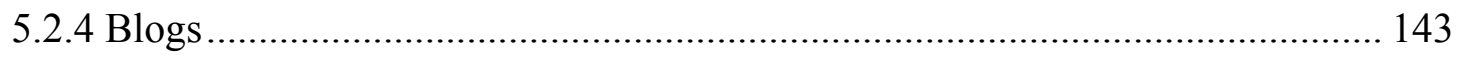

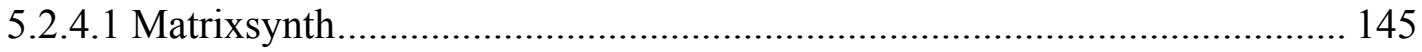

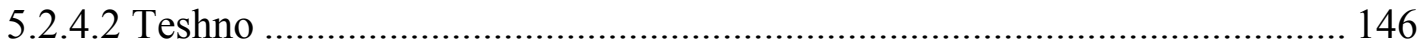

5.2.4.3 LWE: Little White Earbuds .................................................................. 147

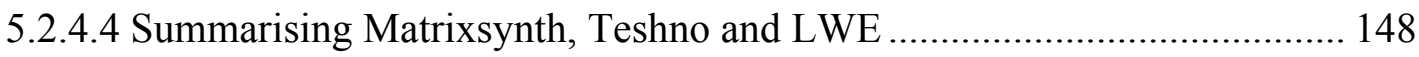

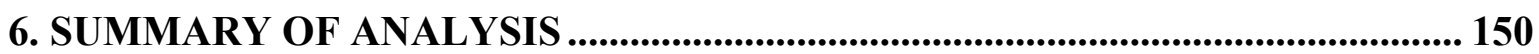

7. FINAL CONCLUSIONS AND FUTURE CONSIDERATIONS ........................... 154

7.1 A brief summary on the structure of the dissertation .......................................... 154

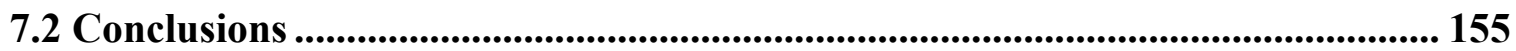

7.3 Importance of this research and new findings ....................................................... 156

7.4 Recommendations for future research .............................................................. 158

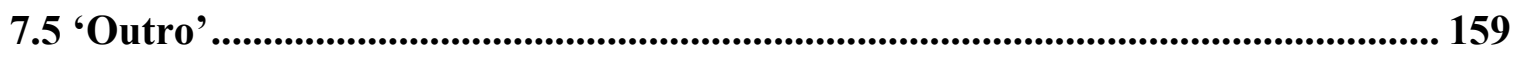

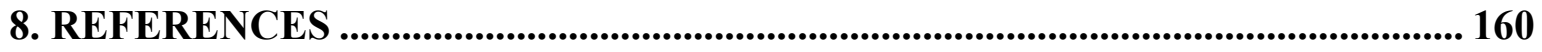


10. ATTACHMENTS

10.1 Attachment 1: Used coding categories of the analysis

- a general table 190

10.2 Attachment 2: Orientation of linguistic data in WATMMF. 190

10.3 Attachment 3: Linguistic data of Facebook Groups...................................... 191

10.3.1 TB-303 Owners Club ...................................................................................... 191

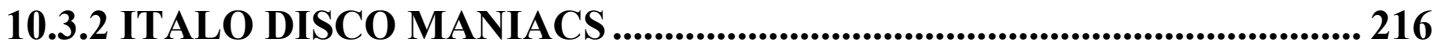

10.4 Attachment 4: The language samples in Herring's faceted classification scheme 300

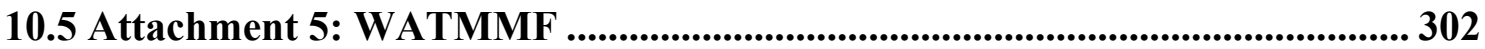

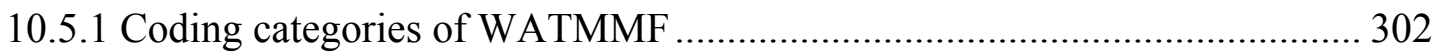

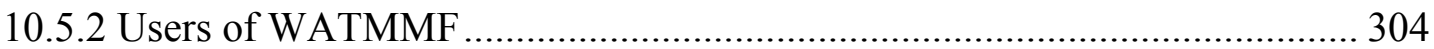

10.6 Attachment 6: Gearslutz ................................................................................... 307

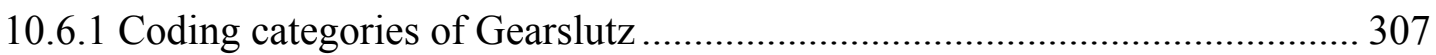

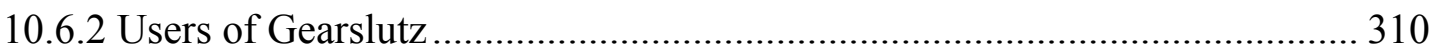

10.7 Attachment 7: Coding categories of Vintage Synth Explorer ........................... 313

10.8 Attachment 8: Coding categories of Resident Advisor ...................................... 316

10.9 Attachment 9: Coding categories of TB-303 Owners Club.............................. 319

10.10 Attachment 10: Coding categories of ITALO DISCO MANIACS .............. 322 


\section{Acknowledgement}

I would like to express my appreciation of those who helped me along my way to become a $\mathrm{PhD}$ candidate since 2010 .

First of all, my deepest gratitude goes to my supervisor, Dr. Csilla Ilona Dér, whose expertise, generous guidance and support made it possible for me to work on this research topic. It was a great pleasure working with her.

I acknowledge the support of Dr. Ágnes Huszár, Dr. Zsuzsa Vladár and Dr. Tamás Gecső who provided invaluable assistance during the development of this dissertation.

I also express my gratitude to my boyfriend, Daniel Irrgang. Without his generous help and continuous feedback, the dissertation would have never reached its present format.

It would not have been possible without my great artist, musician and researcher friends, Annie Goh, Mari Matsutoya, Brian May and Éva Péter, who helped my text to develop with their stylistic suggestions.

I am highly indebted to Prof. Dr. Siegfried Zielinski for giving me the opportunity to teach at the Berlin University of the Arts. The students of my seminar entitled "Visual and Artefact Analysis through the Example of Electronic Music" ensured me an active academic dialogue, which was important in the development of this dissertation.

My thanks and appreciations also go to my former boss at the Macromedia University of Applied Sciences, Prof. Dr. Martin Lücke, who gave me the possibility to organise two panel discussions on the topic of electronic dance music (see more about them in Chapter 1) that also gave important insights to my research.

I would like to express my gratitude towards Prof. Dr. Holger Schulze who applied me to be the part of the research team 'Sound Studies Lab' at the Humboldt University of Berlin.

Moreover, I acknowledge the support of the "Gesellschaft für Musikwirtschaftsund Musikkulturforschung" (GMM), especially for their Summer Institute in Porto (Portugal), where I took part in 2015. The participants there, including Prof. Dr. Carsten Winter and Lorenz Grünewald, gave me important feedback on my work. 
Furthermore, many thanks to my musician friends who always supported me with their insider hint. To mention some of them: Zoltán Balla aka Galactic Jackson, Andy Jenkinson aka Ceephax Acid Crew, Szilvia Lednitzky aka Lower Order Ethics and Martin Maischein aka Goner.

Last but not least, I would like to thank to everyone who supported me mentally along this way: my dear family and all of my friends.

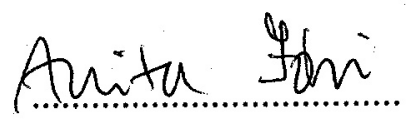

Anita Jóri

Berlin, 20th November 2016 


\section{List of Abbreviations}

CA - Conversation Analysis

CMC - Computer-Mediated Communication

CMCMC - Convergent Media Computer-Mediated Communication

CMD - Computer-Mediated Discourse

CMDA - Computer-Mediated Discourse Analysis

DA - Discourse Analysis

DC - Discourse Community

EDM - Electronic Dance Music

EDMC(s) - Electronic Dance Music Culture(s)

GA - Genre Analysis

IDM - Intelligent Dance Music

LWE - Little White Earbuds

MCA - Membership Categorisation Analysis

MCD - Membership Categorisation Device

MMDA - Multimodal Discourse Analysis

RA - Resident Advisor

SIT - Social Identity Theory

VS - Variationist Sociolinguistics

VSE - Vintage Synth Explorer

WATMM - We Are The Music Makers

WATMMF - We Are The Music Makers Forum 


\section{INTRODUCTION}

\subsection{Motivation}

Electronic dance music has a highly diverse profile in terms of its aesthetics and audiences. Research on its communities has been initiated by scholars in the fields of sociology, cultural studies, public health research, gender studies, and so forth. However, research on the actual language use of the related communities is surprisingly uncommon.

Our observations and aims attempt to fill this gap and suggest a new perspective by looking at the communities of electronic dance music as a discourse community. The 'parent' ${ }^{1}$ discourse community of electronic dance music is just as complex and diverse as the metagenre of electronic dance music itself. With the help of the different methods and approaches of discourse analysis, we are able to analyse the discourse behaviours of the members of the discourse community with regards to community and identity constructions.

The author of this study has a clear personal interest in doing research on such communities, as she has been a member of them as an active musical event visitor as well as an event organiser and lecturer for years. Her main musical interest lies with the following genres: Intelligent Dance Music, braindance, experimental electronica, acid house, industrial techno, Italo disco, neo-classical, and ambient - this interest can be also detected in the selection of the analysed linguistic data. She has organised various electronic dance music-related events in Budapest and podium discussions in Berlin. (The latter dealt with the topics of Berlin's electronic dance music scene ${ }^{2}$ and its genderrelated problems ${ }^{3}$.) Therefore, she is in the position of being an active member of these communities as an applied linguist with a high interest in phenomena related to discourse and music.

\footnotetext{
${ }^{1}$ See more in Chapter 2.5.2.

${ }^{2}$ See more in The survival of electronic, 2015.

${ }^{3}$ See more in Polarity Shift, 2016.
} 
Figure 1 and Figure 2: Panel discussion 'Polarity Shift, Women in Electronic Music', Berghain Kantine, Berlin, October 11, 2015. Photo: Pablo Ruiz Holst
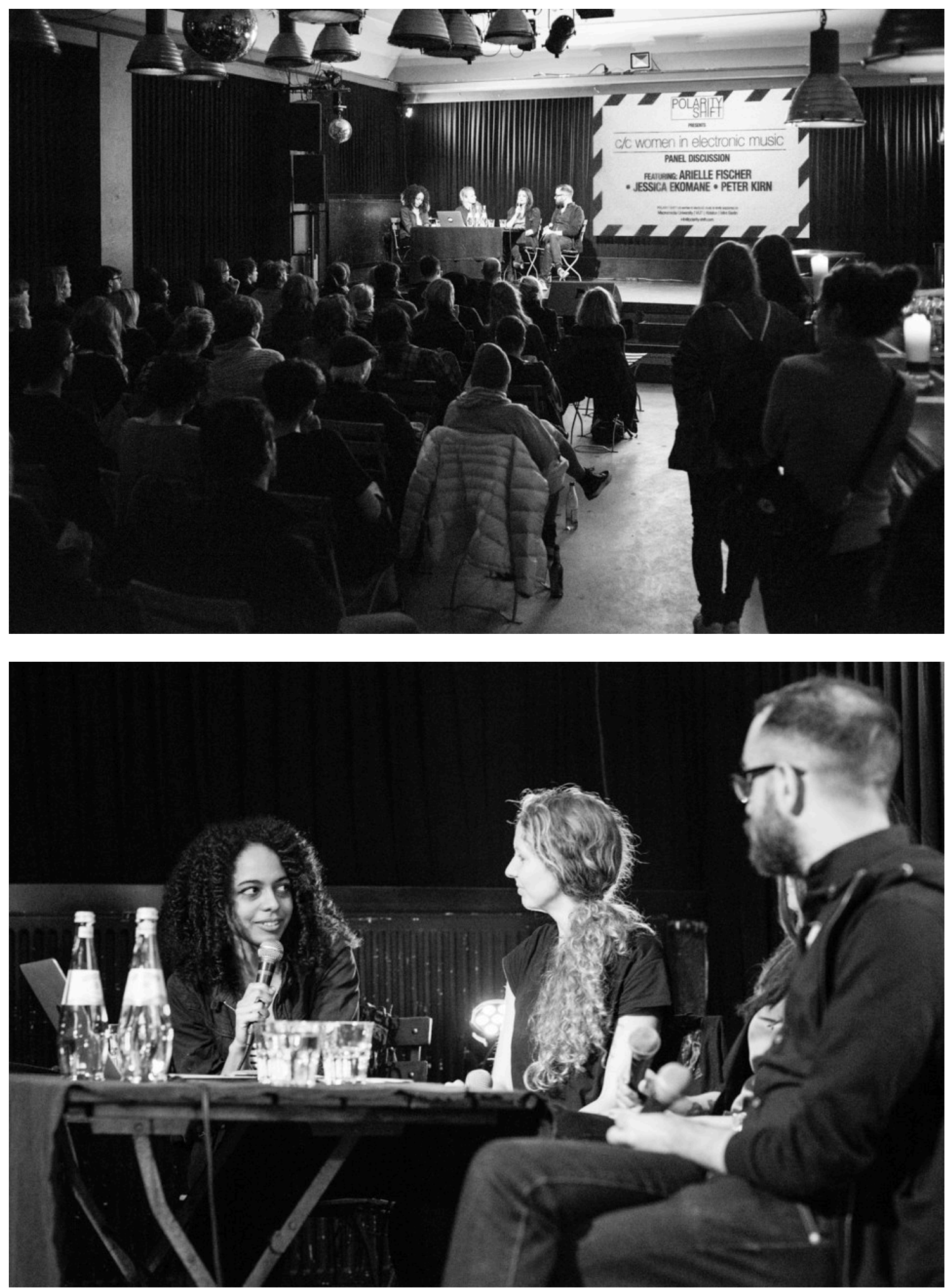


\subsection{Research objectives and questions}

The present study takes further considerations on John M. Swales's (1990) model of discourse community, by focussing on the importance of the processes of identity and community constructions. Therefore, after a broad theoretical investigation, it analyses different language samples from the discourse community of electronic dance music.

The discourse community in question has many specific characteristics in terms of language use, such as the high rate of technical terms, the often-used metaphors and metaphoric expressions, or the importance of expressing one's own ideas (see more in Chapter 5). These features are all important - and almost hidden - signifiers and 'helpers' of the community and (social) identity constructions within smaller communities.

Therefore, the main aim of this study is to answer the following research question: What are the discourse characteristics of the discourse community of EDM?

To answer this question, linguistic data - analysed in Chapter 5 - were collected from different Internet platforms dealing with the questions of electronic dance music, such as the web discussion forums 'We are the Music Makers Forum' and 'Gearslutz', the Facebook Groups 'TB-303 Owners Club' and 'ITALO DISCO MANIACS', the 'classical' websites 'Vintage Synth Explorer' and 'Resident Advisor', and the blogs 'Matrixsynth', 'Little White Earbuds', and 'Teshno'. 


\section{THEORETICAL INVESTIGATION}

\subsection{Introduction to the theoretical investigation}

Due to the complexity of the present study, it is necessary to establish its broad theoretical background.

The study is a highly interdisciplinary investigation; it involves research results from the fields of applied linguistics, cultural studies, musicology, and music history. Therefore, it highlights some important perspectives of these fields in depth in order to provide a better understanding of its complexity. The structure of this chapter will follow this sequence:

Chapter 2.2 summarises the broad spectrum of discourse analysis by focussing on its applied linguistic approaches, which were taken into account in this study: computermediated discourse analysis, multimodal discourse analysis and corpus-based discourse analysis.

Chapter 2.3 introduces different scholars' perspectives (but mainly focussing on Swales's [1990] work) and definitions of discourse community and its related terms such as speech community, communities of practice, cultural community, thought collective (Denkkollektiv), distributed knowledge, forms of life (Lebensformen), and rhetorical community. Finally, the last section focuses on virtual/online discourse communities.

Chapter 2.4 summarises, on the one hand, the history of electronic music and electronic dance music, on the other, the results of public health research and cultural studies research on the topic of electronic dance music.

Based on the aforementioned three subchapters, Chapter 2.5 conceptualises the working definition of the discourse community of electronic dance music.

Finally, Chapter 2.6 gives an overview on the relationship of discourse, music (with a focus on electronic dance music) and identity. 


\subsection{Discourse analysis}

\subsubsection{The notion of discourse and discourse categories}

The term 'discourse' has taken various and very broad meanings, as it has been employed across various disciplines (philosophy, linguistics, anthropology, cultural and media studies, etc.).

Originally the word 'discourse' comes from the Latin discursus, which denotes 'conversation' or 'speech'. To give a comprehensive definition on 'discourse' from a linguistic point of view, we can turn to Cook's (2011) summary: “Discourse can be defined as a stretch of language in use, of any length and in any mode, which achieves meaning and coherence for those involved." (p. 431) Or we find the following definition from Crystal (1992): "Discourse: a continuous stretch of (especially spoken) language larger than a sentence, often constituting a coherent unit such as a sermon, argument, joke, or narrative.” (p. 25) From his definition, we can see that the boundaries are very wide and the term of discourse can include many different phenomena.

Cook's (2011) and Crystal's (1992) definitions on discourse are very close to each other - 'stretch of language' and 'coherent' - but Cook's (2011) version is more precise in terms of length of discourse. $\mathrm{We}^{4}$ agree with him and other scholars (Bowie, 2010, among others) who see discourse as a sequenced communicative event that can also take the form of a single word. On the other hand, Crystal (1992) gives a 'classical' definition to discourse and writes about exact frames for the length of discourse with 'larger than a sentence'.

The terms 'text' and 'discourse' are often mixed up and used with similar meanings, but it is necessary to separate their contents from each other. Brown and Yule (1983) state that text refers to the "verbal record of communicative act" (p. 6). Therefore, text is a result or product of the discourse process (Boronkai, 2009).

One might think that it is easier to get closer to the definition of discourse if we try to define the types of discourse. However, we have to consider that the classifications of discourse are just as vague as the definitions of discourse.

Renkema (2004) distinguishes three approaches in the categorisation of discourse: 1) when the "typology is based on the relation between the discourse situation and

\footnotetext{
${ }^{4}$ Despite the use of the 'authorial we', this thesis is the sole work of its author.
} 
general discourse characteristics" (p. 61); 2) when "abstract forms are the basis for distinguishing general discourse types to which different kinds of discourse can be assigned" (p. 61); and finally 3) when "specific lexical and syntactic characteristics are related to communicative functions" (p. 61).

For the first approach an example could be the work of Steger, Deutrich, Schank, and Schütz (1974, cited in Renkema, 2004) who created the classification of oral discourse. They distinguish between six discourse situations with six distinctive discourse types: 1. presentation; 2. message; 3. report; 4. public debate; 5. conversation; and 6. interview. They also divide oral discourses into the types of monologue and dialogue.

For the second approach, Renkema (2004) mentions Egon Werlich's (1982, cited in Renkema, 2004) discourse typology. His model takes five forms that are fundamental to discourse types: 1 . descriptive; 2. narrative; 3. explanatory; 4. argumentative; and 5. instructive.

Finally, for the third approach, Renkema (2004) examines Biber's (1988) typology. Biber (1988) distinguishes five sets of lexical and grammatical features. 1. "involved vs. informational production"; 2. "narrative vs. non-narrative concerns"; 3. "elaborated vs. situation-dependent reference"; 4. "overt expression of persuasion"; and 5. “abstract vs. non-abstract style” (Biber, 1988, cited in Renkema, 2004, p. 63).

Fundamentally, we can divide 1) written and 2) spoken discourses from each other. The obvious difference between them is the fact that writing is a cultural technique using a material medium to keep record of the conveyed message while speech takes only air (as a carrier of sound waves). Apart from that, there are certain dissimilarities that are less apparent, but due to the topic of the present thesis, it is unnecessary to list all of them here. However, this great divide between speech and writing has been questioned ${ }^{5}$ due to the communication in contemporary virtual environments. The language, for instance, that the users of blogs, Internet forums, social networks, chats, etc. use has the features of both types: written and spoken language. The actual form of it is written, but many stylistic features belong more to the spoken language. Crystal (2001), for instance, names this language as 'netspeak' (p. 48) that is neither written, nor spoken language, but a third form: somehow between the two. In the German literature, we would find, for example,

\footnotetext{
${ }^{5}$ See more, for example, in Halliay's (1989) early work "Spoken and Written Language” or Kress's (1998) later article "Visual and verbal modes of representation in electronically mediated communication: the potentials of new forms of text".
} 
'neue Schriftlichkeit' (Haase, 1997) or 'vermündlichte Schriftlichkeit' (Schmidt, 2000) for this form; or in the Hungarian literature, Bódi (2004) writes about 'írott beszélt nyelv' ('written spoken language' - translated by the author of this study) or Veszelszki (2013) about 'digilektus' ${ }^{6}$. Moreover, those platform users can apply multimodal tools to express their thoughts (e.g. videos, pictures, GIFs, etc.) that give multimodal characteristics to their texts. In this sense, of course, 'text' does not mean the classical written text anymore, but it is a much more opened category with a lot of different modes involved (see more in Chapter 2.2.5.1).

Beside spoken and written discourses, we can distinguish between formal and informal discourse types as well. Formal discourses are planned and can be written or spoken; informal discourses are unplanned and can be written or spoken, but it is usually associated with speech (Cook, 1989). Moreover, we can also divide discourse types by activity types: for example, job interviews, meetings at workplaces, etc.

Finally, it should be noted that already Aristotle divided two types of discourses in his "Rhetoric": 1) dialectic (philosophy) and 2) rhetoric (public) discourses. For him, the dialectic discourse has a superior status over the rhetoric. In philosophy discourse, the audience is participatory, but in public discourse it is a passive mass audience (Porter, 1992). Later, the positive connotation of the dialogic discourse, as opposed to the oneway (mass) communication, became important in philosophy of dialogue ${ }^{7}$ and (critical) communication studies ${ }^{8}$.

As we can see, there are many different ways of how discourse can be categorised, but to get back to the definition of discourse, it is important to remark that, as Cameron and Panović (2014) summarises, there are three basic notions on discourse: 1) discourse as language above the level of sentence that is extended chunks of text (or with other words, discourse as connected text);2) discourse as language in use; and 3) discourse as social practice. The main difference between these three viewpoints lies in between the perspectives of linguistics and social sciences: the first concept - discourse as connected text - was clearly developed in linguistics, the third one - discourse as social practice - in social sciences ${ }^{9}$. The second concept - discourse as language in use comes from linguistics, but it was highly influenced by the perspectives of social

\footnotetext{
${ }^{6}$ We can find many other terms on this phenomenon from different scholars. See more in Veszelszki, 2016.

${ }^{7}$ E.g. Buber, 1970 or Habermas, 1981.

${ }^{8}$ E.g. Enzensberger, 1970 or Flusser, 1996.

${ }^{9}$ It does not mean, of course, that these concepts had been developed completely separately from each other. They have many considerations in common.
} 
sciences.

Based on these different notions on discourse, different approaches to discourse analysis have emerged in social sciences and linguistics. The next chapters take a closer look at the differences between the positions of linguistics and social sciences on the notion of discourse and discourse analysis approaches. They will focus more on the linguistic perspective as this stands in the centre of this research.

\subsection{2 'Discourse' and discourse analysis in social sciences - Foucault and Pêcheux}

In this section, the aforementioned third definition of discourse - discourse as social practice - is explained briefly.

This formulation of discourse dates back to the 1960s, when changes occurred in the conceptualisation of how meaning is constructed through the social use of language. This new angle challenged Saussure's definition of langue and generally the structuralist concept of 'language' (Koteyko, 2006).

In social sciences - based on the abovementioned definition of discourse -, two divergent traditions developed in discourse analysis: 1) the European tradition; and 2) the Anglo-American tradition.

The European tradition is based on Michel Foucault's approach to discourse. The most important key concepts of his philosophical or 'genealogical' approach to discourse defined in his work "Archaeology of Knowledge. And the Discourse on Language" (original French version 1969, English translation by A. M. Sheridan Smith, 1972). Foucault conceptualises discourse as systems of thoughts that are historically determined. Furthermore, it is also important to highlight that he talks about discursive practices.

For him, power was linked to the formation of discourse within specific historical periods; therefore, he also defined discourse as a 'medium' through which these power relations produce speaking subjects. In his other milestone work, "The Order of Things: An Archaeology of the Human Sciences" (1970) (original French version 1966, English, 1970), he argued that power and knowledge ('episteme') are interrelated, because the conditions of discourse have changed from one period's own 'episteme' to another. The structures of power are, according to Foucault, determined and processed through 'dispositifs' (sometimes translated as 'apparatuses') which are meta-structures 
'consisting' of discourses, materialisations of power (e.g. institutions, organisations, technology), and effects of subjectification.

Therefore, the so-called 'Foucauldian discourse analysis', tries to understand how our society is being shaped or constructed by language. It examines and reflects on existing power relations, and how these formations are historically determined.

According to Foucault, discourse is inseparable from ideology which also indicates that meaning is always ideological. Therefore, the Foucauldian discourse analysis is often used in politically oriented studies in social science, philosophy, and historical approaches (see more about this approach in Arribas-Ayllon \& Walkerdine, 2008 and Kendall \& Wickham, 1999). For example, in Germany, this discourse analysis method has been applied in critical traditions of social science and in the upcoming German media theory, particularly in its sub-discipline 'media archaeology'10.

In contrast, in the Anglo-American tradition, the analysis is carried on within a dualistic framework of the linguistic analysis and a political dimension (Koteyko, 2006). The best example for that could be the approach of Critical Discourse Analysis that is based on the French theorist Michel Pêcheux's (1982) work “Language, Semantics and Ideology". He observes discourse as an intermediate link between language and ideology, clarifying the links between the 'obviousness of meaning' and 'the obviousness of the subject' (Pêcheux, 1982, p. 55, cited in Koteyko, 2006).

These traditions, of course, shaped and influenced the linguistic discourse analysis approaches; therefore, it is important to mention them, although the present study undertakes a discourse analysis from a linguistic point of view.

\subsection{3 'Discourse' and discourse analysis (DA) in linguistics}

The aim of this subchapter is to highlight the most important research findings of the linguistic discourse analysis. This summary, of course, cannot be comprehensive, since the field of discourse analysis is too wide, but we will try to list here all results which are

\footnotetext{
${ }^{10}$ Central protagonists for the development of discourse analysis as a defined research field in German social science are, among others, Siegfried Jäger (1999), who published an introductory standard work, "Kritische Diskursanalyse. Eine Einführung" and Jürgen Link, editor-in-chief of the political magazine, kultuRRevolution, an important platform for critical discourse analysis. Later, Link (1997) developed the Foucauldian concepts of discourse and dispositif to a general theory of processes of 'normalisation' in society. In German media theory and media archaeology, this discourse analysis was also used as a method to analyse the interdependent effects between media artefacts or systems and culture, often as historical perspectives. Here, early works were done by Friedrich A. Kittler (1985), Siegfried Zielinski (1985), or Knut Hickethier (1998).
} 
crucial for the present study.

In linguistics, the meaning of discourse has developed in two sub-disciplines: conversation analysis ${ }^{11}$ and the analysis of written text (text analysis).

The 'clear' linguistic definition of discourse - discourse as language above the sentence - goes back to the traditional aim of linguistics: to describe and explain the way language works as a system (Cameron \& Panović, 2014).

The scholars who follow the other linguistic concept of discourse - discourse as language in use - bring their interest to the following questions: "Who is using the language?" and "What purposes it is serving for its users in a particular context?"12 (Cameron \& Panović, 2014, p. 6).

As Cook (2011) summarises: "Discourse analysis can be defined as the use and development of theories and methods which elucidate how this meaning and coherence is achieved.” (p. 431) He also adds that discourse analysis (henceforth DA) (also named as 'discourse studies', e.g. in Angemuller et al., 2014; Renkema, 2004; or van Dijk, 1997) concerns all elements and processes that contribute to communication.

Two problems in terms of DA have to be mentioned here. First, 'discourse analysis' - just as the term 'discourse' - is very variously defined and often loosely used. Second, due to the interdisciplinarity of DA, it is very difficult to divide it from other applied linguistic fields: it is closely connected to psycholinguistics, sociolinguistics, pragmatics and semiotics. This means that if we use DA methods for our research, we have to pay attention to those fields as well. The most problematic perspective of DA is that a pure version of it simply does not exist. With other words, DA does not have only one approach that could be used for different research, but it has many different approaches, methods, and viewpoints.

The main importance of DA lies in the fact that it tries to bring attention to the phenomena that through speaking and writing, we give certain meanings to 'our' world: it is somehow shaped, produced, and at the same time reproduced through language in

\footnotetext{
${ }^{11}$ Conversation analysis studies social interactions in everyday life situations. It has developed from Harold Garfinkel's ethnomethodology and Erving Goffman's conception of the interaction order. In the late 1960s and early 1970s, its theoretical basics were established by the sociolinguists Harvey Sacks, Emanuel Schegloff, and Gail Jefferson (Iványi, 2001).

${ }^{12}$ Here we should highlight the importance of context.
} 
use $^{13}$.

We can find many summaries on DA in the literature (the most recent ones: Angemuller et al., 2014; Bhatia et al., 2008; Gee, 1999; Gee \& Handford, 2012b; Johnstone, 2002; Paltridge, 2006; Widdowson, 2007). As Hammersley (2002) points out, the main difference between them lies in 1) "their focus of research"; 2) in "what sorts of knowledge claim they aim to make"; and 3) in the "kinds of technique they deploy" (p. 2).

We could differentiate between these theories, techniques, and analyses in many other ways too, but this list would be far too long and in terms of the present dissertation it is not necessary to mention all of them. The thesis includes some of the differences in the next chapter about the genealogy of the (applied) linguistic DA.

\subsubsection{A short genealogy of the (applied) linguistic DA}

DA was understood as language analysis beyond the level of single sentences in the 1950s (Cook, 2011). Harris's (1952) early article "Discourse Analysis" was highly influential on the development of the field. In that, he pointed out two important questions: "One can approach discourse analysis from two types of problem, which turn out to be related. The first is the problem of continuing descriptive linguistics beyond the limits of a single sentence at a time. The other is the question of correlating 'culture' and language (i.e. non-linguistic and linguistic behavior).” (Harris, 1952, p. 1)

The 1970s and 1980s saw a number of major works on applied linguistic DA. To mention the most important works from these fruitful decades: 1) Widdowson's (1973) unpublished Ph.D. thesis "An Applied Linguistic Approach to Discourse Analysis"; 2) Sinclair and Coulthard's (1975) work on classroom discourse "Towards an Analysis of Discourse: The English used by Teachers and Pupils" that brings its analysis above the level of the sentence; 3) Coulthard's (1977) general introduction "Introduction to Discourse Analysis"; 4) Brown and Yule's (1983) extensive summary "Discourse Analysis" that gives an overview on the different approaches to discourse; and 5) Stubbs's (1983) sociolinguistic work “Discourse Analysis. The Sociolinguistic Analysis

\footnotetext{
${ }^{13}$ Gee and Handford (2012a) also summarise the faiths of discourse analysts: "We, discourse analysts, want to expose to light the often taken-for-granted workings of discourse, because, like in the study of atoms, cells, and stars, there is here a great wealth scientific knowledge to be gained. But there is also to be gained in how to make the world a better and more human place.” (p. 5)
} 
of Natural Language”.

We also have to mention two works on text analysis from these years that played important roles in the genealogy of DA: van Dijk's (1977) “Text and Context" and the "Introduction to Text Linguistics" by de Beaugrande and Dressler (1981). Van Dijk's (1977) early work explores basic issues in the semantics of discourse and it analyses discourse as sequences of speech acts. On the other hand, Beaugrande and Dressler's (1981) volume defines a text as a communicative occurrence that has to meet the seven standards of textuality: cohesion, coherence, intentionality, acceptability, informativity, situationality and intertextuality (Cook, 2011).

Due to the dominant concern of language teaching and learning in applied linguistics in the 1980s and early 1990s, many works in DA were born with focussing on such topics. Here, good examples can be "Discourse and Learning" edited by Riley (1985); Cook's (1989) "Discourse" that was published in the series "Language Teaching: A Scheme for Teacher Education” of Oxford University Press; McCarthy's (1991) "Discourse Analysis for Language Teachers"; or a later volume "Discourse and Language Education" by Hatch (1992). On this research field, DA played an important role in developing the communicative and the task-based language teaching.

To understand the context of discourses better, DA turned to other traditions. One of these traditions is pragmatics. Pragmatics is interested in "how discourse is structured by what speakers are trying to do with their words, and how their intentions are recognised by their interlocutors" (Cook, 2011, p. 434). Pragmatics' approaches to discourse have grown out of philosophy: The speech act theory was formulated by the philosopher John L. Austin ("How To Do Things with Words", 1962) and later developed by John Searle ("Speech Acts: An Essay in the Philosophy of Language", 1969). Here, we also have to mention Grice's (1975) cooperative and politeness principles in his text "Logic and conversation", which is often used in DA. However, as Cook (2011) puts, one also has to mention the limitations of classical pragmatics: these early theories dealt only with brief invented examples without reference to many significant aspects of context.

DA has been influenced by some philosophers too. Hoenisch (1998) states that DA was highly influenced by Wittgenstein's (1958) work "Philosophical Investigations", mainly because for him, "meaning of a word is its use in the language" (Wittgenstein, 1958, §43, cited in Hoenisch, 1998). Another important key figure has to be mentioned 
here is the Russian philosopher and literary critic Mikhail Bakhtin. The approach of 'dialogical discourse analysis' is based on his concept of 'dialogism', formulated in his literary theory “The Dialogic Imagination” (Bakhtin, 1981).

We also have to add two important sociolinguists to this list: John Gumperz and Dell Hymes. Hymes's (1974) depiction of communicative competence as involving social and psychological factors beyond what is linguistically possible also had a huge impact on DA. Gumperz's (1982) interactional sociolinguistics played an important role in this development. It analyses variations in discourse within a speech community based on Hymes's theories - and studies how these variations affect the unfolding of meaning in interactions and how they correlate with the social order of the community (Mesthrie, 2011).

At this point, we will briefly discuss cultural studies' perspectives on discourse analysis as well. Cultural studies have added the emphasis to the classical text analysis that textual analysis needs to be context sensitive. In addition, cultural studies scholars also brought attention to the fact that many contemporary media products are characterised by a postmodern logic.

\subsubsection{Approaches of (linguistic) DA}

Some forms of DA are closely tied to linguistics and try to bring their claims to facts about grammars and the way different grammatical structures function. Some of them are more interested in description and explanation. Others are interested in tying language to politically, socially, or culturally contentious issues (Gee \& Handford, 2012a).

Here is a short list of approaches to DA: Computer-Mediated Discourse Analysis, Conversation Analysis, Corpus-Based Discourse Analysis, Critical Discourse Analysis, Discourse-oriented Ethnography, Gender Linguistic Approach to Discourse Analysis, Mediated Discourse Analysis, Multilingual Discourse Analysis, Multimodal Discourse Analysis, Narrative Analysis, Systemic Functional Linguistic Discourse Analysis, etc.

The list would be very long if we tried to list each of them here. The main difference between them lies in their focus and the method of analysis and it is vital that these approaches, or methods, cannot be completely divided from each other. In the following chapters, we will summarise the most important theories of the different linguistic DA approaches that have been taken into consideration in the present thesis: 
Computer-Mediated Discourse Analysis as the main framework for this study; and two additional approaches that played important roles in the analysis, Multimodal Discourse Analysis and Corpus-Based Discourse Analysis. The reasons for choosing these approaches see in Chapter 4 about the methods. Here, as mentioned, only the most important theoretical basics of these approaches are summarised, later, their methods will be described in Chapter 5 in depth.

\subsubsection{The main approach: Computer-Mediated Discourse Analysis (CMDA)}

We chose computer-mediated discourse analysis (henceforth CMDA) as a main or 'framework' approach to its investigation, as its language sample is from online sources (from web discussion forums, Facebook Groups, 'classical' websites, and blogs - see more about them in Chapter 5).

To understand CMDA, first of all, we have to define two related terms: ComputerMediated Communication (henceforth $\mathrm{CMC}$ ) and Computer-Mediated Discourse (henceforth CMD) ${ }^{14}$.

There are many different definitions of CMC existing in the literature. McQuail (2005), for example, defines in his mass communication theory, CMC as any human communication that occurs through the use of two or more electronic devices. CMC refers therefore to communications via computer-mediated formats (e.g. chat, email, forums, instant messaging, social network services) and to other forms of text-based interaction (e.g. text-messaging) (Thurlow, Lengel, \& Tomic, 2004). Research on CMC focuses mainly on the social effects of different computer-supported communication technologies. For example, it affects the presentation - and construction - of 'self' and the perception of 'others' (Rasulo, 2008).

CMC and CMD are very closely connected terms. As Herring's (2001) definition states, "[c]omputer-mediated discourse is the communication produced when human beings interact with one another by transmitting messages via networked computers" (p. 612). She also adds that " $[\mathrm{t}]$ he study of computer-mediated discourse (...) is a specialisation within the broader interdisciplinary study of computer-mediated communication (...), distinguished by its focus on language and language use in computer

\footnotetext{
${ }^{14}$ One can often find 'computer-mediated' written without the hyphen ('computer mediated') in the literature (e.g. Thurlow, Lengel, \& Tomic, 2004). This thesis uses the variation with hyphen from Susan C. Herring, who is a pioneer scholar on the field of CMC research.
} 
networked environments, and by its use of methods of discourse analysis to address that focus" (Herring, 2001, p. 612).

To illustrate the place of CMC and CMD in relation to other related academic disciplines, we will use Herring's (2014) own visualisation on the topic

Figure 3: CMC in relation to other academic disciplines (Herring, 2014)

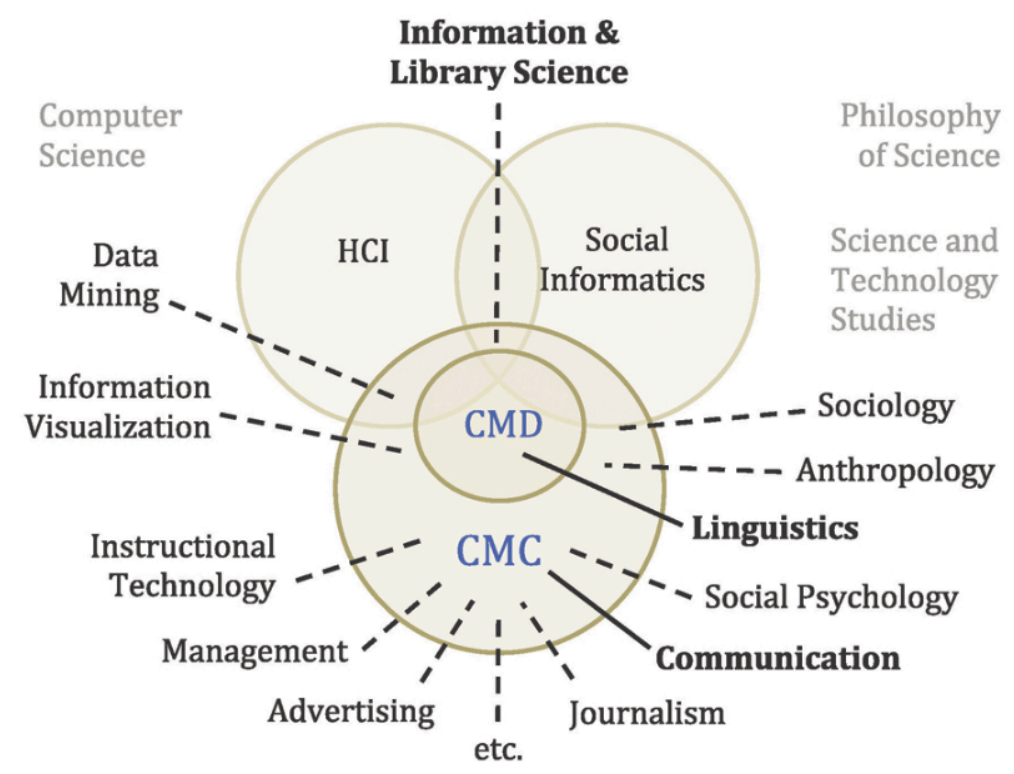

Here we can see that CMC integrates, beside communication, many related fields, such as instructional technology, management, journalism, social psychology, but CMD mainly focuses on the results on linguistics.

Nowadays CMC has been undergoing a shift from occurrence in stand-alone clients (e.g. emailers) to juxtaposition with other content, with other words to convergent media computer-mediated communication (henceforth CMCMC) (a term from Herring, 2009 ) that is especially common on Web $2.0^{15}$ sites (Herring, 2013). CMCMC is "defined as (usually text-based) interactive CMC that occurs on convergent media platforms in which it is typically secondary, by design, to other activities, such as media viewing or game playing" (Herring, 2010). Examples include text comments on photo-sharing sites, text (and voice) chat during multiplayer online games, text (and video) responses to YouTube $^{16}$ videos, etc. (Herring, 2013).

\footnotetext{
${ }^{15}$ See more about the term Web 2.0 in Chapter 5.1.

${ }^{16}$ A global video-sharing website: http://www.youtube.com
} 
Due to these changes in $\mathrm{CMC}$, the research perspectives on CMD have also shifted. Androutsopoulos (2006) calls the earlier linguistically-oriented studies of CMD the 'first wave' that began in the 1990s. For them, the dominant approach was descriptive and the focus of research was a distinct linguistic variety, the so-called 'language of the Internet' that had further categories, such as the language of chat, instant messaging, email, etc. (Androutsopoulos, 2006). Regarding this phenomenon, we should mention Crystal's (2001) book "Language and the Internet", where he coined the aforementioned term 'netspeak'. Research from scholars who follow this 'first wave' descriptive analysis may remain at the level of the characteristics of the medium. On the other hand, a 'new wave' of researchers who draw on sociolinguistics and discourse analysis, are less interested in describing the 'language of CMC', but more interested in understanding the practices of its users (Cameron \& Panović, 2014). They rather aim at "demythologizing the alleged homogeneity and highlighting the social diversity of language use in CMC" (Androutsopoulos, 2006, p. 421). Thus focus has shifted from the medium's effects on the language use to the linguistic choices made by users. The present investigation places its interest in this new wave of research on CMD; therefore, the study does not describe the effects of the medium on the language use, but rather focuses on understanding the chosen resources in different social contexts, with taking the notion of discourse community into account.

CMDA can be used to observe micro-level linguistic phenomena (e.g. lexical choice [Ko, 1996]; sentence structure [Herring, 1998]) as well as any macro-level phenomena (e.g. community [Cherny, 1999; Rasulo, 2008]; gender equity [Herring, 1996]) (Herring, 2004b).

As Herring (2014) puts, CMDA differs from other DA approaches at the following points: 1) it crucially takes the technological affordances of CMC systems into account; 2) it addresses common phenomena in CMC; and 3) its analyses are socially, culturally, and historically situated in the larger digital media context. 


\subsubsection{Additional approaches}

\subsubsection{Multimodal Discourse Analysis (MMDA)}

To understand what multimodal discourse analysis (henceforth MMDA) has established so far, two 'ancestor' traditions should be mentioned: 1) semiological, and the 2) pragmatic approaches; as well as two works by Halliday, 3) "Language as Social Semiotic" (1978) and 4) "Spoken and Written Language" (1989) that were influential on the fields of social semiotics, multimodal studies as well as on MMDA.

1) Semiological - or we could also write semiotic - approaches are based on the theoretical frameworks of semiotics (or semiology). Here we will give no more than a mention to its two pioneers, Ferdinand de Saussure (1966) (semiology) and Charles Sanders Peirce (Hartshorne \& Weiss, 1931) (semiotics), because their theories are wellknown models. However, it is important to remark that based on Saussure's semiology, Roland Barthes ${ }^{17}(1973,1977)$ established his own perspective on visual semiotics that was acknowledged by multimodal studies scholars like Kress and van Leeuwen ${ }^{18}$ later.

2) Of the pragmatic approaches, the 'relevance theory' from Sperber and Wilson (1986) has to be summarised here. The theory states that communication relies on the participants' ability to infer meaning, which are not directly encoded into the message. In this sense, these studies question is not only "what does this say?" - which would be a basic semiological question -, but also "why is this person telling me this?" (Cameron \& Panović, 2014, p. 101). These types of question were also adopted by MMDA scholars.

3) Halliday's (1978) work "Language as Social Semiotic" is a "description of the grammar of English as a set of possibilities, linking each option that the grammatical resources of the language make available (...) to the kinds of meaning we make with it" (Lemke, 2012, p. 81). The framework for that is social semiotics - see more in Kress and Hodge, 1988. At this point, the difference between multimodality and social semiotics has to be clarified. At a basic level, multimodality names the field of work; social semiotics names the theory, which that field is approached with (Lemke, 2012). Connecting social semiotics and MMDA, Kress (2012) writes about 'social semiotic

\footnotetext{
${ }^{17}$ Barthes's $(1973,1977)$ definitions of denotation and connotation should be highlighted here: 1$)$ denotation is the definitional or common sense meaning of a sign. If we take the example of a linguistic sign, the denotative meaning is what the dictionary attempts to provide (Chandler, 2002). The second layer of the meaning is 2) connotation that is more complex and includes broader concepts, ideas and values. In Barthes's point of view, Saussure's model of the sign focused on denotation and it was left to theorists (like Barthes himself) to offer an account of this important dimension of meaning (Chandler, 2002).

${ }^{18}$ See more about their multimodal approach in their early work "Reading Images: The Grammar of Visual Design" (Kress \& van Leeuwen, 1996).
} 
multimodal discourse analysis' to express that these fields cannot be clearly divided from each other.

4) In his other work "Spoken and Written Language”, Halliday (1989) states that "we have passed the peak of exclusive literacy, where only written artefacts had merit, and information resided only in the written message" (p. 98). Kress, van Leeuwen and others have further developed Halliday's ideas and for them, meaning is made through the use of multiple modes of communication as opposed to just language (Kress, 2012).

Later, Kress and van Leeuwen (1996) in their milestone work "Reading Images: The Grammar of Visual Design" criticise Barthes for missing out an important point from his theories: "the visual component of a text is an independently organised and structured message - connected with the verbal text but in no way dependent on it" (Kress \& van Leeuwen, 1996, p. 17, cited in Cameron \& Panović, 2014, p. 102). The context of Kress and van Leeuwen's theories is the systemic-functional linguistic framework based on the abovementioned theories from Halliday $(1978,1989)$. In this framework, one of the key concepts is that language is just one of the many resources for making meaning, so to say, one of the social semiotic systems (Cameron \& Panović, 2014). Moreover, through the 'grammar' of visual design, different modes can be analysed in similar ways (Kress \& van Leeuwen, 1996).

In a multimodal approach, all modes are framed as one field, as one domain. As Kress (2012) puts, they are one connected cultural resource for meaning making. Furthermore, scholars dealing with the question of multimodality - including Anthony Baldry, Gunther Kress, Jay L. Lemke, Kay L. O’Halloran, Ron Scollon, Paul J. Thibault, and Theo van Leeuwen - make a distinction between modes (different semiotic resource systems) and media (different technologies for realising meanings that are made possible by these systems).

The phenomenon of multimodality has become an important research interest across many disciplines. However, multimodality is not the product of digital technology, but - as many scholars state - is a feature of all communication. Even in everyday faceto-face interaction, we do not use only language in the communication process, but also multimodal entities are involved such as gestures, gaze, and postures.

As Jewitt (2009) suggests, "[m]ultimodality can be understood as a theory, a perspective or a field of enquiry or a methodological application” (p. 12). O’Halloran and 
Smith (2011) make a distinction between studies which investigate multimodal phenomena, and multimodal studies as a field of expertise, distinct from linguistics or any other fields.

MMDA brings these earlier research results on 'multimodality' (or 'multimodal studies' - see more in O'Halloran \& Smith, 2011) into discourse analysis frameworks. It is a relatively new field; probably at first, Kress and van Leeuwen (2001) used the terms 'multimodality' and 'discourse' together in their milestone work "Multimodal Discourse. The Modes and Media of Contemporary Communication”. Since that, MMDA has become established within the discourse analytic and social semiotic communities.

Texts, in MMDA, are multimodal semiotic entities in two, three or four dimensions. The interpreter of a semiotic entity produces a coherent, newly made text as a result of her/his own interpretation (Kress, 2012).

There are many different interests and positions between multimodal discourse analysts. The scholars who follow the results of 1) systemic-functional linguistics have adopted different approaches and frameworks to their analyses. The two basic frameworks are Kress and van Leeuwen's (2006) top-down contextual approach and O'Toole's (2010) bottom-up grammatical approach. Based on these two approaches, subsequent research has extended them into new domains (O'Halloran, 2013). For example, Lemke (2002) developed a contextual approach for hypermodality; Kress (2003) for literacy; and Jewitt (2006) for educational research. Another branch of scholars belong to the stream of 2) 'multimodal interactional analysis' that has foundations in interactional sociolinguistics and intercultural communication. To this stream, we can list Sigrid Norris, Ron Scollon, and Suzanne Scollon (O'Halloran, 2013). Some of them have become more interested in the expression of power, knowledge in and through language, and many of them adopted Foucault's notion of discourse (O’Halloran, 2013).

The present study applies some results of MMDA, not only because of the fact that its corpus includes also multimodal texts, but because in general, in the era of Web 2.0, one can hardly exclude multimodal analysis from her/his research. For example, if we think of social network activities, such as posts, comments, reposts, shares, they are seldom 'classical' plain texts; therefore, this dissertation examines some of these multimodal acts (see more in Chapter 5). 


\subsubsection{Discourse Analysis and Corpus Linguistics: Corpus-Based Discourse}

\section{Analysis}

Corpus research started out in the 1960s as a methodological approach, based on collecting and documenting real-life language data. Henry Kučera's and Nelson Francis's book "Computational Analysis of Present-Day American English" (1967) is noted as a fundamental work in this research field. In corpus linguistics, the analysis is based on large collections of authentic texts: corpora.

The meaning of 'discourse' from a corpus linguistic point of view is a "totality of texts produced by a community of language users who identify themselves as members of a social group on the basis of the commonality of their world views" (Koteyko, 2014, p. 21). Additionally, these people share attitudes and beliefs which are reflected in the way they use language (Koteyko, 2006).

Moreover, corpus linguistics sees language as a social construct and emphasises the historical and cultural aspects of meaning production in discourse (Koteyko, 2006). From this perspective, the corpus-based (also mentioned as 'corpus-driven') approach to discourse is focused on how meanings come to be articulated at particular moments in history.

Even though discourse analysis is closely connected to corpus linguistics because of the analysed data, merging the two fields together is only a very recent tendency of research. Some scholars observe discourse studies as "not typically corpus-based analyses" (Biber et. al., 1998, p. 106). However, existing studies such as corpus-based discourse analyses (Baker, 2006; Bathia et al., 2008; Partington et. al., 2004), some recent sociolinguistic research, and Critical Discourse Analysis (Fairclough, 2000) have already highlighted the importance of involving both discourse and corpus analysis. Even Dörnyei (2008) emphasises the importance of 'mixed methods': applying quantitative and qualitative research together. This thesis agrees with the investigation of Dörnyei's 'mixed methods' and follows the ideas of corpus-based and computer-mediated discourse analysis, since it works with a carefully selected online linguistic data.

Due to the Internet, corpus-based discourse analysis has become more popular in recent years, because now it is possible for individual scholars with limited finance to have access to almost unlimited amounts of discourse. As Partington (2004) puts, it has become relatively easy to compile 'specialised corpora' (or 'monogeneric corpora') (p. 
13). This collected corpora "make discourse study feasible since, in a collection of texts of similar type, the interactional processes and the contexts they take place in remain reasonably constant, or at least alter in relatively predictable ways" (Partington, 2004, pp. 13-14). 


\subsection{Discourse community (DC)}

\subsubsection{Definition}

Many forms of DA are focused on social groups because of their meaning-making processes. These groups are called different names, depending on the aspect of social activity that the discourse analysts want to stress: discourse communities (the present thesis uses this term with reference to Swales's [1990] work), speech communities, communities of practice (already mentioned above), activity systems, Discourses, networks, and cultures (Gee, 1999).

The definition of 'discourse community' (henceforth DC) is originally adopted from leading relativist or social constructionist thinkers' works like Perelman and Olbrechts-Tyteca's (1969) “The New Rhetoric”, Kuhn's (1962) “The Structure of Scientific Revolutions" and Fish's (1980) “Is There a Text in this Class?". More specifically, it was developed from the concepts of 'speech community' and 'interpretative community' (Borg, 2003). This study does not take a closer look at the latter concept, as it focuses more on Swales's concept of DC that was built on the notion of speech community. However, to summarise it briefly, 'interpretative community' (Fish, 1980, cited in Borg, 2003) is an open network of people who share ways of reading texts and the participants therefore have a common social derivation of interpretation (Borg, 2003).

As mentioned, the present study uses the definition of discourse community in terms of John M. Swales's (1990) theory in his book “Genre Analysis. English in academic and research settings". His model on DC was influenced by the sociolinguist Nystrand's (1982) earlier work "What Writers Know: The Language, Process, and Structure of Written Discourse" that is an investigation into written discourse. From Swales's perspective, DC can be defined as a group of people who share a specific set of discourses that represents basic values as well.

The pioneer scholars (Nystrand [1982], Herzberg [1986], Porter [1986]) began to operate with the term of DC in the 1980s. Already at this time, Herzberg (1986) remarked:

\footnotetext{
"Use of the term 'discourse community' testifies to the increasingly common assumption that discourse operates within conventions defined by communities, be they academic disciplines or social groups. The pedagogies associated with writing across the curriculum and academic English
} 
now use the notion of 'discourse communities' to signify a cluster of ideas: that language use in a group is a form of social behavior, that discourse is a means of maintaining and extending the group's knowledge and of initiating new members into the group, and that discourse is epistemic or constitutive of the group's knowledge. (...) The idea of 'discourse community' is not well defined as yet, but like many imperfectly defined terms, it is suggestive, the center of a set of ideas rather than the sign of a settled notion.” (p. 1)

After this early discussions ${ }^{19}$ on DC, Swales (1990) tried to clarify these problems around the definition. He built up his notion on DC with a comparison to speech community. Swales states that due to technological developments it is increasingly easy to contact people on the other side of the world; therefore, speech communities can not only be formed in an oral way, but communities are also drawn together in a written way, through literacy. As Swales (1990) mentions, "literacy takes away locality and parochiality" (p. 24). Therefore, a speech community typically inherits its membership by birth, accident or adoption, but a discourse community recruits its members by persuasion, training or relevant qualification (Swales, 1990).

Swales (1990) proposed six defining characteristics that identify a group of individuals as a discourse community. These are the followings:

"1. A DC has a broadly agreed set of common public goals."

"2. A DC has mechanisms of intercommunication among its members."

"3. A DC uses its participatory mechanisms primarily to provide information and feedback."

“4. A DC utilizes and hence possesses one or more genres in the communicational furtherance of its aims."

"5. In additions to owning genres, a DC has acquired some specific lexis."

"6. A DC has a threshold level of members with a suitable degree of relevant content and discoursal expertise." (pp. 24-27)

Swales's model and listed characteristics are based on genre analysis (henceforth GA). For him, 'genres' are types of texts that meet the needs of the 'rhetorical situations' in which they function. As Miller (1984) mentions: “(...) genres can serve both as an index to cultural patterns and as tools for exploring the achievements of particular speakers and writers", and "genres serve as keys to understanding how to participate in the actions of a community" (p. 165). Swales (1990) demonstrates that discourse

\footnotetext{
${ }^{19}$ Additionally, in pedagogy and language learning, DC has been associated with the language use of a group of people learning a foreign language, where the discourse maintains and extends the group's knowledge and initiates new members into the group (Herzberg, 1986).
} 
communities all use genres, many of which are recognisable to people outside the group, but at the same time, groups develop their own conventions for those genres in light of their desired goals.

Originally in GA, the main focus was on the relationship between text and context: what makes a particular genre possible and how it is used. Currently, the view emphasised is how these specialised genres are created and interpreted in specialised contexts (Bhatia \& Gotti, 2006).

The complex analyses of GA often include ethnographic, corpus-based, sociocognitive, and socio-critical discourse analytical approaches.

To turn back to Swales's work, Borg (2003) highlights that there are still many unanswered questions on defining discourse communities. Porter (1986) and Johns (1997) suggested that DC might have common interests, but not necessarily common goals. Another questioned point in Swales's thoughts was the differentiation between written and spoken discourses. Later Swales (1998) attempted to answer this criticism and he differentiated between discourse communities and 'place discourse communities'. In this sense, discourse communities are united only by written communication, but place discourse communities are united by both writing and speech. For Swales, the genres are the discourse community members' vehicles for communication. It is important to mention that these genres are not in all cases sophisticated or intellectual, literary or high browed (Johns, 1997). However, they are representative of the values, needs, and practices of the community that produces them (Johns, 1997).

Since Swales's (1990) work the topic of discourse community has continued to develop amongst scholars. To sum up, it can be stated that discourse community means different notions to different scholars, depending on the perspective of the author. For example, Rafoth (1990) added to the discussion:

"If there is one thing that most of the [discourse community definitions] have in common, it is an idea of language [and genres] as basis for sharing and holding in common: shared expectations, shared participation, commonly [or communicably] held ways of expressing. Like audience, discourse community entails assumptions about conformity and convention." (p. 140)

Or for Porter (1992) "a discourse community is a local and temporary constraining system, defined by a body of texts (or more generally, practices) that are unified by a common focus" (p. 106). 
We also have to add that discourse communities are neither monolithic nor static and can change from time to time into fragmented sub-communities (Bamford \& Bondi, 2005). Therefore, a discourse community has open borders and is unstable, changing and dynamic. Moreover, within a community there can be conflicts and a diversity of practices. When for example individuals are fully initiated, many factors could separate them. If the rebellion is successful, a new group might be created with other rules, values, and aims (Johns, 1997).

As we can see, the term DC is very complex, abstract and contested. We also have to remark that people are generally members of different communities, like cultural organisations, communities with political aims, family associations, etc. with varying levels of involvement and interest (Johns, 1997). Additionally, community membership can be central or peripheral to a person's life.

A highly important point is that discourse communities can also be professional. As Johns (1997) puts, every major profession has its own organisations, practices, textual conventions, and genres. Active community members also carry on informal exchanges, e.g. at conferences, via e-mail, meetings at the office, etc. These written genres of communities are accessible to outsiders for analysis. From those texts, an array of interesting examples can be collected. E.g. one of the most thoroughly studied professional communities is the discourse community of law (e.g. Bhatia, 1993), generally academic/scientific communities (Bizzell, 1992; Duszak, 1997; Swales, 1990; Yerrick \& Gilbert, 2011), and learning communities (Kowch \& Schwier, 1997).

Johns (1997) has, for instance, already pointed to the lack of research on musicians' discourse communities: "However, there are many other professional discourse communities whose genres can be investigated, particularly when students are interested in enculturation. For example, students might study musicians who devote their lives to pursuing their art but who also use written texts to dialogue with others in their profession.” (p. 55) The present study, therefore, tries to fill this gap in research on music communities and investigates to analyse the discourse community of electronic dance music as a whole.

\subsubsection{Related terms}

As mentioned, beside discourse community, there are many other related terms in the 
literature: actor-actant networks (Latour, 1987), communities of practice (Lave \& Wenger, 1991), cultural communities (Clark, 1996), cultures (Geertz, 1973), Denkkollektiv ('thought collectives' [Fleck, 1935]), rhetorical community (Miller, 1994), etc. There are various levels of differences in the meanings of these terms, but some of them are very close to each other.

In the following section, these related terms will be expanded on, which play important roles in understanding and widening the definition of 'discourse community' in terms of electronic dance music.

\subsubsection{Speech community}

It has been mentioned that the concept of discourse communities within a linguistic perspective is developed from the concepts of the sociolinguistic term 'speech communities'. Speech community is an earlier term already used by Bloomfield in the 1930s. At this time, speech community was seen as being composed of those who share similar linguistic rules (Swales, 1990). Later, Labov (1966, cited in Swales, 1990) used speech community in terms of 'shared norms' between members. He stated that New York City is a single speech community and not a collection of speakers living side by side (Swales, 1990). In the 1970s, Hymes (1974, cited in Swales, 1990) defined speech community as community sharing knowledge of rules for the conduct and interpretation of speech.

\subsubsection{Communities of practice}

The first idea of communities of practice was introduced in Lave and Wenger's (1991) work "Situated Learning: Legitimate Peripheral Participation"; later Wenger (1998) expanded the theory in his book "Communities of practice. Learning, meaning, and identity". He states that, "communities of practice are groups of people who share a concern or a passion for something they do and learn how to do it better as they interact regularly" (Wenger, 2006, p. 1). In this sense, learning is a collective activity in a shared domain and at the same time it can be the reason the community comes together, or an incidental outcome of member's interactions (Wenger, 2006). This phenomenon is also described by the 'situated learning theory' (see more in Lave \& Wenger, 1991). 
Communities of practice have three main characteristics (Wenger, 1998 and 2006): 1) The domain: The shared domain of interest defines the community's identity. Membership therefore implies a commitment to the domain and this shared competence distinguishes members from the others. 2) The community: Members engage in joint activities and discussions, they share information, or help each other to pursue their interest in their domain (Wenger, 2006). Therefore, they build relationships in order to learn from each other. Members do not necessarily work together on a daily basis, but the most important is the process of learning. 3) The practice: Members are (social) practitioners; they develop shared experiences, stories and ways of solving problems during the shared practice (Wenger, 2006).

One can see that the idea of community of practice has much in common with discourse communities. The main difference between discourse community and communities of practice lies in the following: In the definition of discourse community, the focus is on texts and language, the genre and lexis that enable members to maintain their goals to communicate efficiently with one another (Johns, 1997). However, communities of practice also refer to genres and lexis, especially to many practices and values that hold communities together or separate them from one another (Johns, 1997) and it is mainly focused on the learning process.

\subsubsection{Cultural community}

Herbert H. Clark's (1996) definition of 'cultural community' is based on his theory of 'common ground' (or 'grounding in communication'). Clark's (1996) 'cultural community' means people are members of certain cultural groups, systems, or networks and the information people have about a community depends on if they are insiders or outsiders. Under inside information he understands, "particular information that members of the community mutually assume is possessed by members of the community" (Clark, 1996, p. 101). In other words, they have their own common ground. In contrast, the outside information is, "types of information that outsiders assume is inside information for that community" (Clark, 1996, p. 101).

Clark (1996) thinks that inside information goes beyond outside information in two ways: 1) "[o]utside information covers only a fraction of the types of information 
insiders actually have" (p. 102); and 2) "inside information surpasses outside information in sheer volume" (p. 102).

To sum up, a cultural community is a set of people with shared expertise that other communities lack, therefore, it can be identified by its expertise. Here is one of the most interesting examples which Clark listed of the phenomenon:

Table 1: An example on common types of expertise and communities they define (Clark, 1996, p. 103)

\begin{tabular}{|l|l|l|}
\hline Basis of expertise & Examples of community & Examples of expertise \\
\hline Subculture & $\begin{array}{l}\text { rock musicians, drug } \\
\text { addicts, teenage gangs }\end{array}$ & $\begin{array}{l}\text { underground resources, } \\
\text { subculture slang, know-how }\end{array}$ \\
\hline
\end{tabular}

Here we have to highlight 'subculture slang'. If we want to apply Clark's thoughts to the topic of the present study, one could clearly take the example of a specific electronic dance music community. An example could be the following:

Table 2: The example of acid house scene on expertise and communities it defines

\begin{tabular}{|c|c|c|}
\hline Basis of expertise & Examples of community & Examples of expertise \\
\hline Subculture ${ }^{20}$ & $\begin{array}{l}\text { early acid house scene in the } \\
\text { UK (late } 1980 \mathrm{~s} \text { - early } \\
1990 \mathrm{~s}^{21} \text { ) }\end{array}$ & $\begin{array}{l}\text { underground resources, } \\
\text { subculture slang, know- } \\
\text { how }\end{array}$ \\
\hline
\end{tabular}

In comparison to discourse community, the concept of cultural community mainly focuses on the common knowledge (common ground) and expertise created by the members of the community. Insider and outsider information specify a member's relationship to the community. Swales's discourse community also takes the common knowledge into account (see the sixth point of DC's characteristics above), but he does not focus on the difference between insiders and outsiders. This point will be very important later in examining the meaning of discourse community through the example of electronic dance music communities, because there these insider and outsider information play an important role in the communication process.

\footnotetext{
${ }^{20}$ We could also use club culture or scene here that are newly accepted notions in youth-subcultural studies - see more on the topic in Chapter 2.4.3.2.3.1.

${ }^{21}$ The (sub)cultural theorists take the period of the acid house movement as a subculture to these years. Due to the fast commercialisation of the electronic dance music scene, the period of 'subculture' ended in the mid-90s.
} 


\subsubsection{Thought collective (Denkkollektiv)}

In an early work, Fleck (1935, II.4) talks about 'thought collectives' (Denkkollektiv) which is a community of people exchanging ideas or maintaining intellectual interaction. Members of that collective continually transform certain ways of perceiving and thinking in their interpersonal space. Due to the reason that those people are part of a certain group, they think in a specific way: the group has a specific characteristic of thought style (Denkstil).

\subsubsection{Distributed knowledge}

Distributed knowledge is originally a standard notion in epistemic logic: "Intuitively, a formula $\varphi$ is distributed knowledge among a group of agents B if $\varphi$ follows from the knowledge of all individual agents in B put together. Semantically, $\varphi$ is distributed knowledge among B iff $\varphi$ is true in all worlds that every agent in B considers possible." (Roelofsen, 2007, p. 255) Distributed knowledge therefore refers to the union of all the knowledge of individuals in the community.

\subsubsection{Forms of life (Lebensformen)}

The expression 'forms of life' (Lebensformen) is used in many different ways ${ }^{22}$ in Wittgenstein's (1958) “Philosophical Investigations”.

Among the others, one of the interpretations of the expression 'forms of life' by Wittgenstein can be that it is a way/style of life, which has something to do with the, "class structure, the values, the religion, the types of industry and commerce and of recreation that characterise a group of people" (Hunter, 1968, p. 234). In other words, this interpretation is based on the fact that there is a close relationship between our life style and the way we use language. In this sense, Clark's 'cultural community' is very close to Wittgenstein's 'form of life'.

\footnotetext{
${ }^{22}$ As Hunter (1968) noted, "he was not very helpful as to what he meant by it" (p. 233).
} 


\subsubsection{Rhetorical community}

Miller (1994) proposed another model of community that differs from speech, discourse and political communities. Her 'rhetorical community' is a "virtual entity, a discursive projection, a rhetorical construct. It is the community as invoked, represented, presupposed, or developed in rhetorical discourse. It is constituted by attributions of characteristic joint rhetorical actions, genres of interaction, ways of getting things done, including reproducing itself.” (Miller, 1994, p. 73) For Miller (1994), rhetorical community is the cultural basis of a genre.

\subsubsection{Discourse community feat. online/virtual community $=$ online/virtual discourse community}

In the following chapter, the concept of online/virtual community will be summarised and combined with the notion of discourse community.

Community formations on the Internet are often interchangeably called online communities (earliest Hiltz, 1985), virtual communities (earliest Rheingold, 1994) or web-based community ${ }^{23}$ (e.g. Bishop, 2009) in the literature. Generally, an online/virtual community ${ }^{24}$ is a computer-mediated social group that shares opinions and experiences online. The group members have a common interest and via online communication they try to receive answers on their questions. Preece (2000) gives the following definition of online community: "a group of people who come together for a purpose online and who are governed by norms and policies" (p. 580).

Online discourse communities consist of a group of people brought together generally "by natural will and a set of shared ideas" (Kowch \& Schwier, 1997). There are many scholars who have dealt with the different questions of online (discourse) communities in social sciences and linguistics. The main difference between their research lies in their research questions: social scientists are more focused on the questions, "how the Internet is changing our lives", and "how communities form and function" (Preece \& Maloney-Krichmar, 2003). Linguists and psychologists try to understand conversation, discourse, interaction and social relationship between the members of those groups.

\footnotetext{
${ }^{23}$ For example, used by the "International Journal of Web Based Communities".

${ }^{24}$ The author of this thesis uses the two terms online and virtual community with the same meaning.
} 
Contemporary research does not see the community as a physical grouping of people anymore, but it is understood as a network of interpersonal ties that provides information, a sense of belonging, support and identity (Rheingold, 1994; Wellman, 2002). As Rasulo (2008) mentions: “An online community is not simply an 'entity' or a 'place', but it is a process that develops over time and involves a complex network of social relationships with identifiable discourse that are formed within the 'infrastructure' of CMC.” (pp. 22-23)

Herring (2004b) has identified six sets of relevant criteria for operationalizing an online community:
1) active, self-sustaining participation; a core of regular participants
2) shared history, purpose, culture, norms and values
3) solidarity, support, reciprocity
4) criticism, conflict, means of conflict resolution
5) self-awareness of group as an entity distinct from other groups
6) emergence of roles, hierarchy, governance, rituals (p. 355)

Of course, not only these characteristics can be applied as potential indicators of online communities. Some of them occur rarely or not at all.

Preece's (2000) 'Online Community Framework' includes four components: 1) people who take part in the communication; shared 2) purposes - why they take part in it; 3) policies they follow in the process; and the 4) software that supports and mediates social interactions between the participants.

Additionally, an online discourse community can use many different genres in order to communicate with each other. By these differences, Preece (2000) distinguishes between web-embedded communities; special purpose communities; listserver communities; UseNet-based communities; discussion-based communities; chat-based communities; MUDs, MOOs ${ }^{25}$; and communities functioning in Asynchronous Learning Networks (ALN).

\footnotetext{
${ }^{25}$ Multi-User Dungeon and Muds Object-Oriented are a multiplayer real-time virtual worlds.
} 


\subsection{Research on electronic dance music}

\subsubsection{Struggle with definitions: electronic music vs. electronic dance music}

The terms 'electronic music' and 'electronic dance music' have taken many different meanings. Often they are used interchangeably - especially in journalistic texts. It is very difficult to give one coherent definition of these terms, as different research fields accord different meanings to them. For example, from a socio-historical point of view, these terms would not mean only a specific type of music, a genre with a distinct musical aesthetics, but they would also include all the cultural features that were created by the different communities and scenes behind them. From the production side, electronic music employs electronic musical instruments and other electronic music technology in its production (Holmes, 2002). This definition excludes electro-mechanical devices, e.g. the electric guitar. Therefore, the purely electronic sound production can be achieved using devices like synthesisers, computers, etc. The term 'electronic' formally denotes applications of the transistor and became popular in the mid-twentieth century (Collins, Schedel, \& Wilson, 2013).

Another difficulty rises in discussing the meaning of 'electronic music' because of the different genres, styles, and streams which are difficult to analyse due to constant changes in trends.

This dissertation focuses on 'electronic dance music' (henceforth EDM), although this term has been adopted by the U.S. music industry and press to describe commercial electronic music in the late 1990 s and early 2000 s. So, we also have to note that the term 'electronic dance music' was later popularised, but historically it is also used for earlier periods. Despite ambiguity around the term EDM, we have decided to use this form, because it immediately gives an idea to the reader that the period of time this research focuses on is from the early 1980s (maybe late 1970s) until today. If we take the term 'electronic music', it includes the whole history of this genre. In this sense, EDM is one of the metagenres of electronic music: 
Figure 4: EDM's place in electronic music

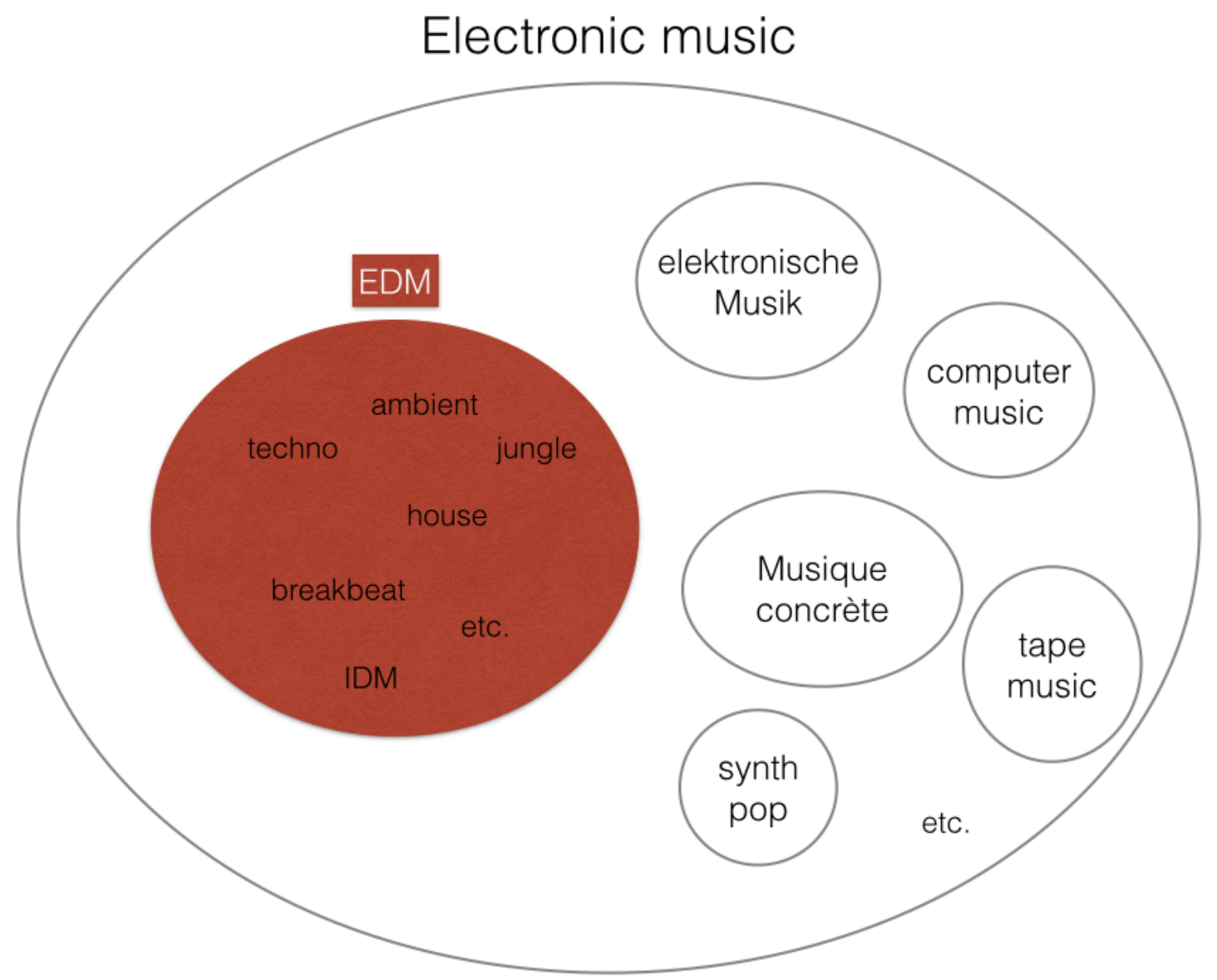

There are many other names used for electronic dance music, e.g. 'dance music', 'dance', or 'club music'. McLeod (2001), for instance, writes about 'electronic/dance music' - with a slash -, because not all the music consumed by electronic dance music communities is necessarily designed for dancing. We agree with McLeod's terminology and argument with the slash, but to keep the wording simpler in the text, this thesis uses the original form: 'electronic dance music' (EDM).

Therefore, electronic dance music is an umbrella term that labels "a heterogeneous group of musics made with computers and electronic instruments - often for the purpose of dancing" (McLeod, 2001, p. 60). It is one of the reasons why there is sometimes confusion in using the term EDM. From the aspect of classification (music genres), EDM is the main category (metagenre) and those smaller streams - like techno, house, etc. - are the genres. In these genres there are many sub- and sub-sub- (etc.) genres, too. Collins at al. (2013) give the following definition on electronic dance music: it "features electronic synthesised and sampled instrumentation, with at least some parts of a percussive nature, in tracks designed for dancing" (p. 102). 
In the following illustration, we can see the main genres of EDM on the left side (house, trance, techno, breakbeat, jungle, hardcore, and downtempo). Here we see the example of house genre and its sub- and sub-sub-genres (etc.).

Figure 5: An example for the different EDM genres (Ishkur's Guide, n.d.) ${ }^{26}$

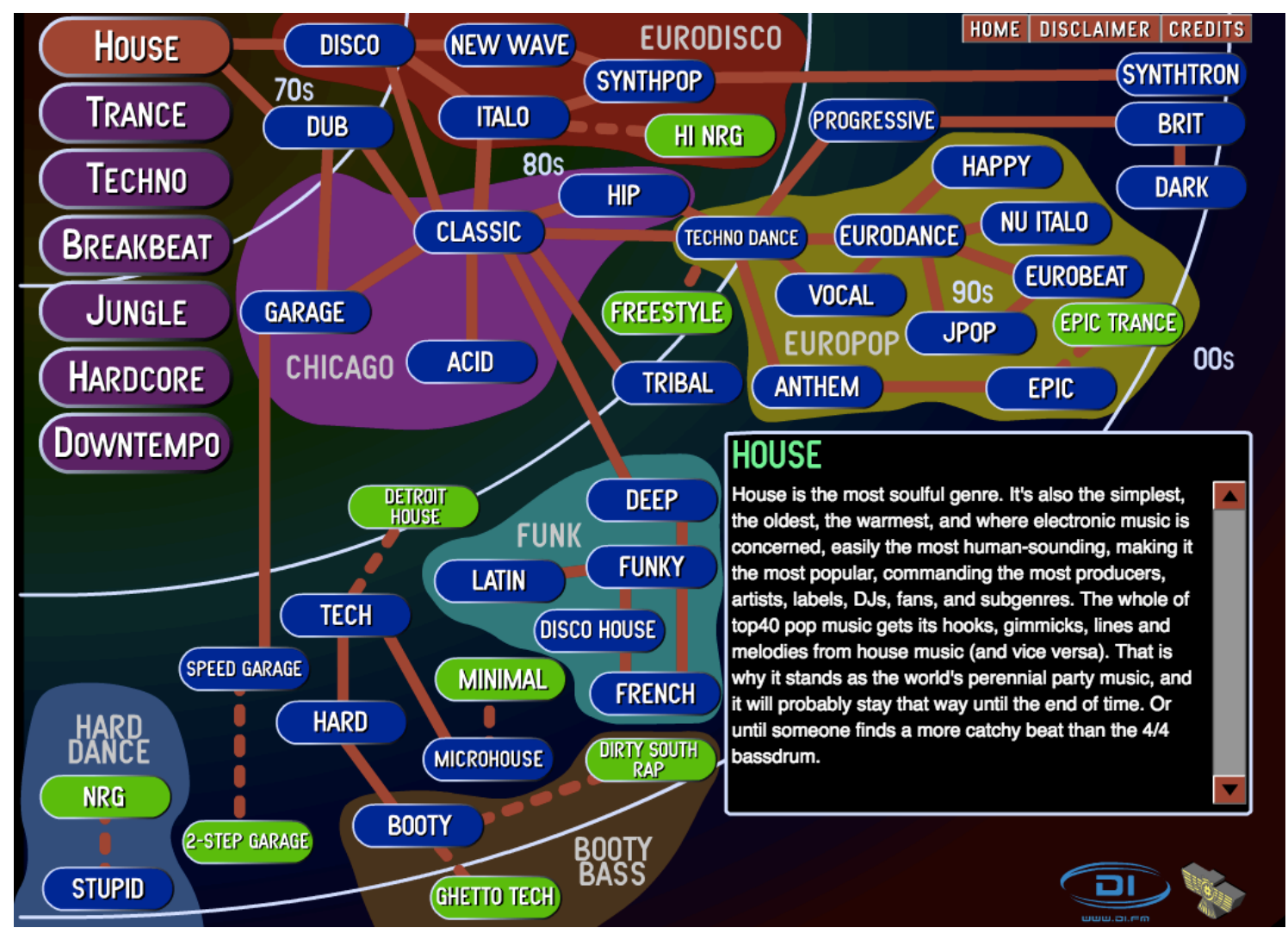

The process of naming new subgenres within EDM communities is very fast. This is a highly individual phenomenon compared to other metagenres in popular music (e.g. rock, metal). This is not only directly related to the rapidly evolving nature of the music in itself but as McLeod (2001) states, "it is also a function of the marketing strategies of record companies, accelerated consumer culture, and the appropriation of the musics" (p. $60)$. He also mentions that this naming process acts as a gate-keeping mechanism that generates a high amount of (sub)cultural capital (Thornton, 1995, cited in McLeod, 2001) needed to enter EDM communities.

To sum up, this thesis understands under electronic dance music the following: it is a metagenre of danceable or non-danceable music styles that employ electronic musical instruments and electronic music technology in their productions. Its history started in the

\footnotetext{
${ }^{26}$ The Ishkur's 'electronic music guide' on Techno.org gives a very useful explanation to EDM genres and at the same time it draws a historical timeline to them. One can click on all genres and subgenres and listen to embedded different music examples as well.
} 
late 1970s and many different communities/scenes have been evolved around its genres and subgenres.

The present thesis will include only a brief history of electronic music, because writing about its entirety in detail is not necessary to the dissertation topic. However, the socio-cultural and historical background of electronic dance music (EDM) will be discussed more in depth.

\subsubsection{A short history of electronic- and electronic dance music}

In the history of electronic music, historical musicologists (e.g. Collins et al., 2013; Manning, 2004) often distinguish between 1) the pre-history of electronic instruments from the 18th century until the end of the Second World War - and 2) the history of electronic music - beginning after the Second World War.

The so-called pre-history integrates all the experimental technological inventions (e.g. in telecommunication, long-distance communication, etc.) that had prominent effects on the development of electronic music. On the other hand, the period of 'real' history of electronic music goes back to the actual inventions in the field of music (production).

\subsubsection{The pre-history of electronic instruments}

Collins et al. (2013) date the beginning of the pre-history of electronic instruments to 1759, when one of the first electronic instruments, a clavichord named 'Denis d'or' and invented by Václav Prokop Diviš was introduced. A similar development was Delaborde's electrically controlled carillon, the 'Clavecin électrique' in the same century.

The 19th century was a fruitful period of time for the pre-history of electronic music because from the phonautograph, through the electromechanical oscillator, to the phonograph, many other early electronic music tools/instruments were created in these years giving new possibilities to musicians to use emerging technologies for musical purposes. As Manning (2004) puts, these early inventions paved the way for the later emergence of electronic instruments. This century saw, for example, Hermann von Helmholtz's 'Klang Synthesiser' - one of the first sound synthesisers. 
The inventions of long-distance communication - e.g. telegraph and telephone were also important stations in this pre-history. For instance, the development of wireless transmission techniques (e.g. radio) resulted in numerous technological inventions that had additional musical applications. The idea of music from a distance found its first realisation in Thadeus Cahill's 'Telharmonium'. The inventor's idea was to create a keyboard instrument, which could broadcast music via dedicated telephone lines (Collins et al., 2013).

The beginning of the 20th century was also very rewarding in new innovations. To mention only a few examples: Nikolai Obukhov's 'Ether' and 'Croix Sonore'; Leon Theremin's 'Theremin'; Jörg Mager's ‘Sphärophon'; René Bertrand's 'Dynaphone'; Friedrich Trautwein's ‘Trautonium'; Laurens Hammond's organ; Pierre Toulon’s 'Celluphon'; etc. (see more in Roads, 1996).

\subsubsection{The history of electronic music}

Based on the aforementioned early developments in the 18th and 19th century, after the Second World War, rapid advances took place in the environment of electronic music. Collins et al. (2013) call this period: 'the post-war sonic boom' (p. 45). An upsurge of interest from many quarters in new sound techniques, and a generally expansionist economic climate provided sufficient incentives for institutions to provide support (Manning, 2004). Many different music studios were brought into live all around the world.

In Paris, a group of musicians - led by Pierre Schaeffer - became dedicated to the advancement of their self-styled 'musique concrète', whilst in Cologne (Germany) musicians - including Karlheinz Stockhausen - at the 'Electronic Music Studio of Nordwestdeutscher Rundfunk' (NWDR) (from 1955, 'Westdeutscher Rundfunk', or WDR) championed the cause of 'elektonische Musik' (Manning, 2004). In Milan (Italy), Luciano Berio, who was influenced by musicians in Cologne, established 'Studio di Fonologia'. Later, several other institutions established studios which imitated the form of the three main ones - Paris, Cologne, and Milan - such as in Berlin, Brussels, Eindhoven, Tokyo, etc. (Manning, 2004; Institut für Medienarchäologie, 2008; Gethman, 2010). 
At the same time, several developments took place in the USA too. A group of musicians in New York established their own school (New York School), led by the famous John Cage. The USA also has a long history of teaching electronic music at a university level; from the beginning, there were several research groups (e.g. ColumbiaPrinceton Electronic Music Center) and electronic music lecturers at universities on both coasts (Manning, 2004).

Many of the basic techniques and technologies of electronic music originate from this period. Collins et al. (2013) mention the following examples: mixing, tape splicing, tape loops, echoes, delays, tape speed and direction, reverb, oscillator, sine, sawtooth, triangle, square, modulators, noise generators, etc. (see more in Collins et al. 2013, pp. $56-58)$.

There was also some commercial support for research in this period. Important examples are the Bell Labs facility in New Jersey and the Philips research facilities in Eindhoven, in the Netherlands (Collins et al., 2013).

Due to the new voltage-controlled ${ }^{27}$ analogue synthesiser inventions, electronic music reached wider audiences, because popular music bands - like The Beatles - also began to use those instruments. After a fruitful period of synthesiser developments, the next important device was the electronic tape and its potentials in the 1960s.

Possibly the greatest change was the so-called 'digital revolution', which was a direct consequence of the development in computers. Digital technology was rapidly developing at the same time as the commercial boom in analogue synthesisers. The first commercial digital workstations in the 1970s were too expensive, but prices soon dropped substantially and they could be reached by more people (Collins et al., 2013).

Electronic music became more and more popular during the 1960s and ' 70 s. The Philips Pavilion at the World Fair of 1958 provided the first mass exposure for electronic music (musique concrète), which was one of the most important landmarks in the popularisation of this music (Collins et al., 2013). Aside from the aforementioned popular music bands, the widespread disco music also helped in spreading electronic music.

We also have to consider that in the period of $1950 \mathrm{~s}-1970 \mathrm{~s}$ a transition occurred in the public consciousness of electronic music, as greater adoption of electronic sound in

\footnotetext{
27 "Voltage control is a principle of easy manipulation of the aspects of electronic sound, allowing the simple interconnection of modules. Variations in represented in an electronic circuit by changing voltage against time." (Collins et al., 2013, p. 66)
} 
film (most notably: the sound of bird screams in Hitchcock's "The Birds", created with a Trautonium), television, and popular music played out (Collins et al., 2013). Science fiction cinema played an especially important role in this process.

By the 1980s, the mainstream were experiencing cultural phenomena like Jean Michel Jarre's mass laser and fireworks concerts, the music genres synth pop and electronic dance music, various video games, home computers, etc. (Collins et al., 2013). Here a mention must be given to an important band which pioneered the all-synthesiser ensemble as a force in popular music, the German Kraftwerk, whose work focused on the human relationships with technology.

Still, a great change was enacted by the birth of different genres of electronic dance music (EDM) in the 1980s.

\subsubsection{Electronic dance music (EDM)}

The roots of electronic dance music can be traced back to four related movements (adopted from Wilson, 2006):

1) New York City dance scene of 1970s (predominantly gay, black and Puerto Rican scene) and later the garage scene in the 1980s

2) Chicago house music scene from the end of $1970 \mathrm{~s}$ and early $1980 \mathrm{~s}$

3) Detroit techno music scene of the early $1980 \mathrm{~s}$

4) British acid house scene of the mid to late 1980s that grew out of dance clubs in the holiday-sun location Ibiza (Spain)

1) Disco and EDM genres share common roots in the gay and black American communities (see more in Tomlinson, 1998). As Brewster and Broughton (2006) state: "Such global forms as house and techno are really nothing more than disco continued by other means." (p. 292) Disco was born in the early 1970s, when DJs at gay dance clubs in New York - and other bigger cities in the USA, like Chicago - mixed danceable soul tunes together.

One of the reasons why disco had to turn into other streams, was the so-called 'Disco Sucks' phenomenon which aimed to stop the production of disco music that was popular in the USA during the 1970s. A key event of the spreading phenomenon was the 'Disco Demolition Night' which took place on July 12, 1979 in Chicago's Comiskey 
Park. It was an ill-fated baseball promotion between the Chicago White Sox and the Detroit Tigers. At the climax of the event, disco records were blown up on the field between the two teams (Reynolds, 1998). However, interestingly this 'discophobia' (Reynolds, 1998) was not limited to white rockers, but many blacks joined to the 'Disco Sucks' movement too.

New York's disco scene changed its profile to 'garage', a song-oriented house sound music genre. Garage was named in homage to the sonic sensibility Larry Levan developed at his legendary club, the Paradise Garage (Reynolds, 1998). The club opened in 1977 and it was named after its location: an indoor truck parking lot in SoHo (Manhattan, New York). Larry Levan was one of the very first examples of the 'DJ-asshaman' (Reynolds, 1998, p. 35), who developed a science of total sound in order to create spiritual experiences for his followers.

(2) Chicago house music was born of a double exclusion. As Reynolds (1998) summarises: "House didn't just resurrect disco, it intensified the very aspects that most offended the discophobes: the mechanistic repetition, the synthetic and electronic textures, the rootlessness, the 'depraved' hypersexuality and 'decadent' drugginess." (p. 24)

House music began as a disc jockey culture which was imported from New York by Frankie Knuckles who DJ-ed at the club Warehouse in Chicago between 1979-1983. The Warehouse was a three-story former factory in West Central Chicago and became a cultic place for thousands of house fans, many gay and black people (Reynolds, 1998). The term 'house' also referred to the kind of music one could hear at the Warehouse.

(3) Shortly afterwards, a group of young, innovative producers from Detroit named Derrick May, Juan Atkins and Kevin Saunderson (the 'Belleville Three') began combining the black grooves of house and hip hop with European synth-sounds of groups (Tomlinson, 1998). The result was 'Detroit techno'.

Detroit techno musicians were influenced by Alvin Toffler's tracts “Future Shock" (1970) and "The Third Wave" (1980), in which he examines the effects of rapid industrial and technological changes upon the society. Toffler's use of the terms 'techno society' and 'techno rebels' influenced the Belleville Three and they began to name their music 'techno' (Reynolds, 1998). It can be also noted that with the growth of the term 
'techno', some communities (also scholars ${ }^{28}$ ) began to use it with a similar meaning to EDM. We should distinctly identify Detroit techno as the seed movement (Collins et al., 2013) and here 'techno' is defined as one of the genres of EDM.

4) Other related genres soon developed, such as acid house, breakbeat, jungle, ambient, trance, etc. These genres employ different music structures and appeal to different class- and ethic-based audiences (Tomlinson, 1998).

Ibiza used to be an inexpensive holiday location for British working-class youth in the early 1980s. The original pre-rave parties were held at an Ibiza club named Amnesia, where local DJs began to play imported house music (or acid house) from New York City and Chicago. Later on, new clubs were continuously opening in Britain in 'Amnesia-style' with 'Ibiza-look and attitude' (Reynolds, 1998) and the 'alternative' Ibiza culture began to spread in the context of the popular acid house ${ }^{29}$ movement in Britain.

During the 'Second Summer of Love' (or sometimes named the 'Summer of Rave') in 1988 and 1989, hundreds of illegal open-air and warehouse acid house parties were organised in London and elsewhere in Great Britain. As Redhead (1997) summarises: "The 'summer of love 1988', itself a reworking of another mythical summer - the summer of love 1967 - looks set to take its place in the hallowed halls of pop legends. While the 1960s once slipped lazily into the early 1970s, pop time has now accelerated with a vengeance - as if reclaiming borrowed time - according to the public phenomenon of acid house little more than a long weekend." (p. 56)

As acid house parties became more popular for British youth, the media started to devote an increasing amount of coverage to the scene, mainly focussing on its association with drug consumption. Due to the provocation of tabloid articles ${ }^{30}$, a general moral panic was spreading in the British society. This panic led to a crackdown on acid house clubs and venues and had a profoundly negative impact on the scene. Additionally, the acid house subculture was also conceived as a form of resistance against Thatcherism (see more in Hill, 2002).

\footnotetext{
${ }^{28}$ They started to use 'techno' with the meaning of EDM because of the critical coverage of 'electronic dance music'. A good example could be the event series 'Techno Studies' at the Berlin University of the Arts (UdK) in 2014 (Techno Studies, 2014).

${ }^{29}$ A subgenre of house, acid house was built on a specific sound determined by the irregular noise of the Roland TB303 bass line.

${ }^{30}$ See some of them in Rave news clipping, n.d.
} 
Figure 6: 'Trip to Hell' - An example for media coverage of acid house movement (The Sun, Nov. 2, 1988, p. $6^{31}$ )

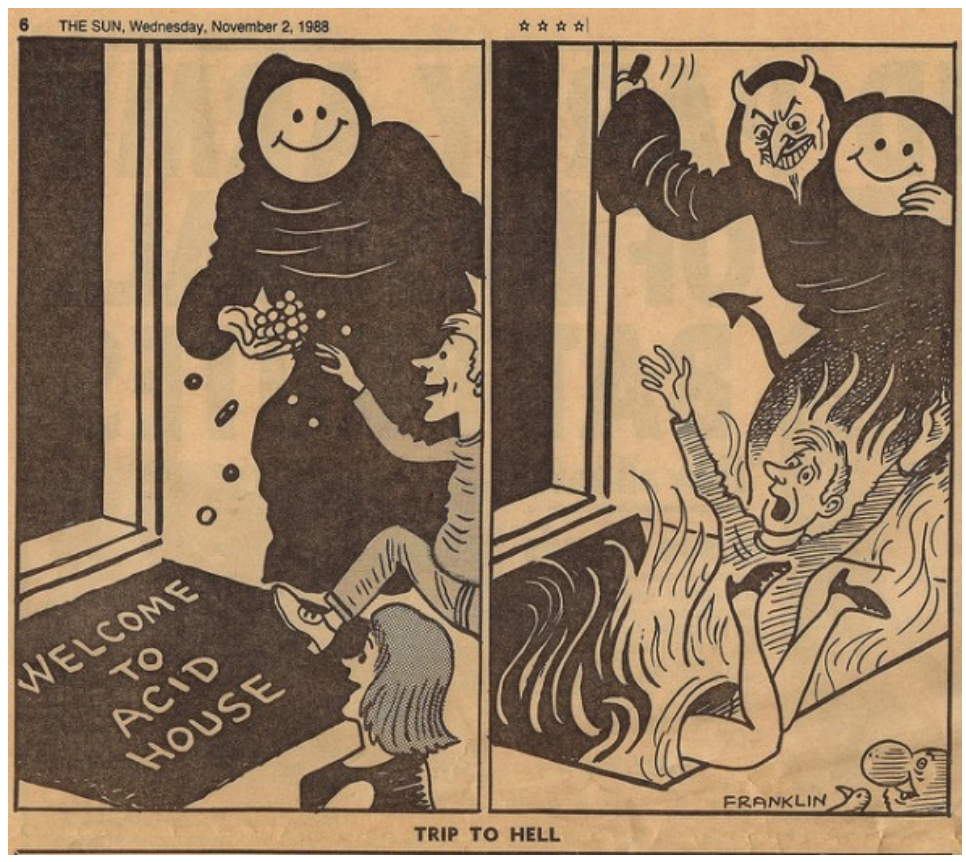

After these early movements in the USA and UK, electronic dance music became more and more popular all around the world, but especially in Europe. Thousands of legal or illegal rave events were organised and many newer genres (e.g. jungle, ambient, downtempo, hardcore) were born from one day to another. The scene entered the mainstream in the mid-90s as entrepreneurial desires became more pronounced. However, smaller communities/scenes continued to exist which tried to stay 'underground', and this is also true for parts of the scene today. The next chapter discusses the topic of club culture(s) in detail that also shows the main features of the scene today.

\subsubsection{Research interests on Electronic Dance Music Cultures (EDMCs)}

There are two competing perspectives in the research on Electronic Dance Music Culture(s) (henceforth EDMCs): 1) public health; and 2) cultural studies, youthsubcultural studies (or post-subcultural studies), and youth studies.

The following chapters summarise the most important concepts in cultural studies, youth-subcultural studies (or post-subcultural studies), and youth studies and only

\footnotetext{
${ }^{31}$ Retrieved from http://history-is-made-at-night.blogspot.de/2013/04/acid-house-trip-to-hell-1988.html [April 12, 2016]
} 
mention the perspectives of public health as this concern is not closely related to the topic of the present study.

\subsubsection{Public health perspectives on Electronic Dance Music Cultures}

There are widespread concerns about social problems associated with electronic music culture, particularly the apparent centrality of amphetamine drug use to the culture's allnight parties. This concern is evident in popular and in governmental health reports.

These studies focus mainly on the amount of attention on the demographics of drug use and other 'risky' behaviours in this culture. As Anderson and Kavanaugh (2007) express, because of that, there are two very different definitions of the event 'rave' too: from the public health issue's perspective, it is a meeting point for youngsters with risky drug abuse behaviour; for the other perspective (cultural studies), it is a much more complex cultural phenomenon and an important youth-based music scene. The main question is how we can gauge its significance for society today - in Reynolds's (1998) words: "Rave is more than music plus drugs; it's a matrix of lifestyle, ritualised behaviour, and beliefs. To the participant, it feels like a religion; to the mainstream observer, it looks more like a sinister cult.” (p. 9)

As mentioned, the results of public health studies are not directly related to the present study, therefore, they will not be described in depth. Of course, one should keep these outcomes in mind, because they are also an important part of the research on this field, but the present dissertation focuses more on the cultural background of the $\operatorname{EDMC}(\mathrm{s})$

\subsubsection{Cultural studies, youth-subcultural studies (or post-subcultural studies), and youth studies}

Cultural studies, youth-subcultural studies (or post-subcultural studies), and youth studies see $\operatorname{EDMC(s)}$ as a site of significant youth cultural identity and, at times, something tantamount to a social movement or alternative lifestyle. This study discusses these three fields - cultural studies, youth-subcultural studies (or post-subcultural studies), and youth studies -, together, because they share common roots in the research on youth and subcultures. They differ in their research focus, methods and mainly in the background of 
different researchers (some from cultural studies, some from sociology and others from different fields); therefore, some studies focus more on the sociological perspectives of youth/subculture phenomena, whilst some highlight the cultural and historical aspects. Scholars from these fields have explored many conceptual issues in their research about Electronic Dance Music Culture(s), including identity, alternative lifestyles, group membership, hedonism, subcultures, gender relations, and drug use. Therefore, from now this study will term these three academic fields together 'cultural studies' in a generic sense.

Where can we find the roots of academic interest in subcultures? Subcultural studies emerged out of two sociological traditions: 1) Chicago School (University of Chicago) in the first half of the twentieth century; and 2) Centre for Contemporary Cultural Studies (CCCS, University of Birmingham) from the 1960s and 1970s. The American tradition highlighted the deviant aspects (behaviour, norms, etc.) of subcultures. On the other hand, the British tradition defined subcultures as sites of resistance to cultural hegemony (Williams, 2007).

The term 'subculture' has been severely criticised ${ }^{32}$ on different grounds, for example that it fails in recognising local variations in youth's responses to music and style and it cannot interpret different group memberships. To deal with these shortcomings, scholars have reworked the concepts of subculture or introduced alternative terms such as 'lifestyle' (Gibbens, 1991), 'neo-tribe' (Bennett, 1999; Maffesoli, 1996; Malbon, 1998), 'post-subculture' (Muggleton, 2000) and 'scene' (Bennett \& Peterson, 2004; Straw, 1991). These contemporary theories are also called 'post-subcultural theories' (see more in Muggleton \& Weinzierl, 2003). These scholars' work moved beyond the notion of static memberships and used these new terms to describe youth groupings. They believe that these terms more appropriately describe youth-based cultures because of its transient groups whose associations are based on periodic gatherings at a dance party. This membership is often temporal and fleeting, and more fluid and dynamic.

\footnotetext{
${ }^{32}$ See more in Bennett \& Kahn-Harris, 2004.
} 


\subsection{Cultural studies' research topics on EDMC(s)}

There are many cultural studies scholars who have been working on the field of EDM, including Andy Bennett, Ben Malbon, Maria Pini, Angela McRobbie, Steve Redhead and Sarah Thornton. Here we would like to separate two main periods of research interest on EDMCs in cultural studies: 1) Studies on the rave era, and 2) studies on the contemporary club culture. ${ }^{33}$ Of course, other categorisations could be also used to broach the issue of research on EDMCs - e.g. by specific topics, by exact research interests -, but to summarise those earlier results in a clear way, we would rather stick to this simple separation by time periods.

\subsection{Cultural studies' results on the rave era}

\subsection{Background}

The early electronic dance music scene was also termed 'rave scene' approximately from the end of 1980s till the mid-1990s. As mentioned, the term 'rave' is used in many different ways in the literature. Interestingly, not only do the different research fields understand it variously, but also sometimes within the same field, different scholars use the term in different ways.

Anderson and Kavanaugh (2007) summarised the basic meaning of the term: "Raves have historically referred to grass-roots organised, anti-establishment and unlicensed all night dance parties, featuring electronically-produced dance music (EDM), such as techno, house, trance and drum and bass." (p. 500) So, 'rave' stands for those early (illegal or legal) events with thousands of people dancing the whole night for different types (genres) of EDM (e.g. techno, house, acid house, etc.).

Despite the expansion of rave culture in mainstream society, people like scene insiders, music industry professionals, or fans of EDM seldom use the word 'rave' today $^{34}$ largely because the scene has declined or changed so dramatically (Anderson \& Kavanaugh, 2007).

But why did cultural studies scholars begin to focus on rave culture right from the

\footnotetext{
${ }^{33} \mathrm{We}$ will not write about the research results of the aforementioned early scenes - e.g. Detroit techno scene -, because they were more local phenomena. Since the rave era (from the end of 1980s), we can talk about global phenomena that spread worldwide.

${ }^{34}$ Even though there are some new local youth movements that try to revive the early rave scene with for example illegal warehouse or outdoor events. See more in VICE, 2016, a documentary film on the 'rave renaissance' in Great Britain.
} 
early 1990s? The group of ravers is considered in several cases as the "prototypical twenty-first century', 'postmodern', 'millennium' youth subculture (Wilson, 2006). Of course, it was enough reason to draw a group of researchers' attention to this youth culture or subculture. On the other hand, the public health warnings on 'deviant' drug consumption gave greater publicity to the topic as well.

Ravers were characterised by their distinct musical preferences, clothing styles, dancing techniques, etc. We should add to this description that rave culture was developing during postmodern times of an increasing mass media and, later, online communication. In these cultural circumstances, youths were interested in technological developments such as the Internet (Wilson, 2006). McGuigan (1992), for instance, calls the rave subculture the first postmodern subculture because of the group's interest in 'hyper-real' computer-generated music that cannot be produced by classical instruments.

These early raves attracted a real mixture of people: 'fashion victims', homosexual and working class people (Rietveld, 1993). Many young 'Gen-Xers' ${ }^{35}$ in the late 1980s and early 1990s responded to cultural tensions by participating at raves (Anderson \& Kavanaugh, 2007). For example, they were responding to fears of economic alienations, or to the issue of conservatism ${ }^{36}$ versus liberalism.

\subsection{Research questions on the rave era}

In the following section, those pressing topics will be highlighted that cultural studies scholars have chosen within rave culture with the aim of grasping the status of contemporary scholarship on $\operatorname{EDMC}(\mathrm{s})$.

One of the most popular research topics on rave culture was 1) youth identity and resistance. Rave culture developed with an alternative lifestyle that resisted mainstream conventions (Anderson \& Kavanaugh, 2007). The behaviour (e.g. illegal drug use) and the crowd at raves caused alarm among parents and policy-makers alike and governments tried to control raves through social policies. Cultural studies scholars generally agreed that the feelings of connectedness in the rave culture functions as a sort of release and therapy for contemporary youths (Tomlinson, 1998 cited in Anderson \& Kavanaugh, 2007). However, some scholars questioned if rave culture is a politically-

\footnotetext{
${ }^{35}$ Members of 'Generation X': The birth cohort born between 1965 and 1980 (Ulrich \& Harris, 2003).

${ }^{36}$ This generation grew up during the Thatcher-era in the UK.
} 
oriented social movement (e.g. Hutson, 2000).

McRobbie (1994), Pini (1997), and Malbon (1998, 1999) see empowerment and social resistance to be an integral part of the escapist ${ }^{37}$ and pleasurable activities of young people. Unlike them, Thornton (1995) suggested that youths are largely concerned with achieving status by becoming integrated into the exclusive, underground rave culture. The most negative view is Redhead's (1997) aspect. He thinks that the 1990s rave culture is characterised by a loss of meaning.

Some other works of cultural srtudies have explored the 2) notion of community. Again there are two sides of opinions between the thinkers. The optimistic side - how Wilson (2006) mentions them -, like Pini (1997), Tagg (1994), and Tomlinson (1998), describes raves as idyllic places for communal experiences and spaces for sharing feelings through music, drug, and dance. On the other hand, Thornton (1995, cited in Wilson 2006) emphasises the subcultural distinctions within the rave culture: the trendy 'in' crowd is distinguished from those who are outside of the scene (the 'out-group') within a social hierarchy.

Jacobson (1995) points out that dance music has always had the mystic edge of society. Therefore, ravers have also created their own secret (youth) society and community where as Tomlinson (1998) mentions, "they even have their own secret language, in the form of the music itself" (pp. 203-204). About the actual language they used, Tannenbaum (1993) added that "[ $\mathrm{t}]$ echno is the ultimate teenage slang, a language elders can't comprehend" (p. 190). The rave generation grew up in a techno-world; they could easily handle new machines, computers, etc. which was different to their parents' and grandparent' generations. This is one of the reasons why technology played an important role in the ideology behind the rave scene. For example, several song titles (e.g. 'Exploding device', 'Rave machine') reflect upon this.

Some other studies focus on the aspect of 3) drug use as an important part of resistance in rave culture. Sometimes these papers see drug use as a positive, stabilising function for participants (e.g. Hitzler, 2002). At this point we can see a substantial difference between the cultural studies and public health research perspectives.

There are many other aspects and topics we could list here, however these three topics are the most relevant ones for the present research.

\footnotetext{
${ }^{37}$ Escapism is used here to denote youngsters aiming to escape from the daily stress, pressure and monotony of working life with clubbing and partying.
} 


\subsection{Cultural studies' results on club culture}

\subsection{1 "Subcultures to clubcultures"}

The title of this chapter is from Redhead's (1997) book "Subcultures to clubcultures: An introduction to popular cultural studies”. Many scholars (e.g. Anderson 2009; Bennett 1999; Redhead 1997; Thornton 1995) maintain that raves were more or less 'over' or had become merged with contemporary club culture by the mid-nineties.

The following diagram illustrates this switch and shows the different terminology used in the literature for these different periods.

Figure 7: Shifts in Electronic Dance Music Culture(s)

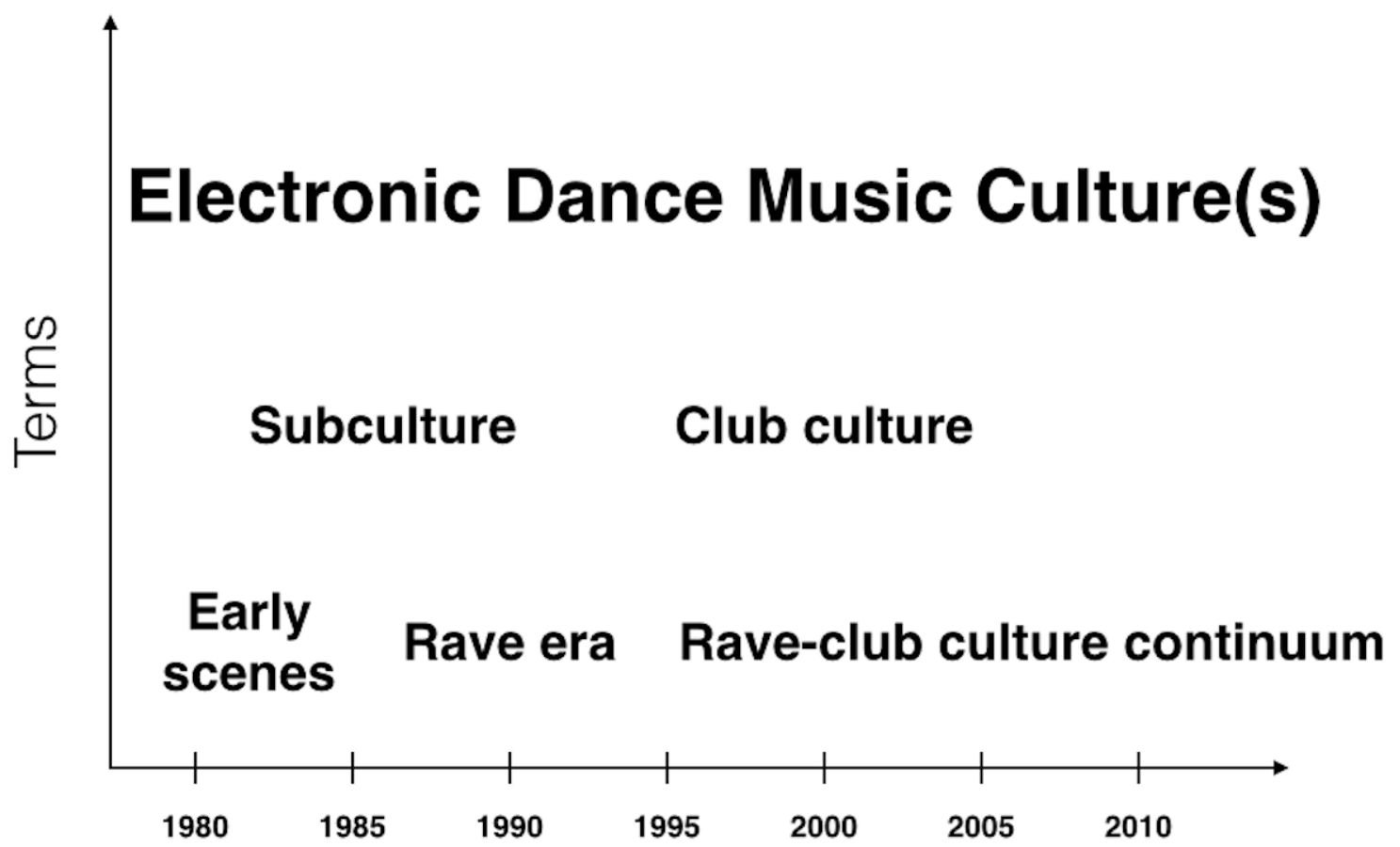

'Electronic Dance Music Culture(s)' is the most general and most commonly used term $^{38}$, which denotes its whole history and culture from the late 1970s till today. (Even though, as mentioned before, the term 'EDM' was popularised later, in the late 1990s, early 2000s.)

The early movements are named as 'early scenes' on this diagram, because they were not global scenes at this time, but more like local phenomena. (For example, the Detroit techno or the Chicago house scene.) Later, due to the rise of 'rave era' and its

\footnotetext{
${ }^{38}$ Also used by the scientific journal of EDM, Dancecult (https://dj.dancecult.net/index.php/dancecult).
} 
increased popularity in many different countries and continents (especially in the U.S. and Europe), we can grasp it as a global phenomenon, but of course, with special local patterns and features (e.g. with different music genres, different ways of organising events).

The expression 'rave-club culture continuum' from Anderson (2009) points to the fact that the 'DIY-organised' illegal raves' locations are moved into clubs and became legal and the forms of organisation turned to be more professional. As mentioned, Thornton (1995, cited in Wilson, 2006) claimed that 'club culture' is less about peace, love, unity and respect - as it was in the rave era -, but more about being trendy. At the same time, the scene became more and more mainstream and a new generation became the new members of it. As Anderson and Kavanaugh (2007) state, "EDM events today have varying degrees of allegiance to rave culture and showcase unique styles in mostly genre-specific sub-scenes" (p. 503). Nowadays, there are huge EDM events of different genres and many DJs can be considered commercial brands ${ }^{39}$. The events or parties themselves have also dramatically changed in form and style, departing significantly from their 'authentic' (in terms of their underground identity as described above) form.

\subsection{The model of scene}

As mentioned before, not only was there a change of a global rave scene to a more legal and professional ${ }^{40}$ club culture, but also the scholarship on 'subculture' changed to other more dynamic models such as scene, lifestyle, and neo-tribes ${ }^{41}$. Therefore, some contemporary scholars focus on these newer groupings phenomena.

Of the newer terms, 'scene' and its prelude 'community' will be defined here, because in terms of the topic of this research they are important concepts.

As mentioned, the concept of 'community' was a prelude of 'scene' and it has been applied to music in two main ways: 1) "community as a shared connection with a

\footnotetext{
${ }^{39}$ For example, David Guetta produced the official song of UEFA EURO 2016 (Guetta, 2016) and he also took part in its opening ceremony.

${ }^{40}$ Of course, there are exceptions, to this where events still have characteristics of DIY-organisations or events can be also illegal.

${ }^{41}$ Maffesoli (1996) used the terms 'neo-tribes' and 'neotribalism' for the sociological concept that states that humans have evolved to live in tribal society and they will naturally form social networks constituting new tribes. Processes of neo-tribalism relate to sensibilities of style and musical taste among contemporary youth, therefore, Maffesoli (1996) predicted that the postmodern era would be the era of neotribalism. Based on his concepts, Bennett (1999) states, in typical postmodern terminology, that "subcultures are better understood as a series of temporal gatherings characterised by fluid boundaries and floating memberships" (p. 600).
} 
locally created musical style, through which people articulate their sense of togetherness"; and 2) "community as a romantic construct, created by the music itself through which individuals can cast music itself as a 'way of life' and a basis for community" (Bennett, 2004, p. 224).

Straw (1991) made a clear distinction between 'musical communities' and 'musical scenes': for him, a musical community presumes a group whose population is rather stable because of the wide range of sociological variables. In contrast, a musical scene is "the relationship between different musical practices unfolding within a given geographical space" (Straw, 1991, p. 373). Scene is a cultural space where a range of musical practices coexist. The participants interact with each other within a variety of processes of differentiation and a scene membership is not necessarily restricted according to class, ethnicity or gender, but may cut across all of them. According to Bennett (2004), Straw's description therefore suggests a far broader and more dynamic series of social relationships than those considered in the context of subculture.

The concept 'music scene' was originally used in journalistic and everyday contexts, but since the 1990s it has become popular in academic research too. Bennett and Peterson (2004) highlighted the opposition between the global music industry, where music is created profit-oriented for mass markets, and scenes where music is produced more likely non-profit-oriented. Music scenes can, therefore, be responsible for the development of the so-called DIY industry, which is the domain of volunteer labour, smaller collectives and 'fans-turned-entrepreneurs' (Bennett \& Peterson, 2004). DIY industry in terms of EDMC means, for example, those collectives that organise events by themselves without any commercial support and whose ways of organisation are often (without a negative connotation) unprofessional - their protagonists have, for instance, never studied professional event management and try to solve problems in individual ways (e.g. friends voluntarily working at the bar, or at the door). McRobbie (2002) also states that the dance/rave culture has strongly influenced shaping and contouring, the energising and entrepreneurial character of the new culture industries. The level of selfgenerated economic activity that 'dance-party-rave' (McRobbie, 2002) organisations entailed, served as a model for many of creative activities. McRobbie (2002) describes an excellent example for that: "Find a cheap place, provide music, drinks, video, art installation, charge friends and others on the door, learn how to negotiate with police and local authorities and in the process become a club promoter and cultural entrepreneur." 
Bennett and Peterson (2004) define three types of scenes: 1) local; 2) translocal; and 3) virtual. 1) They define local scene as a social activity that takes place in a delineated space and over a specific span of time and the scene members mainly meet face-to-face. On one hand, a local scene has the main characteristics of its global scene ${ }^{42}$, but on the other hand, it is always individual and has own patterns and characteristics. Recently many studies were born in order to discover characteristics of local scenes, for example, Spring (2004) traced the rise and fall of a small industrial city, Ruston's (Louisiana, USA) rave scene; Montano (2011) described the changing shape of DJ culture in Sydney's commercial EDM scene; or Van Straaten (2012) gave possible reasons for the commercialisation of Amsterdam's psytrance scene.

2) Bennett and Peterson (2004) state that translocal scenes are those selfconscious local music scenes - focussing on a particular kind of music - that are in regular contact with similar local scenes in distant places. Based on the exchange of recordings, bands, fans and fanzines, they are in contact with each other. The members of translocal scenes meet partly face-to-face, partly virtually. We could list here, for example, D’Andrea's (2007) book “Global Nomads: Techno and New Age as Transnational Countercultures in Ibiza and Goa", in which he describes the translocal and partly virtual - connections between Ibiza, Pune and Goa.

3) Finally, virtual scenes are based on computer-mediated communication that enables fans around the world to come together and influence the scenes' developments. These scene members need never meet face-to-face - but they can, of course (Bennett $\&$ Peterson, 2004). An extraordinary example for virtual scenes could be Whelan's (2008) book "Breakcore: Identity and Interaction on Peer-to-Peer", an informative examination of virtual community from the chatrooms of Soulseek ${ }^{43}$, a file-sharing application and platform used by music enthusiasts. The book focuses on users involved in the genre breakcore $^{44}$ and analyses their conversations in order to illustrate how the individuals define themselves in the scene and how they employ discursive cues to identify 'insiders' and 'outsiders'. As we can see it in Whelan's (2008) example and the cases this study presents, the members, who take part in those online conversations are not only fans, but

\footnotetext{
${ }^{42}$ In this sense, global scene includes all local scenes. For example we can talk about the EDM scene as global, but the Berlin techno scene would be a local scene within it.

${ }^{43} \mathrm{http} / / /$ www.slsknet.org/

44 Breakcore is an EDM genre influenced by jungle, industrial, and hardcore techno (Reynolds, 2013).
} 
also musicians, producers and other professionals. Therefore, we agree with Bennett and Peterson (2004) only partly, because they state that mostly fans create virtual scenes.

Although there are many cases when only fans take part in these conversations - or they initiate or control it, see for example the Facebook Groups in this study -, but many times musicians and others also play very important roles in the communicative events.

The notion of the third scene type, virtual scene plays a very important role in the theoretical background of this study. The aim of this research is to combine the models of virtual scenes and online discourse communities through the chosen examples from $\operatorname{EDMC}(\mathrm{s})$. 


\subsection{Conceptualisation and characteristics of the discourse community of electronic}

\section{dance music}

In the following chapters, most important points of musical discourse analysis will be summarised. Moreover, Swales's (1990) conceptualisation of discourse community will be expanded through the discourse community in question: the discourse community of electronic dance music.

\subsubsection{Musical discourse analysis}

Having touched the most basic theoretical investigations on discourse analysis, discourse community and research on electronic dance music, and merging those fields together, some thoughts must be added to the topic of 'musical discourse analysis'.

Bradby (2003) summarises that musical discourse analysis has been applied in three ways in linguistics: 1) studying song lyrics (e.g. Kreyer \& Mukherjee, 2009; Middleton, 2000; Newman, 2009); 2) giving descriptions of discourses on or about music (e.g. Androutsopoulos, 2008; Whelan, 2008; Widdicombe \& Wooffitt, 1995); and 3) in the analysis of music as discourse (e.g. Agawu, 2008). The third perspective is closer to aesthetics and studies in music theory. From these three aspects, the focus of the present research is on describing discourse about or on music.

Many other variations on the term 'musical discourse' (originally from Tagg, 2003) can also be found in the literature: for example, 'music discourse' (Moore, 2001), 'song discourse' (Murphey, 1992), 'discourse about music' (Blacking, 1982). Here, Tagg's 'musical discourse' will be used with the meaning of any kind of linguistic investigation on the relationship between music and discourse (or language).

Generally, we can say that research on the relationship between music and language from a linguistic point of view still remains on the periphery of interest for linguists. For example, Fóris and Bérces (2007) pointed to this fact in terminology studies; Johns (1997) in research on discourse communities; and Pavlovová (2013) in discourse analysis.

Studying musical discourse is a highly complex and interdisciplinary matter: it has to take into account social, linguistic, psychological, visual, ritual, technical, historical and musicological aspects (Aleshinskaya, 2013). 


\subsubsection{Parent discourse community, discourse communities and sub-discourse communities}

As it has been mentioned before, electronic dance music is an umbrella term or metagenre, which includes many different music genres, subgenres, sub-subgenres, etc. We have also seen that from the perspectives of subcultural studies ${ }^{45}$ or popular music studies, musical communities are mainly developed and organised by the group members' interests in different music genres. So these groups of individuals are always organised into a community (or to a scene, subculture, etc.) by the music genre they are interested in, they work with, or they listen to, etc. To give an example: We can talk about the global electronic dance music scene as a huge category that is built up by smaller (local, translocal or virtual [Bennett \& Peterson, 2004]) scenes, such as Berlin's minimal techno scene, Mannheim's drum and bass scene, or Amsterdam's psytrance scene, etc. The members of these scenes are diverse; they can be musicians, fans, promoters, flyer designers, etc. With introducing linguistic discourse analysis in EDMC(s), we can also see how these musical communities are articulated and formed by the actual discourse between their members.

Moreover, with the concept of discourse community, we can define these mechanisms of community constructions not only by the music genres and their communities, but also by their other special interests (e.g. the discourse community of fans and users of analogue synthesisers) or their profession (e.g. flyer designers', music or event managers' discourse), etc. Those smaller groups would be then the sub-discourse communities or sub-sub-discourse communities (as one could name them after music genre, subgenre, sub-subgenre, etc. [McLeod, 2001]).

The discourse community of electronic dance music is a multi-layered entity: it includes all people that are interested in electronic dance music and willing to communicate on such topics. It means that not only musicians and fans are the part of it, but also people who, for example, work within the scene, such as graphic designers (designing flyers, cover art, etc.), customer care agents at related companies (software/hardware companies producing equipment/instruments for electronic music production), music managers, etc. Here the definition on this discourse community would exclude those individuals who are interested in electronic dance music but never actively communicating in the scene in the sense (written or spoken) on such topics. On the other

\footnotetext{
${ }^{45}$ See more in Chapter 2.4.3.2.
} 
hand, a person like this is hardly imaginable, because if someone is interested in this field, there might be many cases where s/he must enter the discourse - without him/her being aware of it - while expressing an own opinion; e.g. chatting about music or a concert with friends in a bar would be already enough to take part in the (oral) discourse.

Therefore, the author of this study proposes the following categories of discourse community to describe the discourse community in question: The discourse community of electronic dance music is the 1) parent discourse community (Swales, 1990 also uses this classification). The parent discourse community includes all 2) discourse communities discussing any kind of EDM topics. An example could be from the next figure (Figure 8), the discourse community of techno - that is still a huge group of people all around the world, talking about techno and related topics - which would be ordered under the parent DC. This DC has a close relationship with the DC of Detroit techno, a subgenre of techno. But in Figure 8, we can also see another group, the discourse community of the Roland TR-909. This instrument is a historical tool to produce techno music; therefore, members of the DC often exchange information about it. A whole discourse (and at the same time a community) in different forms (e.g. on web discussion forums, in fan groups, etc.) has been developed around the drum machine. Therefore, a discourse community can be established that is specialised in the communication on such topics. This DC is also closely related to techno and Detroit techno communities. As we can see, this group of individuals creates a discourse community by its special interest in an instrument, not by a music genre specifically, but at the same time it remains part of the parent discourse community. 
Figure 8: An example for discourse communities within the parent discourse community of electronic dance music

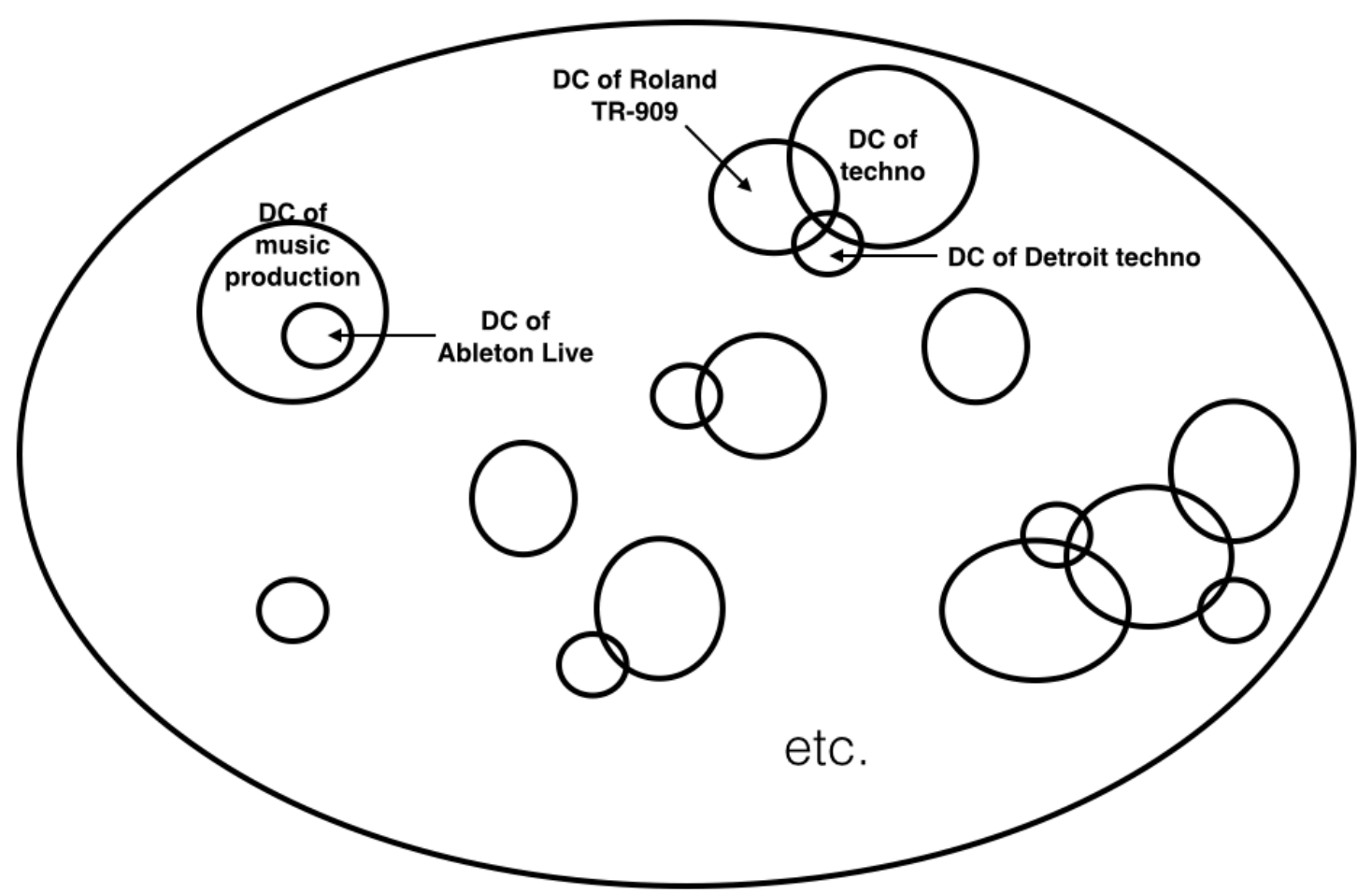

Another example can be seen in Figure 8: the discourse community of music production. This community also includes many individuals talking about different topics of EDM production. Moreover, it has, among others, a 3) sub-discourse community: the discourse community of 'Ableton Live', the music software. These individuals could be ordered into the DC exchanging experience - in different forms - about this software. Within this sub-discourse community, we would imagine a 4) sub-sub-discourse community that would, for example, discuss specific topics about an exact version of the software Ableton Live (e.g. Ableton Live 9.7).

The list would be way too long - or maybe impossible - to thoroughly collect each sub-category and it is also not important in the scope of the present study. Instead, this research highlights these special forms of group and identity constructions by the discourse the members initiate with each other.

To sum up, looking at a group of individuals as a discourse community within EDMCs, allows us to shift the focus of research to the actual discourse that is initiated by the members of the group. Additionally, this discourse helps to construct social groups and identities. 


\subsubsection{The discourse community of electronic dance music in terms of Swales's conceptualisation}

In the next sections, Swales's (1990) conceptualisation of discourse community will be followed in order to analyse the discourse community of electronic dance music.

From Swales's (1990) perspective, the following points can be stated for the discourse community of electronic dance music:

“1. It has a common public goal: communication on electronic dance music and related topics.

2. It has mechanisms of intercommunication: e.g. emails, forum conversations, phone calls, etc.

3. These mechanisms were set up to provide information about electronic dance music.

4. It has more genres in the communicative furtherance, e.g. Internet genres (blogs, forums, webpages, etc.) and multimodal texts (flyers, posters, album cover art, etc.).

5. It has a specific lexis (e.g. pattern, MIDI, loop, etc.).

6. Its common knowledge is based on the topic of electronic dance music and the members have different levels of knowledge.” (Jóri, 2012)

\subsubsection{Common public goals}

As it was mentioned before, Swales's (1990) theory was criticised at the point of common public goal: Porter (1986) and Johns (1997) think that the community does not necessarily have common goals (e.g. a family, or a university's alumni board [Borg, 2003]).

The discourse community of electronic dance music does have a common goal: communicating/changing information on the music or related topics. This study however agrees with Porter and Johns that there might be some communities, where this common goal is not crucial.

Swales (1990) states that these goals can be formally inscribed in documents, or they may be more tacit. In both cases, we find examples in the DC of EDM: for example, in online forums that discuss related topics of EDM, these goals are written in the forum rules or in the general description of the site. On the other hand, in an everyday communicative event - for example, music fans exchanging impressions about an EDM event -, these goals are not articulated formally, but they are still clear and public for all participants of the communication process. 
Swales (1990) also puts that these goals are sometimes high level or abstract. In the discourse community of electronic dance music, we cannot talk about these cases, because the common public goal for the most part simply to communicate and share information or ideas about electronic dance music and related topics. See examples on that in Chapter 5.

\subsubsection{Mechanisms of intercommunication}

As Swales (1990) states, the participatory mechanisms of intercommunication vary according to the community. In the case of the discourse community of electronic dance music these mechanisms of communication can vary as well: emails, Facebook posts, Internet forum comments, conversation pieces, newsletters, flyers, etc.

Here, we also have to define the mechanisms of intercommunication and separate them from genres. The concept of 'intercommunication' is something what we do in our everyday communication processes with one another: writing an email - where the form of email (not the content of it) would be the mechanism of intercommunication -, talking on the phone, holding a presentation at a meeting, commenting friends' pictures on Facebook, etc. Then again, in the case of the email, the genre would be the text of the email. See more examples on these mechanisms in Chapter 5.

\subsubsection{Mechanisms to provide information about electronic dance music}

According to Swales (1990), these abovementioned mechanisms of intercommunication are used by the members of the DC to provide information and feedback.

The information and feedback, of course, vary depending on the aims of a DC. In the DC of EDM, these information exchanges can be, for example, about music, how to use technical equipment, attending events, differences of music genres, artists' discography, etc. 


\subsubsection{Genres in the communicative furtherance}

Swales (1990) uses 'genres' to denote the different types of texts that are used by discourse communities. As mentioned before, Swales (1990) comes from a genre analysis background in linguistics, therefore, this plays a central role in his model.

Discourse communities employ one or more genres in the communication of their aims. Swales (1990) adds that a DC continuously develops discoursal expectations that are articulated through these genres, and at the same time, genres present the operations of the discourse community.

In the DC of EDM these genres can be, for example, texts of emails, multimodal flyers (including pictures and 'classical' texts as well), blog posts, journalistic articles, etc. See more about these genres in Chapter 5.

\subsubsection{Specific lexis}

A DC owns not only specific genres but also specific lexis. Members of a DC require efficient communication exchange between each other. In order to communicate efficiently, the community creates a specific terminology that is well known among the members (Swales, 1990).

The DC of EDM uses highly technical terminology, especially when the community exchanges information about topics on music production. Of course, the level of knowledge of this terminology can vary amongst members. The newer members are less confident in using these terms. For example, when music producers comment on a web discussion forum where the main topic is music production itself, one immediately notices the large amount of technical terms used; but if, for example, music fans - who normally know less about the production side of music - write about music, they use, of course, less technical terms. See more about these cases in Chapter 5.

\subsubsection{Common knowledge}

We believe that it is necessary to complete Swales's sixth point, where he states:

\footnotetext{
"6. A discourse community has a threshold level of members with a suitable degree of relevant content and discoursal expertise. Discourse communities have changing memberships; individuals
} 
enter as apprentices and leave by death or in other less involuntary ways. However, survival of the community depends on a reasonable ratio between novices and experts.” (Swales, 1990, p. 27)

This hypothesis points to the general fact that the level of knowledge varies in the community. Some of the members have broad knowledge on the common interest; some of them are newcomers and know less about the topic. In the discourse community of electronic dance music, these characteristics are very important; therefore, Swales's thoughts should be completed with two points from the aforementioned cultural community (Clark, 1996) and communities of practice (Wenger, 1998) models.

Clark's (1996) model focuses on the so-called 'common ground' between the members of the cultural community. Here we have to highlight Clark's (1996) meaning on insider and outsider information: in the discourse community of electronic dance music, insider information plays a very important role for the members' identities. This insider information is - as Wenger $(1998,2006)$ puts it - the 'shared domain of interest' which defines the community's identity. The members are obviously proud of their knowledge on specific topics and the group building works by communicating this knowledge. Also, they separate themselves from outsiders with their level of knowledge.

\subsubsection{Swales's central notion: 'genre'}

As we could see in Swales's (1990) notion of discourse community, 'genre' (and genre analysis) plays a central role in his models. Swales's (1990), Miller's (1984) and Bhatia and Gotti's (2006) thoughts on genre analysis and genres have been mentioned in Chapter 2.3.1. Here, we would like to expand these thoughts with Swales's (1990) and other scholars' definitions in order to give a working definition on text genre. With it, one will be able to classify the corpus has been selected for this research.

There is much confusion surrounding the notion of genre and its related terms such as register, text type, domain, style, sublanguage, message form, and so forth (Lee, 2001). Genre can be discussed, for example, from the perspectives of folklore studies, literary studies, rhetoric, and linguistics, but the present research focuses only on the latter one: linguistics.

Biber (1988) differentiates genre and text type from one other by stating that genre is based on external, non-linguistic, 'traditional' criteria while text types are based on the internal, linguistic characteristics of the texts themselves. In this view, genre is a 
category assigned on the basis of external criteria (Lee, 2001). External criteria can, for example, be: purpose, activity type, intended audience, while internal criteria can be any linguistic characteristic of the text.

Biber's (1988) external-internal divide is followed in the typology proposed by the Expert Advisory Group on Language Engineering Standards (EAGLES) (1996) in their "Preliminary Recommendations on Text Typology". The advisory statement highlights that every research has its own criteria and researchers can differ in their categorisations.

For Swales (1990), as mentioned before, genre is a central category in terms of discourse community. This research accepts and applies his thoughts on genre, as he explains genres according to their roles in a discourse community. Swales (1990) adds the following points to his working definition of genre:

\footnotetext{
"1. A genre is a class of communicative events."

"2. The principal feature that turns a collection of communicative events into a genre is some shared set of communicative purposes."

"3. Exemplars or instances of genres vary in their prototypicality."

"4. The rationale behind a genre establishes constraints on allowable contributions in terms of their content, positioning and form."

“5. A discourse community's nomenclature for genres is an important source of insight." (pp. 45-
} 58)

1. For Swales (1990), genre plays a significant and indispensable role in communicative events. They vary in their occurrence from common (e.g. news items in newspapers) to rare (e.g. Presidental Press Conferences) (Swales, 1990). For him, a communicative event is not only the discourse itself and its participants, but it also involves its environment of production and reception.

2. According to Swales, these shared sets of communicative purposes should be identified by analysts by undertaking a fair amount of independent and open-minded investigation and genre membership is based on the communicative purpose.

3. Swales's (1990) third statement is based on Rosch's (1975, cited in Swales, 1990) well-known prototype theory from cognitive sciences that is a mode of graded categorisation, where some members of a category are more central than others. Swales puts that an exemplar can become prototypical for the entire genre. 
4. The fourth point states that "established members of a discourse community employ genres to realise communicatively the goals of the community communicatively" (Swales, 1990, p. 52).

5. Active members of a DC tend to have the greatest genre-specific expertise than those ones who are rarely involved in the communication process. These active members give genre names to classes of communicative events that might be adopted from closer discourse communities (Swales, 1990).

To sum up, Swales's (1990) definition of genre is based on his model of discourse communities. For him, a genre comprises a class of communicative events and the members of these events share some set of communicative purposes. The expert members of the parent discourse community recognise these purposes; therefore, they constitute the rationale for the genre. At the same time, this "rationale shapes the schematic structure of the discourse and influences and constrains choice of content and style" (Swales, 1990, p. 58). If specific exemplars of a genre exhibit various patterns of similarity in style and content, they will be viewed as prototypical ones by the parent discourse community.

Here we can clearly see that Swales (1990) revolves around genres in analysing a discourse community. The present research does not focus on genre analysis, however, it finds Swales (1990) theories still highly interesting in terms of discourse communities. For this study, genres play an important role only in the categorisation of the analysed linguistic data - just as it would do any other corpus-based research.

We also have to differentiate between 1) the genre of the platform where the discourse of the discourse community actually takes place ${ }^{46}$ (e.g. different Internet genres) and the 2) text genre (or discursive genre) that is the physical form of the discourse or, with Swales's (1990) words, the entire communication event.

The corpus of this study includes only sources from the Internet, therefore, it explains only Internet genres as platforms for discourses or gathering places for discourse communities - see more about them in Chapter 5.

\footnotetext{
${ }^{46}$ In other words, this is the 'gathering place' for a discourse community.
} 


\subsubsection{Internet genres}

Many recent studies (e.g. Giltrow \& Stein, 2009) deal with the questions of the effects of Internet on genres and on the notion of genre. David Crystal (2011) goes even further with a shift from his earlier thoughts in Crystal, 2001 and 2006 - and warns against using the term 'genre' as a label for the different entities that form Internet discourse because of its homogenous nature. He thinks that one should take a term that is neutral and he proposes to use 'outputs' instead of genre. In this perspective, email, for example, is "one of the outputs of Internet technology" (Crystal, 2011, p. 10).

Despite these newer thoughts on genre and the Internet, we still use the categories text genre and Internet genre to classify the selected linguistic data, because this 'classical' categorisation is better fitting to the scope of this thesis.

Scholars continually have difficulties with classifying genres of the Internet, because the technology changes so fast that these classifications become 'out of date' within a few years. For example, Crystal's (2006) earlier categorisation divides Internet genres into six types: 1) e-mail, 2) chat groups, 3) virtual words ${ }^{47}$, 4) World Wide Web (WWW) (e.g. personal websites), 5) instant messaging $\left.{ }^{48}, 6\right)$ blog.

Summarising other scholars' thoughts on Internet genres as platforms for discourse or gathering places for discourse communities, Bishop (2009) divides seven different types of Internet genres of online communities $\left.^{49}: 1\right)^{\text {personal homepage }}{ }^{50}, 2$ ) message boards, 3) e-mail lists and newsletters, 4) chat groups, 5) virtual words, 6) weblogs and directories, and 7) wikis and hypertext fiction.

From all categorisations, we found Herring's (2007) faceted classification scheme for computer-mediated discourse the most comprehensive. The classification is based on the assumption that "computer-mediated discourse is subject to two basic types of influence: medium (technological) and situation (social)" (Herring, 2007). The medium factors are the following:

(M1) synchronicity

(M2) message transmission

\footnotetext{
47 "Virtual words are imaginary environments which people can enter to engage in text-based fantasy social interaction." (Crystal, 2001, p. 12)

${ }^{48}$ One type of chat that offers real-time text transmission.

${ }^{49}$ He uses the term 'web-based communities'.

${ }^{50}$ Bishop (2009) argues that on a personal website, users can leave messages in guest books or comment underneath the articles and this is the way the discourse is initiated on this platform.
} 
(M3) persistence of transcript

(M4) size of message buffer

(M5) channels of communication

(M6) anonymous messaging

(M7) private message

(M8) filtering

(M9) quoting

(M10) message format

On the other hand, the situation factors are:

(S1) participation structure

(S2) participant characteristics

(S3) purpose

(S4) topic or theme

(S5) tone

(S6) activity

(S7) norms

(S8) code

Here, the content of these categories after Herring (2007) will be summarised, because this categorisation will be applied to classify the collected language sample in Chapter 5.

(M1) Synchronicity relates to the form of participation of the members in the discourse. In asynchronous systems, participants do not have to be logged on at the same time in order to send and receive messages (e.g. email, web discussion forum). In synchronous systems, sender and addressee(s) must be logged on simultaneously (e.g. chat rooms).

(M2) The transmission of message can take the form of message-by-message (one-way) or character-by-character (two-way). Currently, most of the CMC technologies apply one-way transmission.

(M3) Persistence of transcript refers to how long messages remain on the system after they are received.

(M4) Size of message buffer refers to the exact number of characters the system allows in a single message. 
(M5) Channels of communication refer to the different communication channels that the actual CMC system makes available.

(M6) Anonymous messaging, (M7) private messaging, (M8) filtering, and (M9) quoting all refer to technological affordances of CMC systems.

(M10) "Message format determines the order in which messages appear, what information is appended automatically to each and how it is visually presented, and what happens when the viewing window becomes filled with messages.” (Herring, 2007)

(S1) Participation structure refers to the following points:

- number of participants in the online communication situation

- the amount and rate of participation; whether the communication is public

- semi-private, or private

- the extent to which interlocutors choose to interact

anonymously/pseudonymously

- the distribution of participation across individuals

(S2) Participant characteristics are the participants' backgrounds, skills, and experiences, real life knowledge, norms, and interactional patterns.

(S3) Purpose has two levels: group purpose (the common aim) and goals of interaction (the individuals' aims).

(S4) Activities are discursive means of pursuing interactional goals. These activities have associated conventional linguistic practices that signal when that activity is taking place.

(S5) Topic relates to the topic of the discourse.

(S6) "Tone refers to the manner or spirit in which discursive acts are performed." (Herring, 2007)

(S7) Norms refer to conventional practices within the computer-mediated environment and comprise three types: 1) norms of organisation; 2) norms of social appropriateness; and 3) norms of language.

(S8) Code refers to the language or language variety in which computer-mediated interactions are carried out. 


\subsection{Questions of identity}

\subsubsection{Discourse and identity}

Identity is a socially constituted and "dynamic product of the social, historical and political contexts of an individual's lived experiences" (Hall, 2013, p. 31). In a broader sense, "who people are to each other, and how different kinds of identities are produced in spoken interaction and written texts" (Benwell \& Stokoe, 2012, p. 6).

As individuals with own self identities ${ }^{51}$, we use language with our social histories which are partly defined by our memberships in different social groups, 1) into which we are born (e.g. gender, social class, race, etc.), and 2) which we develop through our activities that comprise communities (e.g. school, workplace, hobby groups, etc.) (Hall, 2013). These group memberships play very important roles in the development of our multiple social identities that are not stable or held constant across contexts, but they are rather locally situated and historically constituted (Hall, 2013).

In this sense, we can differentiate between many types of identities, such as educational identity, gender identity, geographical identity, friendship identity, and subcultural identity. Tracy (2002), for instance, distinguishes four basic types of identities: 1) master identities (gender, class, age, ethnicity, etc.); 2) interactional identities (e.g. different roles in particular contexts); 3) relational identities (e.g. friendship, colleague, wife, boyfriend); 4) personal identities (e.g. own personality).

Historically, Hegel's ([1807], 1977, cited in Benwell \& Stokoe, 2012) thoughts in "The Phenomenology of Spirit" had important effects on understanding identity as a product of the social. In his aspects, individuals' self-consciousness never exists alone, but in relationships to the others (Benwell \& Stokoe, 2012).

This shift in looking at identity as a socially created phenomenon, brought sociologists and other thinkers to discuss 'collective identities' in the second half of the 20th century. Two of these newer approaches were the 'social identity theory' in social psychology and variationist sociolinguistics in linguistics (Benwell \& Stokoe, 2012).

\footnotetext{
${ }^{51}$ It has been argued by many scholars that the self has dislocated from private to public sphere in the postmodern era. This dislocation is partly thanked to the globalisation with the faster and closer connections across geographical space (Gibbens, 1991) and to an increase in the mediation of experience by mass printed and electronic media (Grodin \& Lindlof, 1996, cited in Benwell \& Stokoe, 2012). Many thinkers see these phenomena as negative effects on the self, for example Bauman (2004) writes about 'commodified identities' due to continuous consumption), while Flusser (1985) - among others - emphasises positive effects such as getting emphatically closer to the geographically distant others.
} 
'Social identity theory' (henceforth SIT) was developed by Tajfel (1982) and his colleagues in the 1980s. Social identity is defined as a process constituted by a reflexive knowledge of group memberships and an emotional attachment or specific disposition to this belonging (Benwell \& Stokoe, 2012). SIT explores 'in-groups' and 'out-groups' that are the basis for constituting identities by defining ourselves as part or not part of them. At the same time, this phenomenon is flexible and can be changed depending on the activity.

Variationist sociolinguistics (henceforth VS) has a similar understanding of identity to SIT. It focuses on the relationship between social identity and language use. Their research processes often involve long-term ethnographic and participantobservation methodologies. One of the earliest (and well-known) results is from Trudgill (1974), who mapped the correlation of variables on verbs with social variables of social class and sex in Norwich. VS defines identity as a pre-discursive construct that correlates with, or causes particular language behaviours (Benwell \& Stokoe, 2012).

This understanding of identity brings us to its postmodern accounts, where identity is treated as "fluid, fragmentary, contingent and, crucially, constituted in discourse" $^{, 52}$ (Benwell \& Stokoe, 2012, p. 17). Therefore, our social identities are constantly reconstituted in discourse each time we think or speak (Weedon, 1997). There are many existing books about the theoretical accounts on discourse-based approaches to identity (e.g. Harré, 1998; Michael, 1996) and some of them focus on one particular type of identity, such as gender (e.g. Litosseliti, 2006), age (e.g. Nikander, 2003), national identity (e.g. Wodak et al., 1999) and sexuality (e.g. Livia \& Hall, 1997).

As Benwell and Stokoe, (2012) put it, discursive view of identity can be realised in two ways: 1) "as a discursive performance or construction of identity in interaction"; or 2) "as a historical set of structures with regulatory power upon identity" (p. 29). This research takes into account the first way of identity realisation.

For the discursive view of identity, Zimmerman's (1998) classification of identity is very useful. She recognises three types of identities: 1) 'discursive identity', 2) 'situated identity', and 3) 'transportable' identity. 1) Discursive identities are inhabited in the course of the talk's practical activities, e.g. caller-called, interviewer-interviewee, etc. 2) Situated identities are created by situations, e.g. as a caller complaining about a

${ }^{52}$ A similar perspective on 'subjectivity' can be also found in poststructuralist authors' works (e.g. Deleuze \& Guattari, 1987). 
specific topic. Or 3) transportable identities are latent, but they play important roles in different discursive situations, such as male, female, young, etc.

Also, a range of methods have been applied to research questions of discursive performance or construction of identity: CDA, conversation analysis, interactional sociolinguistics, membership categorisation analysis, narrative analysis, politeness theory, positioning theory, etc.

From these approaches, the present study applies conversation analysis and membership categorisation analysis methods in order to take a closer look at its corpus of linguistic data.

\subsubsection{Conversation Analysis}

Generally, Conversation Analysis (henceforth CA) investigates social interactions in situations of everyday life. These naturally occurring interactions can be easily collected in the case of CMC and classic transcripts of records are not needed. CA was developed in the late 1960s and early 1970s by Harvey Sacks and his associates Emanuel Schegloff and Gail Jefferson. The stream was inspired by Harold Garfinkel's ethnomethodology and Erving Goffman's conception of the interaction order. The methods of CA - apart from everyday conversations - have been adapted to embrace more task- and institutioncentred interactions, such as law enforcement, doctor-patient conversations, helplines, etc.

According to Benwell \& Stokoe (2012), CA has an indexical, context-bound understanding of identity. In this perspective, the self is an "oriented-to production and accomplishment of interaction" (Benwell \& Stokoe, 2012, p. 36) and the context for talk is provided by the sequential organisation of turns. Moreover, Schegloff (1992) claims that identity relevance must be demonstrably linked to particular actions in talk.

Four basic CA concepts are the following (summarised according to Drew, 2005): 1) The conversations are made up 'turns' and they are arranged one after another. 2) The concept of 'turn design' presents what exactly goes into a turn. 3) The conversation is not 'just talk', but it achieves 'social actions' like accusing, inviting, joking and offering. 4) Conversational turns do not exist in isolation, but they are connected with each other in an organised way: in 'sequence organisation'. 


\subsubsection{Membership Categorisation Analysis}

Membership categorisation analysis (henceforth MCA) is rooted in ethnomethodology and conversation analysis. MCA pays attention to the situated and reflexive use of categories of everyday and institutional interactions (Benwell \& Stokoe, 2012). It is "concerned with the organisation of common-sense knowledge in terms of the categories members employ in accomplishing their activities in and through talk" (Francis \& Hester, 2004, p. 21).

MCA has its roots in the work of Harvey Sacks $(1974,1992)$ who sees talk as 'culture-in-action' (Hester \& Engin, 1997) focussing on the local management of speakers' categorisation of themselves and others. For this, Sacks (1992) developed his idea of 'membership categorisation device' (henceforth MCD) which constitutes a collection of categories and rules of application. Benwell and Stokoe (2012) mention Sacks's (1974) classical example: “The baby cried. The mommy picked it up.” (p. 38), where Sacks claims that the MCD would be the 'family' that allows the categories 'mommy' and 'baby' to be collected together. Other categories could be, for example, man, teacher, musician, student, etc. These categories are linked to particular actions that Sacks names as 'category-bound activities'. Sacks (1992, vol. 1.) also adds a very important point: "a great deal of the knowledge that members of a society have about the society is stored in terms of these categories" (p. 40-41).

A conceptual development within MCA has been introduced by D. Rod Watson (1978), who extended Sacks's (1974) 'category-bound activities' to the more general notion of 'category-bound predicates'. These are not only activities, or actions that are bound to categories but also a range of characteristics. Back to Sacks's mother-baby example, these predicates would be, for example, the mother's age, her knowledge about the topic of having a baby, and so forth.

Many studies have used MCA to analyse very different discourse types, such us newspaper texts (e.g. Eglin \& Hester, 1990); interview data (e.g. Baker, 2004); TV and radio debate (e.g. Leudar, Marsland \& Nekvapil, 2004). 


\subsubsection{Music-related identities}

Apart from discursive or discourse-related identities, another very important type of identity must promptly be discussed for the scope of this research: music-related identities.

The question of 'identities in music' or the other way around, 'music in identities' (both terms from Macdonald, Hargreaves \& Miell, 2002) have been discussed in different academic fields, such as cognitive and social psychology, sociology, (sub)cultural studies, musicology. Research topics include, for example, 'musical personality'; the relationship between specific identities and music; musical genres as lifestyles; musical taste developing in childhood, etc. (see more in Macdonald et al., 2002). To reflect on the importance of this topic, Simon Frith (2004) as the editor of the four-volume work, "Popular Music. Critical Concepts in Media and Cultural Studies" addresses this in Volume IV with the title, "Music and Identity".

Generally, music can have short-term effects or more deep-seated influence on our beliefs and behaviour. As Macdonald et al. (2002) mention, musical taste is an integral part our self-concepts and it is related to age, level of musical training and aspects of cognitive style and personality.

According to Frith (1996), “[m] usic constructs our sense of identity through the direct experiences it offers of the body, time and sociability, experiences which enable us to place ourselves in imaginative cultural narratives" (p. 124). Moreover, music as a cultural form "is able both to cross borders - sounds carry across fences and walls and oceans, across classes, races and nations - and to define places; in clubs, scenes, and raves, listening on headphones, radio and in the concert hall, we are only where the music takes us" (p. 125).

Therefore, music is an important cultural sphere, where identities are affirmed, challenged, taken apart, and at the same time reconstructed (Connell \& Gibson, 2003). It has effects on both personal and collective identities: on one hand, when we listen to a certain type of music, it is an individual experience and in these moments, individual emotions are awoken; on the other hand, it is also a collective experience, because through listening to music we are drawn "into emotional alliances with the performers and with the performer's other fans" (Frith, 1996, p. 121). In this sense, music also forms groups and communities and with that contributes to the formation of a social identity. 
Here, some thoughts must be added on the relationship between musical subcultures (or scenes, communities, etc.) and identity. These subcultures offer a specific culture and identity; the culture includes the attributes of subcultures like music, image, clothing style, values, norms, behaviours, ideology, etc. These together give a set of 'symbolic resources' that individuals can draw upon, or adopt with the aim of projecting a particular image and hence achieve a different identity and at the same time, challenging the dominant social order. With this, individuals can fully express their identities and they can also experience an alternative form of social reality (Widdicombe \& Wooffitt, 1995).

With these general thoughts on music-related identities in mind, the present dissertation tries to explore different types of musical identities within electronic dance music cultures. It will detect identities, such as fan identity, different music genre identities, or subcultural identities. (See more in Chapter 5.)

\subsubsection{Music-related identities in discourse}

As it was claimed before, this study observes the process of identity construction as a discursive phenomenon. In terms of music-related identities, it is a very important viewpoint, because it also means that individuals who form a music-related discourse community, construct their identities during their discursive activities, for example, in chat rooms, web discussion forums, Facebook Groups, etc. In this sense, multiple linguistic codes and characteristics explain musical identities in a discursive event.

Research on music-related identities in discourse is a relatively new field and there are only a few scholars who deal with these topics. Here, we will name only a few important works that are related to the subject of this study.

An early work of Sue Widdicombe and Robin Wooffitt (1995) "The language of youth subcultures" uses a combination of discourse and conversation analysis methods in order to take a closer look at punks', goths' and rockers' language use to construct subcultural identities and group memberships.

Several papers exist on the questions of hip hop identity and discourse. For example, the collection of papers, "Global Linguistic Flows. Hip Hop Cultures, Youth Identities, and the Politics of Language", edited by Alim, Ibrahim and Pennycook (2009), deals with the topic of hip hop identity from very different points of view. Or another 
example could be Androutsopoulos's $(2007,2008)$ works, which examine Germanspeaking hip hop websites and discussion boards to demonstrate how methods of discourse-centred online ethnography can help to analyse computer-mediated communication. He also analyses language style, genre, and member identities on this hip hop-related language sample.

On the topic of EDM, we found only one work, Andrew Whelan's (2008) aforementioned ${ }^{53}$ book, "Breakcore: Identity and Interaction on Peer-to-Peer" which is thematically very close to the present study. It examines breakcore ${ }^{54}$ identity in chat room conversations. In my opinion, the work has some methodological shortcomings: the author claims that a specific method is not needed to analyse the discourse pieces. The book is more like a 'collection' of the author's own thoughts that are sometimes also difficult to follow. However, it is still a very important signal about the potentials of analysing EDM-related discourses in computer-mediated communication circumstances.

The present study tries to fill this gap of research by creating a discourse analysis with a strong linguistic methodology (see more about the methods in Chapter 4).

\footnotetext{
${ }^{53}$ In Chapter 2.4.3.2.3.2.

${ }^{54}$ Breakcore is an EDM genre, influenced by jungle, hardcore, and industrial music (Reynolds, 2013).
} 


\section{RESEARCH AIMS AND QUESTIONS}

As we could see it in the theoretical part of this study, electronic dance music communities have been researched from the perspectives of sociology, youth culture, cultural studies, public health research (especially in the 1990s 'rave' research), gender studies, etc., but surprisingly research on the language use (and the features) of the discourse community is not common. There are some terminology research groups that investigate the collection of the terminology of electronic (dance) music or translating electronic music-related terminology from English to more minor languages ${ }^{55}$, but their research remain at the level of terms (terminology). By involving discourse analysis to take a closer look at the language use of the discourse community in question, we can open up the scope of research to the level of words, sentences and texts as well.

The observations of this study attempt to fill this gap in existing research and suggest a new perspective by looking at the community of electronic dance music. Namely, looking at this group of individuals as a discourse community that has own dialogues and ways of communication, in order to exchange information on electronic dance music and its related topics. With this perspective, one can analyse the members' behaviours in the communication process with regards to the community and identity and understand phenomena such as common ground, genres in communication, used terminology, or mechanisms of intercommunication, etc.

Electronic dance music is an umbrella term or metagenre which includes many different genres, subgenres, sub-subgenres, etc. (McLeod, 2001). As we could see in Chapter 2.5.2, the sub-communities can be defined not only by the music genres and their communities, but also by their special interest (e.g. the discourse of fans and users of analogue synthesisers) or their profession (e.g. flyer designers', music or event managers' discourse). These smaller groups (sub-communities or sub-sub-communities as one could call them after McLeod, 2001) vary in different ways. The list would be far too long to thoroughly collect all sub-categories and it is also not important to do so in the frame of the present study. It must be noted here that the large amount of music genres ${ }^{56}$ within EDM have effects on the group and identity construction of the subgenres.

\footnotetext{
${ }^{55}$ E.g. an old project from Kenneth Fields (2008) at China Electronic Music Center (CEMC), Central Conservatory of Music about the translation of electronic music terminology from English into Chinese.

${ }^{56}$ See more in McLeod, 2001.
} 
The discourse community of electronic dance music has many specific characteristics in terms of language use. This research focuses on the written discourse of this community, including the analyses of online discourse sources (web discussion forums, Facebook Groups, 'classical websites', and blogs).

Therefore, the main aim of this research is to map this discourse community and create a general overview on its language use and discourse characteristics while applying discourse analysis on linguistic data from different written (and mainly online) sources.

Moreover, based on the earlier discussed theoretical investigations, the dissertation addresses the following research questions in its linguistic analysis:

1. What are the discourse characteristics of the discourse community of EDM? ${ }^{57}$

2. How do these characteristics vary in different sub- (sub-sub-, etc.) discourse communities according to the analysed samples?

3. How do these characteristics reflect on the community and identity construction within the analysed communities?

\footnotetext{
${ }^{57}$ This question has been mentioned in the introduction (Chapter 1).
} 


\section{METHODS}

\subsection{Main framework: Computer-mediated discourse analysis}

As mentioned before, the present study places its main research profile within discourse analysis in the approach to computer-mediated discourse analysis. This is due to the fact that firstly, the corpus of this thesis is composed of online forum posts, multimodal texts available online, and social network activities (posts, comments) from the field of electronic dance music. Secondly, it describes online phenomena through observations of how participants perform actions through the use of language and thus, it defines the features, characteristics, and importance of online/virtual communities in the 'general universe' of the discourse community of electronic dance music.

CMDA applies different methods adapted from the following disciplines: linguistics, communication studies, and rhetoric in order to analyse computer-mediated communication (Herring, 2001). The basic idea is to adapt existing methods - primarily from linguistics - to the properties of digital communication media (Herring, 2013).

In the last decades, many research results were born in the field of CMDA, but the methodological reflection is lagging behind compared to other areas of discourse studies (Androutsopoulos \& Beißwenger, 2008). It can be supplemented by ethnographic observations, interviews, surveys, etc. and the analysis can be either qualitative or quantitative. As Herring (2004b) defines it: "In the broadest sense, any analysis of online behaviour that is grounded in empirical, textual observations is computer-mediated discourse analysis.” (p. 339) Therefore, CMDA is considered as an approach, rather than a 'theory' or a single 'method' (Herring, 2004b).

Susan C. Herring (2004b) proposed a CMDA framework in her study (book chapter) "Computer-mediated discourse analysis: An approach to researching online behaviour", which is one of the most fully articulated frameworks in the field today. This framework summarises the research process of CMDA through the example of a question on virtual community: 
Table 3: Summary of the CMDA research process applied to a hypothetical question about virtual community (Herring, 2004b, p. 365)

\begin{tabular}{|c|c|}
\hline CMDA research process & Application to virtual community \\
\hline Articulate research question(s) & $\begin{array}{l}\text { E.g., "To what extent do two online } \\
\text { professional development environments, } \\
\text { listserv X and website Y, constitute } \\
\text { "community"?" }\end{array}$ \\
\hline Select computer-mediated data sample & $\begin{array}{l}\text { E.g., intermittent time-based sampling } \\
\text { (several weeks at a time at intervals } \\
\text { throughout a year) of public messages from } \\
\text { each group }\end{array}$ \\
\hline $\begin{array}{l}\text { Operationalize key concept(s) in terms of } \\
\text { discourse features }\end{array}$ & $\begin{array}{l}\text { Community } \rightarrow \text { core participants }+ \text { in-group } \\
\text { language }+ \text { support }+ \text { conflict }+ \text { group } \\
\text { self-awareness + roles, etc. }\end{array}$ \\
\hline Select and apply method(s) of analysis & $\begin{array}{l}\text { Frequency counts of, e.g., messages and } \\
\text { message length, rate of response ('core } \\
\text { participants') } \\
\text { Structural analysis of, e.g., abbreviations, } \\
\text { word choice, language routines ('in- } \\
\text { group language') } \\
\text { Pragmatic analysis of, e.g., speech acts of } \\
\text { positive politeness ('support'), etc. }\end{array}$ \\
\hline $\begin{array}{l}\text { Interpret results } \\
\text { 1. summarize/synthesize results of data } \\
\text { analysis } \\
\text { 2. answer research question(s); explain } \\
\text { unexpected results } \\
\text { 3. consider broader implications }\end{array}$ & $\begin{array}{l}\text { 1. Listserv X has community features a, b, } \\
\text { c, ...; website } Y \text { has community features c, } \\
\text { f, ... } \\
\text { 2. Both have some community features; } X \\
\text { is more community-like than Y. This is due } \\
\text { to ... } \\
\text { 3. Results have implications for: CMC } \\
\text { theory (e.g., Media Richness); system } \\
\text { design (e.g., push vs. pull access); research } \\
\text { methodology (e.g., coding categories for } \\
\text { community features) }\end{array}$ \\
\hline
\end{tabular}

As we can see in this table, the research process has five steps and each has an application to the community in question. Of course, the application can differ in terms of the research question and the examined data.

This research follows Herring's (2004b) points on the research process: 1) The research aims and questions could be seen in Chapter 3.; 2) the selected computermediated data sample will be introduced in Chapter 5.; and 3) the key concepts were also seen in Chapter 3: focussing on the questions of discourse community and its members' community and identity constructions. 
4) On the methods, Herring's (2004b) model is organised around the four domains of language: structure, meaning, interaction management, and social phenomena that are summarised in the next table:

Table 4: Four domains of language and CMDA issues and methods as re-organised around them (Herring, 2013, p. 5, based on Herring, 2004b)

\begin{tabular}{|c|c|c|c|}
\hline Levels & Issues & Phenomena & Methods \\
\hline Structure & $\begin{array}{l}\text { Orality; formality; } \\
\text { efficiency; expressivity; } \\
\text { complexity; genre } \\
\text { characteristics, etc. }\end{array}$ & $\begin{array}{l}\text { Typography, } \\
\text { orthography, } \\
\text { morphology, syntax, } \\
\text { discourse schemata, } \\
\text { formatting conventions, } \\
\text { etc. }\end{array}$ & $\begin{array}{l}\text { Structural/Descriptive } \\
\text { Linguistics, Text } \\
\text { Analysis, Corpus } \\
\text { Linguistics, Stylistics }\end{array}$ \\
\hline Meaning & $\begin{array}{l}\text { What is intended } \\
\text { What is communicated } \\
\text { What is accomplished }\end{array}$ & $\begin{array}{l}\text { Meaning of words, } \\
\text { utterances (speech acts), } \\
\text { exchanges, etc. }\end{array}$ & $\begin{array}{l}\text { Semantics, } \\
\text { Pragmatics }\end{array}$ \\
\hline $\begin{array}{l}\text { Interaction } \\
\text { management }\end{array}$ & $\begin{array}{l}\text { Interactivity; timing; } \\
\text { coherence; repair; } \\
\text { interaction as co- } \\
\text { constructed, etc. }\end{array}$ & $\begin{array}{l}\text { Turns, sequences, } \\
\text { exchanges, threads, etc. }\end{array}$ & $\begin{array}{l}\text { Conversation } \\
\text { Analysis, } \\
\text { Ethnomethodology }\end{array}$ \\
\hline $\begin{array}{l}\text { Social } \\
\text { phenomena }\end{array}$ & $\begin{array}{l}\text { Social dynamics; power; } \\
\text { influence; identity; } \\
\text { community; cultural } \\
\text { differences, etc. }\end{array}$ & $\begin{array}{l}\text { Linguistic expressions } \\
\text { of status, conflict, } \\
\text { negotiation, face- } \\
\text { management, play; } \\
\text { discourse styles/lects, } \\
\text { etc. }\end{array}$ & $\begin{array}{l}\text { Interactional } \\
\text { Sociolinguistics, } \\
\text { Critical Discourse } \\
\text { Analysis, } \\
\text { Ethnography of } \\
\text { Communication }\end{array}$ \\
\hline
\end{tabular}

In Herring's (2004b, 2013) table we can see that - as mentioned above - the methods of analysis can be very different depending on the aims of the research. The present study analyses the chosen linguistic data ${ }^{58}$ at every level ${ }^{59}$ of CMDA.

Based on Herring's (2004b, 2013) table above and influenced by Rasulo's (2008) investigation on participant discourse in online community formation, the present study implements the following methods in its analysis in order to answer its research questions:

\footnotetext{
${ }^{58}$ Herring (2004b) also points out that most importantly "the data should be sufficient to address the research question such that tests of statistical significance could meaningfully be conducted on the key findings" (p. 351).

${ }^{59}$ It is important to remark that Herring (2013) has suggested a possible fifth level to the CMDA paradigm: the level of multimodal communication. However, we do not find it necessary to separate this level from the others, because in the coding categories of this research, this viewpoint has been included within every other domain with the help of MMDA (see more in Chapter 5).
} 
Table 5: Used methods and explored issues

\begin{tabular}{|c|c|c|c|}
\hline Language domains & Phenomena type & Explored issues & Analytical method \\
\hline \multirow{5}{*}{ Structure and meaning } & special lexis & $\begin{array}{l}\text { group-specific lexis; signifier of community } \\
\text { sense }\end{array}$ & $\begin{array}{l}\text { Content analysis } \\
\text { and semantics }\end{array}$ \\
\hline & technical terms & common ground; knowledge & $\begin{array}{l}\text { Terminology } \\
\text { studies }\end{array}$ \\
\hline & specific community reference words & refernce to group: in- and out-group language & Content analysis \\
\hline & personal pronouns & $\begin{array}{l}\text { "I"/ "we" vs. "they" = signifiers of individual vs. } \\
\text { social identity }\end{array}$ & $\begin{array}{l}\text { Content analysis } \\
\text { and descriptive } \\
\text { statistics }\end{array}$ \\
\hline & compensatory strategies & $\begin{array}{l}\text { expressions with other tools (not text): their } \\
\text { community markers }\end{array}$ & $\begin{array}{l}\text { Multimodal } \\
\text { discourse analysis }\end{array}$ \\
\hline \multirow[b]{2}{*}{ Interaction management } & concern structures & $\begin{array}{l}\text { signifier of respecting the other members; } \\
\text { initiation response }\end{array}$ & $\begin{array}{l}\text { Conversation } \\
\text { analysis }\end{array}$ \\
\hline & participation & $\begin{array}{l}\text { special roles in a community; power relations and } \\
\text { their roles in community construction and } \\
\text { sustaining }\end{array}$ & $\begin{array}{l}\text { Descriptive } \\
\text { statistics and } \\
\text { conversation } \\
\text { analysis }\end{array}$ \\
\hline \multirow[t]{2}{*}{ Social phenomena } & interpersonal discourse behaviours & $\begin{array}{l}\text { showing divergence or convergence; friendship } \\
\text { building; signifiers of community partnerships; a } \\
\text { way of showing intrerest in one another; } \\
\text { introduce a new topic; vocation and/or avocation; } \\
\text { tools of sustaining a community }\end{array}$ & $\begin{array}{l}\text { Conversation } \\
\text { analysis and } \\
\text { membership } \\
\text { categrosiation } \\
\text { analysis }\end{array}$ \\
\hline & information exchanges & $\begin{array}{l}\text { way of showing interest in one another; showing } \\
\text { mutual influence; sense of belonging }\end{array}$ & $\begin{array}{l}\text { Conversation } \\
\text { analysis }\end{array}$ \\
\hline
\end{tabular}

5) Finally, the interpretation of the results will be presented in Chapter 5.

\subsection{Analytical methods on the four domains of language}

In the following sections, the aforementioned fourth step of this research will be discussed and the used methods proposed in Table 5 will be explained.

To reiterate, this study focuses on the discourse characteristics of the discourse community of electronic dance music and through this, examines the relationship between the language use and the processes of identity and community construction. Therefore, it takes these focal points into account in analysing every domain of language and at the same time, it chooses methods in order to obtain answers to these main questions.

\subsubsection{Structure and meaning}

In Table 5 we can see that the present study analyses the first two domains of language structure and meaning - together, because they are very close to each other in the scope of this research: through analysing the structure of the group's language, we can understand the negotiation of meaning too. 
Within the domains of structure and meaning, following Herring (2004b), these discourse behaviours were analysed: jargon, reference to group, in/out-group language, exchange of knowledge and negotiation of meaning. Therefore, a closer look will be taken at the special lexis, the technical terms, the specific community reference words, the personal pronouns and the compensatory strategies ${ }^{60}$. Within these phenomena types, different subcategories will be defined which we can see in Attachment 1 (Chapter 10.1) on the used coding system.

Examining the special lexis of the sample brings us closer to the group-specific lexis which is understood here as a signifier of community sense: the group members understand them in a specific way that cannot be understood by an out-group person. These terms will be analysed with the help of content analysis and semantics.

The same can be said about the used technical terms: they are also group-specific and signifiers of the common ground of a community. They also signify the members' level of knowledge on the community's common topic. They will be examined with the help of terminology studies.

The specific community reference words (e.g. 'friend', 'mate') will be also examined in order to take a closer look at the in- and out-group language. For that, we will turn to 'classical' content analysis as an analytical method.

Personal pronouns ('I', 'we' and 'they') can indicate community identification and individual and group identity. The frequency of their usage will be analysed with the help of descriptive statistics and content analysis.

This study is also interested in the same community and identity construction phenomena in multimodal texts - emoticons, pictures, videos, etc. as compensatory strategies -, which will be analysed with the help of multimodal discourse analysis (the theoretical basis of the approach has been introduced in Chapter 2.2.5.1).

\subsubsection{Interaction management}

At the level of interaction management, the concern structures and participation of the community members will be analysed.

\footnotetext{
${ }^{60}$ Compensatory strategies refer to the use of emoticons and in the case of Facebook Groups also the Facebook reactions (see more about them in Chapter 5). They replace facial expressions, physical actions and other features of orality (Rasulo, 2008).
} 
Within concern structures, we will take a closer look at the frequency of linking and quoting. They refer explicitly to the content of a previous message in one's response, which can be understood as an initiation response. They also create an extended conversation exchange, as Rasulo (2008) mentions, because they incorporate juxtapositions with two turns within a single message. These concern structures are therefore signifier of respecting the other members and this respect also helps to construct communities and friendships.

With the help of descriptive statistics, the rates of the members' participation will be examined in the conversations. It is intended to figure out if these rates are balanced ('harmonic') or hierarchic within the community: Who take part in the conversations and what roles do they have within the community? Are there any demonstrable power relations in the community? These questions - among others - will be answered by the analysis of the members' conversation participations.

\subsubsection{Social phenomena}

If a research focuses on questions about a community and its identity, Herring (2004b) proposes to implement methods from interactional sociolinguistics, critical discourse analysis, or ethnography of communication in order to analyse the selected linguistic data. Despite her thoughts, conversation analysis and membership categorisation analysis methods are better fitting to the subject of this thesis (see more about their theoretical basis in Chapter 2).

Here we were interested in the interpersonal discourse behaviours and the information exchanges. Interpersonal discourse behaviours show divergence or convergence; signify the community partnerships and reconstruct the level of interest in one another (Rasulo, 2008). They can introduce a new topic (for example asking) and they are also representative of friendship building. Moreover, self-representation and convergence towards community identity and partnerships can be evidenced by participants' use of interpersonal discourse behaviours (Rasulo, 2008).

It is hypothesised that the analysed communities will show evidence for building interpersonal and community friendships by analysing their processes of acknowledging, 
asking for information, inviting feedback, offering advice, thanking, joking, apologising, and negotiating conflicts ${ }^{61}$.

Additionally, the features of information exchanges represent how to show interest in one another and they are evidences for mutual influence, establishing presence or significance and sense of belonging (Rasulo, 2008).

${ }^{61}$ These categories are listed by Rasulo (2008) and the present study is built upon some of her categories. (Some of them were not applicable for the sample of this study.) 


\section{ANALYSIS}

\subsection{Foreword to the analysis}

\subsubsection{Corpus from Web 2.0 environment}

As Androutsopoulos and Beißwenger (2008) point out, CMD studies have been faced with the problems of data collection, because there is a lack of standard guidelines for CMD corpus design and a lack of publicly available CMD corpora. Therefore, this study did not follow a specific approach to select the collected data, but it will be explained later why exactly these samples were reasonable to be chosen.

Bednarek $(2008,2009)$ in her model of a 'three-pronged approach' to analysing linguistic data writes about a) large-scale computerised corpus analysis on the macrolevel; b) semi-automated small-scale corpus analysis on the mesolevel; and c) manual analysis of individual texts on the microlevel. The present study uses the third microlevel approach, the manual analysis, in order to examine the chosen linguistic data. This approach consists of the manual analysis of (one or) a few individual texts ${ }^{62}$.

The written linguistic data used in this study was collected from different web sources between 2010 and 2016. Therefore, the corpus of this research remains, as mentioned before, on the written sources of this DC and the study analyses only written discourses. We believe that in the case of the discourse community of electronic dance music, the analysis of online written discourse is crucial, as we saw it in Chapter 2.4, the members are highly interested in and influenced by such communication forms. If we think of the early rave era, as Wilson puts (2006), its doctrine was a reverence to and celebration of technology, and an implicit and explicit belief in "progress through technology" (p. 80) ${ }^{63}$. This focus on and fascination with technology and its terminology were inextricably linked with the raver interest in communication - particularly in the Internet (Wilson, 2006). Additionally, we should not forget the fact that electronic music is produced by inventions and results of this progressive technology.

Generally, EDM grew along with the Internet, with a wealth of resources to support would-be (or 'bedroom') producers (Collins et al. 2013), while electronic music production equipment has become more affordable over the years. Home production could be followed up by distribution without intermediaries by using online channels and

\footnotetext{
${ }^{62}$ These analyses of individual texts are often used in critical discourse analysis, systemic functional linguistics, and other types of discourse analysis (Bednarek, 2009).

${ }^{63}$ Already mentioned in Chapter 2.
} 
platforms (Collins et al. 2013). To sum up, it can be stated that online communication as a tool for different forms of cultural consumption, creativity, distribution, community construction and resistance is highly important in electronic dance music cultures and scenes.

Therefore, linguistic data was taken from different web discussion forums, Facebook Groups, 'classical' websites, and blogs. Here the aim was to collect a sample from different genres and platforms of communication in order to give a general overview on the language use of the discourse community in question. This broad spectrum can help us to understand different ways of communicating about EDM as well as its different topics.

At this point, we also have to highlight the differences between Web 1.0 and Web 2.0 environments in order to understand the selected Internet genres as sources of the data. In the older Web 1.0 era, the online content creators were only a few people and the users were simply consumers of this content (Krishnamurthy \& Cormode, 2008) while the content was more static rather than dynamic. On the other hand, in the present Web 2.0 environment - that was introduced in 2003/2004 (Krishnamurthy \& Cormode, 2008) -, users are empowered with the right to create content and publish it on the web, all by themselves (Viswanathan, Mathur \& Yammiyavar, 2010) ${ }^{64}$. Therefore, the users became creators and editors of content rather than a mere consumer of it. In media and marketing studies, this phenomenon is also named as 'produser', a neologism that includes both, the 'producer' and the 'user' (Bruns, 2008).

We could also list here many different technological developments that have been introduced in the Web 2.0 era, but for the present study, the most important point about Web 2.0 is the user-generated web content. In terms of language use, the users can be basically anybody with access to technology and basic technological skills. This fact enables researchers to have a wide spectrum of linguistic data: Taking the example of the discourse community of electronic dance music, users who create the content can have very different sociological backgrounds; their knowledge can differ in terms of technical issues, or goals of the community; therefore, they can be hobby musicians, fans, only interested persons, highly educated music producers, etc. With it, we want to emphasise that taking linguistic data from web sources in the Web 2.0 era, helps us to reconstruct

\footnotetext{
${ }^{64} \mathrm{We}$ also have to note that Web 3.0 is in the horizon that - as expected - will be even more connected and opened than Web 2.0 with distributed databases, machine learning and reasoning, natural language processing, etc. (Hendler, 2009).
} 
the characteristics of the written (and partly spoken) discourses of a discourse community. Of course, we have to keep in mind that these sources have the characteristics of language use on the Internet generally (e.g. Crystal, 2001), but they are at the same time very close to everyday discourses and conversations (the latter is one of the reasons, why this study analyses them).

After the establishment of the term Web 2.0, the term 'Discourse 2.0' has become popular among some scholars (e.g. Tannen \& Trester, 2013). They use 'Discourse 2.0' instead of 'computer-mediated discourse', because communication technologies are increasingly moving beyond computers in the classical sense of the term (e.g. voice calls). Discourse 2.0 includes those newer ways of communication that Herring (2009) has already discussed in her definition on 'convergent media computer-mediated communication $^{65}$ (e.g. comments under music videos on YouTube; hashtag ${ }^{66}$ use on Instagram $^{67}$, etc.) (about CMCMC see more in Chapter 2.4.2). Even if there have been some other newer terminology suggestions to solve this problem (e.g. Androutsopoulos's [2011] 'digital networked writing', or Jucker and Dürscheid's [2012] 'keyboard-to-screen communication'), CMD (and CMDA) is the most well known and used concept and makes the link to CMC transparent (Herring, 2013). CMD is still preferred by communication scholars and at the same time by the author of this study.

\subsubsection{The language sample and its ethical questions}

After highlighting the characteristics of Web 1.0 and 2.0 (and Discourse 2.0), the selected language sample will be presented. The data were collected from the following web sources:

\section{a) Web discussion forums}

We Are The Music Makers Forum (WATMMF)

Gearslutz

\footnotetext{
${ }^{65}$ See more above in Chapter 2.2.4.

${ }^{66}$ A hashtag (its sign: \#) is a type metadata tag used mainly on social network that helps for users to find messages with a specific content (see more in Highfield \& Leaver, 2015).

${ }^{67}$ Instagram (https://www.instagram.com) is an online mobile photo-sharing, video-sharing, and social networking service (see more in Highfield \& Leaver, 2015).
} 


\section{b) 'Classical' websites}

Vintage Synth Explorer

Resident Advisor

\section{c) Facebook Groups}

TB-303 Owners Club

\section{ITALO DISCO MANIACS}

\section{d) Blogs}

Matrixsynth

LWE: Little White Earbuds

Teshno

We did not have any difficulties with collecting linguistic data from web discussion forums, 'classical' websites and blogs, because they are available online to anyone without registration for these websites. They therefore do not imply any ethical questions either: people who give out their personal data (even if it is only an anonymous user name) to such websites are aware of the fact that anyone visiting these sites can read their comments. These people read (or are asked to read) the terms and conditions of the website before or during their registrations, where it is always mentioned that the websites do not take responsibility for personal data published by the user with their comments. As Cameron and Panović (2014) mention, until we take linguistic data from a website which can be accessed by anyone, we do not have to think of the ethical questions of using them for research aims.

The problems start with such online platforms as Facebook, where the researcher (here the author of the present study) has to register on the site and only through this registration, $\mathrm{s} /$ he can reach textual sample. This is not true in the case of public Facebook Groups, as they are available to anyone without any registration on the website, but from the chosen two Facebook Groups in this study only the 'TB-303 Owners Club' is a public group, 'ITALO DISCO MANIANCS' is not.

Another problem occurs with collecting linguistic data from Facebook: in the registration process, people have to give their real names for their profiles. (Of course, these names can be fake ones, but we assume here that they are normally real ones.) The following solution was chosen for these problems: the commenters' names were 
graphically masked out and only the first letters of the first- and surnames were kept in order that we can still refer to them during the analysis. Additionally, their pictures were also masked if they depicted a person.

In Chapter 9, we can see the exact sources of the collected data. Moreover, all data from the Facebook Groups are attached with hidden profile names and pictures, because these data cannot be reached - in the case of 'ITALO DISCO MANIACS' - by the readers of this study if not registered members of Facebook.

\subsubsection{Coding categories}

In this short chapter, we would like to introduce the coding system (or codebook) constructed to this analysis.

The explored issues of the different phenomena have been explored in Chapter 4; here we will introduce the subcategories of these phenomena with the help of Table 6:

Table 6: Analysed subcategories (see also as Attachment 1)

\begin{tabular}{|c|c|c|c|c|c|}
\hline Language domains & Phenomena type & Subcategories & Sub-subcategories & Codes/Criteria & Results/Numbers \\
\hline \multirow{19}{*}{ Structure and meaning } & \multirow{6}{*}{ Special lexis } & \multirow{3}{*}{ special adjectives related to: } & $\mathrm{X}$ & & \\
\hline & & & $\mathrm{Y}$ & & \\
\hline & & & $\mathrm{Z}$ & & \\
\hline & & \multirow{3}{*}{$\mathrm{x}$} & $\mathrm{x}$ & & \\
\hline & & & $\mathrm{Y}$ & & \\
\hline & & & $\mathrm{Z}$ & & \\
\hline & \multirow{3}{*}{ Technical terms } & related to $\mathrm{X}$ & - & & \\
\hline & & related to $\mathrm{Y}$ & - & & \\
\hline & & related to $\mathrm{Z}$ & - & & \\
\hline & \multirow{3}{*}{$\begin{array}{l}\text { Specific community reference } \\
\text { words }\end{array}$} & related to $\mathrm{X}$ & - & & \\
\hline & & related to $\mathrm{Y}$ & - & & \\
\hline & & related to $\mathrm{Z}$ & - & & \\
\hline & Personal pronouns & I, we, they & - & & \\
\hline & & emoticons & & & \\
\hline & & memes & & & \\
\hline & & GIFs & & & \\
\hline & Compensatory strategies & pictures & & & \\
\hline & & videos & & & \\
\hline & & other functions of the website & & & \\
\hline \multirow{7}{*}{$\begin{array}{l}\text { Interactional } \\
\text { management }\end{array}$} & \multirow{4}{*}{ Concern structures } & \multirow{2}{*}{ linking } & hyperlink & & \\
\hline & & & sharing & & \\
\hline & & \multirow{2}{*}{ quoting } & other users & & \\
\hline & & & someone else & & \\
\hline & \multirow{3}{*}{ Participation } & number of messages per group member & & & \\
\hline & & participation types & through roles & & \\
\hline & & partcicipation types & through activity & & \\
\hline \multirow{14}{*}{ Social phenomena } & \multirow{11}{*}{$\begin{array}{l}\text { Interpersonal discourse } \\
\text { behaviours }\end{array}$} & agree/disagree & & & \\
\hline & & counterpoint & & & \\
\hline & & acknowledge & & & \\
\hline & & invite/give feedback & & & \\
\hline & & thanking & & & \\
\hline & & sympathise & & & \\
\hline & & joking & & & \\
\hline & & delegate & & & \\
\hline & & negotiate conflict & & & \\
\hline & & ask for infomation & & & \\
\hline & & offering advice & & & \\
\hline & \multirow{3}{*}{ information exchanges } & provide knowledge & & & \\
\hline & & share biographical information & & & \\
\hline & & express ideas and opinions & & & \\
\hline
\end{tabular}

This table was used for the analysis of web discussion forums, 'classical' websites, and Facebook Groups - we will see in Chapter 5.2.4 why it could not be 
applied for blogs -, but the subcategories varied on the different samples. For example, some of the interpersonal discourse behaviours could not be applied to all of them. We will describe these different subcategories in the different chapters of the analysis.

This codebook was created with an inspired by the 'Grounded Theory' (Charmaz, 2000): the codes were inductively and iteratively derived from the study of the phenomenon. First, we read (and re-read) the textual data and then created the aforementioned codebooks for each sample.

Software was not used for the analysis; the whole coding was manually done. (Therefore, there might be some counting errors in the analysis, but the author tried to be as precise as possible with these data.) Only the search engine functions of the websites were used to find key terms.

\subsection{Linguistic analysis}

This chapter will succeed in the following order: It is divided into four main parts by the analysed Internet genres; 5.2.1 Web discussion forums, 5.2.2 'Classical' websites, 5.2.3 Facebook Groups, and 5.2.4 Blogs. In the beginning of these chapters, a detailed description on these Internet genres will be given. Within these parts, the subchapters will be ordered as follows: first we will give 1) a general description of the exact platforms, then 2) examine its characteristics in terms of discourse with the help of Herring's (2007) faceted classification scheme (more about this model in Chapter 5.5.5), and finally we will see 3) the results of the analysis of the language use, which was initiated by the aforementioned codebook (Table 6).

Following Herring's (2007) faceted classification scheme, a summarising table was created for each analysed platform, which can be seen in Attachment 4 (Chapter 10.4). The platforms, which belong to the same Internet genre, usually have the same characteristics. We will therefore always describe them fully in the platform analysed within an Internet genre first, then in the second ones, we will only highlight the points that differ from the first one. (For example, within the Facebook Groups, first, the 'TB303 Owners Club' will be analysed, then the 'ITALO DISCO MANIACS'. Therefore, the classification scheme will be explained on the example of the TB-303 Owners Club in depth and only the differences will be highlighted in the subchapters of ITALO DISCO MANIACS.) 
Moreover, it is important to remark in advance that the present study quotes the original linguistic data word-for-word, leaving all errors (grammatical, spelling, etc.) in them in order to keep their authentic character.

\subsubsection{Web discussion forums}

Web discussion forums ${ }^{68}$ are online platforms for communication among people separated in place and time. They can evolve into communities whose members share information, experience a sense of belonging, and provide mutual support (Herring et al. 2002; Preece, 2000).

The first online discussion forums were introduced in the Web 1.0 era, but they have many features which are reminiscent of Web 2.0 characteristics, for example, the content itself is mainly generated by their users: commenting, asking questions and answering them, creating a new thread, etc. Similar to other web sources, text remains the predominant channel of communication on web discussion forums, even though one can link or add, for example, memes, GIFs, pictures, videos, etc. to her or his comments. Although web discussion forums are older developments, they remain very popular and are still important platforms for communication among web users.

Web discussion forum is a type (or subgenre) of asynchronous chat or message boards. Both asynchronous chat and message board (or bulletin board) denote: interactions that are stored and made available to users upon demand, so they do not have to react on others' comments immediately, but they can catch up with the discussion at any time (even, for example, a year or more later). As Herring (2010) summarises, web discussion forum is an interactive CMC mode and an asynchronous setting of communication, because users do not have to $\log$ on at the same time in order to receive and send messages.

Due to the anonymity of the Internet, people can feel safe on these forums talking about issues that might be considered sensitive, taboo, inappropriate or dangerous in faceto-face public conversation (Herring et al., 2002).

\footnotetext{
${ }^{68}$ In the literature, one can also find it as the terms 'Internet forum', 'online forum', and 'online discussion forum'.
} 
Forums have directory tree structure: a forum is often divided into different categories for the relevant discussions and under these categories are the so-called 'subforums'.

Figure 9: An example for sub-forums (Future Producers, n.d.) ${ }^{69}$

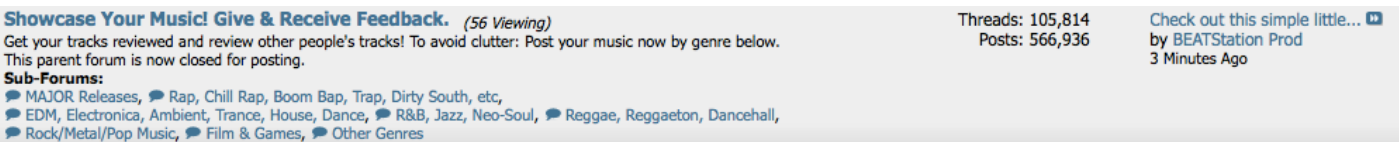

Normally only the registered and logged in users can add their thoughts to the conversations. The unregistered users - also named 'visitors', 'guests', or 'lurkers' - can usually read the conversations, but they cannot post messages.

'Moderators' and 'administrators' play important roles in the communication process. 1) 'Moderators' (short form: 'mod') have granted access to the posts and threads (topics) of all members. They are responsible for moderating the discussion and keeping the forum clean from spam/spambots; therefore, they can delete, merge, move and split posts and threads, warn members, etc. They also answer other users' forum-related questions and complaints. 2) 'Administrators' (short form: 'admin') manage the required technical details for running the site. They have the right to promote members to moderators, or demote this role from them. They are also responsible for managing the rules and creating sections.

The text genre used on forums is the web discussion forum post (short form: forum post, also named as comment). A forum post is a user-submitted message enclosed into a block in a web discussion forum. The texts (or comments) of an online discussion forum are normally shorter, because they focus on one specific topic (Bódi, 2004) and aim to answer main questions. The style of comments is mainly informal and closer to spoken language than to written. Beside the message, they contain the user's details (at least her/his user name) and the date and time it was submitted. Posts are collected in threads, where they appear as blocks after each other. Forum posts can differ in length and content: they can include not only plain texts, but for example, hyperlinks, pictures, emoticons, GIFs, memes, etc. They quite often have a multimodal characteristic.

\footnotetext{
${ }^{69}$ In this screen shot we can see that the main forum is "Showcase Your Music! Give \& Receive Feedback" where the users can share their own music with others and receive a feedback on it. The sub-forums are names of music genres (e.g. EDM, trance, house) which denotes where users should post music tracks into different categories and users who are interested in one specific music style can easily navigate him- or herself with the help of these sub-forum titles. On the right hand side, we can see how many threads and comments these sub-forums have (all together) and who and when added the last content to the discussion and when it was added.
} 


\subsubsection{We Are The Music Makers Forum (WATMMF)}

\subsection{General details about WATMMF}

'We Are The Music Makers' (WATMM) ${ }^{70}$ used to be a website dealing mostly with the music genre Intelligent Dance Music (IDM) ${ }^{71}$, with emphasis on the coverage of artists such as the 'legendary' Aphex Twin ${ }^{72}$, Autechre, Boards of Canada, and Squarepusher (We Are The Music Makers, 2013).

It used to have two main features: 1) a main page with information about artists, news, interviews, releases, etc.; and 2) its forums on a separate site:

http://forum.watmm.com. Today ${ }^{73}$ the main page does not exist anymore (if we open the URL, it has a very limited content with a hyperlink to the forum's site), but the forum is still very active: some features from the main page are kept on the forum site, for instance, the blog list (WATMMF, Blogs, n.d.) of related topics and the downloads (WATMMF, Files, n.d.) of music from the above (and later) mentioned artists.

WATMM had an ancestor site: http://joyrex.com ${ }^{74}$ that was started in mid-1999 as a fan website about Aphex Twin. Interestingly, this early site also gained its first user forums, which was very popular with both fans and artists alike (We Are The Music Makers, 2013).

Administrator James E. Thomas renamed and opened the new site as We Are The Music Makers (named after an Aphex Twin track ${ }^{75}$ ) on April 28, 2002. The new site included other artists too: beside Aphex Twin, Autechre, Boards of Canada and Squarepusher got own sections, and later Ceephax Acid Crew, Chris Clark, Luke Vibert, $\mu$-Ziq, and Plaid.

The We Are The Music Makers Forum is divided into two ${ }^{76}$ sections: 1) 'General Discussion' for discussing general music topics (e.g. releases, news, events); and 2)

\footnotetext{
${ }^{70} \mathrm{http}: / /$ watmm.com

71 'Intelligent Dance Music' (IDM) got its name after a mailing list established in the USA to discuss the work of seminal post-techno producers like Aphex Twin (see more about him in the following chapters) (Sherburne, 2001). Aphex Twin himself, among others, looks at this genre name very critically, because "[i]t's basically saying 'this is intelligent and everything else is stupid.' It's really nasty to everyone else's music." (Gross, 1997) Aesthetically, IDM can take very different forms: danceable or non-danceable, experimental, etc.

${ }_{72}$ See more about him in the following subchaters.

${ }^{73}$ Data from June 2016.

${ }^{74}$ Named after WATMM's administrator James E. Thomas, aka 'Joyrex'. The website does not exist anymore.

${ }^{75}$ From his debut album "Selected Ambient Works 85-92", released on 12 February, 1992.

${ }^{76}$ Earlier it was divided into three sections: 1) Music Discussion; 2) Featured Artists; and 3) Expert Knob Twiddlers (We Are The Music Makers, 2013).
} 
'Expert Knob Twiddlers' (EKT), a forum for aspiring artists to discuss techniques and share their creations:

Figure 10: The two main sections of WATMMF (WATMMF, n.d.)

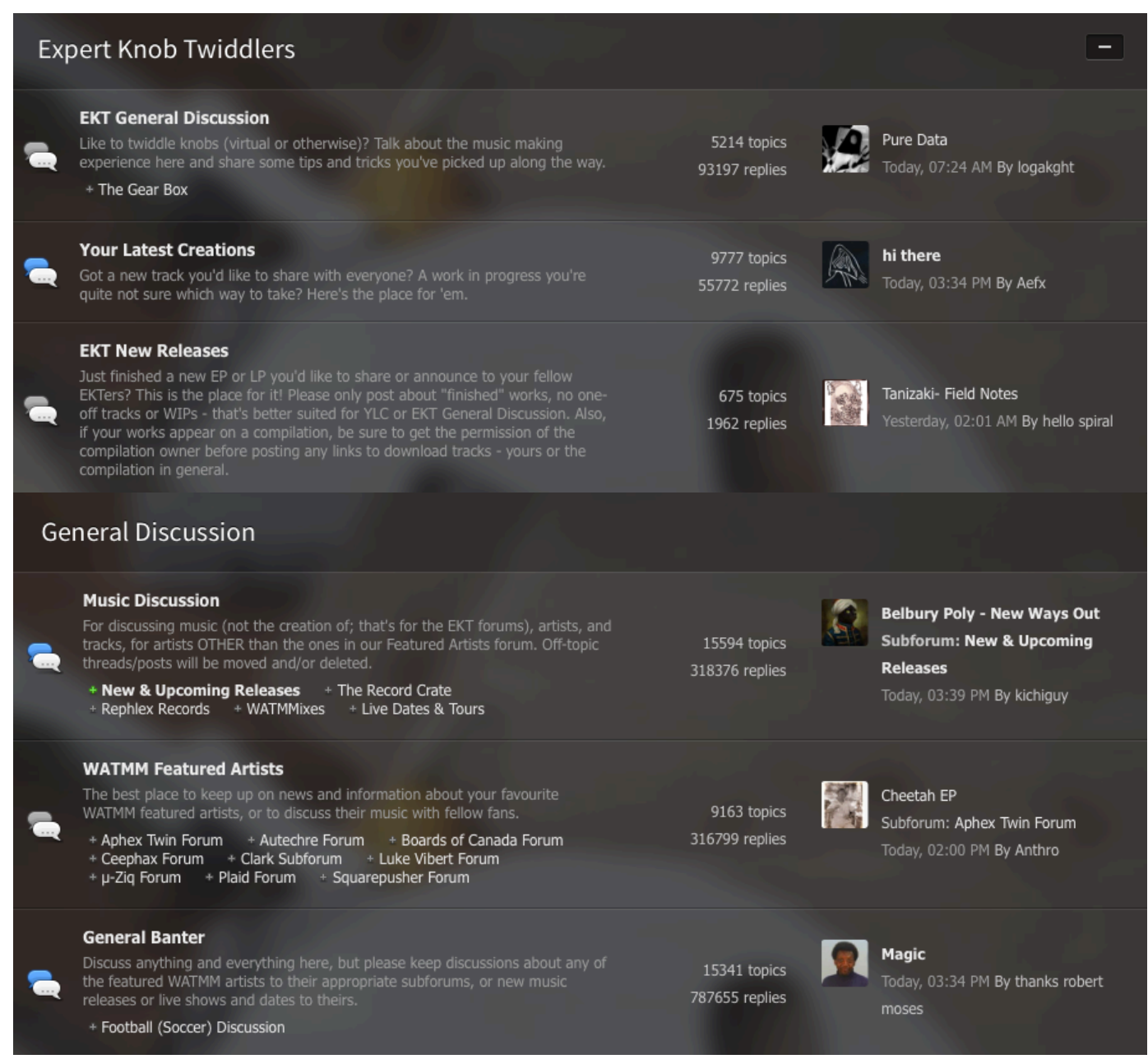

In this figure, an example for sub-forums can be found in the main forum 'Music Discussion': 'New \& Upcoming Releases', 'The Record Crate', and 'Rephlex Records'.

The forum - just as any other web discussion forum - has a long list of rules for its users (WATMMF, Rules, n.d.). They include general rules about post contents, privacy, multiple accounts, etc. Practically anyone can register and become a user of the forum. The site also gives the opportunity to its users to become a 'Supporting Member', by paying $\$ 3.00$ for one year to gain extra access, abilities and features (e.g. see other users' profile under 'Members') (WATMMF, n.d.).

Among many other reasons, this forum was chosen to take linguistics data from, because it is one of the oldest forums in the field of EDM: 
Figure 11: Actual data about WATMMF (n.d.)

1637959 Total Posts 2189 Total Members $\begin{gathered}\text { keanu reeves } \\ 17 \text { years } 1 \text { month } 8 \text { days }\end{gathered} \quad \begin{array}{llll} & \text { Forum exists }\end{array}$

WATMMF was started in 1999 and now (July 2016) has 2189 members and 1637959 posts. These numbers are very high and a high amount of linguistic data could be collected from the posts. One specific thread 'Aphex Twin - Syro, ${ }^{77}$ was chosen from the forum 'Aphex Twin Forum' to analyse its first 500 posts (until page 20).

Aphex Twin Forum is "[t]he place to keep up on Richard's ${ }^{78}$ latest work, news, and information, and a good place to chat with fellow fans". Richard David James (aka Aphex Twin), among other famous musicians around the labels Warp Records and Rephlex Records, originally comes from Cornwall (UK). He and his colleagues often tone these roots in interviews, by referring to the area's mystical qualities and outstanding nature (Aitken, 2003). Aphex Twin started DJing and making music as a teeneger, attending illegal parties and clubs around 1990. He has several aliases; the most famous ones: AFX, Polygon Window, Caustic Window, Universal Indicator, etc. He and Grant Wilson-Claridge founded the label Rephlex Records in 1991 which stopped its activity in 2014. His highly influential discography can be evidenced by his 'title' coined by music journalists: the 'Mozart of techno' (Thompson, 1994).

Aphex Twin Forum's thread 'Aphex Twin - Syro' is about the artist's newest album 'Syro' which was released on September 19, 2014. The thread has the most replies (posts) in Aphex Twin Forum ever, all together 9233 (data from July 10, 2016). It is because Aphex Twin released his last album 'Drukqs' 13 years before Syro, in 2001. This is why the new album was much anticipated and countless rumours had come out before it was released while a huge discussion among the musician's fans was taking place, debating if the news about the release is true or not. The chosen first days of discussion was an interesting period of time in terms of discourse analysis, as there was a general excitement among the fans about this new album release which affected the discourse like a catalyst. Especially because the official press release was shared by the online music publication 'Pitchfork' just a few days later on August 21, 2014.

\footnotetext{
${ }^{77}$ See source in Chapter 9.

${ }^{78}$ Richard (D. James) is Aphex Twin himself.
} 


\subsection{WATMMF in the faceted classification scheme}

For registration on the website, the members of WATMMF need only add a user name to their profiles and optionally they can provide information about their gender, location, country, and website. Data on user habits such as status of users (e.g. 'banned', 'member', 'EKT Plus' - see more on these later in this chapter), the amount of each user's posts and topics, and the date of joining are automatically visible below the user names. Every visitor of the website can access these data without registration. For example:

Figure 12: Public data about user 'Verdant Hickies' (WATMMF, n.d.)

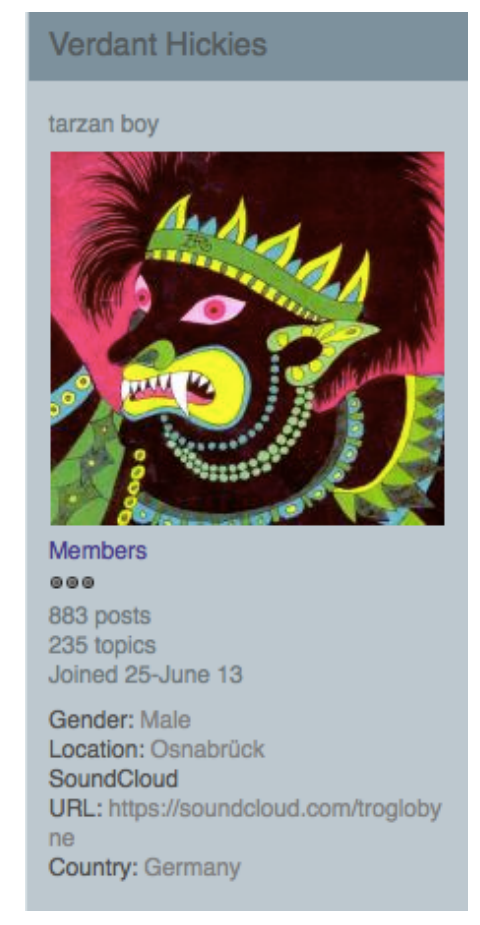

Age, as another optionally given data is always hidden from the users' publicly visible profile. One can access it only if $\mathrm{s} / \mathrm{he}$ is a registered and validated member. Although the author of this study is a registered member of the forum and could reach these publicly inaccessible data, due to research ethics, she has only added the aforementioned publicly accessible ones into Attachment 5 (Chapter 10.5.2). Therefore, the information on user age will be categorised into just three groups: 1) between 18-24 years, 2) between 25-34 years, and 3) between 35-42 ${ }^{79}$ years. (Of course, the users could have given false information on their profiles, but the recent study decided to work with the given information though.)

\footnotetext{
${ }^{79}$ The oldest person was 42 years old.
} 
After a short introduction into the collected data, the following important points can be summarised about WATMMF through Herring's (2007) faceted classification scheme for computer-mediated discourse.

Its medium factors are:

- (M1) Its synchronicity is asynchronous.

- (M2) The message transmission is one-way.

- (M3) The messages remain on the site for an unlimited period of time.

- (M4) The length of the messages has no limitation, but the posts are normally short.

- (M5) The channels of communication are text; visual (static and animated graphics); video and audio channels.

- (M6) The messaging is anonymous: only an e-mail address is required for the verification of the registration. The nickname of the public messages is chosen by the user.

- (M7) Private messaging is available.

- (M8) Filtering is also available: registered users can ignore messages from other users and they can 'report ${ }^{\prime} 80$ each other too.

- (M9) Quoting is available (the content of the original message will stay in the new one.)

- (M10) Message format: the oldest message is placed on the top.

Its situation factors are:

- (S1) The participation structure is:

- One-to-many or one-to-one (with the personal message function)

- Public

- Anonymous with a chosen username

- Rate of participation: from a total of 176 members, who took part in the conversation, 133 have $1-3$ posts, 34 have $4-9$ posts, 9 have 10 or more than 10 posts. Average amount of post per person: 2,84.

- (S2) The participant characteristics ${ }^{81}$ :

- Gender: 57 unknown; 4 female; 115 male

\footnotetext{
${ }^{80}$ A misbehave of a user (a violation of the website's user etiquette) can be 'reported' to the site's admin by other users.

81 'Unknown' means that the users did not give out this information.
} 
- Country: 59 unknown; 117 known: 1 Argentina; 4 Australia; 1 Austria; 1 Belgium; 9 Canada; 1 Croatia; 1 Denmark; 1 Finland; 3 France; 6 Germany; 1 Indonesia; 1 Ireland; 1 Italy; 1 Madagascar; 2 Netherlands; 3 New Zealand; 1 North Korea; 2 Norway; 1 Poland; 1 Seychelles; 4 Sweden; 1 Switzerland; 1 Taiwan; 22 UK; 47 USA

- Age: 124 unknown, 53 known: 10 users between 18-24 years, 29 users between 25-34 years, 14 users between 35-42 years

- Proficiency: they have very good computer skills and as we can see from the statistics, many of them are native English speakers. They are also aware of the features of the forum, as they often use them.

- Status: 79 'members', 21 'supporting members', 5 'members plus', 27 'Knob Twiddlers', 10 'EKT plus', 6 'validating', 9 'restricted', 10 'guest', 3 'banned', 5 'moderators', 1 'site administrator' 82

- Attitudes, beliefs, ideologies: fans of the musician Aphex Twin

- (S3) The purpose of the group is social; the goal of interaction is to share beliefs and opinions.

- (S4) The topic of the group is the aforementioned new album release of Aphex Twin and the theme of exchanges is sharing ideas and experience about the album and the artist.

- (S5) The tone is casual, friendly, cooperative, sometimes critical and sarcastic/ironic.

- (S6) The activity is mainly information and opinion exchange.

- (S7) The norms of organisation (WATMMF) and social appropriateness can be read in the forum rules (WATMMF, Rules, n.d.). The common language is the lingua franca English with 'netspeak' (Crystal, 2001).

- (S8) The codes are analysed in the next subchapter in depth.

\subsection{The language use of WATMMF}

The promotional campaign for 'Syro' began on 16 August 2014, when a blimp featuring the Aphex Twin logo and the number '2014' appeared over London. On the same day, a

\footnotetext{
82 'Members' are registered but not paying members. The difference between the statuses of 'supporting members', 'members plus', 'Knob Twiddlers' and 'EKT plus' lies in the amount of monthly support paid by the members. The more the users pay, the more features they have. See more in WATMMF, Store, n.d. 'Validating' stands for the invalidated e-mail address, 'restricted' members have only a few features, 'guests' are not registered members, and members become 'banned' if they break the forum rules.
} 
graffiti of Aphex Twin's $\operatorname{logo}{ }^{83}$ was reported in front of the Radio City Music Hall and at various other locations in New York (An Aphex Twin, 2014) and later in Los Angeles ${ }^{84}$. On 18 August, Aphex Twin's official Twitter ${ }^{85}$ account posted a link to a hidden service, detailing the album's title and track list and on the same day, the fans started to discuss the album release in WATMMF: User 'Chim' $(\# 1)^{86}$ began the analysed thread with the details about the new album. The news was obviously surprising for many forum users:

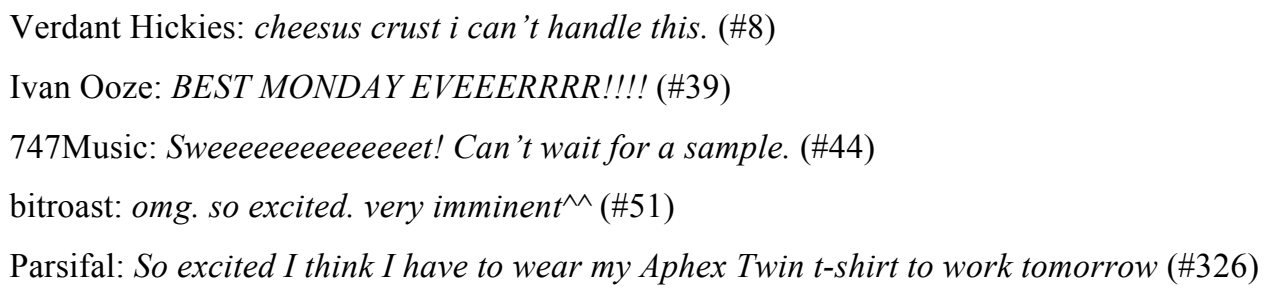

Their excitement was also shown by their use of different compensatory strategies of facial expressions such as emoticons, memes, GIFs, pictures and videos - all together 78 times. The speed of the discussion also testifies their thrill: the analysed 500 posts were written within only 17 hours ${ }^{87}$.

We can already deduce from these first lines that the users are truly Aphex Twin fanatics; they even named him Lord AFX and The Representative. The artist was often mentioned with his different artist aliases and variations of them - AFX, Aphex, Aphex Twin, Richard, Rich, Twin, Twinee, RDJ ${ }^{88}$, Tuss, Phex - a total of 68 times in the data. These were considered community reference words in the analysis, since only those who follow the artist's discography know about these names.

User 'Kavinsky' summarised the aforementioned rumours around the new album: prophecy was true (\#64) and attached the following picture with Aphex Twin's face and logo to his post - a nice example for how the content of text and picture can complete each other:

\footnotetext{
${ }^{83}$ Aphex Twin's logo was published in the cover of his album 'Selected Ambient Works 85-92' in 1992 (Discogs, Selected Ambient Works, n.d.).

${ }^{84}$ See post \#296 in the forum: one of the users posted a photo from Los Angeles.

${ }^{85} \mathrm{https}$ ://twitter.com/aphextwin

${ }^{86}$ The sources of the linguistic data will be remarked with their original places in the thread. (The reader of this study has been informed about the exact hyperlink to the forum - or see it in sources). The hashtag (\#) numbers follow the original numbering of the forum that can be seen at the top-right corner of each forum post. Also, an illustration helps the reader to orientate - see Attachment 2 (Chapter 10.2).

${ }^{87}$ The first post was written at 5:17 PM on 18 August and the 500th post at 10:28 AM on 19 August 2014.

${ }^{88}$ RDJ refers to Richard D. James.
} 
Figure 13: Kavinsky’s picture (\#64)

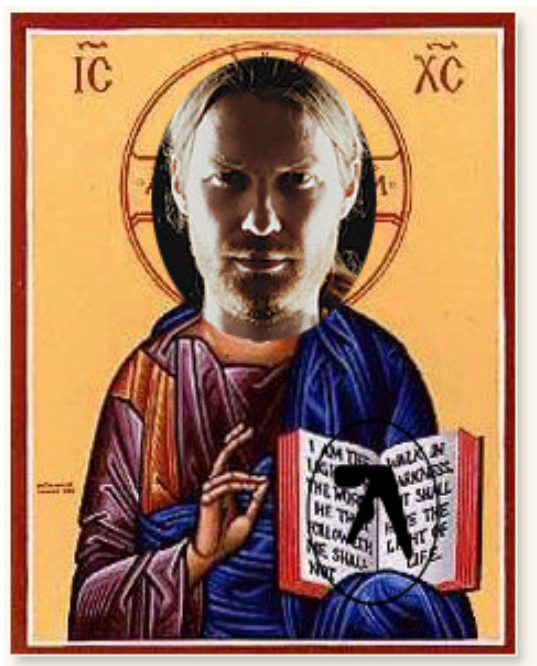

However, not everybody believed the news. There was a general scepticism among the forum users as they thought that it was just another ironic joke on behalf of the artist:

Q27: I still feel like it'll either be some goofy joke album or a hoax. I'll be in disbelief until I have that (...) in my hands. (\#125)

logakght: Wake up, guys. Everything is just a collective dream. There's no new album. (\#166)

Aphex Twin has a very 'special' relationship with Internet communities. Once, without revealing his identity, he trolled ${ }^{89}$ his fans on a web discussion forum and became banned: "I've been banned from message boards [about me], kicked off straight away for winding up other people - which is ironic." (Matos, 2016) This brings us to another interesting Aphex Twin-related topic: his famous irony. His 'evil' smile on his album covers is one of his well-known visual symbols:

89 'Trolling' means in Internet communication - especially in web discussion forums - that someone (the 'troll') starts a discord with the aim of upsetting or outraging the others. 
Figure 14 (left): 'Richard D. James Album' (Discogs, Richard D., n.d.); and Figure 15 (right): 'Come to Daddy' (Discogs, Come to Daddy, n.d.)

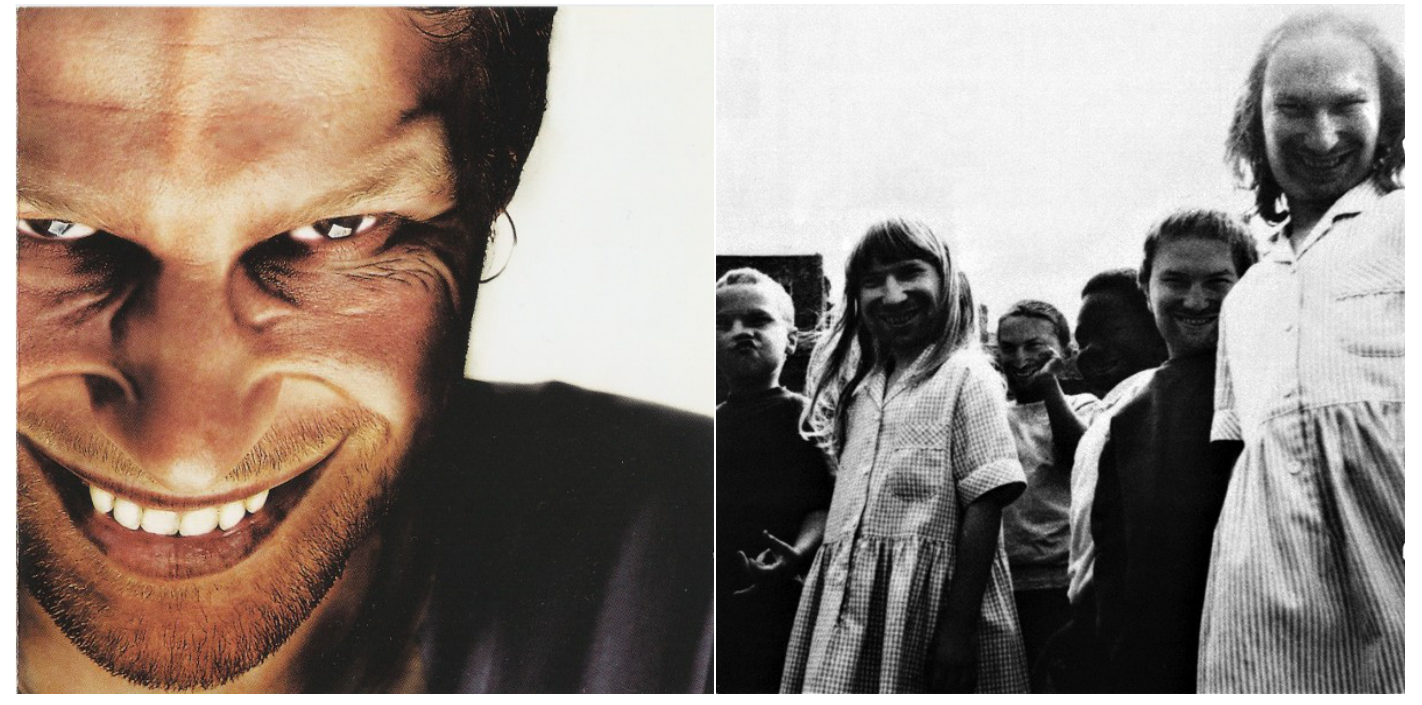

For example, user 'Guest_jasondonervan_*' was pointing to this smile in her/his post: Bet you're grinning like a close-up Richard right now (\#177). This smile is an opposition to the aforementioned rave era's PLUR ideology and the culture of the acid house smiley. This visual irony continued in his music videos 'Come to Daddy' ${ }^{\text {' }}$ and 'Windowlicker' ${ }^{91}$ directed by Chris Cunningham. Therefore, his irony is multidimensional: 1) his behaviour with his fans (see the example about 'trolling'); 2) his visual irony; and 3) his language use as well: he hardly ever gives interviews and when he does, it is difficult to receive longer answers from him. A good example could be an interview with the Spanish magazine El País in 2001. When he was asked about his relationship with his public, he answered: "I hate them." Another question was: "What do you look for when you compose?"; he answered as, "Nothing." Or "How do you know when a song is finished?", Aphex Twin: "When I'm sick of it." (Translated and cited in Sherburne [n.d.]).

This ironic humour is copied by Aphex Twin's fans that is also a typical fan behaviour:

\footnotetext{
auxien: I hope $180 \mathrm{db}_{-}^{92}$ is really 180 decibels so my ears are destroyed and Aphex is the last thing I ever hear. (\#131)

logakght: yeah I was expeting a track named Logakght ${ }^{93}$ (\#185)
}

\footnotetext{
${ }^{90}$ See in YouTube, Come To Daddy, 2012.

${ }^{91}$ See in YouTube, Windowlicker, 2007.

${ }^{92} \mathrm{He}$ was joking about one of the track titles.
} 
The users also tried to find out what the word 'Syro' and the album's track titles stand for, because Aphex Twin has always been famous for his cryptic album and track naming:

Guest_digladwin_*: Not sure what it means, but Syro is an anagram of Rosy. (\#89)

AdieuErsatzEnnui: Or Yors $>$ Yours or sory > sorry (\#90)

chim: Also Sory, as in "Sory you had to wait so long for this"(\#92)

pizza: the last track title is 'anastasia' backwards, btw. (\#108)

tundra: As for track title meanings mentioned at the beginning of the thread, there was a Korg

Minipops drum machine way back when. Also, two tracks with Circlon in the name could be related to the Sequentix Cirklon sequencer. A Cirklon owned by Richard was sold not too long ago through Vemia auctions. (\#124)

In the conversations about these possible meanings, the forum members often used technical terms for the music production such as mix, bpm (beats per minute), and track. Moreover, they were discussing their hopes about the musical aesthetics of the new album by analysing these track titles:

auxien: Oh just look at those titles. It's gonna be mostly acid ${ }^{94}$. I'd bet a dollar on it. (\#279) xxx: I want technical KTPA-like stuff to stay intellectual (\#434)

They were hoping for something ground-breaking as well:

MIXL2: I'm excited by the prospect of hearing some groundbreaking aphex goodness. Whatever it is I'm sure it wont disappoint! (\#281)

xox: $i$ just hope that with this release he'll bring something new to the table (\#392)

The community construction of the fans was confirmed by the frequent use of different community reference words such as my friend, fan, dude, WATTMMers, fellow, mate, fellas, fellettes, forum member, man.

Due to the aforementioned different opinions about the truth of the release and the possible meanings of the album and track titles, the participants often used 'I' (all together 176 times) to give voice to their strong own ideas - I think; I guess; I mean; I'm pretty sure, etc. However, the development of community construction can also be recognised in the use of 'we': are we to assume...?; we will see; we shall see; wish we had a release date, etc.

\footnotetext{
${ }^{93}$ As an ironic answer to the others' comments about guessing the meaning of the track titles and about their expectations of the new album.

94 Acid refers to the EDM subgenres 'acid house' and 'acid techno'.
} 
In the domain of interaction management, we took a closer look at concern structures via linking and quoting, as WATMMF provides, with Herring's (2007) words, mechanisms to facilitate the quoting of a previous message in a response. Using this function is also a signifier of the willingness to keep the community and its conversation together. In most cases, the users kept the others' original messages in their new ones in order to mark which older post they were referring to.

In many cases, the users added hyperlinks to their messages to express their broad knowledge on the community's common topic. They gave different Internet sources to their messages about the album release in question. Many of these were YouTube or SoundCloud links to purported 'leaks' of the Syro sound files, which were then discussed by the users whether they were original or fake.

As mentioned earlier, from the 176 members who took part in the conversation, 133 wrote only 1-3 posts, 34 added 4-9 posts, and 9 users had 10 or more than 10 posts. Therefore, the average amount of post per person is 2,84. From these numbers, we can also see that 43 users actively took part in the discussion and the remaining 133 only occasionally commented.

Here, we have to add some words on the participants' sociological background as well - since the data was available in the users' profiles. We can see a huge difference in the ratio of female and male participants in the thread: from the 119 members who added their genders to their profiles, only four were female. This ratio is a striking and continuous problem in the whole field of EDM which is typically considered to be a male-dominated scene (see more in Rodgers, 2010). Most of the participants come from the following countries: Germany, Sweden, UK and USA. Furthermore, the average age of the 53 users, who added their ages to their profiles, is 30 years.

The roles of the participants were balanced in the conversations and power differences between the members could not be evidenced by their statuses.

The following points can be summarised about the interpersonal discourse behaviours amongst the users. The users often expressed their agreement with each other: good point; yes was just thinking that!; Same here; i believe you; I like the idea. However, as mentioned before, they also had countering points when they were discussing the possible meanings of the track titles and the degree of truth behind the album release. 
They frequently asked for information from each other, which can be explained by the aforementioned mysterious marketing campaign of the album release. The users compared it to the release of the album 'Tomorrow's Harvest' (2013) by the band, 'Boards of Canada':

Philipp Glas: Looks like Warp is gonna do the "BOC" 95 type of marketing with Richard's new album. Good job fellows. (\#308)

The Boards of Canada album was surrounded by a cryptic marketing campaign, when unidentified codes were released through various media channels (the communication strategy showed characteristics of a 'guerrilla marketing' and 'viral marketing' campaign). The fans had to collect and put these codes together to receive access to a new website, containing information about the upcoming release (Michaels, 2013).

This (and this kind of) information is part of the in-group language and knowledge, because 'Philipp Glas' did not have to explain what he means under $B O C$ type of marketing, the others likely understood him, as nobody asked back. At the same time, it is also a mechanism to provide and demonstrate knowledge. User 'Pappilon' added critical words about this phenomenon:

Pappilon: I'm going to predict that this is the time for all aphex fans to get crazy about catalogue numbers and silly detail to demonstrate their knowledge and coolness. (\#395)

The analysed 500 posts represent a highly interesting period of time of discourse among Aphex Twin's fans, because we could experience the construction of a fan-based community via their favourite musician's new album release. The common identity was constructed around their enthusiasm towards the musician, which could be evidenced in their discourse behaviours and language use: via their in-group terminology and knowledge; how they placed themselves into the same group by using the form 'we'; how their excitement was expressed, and so forth.

\footnotetext{
${ }^{95}$ Boards of Canada.
} 


\subsubsection{Gearslutz}

\subsection{General details about Gearslutz}

Gearslutz $\mathrm{z}^{96}$ is a forum for "sharing of information about audio recording and production techniques, the use of recording equipment and experiences in the world of music, audio, post-production and more" (Gearslutz, FAQ, n.d.). Most of the topics relate to technical questions and music production.

Now ${ }^{97}$ it has 873,785 threads, $10,037,981$ posts and 309,649 members (Gearslutz, n.d.). As we can see, it is a very popular forum for recording engineers (amateur or professional) with many active members. Gearslutz was founded by administrator Jules Standen in 2002 (April). It covers its costs by advertising (banners on the site) and members' supports (Gearslutz, n.d.).

The forum is divided into six sections: 'The Forums'; 'News'; 'Marketplace'; 'Gear Shootouts / Audio file uploads / Interviews / Podcasts / Video Vault / Links'; 'Members area'; and 'Q\&A Archives'. In these sections, there are of course, many forums and sub-forums. There is an ever-changing temporary forum ' $\mathrm{Q}+\mathrm{A}$ with composer / performer / artist...' in the section 'The Forums'. Here, the administrators invite different professionals (a composer, performer or artist) to answer users' questions. These question-answer sessions last only for a specific period of time and all of the earlier sessions are stored in the section 'Q\&A Archives'.

The forum has a very useful search engine feature, where its users can find different topics after typing keywords into that. This function was also used to find topics that might be interesting for the present research.

It does not include only electronic music (or EDM) related topics: we would also find forum titles such as 'So many guitars, so little time!'; 'Remote Possibilities in Acoustic Music \& Location Recording'; or 'Songwriting'.

The thread 'Lets talk samplers!' 98 from the sub-forum 'Electronic Music Instruments \& Electronic Music Production' was chosen to take a closer look at its posts. The opening post was on September 18, 2007 and has 414 replies (posts) until now (July 2016). This example was taken as it deals with music production on different levels from

\footnotetext{
${ }^{96}$ See source in Chapter 9.

${ }^{97}$ Data from 11 th July, 2016.

${ }^{98}$ See source in Chapter 9.
} 
amateur to professional. The level of discussions varies in terms of professionalism. This phenomenon can be recognised, for example, from the amount of technical terms used.

\subsection{Gearslutz in the faceted classification scheme}

The publicly accessible data were collected from the user profiles - see the details in Attachment 6 (Chapter 10.6.2).

Gearslutz differs from WATMMF through Herring's (2007) faceted classification scheme at the following points:

- (S1) Rate of participation: 151 users have 1-3 posts, 11 have 4-9, 7 have 10 or more than 10 . Averagely: 2,44 posts per person.

- (S2) Participant characteristics:

- Gender: unknown

- Country: Australia: 7, Belgium: 1, Canada: 6, Czech Republic: 1, Denmark: 2, France: 1, Germany: 3, Netherlands: 5, Norway: 2, Switzerland: 1, UK: 11, USA: 30, unknown: 99

- Age: unknown

- Status: from a total of 169 members, 39 have ' 10 years plus' and 77 have '5 years plus' memberships ${ }^{99}$

- Attitudes, beliefs, ideologies: music producers (with different levels of professionalism)

- (S4) Topic of the group: samplers (music production); topic of exchanges:

sharing ideas and experience about different machines (samplers) with each other

\subsection{The language use of Gearslutz}

User 'roginator' began the thread with a question to her/his fellow forum users:

if you have to take one out of this few... wich would you take and why????

Roland $S 760$

Ensoniq ASR 10

Emu Systems E4xt

\footnotetext{
${ }^{99}$ The membership ' 10 years plus' means that these users are registered on the website since 10 (or more) years. Logically, ' 5 years plus' stands for being registered since at least 5 years.
} 
for electronic music $(\# 1)^{100}$

From this post, one could immediately expect different opinions among the forum users: some might prefer the sampler ${ }^{101}$ 'Roland S 760', others the 'Ensoniq ASR 10', and again others the 'Emu Systems E4x'. This expectation was fulfilled, but interestingly it did not cause conflicts between the members; they always accepted the others' opinions, which helped to maintain a very harmonic and friendly atmosphere to the discussion.

It is not surprising that the participants of the thread used many different music production-related technical terms. Terms such as outputs; filter; pitch and time compression, modulation matrix; stereo outs; analogue filter; mixer; modulation; transmit screen; edit; overdrive; sample; input; polyphony; loop; and resonance were frequently used. This is, of course, part of the in-group language, because outsiders would never understand them.

To break up this very technologically driven conversation, the users often turned to special adjectives to describe the samplers in question and their sounds. The following adjectives were used for the machines: deepest; nice and clean; dirty and bitty; analogue'y, nice clarity; noisy; logical; ergonomic; phenomenal; powerful; smoother; fast; friendly; gritty; bloated; wonderful; heavy, big; killer; impressive; highed; brilliant; pure; sloppy; incredible; amazing; punchy; fabulous; LoFi; complex, golden; ultra simple; interesting, flexible, superb; immediate; exotic; sophisticated; reliable, quick; dry; insane. From these examples we can note that some of them are used according to the sound of the machine - see highlighted ones. This list can be followed by the adjectives used for characterising the sound specifically: crunchy; dirty; nasty; clean; pristine; punchy; fat; artificial; great; bomb; chopping; breezy; dark; pristine; saturated; epic; decent; wide; sexy. As we will see it in later chapters, these adjectives have a highly metaphoric character, which is a very common phenomenon in describing music and sound.

We find the same high rate of occurrence in other types of technical equipment for music production, like Korg ES1; K2000; Emu e64; Yamaha A5000, MPC2000XL; AKAI MPK49; MV-8800; MC-808; SP-404; s770; MV-8000; MKS100, Mirage; RS 290, etc. In

\footnotetext{
100 The original hashtag-numbers of the posts are used for the quotations. (See more in Chapter 5.2.1.1.3)

${ }^{101}$ A sampler is an electronic musical instrument that uses 'samples' (recordings) of sounds that are recorded by the user.
} 
the scope of this study, the aforementioned terminologies are considered to be the part of the in-group language and signifiers of expressing knowledge.

The frequency of these terms points to the fact that most of the members of this discourse community are music producers; some do it professionally, some only as a hobby. It can also be observed from the users' own posted videos: these are highly professional tutorials about using the samplers. For example, after 'dimorley' had posted a video, another user 'Secret Friend' asked him ${ }^{102}$ : how are things? are you working on new music? (\#178). Hence, 'dimorley' is a well-known musician within the community.

Although 'roginator' asked people to join to the conversation about the three types of abovementioned samplers, the other participants opened the topic to other machines and software - e.g. ASR 10; EMU EII; EMU EIII; EMU E4xt; Roland S-750; S5000; MPC 60/3000/2000/4000; E6400, EMU III keyboard; Kurzweil K2600X; Korg ES1; K2000 - as well. 'Roginator' even tried to bring back the discussion to the original samplers in question:

roginator: we must stick to

EMAX 512k

EII $512 \mathrm{~K}$

ADD ONE $512 \mathrm{~K}$

Studio $440512 k$

Mirage $128 \mathrm{~K}$

and things like that (\#105)

However, obviously it was not a successful attempt from her/him, as the others continued their conversations about other machines as well. This also draws our attention to the phenomenon that roles of the participants are balanced and there are no power differences between the members: the person who started the thread has a potentially equivalent power compared to the other users in terms of steering the conversation.

The three 'thread starter' samplers (Roland S 760, Ensoniq ASR 10, and Emu Systems E4xt) were considered to be community reference words as they are the main subjects of the discussion. The number of cases where they were mentioned also proves this fact: the participants referred to them all together 148 times within the 414 posts.

\footnotetext{
${ }^{102}$ His gender is known from the music video he posted, as he added his own name to it.
} 
The terms guys, man, friend and fellow as other community reference words were named only 20 times in the whole thread. Also, the rate of use of the word 'we' compared to ' $\mathrm{I}$ ' is very low: 'we' was mentioned only 15 times against ' $\mathrm{I}$ ' occurred 738 times in the sample. This phenomenon can be explained by the nature of the discussion: the participants presented their own thoughts and experiences about samplers. Therefore, it is not surprising that they used 'I', 'me', and 'my' - mainly referring to their own machines, for example, my ети - and even 'mine' and 'myself' occurred 17 times in the sample. On the other hand, 'they' as a reference word of separation from other groups was mentioned 54 times. By examining these cases, we cannot demonstrate evidence of the phenomenon of community separation by the use of 'they', because in most cases they referred to machines, not to other groups or communities.

Within concern structures, the rate of linking and quoting was extremely high. Linking as a signifier of expressing knowledge occurred 311 times and the users quote others' original messages in their new ones in 181 cases. The latter also proves the tendency of harmonising the discourse: the members answered the others' questions or reacted to their posts while keeping the discourse balanced. However, many posts took the form of a personal 'experience description' without reacting to others in the thread. These messages were usually longer: for example, the 242th post was the longest with 918 words.

The following points can be summarised regarding the participation rate: 169 users took part in the conversation, of which 151 participants added only $1-3$ posts to the thread, 11 were more active and added 4-9 posts, and finally, only 7 users made 10 or more than 10 posts in the forum. Therefore, the average number of posts per person was 2,44 .

Only the place of residence (country and/or city) as sociological information was publicly available on the user profiles - see the collected data in Attachment 6 (Chapter 10.6.2). From the 169 members, 99 did not add such information to their profiles. From the 70 members, who did so, most of them were from English-speaking countries such as Australia, Canada, UK, and USA. Additionally, the information about their membership could also be seen on their profiles. From these data we can consider that most of the participants are experienced forum users, as 39 have ' 10 years plus' and 77 have ' 5 years plus' memberships. 
As mentioned before, the discussion between the forum users was very 'friendly' and only a few counter arguments could be seen. In these cases, they always accepted the others' opinions. One can also prove this discourse 'harmony' with the rate of agreements and the forms they took: I'd agree; Agreed; Spot on; YES! I much prefer...; you're right; very good point here; Yeah fair enough; me too, etc.

This harmony was kept by being 'attentive' with each other, as the members always expressed their thankfulness for the others' advice on how to use their samplers: Thanks for the suggestions.; Thanks for trying to help out.; Thanks for the answers; thanks for the kind words; thanks for your post.; Thanks a lot for that tip!, etc. In addition, they often gave positive feedback to each other too: Great forums here.; Man this will be a nice forum with lots of information.; nice video... especially impressed with those pitched/filtered sounds.., etc. To express compassion, the word 'thumbsup' and its emoticon: ${ }^{103}$ were often used as compensatory strategies of hand gestures.

Joking was not common in the thread, since its subject is a highly professional topic. However, asking for information appeared all the more: the members selfconfidently asked specific questions to each other. The aforementioned friendly atmosphere probably helped them not to be shy about asking even the most beginner questions.

Regarding the types of information exchanges it can be added that most of the posts provided information, mainly on personal experiences with different samplers. These also included their own ideas and opinions (I think; I'd say; Personally...; Speaking only for myself; I guess; as far as I know; In my opinion, etc.). The professionalism of the thread can be evidenced by the rate of sharing biographical information too; in 414 posts we found only three examples: 1) I lived in Germany for maybe 9 years and found it there; 2) my first sampler in 1991 was... 3) In 2000 I sold $m y . .$. However, these personal data also referred to various samplers.

To sum up, the thread 'Lets talk samplers!' has given us an extraordinary example of conversation on a professional music production topic. The community construction could be evidenced by the technical terminology and its high-level use in expert topics by the forum members. Here, we could observe a community construction based on the

\footnotetext{
${ }^{103}$ Source: https://www.gearslutz.com/ [August 17, 2016]
} 
participants' profession and not on being a fan of a musician or a genre, etc. Therefore, this discourse community is not fan-based, but profession- and common-interest-based.

\subsubsection{Summarising the web discussion forums}

We saw two web discussion forums with very different themes. In the case of the thread 'Aphex Twin - Syro' of WATMMF, we could observe a fan-based discourse community that was excited about the musician Aphex Twin's new album release. This excitement affected the mechanism of community construction that was also closely connected to the members' identity as being a fan of the musician. Aphex Twin's own discourse characteristics, how he communicates with his fans, highly influenced the way of communication among the members: its ironic and sarcastic humour was evidenced by the analysis of the sample.

On the other hand, in the case of the thread 'Lets talk samplers!' of Gearlutz, a highly professional discourse about music production could be detected. This professionalism was evidenced by the frequent use of technical terminology that was a signifier of broad knowledge (and common ground) of music production. Here the community construction could not be proved by the use of community specific terminology, but the fact that these professionals have the same activity (full-time or hobby music producers) evidences that they have similar discourse characteristics.

\subsection{2 'Classical' websites}

This study understands under 'classical' websites the type of websites that are mainly built up by its online articles ${ }^{104}$. We prefer adding the adjective 'classical' to this genre, because if we use the term 'website' itself, it refers to any types of websites on the Internet and would include also blogs, forums, personal websites, etc. - all those Internet genres this research takes linguistic data from.

There are many different types of 'classical' websites in terms of their topics: they can be a personal website; a website of an organisation (e.g. a company, a university, a museum, etc.); a website of a community, etc. Both analysed websites, Vintage Synth Explorer and Resident Advisor are 'classical' websites of an organisation.

\footnotetext{
${ }^{104}$ Of course, they can have additional features, such as forum or chat, but these are not the part of the main profile of
} the website. 
Generally, websites have dual nature: 1) they include the situation of mass media communication; and 2) just as books, they are able to form and change situations by presenting hyperlinks, pictures, classical texts, any other types of information (Ropolyi, 2006).

The main content of 'classical' websites is created by their editorial teams (or a single person), but their readers/users often have the possibility to comment under web content and discuss its topics. This feature is for instance a typical Web 2.0 characteristic. The present research has taken examples only from the user-generated ${ }^{105}$ contents, because they have conversational/discoursal characteristics.

Not all websites let their users leave comments - see examples in the chapter about blogs - and there are some of them, which sometimes allow it, sometimes not. With these comments, users and perhaps even the authors of articles can start a discussion on the (related) topic and content of the article. Normally one has to be a registered user of the website to be able to leave a comment.

\subsubsection{Vintage Synth Explorer}

\subsection{General details about Vintage Synth Explorer}

Vintage Synth Explorer (henceforth VSE) is a website for vintage-, digital-, and software synthesisers, and other forms of electronic music instruments.

VSE was created by musician Matt Friedman as his personal website in 1996 and has become one of the leading online resources on synthesisers. On the website, "[d]etailed descriptions and reviews, pictures, audio and video demos, technical specifications, lists of famous users, links, and much more provide the ultimate way to learn about these instruments.” (Vintage Synth Explorer, n.d.)

The site has many features: a huge collection of data about synthesisers (under 'SYNTHS, browse the gear'); an own forum (Vintage Synth Explorer, Forum, n.d.); a synth finder tool (under 'SYNTHFINDER, find the right one'); a collection of resources (Vintage Syth Explorer, Resources, n.d.), where one can find even more information about synthesisers.

\footnotetext{
${ }^{105}$ In marketing, its opposite, the not user-generated content is named as 'marketer-generated' content (see more in Bronner \& De Hoog, 2010).
} 
One of the reasons why this site was chosen to take linguistic data from, is its comment function: the registered users of the website can comment underneath the articles, lending the site interactive characteristics to it. With it, we can experience how users react to professional articles and how they share their ideas about the actual topic.

From this website, we collected all comments of 10 articles that present different synthesisers. The articles were chosen about different types of synthesisers from a variety of brands with at least 40 comments below them, with the aim of detecting discussions between the users of the site (see exact sources in Chapter 9).

\subsection{Vintage Synth Explorer in the faceted classification scheme}

The following important points can be remarked about the users' comments of Vintage Synth Explorer through Herring's (2007) faceted classification scheme for computermediated discourse.

Its medium factors are:

- (M1) Its synchronicity is asynchronous.

- (M2) The message transmission is one-way.

- (M3) The messages remain on the site for an unlimited period of time.

- (M4) The length of the messages has no limitation, but the comments are normally short.

- (M5) The channels of communication is text (including hyperlinks)

- (M6) The messaging is anonymous: only an e-mail address is required for the registration. The nickname of the public messages is chosen by the user.

- (M7) Private messaging is not available.

- (M8) Filtering is not available, but the users can report the others.

- (M9) Quoting is not available.

- (M10) Message format: the newest comment is placed on the top.

Its situation factors are:

- (S1) The participation structure is:

- One-to-many

- Public 
- Anonymous with a chosen username; not anonymous if one logs in with her/his Facebook account

- Rate of participation:

- (S2) The participant characteristics ${ }^{106}$ :

- Gender/Age/Country/Status: unknown

- Attitudes, beliefs, ideologies: being interested in synthesisers or related topics

- (S3) The purpose of the group is social; the goal of interaction is to share beliefs and opinions.

- (S4) The topic of the group is different models of synthesisers and the theme of exchanges is sharing ideas and experience about these different instruments.

- (S5) The tone is casual, friendly, cooperative, and sometimes critical.

- (S6) The activity is mainly information and opinion exchange.

- (S7) The norms of organisation (Disqus) and social appropriateness can be read in the terms and policies (Disqus, Terms and Policies, n.d.). The common language is the lingua franca English with 'netspeak' (Crystal, 2001).

- (S8) The codes are analysed in the next subchapter in depth.

\subsection{The language use of Vintage Synth Explorer}

The topics of the ten chosen articles are as follows: the sampler 'Akai S1000'; the sampler workstation 'E-mu Emax'; the digital synthesisers 'Kawai K1' and 'Yamaha DX7'; the analogue synthesisers 'Korg MS-20', 'Moog Minimoog', 'Roland Juno-60' and 'Roland TB-303'; the bass station 'Novation Bass Station'; and the drum machine 'Roland TR-808'. The 10 articles had all together 834 comments. Here, as mentioned before, we were interested in the users' reactions to these articles.

By analysing the content of these comments, four different types can be distinguished: 1) the ones with listing musicians who used the machine in question - e.g. S1000kb has been used by Klaus Schulze; 2) user questions about the machine - e.g. How many samples can be created and stored to disk (rather than the number of voices)?; 3) the ones that express their own opinions about the machine and describe their own experiences with it - e.g. love it for bass and warm strings. It's a great musical

\footnotetext{
106 'Unknown' means that the users did not give out this information.
} 
instrument that once you get your hands on it, it will give you inspiration; and finally, 4) the ones that discuss the prices and availability of the machines - e.g. I'll never understand the current prices. I guess it's due to all the collectors and electro 'musician' fan boys.

By comparing the commenting function of 'classical' websites to web discussion forums, it can be said that the analysed articles function as threads in a forum: they propose the main topic of the conversation to follow.

Just as in Gearslutz (Chapter 5.2.1.2.3), the discussions in Vintage Synth Explorer also touched on music production topics. Therefore, the use of technical terms was common among the commenters. They also explained their machines with the help of special adjectives such as sturdy, roadworthy; hassle; wonderfully gritty; creamy; delightful; spooky; lazy; difficult; ridiculous; futuristic; smooth; killer. We can find the same metaphoric adjectives used for describing a sound or music: wicked; dark; warm; tempting; perfect; bizarre; scary; lush; soft; pure evil; wishy, washy; noisy; warm; crazy; vivid; cartoony; melodic; snappy; lead; rubbery.

One of the main differences between the analysed Gearslutz and VSE threads is that in VSE the commenters expressed their emotions towards their machines more often: in short: i love this unit; absolutely love it; I really love it; I'm in love with his sound!! This last example brings us to another typical aspect of discussing music production equipment with members of the discourse community - the application of anthropomorphic roles and features to the artefact: the daddy of modern-day rack samplers; king of monosynth; my boy, Poly Phonic... In these cases we can remark that these are all male roles: he, daddy, king, and boy. This phenomenon also confirms the aforementioned masculine nature of the whole music scene in question.

The aforementioned ten machines as subjects of the selected articles were considered specific community reference words, as discourse communities are created around these machines. Their names (and different nicknames) were mentioned all together 230 times within the 834 comments. Another type of specific community reference words was the community-related terminology such as folks, guys, man, my friend, and people (as addressing the others). We could not find evidence for community construction by using these terms, since they were mentioned only 16 times, which is a very low rate in this large sample. 
Within community reference words, a third branch was distinguished: the nostalgia- or past-related expressions, as the comments were often augmented with nostalgic memories. These expressions or anecdotes were always related to different machines: ...is from an era when build quality really mattered; Everyone wanted one back then.; It has its place in history, and will probably stay there.; The Emax II is a nice nostalgia...; Back in the 90s, late 80s standard rompler stuff...; Great Roland sound from the past.; I remember I used this in the mid-80s; etc.

Again, there was no evidenced community construction by the use of personal pronouns either: the word 'I' was used 551 times in the sample, but 'we' only four times. The latter is a very low and it points to the fact that the commenters do not consider themselves to be part of a community. However, despite the fact that community formation cannot be evidenced by the personal pronouns, one can still believe that the people who have the same interest - and often communicate about topics that are related to this interest - belong to one discourse community. Swales (1990) describes this phenomenon with 'The Café Owner Problem': Café owners A, B, and C occupy the same professional roles in life; they interact with the same clienteles, "they originate, receive and respond to the same kind of messages for the same purposes; they have an approximately similar range of genre skills" (Swales, 1990, p. 25). Although café owners $\mathrm{A}, \mathrm{B}$, and $\mathrm{C}$ might never talk to each other, they belong to the same discourse community, because they all have lines of communication back to base. Swales's example is not quite like the website user group in question, as they even talk to each other.

The occurrence of compensatory strategies such as emoticons, hyperlinks and videos was not that common: emoticons appeared only 19 times; hyperlinks 43 times in the sample. The latter were mainly YouTube videos or articles such as reading recommendations.

In the structures concerned, we can highlight only the scoring system of the website: the members can rate a comment with a plus or a minus. The users turned to this function to express their sympathy 60 times which is not a high rate if we compare it, for example, to the Facebook Groups.

Not much can be added about the participation rate, because nearly every single comment was written by a different person. (See user names and rates of participation in Attachment 7 [Chapter 10.7].) 
Only a few cases were identified when the users commented on others' messages. In most cases, the comments were 'monologues' about their own opinions. Therefore, the types of interpersonal behaviours such as agreement/disagreement, acknowledgement and negotiation of conflict were not common. However, a comment for counterpoint was found which criticises all comments about listing musicians who have used the "Akai S1000':

Takashi Waranabe: For this machine, it's useless to say "It is also used by.. ".Anyone produced electric music in this age must have used this machine at least once, it is hard to believe if someone says he/she didn't.

The users often asked each other for information about the different machines. In most cases the question was answered, for which the questioner always thankfully responded. These answers were mostly advice on the functions of the machines or about how and where to purchase them. At this point, we also have to highlight that such online commenting functions (and web discussion forums) play a very important role in consumer behaviour since these platforms are used to search for products and services by their visitors (Evans et al., 2001).

To summarise the language usage of this 'classical' website - based on the ten analysed articles and their user comments - we can state that the community construction of the participants was evidenced only by their common interest manifested within the topics of the related article. Their extensive knowledge on such topics could be experienced by the often-used technical terminology.

\subsubsection{Resident Advisor}

\subsection{General details about Resident Advisor}

Resident Advisor ${ }^{107}$ (henceforth RA) is an online music magazine (or fanzine) and community platform dedicated to showcasing electronic music, artists and events across the globe (Resident Advisor, About, n.d.). It was established in 2001 and currently has almost three million readers a month (Resident Advisor, About, n.d.).

The platform has three main functions: 1) its 'Magazine' provides shorter news, music, tech, and event reviews, longer thematic articles, own video documentaries; 2) the

\footnotetext{
${ }^{107}$ See source in Chapter 9.
} 
section 'Events' lists current EDM events ${ }^{108}$ worldwide, presents clubs and event photos; and 3) its 'Music' part presents artists, DJ charts, labels and podcasts. RA is multifunctional, but it is still mostly known for its event listings.

For the collected data, we chose 10 pieces of event descriptions from different clubs and promoters in Berlin; 10 event reviews from London (written by journalists), and 10 album reviews (again, written by journalists) that have at least 40 comments by the website users. There are many different types of journalistic articles that could have been included in the present study, but we found event reviews, descriptions and album reviews the most interesting for the research aims, because they intensively apply terminology to musical events and tracks alike. An event review focuses on the evaluation of a specific event - in our case, an EDM event. An event description is a marketing tool which tries to receive greater attention from its audience or potential audience. Its aim is to invite more people to an event. Finally, an album review evaluates a music album from different perspectives (e.g. music aesthetics, design).

\subsection{Resident Advisor in the faceted classification scheme}

The characteristics of the 'classical' website Resident Advisor in Herring's (2007) faceted classification scheme differ from the aforementioned Vintage Synth Explorer at the following points:

- (S2) Attitudes, beliefs, and ideologies: at least being interested in EDM events and music.

- (S4) The topic of the group is the EDM events and albums described in the articles (written by the journalists of the website); and the theme of exchanges is sharing ideas, again, about these events and albums.

\subsection{The language use of Resident Advisor}

Some details about the selected linguistic data: All together 583 comments were added to the ten album reviews; 67 to the event descriptions; and 201 to the event reviews.

To analyse the content of the selected journalistic articles, we would need another type of coding system, since these text genres have another characteristic: they are

\footnotetext{
${ }^{108}$ RA also sells tickets to different events with its own online ticketing system.
} 
written by one person ${ }^{109}$ (normally a journalist) as a one-way communication and the interpersonal discoursal and conversational behaviour cannot be detected in them. Therefore, their importance in terms of the analysed discourse community have to be highlighted here - however, their content will not be analysed in detail. These text genres are definitely part of the discourse of the community in question; people who are interested in EDM topics read them, widen their knowledge with the help of them, and perhaps communicate about them. As we have seen it in Swales's (1990) model of discourse community, these text genres are community-specific and tools of communication among the members of a DC.

In this sense, only the 851 comments of these articles will be analysed in this section, as they have conversational character.

The opinions about the selected event descriptions and event and album reviews among the commenters were varied; some reacted with positive, some with negative feedback to them. It was very interesting to see that it was always an important factor what the majority think about these texts and the events or albums. If the general opinion was positive, only positive feedback was expected from everybody ${ }^{110}$. We evidenced this phenomenon by analysing the results of the website's comment rating system: the users can give a plus (+) or a minus (-) to the others' comments. Therefore, this system was considered a type of concern structure. It seems to be an important tool to give feedback to each other: all together 3.234 pluses and 726 minuses were given to the analysed 851 comments. Some commenters found it unfair to receive a minus:

Pegmayer: This was just a question. But I suppose everyone who dares to question anything just gets negative votes. So you almost are not rational thinking people here, you are just belief devotees.

Ben-Cohen: Minus the personal attacks, it would help if you outlined what part of my comment you disliked, or disagreed with. (Ryce, 2016) ${ }^{111}$

These comments also confirm the aforementioned observation about the community's expectations in terms of positive or negative feedback. For example, user 'sukkat' expressed her/his fairly negative opinion, First half good, second half descends into some IDM bollocks., about the mix CD 'Kern Vol. 3' by Objekt, for what s/he received -13 scores from the other users, just because the majority had a positive opinion about the mix.

\footnotetext{
${ }^{109}$ Rarely by more people.

${ }^{110}$ Even if a person gives a well-founded critique, it will not be accepted by the others.

${ }^{111}$ Here, the authors of the articles are given to the quotations. See the list of the original sources in Chapter 9.
} 
Also, minus points are given, when for example someone adds an obviously 'outsider' comment. For example, 'VanessaBittante' received -14 scores to her/his comment, Do you know at what time Ben Klock will be playing? So I can buy the right ticket! Cheers, below the event review 'Dekmantel x The Hydra in London' (Titmus, 2015). With this comment, 'VanessaBittante' expressed that s/he knows only the headliner ${ }^{12}$ musician Ben Klock ${ }^{113}$ of all the artists playing there. Therefore, $\mathrm{s} / \mathrm{he}$ is considered to be a kind of an outsider who wants to attend this party just because $\mathrm{s} / \mathrm{he}$ has heard about only one well-known musician from the scene. This and this kind of phenomena can be explained by the questions of authenticity in music scenes. In EDM, this is closely connected to the concepts of 'underground' (less known, commercially not supported) and 'mainstream' (popular, mass media-supported music) scene(s) and music. As Resident Advisor tries to support the underground electronic dance music scene, it is generally expected from its users or readers that they represent the same 'philosophy'. Therefore, if someone visibly prefers mainstream - or commercial - scenes, s/he will not be accepted by the reader/user community.

The comments that receive -3 or less scores are even hidden from the website they are the so-called 'downrated' comments. Here is an example from commenter 'Pegmayer', who received -11 scores:

Figure 16: An example for 'downrated comment' (Unicomb, 2016)

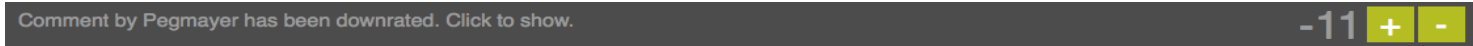

If someone wants to see these downrated comments, s/he has to click on the minimised representation. We consider this phenomenon to be a censorship process that is initiated by the user community.

This readership can be also very critical of the authors of the articles and often gives negative feedback. The event review 'Levon Vincent in London' (Hulyer, 2015), for instance, received a negative coverage from Resident Advisor's audience:

darkarx: This review is a joke. Two paragraphs about events and venues. And two sentences on the Levon Vincent set. I was there with four other people, all of whom have spent half their lives in nightclubs, and everyone was blown away by Levon's set. Musically, he's a clean break from almost anyone else playing in London right now, rowdy, intelligent, moving house music. A revelation. And Dolan Bergin has been putting on good events for years, but he's also a fantastic selector, often the

\footnotetext{
${ }^{112}$ The most well-known musician in the lineup.

${ }^{113}$ A resident DJ at the famous Berlin Club 'Berghain'.
} 
best set of these nights, even tho he's egoless enough to play true warm up sets. RA - get back to reviewing the music, the bored London insider tone is a real shame. (Hulyer, 2015)

TheHydra: quite honestly the most depressing review we've ever read, you are definitely too grumpy to go out. (Hulyer, 2015)

'Darkarx's' comment was scored with 29, 'TheHydra's' one with 36 points.

Just as in the other samples, the commenters of the analysed articles often used metaphorical adjectives in order to describe the events or albums in questions.

Interestingly, they applied only a few technical terms in their descriptions of music. This result might be explained by the hypothetic assumption that the audience of Resident Advisor incorporate more fans (and promoters, as they use the website to advertise their events) than musicians. This can be evidenced by the commenters' language use: how they express their feelings towards music - e.g. I'm feeling Butterflies none the less.; Looking forward to the new LP; Goosebumps. Goosebumps everywhere.; and how they articulate their excitements about an upcoming event - e.g. Gonna be a banger!!; cant wait to have him over and feel very honoured to warm up for him!!!!.

Community construction could be evidenced neither by the use of specific community reference words - such as the word guys or all the event and album titles and the related musicians' names -, nor by the use of the word 'we'. The latter, for instance, was used only 31 times within 851 comments. The same phenomenon was detected in the case of the word 'they' - as a signifier of community separation - which was mentioned only 69 times, mainly referring to bands (with more members).

Apart from the aforementioned rating system as a concern structure, other types, such as linking, quoting and using hashtags hardly ever appeared.

The participation rate was not examined in this sample, as we saw in the case of Gearlutz, these commenters leave only a few posts (mostly one), therefore, it is useless to analyse these numbers.

It can be added to the interpersonal behaviours that counterpoints and disagreements were common, which were expressed by either answers or the help of the scoring system. Moreover, asking for information and offering advice were also frequent phenomena. These were experienced mostly in the case of event descriptions, where the 
event attendees were asking questions about the running order ${ }^{114}$, entrance fee, start time of the event, etc.

Providing knowledge as a type of information exchange occurred when the commenters were giving advice to each other - e.g. Only solution to get a ticket, keep refreshing the page to be the first. I did it during a few hours this afternoon and it worked. As there were only a few cases where the participants shared biographical information with each other, in most cases the comments expressed ideas and opinions.

By analysing the user comments of the 'classical' website, Resident Advisor, we could experience the discoursal behaviour of a fan-based community that identifies itself - through the profile of the website - to be the part of the underground EDM scene(s). With the help of the scoring system, the participants could express their sympathy or unconcern for the others' comments. This works as a censorship system on the website, where not only comments which were too negative could be filtered out, but those which were not 'authentic' or 'underground' enough as well.

\subsubsection{Summarising 'classical' websites}

Similar to the web discussion forums, in the case of 'classical' websites we saw two platforms with very different characteristics and thematic. The audience of Vintage Synth Explorer is highly interested in music production equipment such as samplers, synthesisers, and drum machines. It does not mean necessarily that the website's readers are all music producers, but they are at least interested in such topics. By analysing the comments of the website, it could be evidenced that its users or readers belong to the discourse community of music producers and vintage music equipment fans.

On the other hand, the audience of Resident Advisor created a fan-based discourse community that identifies itself through the ideologies of underground electronic dance music scene(s). It was evidenced by the use of the highly interesting scoring system of the website: the commenters can give 'points' $(+1$ or -1$)$ to the others' comments to signify their opinions about it. The comments that receive more than -3 scores are even hidden from the website. This censorship is a strong tool of community construction: it indicates who is accepted as 'insider' or who is not. However, this scoring system could function as a 'gatekeeper', selecting the 'undesirable' elements.

\footnotetext{
${ }^{114}$ The exact timetable of the event: which musician plays at what time.
} 


\subsubsection{Facebook Groups}

Facebook $^{115}$ is an online social networking service. The website was launched in 2004 by Mark Zuckerberg, along with fellow Harvard College students and roommates. Initially it was opened only to Harvard students, later it was expanded to higher education institutions around the Boston area. Since 2006, anyone older than $13^{116}$ has been allowed to become a registered user of Facebook.

Here we will not write more about the history and features of Facebook, because only one function of this social network is included in this research: the 'Facebook Group'. Facebook Groups ${ }^{117}$ and their contents are created by the members of the groups (Facebook users), therefore, here we can talk about a clear user-generated content. Members can comment and 'like' 118 posts within the group; with the aim - as 'promised' on the website -: "to discuss anything with just the people you want" (Facebook, Facebook Groups, n.d.). Facebook Groups normally have an 'exclusive' character, because in most cases only the 'right' people can be part of it: "You can make each space special to share the right stuff with the right people." (Facebook, Facebook Groups, n.d.)

A Facebook Group can be 1) public, 2) closed, or 3) secret. To the 1) public groups anyone can join and there is no data restriction, everybody has access to all the posts and has the right to post even without being a member. To the 2) closed groups, one has to be added or invited by a member and only these members can read its content and post. The 3) secret groups have the most strict privacy settings: a person has to be added or invited to the group; only current and former members can see the group's name and its group description (all other users would not know that this group exists at all); only current members can see who is in the group, the group tags, etc. (see more in Facebook, What are the privacy, n.d.).

Members can be blocked (with a restriction of rights) or removed from a group (e.g. in case of inappropriate behaviour), or they can leave or unfollow groups.

Facebook Groups are a very interesting form of online community building. We chose the groups 'TB-303 Owners Club' and 'ITALO DISCO MANIACS' to analyse, because from the titles and descriptions of the groups one can suspect a high degree of involvement with 1) a specific and, in this case, legendary electronic music production

\footnotetext{
${ }^{115} \mathrm{https}: / / \mathrm{www}$.facebook.com

116 It can vary depending on the local law.

${ }^{117}$ See more about them in the following chapters.

${ }^{118}$ Highlighting comments by clicking on an icon that expresses the user's 'attitude' towards it.
} 
technology and 2) electronic music artists. Our aim was to examine these groups' 'exclusivity' in terms of language use: Can we recognise group membership identity markers in members' posts and their language use?

A Facebook Group is a subgenre of asynchronous chat (Crystal, 2006) or message board (Bishop, 2009), because members of a Facebook Group can post their messages anytime and people can react on them, again, anytime later.

There are two types of text genres used in Facebook Groups: posts and comments. Members of Facebook Groups can leave posts on the group's timeline. Facebook Group posts can differ in length and content: just like forum posts, they can include not only plain texts, but, for example, hyperlinks, pictures, emoticons, GIFs, memes, etc. In most of the cases, they have multimodal characteristics. Apart from the content of the post again, as with forum posts - one can see the member's name and profile picture of the member, who posted it as well as the day, when it was posted. A Facebook Group post functions as a forum thread: the person who posts initiates a discussion topic. However, it should be mentioned that a reaction or comment to a post is not obligatory and often they are uncommented.

Aside from leaving a post in a Facebook Group, members have the possibility to react and comment on posts. If we stay at the comparison with forums, comments function as forum posts after a thread. A whole discussion can start with these comments. Under a comment, other members can answer and comment on comments. 
Figure 17: An example for a Facebook Group post and comment (source: Facebook Group 'Rephlex Rephreshed', [not analysed group])

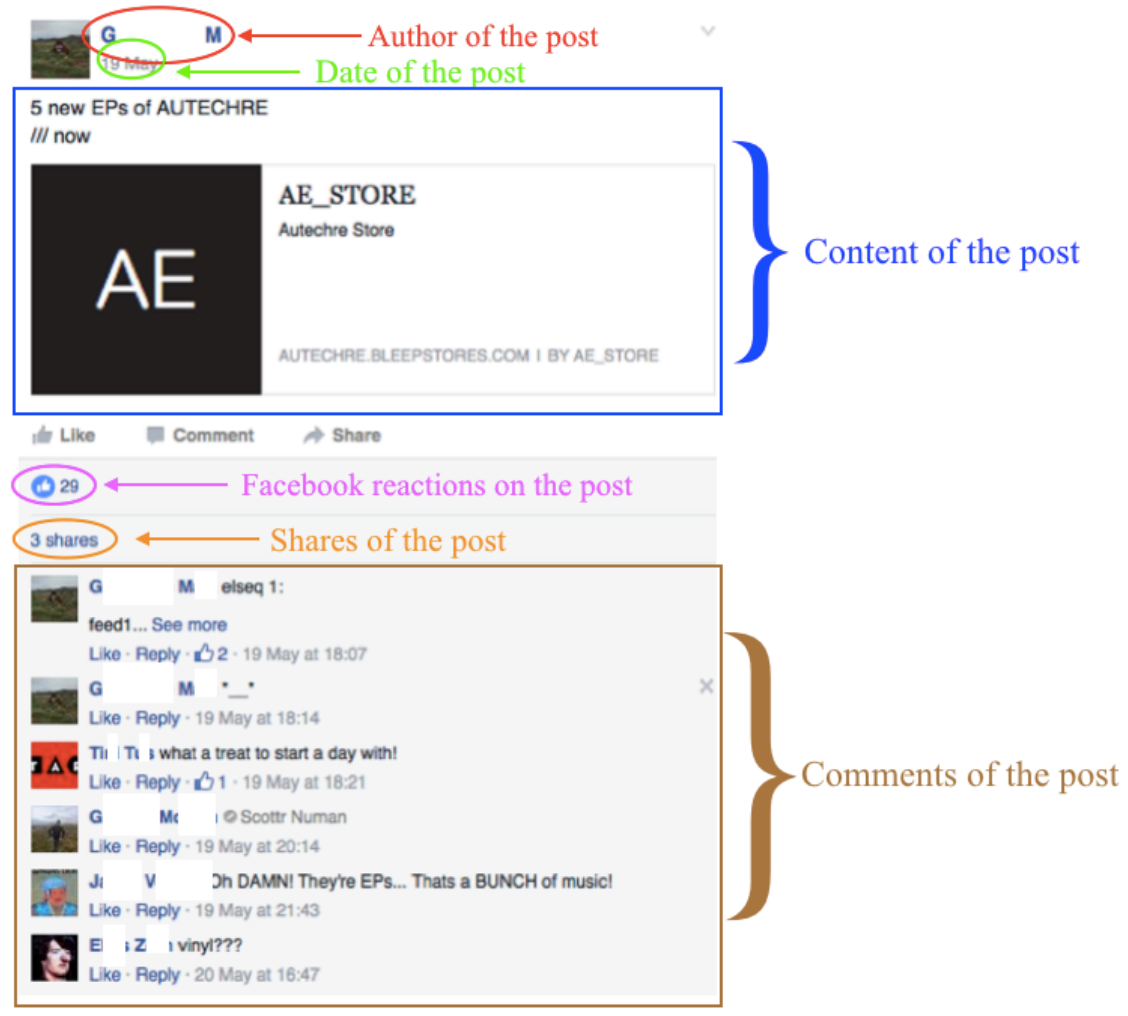

\subsubsection{TB-303 Owners Club}

\subsection{General details about the TB-303 Owners Club}

The TB-303 Owners Club ${ }^{119}$ is a restricted public Facebook Group in terms of its topic and membership: It is dedicated exclusively to owners of Roland TB-303 bass line only. As it is written in the group description:

"Remember, this group is for TB-303 owners only.

1. You must submit a photo of your TB-303 to be allowed to join this club.

2. You can specify to keep your photo private if you don't want anyone to see your unit.

3. If you have a friend that you know has a TB-303 please suggest this group to them." (TB-303

Owners Club, Description, n.d.)

So new members are accepted only if they submit a photo of their TB-303 including its serial number. As it is a public group, anyone can read its content. Currently, it has two administrators and 858 members (data from 2016 July).

\footnotetext{
${ }^{119}$ See source in Chapter 9.
} 
The Roland TB-303 ('Transistor Bass') is one of the most influential instruments in the history of electronic dance music. Of the monophonic analogue bass synthesiser, only 10.000 units were manufactured between 1982 and 1984. It was originally produced to guitarists for bass accompaniment that helped them practicing alone, but it never became popular among them because of its inauthentic sound.

Later, Chicago house producers discovered a creative way to use this instrument by applying its built-in effects to its programmed sound patterns. The result was the socalled 'acid sound' that led to the establishment of a completely new music genre: acid house. This 'wrong' way of using an instrument also represents the 'creative perversion of technology' (Vitos, 2014) by those early producers.

In the 1980s, the instrument was relative cheap to acquire because of its failure amongst the original target group. Its current price is between 2000-3000 Euro ${ }^{120}$, depending on its actual condition. The TB-303 became a mythical and must-have piece of equipment among acid house ${ }^{121}$ and acid techno ${ }^{122}$ producers. Aside from this group, there are also many analogue synth fans and instrument collectors, who own it as a prestige object without practicing music production.

The reasons why it has such a high price nowadays are complex, and here it can only be speculated: 1) it has a historical value for musicians who want to produce the 'original' acid sound; 2) this corresponds with the phenomenon of nostalgia or vintage as a key role in making something more popular/valuable; and the other reason is that 3) only 10.000 units were produced.

Even if many software and hardware (even analogue) clones exist today, most of the musicians and fans only believe in the original machine and consider the clones' sound to be noticeably different (Reynolds, 2013).

With the chosen Facebook Group comments, we want to illustrate some characteristics of the language use of individuals who take part in the discourse of TB303. This discourse is especially important because of the aforementioned creative use of the instrument. The original manual did not include those 'new' functions, which were

\footnotetext{
${ }^{120}$ Actual (summer 2016) price on the German eBay (http://www.ebay.de).

121 Acid house is a subgenre of the genre house music (see more about EDM genres in Chapter 2.4.1) developed in the mid-1980s in Chicago, USA. The style is defined primarily by the 'squelching' sounds of the famous analogue bass line TB-303.

${ }^{122}$ Acid techno is one of the subgenres of techno that developed out of acid house. The sound of TB-303 is a very important landmark of the subgenre, but aesthetically it is considered 'darker' than acid house.
} 
discovered by the EDM musicians; therefore, the members exchange experience in order to learn how to use of their instrument in these new ways.

The discourse, in part through the community's specific lexis, helps to keep the group together, building friendships, connections, creating opinion leaders, and sharing ideas and thoughts.

\subsection{The TB-303 Owners Club in the faceted classification scheme}

The following important points can be remarked about the Facebook Group through Herring's (2007) faceted classification scheme for computer-mediated discourse.

Its medium factors are:

- (M1) Its synchronicity is asynchronous.

- (M2) The message transmission is one-way.

- (M3) The messages remain on the site for an unlimited period of time.

- (M4) The length of messages has no limitation, but the posts are normally short.

- (M5) The channels of communication are text; visual (static and animated graphics); video and audio channels.

- (M6) The messaging is not anonymous: a Facebook registration is needed with an own profile.

- (M7) Private messaging is available.

- (M8) Filtering is also available: registered users can ignore messages from other users and they can report other users.

- (M9) Quoting is not available.

- (M10) The message format is: the newest message is on top.

Its situation factors are:

- (S1) The participation structure is:

- One-to-many or one-to-one (with the personal message function)

- Public

- Not anonymous

- Rate of participation: for this, one should analyse all available data from the Facebook group (all posts, members data, etc.) 
- (S2) The participant characteristics:

- Gender/country/age/proficiency: based on research ethical reasons and personal data, the author of this study does not want to give out such information

- Attitudes, beliefs, ideologies: about the bass line Roland TB-303

- (S3) The purpose of the group is social; the goal of interaction is to share beliefs and opinions.

- (S4) The topic of the group is TB-303 and related topics; the theme of exchanges is sharing ideas and experience about the usage of the instrument. - (S5) The tone is casual, friendly, and sometimes critical (not against the other members, but normally about a fact outside of the group, e.g. about the high prices of the instrument)

- (S6) The activity is mainly information and opinion exchange.

- (S7) The norms of organisation (Facebook) and social appropriateness can be read in terms and policies (Facebook, Policies, n.d.). The common language is the lingua franca English with 'netspeak' (Crystal, 2001).

- (S8) The codes are analysed in the next subchapter in depth.

\subsection{The language use of the TB-303 Owners Club}

All posts and comments of the Facebook Group were analysed from April 1-30, 2016. During this period of time, the members of the group posted 31 posts and added 87 comments to them. The topics of the posts are various: some of them are exact questions about the TB-303 functions; some are about the music produced partly with the help of the Roland TB-303; a few are about own music, etc.

In analysing this Facebook Group, we were interested in how a discourse community is constructed around a specific technological item. How can this object determine the identity of a discourse community?

In Attachment 9 (Chapter 10.9), we can see the coding system which was followed during the analysis of these 31 posts and 87 comments.

Within the domains of structure and meaning, the frequently used music- and machine-related adjectives were analysed that were used by the members of the Facebook Group. We found the following examples for music-related adjectives: grimy acid house; 
pulsating hi-hats and cymbals; crafty percussion; great acid; deep and late night vibes; creates motion that fluid and full; driving kick drum; fantastic tones; sweeping builds; intense dopeness. Within these examples we can easily recognise many structural metaphors (Lakoff \& Johnson, 1980; Kövecses, 2010) - in bold. In structural metaphors, the source domain provides a rich knowledge structure for the target concept (Kövecses, 2010). In every case, the target concept is the music itself. It is not a surprising phenomenon, because talking about music can generally be very difficult, therefore, we often use metaphors or metaphorical expressions in order to express our thoughts on music (see more in Jóri, 2015).

The same phenomenon can be seen in the case of using machine-related adjectives. The members of the Facebook Group used the following adjectives on different - but mainly for their Roland TB-303s - music production equipment: robust; healthy; great; absolutely beautiful; mint; strident and proud. These adjectives can be also understood as metaphorical expressions, because some of them - e.g. healthy; proud - sound 'strange' being used on a machine; they would normally be used to describe a living being. Here we can clearly see examples for the phenomenon of how users of the TB-303 give human characteristics to their machines and emphatically project emotions onto them. The phenomenon can be explained through the members' passionate - often even fetishist - feelings towards their instrument:

THE ANALOG ROLAND ORCHESTRA: GRAND SILVER PLASTIC MACHINE. ACID. WAYS TOO EXPENSIVE BUT WORTH EVERY CENT. I MEAN SURE YOU CAN HAVE A WAYS CHEAPER EMU AND FAKE BUT ISNT IT GOOD TO TURN THE REAL KNOBS. YEAH. PEOPLE WHO WANTS THAT SOUND, BUY ACIDLAB BASSLINES - THE BEST EMU OF THIS BUT IF YOU WANT TO HAVE THIS FEELING YOU HAVE TO GIVE SOMEONE 1500 DOLLARS OR 1000 EURO $^{I 23}$ AND YOU GET IT. ACID PURE. YOU CAN WATCH THIS SILVER BOX FOR HOURS AND SHE WILL LOVE YOU AND YOU WILL TURN HER KNOBS AND SHE WILL LOVE YOU AND YOU WILL LOVE HER.

NICE RELATIONSHIP.

I LOVE MINE AND I M HAPPY AND IT WAS WORTH 1000 EURO. ${ }^{124}$

This brings us to the next interesting case we want to discuss in this analysis: when members use anthropomorphic expressions on their machines: small silver family; our little friends; one of my guys, little sister; beautiful baby. In these examples, the TB-

\footnotetext{
${ }^{123}$ The comment is from 2008. At this time the 303's price was much lower than at present.

${ }^{124}$ The example is taken from another analysed source: one of the articles of Vintage Synth Explorer - see source in Chapter 9: Vintage Synth Explorer, article: Roland TB-303.
} 
303 is treated as a 'friend', 'a family member' or as an 'own child'. As T.M.G. wrote in a comment: Family $+303=$ Love.

Another good example from the collected sample is the following post from K.B.K.V. from April 12:

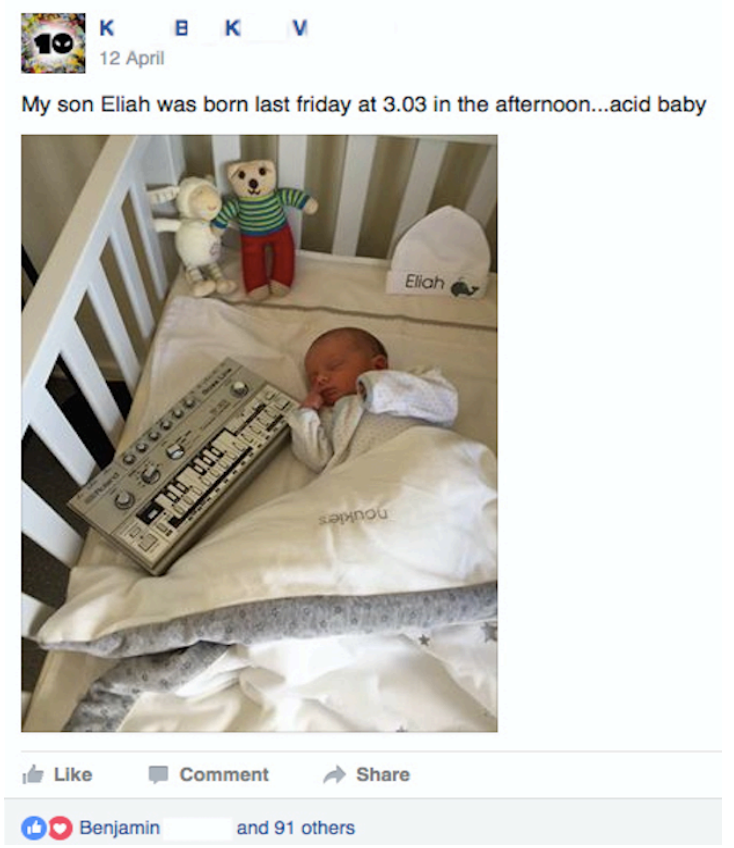

K.B.K.V. has a newborn baby - who was born on the date ' 3.03 ' - and took a photo of him and the TB-303 together. He received all together 92 'Facebook reactions' from the other members. Since 2016, Facebook has six different types of reactions (before, only 'Like' could be used as a reaction):

Figure 18: Facebook reactions (Facebook, Reactions Now Available, 2016)

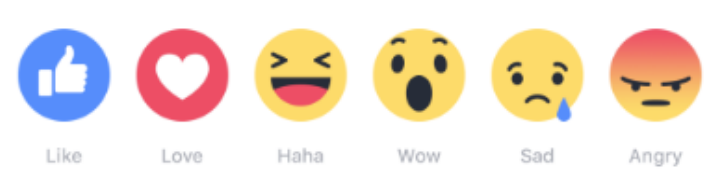

They are compensatory strategies to express feelings about a post: to like or love, to find something funny, astonishing, sad or infuriating. In the abovementioned post, the 92 members used the 'like' and 'love' reactions and 13 of them also congratulated him in the form of a comment underneath the post. In these comments, many members were joking: first, they expressed their congratulations for the 'beautiful' machine, and only then for the baby: 
With these examples we can prove the fact that some of the TB-303 owners treat their machines as humans and that they are big fans or enthusiasts of their objects. The members express their 'fanaticism' also through their numerologies: they remark and collect things that have some kind of connection with '303'. As K.B.K.V. writes in his post: My son Eliah was born last friday at 3.03 in the afternoon...acid baby. S.A. comments under it: my son was born 03.03.2013...in the morning. it's also an acidline!!! and F.S. adds to it: karma, and my girlwas born in room $303 @$ hospital.

While analysing the community's language use in the domains of structure and meaning, it is easy to see that the community often uses technical terms that are mainly connected with the functions of the synthesiser or they are related to music production generally: knob; mod; modded; sequencer; groovebox; remix; programming mode; mix; noise ratio; low notes; compressor; high ratio; long release time; loop. These terms are also examples of expertise in the community. Members with a higher level of knowledge on the topic, obviously use these terms with more self-confidence.

The group also uses many specific community reference words that are signifiers for holding the community together. These terms were categorised into four types: the ones that are related to 1) the Roland TB-303; to 2) music genres (scenes); to 3) relationships; and to 4) the Facebook Group itself. 1) Statistically, the group only mentioned the term TB-303 (or its different variations: Roland TB-303; TB-303; 303; TB303; tb303; $t b-303$, etc.) 13 times, but this number would be much higher if we added the aforementioned metaphors used for the synthesiser and its referential pronouns (e.g. it, he, she, this, that). 2) Another typical community reference word is the music genre that the members produce with their machines: 'acid' that can refer to the genres acid house and acid techno. Surprisingly these terms were used only 13 times in the sample, but we can still believe that it is part of the in-group language use, as mentioned before, the members of this Facebook Group are the part of the acid house and acid techno virtual scenes (Bennett \& Peterson, 2004).

\footnotetext{
${ }^{125}$ Here a screenshot of the comment was pasted to keep the original usage of the compensatory strategies (emoticons).
} 
To show another example for the terms that help to build the community together, we also want to focus on ones that relate to friendships and relationships between the members. Of these, the following were used all together 15 times in the sample: mate; bro; friend, man, guys, member, group, Facebook Group. The fact that these terms are often used in the comments proves that the members treat the community as a 'friendship community'.

By analysing the use of singular and collective personal pronouns, we wanted to find evidence for collective identity. We predicted that the group would use the collective 'we' frequently. This cannot be proved from this sample, because the community used 'we' and 'our' only 9 times. In contradiction, the members used 'I' and its related forms 'me' and 'my' all together 65 times. So, from the personal pronouns we cannot present evidence for collective or group identity.

As mentioned before, one type of compensatory strategies to express emotions and thoughts: Facebook reactions. Now we have to add some points about the other types of strategies used by the members: emoticons, pictures and 'Facebook stickers'.

We found different types of emoticons in the sample; some were Facebook's own graphics - for example in the screenshot above - and some of them took the form of the classical emoticon, such as ': )'. For the scope of this study, it is not necessary to separate these types from each other: We consequently counted all of them together and found out that the members used them only 22 times in the analysed sample. This was a surprisingly low number and we seek to explain it with the focus of the group (TB-303) which could be considered a 'serious' topic. One can also support this theorem with the fact that members used the most emoticons and Facebook reactions in the aforementioned post about K.B.K.V.'s baby. It is not surprising that in the case of such a personal and emotional topic, the members use more compensatory strategies. Of the five used Facebook stickers, three were also emoticons (three different smileys) and two were types of 'like icons'. Four of them were used by the same member, so we can understand this as her/his habitual behaviour and not as a general group feature.

From the eight pictures that were posted, six illustrate own TB-303s and other music production equipment and two of them depict something else. This indicates that the group members post their pictures about their TB-303s as a tool to show their machines proudly to the others. As it was mentioned in the introduction about the group, one of the requirements of being added to the group is that one has to send her/his own 
bass line with serial number to the administrator. One can do it in form of a private message or s/he can publicly post in the group. Therefore, many members post these pictures publicly in the group timeline.

In the domain of interaction management, we were interested in the concern structures via linking, quoting, tagging, and using hashtags and in the features of the members' participation.

Within linking, we can separate any kind of 1) hyperlinks from the Internet and 2) sharing an earlier Facebook post from another Facebook site (this can be a member's own profile, an institution's/organisation's profile, another Facebook Group, etc.). In most of the cases the group members linked music or music videos external to Facebook ${ }^{126}$. Linking and sharing music with each other is a tool for expressing knowledge in the discourse community and at the same time it motivates the other members for reaction: they might 'like"127 it, start a discussion, and/or express their opinions about it.

As we can see it in Attachment 3 (Chapter 10.3.1) the group members did not quote anyone in their posts and comments. This may be due to the functions of the website: quoting is more common on web discussion forums, where one can directly answer someone else's comment while keeping the original text. On Facebook this function is not available ${ }^{128}$.

By 'tagging' a person within a message, her/his public Facebook profile can be directly accessed by clicking on the person's name. In this case, there was a hyperlink function linking the person's own profile, but users who tag another person in a comment often do it in order to directly address the message to a person. In a Facebook Group, tagging can be also understood as a tool for community construction, because addressing someone in a message encourages the addressee, who receives a notification about having been tagged, to be an active part of the group and react to the post. From the eight cases where someone was tagged, seven cases were the latter mentioned type of tagging: to address someone directly. Here is an example:

\footnotetext{
${ }^{126}$ Mainly from YouTube or Soundcloud (http://www.soundcloud.com).

${ }^{127}$ As a Facebook reaction.

${ }^{128}$ For example, in a web discussion forum, one can directly answer someone else's comment while keeping her/his original message. One cannot do that in Facebook.
} 


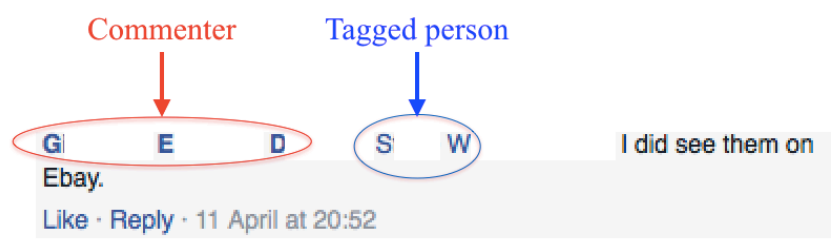

Using a hashtag (\#) on Facebook also implies a hyperlink function which collects all posts that used the same hashtag-word. In the scope of this research, hashtag use can be thought of as an expression of knowledge, because a person who uses a hashtag is aware of the fact that thousands ${ }^{129}$ of other people can be reached by her/his post.

Remaining in the domain of interaction management, we had a closer look at the rates of the participation. 41 members - one of whom is the administrator himself - from a total of 856 took part in the conversations during this month. The powerful role of the administrator within the group is remarkable: he ('B.B.') accepts or rejects the new members. As mentioned before, only those who send in photos of their TB-303s can become part of the group who send their photos of their TB-303s. After 'B.B.' checked these photos, a person can be accepted or rejected to be the part of the Facebook Group. 'B.B.' is normally an active member of the group, but within this one month, he posted only 3 posts and added 1 comment to others' posts. Another interesting point about the administrator is that we expected his posts to be the most popular ones, since he is the most powerful member of the group. This cannot be proved from the sample, because his posts were not that popular. We considered those posts that received more (at least 10) Facebook reactions on their posts as popular. For example, the aforementioned post about the baby received 92 reactions. B.B.’s two posts received only 6 likes.

The activity of the members was coded as follows: 1) 'active' if this person had at least 10 comments or posts; 2) 'moderate' if s/he left between $4-9$ comments or posts; 3 ) 'occasional' if someone had 1-3 comments or posts; and coded as 4) 'no activity' if s/he left no comments or posts. Because from the total 119 activities (posts and comments), at least 10 conversation pieces can be considered active. The results were the following: only 2 members were in the 'active' category, 8 in the 'moderate' and 31 had 'occasional' activity. This also means that the rate of the activity is balanced out between the members: statistically from a total of 119 activities, the average activities per person would be 2,9 . This is nearly what the members actually show in their activity, because as

\footnotetext{
${ }^{129}$ Depending on the personal security settings.
} 
mentioned, 31 of them had between 1-3 comments and/or posts. We consider this phenomenon as a balanced conversation among the participants, which also points to the 'harmonic' relationship between them.

This balance and near harmony could be seen also in the analysis of the social phenomena's domain. There was literally no disagreement among the members in this one month. This is not surprising, as this group was created for the owners and 'fans' of TB-303s.

The members of the group often post a piece of their own or someone else's music or - as mentioned before - a photograph of their music production equipment. In these cases, the others normally give a feedback to the person who posted it, which can take the form of a Facebook reaction (mostly a 'like') or a written text: that's all you need mate!! It's brilliant!!; Lovin it.; Intense dopeness. These posts can also be considered as invitations, as the member who posts these comments knows that others might answer or give feedback concerning it - so gaining attention may be the basic main motivation. The community members often ask for information about their machines from each other:

Give me a short description if you are able. (Attachment 3.1/1a)

Any tt303 owners know how to access tb303 style programming mode? (Attachment 3.1/2)

Anyone knows where I can download those sheets to write your notes in. (Attachment 3.1/7)

does anyone make those plastic coverings... (Attachment 3.1/7)

Is there any routine maintenance that needs.. (Attachment 3.1/12)

Regarding information exchanges, we can presume that in most of the cases, they provide knowledge (see cases in Attachment 9 [Chapter 10.9]). We include here not only those posts and comments that provide exact knowledge via their written texts, but also those symbolic posts that share, for example, a single link to a music video or track, because this also expresses that the person who posted them is informed about it and 'owns' knowledge on such things.

The majority of biographical information shared in the group relates to personal equipment. This takes the form of photography with or without a short description. The phenomenon of sharing photos of music production equipment was also considered as a representation for establishing a sense of belonging: they belong to those people who own these machines and they probably have the same taste of music and interest in music production. 
To sum up the language use of the TB-303 Owners Club: we could see evidence for community and ideology construction through the special jargon of members (mostly on the TB-303), their cooperative discursive behaviours (no disagreement or conflict), the special knowledge they share with each other (about music production, using instruments, etc.) and the characteristics of member participation in the conversations (balanced out and harmonic).

\subsubsection{ITALO DISCO MANIACS}

\subsection{General details about ITALO DISCO MANIACS}

ITALO DISCO MANIACS ${ }^{130}$ is a closed Facebook Group for people who are passionate about the music genre 'Italo disco'. Italo disco (or simply 'Italo') is an EDM genre that originated in Italy and was mainly produced at the end of the 1970 s to the mid-1980s. It has many elements from classical disco music of the 1970s, but at the same time it includes electronic music equipment in its production (e.g. synthesisers).

Due to newer retro phenomena in EDMC, Italo disco is currently experiencing a comeback: many festivals and events ${ }^{131}$ are dedicated to the genre and newer labels ${ }^{132}$ are founded to press music of contemporary artists' and repress older ones. According to Greverus (1979), modern nostalgia arises due to an identity crisis in the present, which will be then compensated by turning to the idealised and idyllic past. Consequently, nostalgia is then a new way of understanding time and space (Boym, 2001), because past will receive a more positive connotation. Scholars also think that nostalgia in popular music culture constructs social identity (van Dijck, 2006) and it helps us to identify particular generations ${ }^{133}$ (Davis, 1979). On the other hand, others see this phenomenon more negatively: in their opinion, nostalgia is an "impediment to progress or reactionary" (Pickering \& Keightley, 2006). We assume that in the case of Italo disco, nostalgia has a positive effect on the scene, because musicians (DJs or producers) are inspired by earlier musical developments, also as a vocal and synthesiser enriched alternative, or as a

\footnotetext{
${ }^{130}$ See source in Chapter 9.

${ }^{131}$ For example, the 'New Dance Fantasy Summer Festival' (n.d.) in Berlin or the 'Magic Waves Festival' (n.d) also in Berlin.

${ }^{132}$ For example, Moustache Records from Rotterdam (Resident Advisor, Moustache Records, n.d.) or No More Pop (http://nomorepop.net).

${ }^{133}$ We can discuss topics and memories from the past with people who also took part in these happenings and they probably have the same age like us.
} 
counter-reaction, to the "minimal" ${ }^{134}$ trend in EDM in the recent years. We will see many examples on the social identity constructed around nostalgia in Chapter 5.2.3.2.3 on the language use of ITALO DISCO MANIACS.

Many music collectors started to collect Italo disco records that were nearly completely undiscovered until the present years. A lot of people try to get these unknown records before everybody else - especially before the records get famous and correspondingly expensive (Johannsen, 2015). This kind of dedicated collector's motivation indicates strong identity building.

The Facebook Group ITALO DISCO MANIACS focuses on this 'rediscovering' phenomenon of 'rediscovery' usually by posting YouTube videos, but also via news, articles, pictures of cover art works, etc. about undiscovered Italo disco music. Therefore, the administrator of the group is quite strict with posts and deletes the contents that have already been posted: Do not post songs double. $++++++++++++I$ delete it. (ITALO DISCO MANIACS, Description, n.d.)

The group was created in March 2015 and has 1 administrator, 2 moderators, and 1756 members (2016 July).

\subsection{ITALO DISCO MANIACS in the faceted classification scheme}

The characteristics of the Facebook Group ITALO DISCO MANIACS in Herring's (2007) faceted classification scheme differ from the aforementioned TB-303 Owners Club at the following points:

- (S2) The group's attitudes, beliefs and ideologies are about being a fan of the music genre Italo disco and the whole scene and culture around it.

- (S4) The main topic of exchanges is the genre itself and its related topics.

- (S5) Apart casual, friendly and critical, the tone of language use can be also emotional (see some examples in the next subchapter).

\footnotetext{
${ }^{134}$ Minimal EDM, especially 'minimal techno', follows minimal track structures and patterns, mostly in the tradition of Detroit techno.
} 


\subsection{The language use of ITALO DISCO MANIACS}

One specific period of time was chosen, June 1-30, 2016 to analyse all posts of the Facebook Group. Within this duration, the group members added 120 posts to the group's timeline and they were commented on 259 times. From these numbers, we consider the group an active one, as the members created an average of 4 posts a day during the analysed 30 days.

As mentioned before, the main aim of the group is to share newly discovered old (or sometimes new) Italo disco songs with each other. This sharing normally takes the form of a YouTube video hyperlink (the video, or track, was often uploaded to YouTube by the same user posting its link). From a total of 120 posts, the person who created the post added this type of link to her/his message 112 times. Others could then comment on these videos - for instance whether they liked it or not - or they could react to the video with the help of the aforementioned Facebook reactions (without writing a comment under it). The members of ITALO DISCO MANIACS obviously prefer to use this latter version of reactions: they added 465 Facebook reactions to the 120 posts. Facebook reactions also express empathy and they help to keep the group alive, because even if nobody leaves a comment under a post, the author of the post still receives feedback.

In the domain of structure and meaning, firstly, we analysed the special adjectives that were related to different (music) tracks. The following examples were used in the sample: great track, dirty, sweet song, amazing, strange slowdown, bomb!, beauty instrumental, corny rapping, nice one, sweet vocal, ВОМB, tooo cheap ;)))), Bomb, very hot, very sophisticated, Obscure girl of Italo, superfluous, cheap, wonderful, great, hot girl of italo, such a beauty, bumped up, awesome crasher, nice, lovely, extremely rare, beautiful, swansong of italo disco, Hot Cosmic ${ }^{135}$ Italo!, disco magic, obscure, ridiculous, strange, highly enjoyable, powerful. (Many of them were used more than once - see the exact numbers and results in Attachment 10 [Chapter 10.10]). From these adjectives one can already see that the group members often identify Italo disco music with human characteristics - see the highlighted examples. Many of these examples have a sexual character: bomb, very hot, hot, and they are mainly related to female figures ${ }^{136}$ : hot girl, obscure girl, a beauty. We can find an explanation to this phenomenon in the

\footnotetext{
135 'Cosmic' also refers to a subgenre of Italo disco: 'cosmic' or 'cosmic disco'. It has a spacy hypnotic style that was unique to northern Italy and developed by the legendary DJ Daniele Baldelli (Reynolds, 2013). The use of the spaceship emoji ( ) also refers to this genre.

${ }^{136}$ Partly because of the female vocalists of these songs.
} 
history of disco culture in the USA and its role in popularising the sexual revolution that started in the 1960s and expanded in the 1970s. Also, disco helped to spread feminist ideas about women’s sexuality (Echols, 2010). As Shapiro (2000) states, “(...) disco attempted to create a pleasure dome in which the rhythms of eroticism were inseparable from those of the machine" (p. 41). This tradition continued in Italo disco too and an excellent evidence of this can found in the song "Love to Love you Baby"137, written by the famous Boston-based gospel singer Donna Summer and the German music producer Giorgio Moroder which highlighted female sexual pleasure (Martin, 2012). In terms of popularity, the song also reached number two in the US-American charts (Shapiro, 2000).

This 'sexual character' of the genre can also be observed in the emojis used in the Facebook Group. Apart from the 'classical' smiley, the following high-heeled shoe emoji was found in the sample:

Figure 19: High-heeled shoe emoji ${ }^{138}$

The group members often used the above emoji, nicely symbolising the aforementioned character of the music genre. Another fitting example would be the following expression: sexy red ${ }^{139}$ vinyl, which was added to the attribute of a record.

Within the special lexis, we also took a closer look at the rate of using Italian language as a sign of 'authenticity' to the music genre in question. 11 cases were found where the members turned to Italian language to express their thoughts, mostly about music: preg; minuto; bella canzone; un altro bella canzone; simpatico; el classico; (automatica)more; grande; No es lo que yo Ilamaría Italo disco.; complimentoni; Grazie!; ragazzi. Additionally, the group sometimes mentions Italy or Italian culture (I do like pizza. I do like pasta.) as well. These phenomena are considered symbols for cohesive force within the discourse group, as only in-group members know that using Italian language has a positive connotation in amongst themselves.

Another type of special lexis was visible in the sample: the members of ITALO DISCO MANIACS often use nostalgia- or past-related expressions such as original; $80 \mathrm{~s}$ and 90s; classic; legendary; it's from 1978; forgotten; 'That video and music was one of

\footnotetext{
${ }^{137}$ See more about the first release on the label 'Casablanca Records' in Discogs, Love To Love You Baby (n.d.).

${ }^{138}$ Source: http://www.facebook.com

139 'Red' refers to the colour of the object.
} 
my teenage years anthem. '; 80s lovers; Italy 1982; was still possible in 1990; early disco magic; mega classic; I remember...; forever; memory lane; reminded me..; childhood memories; strong classic. The reasons for this result can be found in the aforementioned (in Chapter 5.3.2.3.1) retro or nostalgia phenomenon that indicates not only passion towards music, but also any kind of cultural memory from earlier times (here in this context, mainly the 1980s). A good example for this is a post from the member 'O.G.' on June 14 (see Attachment 10.3.2/65 [Chapter 10.3]), when he recommended the movie 'The Wolfpack' ${ }^{140}$ (2015) to the other members, for the sole reason that the song 'Tarzan Boy’ (YouTube, Tarzan Boy, 2012) by Baltimora - a big Italo disco hit from 1985 - is played in one scene.

There are many technical terms related to DJing or generally to records in the sample, for example: reissue, release, DJ, re-released, record, order, vinyl, mix, repress, 12 inch, compilation, label, press, 7 inch, extended, cover, A side'rs or B side'rs, 8-bit, remixed, reissue, copy, $L P$, edit, mastering, extended, set. The highlighted terms refer to the discovery of Italo disco records mentioned earlier. If the rediscovered records become popular amongst the fans and there are only a few original copies available, record labels initiate the process to repress them. The high rate of use of these terms is not surprising, as the group is created for fans ('maniacs') of Italo disco records. From the comments it can be assumed that some members are DJs or vinyl collectors. Therefore, they often discuss where and how to find rare records for cheaper prices:

\footnotetext{
${ }^{140}$ See more about the film here: http://www.thewolfpackfilm.com
} 


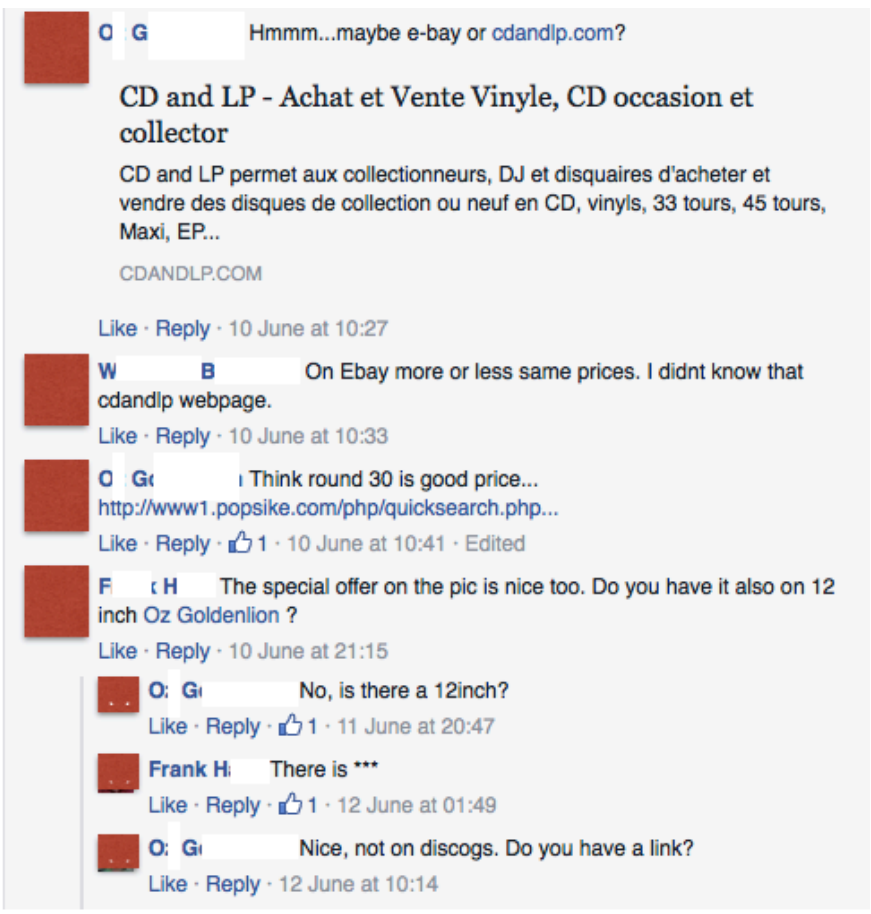

These recommendations help to keep the group together, since the main aim is to rediscover these records together. Thus the main signifier of knowledge on such topics is a post about newly discovered music.

Italo disco fans have different opinions on the versions of the music: some prefer the songs with vocals (vocal version), some without (instrumental version). Another disagreement occurs through this: the preference of the record's A or B side ${ }^{141}$. The next conversation piece summarises this disagreement nicely:

O.G.: if every member of this group would give his/her preference for vocal or instrumental....that would be something....wouldn't it? ;)

K.C.: A side'rs or B side'rs :)))

O.G.: I expect every member to vote A (vocal) or B (instrumental) for every song posted here from right now on! :)

Due to this difference, many technical terms related to music aesthetics are noticeable in the sample: vocal, bassline, instrumental, vocoder, funky parts, lyrics, etc.

Italo disco (or Italo) was analysed as a community reference word and it was evidenced by the rate of its usage: the members named the music genre 37 times. However, the Facebook Group-related community reference words (member, FB group, maniacs) were used only 6 times in the sample, presenting a very low rate.

${ }^{141}$ The A-side of a record is always the 'hit' side with the vocal version, which is mainly promoted by the musician or the record label. The B-side contains other less known tracks or other versions (e.g. instrumental) of the A-side hit. 
Evidence for community construction could not be found in the personal pronouns either: the word 'we' occurred only 2 times in the linguistic data. This also stands true for 'they' as a signifier of separation from out-groups, because surprisingly, it was used only once.

However, interesting results could be found in the group's compensatory strategies. As mentioned before, Facebook reactions were used 658 times within the 120 posts and 259 comments. This number is very high and we would account for it as a compensatory strategy for expressing sympathy - this is also a type of interpersonal discourse behaviour - and it helps to keep the discourse community together.

The often-used heart symbol ${ }^{142}$ (or emoji) confirms the consideration of Italo disco being an emotional music genre. In addition, the members of ITALO DISCO MANIACS expressed their feelings towards music via expressions such as wow, ohohohoh and a high rate of use of exclamation marks.

In the domain of interaction management, we analysed the concern structures via linking and quoting. As already stated, the members shared a hyperlink in each post with the others. This usually takes the form of a music video, but we can also find hyperlinks to online audio distribution platforms, musical databases, events, etc. These hyperlinks symbolises the members' level of knowledge on the common topic of the group: the music genre Italo disco. It is almost a competition among the most active members, how many posts they can add to the group: 'O.G.' created 44 posts, 'K.C.' 21, and 'F.H.' 6. Comparing these numbers to the total 120 posts, we can acknowledge that the active members led the conversations. This is especially evident if we look at the numbers of their comments too: 'O.G.' added 105, 'K.C.' 29, and 'F.H.' 36. It is important to note that 'O.G.' is one of the moderators of the group and 'F.H.' is the administrator. Therefore, their powerful roles are obvious, which can also be noted in the rate of participation by other members. From a total of 54 members, who took part in the discourse, only 6 could be considered active, another 6 moderate posters ${ }^{143}$ and/or commenters ${ }^{144}$ and the remaining 42 people only occasionally (1-3 times) added posts to the group's timeline or commented posts. In this sense, the conversation is not balanced

\footnotetext{
${ }^{142}$ Its manifestation is: ","

${ }^{143}$ Here it refers to the person who creates a post.

${ }^{144}$ Here it refers to the person who comments a post.
} 
among the group members, because the roles of the group leaders are more powerful than the others.

After having examined the interpersonal discourse behaviour of the group, it can be summarised that there is a general consensus among the members. It has been mentioned that the one common counterpoint among the members is the issue of 'vocal vs. instrumental version' of a song. However, even if they disagree with each other, they always accept the other's opinion:

F.H.: Don't like the vocals sounds like the brave son.....Matter of taste

(...)

O.G.: There are much worse or too clean sounding cases of DM-clones..especially in Germany. I think these are too original to dismis them as just DM-soundalikes although you hear echo's of older synthpopbands in them.

F.H.: For me the DM thing is over. Of course I still like some old songs of them but I can't hear anymore new synth pop groups which copy the vocals so much.

O.G.: A case of DM-saturation... ;)

O.G.: Once in a while I still really like DM and soundalikes

F.H.: a question of taste ... why not .it's only my personal opinion...

O.G.: $i$ respect that of course (Attachment 10.3.2/17a+b [Chapter 10.3])

There are several cases where members agree with each other. These agreements mostly took the form of me too, I thought the same, and of course. Additionally, they often expressed their thankfulness to each other, which also kept the conversation balanced. The few cases of asking for information, offering advice, and joking also helped to keep the discourse continuous. In terms of jokes, we found a nice example of wordplay from member 'O.G.' who merged the words 'amazing' and 'Asian' together and playfully created amasian. 'O.G.' added this new word as a comment under the music video of a Chinese version of an Italo disco song.

The information exchanges provided knowledge in most cases, since the posters shared music videos or other hyperlinks with each other. Interestingly, biographical information was shared only when the participants wrote about a memory of their lives. This is closely connected to the aforementioned nostalgia phenomenon.

Through the example of the Facebook Group ITALO DISCO MANIACS we could examine the characteristics of the language use of a specific discourse community that is built upon the music genre of Italo disco. Therefore, the social cohesion of the 
group was created around this genre. We could also see that the nature of the music - it was produced in the $1980 \mathrm{~s}$, its aim is to express emotions, etc. - was highly influential on the discourse among the members of the group.

The Italo disco fans balanced their conversations with agreements and negotiations of conflicts, holding the discourse community together. Hence, this language sample presented an example of a fan-based virtual community created to build up a friendly atmosphere to share ideas and knowledge on newly rediscovered Italo disco songs.

\subsubsection{Summarising the analysed Facebook Groups}

By analysing the language use of the two Facebook Groups TB-303 Owners Club and ITALO DISCO MANIACS we have experienced the discourse characteristics of two fanbased discourse communities. The TB-303 Owners Club was constructed by people who own the analogue synthesiser Roland TB-303. It was evidenced in the analysis that the members of the community are also 'fanatics' of this machine and they often use anthropomorphic adjectives and nouns when they communicate about it.

The other group, ITALO DISCO MANIACS was constructed by the music genre Italo disco fans, DJs and producers. The aim of the community is to rediscover unknown Italo disco music with posting music and music videos to the Facebook Group's timeline. The characteristics of the music genre - expresses romanticism, emotions, affections, and sexuality - highly influenced the characteristics of the discourse. It was evidenced by the analysis of the group's language use that showed an interesting tendency of 'emotionally driven' discourse.

\subsubsection{Blogs}

Many academic fields have dealt with the topic of blogs: psychology, sociology, linguistics, media and cultural studies, etc. In linguistics, the focus of research is mainly on the different linguistic features of using language online.

Blogs are frequently changed web pages in which dated entries are normally listed in reverse chronological sequence (the newest entry appears first) (Herring, 2004a). These entries are also named as 'posts' and their authors are the 'bloggers'. Blogs got 
popular in the early 2000s and until today they play very important roles, for example, in journalism and politics.

The terms weblog and blog are usually used synonymously, but scholars draw a difference between them. Bishop (2009) states that "a blog is intrinsically motivated, based on the owners own thoughts and emotions whereas the weblog is extrinsically motivated based on media that the actor has consumed and experiences the author has had with others" (p. 7).

In the literature, we can find many different categorisations of blog types. These classifications are based on the blogs' 1) content (e.g. personal journals or diaries, notebooks, and filters [Blood, 2000; Miller \& Sheperd, 2004; Herring, 2004a]); or 2) stylistic elements (e.g. it is written in an autobiographical style, participative manner, or it has a neutral observational position [Lomborg, 2009]); 3) or based on what is the role or position of the author (e.g. private or professional author [boyd, 2006]). For the last categorisation, Brake (2007, cited in Lomborg, 2009) writes about four types of blogs concerning the relationship between the author and the audience: a blog can be 1) one-toone; 2) one-to-many; 3) many-to-many; and 4) a-communicative (in the last case, the blog is a self-therapy with no intended audience).

Based on these earlier categorisations, Lomborg (2009) suggests a typological framework for classification of weblogs that, we believe, is a useful tool for analysing blog genres. Lomborg (2009) proposes three axes among blog genres: 1) content axis: internal-topical; 2) directionality axis: monological-dialogical; and 3) style axis: intimate-objective.

Figure 20: Lomborg's (2009) Typological dimensions for description of weblogs

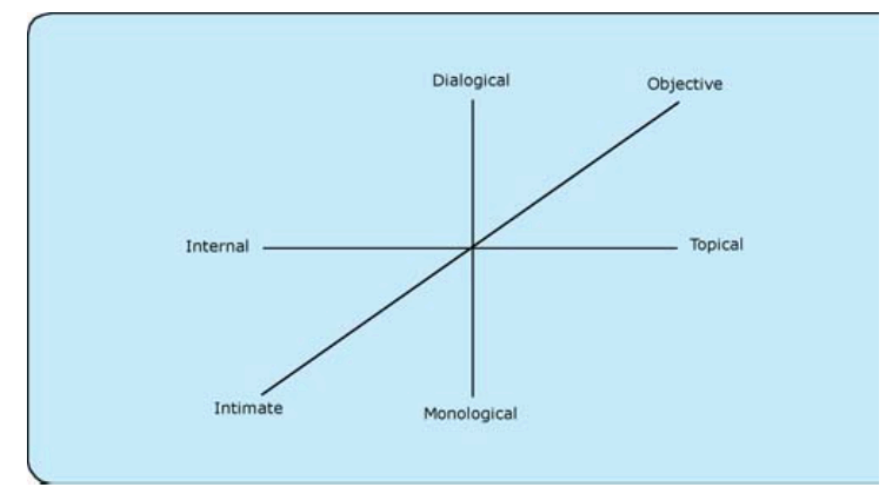

The content axis presents whether the blog is personal, by showing own experiences and emotions, or it communicates only topic-oriented (subject-based) 
information to its audience. On the directionality axis, one can see if the blog is opened to free conversations between audience and author, or not. Finally, the style axis, focuses on the style of the blog, whether it is personal or objective. Of course, a blog can be placed at any points of the axes, not only at the end poles of them.

As Lomborg (2009) mentions, this framework can help draw attention to nuances, because these stylistic differences has impact upon the social uses and communicative qualities of weblogs.

For the present research, the following blogs were chosen to analyse: 1) Matrixsynth; 2) Teshno; and 3) Little White Earbuds (see their sources in Chapter 9). The language use of these blogs cannot be analysed by the coding categories which were used in the earlier subchapters, because we could hardly find any user comments on these platforms. However, we believe it is still important to give a mention to these websites, as they play a significant role in the online discourse on EDM topics and as blogs are although showing different communicational structures compared to, for example, forums - generally attributed as classical Web 2.0/social media (Bruns, 2008). Therefore, we will analyse only their basic characteristics with the help of the aforementioned typological dimensions by Lomborg (2009).

\subsubsection{Matrixsynth}

Matrixsynth $^{145}$ is a collaborative blog written by its supporting members. To become a member, one has to pay at least $\$ 1^{146}$ a month. It currently has $89^{147}$ members.

The blog is specialised for synthesisers, as its motto says: "Matrixsynth. Everything synth". It is hosted on 'Blogger', a blogging platform owned and hosted by Google. Its first post dates back to July 20, 2005, but its ancestor platform was created earlier, in 1997 "before The Matrix movies ever existed BTW” (Matrixsynth, Five Years, 2010) as a personal portal for the various synth sites Chris Carter, its creator, visited. So, in the beginning it was a personal blog, but then it turned to be a blog with multipleauthors.

\footnotetext{
${ }^{145}$ See source in Chapter 9.

${ }^{146}$ There are other options listed on the site: if one pays $\$ 5$ a month, s/he receives a Matrixsynth T-Shirt, cards and magnet; if one pays $\$ 10$ a month, s/he receives, apart those fan objects that were listed at the $\$ 5$-version, an extra Matrixsytnh cap. (Matrixsynth, Support, n.d.)

${ }^{147}$ The list contains only those ones who wanted to give their original or alias names to the list. So there might be some other members, who are not on this list (Matrixsynth, Support, n.d.).
} 
He started tracking everything synthesiser-related. The blog grew steadily and people started sending things to him, so it turned into a place for anyone synthesiser enthusiasts to share and promote what they were doing with their synths (or related topics) (Matrixsynth, Five Years, 2010).

Chris Carter tells his emotional story about the history of Matrixsynth in one of his posts. He also writes about how much time he spends on writing this blog and how much he likes doing it:

\footnotetext{
“The site pretty much is a full time job including weekends. How do I do it? I love it!!! (...) It doesn't feel like work to me and even though things are not automated, I have a rhythm and a routine that I have relatively mastered. It took a couple of years to get that rhythm down. Now it's a bit of an addiction." (Matrixsynth, Five Years, 2010)
}

To give some numbers to the blogposts: for example, in 2015, there were 13449 posts (Matrixsynth, Archives, n.d.) on the blog. It has a wide audience from all around the world, the main site-visitors are from the USA, UK and Germany (Matrixsynth, Happy New, 2012). In 2008, it had 5.214.272 page views (Matrixsynth, Four Years, 2009), making it a very well visited and widely read blog.

Based on Longborg's (2009) axis model, Matrixsynth's content is partly topical and partly internal, because many posts include very personal experiences and emotions, but many of them are more informative. Matrixsynth allows its readers to comment on its posts, but the number of comments on the site is very low. One of the reasons for that might be the high numbers of daily posts. For example, in 201536 (Matrixsynth, Archives, n.d.) posts appeared on the site on average daily. Another reason is that Matrixsynth has a closed Facebook group ('The MATRIXSYNTH Lounge') for its readers with the aim of sharing music and engaging in discussion with each other. On the third, style axis, we can add that Matrixsynth's posts - just as in the case of content axis are partly personal and party objective.

\subsubsection{Teshno}

Teshno is a personal blog of freelance writer Kristan J. Caryl. He writes to different magazines such as DJ Mag, Mixmag, Redbull Music Academy and Resident Advisor. The blog contains his own house and techno music agenda "in an often indulgent way" 
(Teshno, n.d.). Caryl adds "it's an outlet which allows me to behave like that where the other, more professional, on and off-line mags I work for do not.” (Teshno, n.d.)

The blog was born in 2009 is not active every day. It was more active in earlier years such as 2014, but not anymore. One can see that Caryl treats his blogging activity as a hobby and something joyful in his life - something he mentions in the introduction to the blog (Teshno, n.d.). There are different topics and types of posts on the blog: article-type, interviews (with mostly musicians), music reviews, etc. The blog has more than 6500 likers ${ }^{148}$ on Facebook (Facebok, Teshno, n.d.) which allows us to conclude that it has a wide readers' circle.

Again, if we read this blog within Longborg's (2009) axes, we can describe it as following: to its 1) content axis: Teshno has clearly internal content, because it is a personal blog with his own ideas and impressions (especially in the album reviews) and the chosen topics are based on the author's own interest; to its 2) directionality axis: the blog allows to leave comments to its readers, but it is not common, therefore, it is more monological than dialogical; and finally to its 3 ) style axis: most of the cases it has a personal style - the reason for that is again the form of blogging: writing a personal blog.

We chose this blog to analyse, because it is a typical personal (one author) blog and its topics are different, but mainly focussing on two genres of EDM: techno and house. The main character of the blog is the author, Caryl himself. He chooses the topics, expresses his own opinion and brings his readers' attention to his own interests.

\subsubsection{LWE: Little White Earbuds}

Little White Earbuds (henceforth LWE) was started in 2005 for "podcasts, reviews, features, interviews, and think pieces from all corners of the electronic music spectrum: house, techno, bass music and beyond" (LWE Facebook, 2016). It was founded, published and edited by Steve Mizek, a Chicago-based DJ and head of the record label 'Argot'.

After 10 years, LWE stopped its activity in October 2015, because the editorial staff did not have time to work for the blog anymore. As it was mentioned in the last post, they all moved forward and started to work for other sites or companies (LWE, Goodbye,

\footnotetext{
${ }^{148}$ Data from June 2016.
} 
2015). The staff consisted of nine people with different roles (e.g. social media manager, podcast producer, graphic designer, etc.) (LWE, Contact, n.d.) and over its ten years the blog had more than 30 contributors (LWE, Goodbye, 2015). The site had different types of posts: interviews, podcasts, features (many times with a historical focus), artists' interviews, and reviews. The articles mostly focus on music. The blog turned from a WordPress website into a professional online music publication which one can also see from the length of the articles. Its Facebook (Facebook, Little White Earbuds, n.d.) profile has more than 10.000 likes $^{149}$, indicating a large readership. Its activity was funded by advertising revenue, sales commissions from Juno Records, Mizek himself (LWE, Open Letter, 2014) and a likely modest amount of donations from its readership. Anybody could send them an article to post, but LWE had "high standards for quality control that readers have come to expect" (LWE, Open Letter, 2014). As Mizek added "I want to be certain LWE's reviews and features are the result of genuine enthusiasm rather than relentless PR and the vague 'need' to have something to say every day." (LWE, Open Letter, 2014)

Again, if we analyse this blog with the help of Lomborg's (2009) axes, we can state that its 1) content is more topical than internal, because its articles' (posts) aims were mainly to communicate information about a specific topic; 2) its directionality is mainly dialogical, because its readers quite often add their thoughts in form of comments underneath the posts; and 3) its style is more objective than intimate, because as mentioned above, the blog turned into an online 'magazine' with many contributors and became journalistic platform with articles on different topics of EDM.

This blog was taken - although it stopped its activity - to mention here, because it is a great example of how a blog can turn into a professional journalistic platform, therefore, its posts are professionally written contributions with an objective style.

\subsubsection{Summarising Matrixsynth, Teshno and LWE}

As we could see in the earlier chapters, these weblogs are very different in terms of topics, style and aims. Matrixsynth is a blog about synthesisers, written by different contributors in partly personal, partly objective style. Teshno is a personal blog of Kristan J. Caryl about his own interest in techno and house genres with mainly a personal style.

\footnotetext{
${ }^{149}$ Data from June 2016.
} 
Finally, LWE was a professional online publication with different articles on music (techno and house) with a mainly objective style.

This is exactly the reason why we chose these platforms: they represent very different schemas and characteristics of blogs and give very different examples of texts to analyse. 


\section{SUMMARY OF ANALYSIS AND RESEARCH FINDINGS}

This chapter summarises the data analysis presented in the previous chapter with the specific aim of focussing on answering the research questions (presented in Chapter 3 ) as well as emphasising the research findings.

To answer the first research question of the study - What are the discourse characteristics of the discourse community of EDM? -, we shall list ${ }^{150}$ a collection of characteristics here that were analysed with the help of the chosen methods. The discourse community of electronic dance music has individual discourse characteristics ${ }^{151}$ in terms of:

- $\quad$ special lexis (e.g. special adjectives related to music [grimy acid house] and machines [robust, healthy] in the case of the Facebook Group TB-303 Owners Club)

- technical terms (e.g. the music production-related terms [filter, mixer, modulation] in the case of Gearslutz)

- specific community reference words (e.g. AFX, Aphex, Aphex Twin, Richard, Rich, Twin, Twinee, RDJ, Tuss, Phex in the case of WATMMF)

- compensatory strategies (e.g. emoticons and videos in the Facebook Groups; GIFs, memes, and pictures in WATMMF)

- concern structures (e.g. quoting in web discussion forums)

- participation (e.g. the number of messages per group member in the cases of Facebook Groups)

- interpersonal discourse behaviours (e.g. inviting and giving feedback in Resident Advisor)

- information exchanges (e.g. sharing biographical information about nostalgic feelings towards analogue synthesisers on Vintage Synth Explorer)

The present study analysed six different language samples in depth and summarised the basic characteristics of three additional ones. The aim of selecting an extensive sample was to present diverse discourse circumstances, on the one hand, to

\footnotetext{
${ }^{150}$ This list, of course, cannot be comprehensive; it is only according to the selected linguistic data and chosen analytical methods.

${ }^{151}$ These categories are the results of this research.
} 
map - at least a part of ${ }^{152}$ - the discourse community of electronic dance music, and on the other hand, to answer the second research question - how do these characteristics vary in different sub- (sub-sub-, etc.) discourse communities according to the analysed samples? - from a broad perspective. We wanted to cover as many as possible of the different DC topics, in the limited scope of a dissertation.

The carefully selected sample included web discussion forums: We Are The Music Makers Forum (WATMMF) and Gearslutz; 'classical' websites: Vintage Synth Explorer and Resident Advisor; Facebook Groups: TB-303 Owners Club and ITALO DISCO MANIACS; and blogs: Matrixsynth, Little White Earbuds, and Teshno. For a clearer understanding of the phenomena under investigation, this broad spectrum of the selected sample is summarised in the next table:

Table 7: The spectrum of the language sample

\begin{tabular}{|c|c|c|c|c|c|c|c|c|}
\hline Sample & Internet genre & $\begin{array}{c}\text { Amount of } \\
\text { data/text genre }\end{array}$ & Type of topic & Exact topic & $\begin{array}{c}\text { Related discourse } \\
\text { communities }\end{array}$ & Related EDM genre(s) & $\begin{array}{l}\text { Related virtual } \\
\text { scene(s) }\end{array}$ & $\begin{array}{l}\text { Members of the } \\
\text { discussions }\end{array}$ \\
\hline $\begin{array}{l}\text { WATMMF, thread } \\
\text { 'Aphex Twin - } \\
\text { Syro' }\end{array}$ & web discussion forum & 500 forum posts & $\begin{array}{l}\text { music; album } \\
\text { review }\end{array}$ & $\begin{array}{l}\text { Aphex } \\
\text { Twin's new } \\
\text { album }\end{array}$ & $\begin{array}{l}\text { DC of IDM; DC of } \\
\text { braindance; DC of Aphex } \\
\text { Twin fans; DC of SYRO; } \\
\text { etc. }\end{array}$ & $\begin{array}{l}\text { IDM; braindance; } \\
\text { experimental } \\
\text { electronica; ambient }\end{array}$ & $\begin{array}{l}\text { Aphex Twin's fans; } \\
\text { VS of braindance; } \\
\text { IDM; etc. }\end{array}$ & $\begin{array}{l}\text { Aphex Twin's fans; } \\
\text { other musicians; } \\
\text { interested people }\end{array}$ \\
\hline $\begin{array}{l}\text { Gerslutz, thread } \\
\text { 'Lets talk } \\
\text { samplers!' }\end{array}$ & web discussion forum & 414 forum posts & $\begin{array}{l}\text { music } \\
\text { production }\end{array}$ & samplers & $\begin{array}{l}\text { DC of EDM music } \\
\text { producers; discourse } \\
\text { communities of different } \\
\text { music production } \\
\text { softwares; etc. }\end{array}$ & techno, house, etc. & $\begin{array}{l}\text { virtual scene of } \\
\text { techno; house; etc. }\end{array}$ & music producers \\
\hline $\begin{array}{l}\text { Vintage Synth } \\
\text { Explorer }\end{array}$ & 'classical' website & $\begin{array}{l}834 \text { website } \\
\text { comments }\end{array}$ & $\begin{array}{l}\text { music } \\
\text { production, } \\
\text { equipment }\end{array}$ & $\begin{array}{l}\text { different } \\
\text { music } \\
\text { production } \\
\text { equipment }\end{array}$ & $\begin{array}{l}\text { DC of synthesiser fans, DC } \\
\text { of music producers; DC of } \\
\text { EDM music producers; etc. }\end{array}$ & techno, house, etc. & $\begin{array}{l}\text { virtual scene of } \\
\text { techno; house; etc. }\end{array}$ & music producers \\
\hline Resident Advisor & 'classical' website & $\begin{array}{l}851 \text { website } \\
\text { comments }\end{array}$ & event, music & $\begin{array}{l}\text { different per } \\
\text { article }\end{array}$ & $\begin{array}{l}\text { DC of techno; DC of } \\
\text { house; DC of experimental } \\
\text { electronica; DC of event } \\
\text { promoters; DC of music } \\
\text { journalists; etc. }\end{array}$ & $\begin{array}{l}\text { techno, house, } \\
\text { experimental } \\
\text { electronica; etc. }\end{array}$ & $\begin{array}{l}\text { virtual scene of } \\
\text { techno; virtual scene } \\
\text { of Squarepusher } \\
\text { fans; etc. }\end{array}$ & $\begin{array}{l}\text { jornalists; } \\
\text { promoters; fans; } \\
\text { musicians }\end{array}$ \\
\hline $\begin{array}{l}\text { TB-303 Owners } \\
\text { Club }\end{array}$ & $\begin{array}{l}\text { social network: } \\
\text { Facebook Group }\end{array}$ & $\begin{array}{l}32 \text { posts and } 87 \\
\text { comments }\end{array}$ & $\begin{array}{l}\text { music, event, } \\
\text { music } \\
\text { production }\end{array}$ & $\begin{array}{l}\text { Roland TB- } \\
303 \text { and } \\
\text { related } \\
\text { topics }\end{array}$ & $\begin{array}{l}\text { DC of Roland TB-303; DC } \\
\text { of analog synthesisers; DC } \\
\text { of acid house; DC of acid } \\
\text { techno; etc. }\end{array}$ & acid house; acid techno & $\begin{array}{l}\text { virtual scene of acid } \\
\text { house and acid } \\
\text { techno }\end{array}$ & musicians; fans \\
\hline $\begin{array}{l}\text { ITALO DISCO } \\
\text { MANIACS }\end{array}$ & $\begin{array}{l}\text { social network: } \\
\text { Facebook Group }\end{array}$ & $\begin{array}{l}122 \text { posts and } \\
259 \text { comments }\end{array}$ & $\begin{array}{l}\text { music, event, } \\
\text { lifestyle }\end{array}$ & $\begin{array}{l}\text { music gentre } \\
\text { 'Italo disco' } \\
\text { and related } \\
\text { topics }\end{array}$ & $\begin{array}{l}\text { DC of Italo disco; DC of } \\
\text { Italo disco fans; DC of } 80 \mathrm{~s} \\
\text { music fanst; etc. }\end{array}$ & $\begin{array}{l}\text { Italo disco; cosmis } \\
\text { disco }\end{array}$ & $\begin{array}{l}\text { virtual scene of Italo } \\
\text { disco }\end{array}$ & $\begin{array}{l}\text { fans, musicians, } \\
\text { DJs }\end{array}$ \\
\hline Matrixsynth & blog & 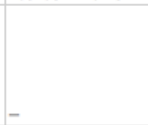 & $\begin{array}{l}\text { music } \\
\text { production, } \\
\text { equipment }\end{array}$ & $\begin{array}{l}\text { different } \\
\text { topics on } \\
\text { synthesisers } \\
\text { and related } \\
\text { topics }\end{array}$ & $\begin{array}{l}\text { DC of synthesiser fans, DC } \\
\text { of music producers; DC of } \\
\text { EDM music producers; etc. }\end{array}$ & techno, house, etc. & $\begin{array}{l}\text { virtual scene of } \\
\text { techno; house; etc. }\end{array}$ & musicians; fans \\
\hline Teshno & blog & - & event, music & different & $\begin{array}{l}\text { DC of techno; DC of } \\
\text { house; DC of clubbing; DC } \\
\text { of nightlife; etc. }\end{array}$ & techno, house & $\begin{array}{l}\text { virtual scene of } \\
\text { techno; virtual scene } \\
\text { of house }\end{array}$ & blogger, readers \\
\hline $\begin{array}{l}\text { Little White } \\
\text { Earbuds }\end{array}$ & blog & - & $\begin{array}{l}\text { music, } \\
\text { discography, } \\
\text { music } \\
\text { production }\end{array}$ & different & $\begin{array}{l}\text { DC of the different } \\
\text { musicians; DC of techno, } \\
\text { house; etc. }\end{array}$ & techno, house, etc. & $\begin{array}{l}\text { virtual scene of } \\
\text { techno; house; etc. }\end{array}$ & $\begin{array}{l}\text { fans, journalists, } \\
\text { musicians }\end{array}$ \\
\hline
\end{tabular}

Table 7 shows that the selected sample has multidimensional characteristics: the different data vary in terms of Internet genres - web discussion forums; 'classical' websites; Facebook Groups; and blogs - and their topics - music; music production; musical event; and lifestyle. Also, they are part of different (sub-sub- [etc.]) discourse

\footnotetext{
${ }^{152}$ Since EDM has so many different community formations (subgenres, scenes, interest groups, etc.), a life-long research would not be enough to detect the characteristics of all discourse (and sub-sub- (etc.) discourse) communities, which additionally are, as are discourses in general, ever changing and process-based.
} 
communities: DC of IDM; DC of Aphex Twin's fans; DC of EDM music producers; DC of synthesiser fans; DC of techno, etc. They cover different EDM genres and they are part of the virtual scenes of these genres as well: IDM, braindance, ambient, techno, house, experimental electronica, acid house, acid techno, Italo disco, etc. Finally, the members of these conversations were fans, interested people, music producers (hobby or full-time), journalists, promoters, DJs, etc.

Consequently, the discourse characteristics of these communities vary from each other in different ways: their terminology, communication structure, and tools of communication. The main differences could be seen in the specific community reference words and terminology used by the participants of the conversations. These terms differed depending on the topic of the sample (e.g. music making [Gearslutz], fan-based topic [WATMMF], sharing ideas or new findings about music [ITALO DISCO MANIACS], etc.). The presented examples also proved that these expressions and terminology could only be understood by the different group members. Their communication structures differed mostly in their interaction managements and social phenomena: for example, the website comments of Resident Advisor often gave direct critiques to the author of the articles they were commenting on, or to their commenter fellows. Finally, their tools of communication varied by the topic of the community and the equipment of the Internet genre. For example, in the case of more 'serious' topics of Vintage Synth Explorer, hardly any compensatory strategies were used, but the participants of WATMMF often turned to these tools.

The analysis of the selected linguistic data also answered the third research question related to community and identity constructions: How do these characteristics reflect on the community and identity construction within the analysed communities?

The data showed that the use of special terminology indicates social identities: as mentioned, they are a signifier of in-group language and partly hold the community together. The participants of the discourse communities identified themselves to be the part of these social groups by using community specific terminology. Social identities and community constructions became clearly visible by analysing the interaction management of the data. Concern structures showed that the participants often quoted each other - if it was an available function of the website - to show their respect and initiation response to the others. Of course, sometimes this response could be not only friendly but also offensive (e.g. in the case of Resident Advisor and VSE). We have seen 
an interesting example of 'gatekeeping' and 'filtering' outsiders ${ }^{153}$ in the case of Resident Advisor, where the users give minus and plus points to their fellows' comments. With this method, the members filtered 'objectionable' comments. These comments were criticised for their inauthenticity and for being too negative compared to the majority that had a positive opinion on the subject of the article. Or another good case in point would be the almost 'aggressive' website comments of Vintage Synth Explorer, when a 'noob' (their own terminology - which means 'newcomer') ask a beginner's question. However, this kind of behaviour could not be detected in the forum Gearslutz. There the discourse atmosphere was friendly and harmonious. This phenomenon can have multiple and complex reasons. Here, we will highlight only one of them: The atmosphere could have been friendly in the examined thread of Gearslutz as even if the users asked 'beginner' questions about a specific sampler, one could see that these people were still widely experienced in music production. So, there were no such 'uneducated' questions as in the case of VSE. Therefore, we do not know how Gearslutz users would react to such types of messages.

Social phenomena showed that the community members were intent on building community partnerships and showing interest in one another by their interpersonal discourse behaviours such as thanking, asking for information, inviting feedback, offering advice, and joking. Additionally, the features of information exchanges represented mutual influence (e.g. providing knowledge in the case of Vintage Synth Explorer) and established significance and sense of belonging (e.g. sharing biographical information in the TB-303 Owners Club).

However, the use of the personal pronoun 'we' as a sign of community construction could not be evidenced in the sample, as the rate of usage was very low in nearly every case, except for the WATMMF sample. Therefore, we suggest to exclude this perspective from future investigations. (However, there are some other types of samples where personal pronouns represent sense of belonging to a community; for example, in Rasulo's [2008] CMDA research they played important roles in the results.)

\footnotetext{
${ }^{153}$ Here we take the example of Resident Advisor, but we could have written about the phenomenon of acceptance or non-acceptance within all the other communities as well.
} 


\section{FINAL CONCLUSIONS AND FUTURE CONSIDERATIONS}

This chapter will give a brief summary on the entire dissertation (Chapter 7.1), draw conclusions from the research findings (Chapter 7.2), highlight the importance of this research (Chapter 7.3), give recommendations for future research (Chapter 7.4), and include a short final paragraph, an 'outro' (Chapter 7.5).

\subsection{A brief summary on the structure of the dissertation}

After introducing the research topic in Chapter 1, the dissertation focussed on its theoretical background in Chapter 2. The study is a highly interdisciplinary investigation; it involves research results from the fields of applied linguistics, cultural studies, media studies, musicology, and music history. Therefore, Chapter 2 summarised the most important research results on EDM and discourse community and their related topics. It was thematically sorted: Chapter 2.2 took a closer look at the broad spectrum of the term 'discourse' and discourse analysis by focussing on its applied linguistic approaches. It highlighted its main approaches: computer-mediated discourse analysis, multimodal discourse analysis and corpus-based discourse analysis.

Chapter 2.3 introduced different scholars' perspectives (but mainly focussing on Swales's [1990] work) and definitions of discourse community and its related terms (speech community, communities of practice, cultural community, thought collective, distributed knowledge, forms of life, and rhetorical community). Finally, the last section of this subchapter focused on virtual/online discourse communities, as the present study was analysing such communities.

Chapter 2.4 summarised, on the one hand, the history of electronic music and electronic dance music, on the other, the results of public health research and cultural studies research on the topic of electronic dance music.

Based on the aforementioned three subchapters (2.2, 2.3, and 2.4), Chapter 2.5 conceptualised the working definition of the discourse community of electronic dance music.

Finally, Chapter 2.6 gave an overview on the relationship of discourse, music (with a focus on electronic dance music) and identity, as these definitions play important roles in answering the research questions. 
Building on this broad spectrum of theories, the study addressed the following research questions (Chapter 3):

1. What are the discourse characteristics of the discourse community of EDM?

2. How do these characteristics vary in different sub- (sub-sub-, etc.) discourse communities according to the analysed samples?

3. How do these characteristics reflect on the community and identity construction within the analysed communities?

In Chapter 4, a special analytical methodology was built up - based on Herring's (2004b) CMDA paradigm and influenced by Rasulo's (2008) work - in order to answer these research questions. The main framework of the dissertation was computer-mediated discourse analysis - since its language sample had been taken mainly from Internet sources -, but it used some methods of content analysis, conversation analysis, descriptive statistics, membership categorisation analysis, multimodal discourse analysis, semantics, and terminology studies too.

Based on this methodology, the different samples were analysed in Chapter 5. The user-generated contents of two forum threads ("Aphex Twin - Syro" of We Are The Music Makers Forum and "Lets talk samplers!” of Gearslutz), two 'classical' websites (Vintage Synth Explorer and Resident Advisor) and two Facebook Groups (TB-303 Owners Club and ITALO DISCO MANIACS) were analysed. The general characteristics of these platforms were highlighted with the help of Herring's (2007) faceted classification scheme for computer-mediated discourse. Additionally, the chapter described the general characteristics of three blogs: Matrixsynth, Teshno, and Little White Earbuds.

Finally, Chapter 6 summarised the results of the analysis.

\subsection{Conclusions}

The present study opens up a new perspective on research of electronic dance music. By looking at the communities of EDM as discourse communities, the research focus shifted from sociological and cultural features ${ }^{154}$ of the communities to the actual analysis of discourses and language use within these groups.

\footnotetext{
${ }^{154}$ Of course, one cannot analyse this field without taking these perspectives into consideration, but the focus of research here was not on them.
} 
Therefore, this study saw discourse as language in use and as a tool for expressing identity: The study presented different examples of how identity construction works through discourse and how discourse influences these mechanisms. Moreover, on further consideration of the model of discourse community, the processes of community construction could be described through the selected sample.

Based on the investigations of the present study, the following final conclusions shall be listed here (see more in Chapter 6):

- The parent discourse community of electronic dance music consists of many different smaller discourse communities which are also divided into other sub(sub-sub-, sub-sub-sub-, etc.) discourse communities.

- These discourse communities have very different characteristics in terms of discourse and at the same time in terms of identity and community construction.

- They also belong to different scenes (local, translocal and virtual) which have effects on their language use as well. (E.g. in terms of discussed topics.)

- In terms of language use and discourse characteristics - according to the analysed online samples -, the (parent) discourse community of electronic dance music:

- has a specific lexis (technical terms, community reference words, etc.)

- uses different genres in the communicative furtherance (forum posts, Facebook Group posts, classical website comments, etc.)

○ has group-specific compensatory strategies ${ }^{155}$, concern structures, interpersonal discourse behaviours, types of information exchanges, and discoursal participation

Therefore, these characteristics are all part of the here-described model of the discourse community of electronic dance music. This model is based on the theoretical investigation drawn in Chapter 2 and the linguistic analysis expounded in Chapter 5 and summarised in Chapter 6.

\subsection{Importance of this research and new findings}

As mentioned, one of the most important results of this research lies at its pioneer nature of perspective in both the methods applied as well as the communities (EDM) analysed: (1) bringing (computer-mediated) discourse analytical perspectives (2) through the model

\footnotetext{
${ }^{155}$ This characteristic is typically true for online sources.
} 
of discourse community (3) to the studies of electronic dance music (4) via analysing music-related identities.

The following illustration can be seen as a synopsis of the related research fields involved in this study:

Figure 21: Related research fields of the discourse community of electronic dance music

Discourse analysis

approaches

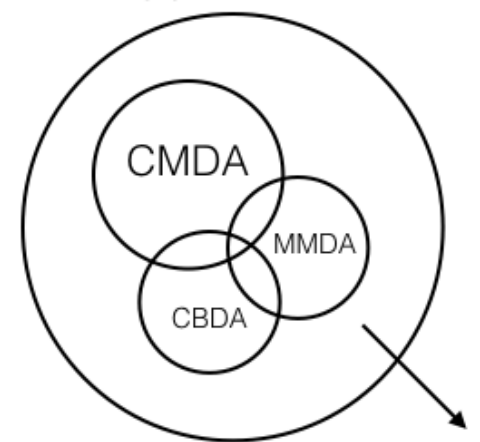

The discourse community of

electronic dance music
Theories of
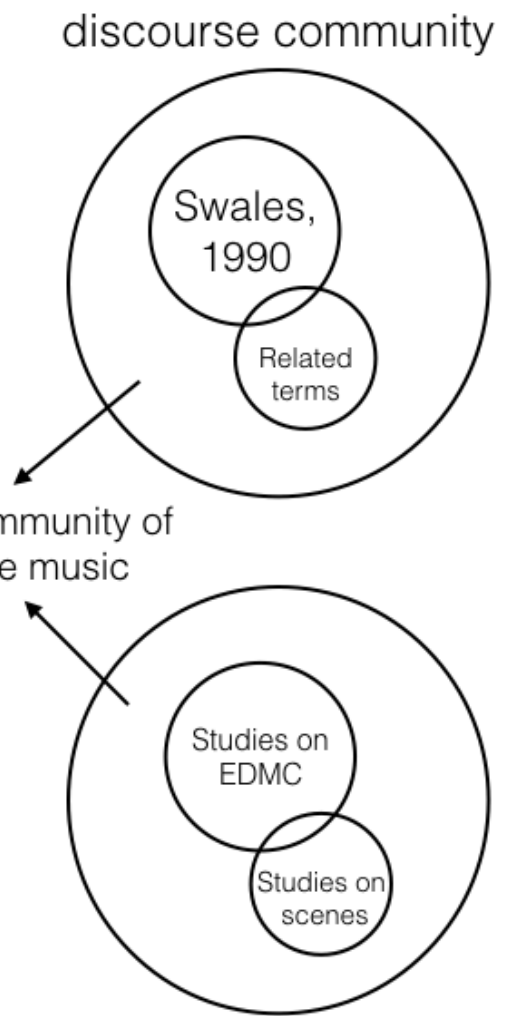

Cultural studies' results

\section{identities in discourse}

This study involves therefore the perspectives of (applied) linguistic discourse analysis approaches, such as computer-mediated discourse analysis, multimodal discourse analysis, and corpus-based discourse analysis; the theories of discourse community; the questions of music-related identities in discourse; and last but not least, the research results of cultural studies on electronic dance music.

The model of the discourse community of electronic dance music involves all these fields and fills research gaps in them:

- In the field of computer-mediated discourse analysis, this study brings in new perspectives with generally analysing online/virtual discourses on music-related 
topics. As many CMDA researchers - e.g. Androutsopoulos \& Beißwenger, 2008; Herring, 2013 - have pointed out the lack of research on social networks, this research also includes such topics (by analysing the language use of the selected Facebook Groups) into its analysis. Furthermore, its coding system of analysis (see in Chapter 5) can be used for further investigations on similar or related research topics (e.g. examining discourse characteristics of another music-related discourse community).

- The model of discourse analysis by Swales (1990) has been somewhat forgotten in recent years. This study highlights the importance of this model by bringing it into a new perspective through the example of EDM and its online/virtual communities.

- Recently, only a few researchers (e.g. Androutsopoulos, 2007; Widdicombe \& Wooffitt, 1995) have done research on the topic of music-related identities in (or through) discourse. By applying the methods of conversation analysis and membership categorisation analysis suggested in this study, this research field can adapt a cluster of established analytical methodologies for further investigations.

- The cultural studies research on electronic dance music culture(s) can also profit from this study, since, on the one hand, their results cannot be excluded from this analysis and on the other hand, the results of this study also presented new insights to the research on scenes (e.g. Bennett \& Peterson, 2004) - especially on virtual scenes.

Therefore, we believe that the present study helps for further investigations to analyse the discourse behaviours of any other music-related (online) discourse communities by its model and analytical methodology.

\subsection{Recommendations for future research}

This new perspective of research on EDM opens up a whole new field of further investigations. It can lead to many different directions:

We believe that it could be helpful, for example, on the field of gender studies, since, as mentioned before, EDMC is a mostly male-dominated culture and with such research one could understand the deeper reasons behind the phenomena. For example, 
by analysing the gender differences in discourses and language use, the results might give an answer to why less women are involved in the field.

Furthermore, not only can the audience behaviour be understood better with the approach illustrated, but we believe that it could help to understand the behaviour and beliefs of groups and audiences, too. Looking at a group of individuals not as fans, not as members of a subculture or a scene, but as members of a discourse community (communicating, producing meaning and inter-social relations, etc.) opens up new possibilities e.g. for marketing research too. By understanding the language use of those individuals, not only the group's general social practices (including clothing, group and identity building) are taken into account, but also the language use as a social practice of the group in particular. This perspective could be adopted also in marketing research on target markets and at the same time, expanding the one-sided (sender/receiver) "target group" perspective.

If anyone wanted to use the described methodology to analyse another musicrelated discourse community, it is highly recommended to rethink the coding categories used in this study. We believe that these categories differ from community to community, but there might be some basic categories which could be used for any other communities as well ${ }^{156}$. Furthermore, to receive more reliable results and numbers, it is also recommended to use software for discourse analysis (of course, depending on the type and amount of analysed data).

\section{5 'Outro'}

The author of this study has just stepped on this new path of research and will keep on following this new direction with bringing such different fields together. As John Cage, who was exploring new paths in modern music, said in an interview by James (1981), "You can become narrow minded, literally, by only liking certain things, and disliking others. But you can become open-minded, literally, by giving up your likes and dislikes becoming interested in things." (p. 218)

\footnotetext{
${ }^{156}$ As for example, this study could use Herring's and party Rasulo's categories, even though they analysed different communities with different purposes.
} 


\section{REFERENCES}

Agawu, K. (2008). Music as Discourse. Semiotic Adventures in Romantic Music. Oxford: Oxford University Press.

Aitken, S. (2003). Rephlexology. Retrieved from http://www.stuartaitken.com/post/43555798376/aphextwin [August 1, 2016]

Aleshinskaya, E. (2013). Key concepts of musical discourse analysis. Research in Language, 11(4), 423-444. doi: 10.2478/rela-2013-0007

Alim, H. S., Ibrahim, A., \& Pennycook, A. (Eds.) (2009). Global Linguistic Flows. Hip Hop Cultures, Youth Identities, and the Politics of Language. New York: Routledge.

An Aphex Twin blimp is flying over London. (2014, August 16). Retrieved from http://www.factmag.com/2014/08/16/an-aphex-twin-blimp-is-flying-over-london/ [June 10, 2016]

Anderson, T. L. (2009). Rave Culture: The Transformation of Electronic Dance Music Scene. Philadelphia: Temple University Press.

Anderson, T. L., \& Kavanaugh, P. R. (2007). A “Rave” Review: Conceptual Interests and Analytical Shifts in Research on Rave Culture. Sociology Compass, 10, 1(2), 499519.

Androutsopoulos, J. (2006). Introduction: Sociolinguistics and computer-mediated communication. Journal of Sociolinguistics, 10(4), 419-438.

Androutsopoulos, J. (2007). Style online: Doing hip-hop on the German-speaking Web. In M. Heller, \& R. J. Watts (Eds.), Language, Power and Social Process (pp. 279320). Berlin; New York: Mouton de Gruyter.

Androutsopoulos, J. (2008). Potentials and Limitations of Discourse-Centred Online Ethnography.Language@Internet, 5. Retrieved from http://www.languageatinternet.org/articles/2008/1610/ [May 16, 2016]

Androutsopoulos, J. (2011). Language change and digital media: A review of conceptions and evidence. In T. Kristiansen, \& N. Coupland (Eds.), Standard Language and Language Standards in a Changing Europe (pp. 145-161). Oslo: Novus.

Androutsopoulos, J., \& Beißwenger, M. (2008). Introduction: Data and Methods in Computer-Mediated Discourse Analysis.Language@Internet, 5. article 2. Retrieved 
from http://nbn-resolving.de/urn:nbn:de:0009-7-16090 [January 15, 2016]

Angemuller, J., Maingueneau, D., \& Wodak, R. (2014). The Discourse Studies Reader. Amsterdam: John Benjamins Publishing Company.

Arribas-Ayllon, M., \& Walkerdine, V. (2008). Foucauldian discourse analysis. In C.

Willing, W. Stainton-Rogers (Eds.), The Sage Handbook of Qualitative Research in Psychology (pp. 91-108). London: SAGE Publications.

Austin, J. L. (1962). How To Do Things With Words? Cambridge, MA: Harvard University Press.

Baker, C. (2004). Membership categorization and interview accounts. In D. Silverman (Ed.), Qualitative Research: Theory, Method and Practice (pp. 162-176). London: SAGE Publication.

Baker, P. (2006). Using corpora in discourse analysis. London; New York: Continuum. Bakhtin, M. (1981). The Dialogic Imagination. Four essays by M. M. Bakhtin. Ed. M. Holquist., Transl. E. Caryl, M. Holquist. Austin, TX: University of Texas Press.

Bamford, J., \& Bondi, M. (Eds.) (2005). Introduction. In J. Bamford, \& M. Bondi (Eds.), Dialogue within Discourse Communities. Metadiscoursive Perspectives on Academic Genres (pp. VII-XXIV). Tübingen: Max Niemeyer Verlag.

Barthes, R. (1973). Mythologies. (Trans. A. Lavers). London: Paladin.

Barthes, R. (1977). Image, Music, Text. (Transl. S. Heath). New York: Hill and Wang. Bauman, Z. (2004). Identity. Cambridge: Polity Press.

Beaugrande, R. De, \& Dressler, W. U. (1981). Introduction to Text Linguistics. London: Longman.

Bednarek, M. (2008). Emotion talk across corpora. Basingstoke; New York: Palgrave Macmillan.

Bednarek, M. (2009). Corpora and Discourse: A Three-Pronged Approach to Analyzing Linguistic Data. In M. Haugh, K. Burridge, J. Mulder, \& P. Peters (Eds.), Selected Proceedings of the 2008 HCSNet Workshop on Designing the Australian National Corpus (pp. 19-24). Somerville, MA: Cascadilla Proceedings Project.

Bennett, A. (1999). Subcultures or neo-tribes? Rethinking the relationship between youth, style and musical taste. Sociology, 33(3), 599-617. 
Bennett, A. (2004). Consolidating the music scenes perspective. Poetics, 32(3-4), 223234.

Bennett, A., \& Kahn-Harris, K. (2004). After Subculture. Critical Studies in Contemporary Youth Culture. London: Pelgrave Macmillan.

Bennett, A., \& Peterson, R. A. (Eds.) (2004). Music Scenes: Local, Translocal, and Virtual. Nashville, TN: Vanderbilt University Press.

Benwell, B., \& Stokoe, E. (2012). Discourse and identity. Edinburgh: Edinburgh University Press.

Bhatia, V. K. (1993). Analyzing genre: Language use in professional settings. London \& New York: Longman.

Bhatia, V. K., Flowerder, J., \& Jones, R. H. (Eds.) (2008) Advances in discourse studies (pp. 145-216). London: Routledge. Section 3: Corpus-based discourse analysis.

Bhatia, V. K, \& Gotti, M. (2006). Introduction. In V. K. Bhatia, \& M. Gotti (Eds.), Explorations in Specialized Genres (pp. 9-17). Bern; Berlin; Bruxelles; Frankfurt am Main; New York; Oxford; Wien: Peter Lang.

Biber, D. (1988). Variation across speech and writing. Cambridge: Cambridge University Press.

Biber, D., Conrad, S., \& Reppen, R. (1998). Corpus Linguistics: Investigation Structure and Use. Cambridge: Cambridge University Press.

Bishop, J. (2009). Enhancing the understanding of genres of web-based communities: the role of the ecological cognition framework. International Journal of Web Based Communities, 5(1), 4-17.

Bizzell, P. (1992). Academic Discourse and Critical Consciousness. Pittsburgh, PA: University of Pittsburgh Press.

Blacking, J. (1982). The structure of musical discourse: The problem of the song text. Yearbook for traditional music, 14, 15-23.

Blood, R. (2000, September 7). Weblogs: A History and Perspective. Retrieved from http://www.rebeccablood.net/essays/weblog history.html [April 14, 2016]

Bódi, Z. (2004). Az írás és a beszéd viszonya az internetes interakcióban. Magyar Nyelvör, 128(3), 286-294. 
Borg, E. (2003). Discourse Community. ELT Journal, 57(4), 398-400.

Boronkai, D. (2009). Bevezetés a társdadalomelemzésbe. Budapest: Ad Librum.

boyd, d. (2006). A blogger's blog: Exploring the definition of a medium. Reconstruction, 6(4). Retrieved from http://reconstruction.eserver.org/Issues/064/boyd.shtml [June 9, 2016].

Boym, S. (2001). The Future of Nostalgia. New York: Basic Books.

Bowie, J. (2010). Proto-discourse and the emergence of compositionality. In M. A. Arbib, \& D. Bickerton (Eds.), The Emergence of Protolanguage: Holophrasis vs compositionality (pp. 19-34). Amsterdam; Philadelphia: John Benjamins.

Bradby, B. (2003). Discourse analysis. In D. Horn, D. Laing, P. Oliver \& P. Wicke (Eds.), Continuum encyclopedia of popular music of the world (pp. 67-70). London, New York: Continuum.

Brake, D. (2007). Personal Webloggers and their audiences: Who do they think they are talking to? In M. Lüders, L. Prøitz, \& T. Rasmussen (Eds), Personlige medier: Livet mellom skjermene. Oslo: Gyldendal Akademisk.

Brewster, B., \& Broughton, F. (2006). Last Night a DJ Saved My Life. London: Headline Book Publishing.

Bronner, A. E., \& De Hoog, R. (2010). Consumer-generated versus marketer-generated websites in consumer decision making. International Journal of Market Research, 52, 231-248.

Brown, G., \& Yule, G. (1983). Discourse Analysis. Cambridge: Cambridge University Press.

Bruns, A. (2008). Blogs. Wikipedia. Second Life. And Beyond. New York: Peter Lang.

Buber, M. (1970). I and Thou. New York: Scribner.

Cameron, D., \& Panović, I. (2014). Working with Written Discourse. Los Angeles;

London; New Delhi; Singapore; Washington DC: SAGE Publications.

Chandler, D. (2002). Semiotics for Beginners. Retrieved from http://visualmemory.co.uk/daniel/Documents/S4B/ [February 10, 2016]

Charmaz, K. (2000). Grounded Theory: Objectivist and Constructivist Methods. In N. K. 
Denzin, \& Y. S. Lincoln (Eds.), Handbook of Qualitative Research (pp. 509-536). Thousand Oaks, CA: Sage Publishing.

Cherny, L. (1999). Conversation and Community: Chat in a Virtual World. Stanford, CA: Center for the Study of Language and Information.

Clark, H. H. (1996). Using language. Cambridge: Cambridge University Press.

Collins, N., Schedel, M., \& Wilson, S. (2013). Electronic Music. Cambridge: Cambridge University Press.

Connell, J., \& Gibson, C. (2003). Sound Tracks. Popular Music, Identity and Place. London; New York: Routledge.

Cook, G. (1989). Discourse. Oxford: Oxford University Press.

Cook, G. (2011). Discourse Analysis. In J. Simpson (Ed.), The Routledge Handbook of Applied Linguistics (pp. 431-444). New York; London: Routledge.

Coulthard, M. (1977). An Introduction to Discourse Analysis. London: Longman.

Crystal, D. (1992). Introducing Linguistics. Harlow: Penguin.

Crystal, D. (2001). Language and The Internet (1st ed.). Cambridge: Cambridge University Press.

Crystal, D. (2006). Language and The Internet (2nd ed.). Cambridge: Cambridge University Press.

Crystal, D. (2011). Internet Linguistics: A Student Guide. London; New York: Routledge. D’Andrea, A. (2007). Global Nomads: Techno and New Age as Transnational Countercultures in Ibiza and Goa. London; New York: Routledge.

Davis, F. (1979). Yearning for yesterday: a sociology for yesterday. New York: Free Press.

Deleuze, G., \& Guattari, F. (1987). A Thousand Plateaus. Capitalism and Schizophrenia. Minneapolis, MN: University of Minnesota Press.

van Dijck, J. (2006). Record and hold: popular music between personal and collective memory. Critical Studies in Media Communication, 23(5), 357-374.

van Dijk, T. A. (1977). Some Aspects of Text Grammars. A Study in Theoretical Linguistics and Poetics. The Hague; Paris: Mouton. 
van Dijk, T. A. (1997). The Study od Discourse. In T. A. van Dijk (Ed.), Discourse as a Structure and Process (pp. 1-34). London; Thousand Oaks; New Delhi: SAGE Publications.

Discogs, Come To Daddy. (n.d.). Retrieved from https://www.discogs.com/de/AphexTwin-Come-To-Daddy/master/27457 [August 15, 2016]

Discogs, Love To Love You Baby. (n.d.) Retrieved from https://www.discogs.com/de/Donna-Summer-Love-To-Love-YouBaby/release/7145922 [May 12, 2016]

Discogs, Richard D. James Album. (n.d.). Retrieved from https://www.discogs.com/de/Aphex-Twin-Richard-D-James-Album/master/510 [August 15, 2016]

Discogs, Selected Ambient Works 85-92. (n.d.). Retrieved from https://www.discogs.com/de/Aphex-Twin-Selected-Ambient-Works-85-92/master/565 [June 18, 2016]

Disqus, Terms and Policies. (n.d.). Retrieved from https://help.disqus.com/customer/portal/topics/215159-terms-and-policies/articles [August 20, 2016]

Dörnyei, Z. (2008). Research methods in applied linguistics. Oxford: Oxford University Press.

Drew, P. (2005). Conversation analysis. In K. L. Fitch, \& R. E. Sanders (Eds.), Handbook of Language and Social Interaction (pp. 71-102). Mahwah, NJ: Lawrence Erlbaum.

Duszak, A. (1997). Culture and Styles of Academic Discourse. Berlin: Mouton de Gruyter.

EAGLES Document EAG-TCWG-TTYP/P. Preliminary recommendations on text typology. (1996). Retrieved from http://www.ilc.cnr.it/EAGLES/texttyp/texttyp.html [April 3, 2016]

Echols, A. (2010). Hot Stuff: Disco and the Remaking of American Culture. New York: W. W. Norton \& Company, Inc.

Eglin, P., \& Hester, S. (1999). Moral order and the Montreal massacre: A story of membership categorization analysis. In P. L. Jalbert (Ed.), Media Studies: 
Ethnomethodological Approaches (pp. 195-230). Lanham, MD: University Press of America; and International Institute for Ethnomethodology and Conversation Analysis.

Enzensberger, H. M. (1970). Baukasten zu einer Theorie der Medien. Kursbuch, 20, 159186.

Expert Advisory Group on Language Engineering Standards (EAGLES). (1996, June).

Evans, M., Wedande, G., Ralston, L., \& van t'Hul S. (2001). Consumer Interaction in the Virtual Era: Some Solutions from Qualitative Research. Qualitative Market Research, $4(3), 150-159$.

Facebook, Facebook Groups. (n.d.). Retrieved from https://groups.fb.com [June 22, 2016]

Facebook, Little White Earbuds. (n.d.). Retrieved from https://www.facebook.com/littlewhiteearbuds/?fref=ts [June 5, 2016]

Facebook, Policies. (n.d.). Retrieved from https://www.facebook.com/policies [July 20, 2016]

Facebook, Reactions Now Available. (2016, February 26). Retrieved from http://newsroom.fb.com/news/2016/02/reactions-now-available-globally/ [June 1, 2016]

Facebook, Teshno. (n.d.). Retrieved from https://www.facebook.com/teshno/?fref=ts [June 10, 2016]

Facebook, What are the privacy. (n.d.). Retrieved from https://www.facebook.com/help/220336891328465 [June 20, 2016]

Fairclough, N. (2000). New labour, new language? London: Routledge.

Fields, K. (2008). Electronic Music Terminology: Translation, Ontology, Knowledge Base. Retrieved from http://www.ems-network.org/spip.php?article241 - nb1 [August $15,2015]$

Fish, S. (1980). Is There a Text in This Class? The Authority of Interpretative Communities. Cambridge; London: Harvard University Press.

Fleck, L. (1935). Entstehung und Entwicklung einer wissenschaftlichen Tatsache. Einführung in die Lehre vom Denkstil und Denkkollektiv. Benno Schwabe und Co. 
Flusser, V. (1985). Ins Universum der technischen Bilder. Göttingen: European Photography.

Flusser, V. (1996). Kommunikologie. Mannheim: Bollmann.

Fóris, Á., \& Bérces, E. (2007). A zenei szaknyelv és a zenei lexikográfia aktuális kérdései. Magyar Nyelvőr, 131, 270-286.

Foucault, M. (1970). The Order of Things: An Archaeology of the Human Sciences. New York: Pantheon Books.

Foucault, M. (1972). The Archeology of Knowledge. London: Longman.

Francis, D., \& Hester, S. (2004). An Invitation to Ethnomethodology. London: SAGE Publications.

Frith, S. (1996). Music and Identity. In S. Hall, \& P. D. Gay (Eds.), Questions of Cultural Identity (pp. 108-127). London: SAGE Publications.

Frith, S. (Ed.) (2004). Popular Music. Critical Concepts in Media and Cultural Studies. Volume IV, Music and Identity. London: Routledge.

Future Producers. (n.d.). Retrieved from http://www.futureproducers.com/forums/ [April $1,2016]$

Gearslutz. (n.d.). Retrieved from https://www.gearslutz.com/board/ [July 12, 2016]

Gearslutz, FAQ. (n.d.). Retrieved from https://www.gearslutz.com/board/faq.php [July 1, 2016]

Gee, J. P. (1999). An Introduction to Discourse Analysis: Theory and Method. London: Routledge.

Gee, J. P., \& Handford, M. (2012a). Introduction. In same J. P. Gee, \& M. Handford (Eds.), The Routledge Handbook of Discourse Analysis (pp. 1-6). London; New York: Routledge.

Gee, J. P., \& Handford, M. (2012b). The Routledge Handbook of Discourse Analysis. London; New York: Routledge.

Geertz, C. (1973). The Interpretation of Cultures. Selected Essays. New York: Basic Books.

Gethmann, D. (Ed.) (2010). Klangmaschinen zwischen Experiment und Medientechnik. 
Bielefeld: Transcript.

Gibbens, A. (1991). Modernity and Self-Identity. Self and Society in the Late Modern Age. Cambridge: Polity.

Giltrow, J., \& Stein, D. (2009). Genres in the Internet: Issues in the Theory of Genre. Amsterdam; Philadelphia: John Benjamins.

Greverus, I.-M. (1979). Zur Kulturstimmung Nostalgie. In I.-M.Greverus, Auf der Suche nach Heimat (pp. 171-181). Munich: Beck.

Grice, H. P. (1975). Logic and Conversation. In P. Cole, \& J. L. Morgan (Eds.), Syntax and Semantics (pp. 41-58). Vol. 3. Speech Acts. New York: Academic Press.

Grodin, D., \& Lindlof, T. R. (Eds.) (1996). Constructing the Self in a Mediated World. London: SAGE Publications.

Gross, J. (1997, September). APHEX TWIN. Interview by Jason Gross. Perfect Sound Forever. Retrieved from http://www.furious.com/perfect/aphextwin.html [April 30, 2016]

Guetta, D. (June 10th, 2016). David Guetta ft. Zara Larsson - This One's For You (Music Video) (UEFA EURO 2016 ${ }^{\mathrm{TM}}$ Official Song) [video file]. Retrieved from https://www.youtube.com/watch?v=MoHnffhBwqs [June 11, 2016]

Gumperz, J. J. (1982). Discourse Strategies. Cambridge: Cambridge University Press.

Haase, M., Huber, M., Krumeich, A., \& Rehm, G. (1997). Interkommunikation und Sprachwandel. In R. Weingarten (Ed.), Sprachwandel durch Computer (pp. 51-85). Opladen: Westdeutscher Verlag.

Habermas, J. (1981). Theorie des kommunikativen Handelns. Frankfurt am Main: Suhrkamp.

Hall, J. K. (2013). Teaching and Researching Language and Culture. New York: Routledge.

Halliday, M. A. K. (1978). Language as Social Semiotic. Ithaca, NY: Cornell University Press.

Halliday, M.A.K. (1989). Spoken and Written Language. Oxford: Oxford University Press.

Hammersley, M. (2002). Discourse Analysis: A Bibliographical Guide. Retrieved from 
http://www.tlrp.org/rcbn/capacity/Activities/Themes/In-depth/guide.pdf [February 19, 2016]

Harré, R. (1998). The Signal Self: An Introduction to the Psychology of Personhood. London: SAGE Publications.

Harris, S. Z. (1952). Discourse Analysis. Language, 28(1), 1-30.

Hartshorne, C., \& Weiss, P. (Eds.) (1931). Collected Papers of Charles Sanders Peirce. Cambridge: Harvard University Press.

Hatch, E. (1992). Discourse and Language Education. Cambridge: Cambridge University Press.

Hegel, G. W. F. [1807] (1977). Phenomenology of Spirit. (transl. A. V. Miller). Oxford: Clarendon Press.

Hendler, J. (2009). Web 3.0 Emerging. Computer, 43(1), 111-113.

Herring, S. C. (1996). Posting in a different voice: Gender and ethics in computermediated communication. In C. Ess (Ed.), Philosophical perspectives on computermediated communication (pp. 115-145). Albany; NY: SUNY Press.

Herring, S. C. (1998). Le style du courrier électronique: variabilité et changement. Terminogramme, 84-85 (March), 9-16.

Herring, S. C. (2001). Computer-mediated discourse. In D. Schiffrin, D. Tannen, \& H. E. Hamilton (Eds.), Handbook of discourse analysis (pp. 612-634). Oxford: Blackwell.

Herring, S. C., Job-Sluder, K., Scheckler, R, \& Barab, S. (2002). Searching for Safety Online: Managing "Trolling” in a Feminist Forum. The Information Society, 18, 371384.

Herring, S. C. (2004a, January). Bridging the Gap: A Genre Analysis of Weblogs. Presented at the 37th Hawaii International Conference on System Sciences. doi: 10.1109/HICSS.2004.1265271

Herring, S. C. (2004b). Computer-mediated discourse analysis: An approach to researching online behavior. In S. A. Barab, R. Kling, \& J. Gray (Eds.), Designing for virtual communities in the service of learning (pp. 338-376). Cambridge; New York: Cambridge University Press. 
Herring, S. C. (2007). A Faceted Classification Scheme for Computer-Mediated Discourse.Language@Internet, 4. Retrieved from http://www.languageatinternet.org/articles/2007/761 [May 20, 2016]

Herring, S. C. (2009, October). Convergent media computer-mediated communication: Introduction and theory. Paper presented at the panel on Convergent Media Computer-Mediated Communication, Internet Research 10.0, Milwaukee, WI.

Herring, S. C. (2010). Computer-mediated conversation Part I: Introduction and overview.Language@Internet, 7, article 2. Retrieved from http://www.languageatinternet.org/articles/2010/2801 [May 29, 2016]

Herring, S. C. (2013). Discourse in Web 2.0: Familiar, Reconfigured, and Emergent. In D. Tannen, \& A. M. Trester (Eds.), Discourse 2.0: Language and New Media (pp. 126). Washington, DC: Georgetown University Press.

Herring, S. C. (2014). Research: Computer-mediated communication. ASIS\&T Bulletin, 40(3). Retrieved from http://www.asis.org/Bulletin/Feb-14/FebMar14_Herring.html [March 18, 2016]

Herzberg, B. (1986). The Politics of Discourse Communities. Paper presented at the CCC Convention. New Orleans.

Hester, S., \& Engin, P. (1997). Culture in Action: Studies in Membership Categorization Analysis. Boston, MA: International Institute for Ethnomethodology and University Press of America.

Hickethier, K. (1998). Geschichte des deutschen Fernsehen. Stuttgart; Weimar: J. B. Metzler.

Highfield, T., \& Leaver, T. (2015). A methodology for mapping Instagram hashtags. First Monday, 20(1). Retrieved from http://www.firstmonday.dk/ojs/index.php/fm/article/view/5563/4195\#author [June 18, 2016]

Hill, A. (2002). Acid House and Thatcherism: noise, the mob, and the English countryside. The British Journal of Sociology, 53(1): 89-105.

Hiltz, S. R. (1985). Online Communities: A Case Study of the Office of the Future. Norwood, NJ: Ablex Publishing Corp. 
Hitzler, R. (2002). Pill Kick: The Pursuit of "Ecstasy" at Techno Events. Journal of Drug Issues, 32, 459-466.

Hoenisch, S. (1998). A Wittgensteinian Approach to Discourse Analysis. Retrieved from http://www.criticism.com/da/lw_da.html [June 18, 2015]

Holmes, T. B. (2002). Electronic and Experimental Music: Pioneers in Technology and Composition. London: Routledge.

Hunter, J. F. M. (1968). "Forms of Life” in Wittgenstein's Philosophical Investigations. American Philosophical Quarterly, 5(4), 233-244.

Hutson, S. (2000). The Rave: Spiritual Healing in Modern Western Subcultures. Anthropological Quarterly, 73, 35-49.

Hymes, D. (1974). Foundations in Sociolinguistics: An Ethnographic Approach. Pennsylvania, University of Pennsylvania Press.

Institut für Medienarchäologie (Ed.) (2008). Zauberhafte Klangmaschinen. Von der Sprechmaschine bis zur Soundcard. Mainz: Schott Music.

Ishkur's Guide to Electronic Music V2.5. (n.d.). Retrieved from http://techno.org/electronic-music-guide/ [May 15, 2016]

ITALO DISCO MANIACS, Description. (n.d.). Retrieved from: https://www.facebook.com/groups/1577180732528869/ [July 15, 2016]

Iványi, Zs. (2001). A nyelvészeti konverzációelemzés. Magyar Nyelvőr, 125(1), 74-93. Jacobson, M. (1995). Disco does not suck, Beavis. Esquire, February, 136.

Jäger, S. (1999). Kritische Diskursanalyse. Eine Einführung. (2nd ed.) Duisburg: DISS. James, R. S. (1981). Expansion of Sound Resources in France, 1913-1940, and Its Relationship to Electronic Music. Ph.D. diss. Ann Arbour, MI: University of Michigan.

Jewitt, C. (Ed.) (2009). Handbook of Multimodal Analysis. London: Routledge. Jewitt, C. (2006). Technology, Literacy and Learning: A Multimodal Approach. London: Routledge.

Johannsen, F. (2015, July 3). Rewind: An Expert on How Italo Disco Became Cool Again. Electronic Beats. Retrieved from http://www.electronicbeats.net/rewind-an- 
expert-on-how-italo-disco-became-cool-again/ [August 15, 2015]

Johns, A. M. (1997). Text, Role and Context: Developing Academic Litrecies (pp. 5171). Cambridge: Cambridge University Press.

Johnstone, B. (2002). Discourse Analysis. Oxford: Blackwell.

Jóri, A. (July 11, 2012). On the discourse community of electronic music. Retrieved from http://www.soundstudieslab.org/on-the-discourse-community-of-electronic-music/ [August 10, 2015]

Jóri, A. (2015). A metaforikus nyelvi kifejezések vizsgálata a "funkkal szaggatott androidtechno" területén. In A. Jóri, \& M. Folmeg (Eds.), Világ és nyelv szenvedéllyel (pp. 288-297). Budapest: Tinta könyviadó.

Jucker, A. H., \& Dürscheid, C. (2002). The Linguistics of Keyboard-to-screen Communication. A New Terminological Framework. Linguistik online, 56. Retrieved from http://www.linguistik-online.org/56_12/juckerDuerscheid.html [June 15, 2016]

Kendall, G., \& Wickham, G. (1999). Using Foucault's methods. London: SAGE Publications.

Kittler, F. A. (1985). Aufschreibesysteme 1800/1900. Munich: Wilhelm Fink.

Ko, K.-K. (1996). Structural characteristics of computer-mediated language: A comparative analysis of InterChange discourse. Electronic Journal of Communication, 6(3). Available http://www.cios.org/www/ejc/v6n396.htm [March 15, 2016]

Koteyko, N. (2006). Corpus Linguistics and the Study of Meaning in Discourse. The Linguistics Journal, 2. Available http://www.linguisticsjournal.com/2014/01/09/corpus-linguistics-and-the-study-of-meaning-in-discourse/ [June 6, 2015]

Koteyko, N. (2014). Language and Politics in Post-Soviet Russia: A Corpus Assisted Approach. London: Pelgrave.

Kövecses, Z. (2010). Metaphor. Oxford: Oxford University Press.

Kowch, E., \& Schwier, R. (1997, February). Building learning communities with technology. Presented at the National Congress on Rural Education, Saskatchewan, Canada.

Kress, G. (1998). Visual and verbal modes of representation in electronically mediated 
communication: the potentials of new forms of text. In I. Snyder (Ed.), Page to Screen: Taking literacy into the electronic era (pp. 53-79). London: Routledge.

Kress, G. (2003). Literacy in the New Media Age. London: Routledge.

Kress, G. (2012). Multimodal Discourse Analysis. In J.P. Gee, \& M. Handford (Eds.), The Routledge Handbook of Discourse Analysis (pp. 35-50). London; New York: Routledge.

Kress, G., \& Hodge, R. (1988). Social Semiotics. Cambridge: Polity.

Kress, G., \& Van Leeuwen, T. (1996). Reading Images: The Grammar of Visual Design (1st ed.). London: Routledge.

Kress, G., \& Van Leeuwen, T. (2006). Reading Images: The Grammar of Visual Design (2nd ed.). London: Routledge.

Kress, G., \& van Leeuwen, T. (2001). Multimodal Discourse: The Modes and Media of Contemporary Communication. Oxford: Oxford University Press.

Kreyer, R., \& Mukherjee, J. (2009). The style of pop song lyrics: A corpus-linguistic pilot study. Anglia-Zeitschrift für englische Philologie, 125(1), 31-58. doi: 10.1515/ANGL.2007.31

Krishnamurthy, B., \& Cormode, G. (2008). Key differences between Web 1.0 and Web 2.0. First Monday, 13(6). Retrieved from http://firstmonday.org/ojs/index.php/fm/article/view/2125/1972 [June 16, 2016]

Kučera, H., \& Francis, W. N. (1967). Computational Analysis of Present-Day American English. Providence, RI: Brown University Press.

Kuhn, T. S. (1962). The Structure of Scientific Revolutions. Chicago, IL: University of Chicago Press.

Labov, W. (1966). The Social Stratification of English in New York City. Washington, DC: Center for Applied Linguistics.

Lakoff, G., \& Johnson, M. (1980). Metaphors We Live By. London: University of Chicago Press.

Latour, B. (1987). Science in action. Cambridge: Harvard University Press.

Lave, J., \& Wenger, E. (1991). Situated Learning: Legitimate Peripheral Participation. Cambridge: Cambridge University Press. 
Lee, D. Y. W. (2001). Genres, registers, text types, domains, and styles: clarifying the concepts and navigating a path through the BNC jungle. Language Learning \& Technology, 5(3), 37-72.

Lemke, J. L. (2012). Multimedia and discourse analysis. In J.P. Gee, \& M. Handford (Eds.), The Routledge Handbook of Discourse Analysis (pp. 79-89). London; New York: Routledge.

Lemke, J. L. (2002). Travels in Hypermodality. Visual Communication, 1(3), 299-325.

Leudar, I., Marsland, V., \& Nekvapil, J. (2004). On membership categorization: “Us", "them" and "doing violence" in political discourse. Discourse and Society, 15(2-3), 243-266.

Link, J. (1997). Versuch über den Normalismus. Wie Normalität produziert wird. Wiesbaden: Westdeutscher Verlag.

Litosseliti, L. (2006). Gender and Language: An Introduction and Resource Book. Oxford: Oxford University Press.

Livia, A., \& Hall, K. (Eds.) (1997). Queerly Phrased: Language, Gender and Sexuality. Oxford: Oxford University Press.

Lomborg, S. (2009). Navigation the blogsphere: Towards a genre-based typoology of weblogs. First Monday, 14(5). Retrieved from http://ojphi.org/ojs/index.php/fm/article/view/2329/2178 [June 10, 2016]

LWE, Contact. (n.d.). Retrieved from http://www.littlewhiteearbuds.com/contact .V2uJbWMglE4 [June 5, 2016]

LWE, Goodbye LWE. (2015, October 5). Retrieved from http://www.littlewhiteearbuds.com/alert/a-letter-from-lwes-editor-in-chief/ .V2uMJGMglE4 [June 5, 2016]

LWE, Open Letter. (2014, June 2) Retrieved from http://www.littlewhiteearbuds.com/alert/a-letter-from-lwes-editor-in-chief/ .V8yWN2UglE4 [June 5, 2016]

Macdonald, R. A. R., Hargreaves, D. J., \& Miell, D. (2002). Musical identities. Oxford: Oxford University Press.

Maffesoli, M. (1996). The Time of the Tribes: The Decline of Individualism in Mass 
Society. London: Sage.

Magic Waves Festival. (n.d.). Retrieved from

https://www.facebook.com/events/327091780776761/?active tab=posts [May 10, 2016]

Malbon, B. (1998). Clubbing: Consumption, identity and the spatial practices of everynight life. In T. Skelton, \& G. Valentine (Eds.), Cool places: Geographies of youth cultures (pp. 266-286). New York: Routledge.

Malbon, B. (1999). Clubbing: Dancing, ecstasy and vitality. New York: Routledge.

Manning, P. (2004). Electronic and Computer Music. Oxford: Oxford University Press.

Martin, W. (May 21, 2012). Endless Summer: A Disco Diva's Enduring Lesson about Female Sexuality. Psychology Today. Retrieved from https://www.psychologytoday.com/blog/stepmonster/201205/endless-summer-discodivas-enduring-lesson-about-female-sexuality [August 15, 2016]

Matos, M. (July 19, 2016). A Brief History of Aphex Twin Trolling His Fans. Vice Magazine. Retrieved from https://thump.vice.com/en_us/article/brief-history-aphextwin-trolling-fans-cheetah-ep [August 2, 2016]

Matrixsynth, Archives. (n.d.). Retrieved from http://www.matrixsynth.com/p/archives.html [10 August, 2016]

Matrixsynth, Five Years Of Matrixsynth. (2010, July 20). Retrieved from http://www.matrixsynth.com/2010/07/5-years-of-matrixsynth.html [10 May, 2016]

Matrixsyth, Four Years of Matrixsynth. (2009, July 20). Retrieved from http://www.matrixsynth.com/2009/07/four-years-of-matrixsynth.html [1 August, 2016]

Matrixsynth, Happy New Year. (2012, December 31). Retrieved from http://www.matrixsynth.com/2012/12/happy-new-year.html [7 August, 2016]

Matrixsynth, Support Matrixsynth. (n.d.).http://www.matrixsynth.com/p/supportmatrixsynth.html [June 12, 2016]

McCarthy, M. (1991). Discourse Analysis for Language Teachers. Cambridge: Cambridge University Press.

McGuigan, J. (1992). Cultural populism. New York: Routledge. 
McLeod, K. (2001). Genres, Subgenres, Sub-Subgenres and More: Musical and Social Differentiation Within Electronic/Dance Music Communities. Journal of Popular Music Studies, 13, 59-75.

McRobbie, A. (1994). Postmodernism and popular culture. London: Routledge.

McRobbie, A. (2002). Clubs to companies: notes on the decline of political culture in speeded up creative worlds. Cultural Studies, 16(4), 516-531.

McQuail, D. (2005). McQuail's Mass Communication Theory. London: SAGE Publications.

Mesthrie, R. (2011). The Cambridge Handbook of Sociolinguistics. Cambride: Cambridge University Press.

Michael, M. (1996). Constructing Identities: The Social, the Nonhuman and Change. London: SAGE Publications.

Michaels, S. (April 30, 2013). Boards of Canada announce first new album in eight years. The Guardian. Retrieved from https://www.theguardian.com/music/2013/apr/30/boards-of-canada-tomorrows-harvest [July 30, 2016]

Middleton, R. (Ed.) (2000). Reading Pop. Approaches to Textual Analysis in Popular Music. Oxford: Oxford University Press.

Miller, C. R. (1984). Genre as Social Action. Quarterly Journal of Speech, 70, 151-167.

Miller, C. R. (1994). Rhetorical Community: The Cultural Basis of Genre. In A. Freedman, \& P. Medway (Eds.), Genre and the new rhetoric (pp. 67-78). London; Bristol, PA: Taylor \& Francis.

Miller, C. R., \& Shepherd, D. (2004). Blogging as Social Action: A Genre Analysis of the Weblog Into the Blogosphere: Rhetoric, Community, and Culture of Weblogs. Retrieved from http://conservancy.umn.edu/bitstream/handle/11299/172818/Miller_Blogging as S ocial Action.pdf?sequence $=1 \&$ isAllowed $=y$ [April 20, 2016]

Montano, E. (2011). Festival Fever and International DJs: The Changing Shape of DJ Culture in Sydney's Commercial Electronic Dance Music Scene. Dancecult, 2(1), 63 89. 
Moore, A. F. (2001). Categorical conventions in music discourse: Style and genre. Music \& letters, 82(3), 209-223.

Muggleton, D. (2000). Inside Subculture: The Postmodern Meaning of Style. Oxford: Berg.

Muggleton, D., \& Weinzierl, R. (2003). The post-subculture reader. Oxford: Berg. Murphey, T. (1992). Discourse of Pop Songs. TESOL Quarterly, 26(4), 770-774.

New Dance Fantasy Summer Festival at Griessmühle. (n.d.). Retrieved from https://www.residentadvisor.net/event.aspx?825604 [May 2, 2016]

Newman, M. (2009). “That's all concept. It's nothing real!”: Reality and Lyrical Meaning in Rap. In H. S. Alim, A. Ibrahim, \& A. Pennycook (Eds), Global Linguistic Flows. Hip Hop Cultures, Youth Identities, and the Politics of Language (pp. 195-212). New York: Routledge.

Nikander, P. (2003). Age in Action: Membership Work and Stage of Life Categories in Talk. Helsinki: Academia Scientiarum Fennica.

Nystrand, M. (1982). What Writers Know: The Language, Process, and Structure of Written Discourse. New York: Academic.

O’Halloran, K. L. (2013). Multimodal Discourse Analysis. In K. Hyland, \& B. Paltridge (Eds.), The Bloomsbury Companion to Discourse Analysis (pp. 120-137). London; New York: Continuum.

O’Halloran, K. L., \& Smith, B. A. (2011). Multimodal Studies. In K. L. O’Halloran, \& Smith, B. A. (Eds.), Multimodal Studies. Exploring Issues and Domains (pp. 1-16). New York; London: Routledge.

O’Toole, M. (2010). The Language of Displayed Art (2nd ed.). London; New York: Routledge.

Paltridge, B. (2006). Discourse Analysis: An Introduction. London: Continuum.

Partington, A., Morley, J., \& Haarman, L. (Eds.) (2004). Corpora and Discourse. Bern; Berlin; Bruxelles; Frankfurt/M.; New York; Oxford; Wien: Peter Lang.

Partington, A. (2004). Corpora and discourse, a most congruous beast. In A. Partington, J. Morley, \& L. Haarman (Eds.), Corpora and Discourse (pp. 11-20). Bern, Berlin, Bruxelles, Frankfurt/M., New York, Oxford, Wien: Peter Lang. 
Pavlovová, M. (2013). Complex linguistic analysis of musical discourse: The genre of concert notice. Saarbrücken: LAP.

Pêcheux, M. (1982). Language, semantics and ideology: Stating the obvious. London: Macmillan.

Perelman, C., \& Olbrechts-Tyteca, L. (1969). The new rhetoric: A treatise on argumentation. (Trans. J. Wilkinson and P. Weaver). Notre Dame: University of Notre Dame Press.

Pickering, M., \& Keightley, E. (2006). The modalites of nostalgia. Current Sociology, 54(6), 919-940.

Pini, M. (1997). Women and the early British rave scene. In A. McRobbie (Ed.), Back to reality: Social experience and cultural studies (pp. 152-169). Manchester: Manchester University Press.

Polarity Shift. (2015, October 26). Retrieved from http://www.mhmkinternational.org/news-details/datum/2015/10//polarity-shift-a-successful-paneldiscussion-and-female-takeover-in-berghain-kantine.html [August 12, 2016]

Porter, J. E. (1992). Audience and Rhetoric: An Archaeological Composition of the Discourse Community. New Jersey: Prentice Hall.

Porter, J. E. (1986). Intertextuality and the Discourse Community. Rhetoric Review 5(1), $34-47$.

Preece, J. (2000). Online Communities. Designing Usability, Supporting Sociability. West Sussex: John Wiley and Sons LTD.

Preece, J., \& Maloney-Krichmar, D. (2003). Online Communities: Focusing on sociability and usability. In J. Jacko, \& A. Sears (Eds.), The Human-Computer Interaction Handbook (pp. 596-620). New Jersey: Mahwah, Lawrence Erlbaum Associates Inc. Publishers.

Rafoth, B. A. (1990). The concept of discourse community: Descriptive and explanatory adequacy. In G. Kirsch, \& D.H. Roen (Eds.) A sense of audience in written communication. Written Communication Annual Vol. 5 (pp. 140-152). Newbury Park, CA: SAGE Publications.

Rasulo, M. (2008). The role of participant discourse in online community formation. 
Rome: Aracne.

Rave News Clipping. (n.d.). Retrieved from

http://www.webm8.co.uk/riddler/newspaper_clippings/06-rave/index.htm [April 15, 2016]

Redhead, S. (1997). Subcultures to clubcultures: An introduction to popular cultural studies. Malden, MA: Blackwell.

Renkema, J. (2004). Introduction to Discourse Studies. Amsterdam; Philadelphia: John Benjamin's Publishing Company.

Resident Advisor, About. (n.d.) Retrieved from https://www.residentadvisor.net/about.aspx [August 22, 2016]

Resident Advisor, Moustache Records. (n.d.). Retrieved from https://www.residentadvisor.net/record-label.aspx?id=2841 [January 2, 2016]

Reynolds, S. (1998). Generation ecstasy: Into the world of techno and rave culture. Toronto: Little, Brown and Company.

Reynolds, S. (2013). Energy Flash: A Journey Through Rave Music and Dance Culture. London: Faber \& Faber.

Rheingold, H. (1994). A slice of life in my virtual community. In L. M. Haraisim (Ed.), Global networks: Computers and International Communication (pp. 57-80). Cambridge, MA: MIT Press.

Rietveld, H. (1993). Living the dream. In S. Redhead (Ed.), Rave Off: Politics and Deviance in Contemporary Youth Culture (pp. 41-78). Aldershot, Brookfield, VT: Avebury.

Riley, P. (Ed.) (1985). Discourse and learning. London; New York: Longman.

Roads, C. (1996). Early Electronic Music Instruments: Time Line 1899-1950. Computer Music Journal, 20(3), 20-23.

Rodgers, T. (2010). Pink Noises. Women in Electronic Music and Sound. Durham, NC: Duke University Press.

Roelofsen, F. (2007). Distributed Knowledge. Journal of Applied Non-Classical Logic, $17(2), 255-273$.

Ropolyi, L. (2006). Az Internet természete. Internetfilozófiai értekezés. Budapest: 
Typotex.

Rosch, E. (1975). Cognitive representation of semantic categories. Journal of Experimental Psychology (General), 104, 192-233.

Sacks, H. (1974). On the analysibality of stories by children. In R. Turner (Ed.), Ethnomethodology (pp. 216-232). Harmondsworth: Penguin.

Sacks, H. (1992). Lectures on Conversation. Vol. 1-2. (Ed. G. Jefferson). Oxgford: Blackwell.

de Saussure, F. (1966). Course in General Linguistics. NY: McGraw-Hill Book Company.

Schegloff, E. A. (1992). In other context. In A. Duranti, \& C. Goodwin (Eds.), Rethinking Context: Language as an Interactive Phenomenon (pp. 193-227). Cambridge: Cambridge University Press.

Schmidt, G. (2000). Chat-Kommunikation im Internet - eine kommunikative Gattung? In C. Thimm (Ed.), Soziales im Netz. Sprache, soziale Beziehungen und Kommunikationskulturen im Internet (pp. 109-129). Wiesbaden: Opladen.

Searle, J. R. (1969). Speech Acts: An Essay in the Philosophy of Language. Cambridge: Cambridge University Press.

Shapiro, P. (2000). Disco: Playing with a different sex. In P. Shapiro (Ed.), Modulations. A History of Electronic Music: Throbbing Words on Sound (pp. 38-57). New York: Caipirinha Productions, Inc.

Sherburne, P. (2001). 12k: between two points. Organised Sound, 6(3): 171-176. Cambridge: Cambridge University Press.

Sherburne, P. (n.d.) A conversation with Aphex Twin. Pitchfork. Retrieved from http://pitchfork.com/features/cover-story/reader/aphex-twin/ [August 1, 2016]

Sinclair, J. M., \& Coulthard, M. (1975). Towards an Analysis of Discourse. The English Used by Teacher and Pupils. Oxford: Oxford University Press.

Sperber, D., \& Wilson, D. (1986). Relevance: Communication and Cognition. Oxford: Basil Blackwell. 
Spring, K. (2004). Behind the Rave: Structure and Agency in a Rave Scene. In A. Bennett, \& R. A. Peterson (Eds.), Music Scenes. Local, Translocal, and Virtual (pp. 48-63). Nashville, TN: Vanderbilt University Press.

Van Straaten, E.-M. A. (2012). "What are we doing here?” Nostalgic Desires for a Cosmopolitan Sensory Aesthetic in the Amsterdam-based Psytrance Scene. Dancecult, 4(3), 65-85.

Steger, H., Deutrich, H., Schank, G, \& Schütz, E. (1974) Redekonstellation, Redekonstellationstyp, Textexemplar, Textsorte im Rahmen eines Sprachverhaltensmodells. Begründung einer Forschungshypothese. In H. Moser (Ed.), Gesprochene Sprache. Jahrbuch 1972 des Instituts für Deutsche Sprache (pp. 39-97). Düsseldorf: Schwann.

Straw, W. (1991). Systems of articulation logics of change: communities and scenes in popular music. Cultural Studies, 5(3), 368-388.

Stubbs, M. (1983). Discourse Analysis. The Sociolinguistic Analysis of Natural Language. Oxford: Basil Blackwell.

Swales, J. M. (1990). Genre Analysis. English in Academic and Research Settings. Cambridge: Cambridge University Press.

Swales, J. M. (1998). Other Floors, Other Voices: A Textography of a Small University Building. New Jersey: Mahwah, Lawrence Erlbaum Associates.

Tagg, P. (1994). From refrain to rave: The decline of figure and the rise of ground. Popular Music, 13(2), 209-222.

Tagg, P. (2003). Analyzing popular music: Theory, method and practice. Cambridge: Cambridge University Press.

Tajfel, H. (1982). Social Identity and Intergroup Relations. Cambridge: Cambridge University Press.

Tannen, D., \& Trester, A. M. (Eds.) (2013). Discourse 2.0: Language and New Media. Tannenbaum, R. (1993). Techno inferno. GQ, September, 189-190, 199-200.

TB-303 Owners Club. Description. (n.d.). Retrieved from https://www.facebook.com/groups/tb303ownersclub/ [August 20, 2016] 
Techno Studies. (2014, December 10). Retrieved from http://www.berlin-mitteinstitut.de/12-13-12-2104-techno-studies-aesthetik-geschichtsschreibungelektronischer-tanzmusik-tagung-universitaet-der-kuenste/ [January 20, 2016]

Teshno. (n.d.). Retrieved from http://www.teshno.com [March 20, 2016]

The survival of electronic music scene. (2015, June 9). Retrieved from http://www.macromedia-fachhochschule.de/news-detils/datum/2015/06//the-survivalof-electronic-music-scene-panel-discussion-and-party-in-berghain-kantine.html [August 12, 2016]

Thompson, B. (1994). Aphex Twin: The Mozart of Techno. MOJO, 1994, JanuaryFebruary.

Thornton, S. (1995). Club cultures: Music, media and subcultural capital. Hanover: Wesleyan University Press.

Thurlow, C., Lengel, L., \& Tomic, A. (2004). Computer Mediated Communication: Social Interaction and the Internet. London: SAGE Publications.

Toffler, A. (1970). Future Shock. New York: Bantam Books.

Toffler, A. (1980). The Third Wave. New York: Bantam Books.

Tomlinson, L. (1998). “This ain't no disco? ... or is it: Youth culture and the rave phenomenon. In J. Epstein (Ed.), Youth culture: Identity in postmodern world (pp. 195-211). Malden, MA: Blackwell.

Tracy, K. (2002). Everyday Talk: Building and Reflecting Identities. New York: Guilford Press.

Trudgill, P. (1974). The Social Differentiation of English in Norwich. Cambridge: Cambridge University Press.

Ulrich, J. M., \& Harris, A. L. (Eds.) (2003). GenXegesis. Madison, WI: University of Wisconsin Press.

Veszelszki, Á. (2013). Digilektus és netszótár. Irodalomismeret, 2013/1, 184-97.

Veszelszki, Á. (2016). A netnyelvészet terminológiai és kronológiai áttekintése. In G. Balázs (Ed.), Jelentés a magyar nyelvről, 2010-2015 (pp. 56-73). Budapest: IKU, Inter Nonprofit Kft. 
VICE (May 23rd, 2016). Britain's Illegal Rave Renaissance: LOCKED OFF. [video file] Retrieved from https://www.youtube.com/watch?v=h3t3YnVgY9k [June 10, 2016]

Vintage Syth Explorer. (n.d.). Retrieved from http://www.vintagesynth.com [July 27, 2016]

Vintage Syth Explorer, Forum. (n.d.) Retrieved from http://www.vintagesynth.com/forum/ [May 20, 2016]

Vintage Syth Explorer, Resources (n.d.) Retrieved from http://www.vintagesynth.com/resources/ [May 20, 2016]

Viswanathan, G., Mathur, P. D., \& Yammiyavar, P. (March 20-24, 2010). From Web 1.0 to Web 2.0 and beyond: Reviewing usability heuristic criteria taking music sites as case studies. Presented at India HCI 2010 Interaction Design for International Development 2010 (pp. 207-225). Retrieved from http://www.idc.iitb.ac.in/ anirudha/pdfs/compilation 2.pdf [April 25, 2016]

Vitos, B. (2014). Along the Lines of the Roland TB-303: Three Perversions of Acid Techno. Dancecult, 6. Retrieved from https://dj.dancecult.net/index.php/dancecult/article/view/460/462 [August 15, 2015]

WATMMF. (n.d.). Retrieved from http://forum.watmm.com [July 3, 2016]

WATMMF, Blogs. (n.d.). Retrieved from http://forum.watmm.com/blogs/ [July 13, 2016]

WATMMF, Files. (n.d.). Retrieved from http://forum.watmm.com/files/ [July 11, 2016]

WATMMF, Rules. (n.d.). Retrieved from http://forum.watmm.com/index.php?app=forums\&module=extras\&section=boardrules [July 5, 2016]

WATMMF, Store. (n.d.) Retrieved from http://forum.watmm.com/store/ [June 10, 2016]

Watson, D. R. (1978). Categorization, authorization and blame-negotiation in conversation. Sociology 12(1), 105-113.

We Are The Music Makers. (2013, May 6). Retrieved from http://bocpages.org/wiki/We Are The Music Makers [May 5, 2016]

Weedon, C. (1997). Feminist practice and poststructuralist theory (2nd ed.). Oxford: Blackwell. 
Wellman, B. (2002). Designing the Internet for Networked Society: Little boxes, globalization, and networked individualism. Communication of the ACM, 45(5), 9196.

Wenger, E. (1998). Communities of practice. Learning, meaning, and identity. Cambridge: Cambridge University Press.

Wenger, E. (2006). Communities of practice: a brief introduction. In J. Skalicky, \& M. West (Eds.), UTAS Community of Practice Initiative. Readings and resources.

Retrieved from http://www.teachinglearning.utas.edu.au/ data/assets/pdf file/0007/185605/CoP-Reader-Complete.pdf [August 11, 2015]

Werlich, E. (1982). A text grammar of English. Heidelberg: Quelle \& Meyer.

Whelan, A. (2008). Breakcore. Identity and Interaction on Peer-to-Peer. Cambride: Cambride Scholars Publishing.

Widdicombe, S., \& Wooffitt, R. (1995). The Language of Youth Subcultures. Social Identity in Action. New York; London; Toronto; Sydney; Tokyo; Singapore: Harvester Wheatsheaf.

Widdowson, H. G. (1973). An Applied Linguistic Approach to Discourse Analysis. Unpublished Ph.D. Thesis, Department of Linguistics, University of Edinburgh.

Widdowson, H. G. (2007). Discourse Analysis. Oxford: Oxford University Press.

Williams, P. J. (2007). Youth-Subcultural Studies: Sociological Traditions and Core Concepts. Sociology Compass, 1(2), 572-593.

Wilson, B. (2006). Flight, Fight, or Chill. Subcultures, Youth, and Rave into the TwentyFirst Century. Montreal \& Kingston; London; Ithaca: McGill - Queen's University Press.

Wittgenstein, L. (1958). Philosophical Investigations. (Trans. G.E.M. Anscombe). New York: Macmillan.

Wodak, R., de Cillia, R., Reisigl, M., \& Liebhart, K. (1999). The Discourse Construction of National Identity. Edinburgh: Edinburgh University Press.

Yerrick, R. K., \& Gilbert, A. (2011). Constraining the discourse community: How science discourse perpetuates marginalization of underrepresented students. Journal Of Multicultural Discourses, 6(1), 67-91. 
YouTube, Come To Daddy. (2012, March 8). Retrieved from https://www.youtube.com/watch?v=h-9UvrLyj3k [August 1, 2016]

YouTube, Tarzan Boy. (2012, October 4). Retrieved from https://www.youtube.com/watch?v=N 724ja9d48 [August 12, 2016]

YouTube, Windowlicker. (2007, April 23). Retrieved from https://www.youtube.com/watch?v=7MBaEEODzU0 [August 1, 2016]

Zielinski, S. (1985). Zur Geschichte des Videorecorders. Berlin: Wissenschaftsverlag Volker Spiess.

Zimmerman, D. H. (1998). Identity, context and interaction. In C. Antaki, \& S. Widdicombe (Eds.), Identities in Talk (pp. 87-106). London: SAGE Publications. 


\section{SOURCES OF LINGUISTIC DATA}

\section{1) Web discussion forums}

\section{- We Are The Music Makers Forum}

First 500 posts from the thread 'Aphex Twin - Syro'

- Available at http://forum.watmm.com/topic/84544-aphex-twin-syro/

\section{- Gearslutz}

All posts (414 pieces until July 10, 2016) from the thread 'Lets talk samplers!'

- Available at https://www.gearslutz.com/board/electronic-musicinstruments-electronic-music-production/145494-lets-talk-samplers.html

\section{2) 'Classical' websites}

\section{- Resident Advisor}

Event descriptions from different clubs in Berlin:

- 2011, September 24: Klubnacht - Semantica Nacht at Berghain/Panorama Bar, https://www.residentadvisor.net/event.aspx?260598\&comments=1

- 2012, January 20: Diynamic Nacht at Watergate, https://www.residentadvisor.net/event.aspx?320517

- 2012, April 20: Frühlingsfest der Tanzrealitaet at Ritter Butzke, https://www.residentadvisor.net/event.aspx?358451

- 2012, July 20: Leisure System. 16 \& Panoramabar at Berghain/Panoramabar, https://www.residentadvisor.net/event.aspx?366779

- 2013, April 12: Deep Fried \#16 with Anthony 'Shake' Shakir Rndm, Barbara Preisinger, Wittes at ://about blank, https://www.residentadvisor.net/event.aspx?462857

- 2013, July 19: Tresor meets Time To Express and Beachcoma at Tresor, https://www.residentadvisor.net/event.aspx?493896

- 2013, November 22: Dystopian with Recondite Live, Kobosil, Rødhåd, Alex.Do at Arena Club, https://www.residentadvisor.net/event.aspx?527858 
- 2014, April 11: We Start To Say Goodbye Festival, u.e. Noze, Emerson, Empro at Magdalena, https://www.residentadvisor.net/event.aspx?575119

- 2014, August 29: David Morales’ Reminder at Prince Charles, https://www.residentadvisor.net/event.aspx?618606

- 2015, June 20: Seven Years of Killekill at Suicide Circus, https://www.residentadvisor.net/event.aspx?709810

Event reviews from London:

- Szatan, G. (2016, July 8). Beyond The Wizards Sleeve in London. Retrieved from https://www.residentadvisor.net/reviews/19488

- Jaward, I. (2016, June 24). Lone live in London. Retrieved from https://www.residentadvisor.net/reviews/19394

- Titmus, S. (2015, December 9). Dekmantel x The Hydra in London. Retrieved from https://www.residentadvisor.net/reviews/18287

- Hulyer, J. (2015, November 19). Floating Points live in London. Retrieved from https://www.residentadvisor.net/reviews/18173?comments=2

- Gamp, J. (2015, November 4). Squarepusher Live in London. Retrieved from https://www.residentadvisor.net/reviews/18034

- Nicholas, T. (2015, November 2). Jeff Mills in London. Retrieved from https://www.residentadvisor.net/reviews/18032

- Hulyer, J. (2015, October 9). Levon Vincent in London. Retrieved from https://www.residentadvisor.net/reviews/17943

- Titmus, S. (2015, July 31). Bicep and Space Dimension Controller in London. retrieved from https://www.residentadvisor.net/reviews/17631

- Spyrou, A. (2015, July 6). Surgeon and Jo Johnson in London. Retrieved from https://www.residentadvisor.net/reviews/17394

- Stannard, J. (2015, July 27). Terry Riley in London. Retrieved from https://www.residentadvisor.net/reviews/17525

Album reviews with at least 40 comments by users

- Unicomb, M. (2016, July 8). Object - Kern Vol. 3. Retrieved from https://www.residentadvisor.net/reviews/19347 
- Ryce, A. (2016, June 2). Autechre - elseq 1-5. Retrieved from https://www.residentadvisor.net/reviews/19091

- Finlayson, A. (2016, April 25). Andy Stott - Too Many Voices. Retrieved from https://www.residentadvisor.net/reviews/18982

- Tantum, B. (2016, April 5). Moderat III. Retrieved from https://www.residentadvisor.net/reviews/18817

- Beta, A. (2016, March 28). Various - Selectors 001: Motor City Drum Ensemble. Retrieved from https://www.residentadvisor.net/reviews/18853

- Ryce, A. (2016, February 18). Skee Mask - Shred. Retrieved from https://www.residentadvisor.net/reviews/18584

- Unicomb, M. (2016, January 11). Baby Ford - fabric 85. Retrieved from https://www.residentadvisor.net/reviews/18397

- Lynch, W. (2015, December 17). Richie Hawtin - From My Mind To Yours. Retrieved from https://www.residentadvisor.net/reviews/18329

- Kakaire, C. (2015, November 10). Floating Points - Elaenia. Retrieved from https://www.residentadvisor.net/reviews/18108

- Finlayson. A. (2015, October 27). Jeff Mills - Exhibitionist 2. Retrieved from https://www.residentadvisor.net/reviews/18029

\section{- Vintage Synth Explorer}

Articles on synthesisers and their comments (author and date are not signed on the website):

- Roland TB-303 bass line: http://www.vintagesynth.com/roland/303.php

- Roland Juno 60: http://www.vintagesynth.com/roland/juno60.php

- Moog Minimoog: http://www.vintagesynth.com/moog/moog.php

- Korg MS-20: http://www.vintagesynth.com/korg/ms20.php

- Yamaha DX7: http://www.vintagesynth.com/yamaha/dx7.php

- Roland TR-808: Rythm Composer: http://www.vintagesynth.com/roland/808.php

- E-mu Emax: http://www.vintagesynth.com/emu/emax.php

- Novation Bass Station: http://www.vintagesynth.com/novation/nov_bsk.php

- Akai S1000: http://www.vintagesynth.com/akai/s1000.php 
- Kawai K1: http://www.vintagesynth.com/kawai/kawaik1.php

3) Facebook Groups (screenshots attached in Attachment 3 [Chapter 10.3])

- TB-303 Owners Club

- all posts (31 pieces) and their 87 comments from 1-30 April, 2016: https://www.facebook.com/groups/tb303ownersclub/

\section{- ITALO DISCO MANIACS}

- all posts (120 pieces) and their 259 comments from 1-30 June, 2016 https://www.facebook.com/groups/1577180732528869/?fref $=$ nf

\section{Blogs}

\section{- Matrixsynth}

- General analysis of http://www.matrixsynth.com

\section{- Teshno}

- General analysis of http://www.teshno.com

\section{- LWE: Little White Earbuds}

- General analysis of http://www.littlewhiteearbuds.com 


\section{ATTACHMENTS}

10.1 Attachment 1: Used coding categories of the analysis - a general table

\begin{tabular}{|c|c|c|c|c|c|}
\hline \multirow[t]{10}{*}{ Language domains } & Phenomena type & Subcategories & Sub-subcategories & Codes/Criteria & Results/Numbers \\
\hline & \multirow{6}{*}{ Special lexis } & \multirow{3}{*}{ special adjectives related to: } & $\mathrm{X}$ & & \\
\hline & & & $\mathrm{Y}$ & & \\
\hline & & & $\mathrm{Z}$ & & \\
\hline & & & $\mathrm{x}$ & & \\
\hline & & $\mathrm{x}$ & $\mathrm{Y}$ & & \\
\hline & & & $\mathrm{Z}$ & & \\
\hline & & related to $\mathrm{X}$ & - & & \\
\hline & Technical terms & related to $Y$ & - & & \\
\hline & & related to $\mathrm{Z}$ & - & & \\
\hline \multirow{10}{*}{ Structure and meaning } & Snecific community reference & related to $\mathrm{X}$ & - & & \\
\hline & $\begin{array}{l}\text { specific community reference } \\
\text { words }\end{array}$ & related to $\mathrm{Y}$ & - & & \\
\hline & & related to $Z$ & - & & \\
\hline & Personal pronouns & I, we, they & - & & \\
\hline & & emoticons & & & \\
\hline & & memes & & & \\
\hline & & GIFs & & & \\
\hline & Compensatory strategies & pictures & & & \\
\hline & & videos & & & \\
\hline & & other functions of the website & & & \\
\hline \multirow{7}{*}{$\begin{array}{l}\text { Interactional } \\
\text { management }\end{array}$} & \multirow{4}{*}{ Concern structures } & linking & hyperlink & & \\
\hline & & & sharing & & \\
\hline & & guoting & other users & & \\
\hline & & & someone else & & \\
\hline & \multirow{3}{*}{ Participation } & number of messages per group member & & & \\
\hline & & narticination tynes & through roles & & \\
\hline & & participation types & through activity & & \\
\hline \multirow{14}{*}{ Social phenomena } & \multirow{11}{*}{$\begin{array}{l}\text { Interpersonal discourse } \\
\text { behaviours }\end{array}$} & agree/disagree & & & \\
\hline & & counterpoint & & & \\
\hline & & acknowledge & & & \\
\hline & & invite/give feedback & & & \\
\hline & & thanking & & & \\
\hline & & sympathise & & & \\
\hline & & joking & & & \\
\hline & & delegate & & & \\
\hline & & negotiate conflict & & & \\
\hline & & ask for infomation & & & \\
\hline & & offering advice & & & \\
\hline & \multirow{3}{*}{ information exchanges } & provide knowledge & & & \\
\hline & & share biographical information & & & \\
\hline & & express ideas and opinions & & & \\
\hline
\end{tabular}

10.2 Attachment 2: Orientation of linguistic data in WATMMF

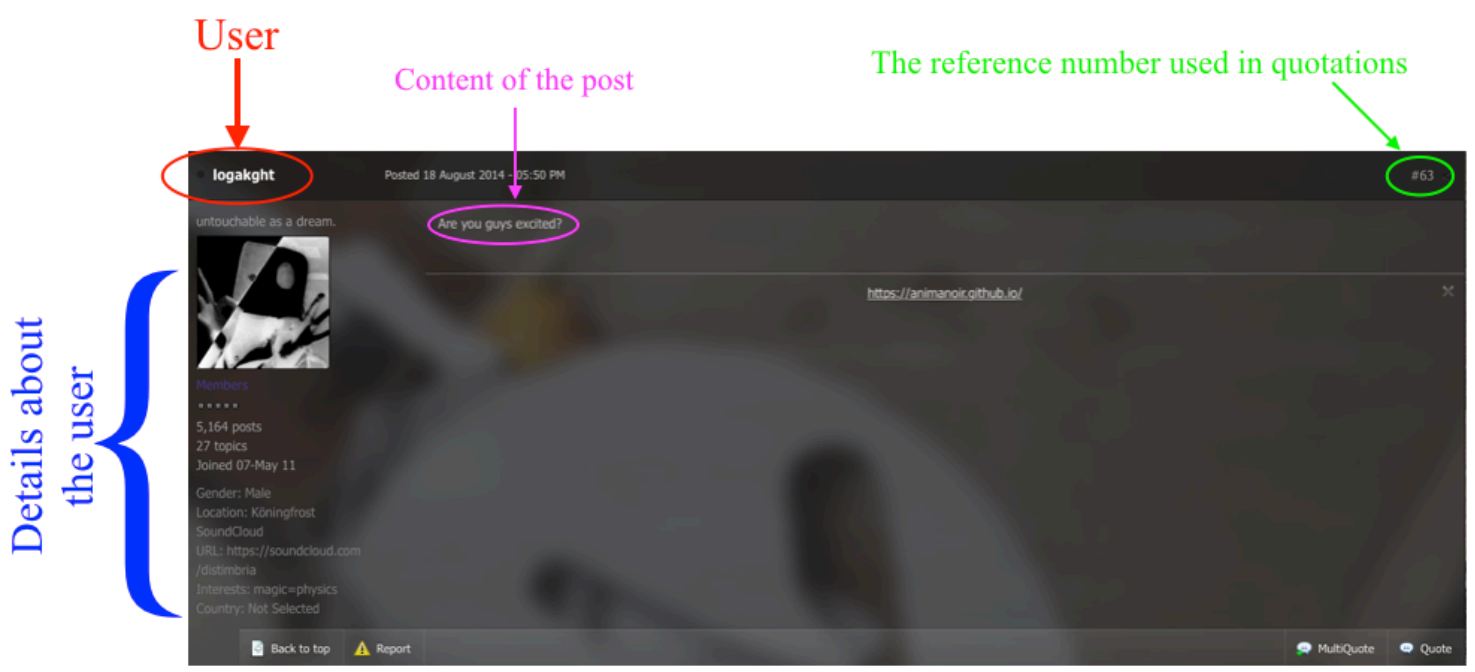


10.3 Attachment 3: Linguistic data of Facebook Groups

\subsubsection{TB-303 Owners Club}

1a)

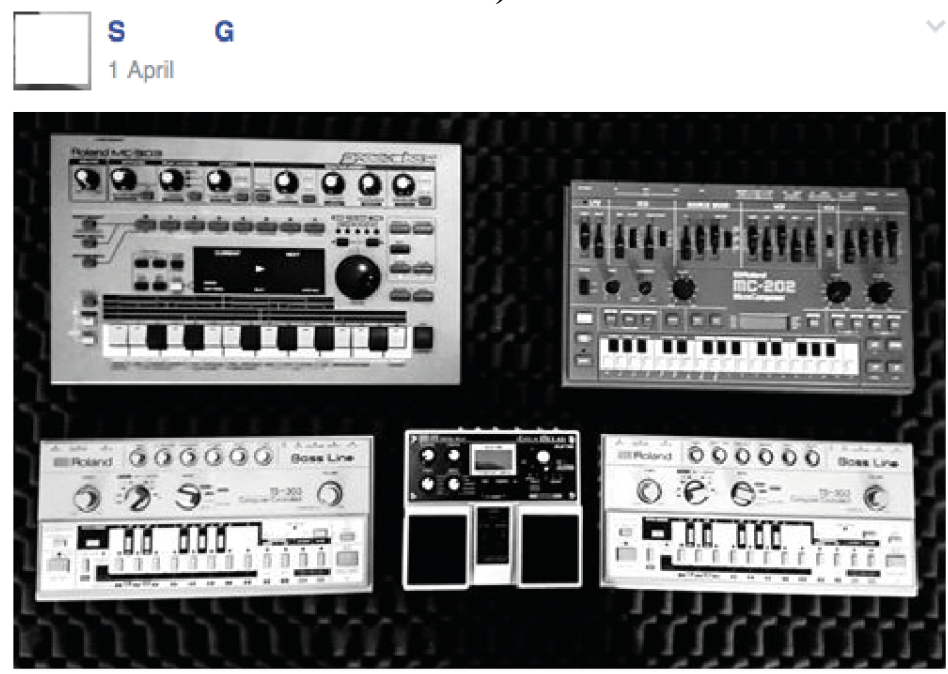

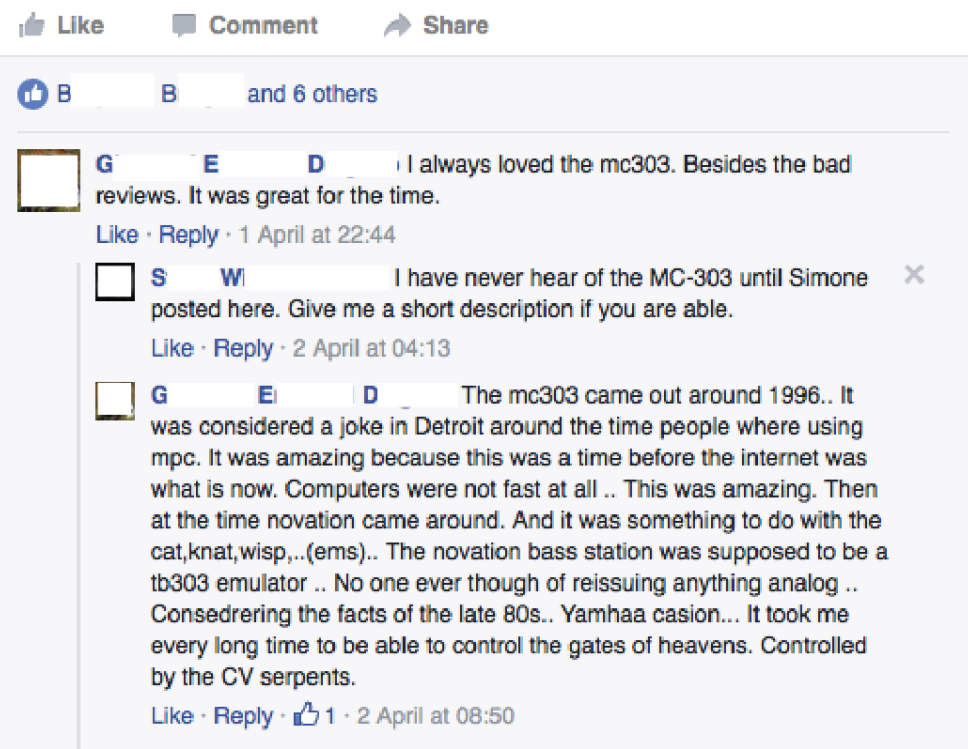

1b)

[ S G simple to use, l use it also as a sequencer to control tb303 or mc202 with kenton pro solo.but the best groovebox always have the mc808 \& mc909 (:)

Like - Reply + 2 April at 16:20 
2)

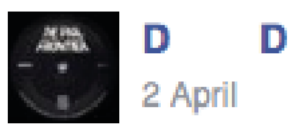

\section{Any tt303 owners know how to access tb303 style programming mode?}

\begin{tabular}{|c|c|c|}
\hline Like & Comment & $\Rightarrow$ Share \\
\hline & RTFM - & 14 of the manual \\
\hline
\end{tabular}

3)

$\left[\begin{array}{l}\text { R } \\ 5 \text { April }\end{array}\right.$

C J

As the acid house sound is making a huge comeback worldwide this tune falls nothing short of what its set out to do. The grimy acid bass line finds its way deep in the mix as the pulsating hi-hats and cymbals help build the tune to its peak. Its at this point when you cant help but notice the crafty percussion which really makes the groove shine. A true representative of what the acid house sound is all about.

Poor Boy Rich brings life to his Class Warfare EP. Driving kick drum and fantastic tones set the beginning of this track off with a tone of whats to come. Through the production quality all the way through the sweeping builds you cant help to hear that underlying acid line take shape. As this evolving song finds its peak you you get submerged into its deep and late night vibes that create somewhat of a motion thats fluid and full.

\section{Traxsource}

M.TAMAXSOURCE.COM

It Like $\quad$ Comment $\Rightarrow$ Share

4)

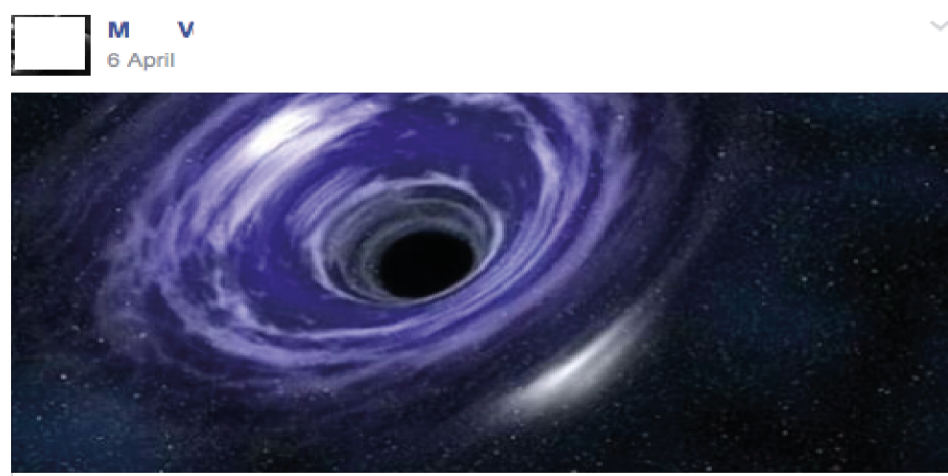

Wormhole 128kbs \#Preview

Live recorded acid techno track. Enjoy!

SOUNDCLOUD.COM I BY HCLOA

IIt Like $\quad \square$ comment $\rightarrow$ Share

(1) 3 
Hello. My name is Steve and I work at Foland. Unfortunately, we have to recall the "Transistor Bass" 303 for safety issues. Please send them all to my house while I fix them for you. I do not know how long it will take, but we at Foland take your safety very seriously. It may take a while.

It) Like $\quad \square$ Comment Share

(1) 12

E J Ooh....this sounds serious. Should I send my Jupiter 8 as well just so can make sure it is ok?

Like - Reply - 131 - 9 April at 01:13 - Edited

79 S W I will, erm... I mean we at foland expect to have our hands full for quite some time, however if you truly feel your unit to be faulty, and that it may catch fire at any time, then by all means send in that Jupiter $\mathbf{8}$. Next day priority shipping! Like - Reply - 9 April at 01:34 - Edited

(2) Write a reply...

J I'm glad I kept most of my original boxes...packing these now to get them to you safely.

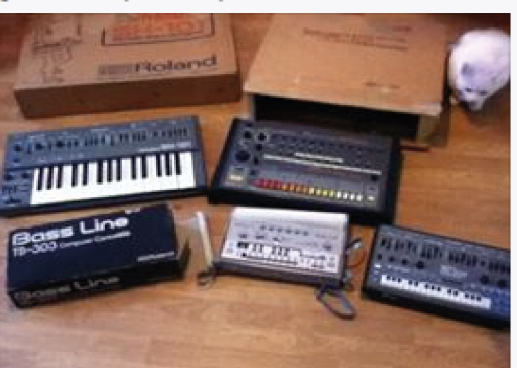

Like - Reply - 33 - 9 April at 01:23 
5b)

S W Best to send them all in. Those cardboard boxes are now hazardous as well because they have been drying out for $30+$ years.

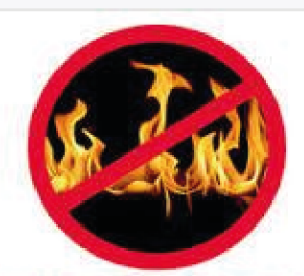

\section{REMOVE THE FIRE HAZARD}

Like - Reply - 9 April at 01:25 - Edited
Fif $M A$
W hey! It's my cat

Like - Reply - 9 April at 02:32

Q W W Do not. I repeat, do NOT send the cat. Like - Reply + 9 April at 05:09

[] E J Tabby-303

Like - Reply + 9 April at 05:12

- M T and on the pictures it's my $303 ; 808,101,202$

Like - Reply - $131 \cdot 9$ April at $16: 11$

A. Write a reply.

G E D Hahahahah

Like - Reply - 9 April at $01: 28$

$\square$ S W This is no laughing matterl Now tell all of your friends and remember "UPS Next Day Air" Like - Reply + 9 April at 01:30

- G E D Hahaha no. I have them all. And any

m reminders I will send my from army for them. Like - Reply - 9 April at 01:33

6)

G

11 April

New 303 rec

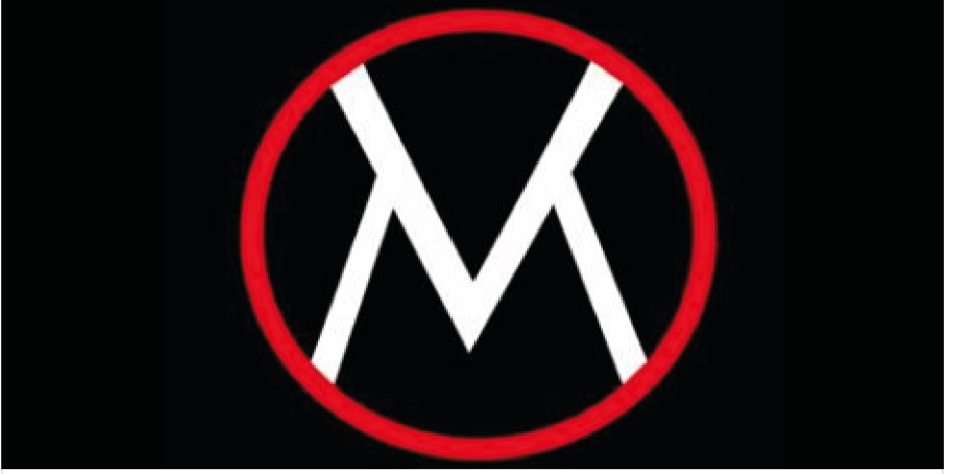

Radio Alert 2 (EDIT 1)

Hardware Techno Experience

SOUNDCLOUD.COM || BY VAZ-MAS

If Like $\quad$ Comment Share 
G E D

11 April

Anyone know where I can download those sheets to write your notes in.

If Like $\quad \rightarrow$ Comment Share

(B) 1

M C S http:/Www.dinsync.info/2010/07/tb-303-pattern-

sheet.hitml

Din Sync: TB-303 Pattern Sheet

A blog relating to vintage analog Roland " $x 0 x$ " musical

instruments. Primarily focusing on the $\mathrm{SH}-101, \ldots$

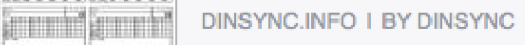

Like - Reply + 35 - 11 April at 17:18

S W Along the same lines, does anybody make those

plastic coverings to protect the paint around the knobs any longer?

Like - Reply - 11 April at 18:16

M T I have a files..

Like - Reply - 11 April at 19:01

W w damaged paint is street cred (P)

Like - Reply - 11 April at 19:20

Q S W W V I guess you are right. I am not planning on selling it anyways. Probably ever. Good talk! Like - Reply - 11 April at 19:41

7 G E $\quad$ D $S$ W I did see them on Ebay.

Like - Reply - 11 April at 20:52

D S W G G G I used to see them all of the time as well. Now I can not find them! Like - Reply - 11 April at 21:36 
My first release on Balkan Vinyl is a remix of Acidulant Malta track "the Acid Music" , https://balkanvinyl.bandcamp.com/. . ./the-acid-music-dylabs-gh... .

Check out the whole EP, it is some great acid.

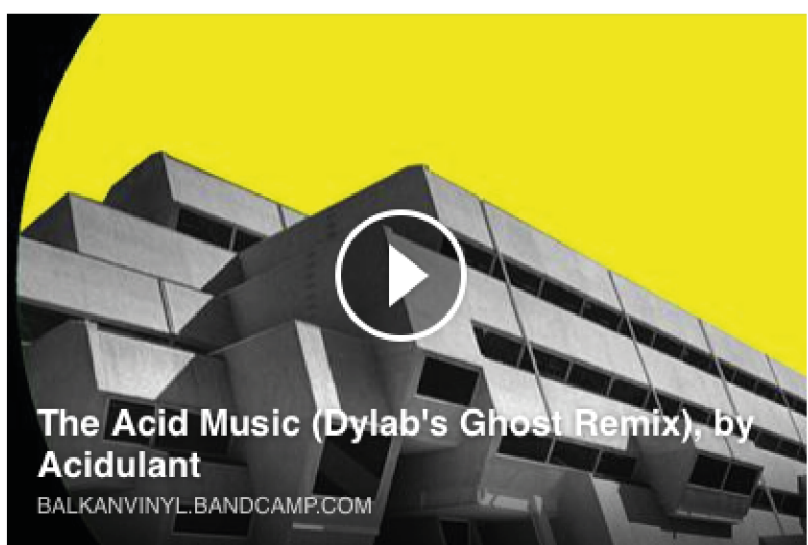

The Acid Music (Dylab's Ghost Remix), by Acidulant

from the album Doing It Right

BALIKANVINYL.BANDCAMP.COM

1. Like $\quad$ Comment $\Rightarrow$ Share
B $B$ B and 4 others

9)

$\square \begin{aligned} & M \quad V \\ & 12 \text { April }\end{aligned}$

Check out our liveset @twidl HCLO4 \#acid

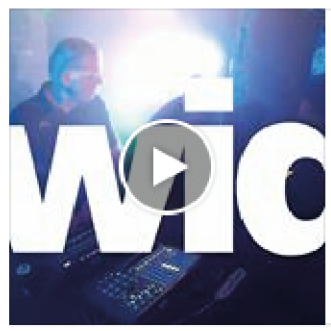

HCLO4 // Twidl Sessions // March '16// Club Innocent

HCLO4 in tha housel!! Acid, acid some more acid and more ACID! If you are a fan of the TB303 sound and are living for acid then this is yours. This is a true...

YOUTUBE.COM

If Like $\square$ comment $\Rightarrow$ Share

(C) 1 


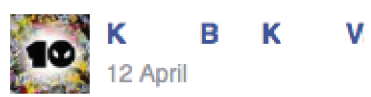

My son Eliah was born last friday at 3.03 in the afternoon...acid baby

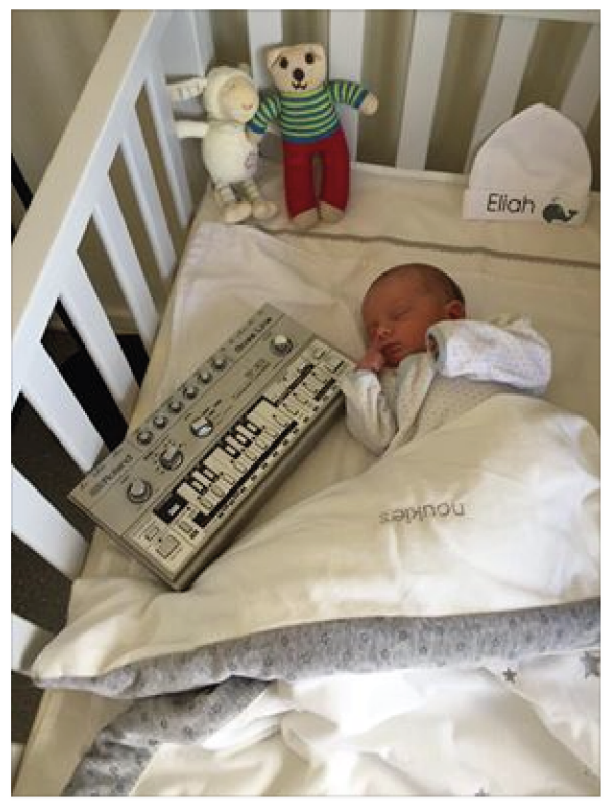

It Like $\quad$ Comment $\Rightarrow$ Share

(1) B B and 91 others

2. $\mathrm{T} \quad \mathrm{N}$ bravo

93. See translation

Like - Reply - 1 1 - 12 April at 13:17

(10. $K$ B $K \quad V$ thanks mate

Like · Reply · 13 1 12 April at 13:25

d. Write a reply...

이 ()

6) E F Congratulations

A Like - Reply - B 1 - 12 April at 13:19

10. $\mathrm{K}$ B $\mathrm{K} \quad \mathrm{V}$ thanks!

Like · Reply - 12 April at 13:25 
10b)

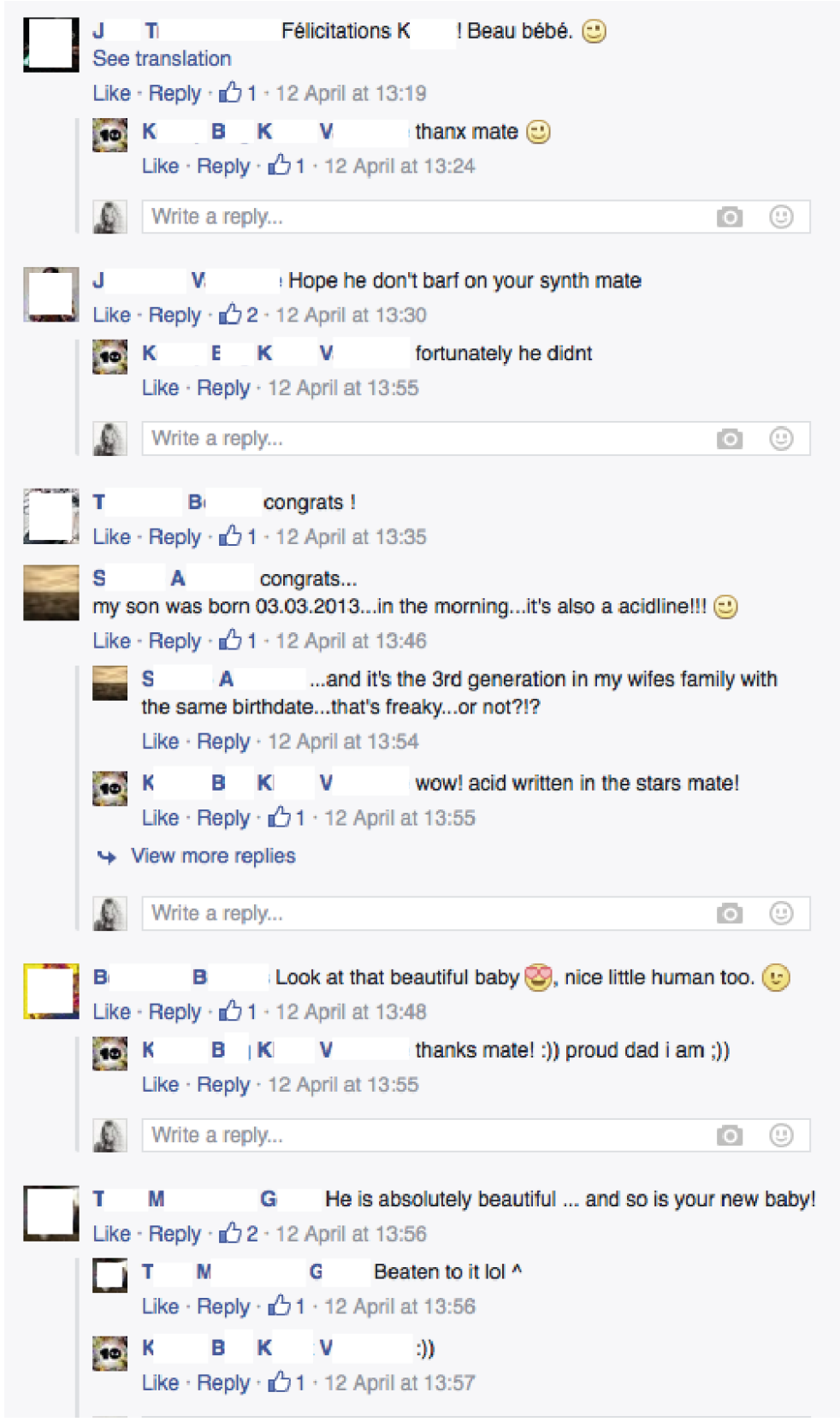


10c)

M V Concratulations

Like - Reply · 132 - 12 April at 14:03

S S Congrats matel We had the 303 playing to our baby girl while she was in the womb and then tight after she was born too... Sounds like stomach sounds to them! (9)

Beautiful boy!

Like - Reply · 13 - 12 April at 14:47

(10) K B $K \quad V \quad$ thanks mate! i ll test your tip today ;))

Like - Reply + 12 April at 14:59

Write a reply...

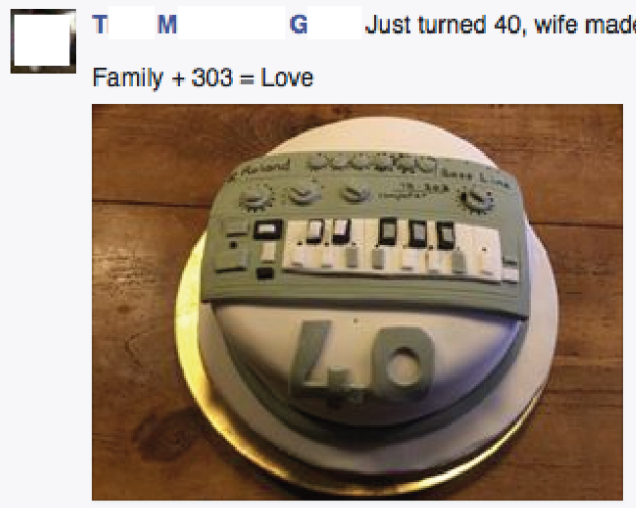

Like - Reply : 12 - 12 April at 14:50

S W Send me all of her sisters!!! Like - Reply - 13 April at 03:5?

6. Write a reply...

K B Congrats!

Like - Reply - 31 + 12 April at 17:00

Fis congrats! karma, and my girl was born in room $303 @$

hospital (:)

Like - Reply 132 - 12 April at 19:02

G R Be great if that small silver family air loom was passed on to the next generation of acid (-) peace bro

Like - Reply $\cdot 32$ - 13 April at 04:00

made...Was grave!

Like - Reply - 13 April at 04:02 
11a)

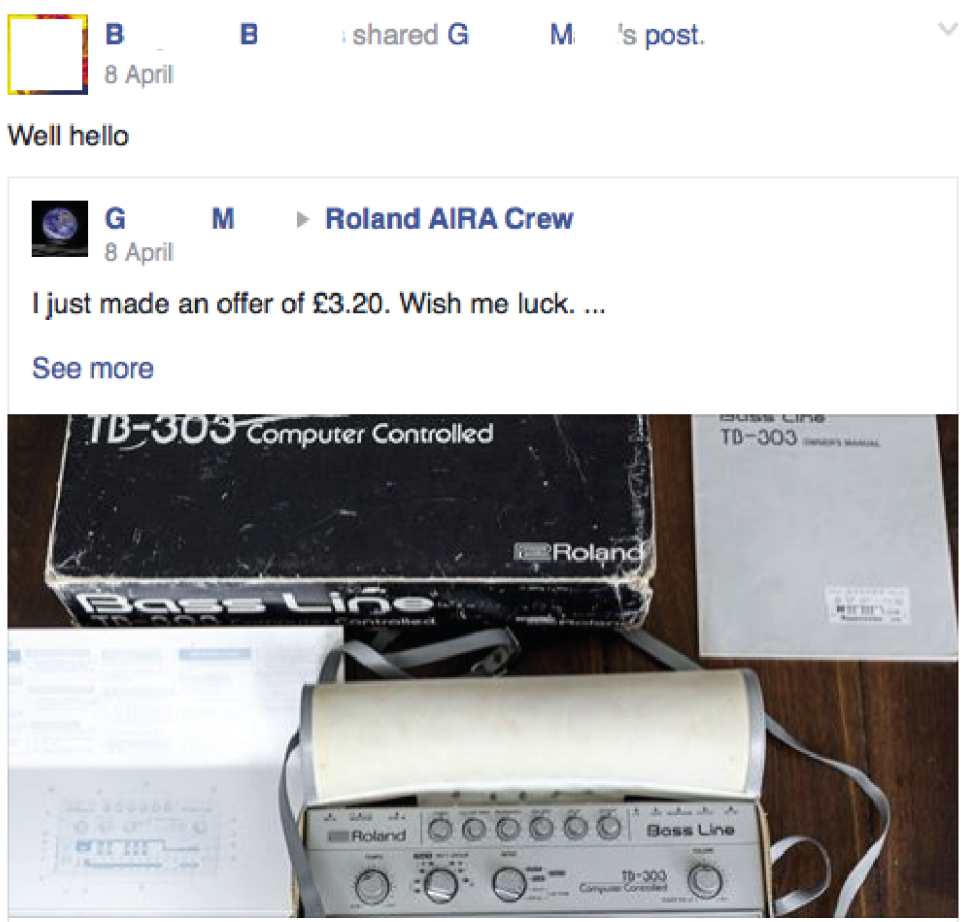

Roland TB-303 **BOXED** Mint w.orig. Manuals \&Pouch + CV input mod

Roland TB-303 **BOXED** Mint w.orig. Manuals \& Pouch + CV input mod in Musical Instruments, Pro Audio Equipment, Synthesisers \& Sound Modules I eBay

EBAYCO.UK

It Like $\quad \Rightarrow$ Comment Share

(G) 12

6. Edward Flory Listing it as 'mint' is a bit cheeky as there's paint worn off around the cut off and res knobs, they definitely didn't leave the factory like that! It does look to be in very nice condition though, don't get me wrong Like - Reply - 31 - 8 Aprill at 18:06

1. Brandon M. Rogers Also the Kenton (assuming) mod on the back. Would probably get more if he swapped in a stock one Like - Reply - 8 April at 18:10

1. Edward Flory Yep. The buy it now seems quite hopeful. I wonder what the most a stock (or near-stock) one has gone for Like - Reply - 8 April at 18:21 
11b)

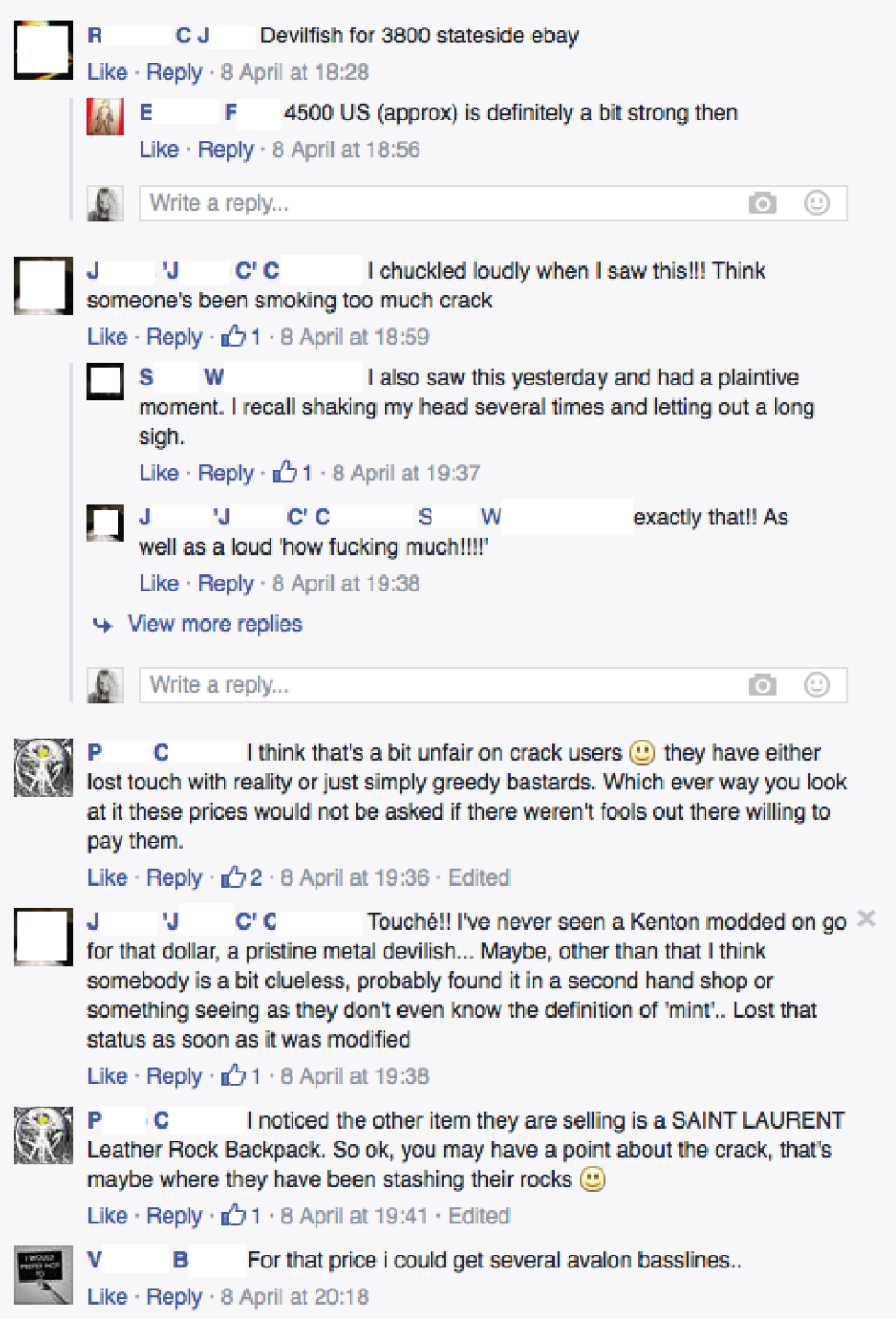

\section{1c)}

G A Never seen this mod before .... Is it really worth an extra 8 or 900 quid ffs what's going on out there
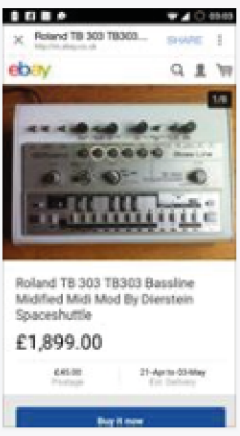

Like - Reply $131+13$ April at 04:05

a w This reminds me of the time I sewed the head of a Hippopotamus onto a Panda Bear. I regret it to this day. Like - Reply $\cdot \$ 3+13$ April at 04:09 
$\square_{13 \text { April }}$ S

TB-303 Capacitor change. Is there any routine maintenance that needs to be done on our little friends? One of my guys is robust and healthy, the other sounds like it is playing through a compressor with a high ratio and long release time. Not as strident and proud as the first. Still sounds OK, but with a lesser so signal to noise ratio on the low notes.

It. Like $\quad \Rightarrow$ Comment $\quad \rightarrow$ Share

W V Can be many other things. Higher noise levels could be failing transistor in power section for instance (q45)

Like - Reply - 13 April at 07:03

$\square$ s W Thank you

Like - Reply + 13 April at 14:38

6. Write a reply...

6ay $P$ C $\quad P$ B should know

Ulk Like - Reply + 13 April at 14:19

$\square$ s W Thanks!

Like - Reply - 31 - 13 April at 14:38

13)

-

B B

14. April

On VEMIA http://www.spheremusic.com/Bargaindtl.asp?ltem=15462

Like

Comment

Share 


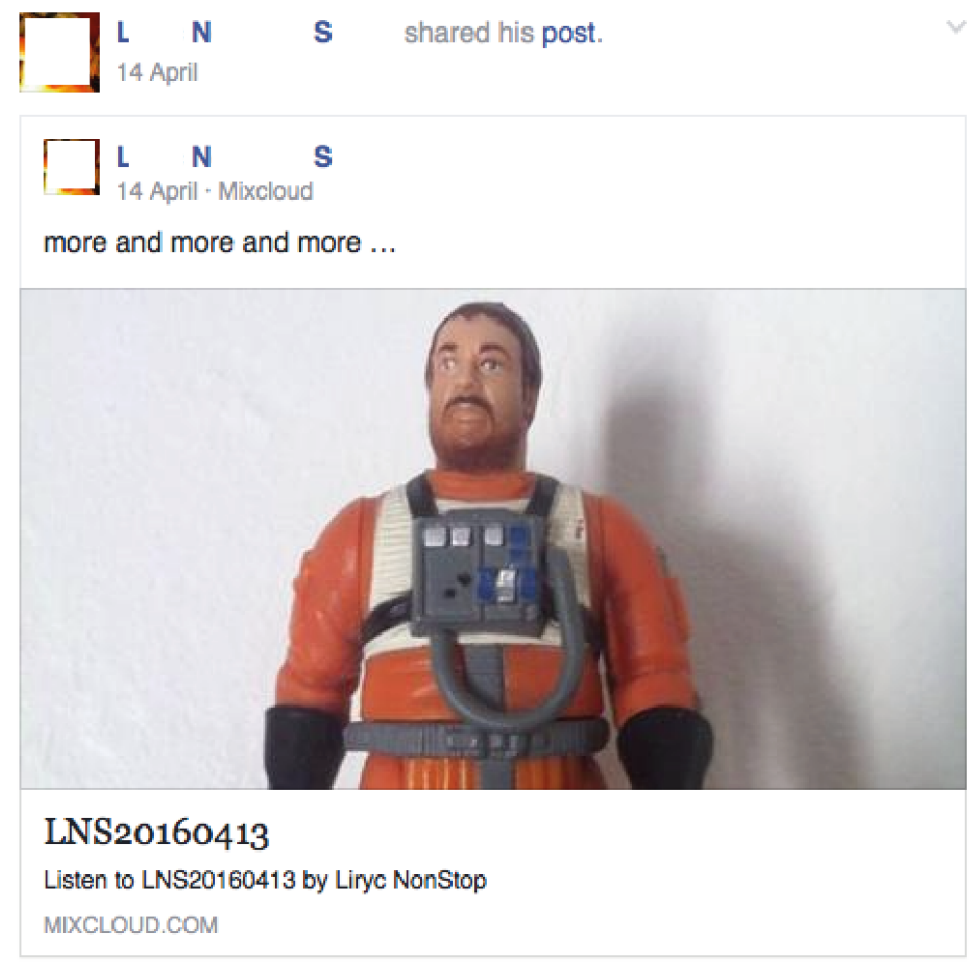

\begin{tabular}{ll} 
It Like & Comment $\rightarrow$ Share \\
\hline в & в
\end{tabular}

15)

$\left[\begin{array}{l}\text { M April } \\ \hline\end{array}\right.$

Greetings from Acid Castello

and \#AcidFilmFestival! (:)

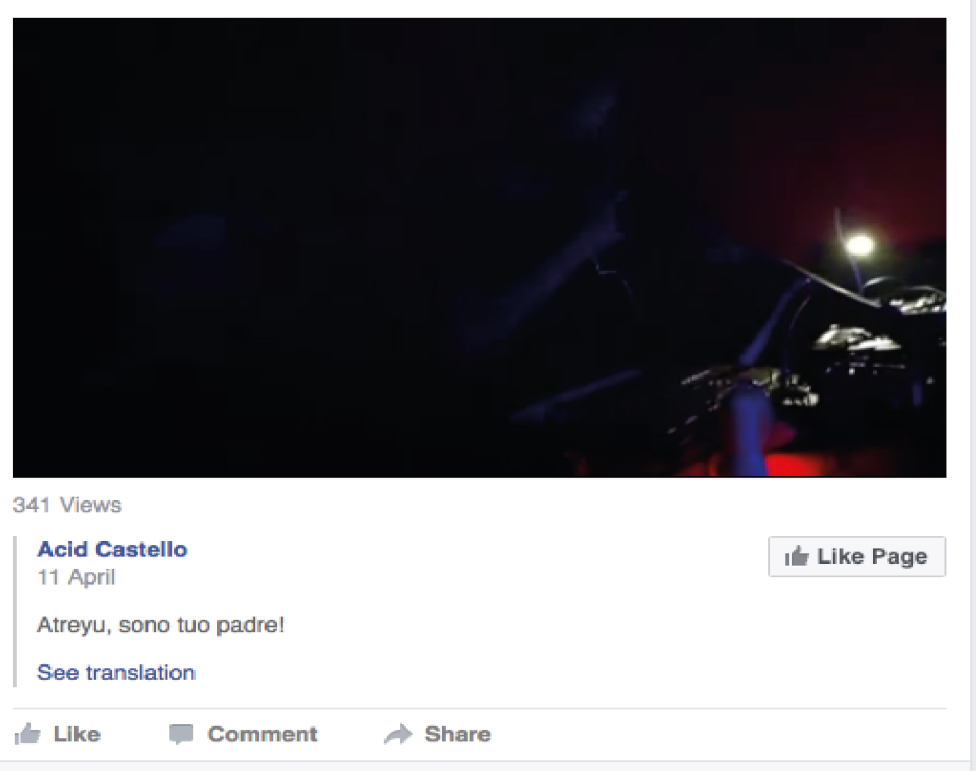




See translation
y a carrément des morceaux dont je ne me souvenais plus! :-:

17)

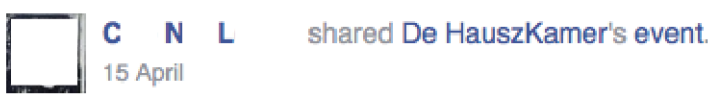

https://www.facebook.com/events/773976079399208/

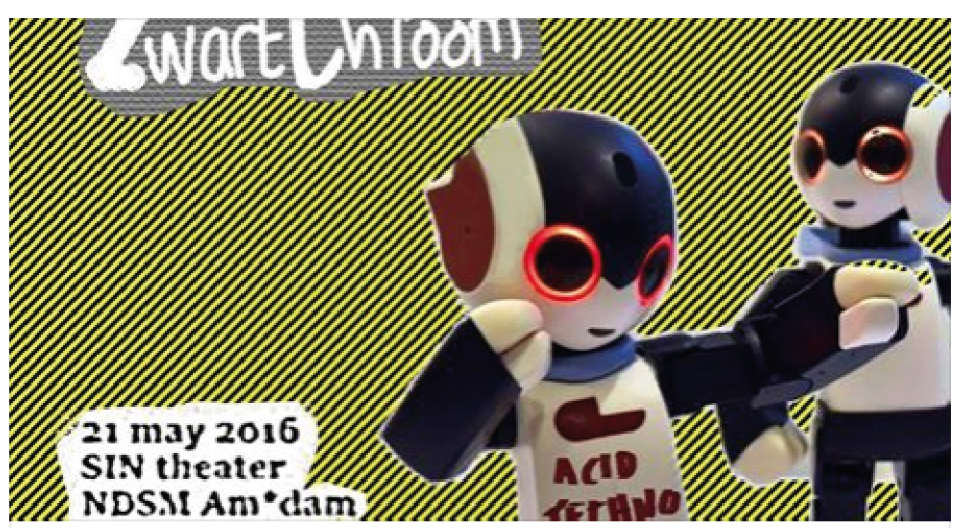

21 De Hauszkamer $\mathbf{X L}$

21 Sat 23:00 - SIN theater NDSM, adres: TT Neveri...

MAY 18 people interested . 5 people going

$\star$ Interested

It Like Comment $\Rightarrow$ Share 


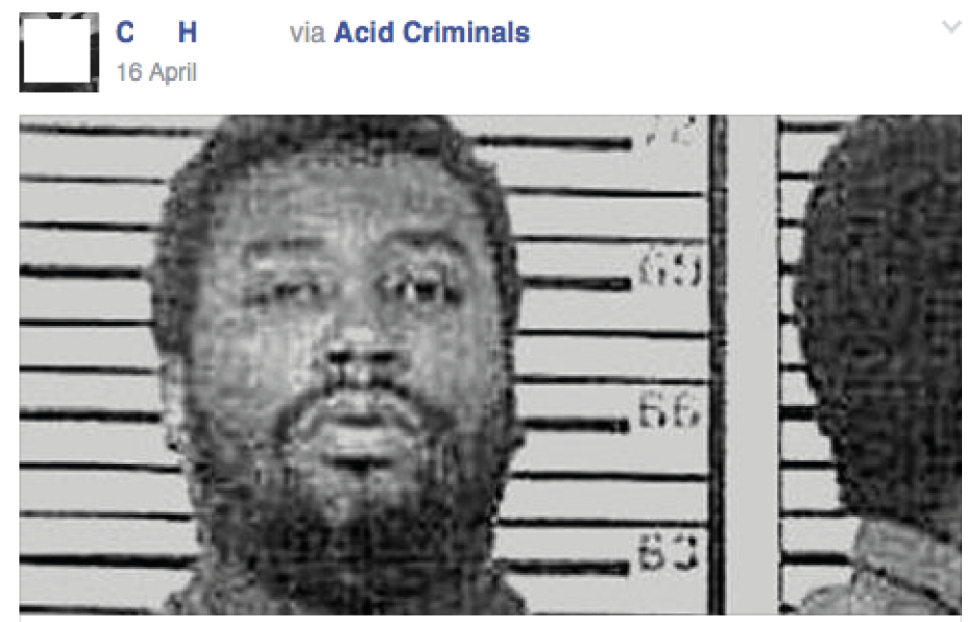

Ole Dirty Acid = Sample

Dark side, bass breaks from Acid Criminals

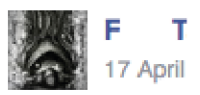

Hardware prod!

Free download

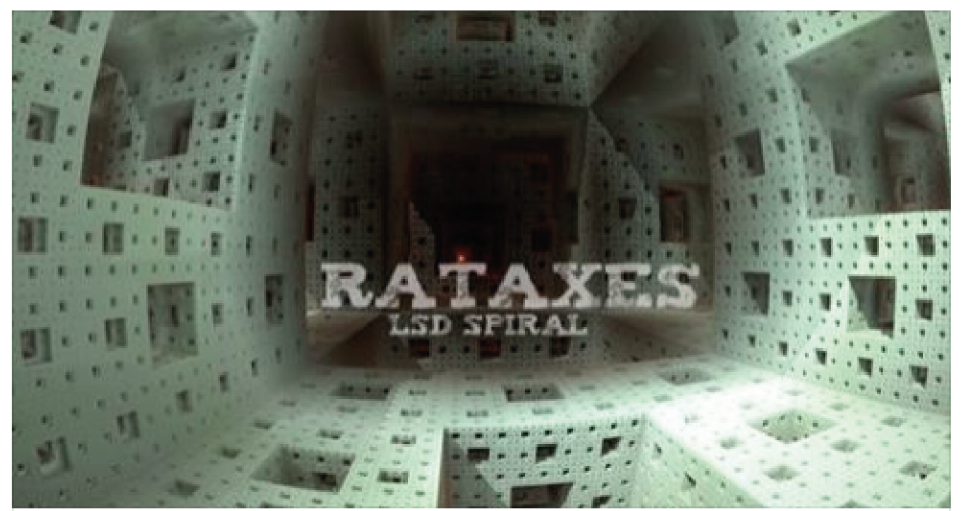

RaTaXeS - SA - lsd spiral

So $\phi$ 's memories track

SOUNDCLOUD.COM I| BY RATAXES23

It Like $\quad \Rightarrow$ comment Share 


\section{$\mathbf{J}$
18,April}

"Cassette Acids"

* Get it here - https://www.etsy.com/. . ./justin-paton-cassette-acids-albumac...

$+$

* Hear it here - https://soundcloud.com/feline... . . . ./justin-paton-cassetteacids

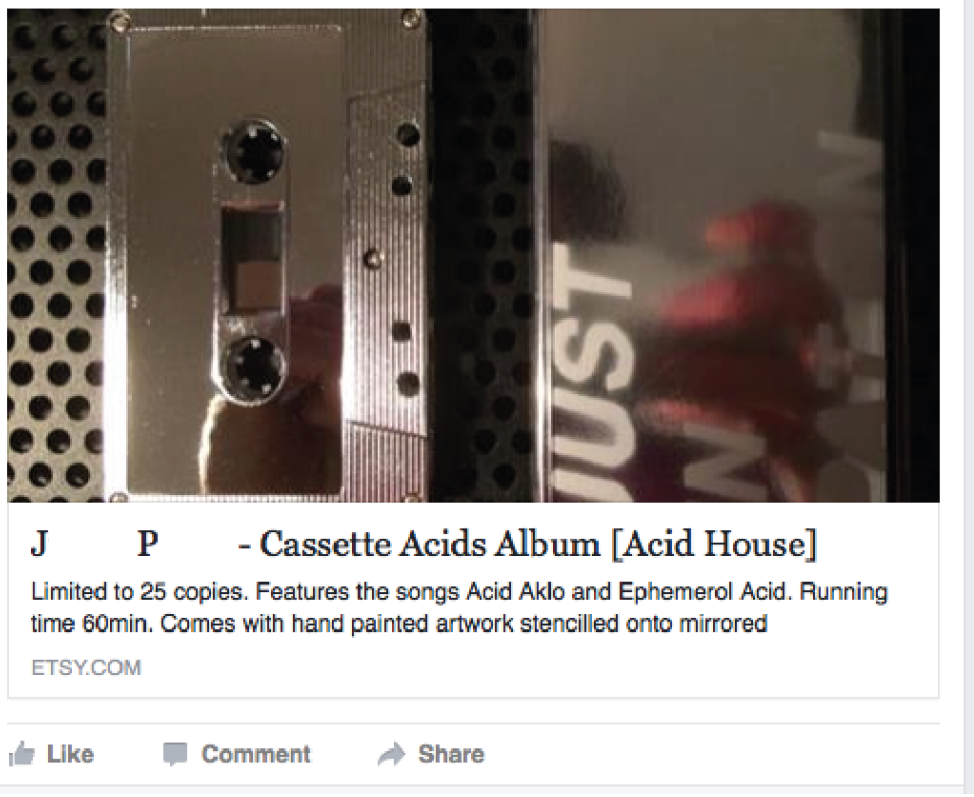




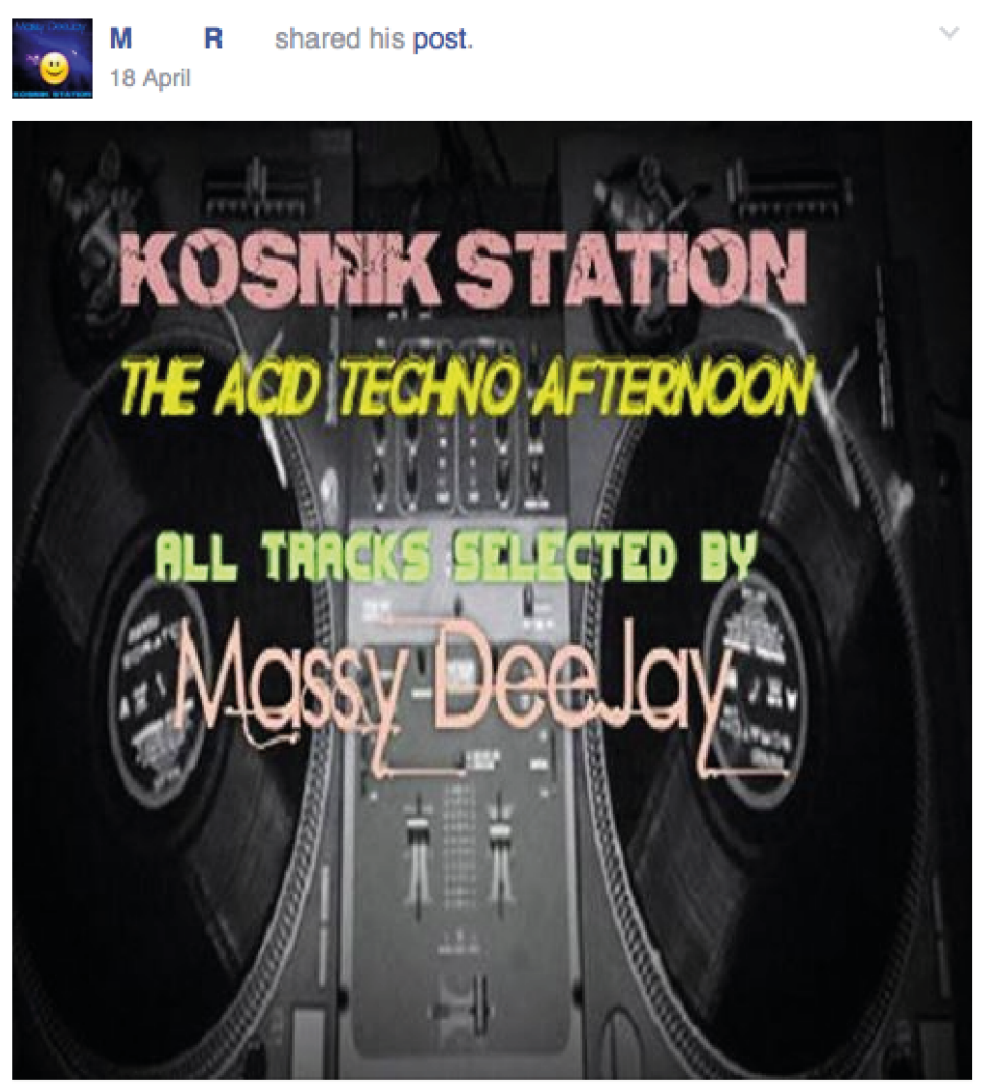
M R
18 April
NEXT UP ON KOSMIK STATION WEB RADIO
01.30 PM (Cet Time) $\gg \gg$ The ACID Techno Afternoon Back to the Oldschool, celebrating the TB-303 sound II
Tune in @ bit.ly/1...
See more
II Like Comment 
P. ${ }_{19}^{\text {April }} \quad \mathbf{R} \quad$ shared his post.

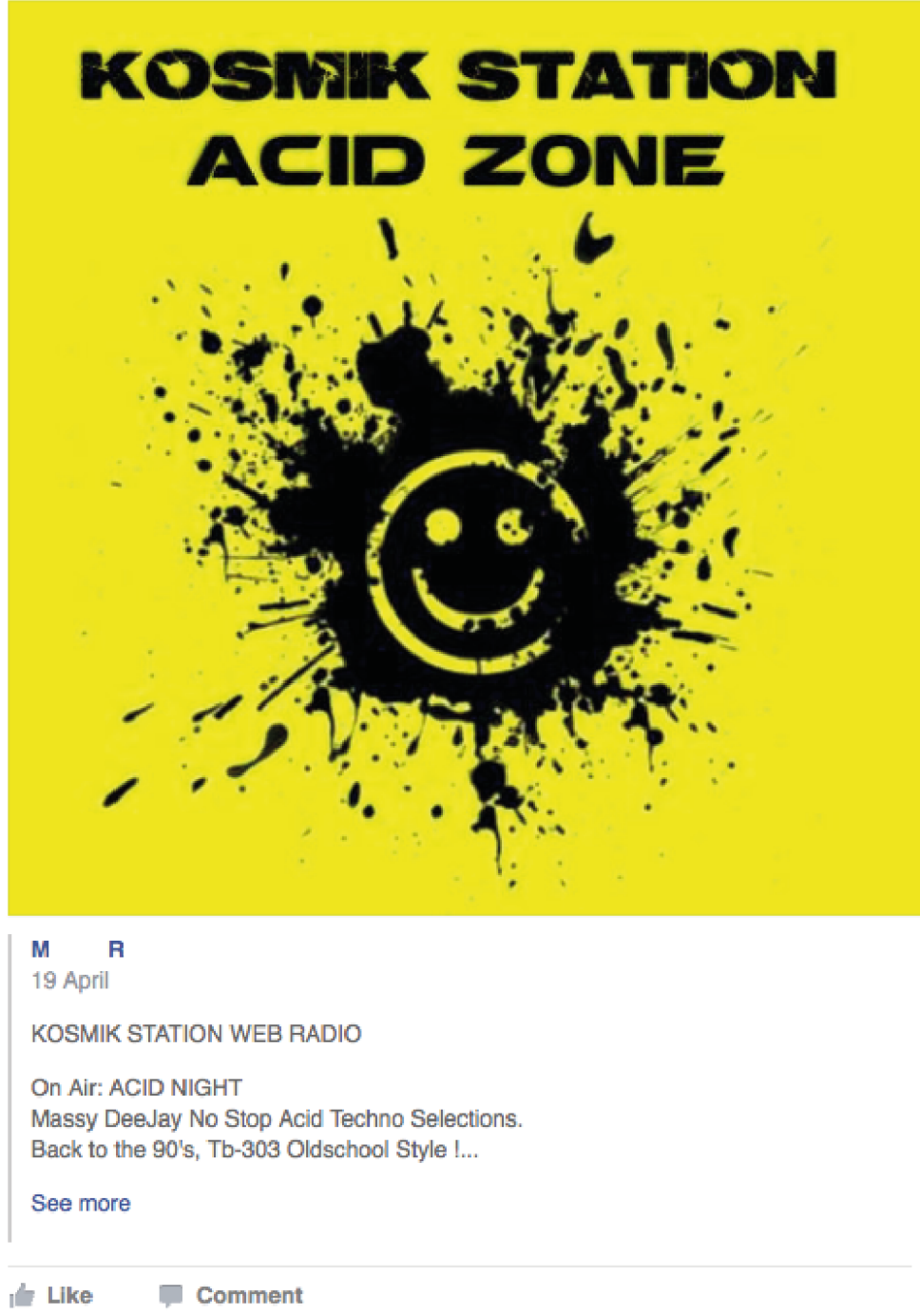


23)

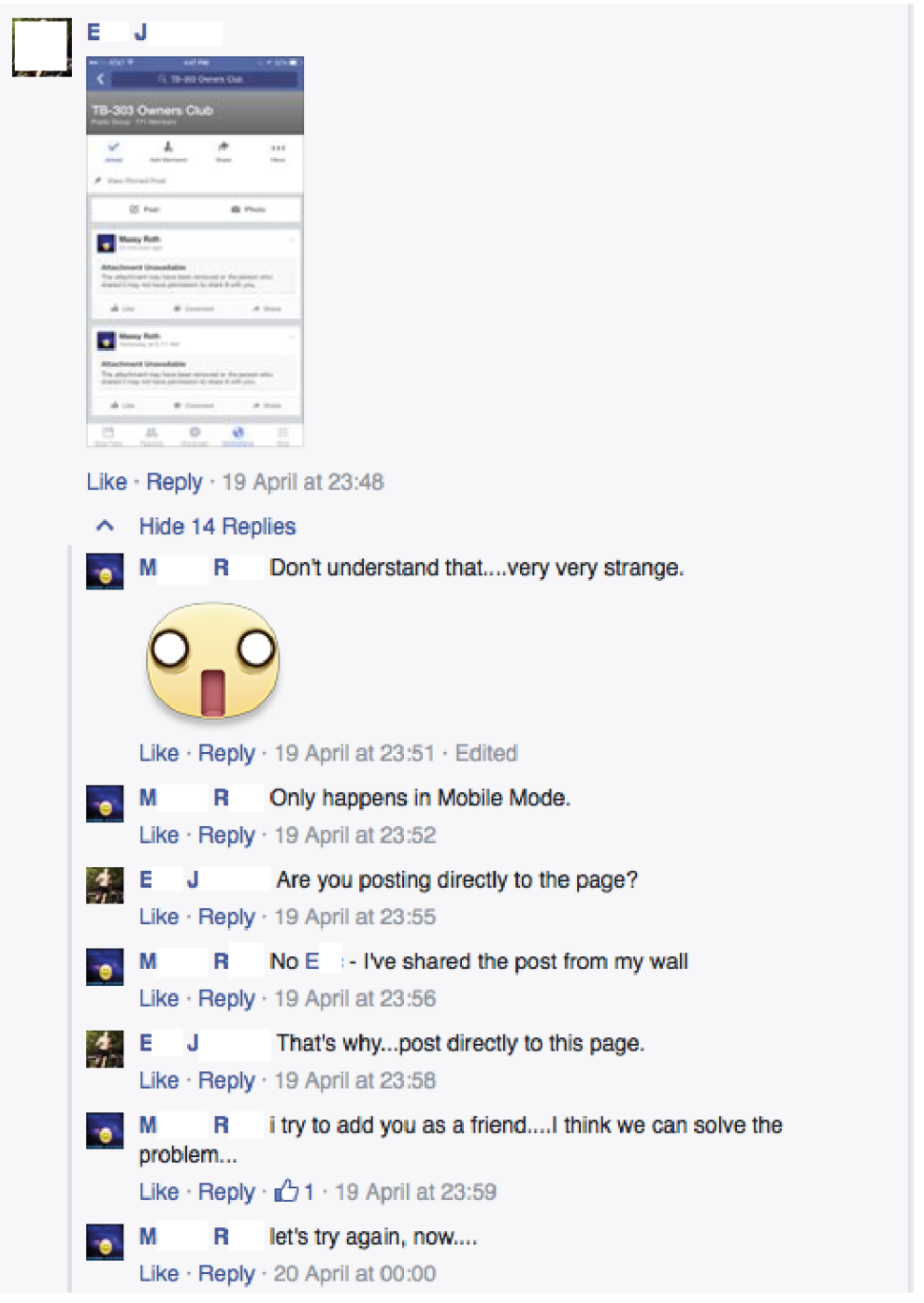

24)

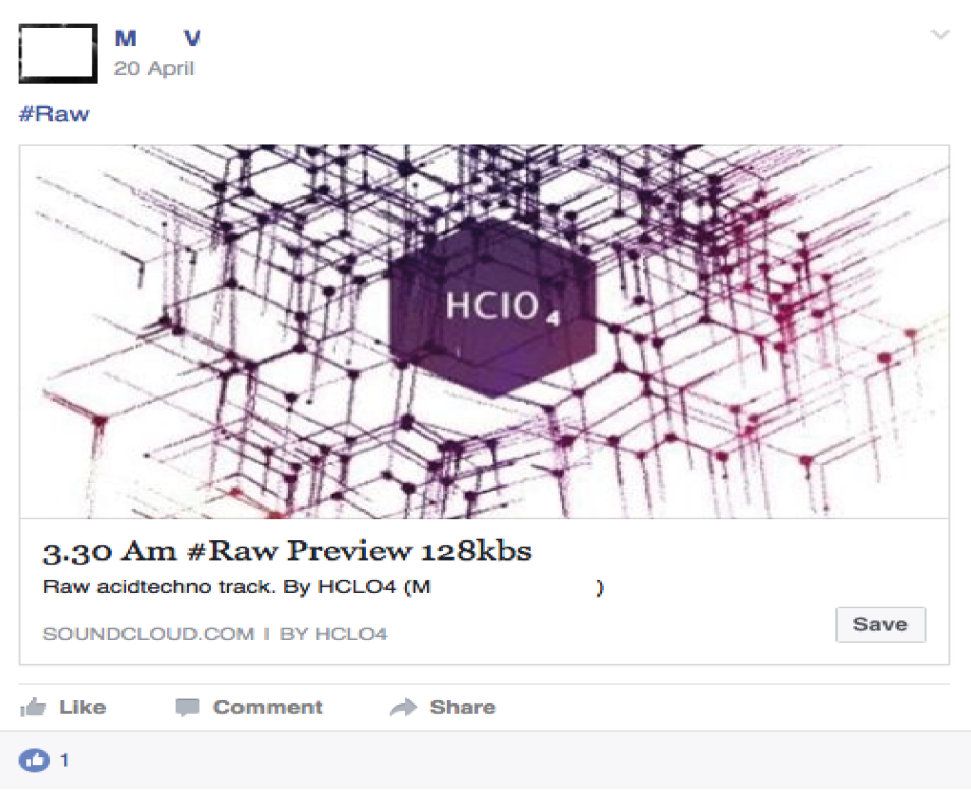




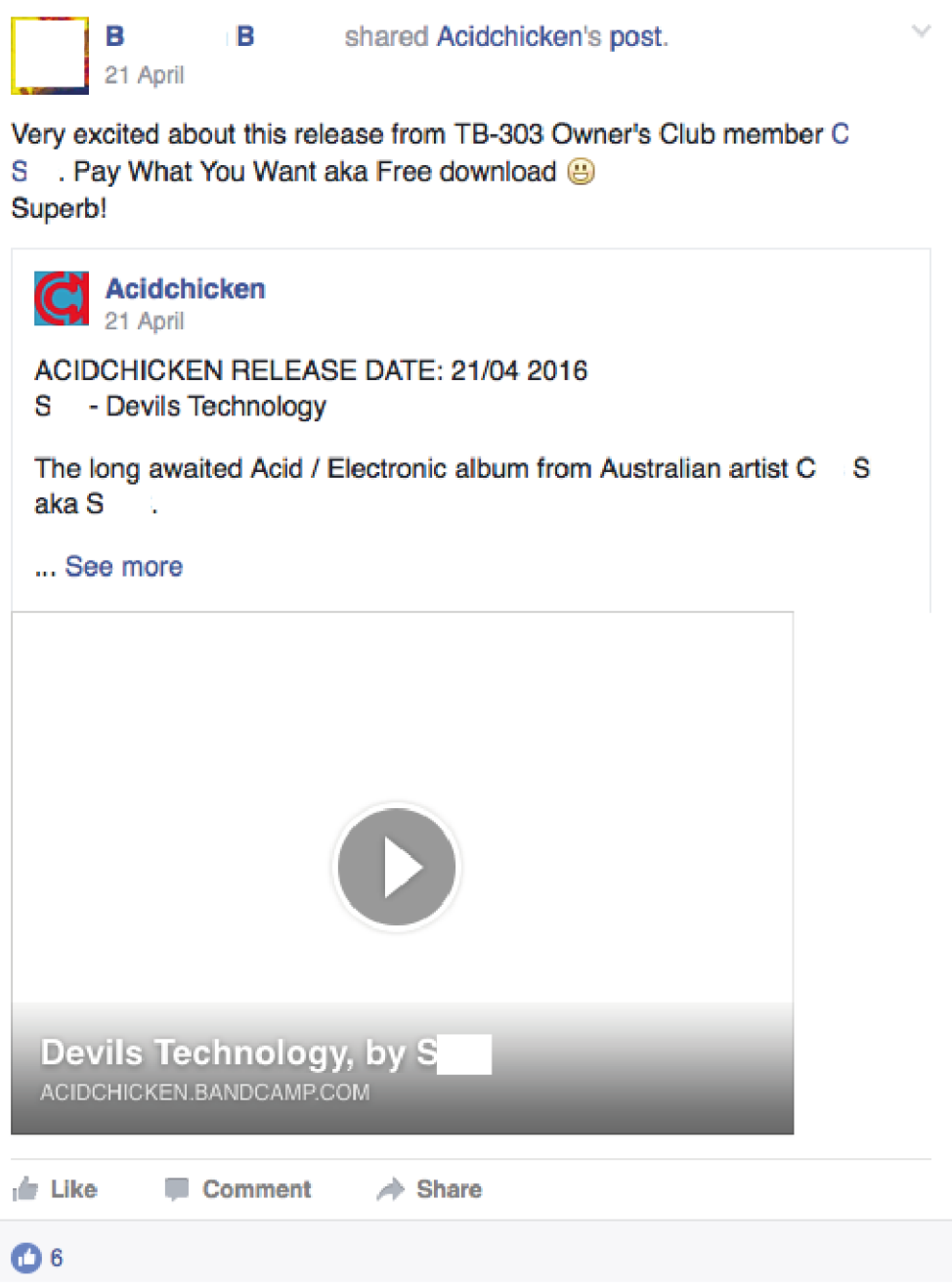




$$
\text { L. }
$$

Thanks again for the add guys! My humble live set up.

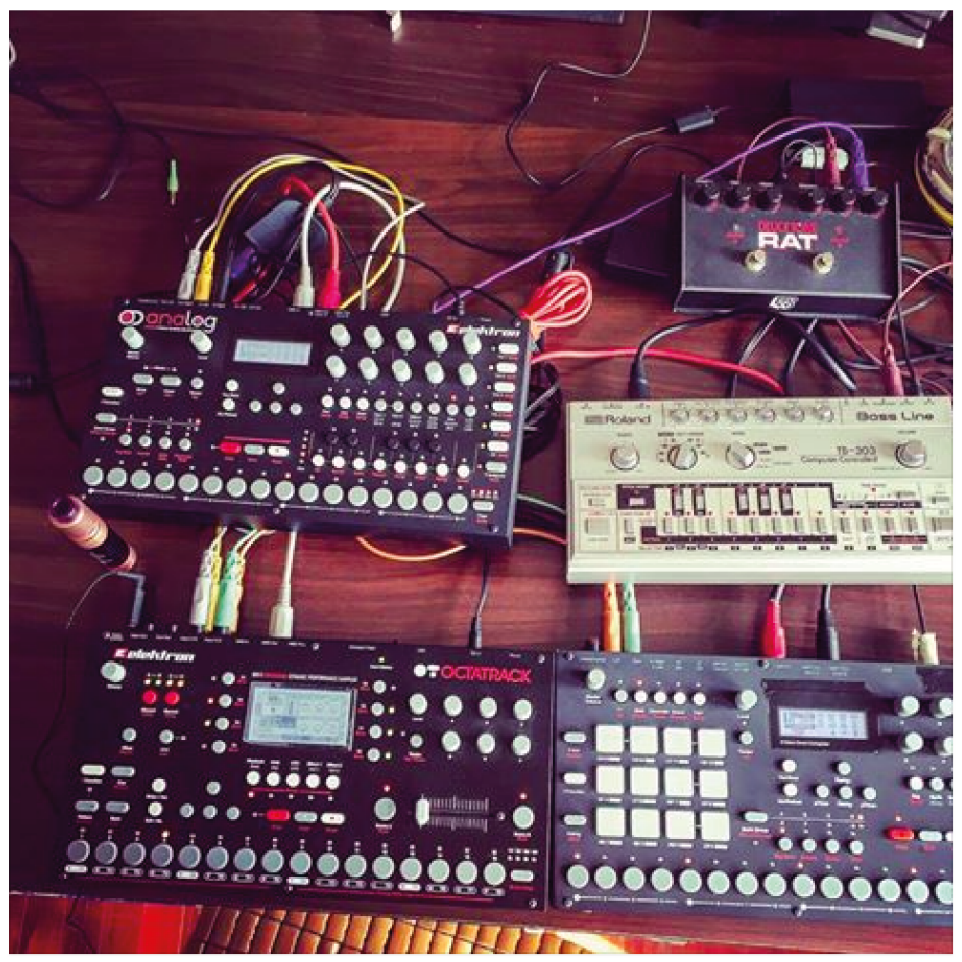

$$
\begin{aligned}
& \text { It Like } \quad \text { Comment } \quad \rightarrow \text { Share } \\
& 00 \text { в B and } 23 \text { others } \\
& \text { B K K That is all u need matel! Its briliant!! }
\end{aligned}
$$

A $\mathrm{A}$ the deucetone rat rocks but only the first edition...I have a rat with ruetz mod I love it

26b)

[.] R I I I like to get the beast pedal instead but this is
very useful for $2 \times 303$ s or a 303 and a BD Like - Reply - $31 \cdot 21$ April at 14:15

Write a reply...

J K Lovin it.

Like - Reply - 1 1 - 21 April at 22:17 


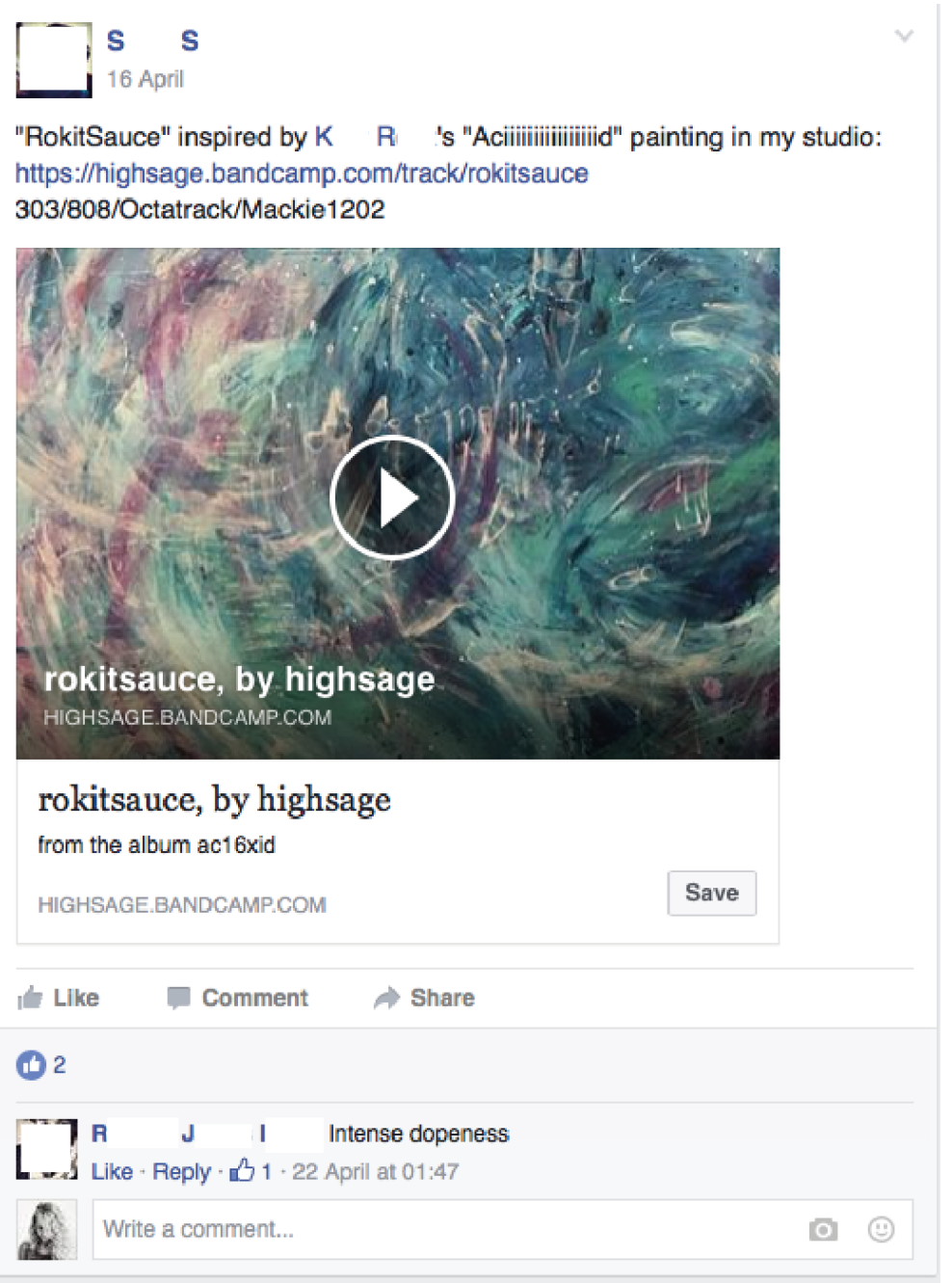


28)

L 22 April $\quad$ P shared his video.

just a loop on the little sister $($ )

https://www.facebook.com/boucles.alternees/videos/866989450093131/

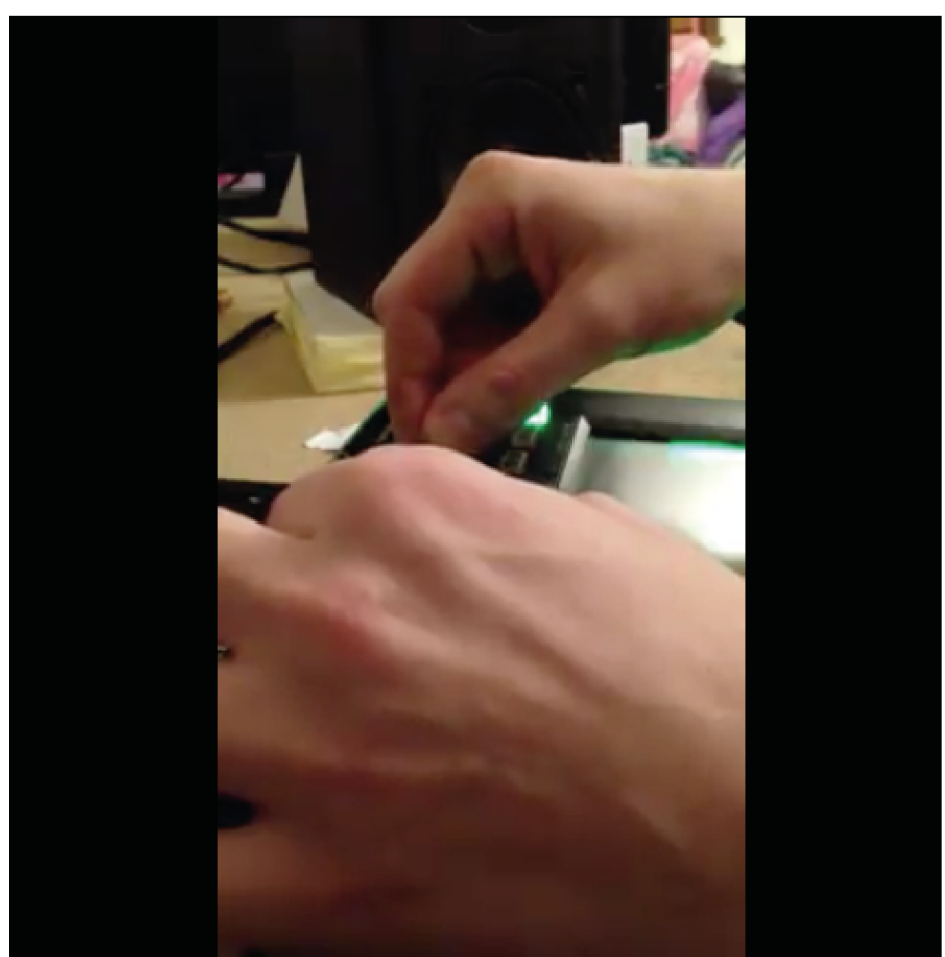

903 Views

C

21 April

plus qu'as faire le reste $(9)$

See translation

It Like Comment $\Rightarrow$ Share

(1) 2 
$\square=\frac{\mathbf{N}}{22 \text { April }}$ S shared his post.

$\square \underset{22}{\mathbf{L}} \underset{\text { April }}{\mathbf{N}}$ Mixcloud

life fucking goes on

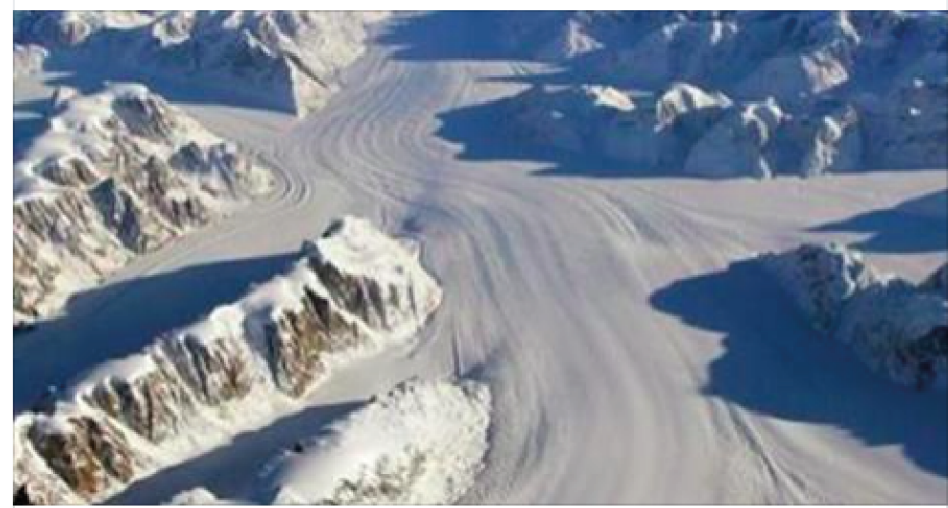

LNS20160406 * DARKER \& FASTER

Listen to LNS20160406 * DARKER \& FASTER by L N S MIXCLOUD.COM

I Like Comment $\rightarrow$ Share 
(B) ${ }_{22}^{\mathrm{s}} \mathrm{spril}$

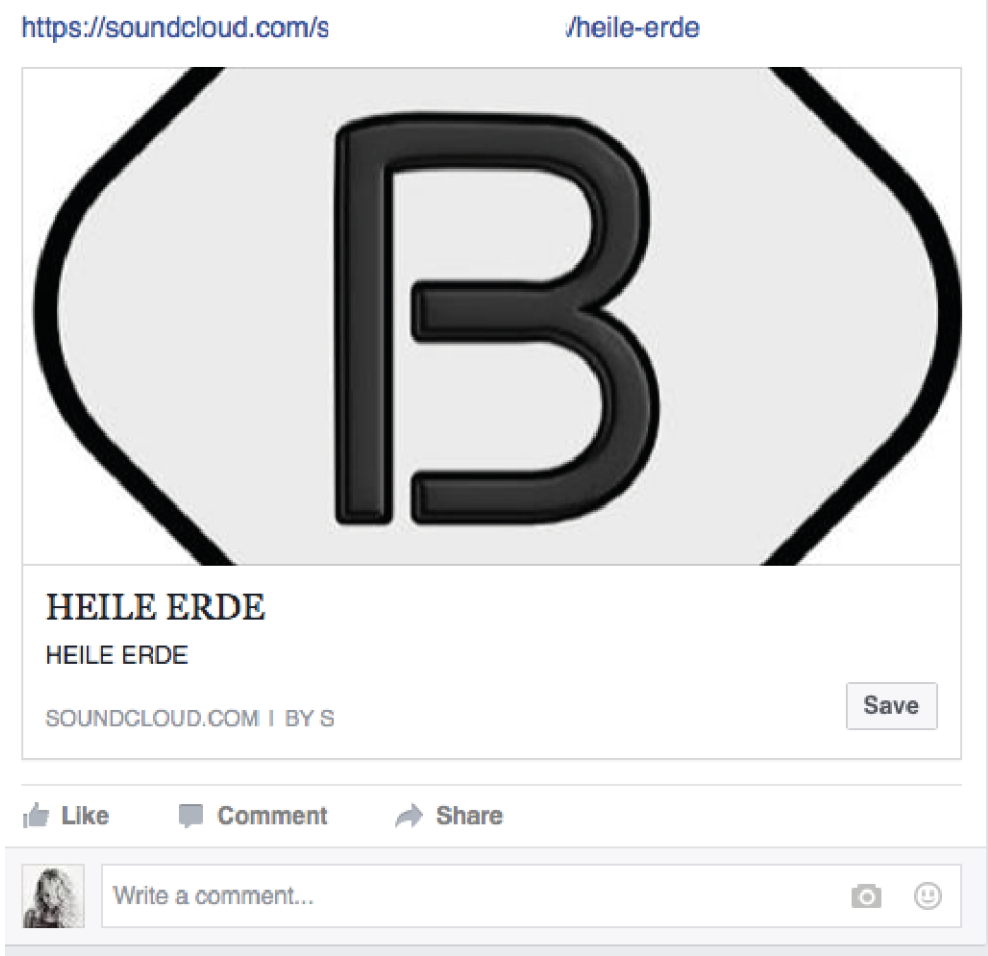

31)

(B) ${ }_{29}^{\mathrm{s}} \mathrm{s}$

HappY MayDay !!

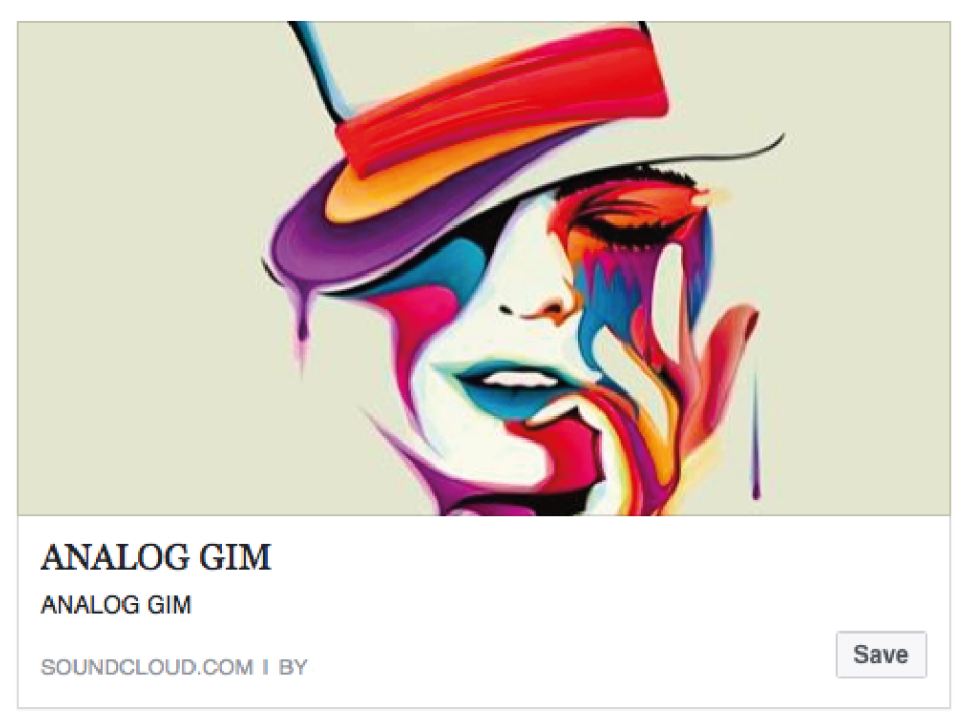

${ }_{1}+$ Like $\quad$ Comment $\Rightarrow$ Share 


\subsubsection{ITALO DISCO MANIACS}

1)

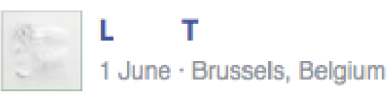

https://www.youtube.com/watch?v=XnnZFQk-k2A

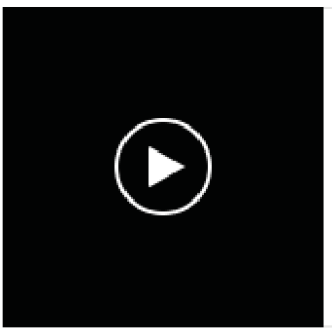

Ayx Non И Un Ufo - Ayx Disco

(Vinyl).wmv

http://bboybreaks.com Download all bboy music on

this site

YOUTUBE.COM

If Like

Comment

$\rightarrow$ Share

(4) 2

2)

\begin{tabular}{l|l|l|l}
$\mathbf{P}$ & $\mathbf{P}$ & $J$ \\
1 & June
\end{tabular}

https:/www.youtube.com/watch?v=5afjNeYwm4Q

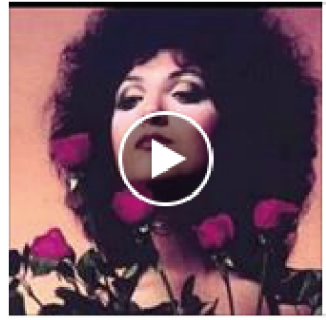

Marcella Bella -- Nell'aria

Anno 1983...

It Like

Comment

YOUTUBE.COM

(1) 1 
O G

1 June · Delft, Netherlands

https://www.youtube.com/watch v $=$ KBILReeo0CQ

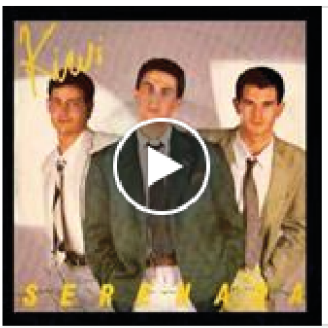

Kiwi - Serenada (Italo-Disco on 7")

Label: CBS Cat \#: CBS A 6179 Format: 7 " Country:

Italy Released: 1985 Genre: Italo-Disco

It) Liké

ॠ Comment

$\rightarrow$ Share

(6) 1

4)

L_ 1 June · Kraków, Poland

Love!

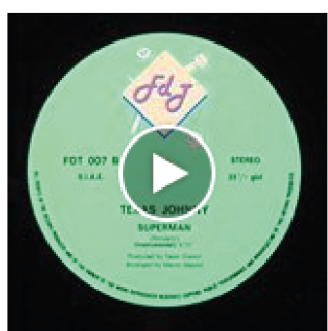

Texas johnny - Superman

(Instrumental 1984 Fuori Di Testi)

Tremenda...

It Like Comment $\rightarrow$ Share

(C) 3

-7 K C And total addicted for years... (:)

Like - Reply + 1 June at 16:34.

5)

L $\quad$ T

1 June - Brussels, Belgium

and side $B$

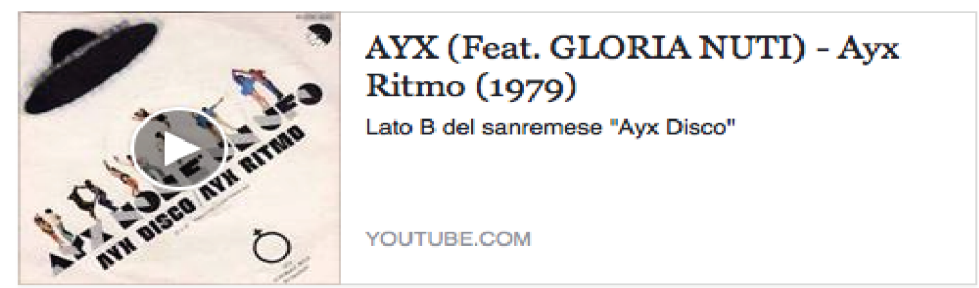

LIike Comment $\rightarrow$ Share 


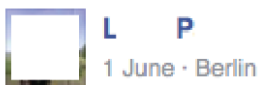

Grey Afternoon

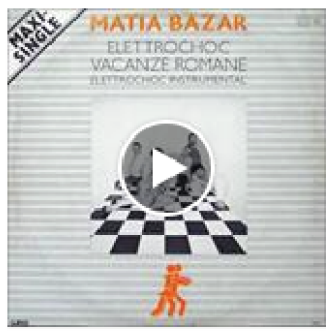

Matia Bazar - Elettrochoc

(Strumentale)

Rara versione di "Elettrochoc" (1983) dei Matia Bazar...Inedita su CD!

YOUTUBE.COM
It Like
Comment
$\Rightarrow$ Share

(1) 4

$7 \mathrm{C} \quad \mathrm{C} \quad$ Wow!

Like - Reply + 1 June at 16:42

7)

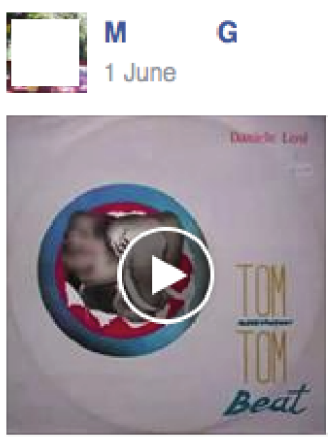

\section{Daniele Losi - Tom Tom Beat}

Zyx Music, Italo Disco 1985 Amazon Download: http:/www.amazon_de/Tom-

Beat/dp/B001RA4NJG/ref=sr_1_fikmro_1?

ie=UTF8 \& qid $=1382080252 \& \mathrm{sr}=8-1$ -

fkmro\&keywords=daniel...

YOUTUBE.COM

If Like $\quad$ Comment $\Rightarrow$ Share

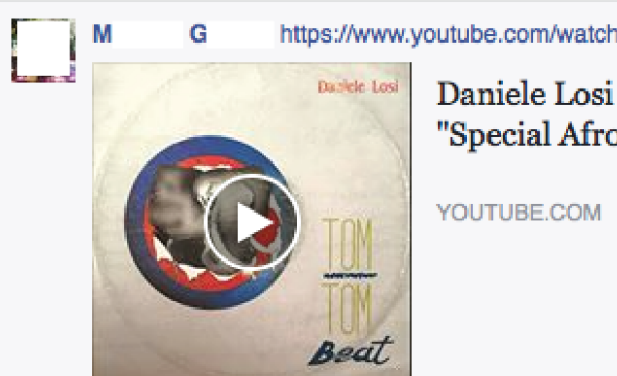

Like - Reply - 13 - 1 June at 19:00 


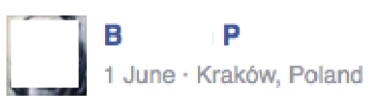

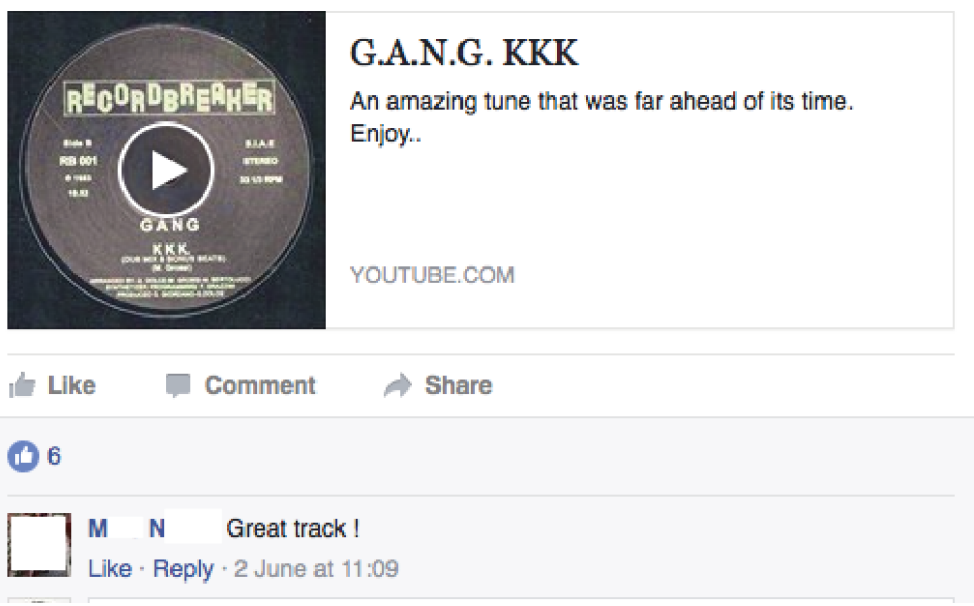

9)
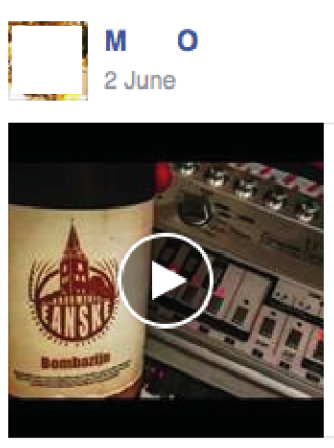

Found her at the swingersclub

Our second love.. Italo Discol Found her at the

swingers club. By the Nerds With Acid. Italo Disco clip starring us $\&$ our beautiful cats, in space on synthes...

it Like

Comment

YOUTUBE.COM

$\rightarrow$ Share 
O G

3.June - Delft, Netherlands

https://www.youtube.com/watch?v=rmnDgOu6oNM

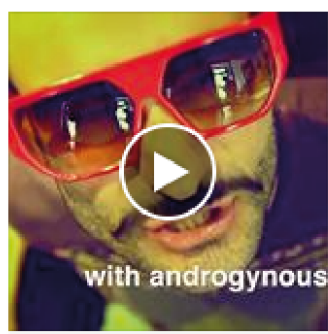

BOTTIN: DIRTY - Video teaser with Mauricius (the greatest PR in Milan)

BOTTIN: DIRTY out november 2012 on screen printed 12" vinyl \& digital http://www. beatport.com/re...

II Lilke $\quad$ Comment $\quad \Rightarrow$ Share

(1) 2

O G $\quad$ "dirty italo disco"
Like - Reply - 131 - 3. June at 09:56

11)

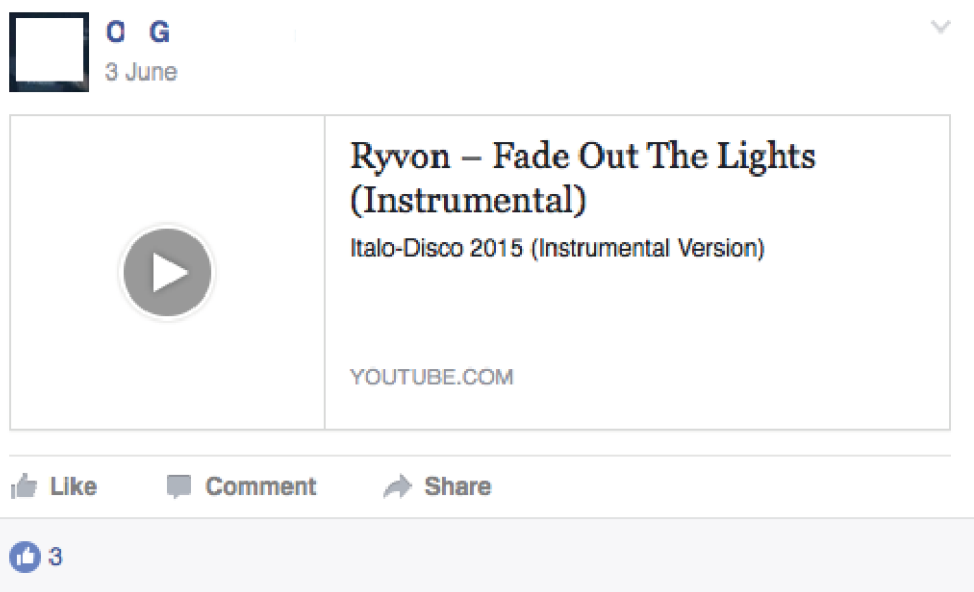




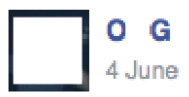

https://www.youtube.com/watch?v=U8QB_ri_CgM

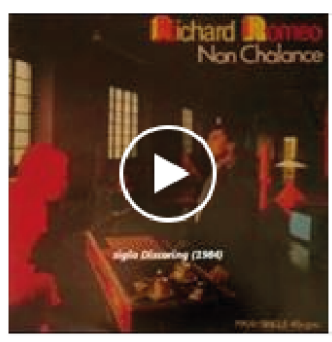

Sigla Discoring 1984 - "Non Chalance" - R.Romeo

Una delle sigle finali di Discoring, storica trasmissione musicale inserita nel palinsesto interno di "Domenica in"; versione Mix.

YOUTUBE.COM

$\prod_{3}^{\text {F June }}$ H

https://www.youtube.com/watch?v=VGjiFoH-wf8

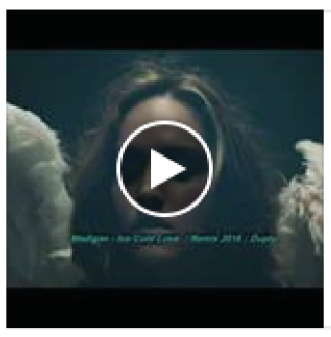

Madigan - Ice Cold Love / Remix 2016 / duply

Madigan - Ice Cold Love / Remix 2016 / duply Italo

Disco Remix

https:/www.youtube.com/channel/UCFlugzDwS1 R...

YOUTUBE.COM

Il) Like $\quad$ Comment $\Rightarrow$ Share

(1)

14)

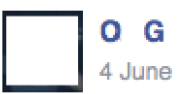

https://www.youtube.com/watch?v=ij7oyvb_1Rc

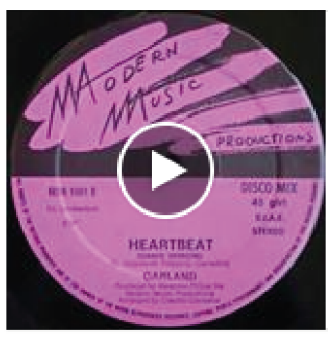

Garland - Heartbeat (Dance

Version) 1986
It) Like
Comment
$\Rightarrow$ Share

(1) 1 


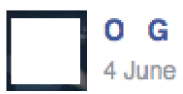

ordered reissue today....sweet song

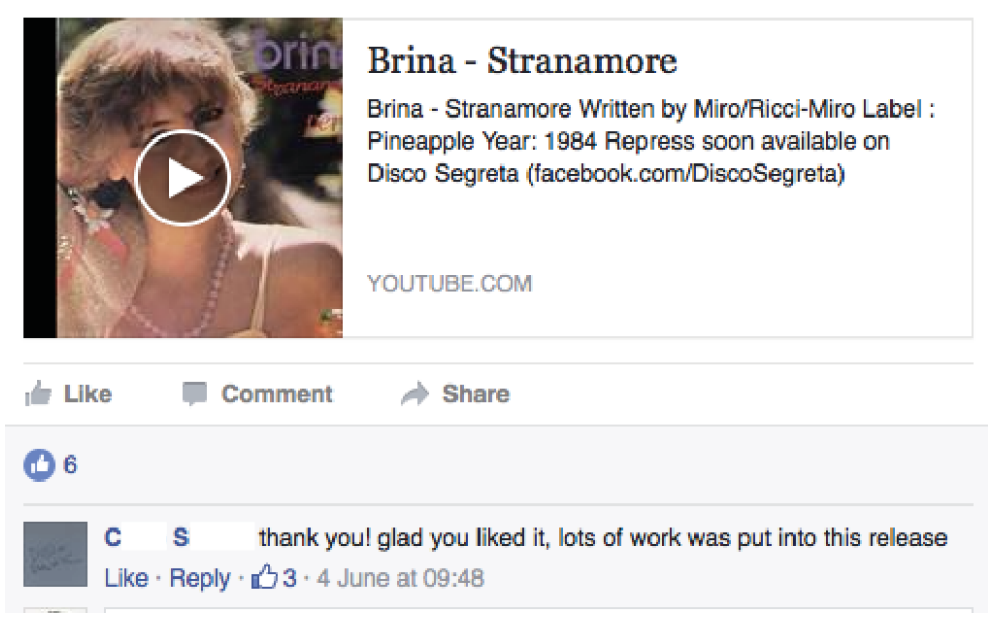

16)

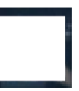

O G

4 June

Master DJ Cioni

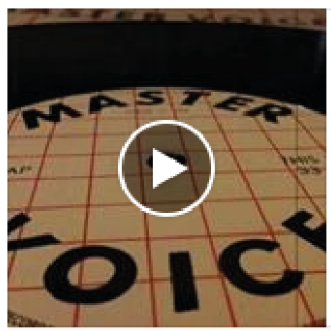

Master Voice - Disco Mix - Riccardo

Cioni DJ

MASTER VOICE Vinyl - 12" - 33 1/3 RPM - Limited

Edition - Mixed - Unofficial Rel. Only 1000 Copies DJ

Mix - Giorgio Giordano - Riccardo Cioni 1982 Disco. .

YOUTUBE.COM

\begin{abstract}
It) Like
, Comment

Share
\end{abstract}

( 1 
17a)

O G

2 June - Delft, Netherlands

https://clone.nl/item40165.html

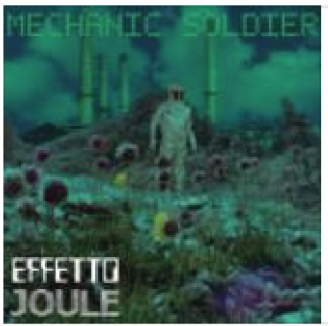

Effetto Joule - Mechanic Soldier (LP)

Medical Records in collaboration with Crispy Nuggets returns to ltaly for it's 59 th release. Hailing from..

CLONE.NL

Save

It. Like

D Comment

$\rightarrow$ Share

(1) 2

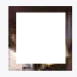

G H amazing band... I've been waiting on this for a long time https://www.youtube.com/watch?v=35R.J2k6MQA8

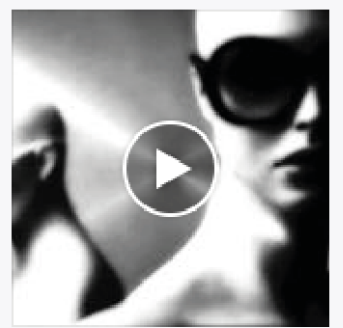

EFFETTO JOULE - Pleasure For Fantasy

YOUTUBE.COM

Like - Reply - $B 2+3$ June at 09:07

O G

Yes, I knew that did much more than the Roberspierre-track that was re-released recently so and was waiting for more also. Like - Reply - 3 June at 09:52

F H Don't like the vocals sounds like the brave son.....Matter of taste

A Hide 11 Replies

O G the brave son?

Like - Reply - 131 - 4 June at 00:43

0 G is that a band or you mean literally?

Like - Reply * 4 June at 00:47

O G juvenile?

Like - Reply - 4 June at 00:49

D $\mathrm{F}$ yes it sounds to much DM for me.

Like - Reply - 4 June at 07:15 - Edited 
17b)

$\square \quad \mathrm{F} \quad \mathrm{H} \quad$ In german we say the brave son.....No rough edges. Like - Reply + 4 June at 07:20

O G There are much worse or too clean sounding cases of DM-clones..especially in Germany. I think these are too original to dismis them as just DM-soundalikes although you hear echo's of older synthpopbands in them.

Like - Reply + 4 June at 09:00 - Edited

$\square$ F H For me the DM thing is over. Of course I still like some old songs of them but I can't hear anymore new synth pop groups which copy the vocals so much.

Like - Reply - 31 - 4 June at 08:59 - Edited

$0: G \quad$ A case of DM-saturation... (9)

Like - Reply - 4 June at 09:00

O : G Once in a while I still really like DM and soundalikes Like - Reply + 131 - 4 June at 09:01

F H a question of taste ... Why not .It's only my personal opinion...

Like - Reply + 131 - 4 June at 09:05

O G i respect that of course

Like - Reply - 131 - 4 June at 09:06

(1) Write a reply...

O G I ordered record today.

Like - Reply - 131 - 4 June at 00:47

U) M https:/www.youtube.com/watch?v=4ej669tQbA4

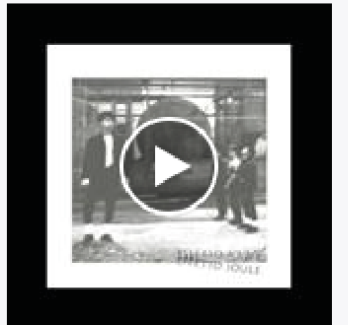

Effetto Joule - Robespierre

(Flemming Dalum Remix)

Like - Reply - 4 June at 12:55 
$\square$ F J June

I do like pizza. I do like pasta. And I really do miss italo pop and disco like from the 80 s and $90 \mathrm{~s}$. How about some holiday mood? Prego! (:) Free download on www. com.

SoundCloud-Link: https://soundcloud.com/ /piccola-musica

Thanks for listening!

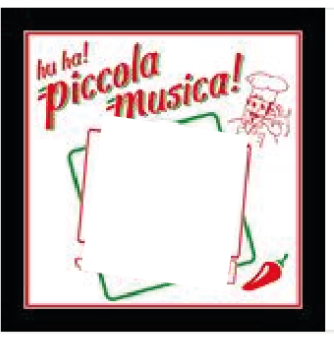

F J L - Piccola Musica

Song Title: Piccola Musica I Artist: F J

Official Website: http://www.

download on http://Www

com

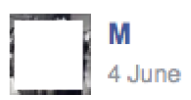

T

The Soundwork-Shoppers aka Piero Umiliani. $90^{\circ}$ minuto closing theme

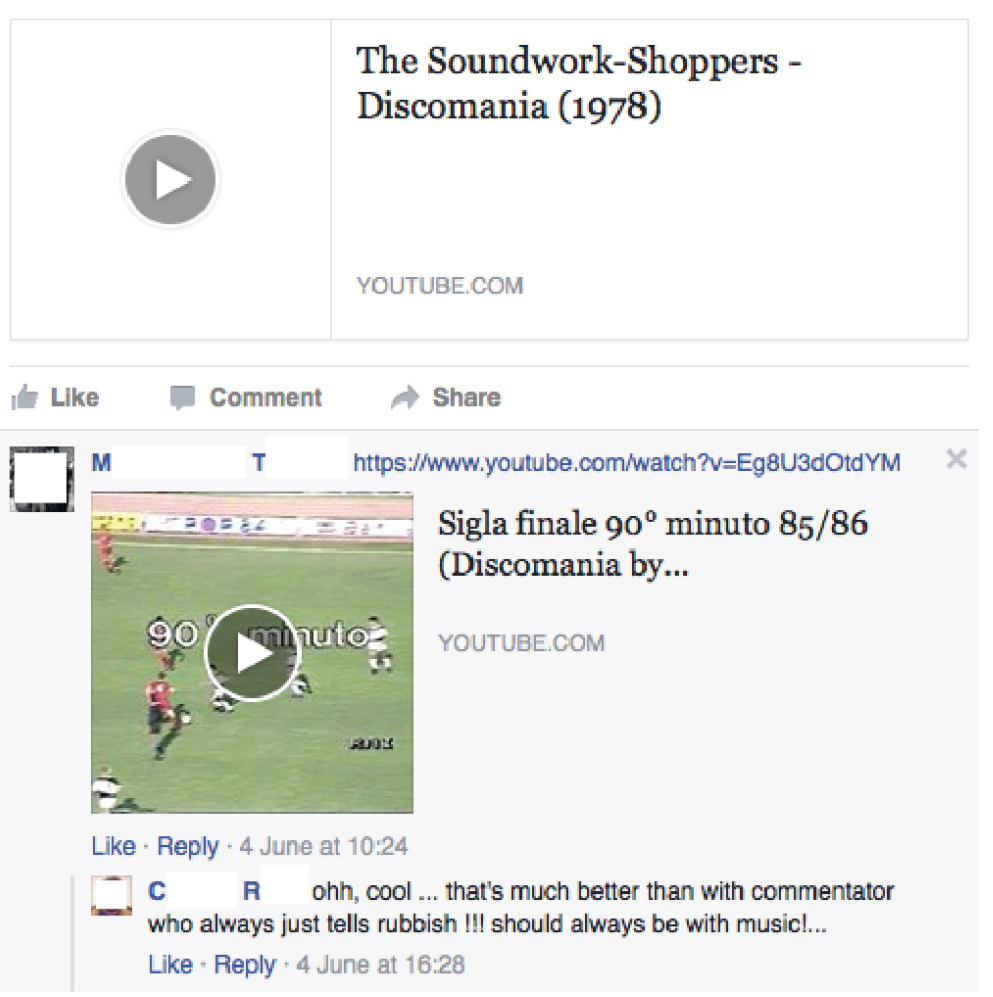



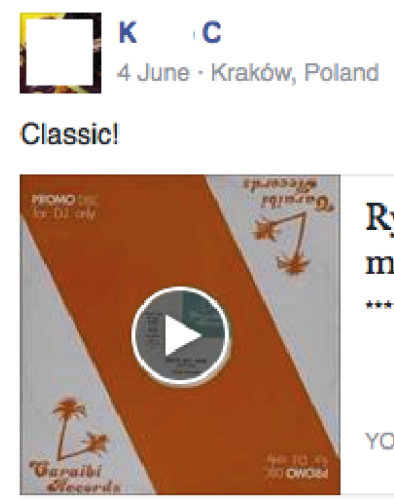

Ryan Dalmini - She's my love (dada mix) 1985

$* * * *$

YOUTUBE,COM
1. Like
Comment
$\rightarrow$ Share

(4) 3

0 G ohohoooooh (9)
Like - Reply - $131 \cdot 4$ June at 16:3

instr.

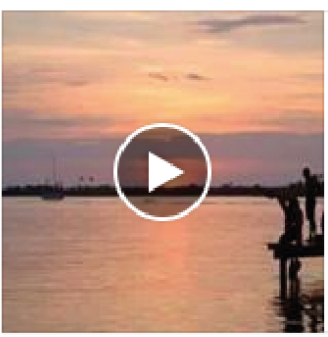

Stupid Set - Don't Be Cold (In The Summer Of Love) (Instrumental) (C) 1983

Label:Italian Records Catalog\#:EXIT M 511 Format:Vinyl, $12^{n}$ Country:Italy Released:1983...

YOUTUBE.COM

1 LIke

Comment

Share

(6) 2

F H prefer the vocal version $\quad$ Hon 144

Like - Reply + 4 June at 16:39

O G yeah me too, but that's already posted so...

Like - Reply + $131+4$ June at 16:41

o G bassline stays fat...there's a strange slowdown round $2 \mathrm{~m} 20$ s in this clip...can't check the vinyl here but I doubt it's on there.

Like - Reply - 4 June at 16:48 - Edited

o G what's with all the animals here?

Like - Reply - 4 June at $16: 47$ 


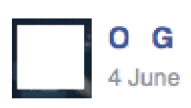

https://www.youtube.com/watch?v=75k79a9iFkM

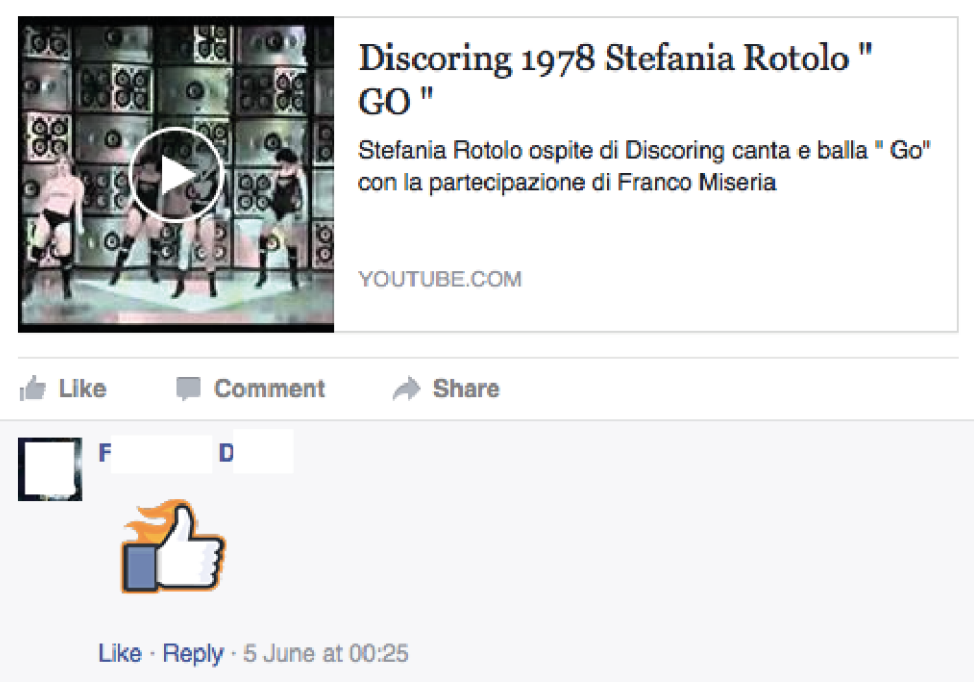

23)

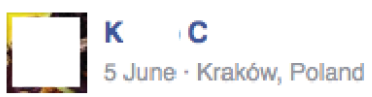

Supposedly someone have this record... but I don't believe it $(\mathcal{)}$...

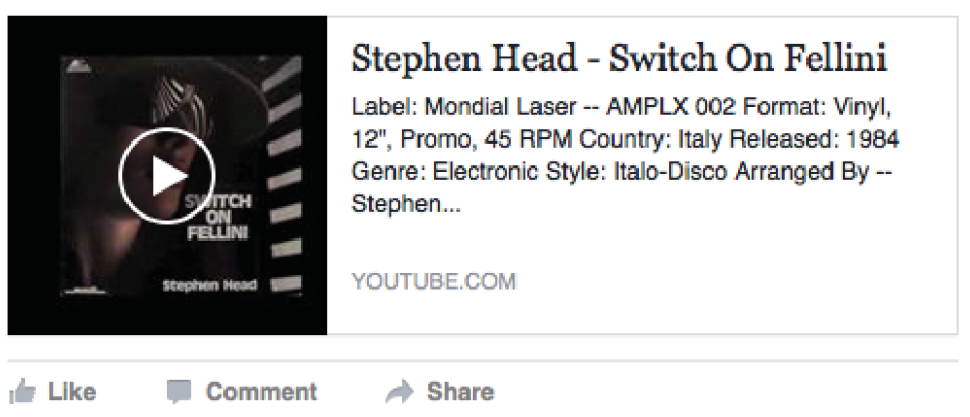


O G

12 June 2015

https://www.youtube.com/watch?v=OAJoFxN_A5w

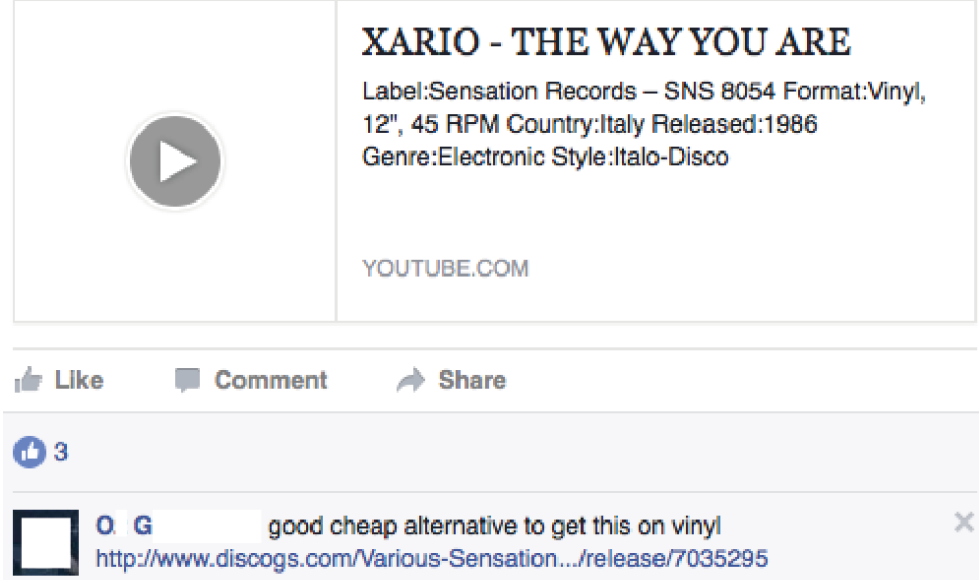

Various - Sensation Records Compilation

No. 2

DISCOGS.COM

12 June 2015 at 00:52 + Edited + Like + 131

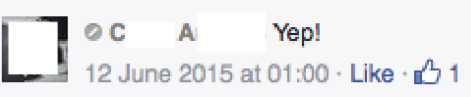

o C A and a amazing cover.... is that femke or not?

12 June 2015 at 01:03 + Like + 1

o G wouldn't know, i could ask Ron...

12 June 2015 at 01:04 - Like

O C A i did...silence...shhhhhht

12 June 2015 at 01:09 - Like

O G dark silence....aaaahh

12 June 2015 at $09: 28$ - Like + 131 
24b)

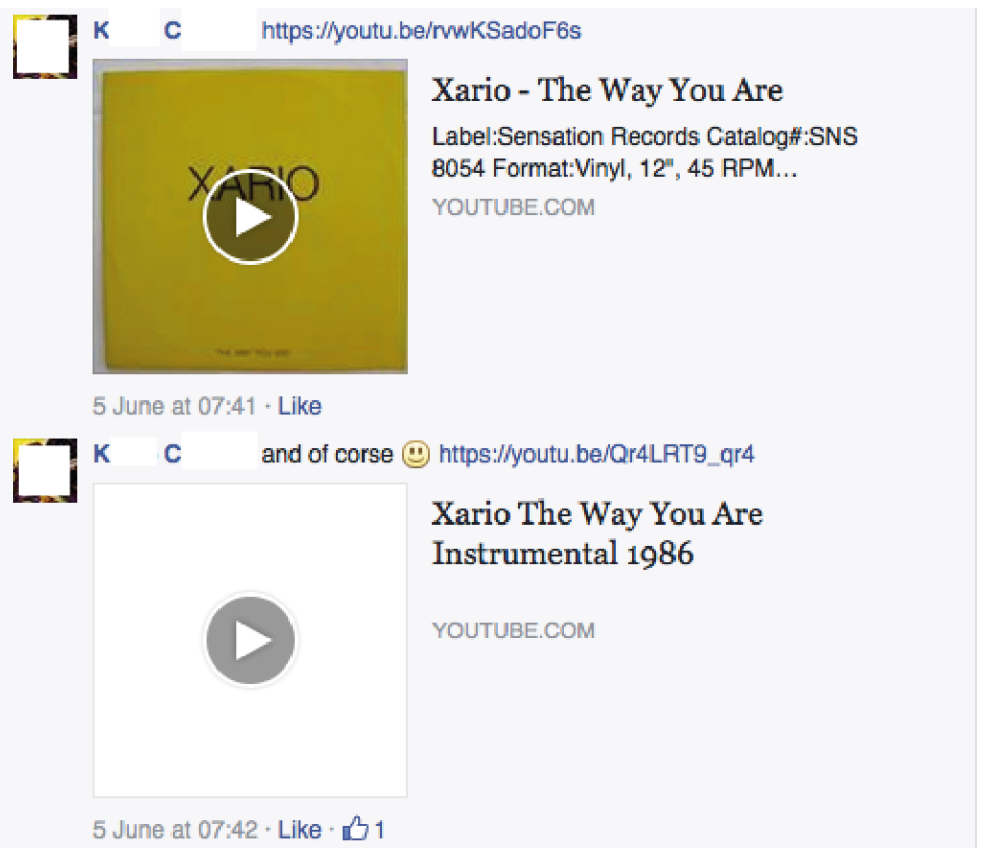

25)

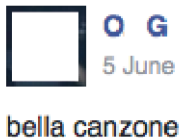

See translation

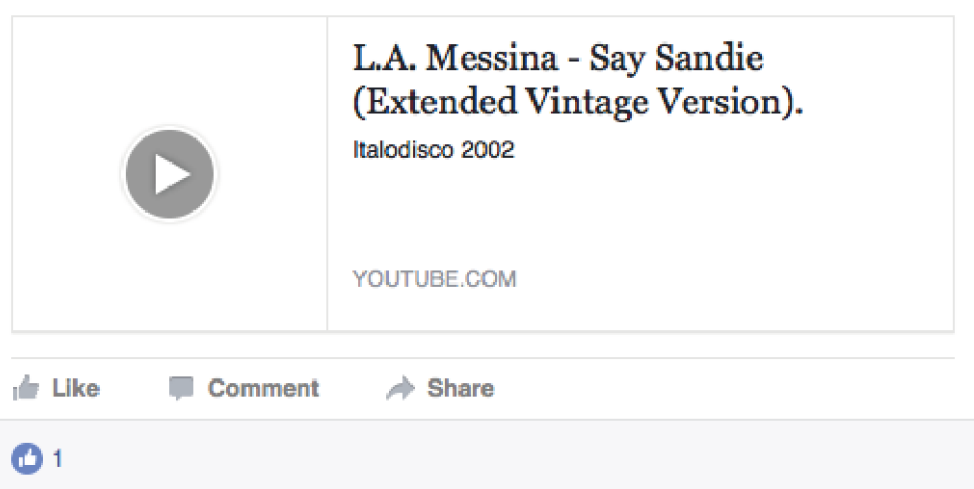


$\square$ o G

un altro bella canzone

See translation

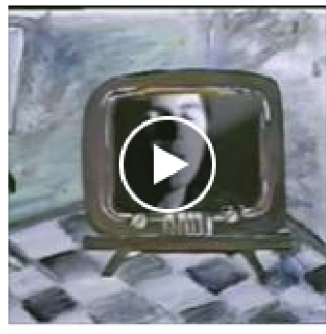

Silver Pozzoli - From you to me

80 's Video Clip

It. Like

Comment

Share

27)

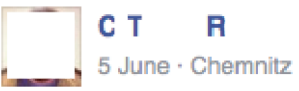

simpatico...

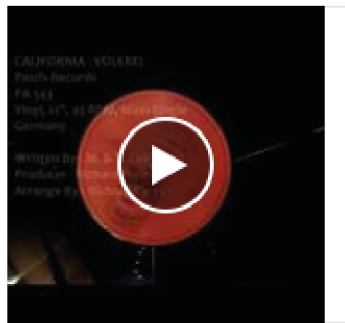

California - Volerei (Vocal Original Version) With Lyrics

One Of The Rarest Vinyl Record Of The World From

My Personal Colection. Label: Pasch-Records

Catalog\#: PA 543 Format: Vinyl, 12", 45 RPM,...

YOUTUBE.COM

H. Llke Comment $\quad \Rightarrow$ Share

(C) 1 


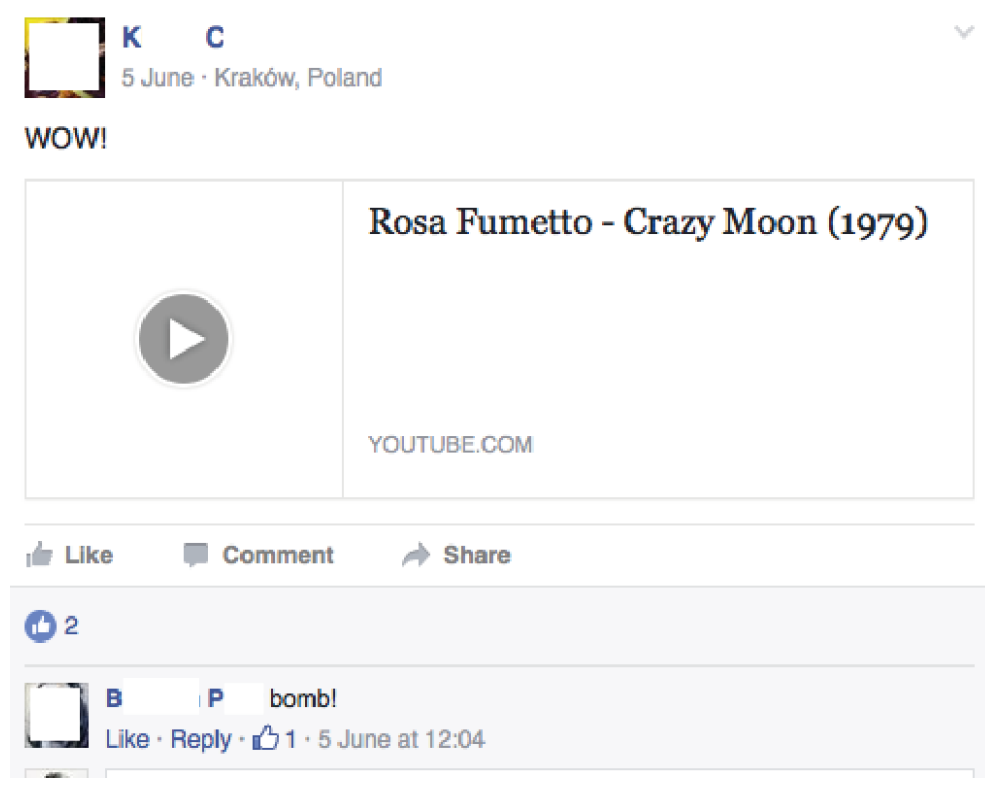

29)

$\prod_{\text {BOMB }}^{\text {7 June }}$
F

Cometa Music Hall - Cometa Music Hall

Label: Phantom Record - PH 004 - Format: Vinyl 7

DISCOGS.COM

Save

it Like Comment $\Rightarrow$ Share

(4) 4

K C tooo cheap ;))

Like - Reply - 132 - 7 June at 01:15 
$\square$ O G

shared GayCatPark's post.

Source of Duke Lake - Do You!

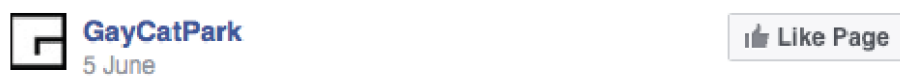

https://soundcloud.com/d..../you-cant-understand-sequencer-1982

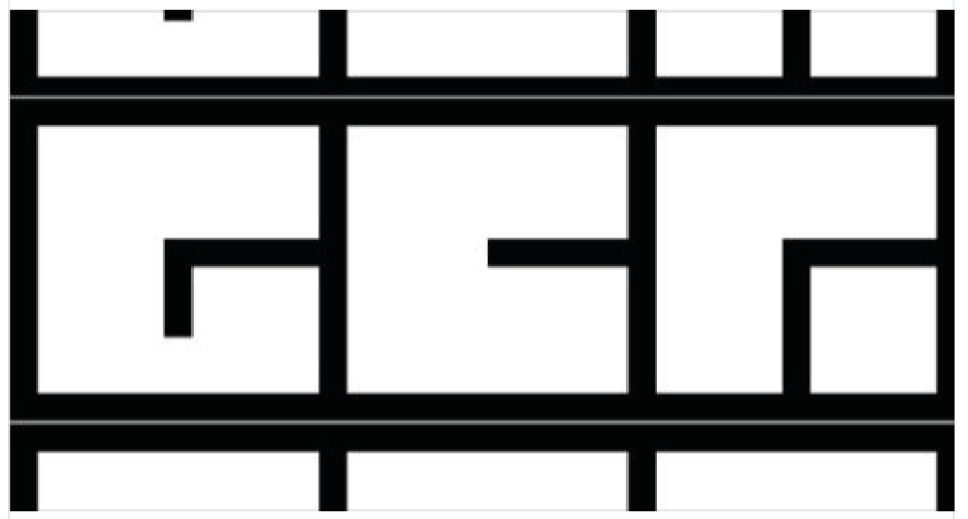

You can't understand sequencer 1982

This is the second version of this song where we tried to make it closer to Italo Disco sound requests, made at home with a few musical instruments. JEN SX1000, EKO Ritmo 20, CASIO VL01. Overdub with

SOUNDCLOUD.COM I BY DAVIDEGATT|

\section{It. Like Comment}

(6) 1

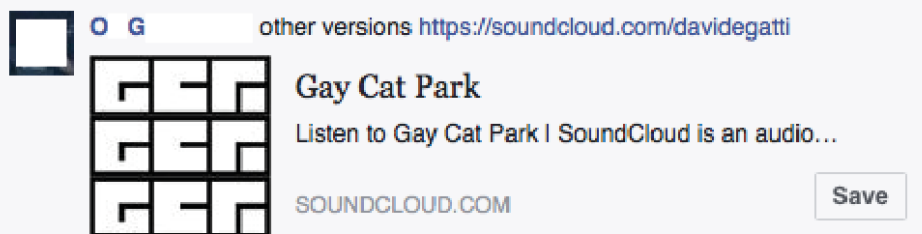

Like - Reply - 13 - 5 June at 12:13 

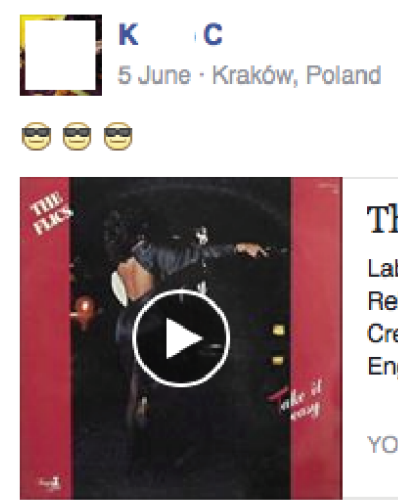

The Flics - Take It Easy (1984)

Label: Tanga Label Catalog\#: TL 007 Country: Italy

Released: 1984 Genre: Electronic Style: Italo-Disco

Credits:Arranged By - D. Francesconi \& D. Martin

Engin...

YOUTUBE.COM

If Like $\quad$ Comment $\Rightarrow$ Share

$00^{3}$

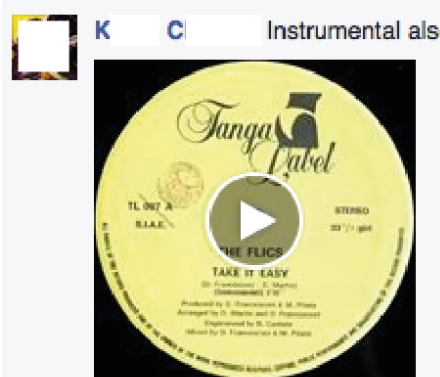

The Flics - Take It Easy

(Instrumental Version) 1984

Like : Reply + 5 June at 18:40

L] к с $\quad$ But Vocal Rulezzzz (P) Like - Reply + 5 June at 18:44 


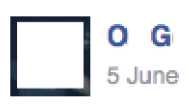

recollactioooon!

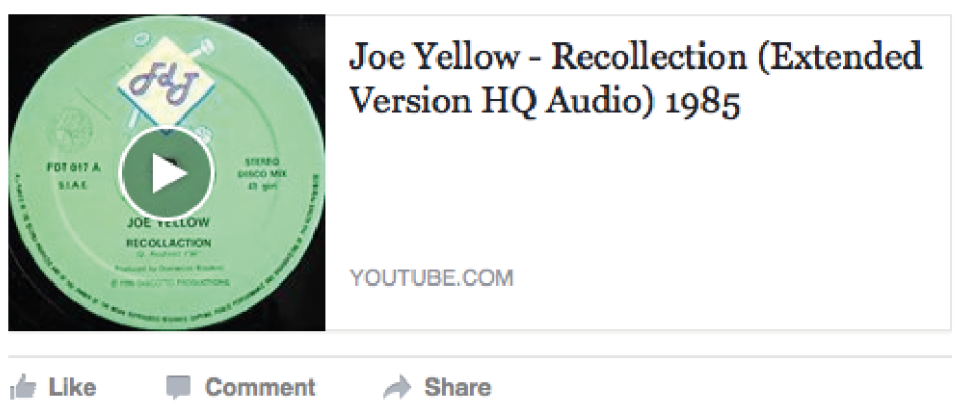

(1) 2

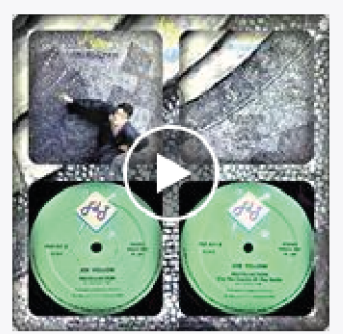

JOE YELLOW -

RECOLLECTION (VOCAL, I'M...

Like - Reply - 31 - 5 June at $18: 10$

[] K IC Instrumental start at 06:53 (9)

Like * Reply - 131 - 5 June at 18:41

$\square \circ \mathrm{G} \quad$ close enough (-)

Like - Reply - 5 June at 19:09 
33)

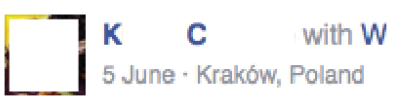

B

Beauty Instrumental!

Body Games - Stop Love
Instrumental 1983


$\square$ O G

https://www.youtube.com/watch?v=XDndfNDiaRE

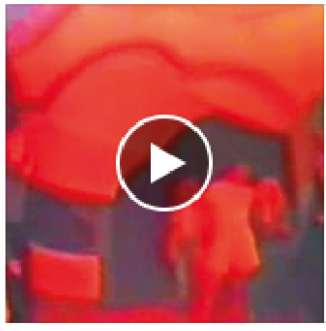

sun la shan rose from tokyo xvid

YOUTUBE.COM

It Like Comment $\Rightarrow$ Share

(b) 3

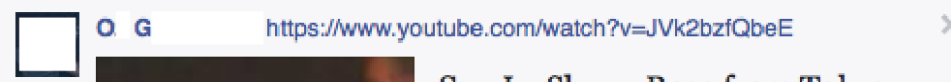

Sun La Shan - Rose from Tokyo -

SOS Version

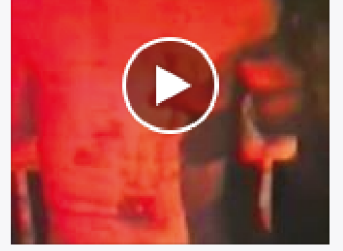

YOUTUBE.GOM

Like - Reply +5 June at 10:22

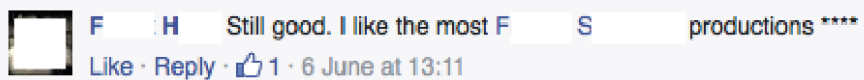
o G
me too!

Like - Reply - 31 - 6 June at 13:35

35a)

$\prod_{6 \text { June }}^{\text {F }} \mathbf{H}$

https://www.youtube.com/watch?v=ZHNVWEh72mg

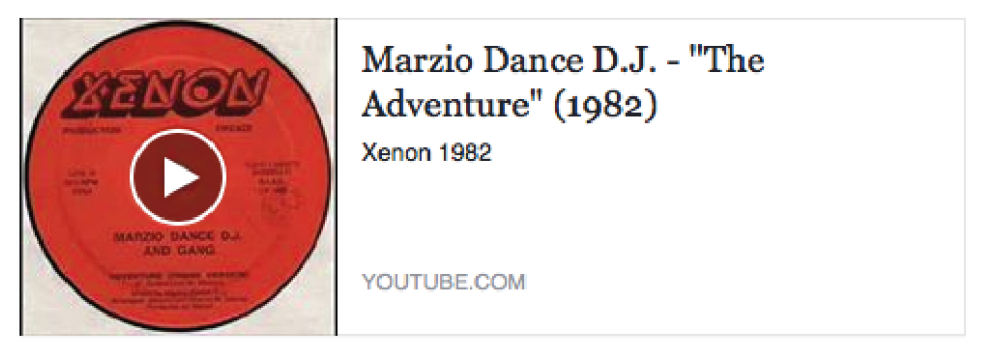

14 Lilke $\square$ Comment $\Rightarrow$ Share

(1) 15 
35b)

H https:/www.youtube.com/watch?v=PBXKQrTXoPA

\section{DANGE D.A. FARZIO DANCE FEAT XENON -}

- 2319 SYMPHONY (1983

Y $(1)$ youtube.Com

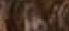

Like - Reply + $131+6$ June at $13: 17$

[ o G One of the first italo disco records I ordered. (9) Like - Reply + 131 - 6 ل June at 19:09

[ 0 G I mean Rap-O-Hush (the image of this clip)

Like - Reply - 6 June at 19:11

- F H The vocoder version is great

Like - Reply - 6 June at 19:11

[ 0 G like both also the somewhat corny rapping (:)

Like - Reply - 6 June at 19:12

6. Write a reply...

() (4)

- F H https:/www.youtube.com/watch?v=69duModh7TI

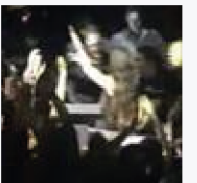

MARZIO DANCE - L'imperatore

In Kamasutra Disco party "Spiritika" pauraaaaaa!!

YOUTUBE.COM

Like - Reply + $131+6$ June at 13:20 
35c)

F $\quad$ H https:/www.youtube.com/watch?v=ducCt2fQVUg

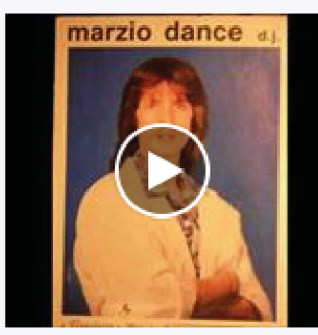

Discoteca XENON Marzio Dance DJ

Like - Reply * 3 - 6 June at 13:23

[ A R Another nice one: https://www.youtube.com/watch? $\mathrm{v}=\mathrm{ekeH}$ 2NsLwD8

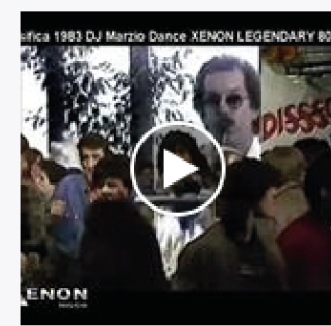

Disco Xenon Classifica

Xenon 1983 DJ Marzio...

Like - Reply $\cdot 33 \cdot 6$ June at 19:02

6. Write a reply...

G H I once paid a crazy price for Marzio - Adventure in peak italo fever... anyone else? no regrets though $(9)$

Like - Reply - 1 1 - 6 June at 13:48

[ 0 G also paid more than what copies are going for now...no $x$ regrets also... (-)

Like - Reply : 1 1 : 6 June at 19:06

6. Write a reply...

F D Legendary and simply amazing releases $\square$ Like - Reply + 4 - 6 June at 14:11 
$\int_{\text {6. June }}^{\text {A }}$ R

New mix - enjoy!!!

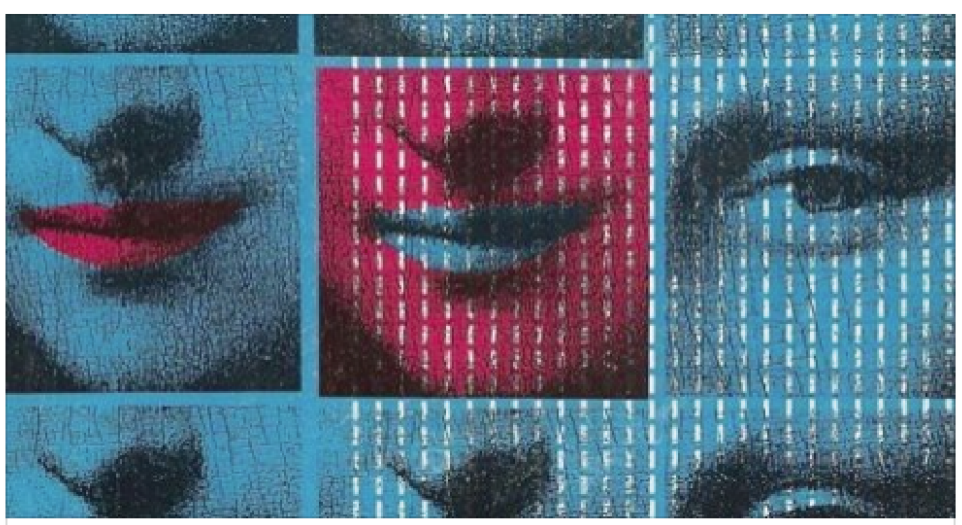

Italo / Euro Disco Monnalisa Mix

New mix featuring a collection of faster Italo / Euro disco at around 130bpm. Mixed on two turntables - vinyl only! Named after the great 'Deblanc' track Monnalisa.

Thanks to a great record store in

SOUNDCLOUD.COM I BY AREAD

Save

Like Comment $\rightarrow$ Share

3 


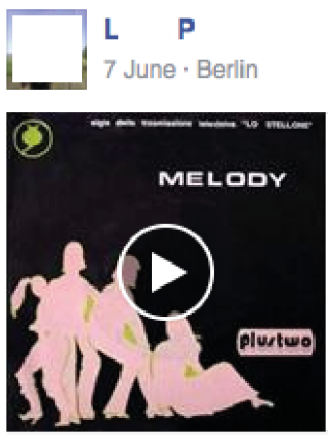

Plustwo - Melody

Label: MIO Records (2) Catalog\#: DMI 002

Format:Vinyl, $7^{\prime \prime}$ Country: Italy Released: 1983 Genre:

Electronic Style: Italo-Disco Credits: Composed By -

A. Bianch...

YOUTUBE.COM

It Like $\quad \square$ Comment $\Rightarrow$ Share

(1) 6

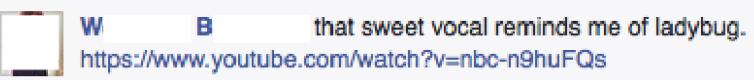

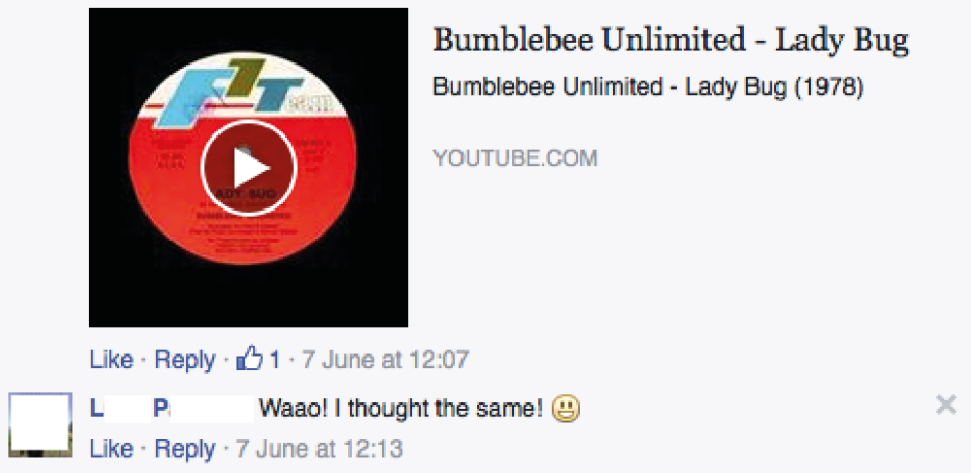

38)

S L L : V
7 June

Hello!

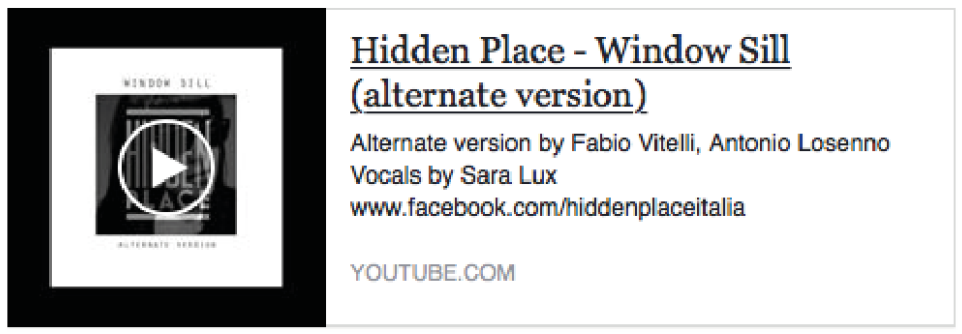

It Llke $\quad \square$ Comment $\Rightarrow$ Share

(6) 1 
39a)

F 7 June

Next Bomb on Phantom Records ....For a good price. This old music l'm looking for.Very hot

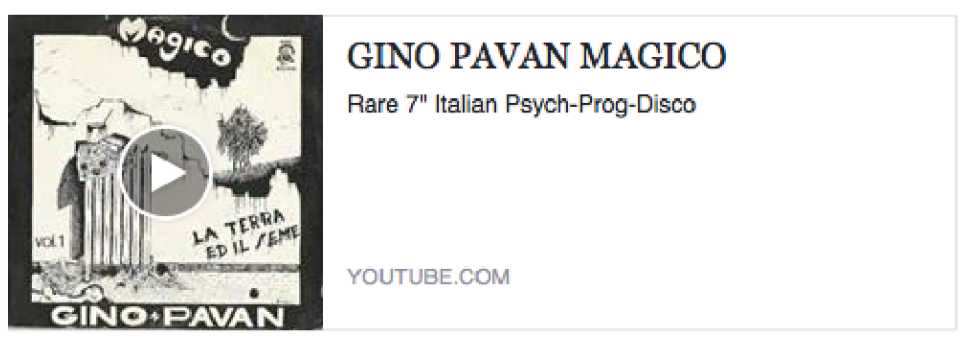

It Like $\quad \square$ Comment $\Rightarrow$ Share

(1) $14 \quad 14$

C S SOON (:)

Like - Reply - 13 - 7 June at 12:04

O G very sophisticated.

Like - Reply : 13 1 + 7 June at 22:47

- F H Yes it is. I would like a Phantom Records Compilation with 12 inch outcouplings....

Like - Reply $\cdot$ B 1 - 7 June at 22:53

- O G never heard about this label but looks like worth checking out...

Like - Reply + 7 June at 23:01

D O G Ah, I know Carlotto - Come With Me

Like - Reply · $131 \cdot 7$ June at 23:02 
39b)

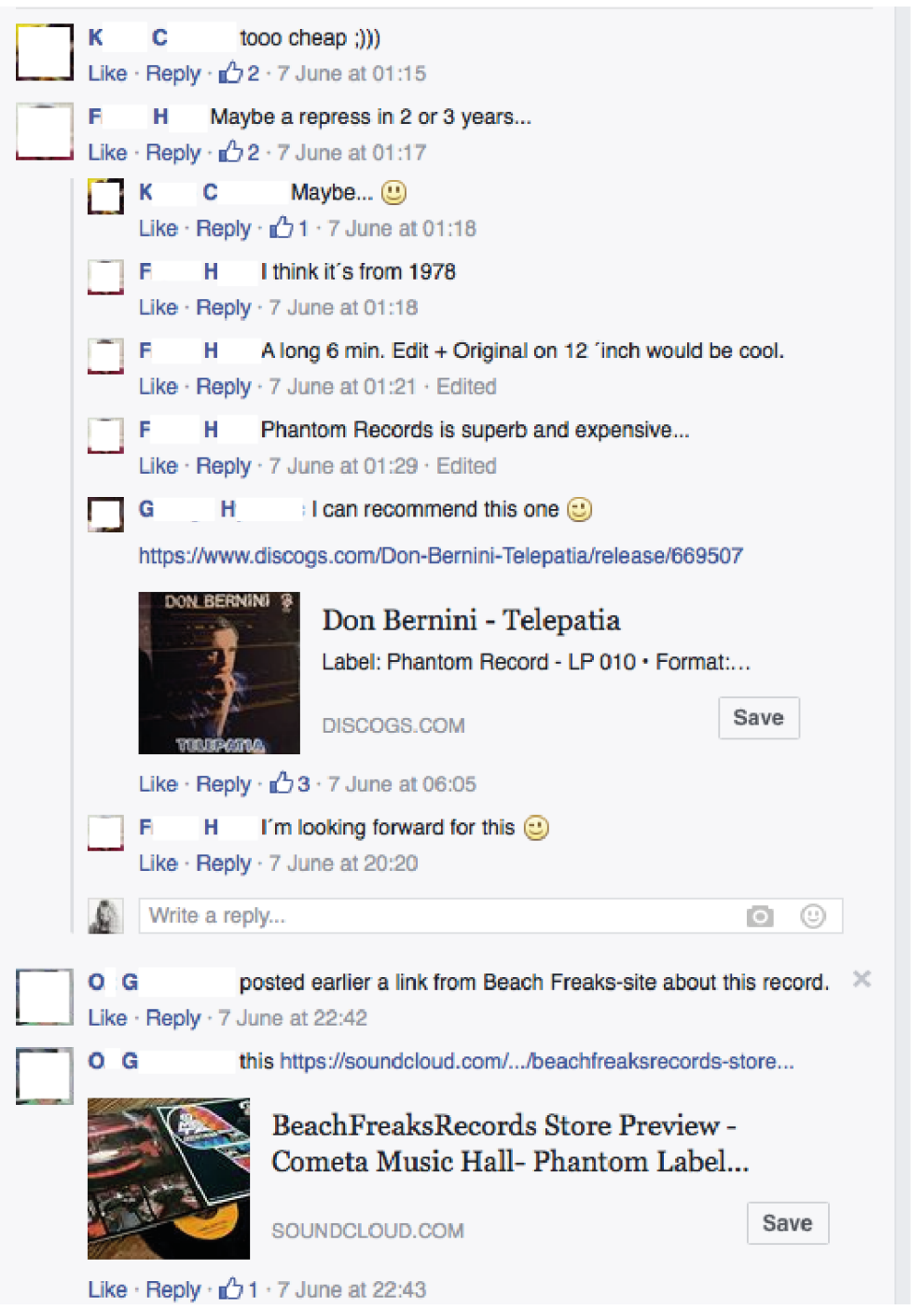


D $\quad$ C
8 June - Adelaide, SA, Australia

https://soundcloud.com/. . ./italonudisdto-present-raf-ti-prete... .

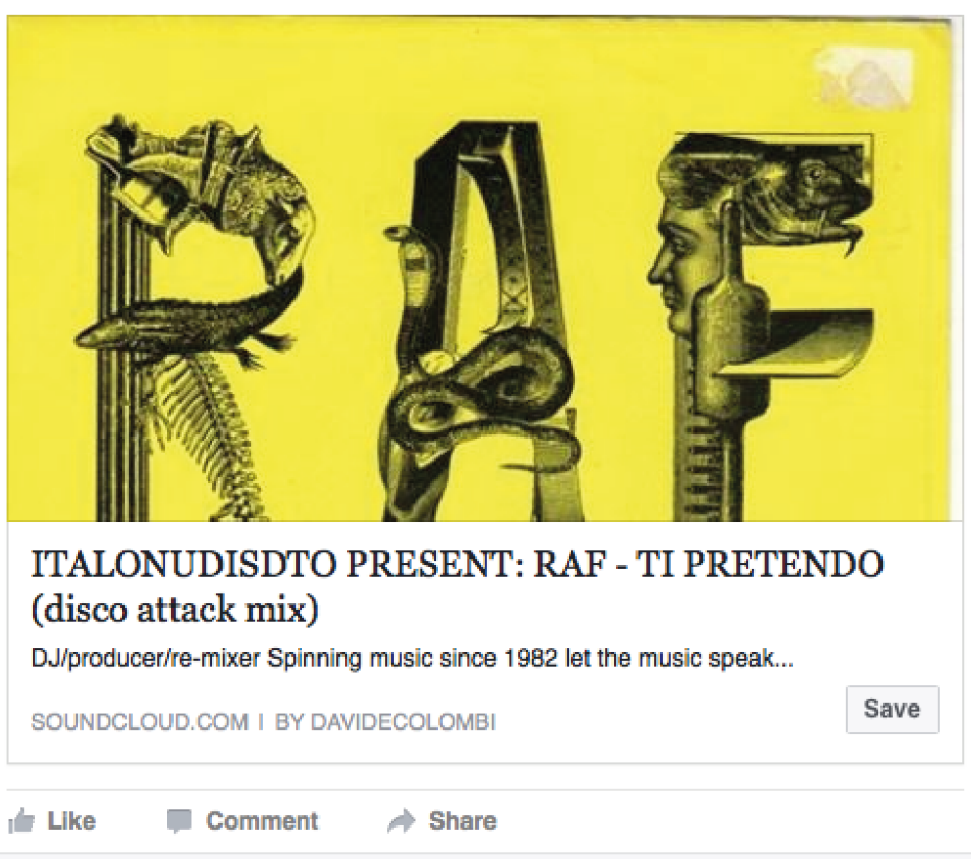

41)

$\left[\int_{\text {8 June - Kraków, Poland }}^{\mathrm{K}} \quad \mathrm{C}\right.$

Another Obscure girl of Italo... (2)

\begin{tabular}{|l|l|}
\hline & $\begin{array}{l}\text { Mavì - Tocca Qui (Oblie Moi) } \\
\text { (Audio skips are noticeable) Label: Disco In - NPS } \\
\text { 14615 Format: Vinyl, 7", 45 RPM Country: Italy } \\
\text { Released: 1981 Genre: Electronic Style: Italo-Disco }\end{array}$ \\
\hline & YOUTUBE.COM \\
\hline 14 Like $\quad \square$ Comment & \\
\hline &
\end{tabular}


$\square$ D $\quad$ B

https://www.youtube.com/watch?v=iNtYHswzFzM\&app=desktop

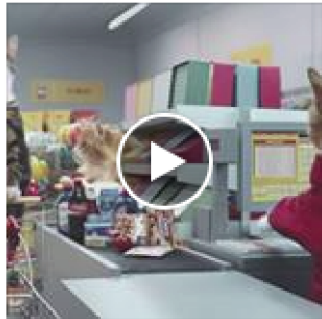

\section{Netto-Katzen}

Süße Katzen kaufen im Netto Marken-Discount ein.

Netto präsentiert ein absolut süßes Katzen-Video.

Miau! Bei uns im Netto Marken-Discount sind die

Katzen los...

YOUTUBE.COM

It Like

Comment

$\rightarrow$ Share

(C) 1 

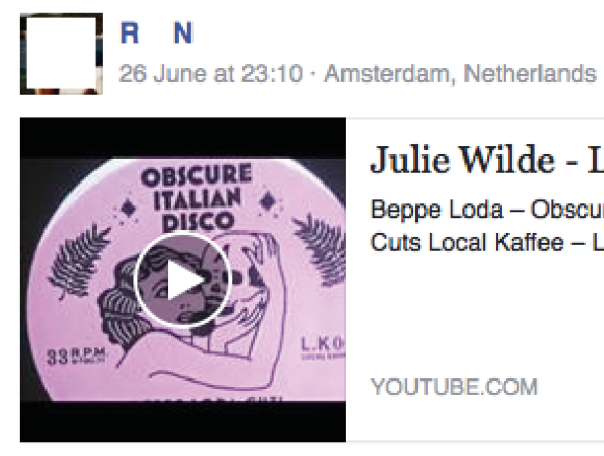

Julie Wilde - Love Tunnel

Beppe Loda - Obscure Italian Disco * Beppe Loda

Cuts Local Kaffee - LKO6 Vinyl, 12", 33 13/3 RPM US

It Lilke $\quad \square$ Comment $\Rightarrow$ Share

(C) 12

F $\mathrm{H}$ Nice one *

Like - Reply + $131 \cdot 27$ June at 00:17

$\square$ R N This one is also on the same compilation by Beppe Loda, $x$ but I see you have already posted it a while back. Still in stock at a couple of places if you don't have the OG press! : https $/ /$ www.youtube.com/watch?v=rrbXEd-puno

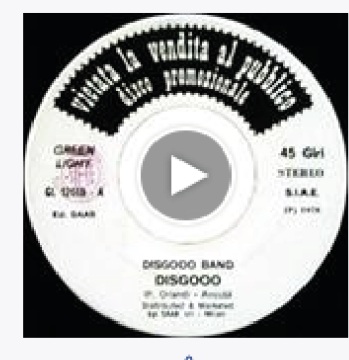

DISGOOO BAND - Disgooo , 1978, Italian , Disco ,...

YOUTUBE.COM

Like - Reply + 32 - 27 June at 00:20

$\square$ F $\quad \mathrm{H} \quad$ Great I think I'll order.

Like * Reply + 27 June at 00:21

$\square$ F H But this Revance is superfluous on that 12 inch because it's easy to get and nothing special for my taste.

Like - Reply + 27 June at 01:10 - Edited

M K nice compilation, but why edit those, these are good 7 inches have them both

Like - Reply + 1 1 - 27 June at 08:16 - Edited

$\square$ R N I guess extended for D.J use? Like * Reply + 27 June at 09:53

M K its indeed much better to mix those from a 12, cant say if they are extended cause i dont have the comp.

Like - Reply - 27 June at 10:25 
C T I P

10 June : Chemnitz

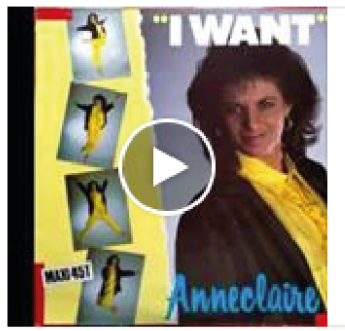

Anneclaire I Want 1986

Euro Disco - France

YOUTUBE.COM

It Like $\quad$ Comment $\Rightarrow$ Share

(1) 2

45)

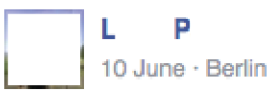

Uhh, a Classic was missing here (:)

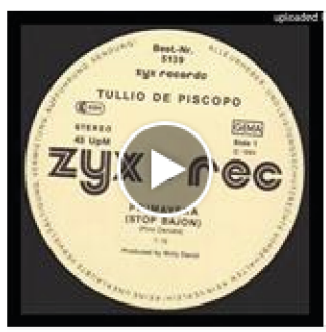

Tullio De Piscopo - Primavera (Stop Bajon)

Slow track went down well in Schoom, Genesis,

Pasha back in the day Label:ZYX Records - 5139

Format:Vinyl, 12", Maxi-Single, 45 RPM...

YOUTUEE.COM

It Llke $\quad$ Comment

$\rightarrow$ Share

(1) 5

W B Good and cheap one.

_. Like - Reply - 32 - 10 June at 19:21

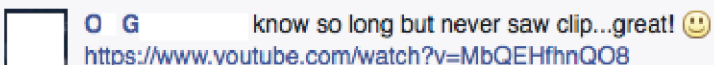

Like - Reply + 131 - 10 June at 19:29 - Edited 
$\square$ O G

8 June

Found out just now this is Italian....I thought German cause I have German pressing. Nice b-side!

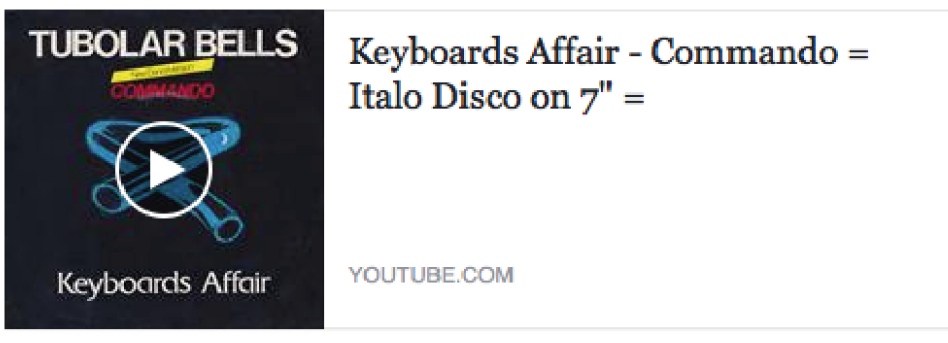

Il- Like $\quad$ Comment $\Rightarrow$ share

(1) 11

$\square$ F D Classic B side $[3$

Like - Reply + 1 1 + 8 June at 13:05

к c 00000000000

Like - Reply $\cdot \mathbf{1} 1$ - 9 June at 02:32

T B el classico

Like : Reply : $\$ 1$ : 11 June at 01:49

47)

[]$_{11 \text { June }}^{T} \quad J$

We are CYBER CHILDREN! Listen to our New Italo Disco Track "JABDAH PART 2"

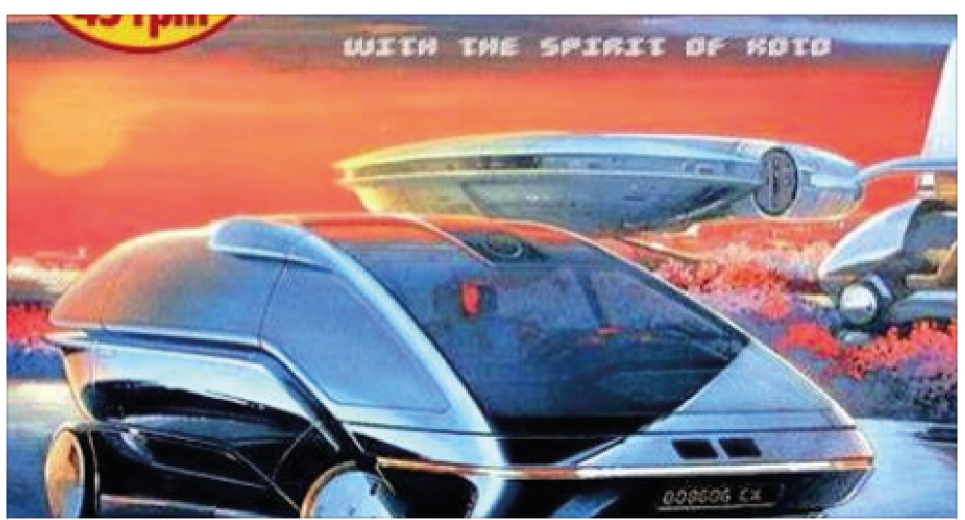

CYBER CHILDREN - JABDAH PART 2

Listen to CYBER CHILDREN - JABDAH PART 2 by IAN COLEEN \#np on \#SoundCloud

SOUNDCLOUD.COM I BY ELECTRO-RAIDERZ

it Like

$\square$ Comment $\Rightarrow$ Share

(1) 


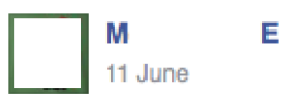

forgotten track

SALVY \& GIULY - Stop The World
WmV
Artista: SALVY \& GIULY Cancion: Stop The World
Año: 1984 Lugar: Italo Genero: Italo Disco
Aaronmivamx Production's

49)

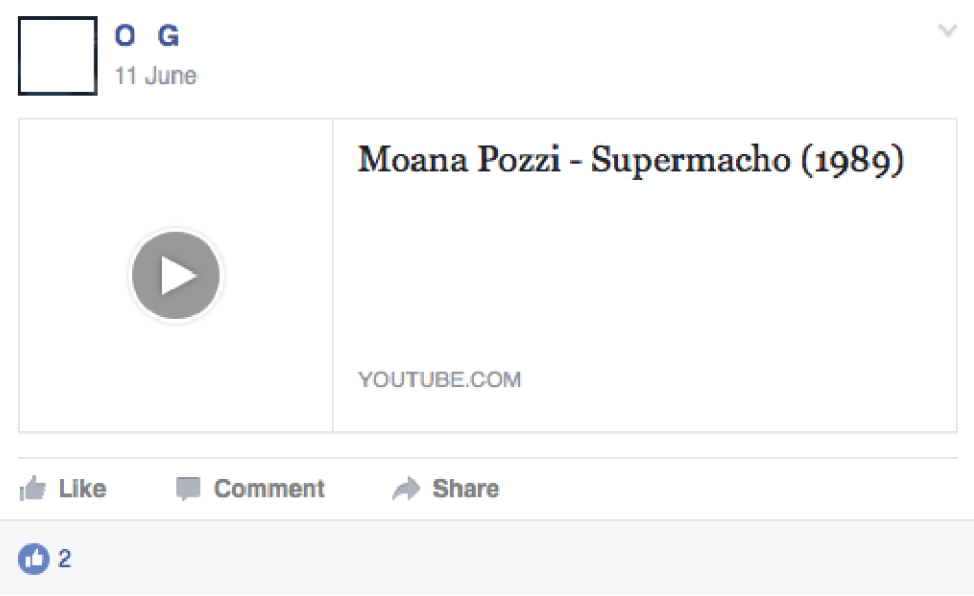


$\longrightarrow \circ \mathrm{G}$

shared C L 's post.

4 June

$\square_{4 \text { June }}^{\text {C L }}$

hopefully around that age I'Il have a friend to make music with this way.... swingin' electrofunk

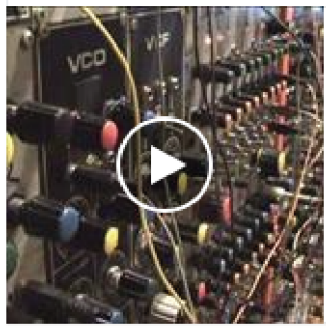

The Analog Session - N5 From

Outer Space

The second video-clip of The Analog Session,

featuring Alexander Robotnick \& Ludus Pinsky. It has

been released by This Is Music LTD (digital \&...

It Like

, Comment

YOUTUBE.CON

(1) 6

$$
\text { D V Heel dik }
$$

See translation

Like - Reply $:$ 1 1 - 4 June at 14:30

- W B That video and music was one of my teenage years anthem.

Like - Rieply 9 - June at 00:04

D G This is from 2009 or older?

Like - Reply + 9 June at 00:15

- W B I think 2009

C. Like - Reply - $\$ 1$ - 9 June at 00:20 - Edited

[. W B Well it was posted on youtube in 2009.

Like $\cdot$ Reply $\cdot 9$ June at 00:22

$\square$ o G I think it's not much older. Looks like kinda spontanious session to me actually.

Like - Reply - 11 June at 20:49 


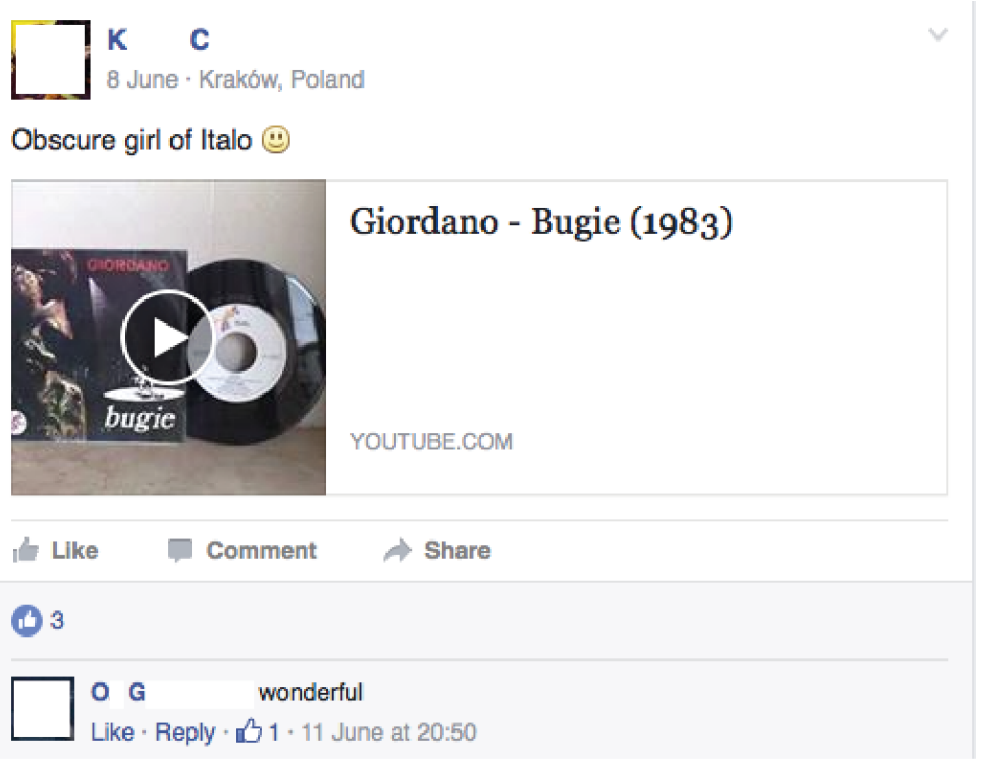

52)

L $\quad$ P
8 June - Berlin

Eyes without...

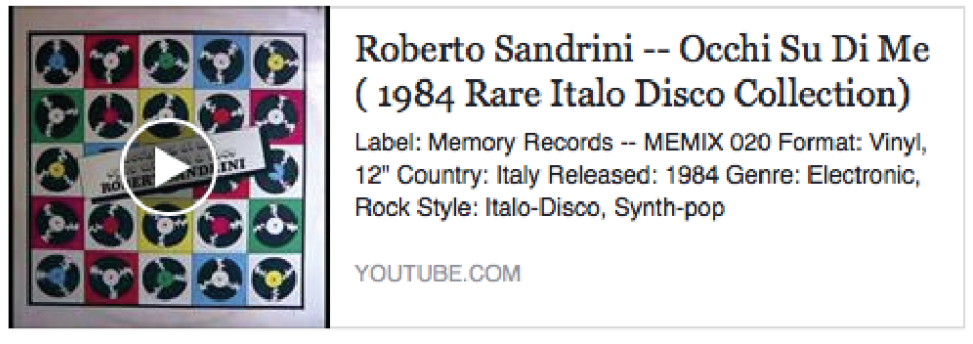

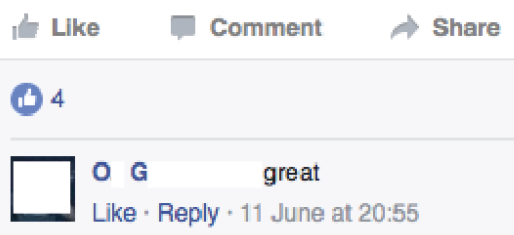




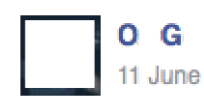

https://www.youtube.com/watch?v=xUBu_WWG7lc

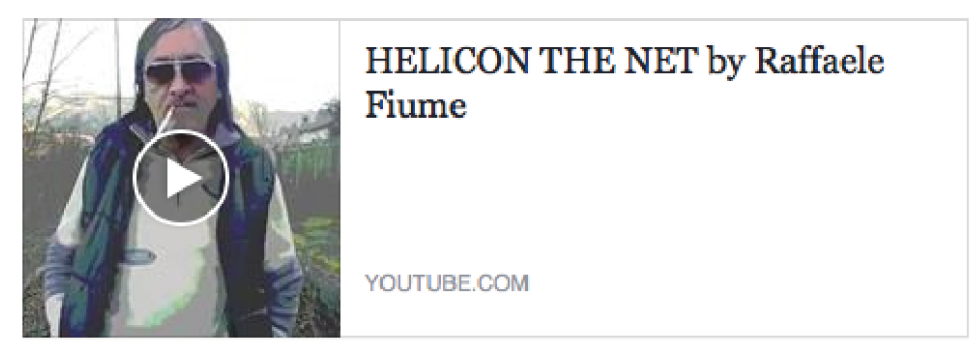

It) Like $\quad$ Comment $\rightarrow$ Share

54)

B
11 June Kraków, Poland

Italo (not that italo) (-)

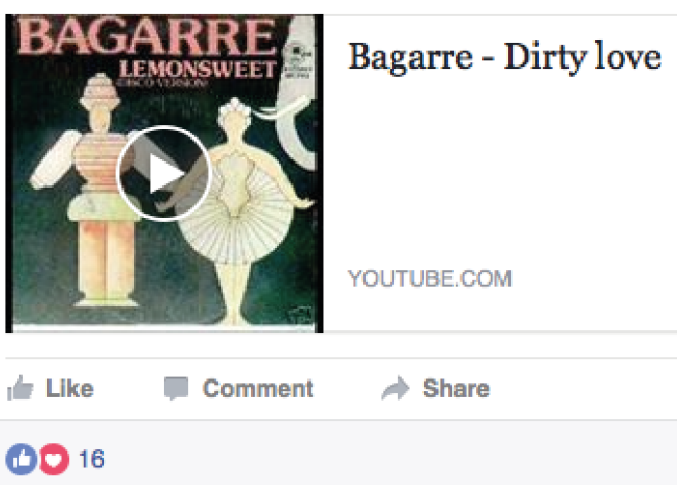




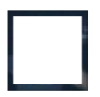

O G

11 June

https://www.youtube.com/watch?v=E7ZD83ml-dk

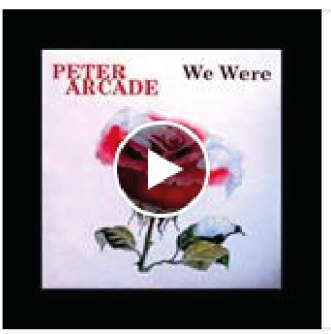

Peter Arcade - We Were 106

it) Like $\quad$ Comment

$\rightarrow$ Share

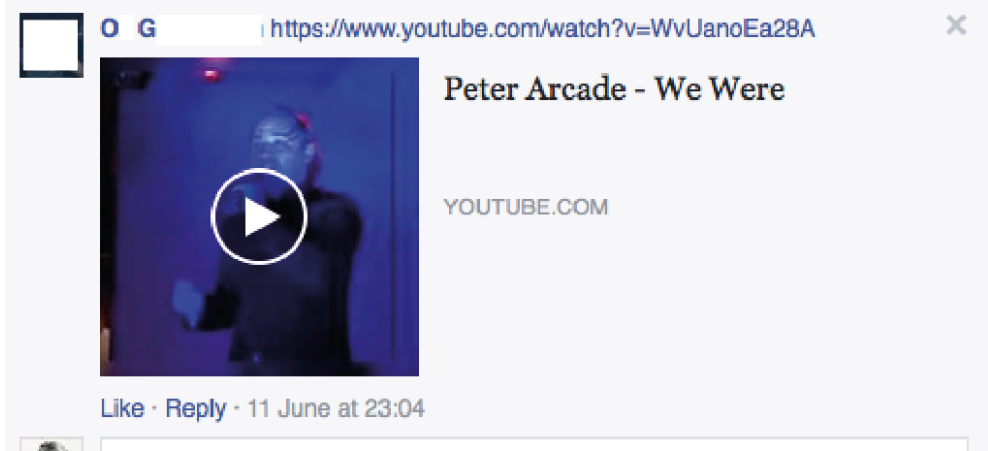




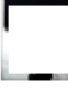

A $\mathrm{K}$

11 June

Maybe it has been posted already, but as a thank you to everyone, here's one of my top 10:

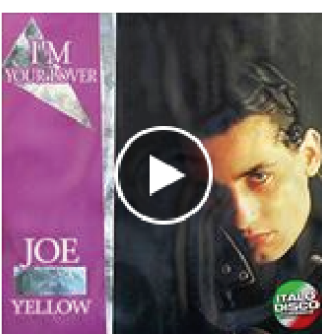

Joe Yellow - I'm Your Lover (Italo

Disco)

ZYX Music Italo Disco Classic, 1986 ZYX Records --

ZYX 5472 Amazon Download:

http:/www.amazon_de/gp/product/B007NCEQ3U/re...

YOUTUBE.COM

it Like

Comment

A Share

(6) 1

O G You ever saw this A K ?

https:/www.youtube.com/watch? $\mathrm{v}=\mathrm{zqUUU}$-Oe-tM

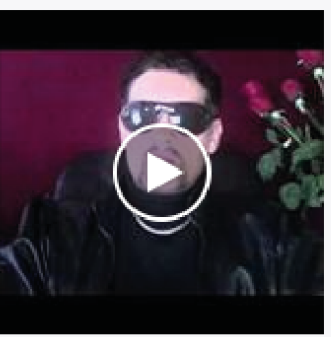

*Joe Yellow (Ricchini

Domenico)* Interview*...

Like - Reply - 11 June at 20:46

$\square$ A $K$ Never watched it. But doing it right now, thank you! Like - Reply : 1 1 1 June at 23:13

\section{7)}

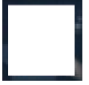

O G

11. June

https://www.youtube.com/watch?v=hyA2K2U_nJE

Cristina Hansen - Lady Godiva. 1987

ItaloDisco 1987

YOUTUBE.COM 


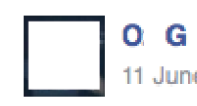

hot girl of italo

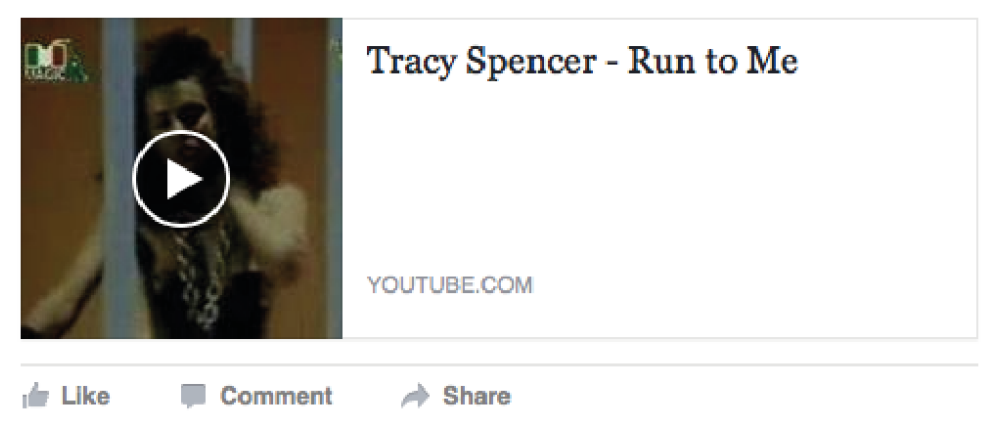

(1) 2

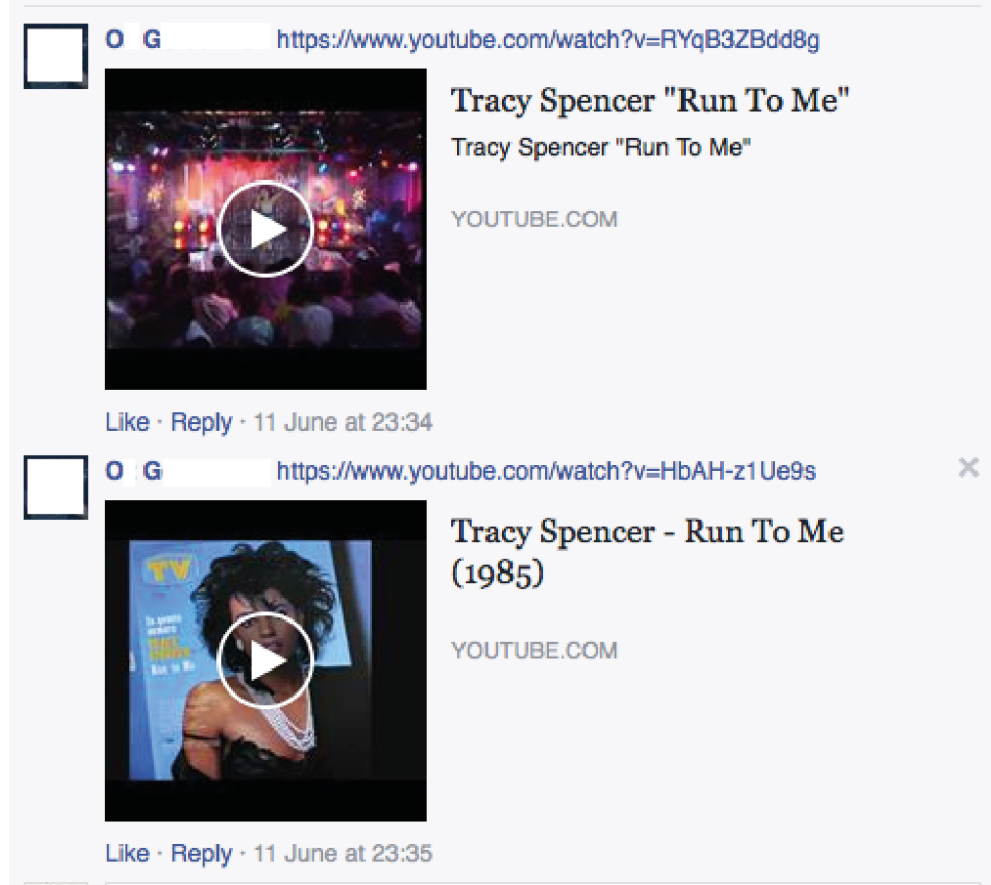


$\int_{12}^{K} \quad \mathbf{C}$ June $\cdot$ Kraków, Poland
Classic!

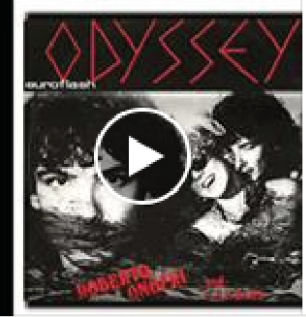

Roberto Onofri \& D.J.P. BandOdyssey (Very Rare Italo-Disco)

Artist: Roberto Onofri And D.J.P. Band Single: Odyssey Side A Label: Master Program Catalogif: MAS PRG 305 Format: Vinyl, 12", Maxi-Single, 45...

YOUTUBE.GOM

It Like

Comment

Share

(4) 2

60a)

W
Such a beauty, well, both of them!

Nadia Cassini - Passaporto Per La Follia (1977)

YOUTUBE.COM

It Like
(4) Comment

- W B Lucky youl Thought people asked more for this but $35 €$

_. isn't bad at all for 7 inches.

Like - Reply - 10 June at 10:06

- G It's not the cheapest, got it for like 20 I thought together with two

other records you see here. Made a picture for facebook when I got them a while ago.

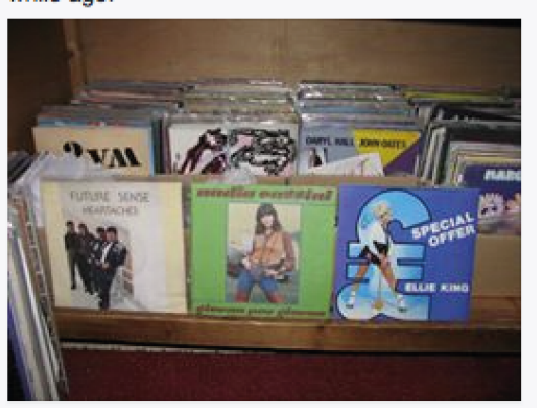

Like - Reply - 33 - 10 June at 10:18 - Edited

- W B Not bad at all! A new one on discogs they sell for 50 .

Like - Reply $\cdot B 1+10$ June at 10:20 
60b)

o G Hmmm...maybe e-bay or cdandlp.com?

CD and LP - Achat et Vente Vinyle, CD occasion et collector

CD and LP permet aux collectionneurs, DJ et disquaires d'acheter et vendre des disques de collection ou neuf en $C D$, vinyls, 33 tours, 45 tours, Maxi, EP...

CDANDLP.COM

Like - Reply · 10 June at 10:27

- W B On Ebay more or less same prices. I didnt know that cdandlp webpage.

Like - Reply - 10 June at 10:33

o G Think round 30 is good price..

http:/www1 , popsike.com/php/quicksearch,php...

Like - Reply · 1 10 June at 10:41 - Edited

- F H The special offer on the pic is nice too. Do you have it also on 12 inch $\mathrm{Oz}$ Goldenlion?

Like - Reply - 10 June at 21:15

[ O G No, is there a 12inch?

Like - Reply - 11 - 11 June at 20:47

- $F$ H There is $* * *$

Like - Reply - 31 - 12 June at 01:49

[ 0 G Nice, not on discogs. Do you have a link?

Like - Reply - 12 June at 10:14

61)

O $\mathbf{G}$

quite pumpep up (new gen)sound but kinda like it...the new gen italo disco anthem? $(9)$

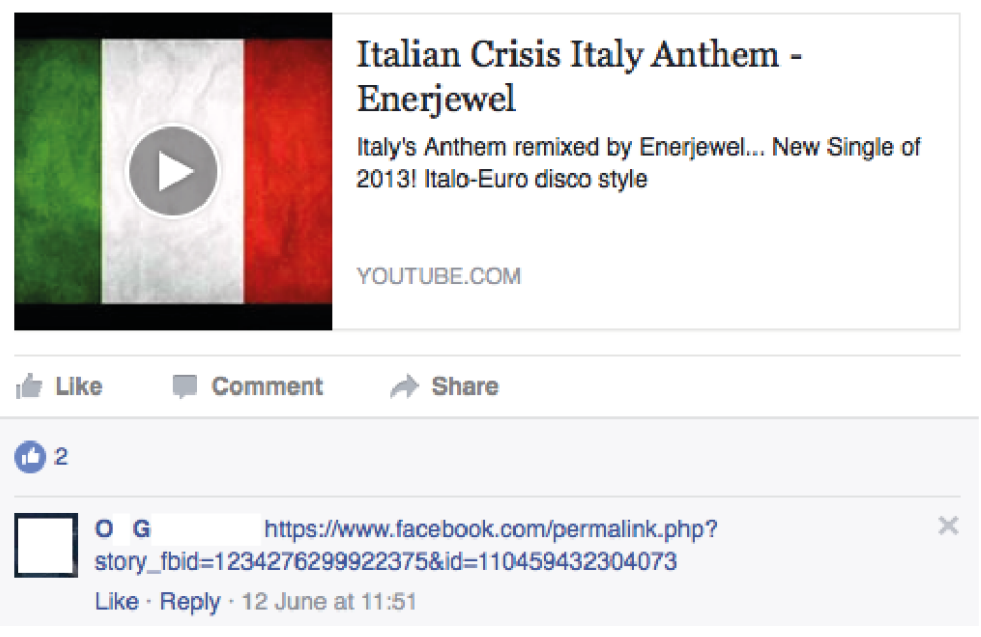


L_ K $\begin{aligned} & \text { K } \\ & 12 \text { June } \cdot \text { Krakow, Poland }\end{aligned}$

LSD!

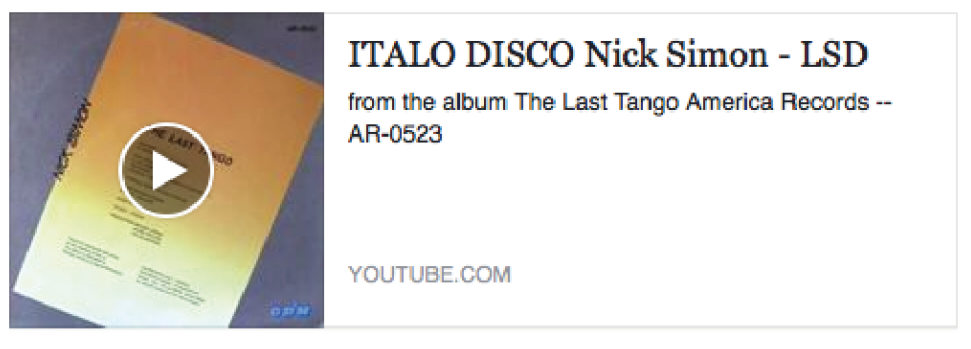

\begin{tabular}{lll} 
IL Like & W Comment \\
\hline (1) 8 & 8
\end{tabular}

(1) 8

[ 0 G nice one!

Like - Reply - 12 June at 10:26

D P H cool YT canal I! it is mine (:)

Like - Reply : 132 - 12 June at 12:22

[ o G ha, didn't realise...gonna check more now (:) Like - Reply : $\leftrightarrow 1$ - 12 June at 12:25

i. Write a reply...

이 (ㄱ)

[ 0 G ardered a copy just now (9)

Like - Reply - 12 2 12 June at 12:23

Post a stick

63)

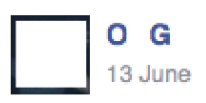

Another amazing asian cover of italo (:)

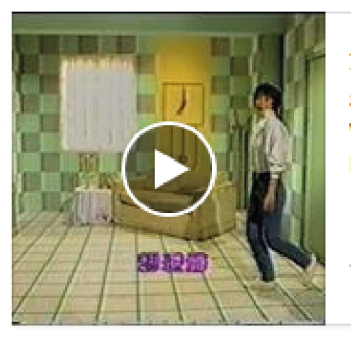

金曲重溫: 葉背文 Cha Cha Cha 1986

STEREO remix from LP record Music copyright :

WMG Film footages copyright : Television Broadcasts Limited

YOUTUBE.COM

It Like $\quad$ Comment $\Rightarrow$ Share

(6) 6

O G amasian (1)

Like - Reply + 131 - 13 June at 09:59 

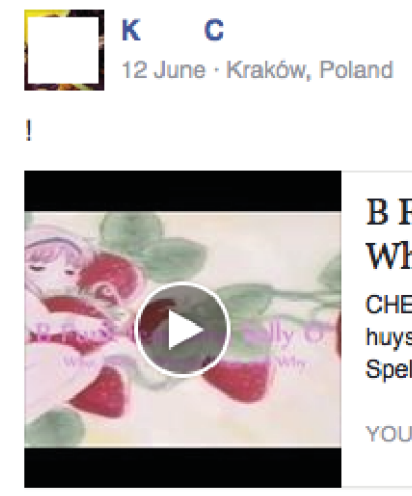

B Funk featuring Sally O' - Who, What, Where, When and Why

CHECK MY MIXES http $/$ /Www.mixcloud.com/jadranhuys/ From the B.Funk Featuring Sally $\mathrm{O}^{\prime}$-- Magic Spell LP Label: Phoenix Productions -- PHOF $4001 \ldots$

YOUTUBE.COM

It) Llke $\quad$ Comment $\quad \Rightarrow$ Share

(1) 3

K C and of corse Instrumental editrver (:)

hitp://mp3xi.org/.../3015190-b_funk_feat_sally_o-who.../

B. Funk feat Sally $O$ Who What Where When And Why (Flemming Dalum edit) слушать онлайн и скачать...

B. Funk feat Sally $O$ Who What Where When And Why (Flemming Dalum edit) (1 песня) скачать или слушать онлайн бесплатно MPSXL.ORG

Like - Reply - 132 - 12 June at 01:50

F H still have the Album of them . Cool Italo Disco with funky parts . Like - Reply : $132+14$ June at 08:33

\section{5)}

O G

14 June

if you haven't seen this movie Wolfpack maybe you will after seeing this clip. (:)

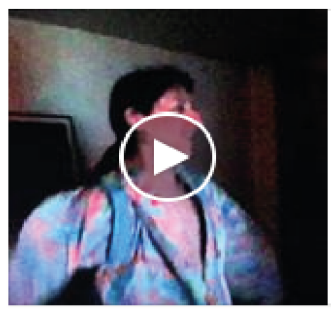

'The Wolfpack' (Angulo Brothers) Tarzan Boy by Baltimora.
It Like
Gomment
$\Rightarrow$ Share

(1) 2

O G it was on dutch tv this monday but saw it in the cinema myself some weeks ago. You can watch this till june 20th here (don't know if this work abroad though). http//www.npo.nl/2doc-the-wolfpack/13-062016/VPWON_1235287

2Doc: The Wolfpack - 2Doc:

De familie Angulo besluit hun zes zoons binnen te houden en thuis les te geven. Vader geeft hen films, veel films. De opgroeiende broers leren de wereld kennen door middel van de films die zij zien.

NPO.NL

Like - Reply - 14 June at 20:04 


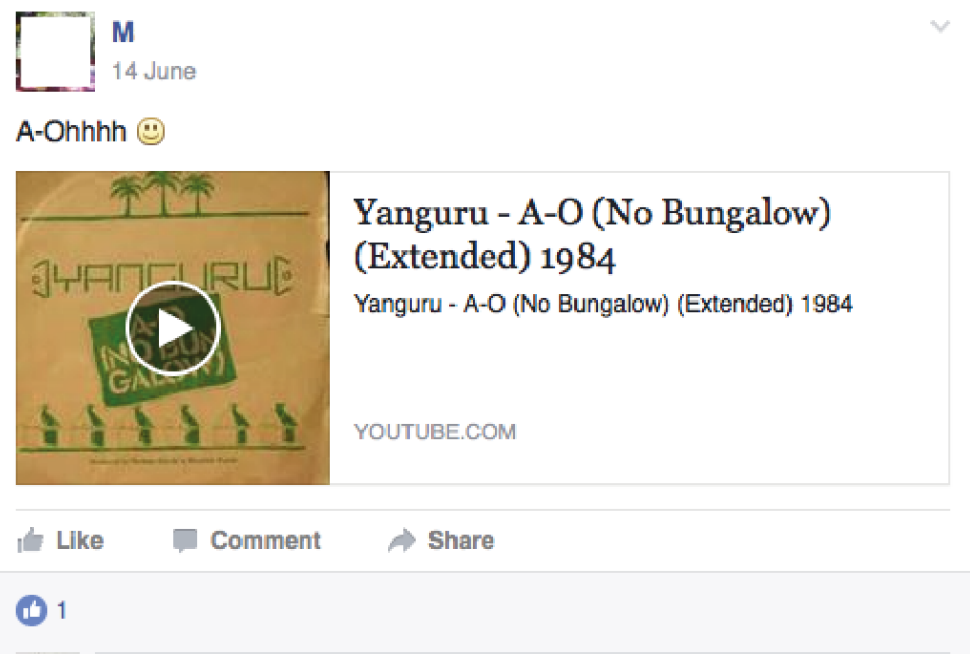

67)

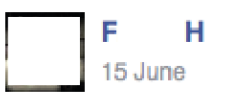

https://www.youtube.com/watch?v=zmOit3aiw_s

Oxid - Bright Heron (Voom Voom
Music, Italy 1977)
for mixes \& more visit
http:/soundcloud.com/bonedisco




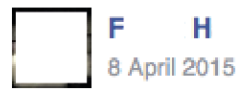

https://www.youtube.com/watch?v=zvWBQJoFLJs

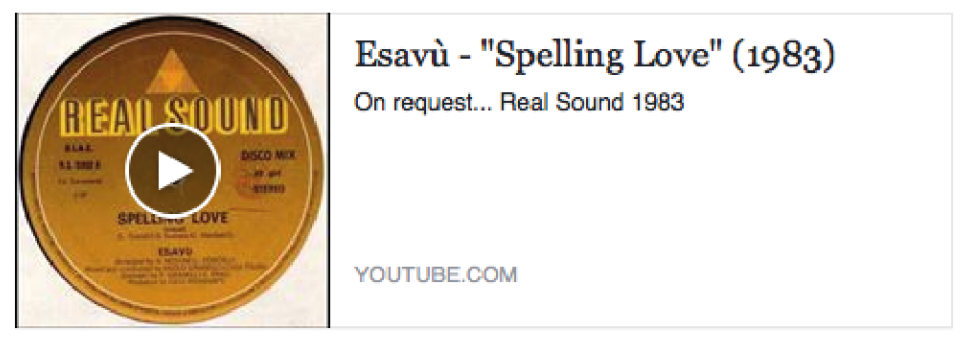

It Like $\quad$ Comment $\Rightarrow$ Share

(1) 8

D G I!!

8 April 2015 at 22:03 - Like

$\square$ F $\quad$ H O

8 April 2015 at 22:04 - Like

O G https://www:youtube.com/watch?v=g-rEuOtMsRE

15 June at 12:39 - Edited - Like

$\square$ o G Lyrics i could write down so far...

Esavu - Spelling Love... See more

15 June at 12:49 : Like $\cdot 131$ 
O G

15 June

(automatica)more patrizia

See translation

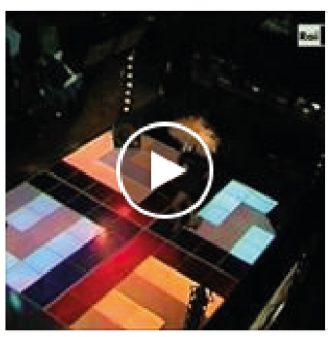

PATRIZIA PELLEGRINO - Matta Ta (HIT PARADE 1982 - versione integrale)

Divertente e trash quanto basta, la soubrette napoletana cercherà di bissare il precedente.

YOUTUBE.COM

it Like $\quad \square$ comment $\Rightarrow$ Share

$\theta=4$

O G

never saw this as leader of show $(9)$

https:/www.youtube.com/watch?v=jlVyhjk7eCQ

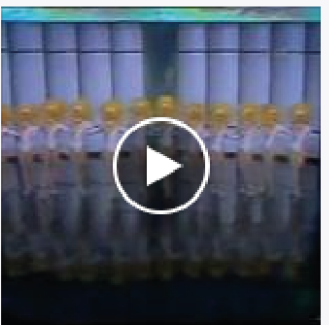

PATRIZIA PELLEGRINO -

BENG!! ( SIGLA TV " GRAN...

Like - Reply · 15 June at 13:20 
$\square$ C June $_{14 \text { Juned }}^{\text {C }}$ R shared memory.

!!!!!!!!!!!!!!!!!!!!!!

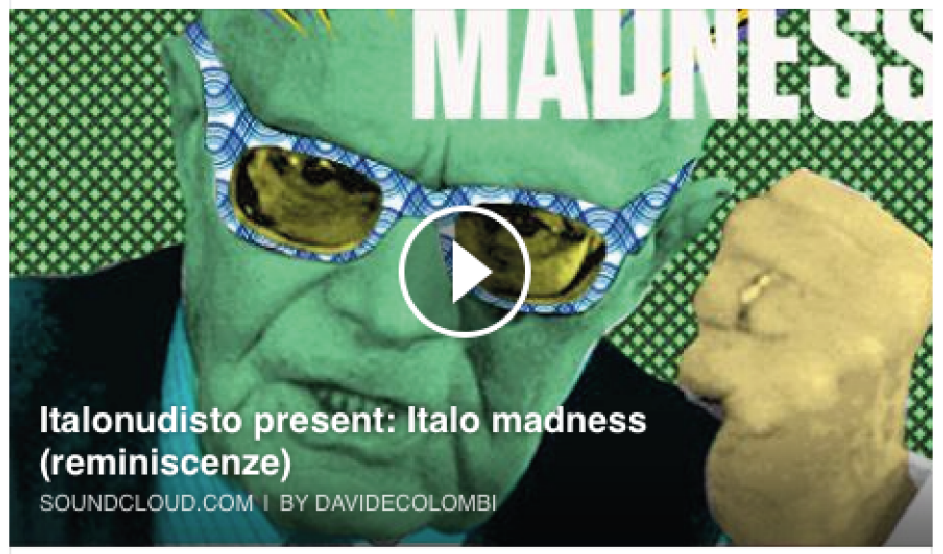

Italonudisto present: Italo madness (reminiscenze)

There are more then 60 tracks on this mix. I had a lot of fun with this set, which takes me right back to my first step into dance music as this is more or less the music I was playing. At that ti

SOUNDCLOUD.COM || BY DAVIDECOLOMB

Save

It Like Comment

(1) 3

O G Listening this through now...grandel Never heard of this guy from Australia.

Like - Reply - 15 June at 20:10 - Edited

71)

$\left[\begin{array}{lc}\text { K } & \text { C } \\ 16 \text { June } \cdot \text { Kraków, Poland }\end{array}\right.$

(8)

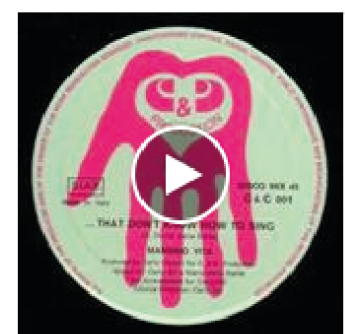

Massimo Vita - That Don't Know

How To Sing

If Like

Comment

Share

(1) 2 
$7 \mathrm{~K} \quad \mathrm{c}$

19 June at 08:42+ Kraków, Poland

Awesome crasher from Massimo Noe... WOW!

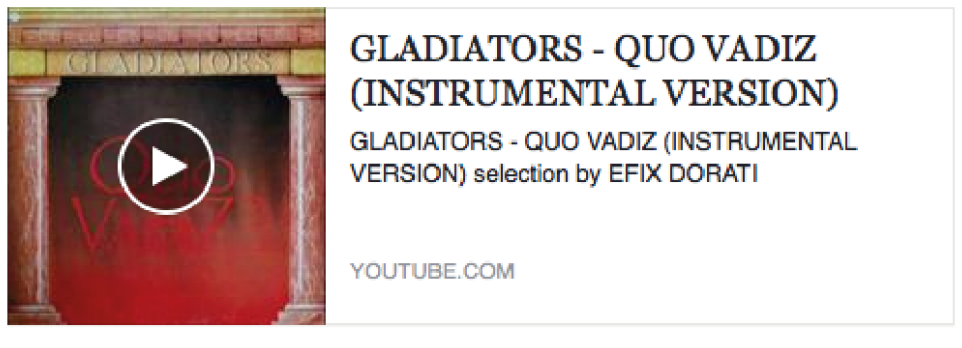

It Like Comment $\quad \rightarrow$ Share

(1) 4

O G nice tip, think never heard so indeed wow!

Like - Reply + 21 June at 11:41

O G why not some vocals (9) https:/www.youtube.com/watch?

$v=i p 7 R T G F B i H Y$

Gladiators - Quo Vadiz

(Extended Mix) (1984)

YOUTUBE.COM

Like - Reply + $131+21$ June at 11:42

O. G now I heard the vocals i think i heard but thanks for $\mathrm{X}$ reminding anohow $(\bullet)$

Like - Reply + $131 \cdot 21$ June at 11:46

F H prefer without too.

Like - Reply : 131 - 21 June at 19:31

O G if every member of this group would give his/her

preference for vocal or instrumental....that would be

something.... wouldn't it? (-)

Like - Reply - 131 - 21 June at 19:52 - Edited

] K C A side'rs or B side'rs :))

Like - Reply : 1 1 - 21 June at 19:55

O G i expect every member to vote A (vocal) or B (instrumental) for every song posted here from now on! (-)

Like - Reply - 131 - 21 June at 20:13 - Edited 
73)

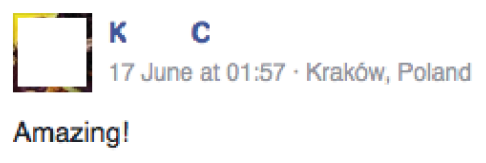

Like Comment $\rightarrow$ Share


$\square$ J $\quad$ H shared his post.

16/06/16 My latest vinyl only mix! Cruisin' full throttle through an 8-bit landscape leaving only pixelated dust behind, driven to magic emotions! Check it here https://www.mixcloud.com/.../driven-to-magic-emotions-italo.../ Shout out to Ferenc Dos Santos, Danny Wolfers, James Penrose, George Hysteric, Otto Kraanen, David Vunk, Mima Mihajlovic, Alexander Robotnick, Edward Upton, Neeme Oja, Fred Ventura, Paolo Gozzetti, Flemming Dalum, Celina Seng, Sebastian Hyboid, Alessandro Adriani, Loek van Beers, Nick Smith, Camille Bertin, Murphy Jax, @Alessandro Parisi and of course you!

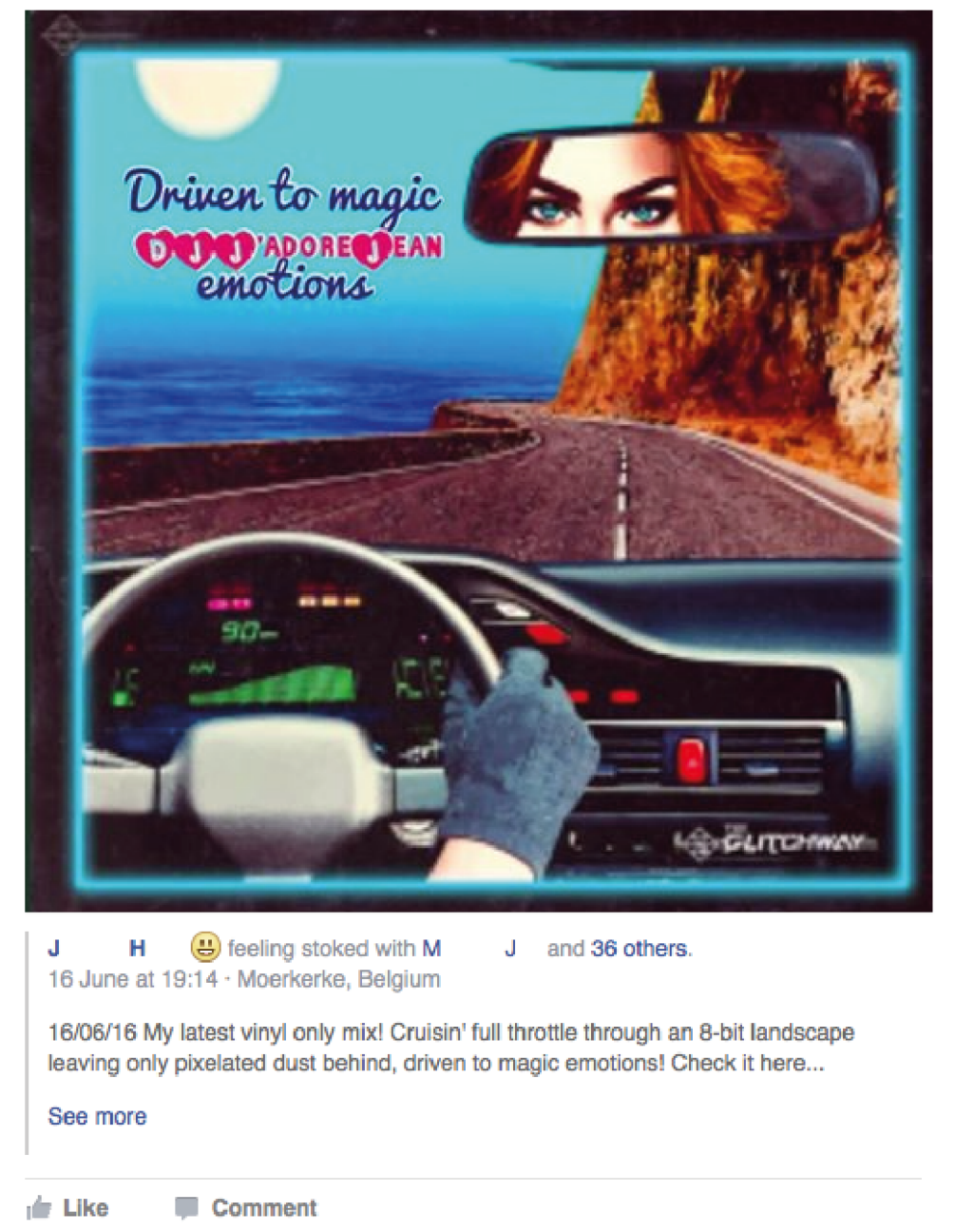


$\square$

L V

17 June at 19:38

happy friday!

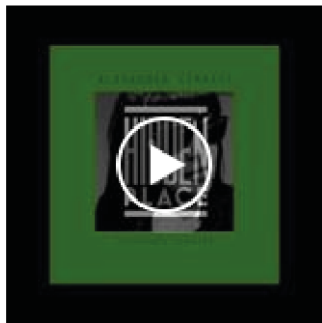

Hidden Place - Alexander Strasse (alternate version)

Alternate version by Fabio Vitelli, Antonio Losenno

Vocals by Sara Lux

www.facebook.com/hiddenplaceitalia

YOUTUBE.COM

It Like

Comment

Share

(B) 1

76a)

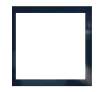

O G

17 June at 22:03

https://www.youtube.com/watch?v=sLMjey4OBwA

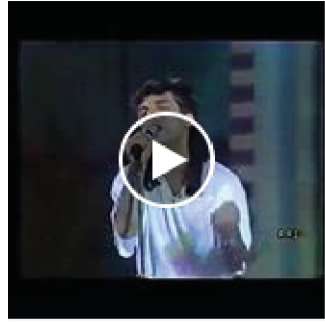

ARMANDO MANGO \& DUM DUM

POP - IL SOLE NASCERA' (1986)

BRANO INSERITO SU GENTILE RICHIESTA

It Like $\quad$ Comment $\quad \Rightarrow$ Share

o G hitps://www.youtube.com/watch?v=22Fvari-MJY

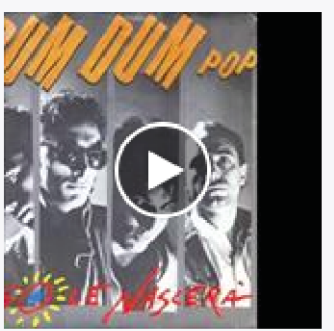

Dum dum pop - Il sole Nascerà

da vinile (restaurata)

YOUTUBE.COM

Like - Reply - 17 June at 22:03

J C $\quad$ P No es lo que yo llamaria italo disco $(\because)$

See translation

Like - Reply + 17 June at 23:54

$\square$ ○ G Well it doesn't have to be strictly "italo disco" whatever YOU think that it is.... (:)

Like - Reply - 18 June at 10:23 - Edited 
76b)

G $M$ Thanks ही ही ही

Like - Reply - 131 - 19 June at 15:48

o $G$ refreshing to hear italothemes passing by here

reworked/remixed!

Like - Reply - 12 2 20 June at 13:35 - Edited

77a)

O G

17 June at 22:2?

https://WWW.youtube.com/watch? $\mathrm{V}=$ INicfLo Yc9A

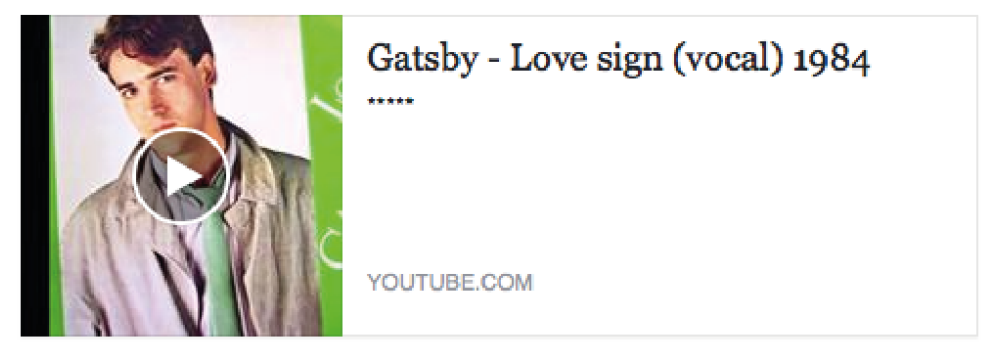

Like Comment $\Rightarrow$ Share

(6) 2

M E cheaper option:

https:/www.discogs.com/Various-Only-For-DJ/release/853294 (9)

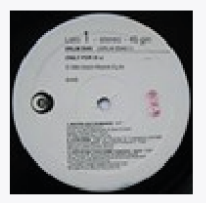

Various - Only For D.J.

Label: Ricordi - SRLM 2045 - Format: Vinyl 12

DISCOGS.COM

Save

Like - Reply - 13 1 - 17 June at 22:25

o G oh I thought listening to youtube -9

Like - Reply - 17 June at 22:25

- G nice candidate for next reissue on Dark Entries

Like - Reply = 132 + 17 June at 22:26

K C : Don't forget about lovely Instrumental $(9)$ https://youtu.be/- $\quad \times$ OANKJGIKI

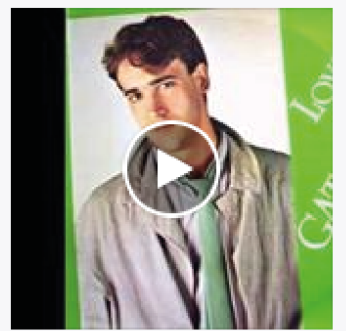

Gatsby - Love Sign Instrumental Version 1984

Like - Reply * 18 June at 00:23 
77b)

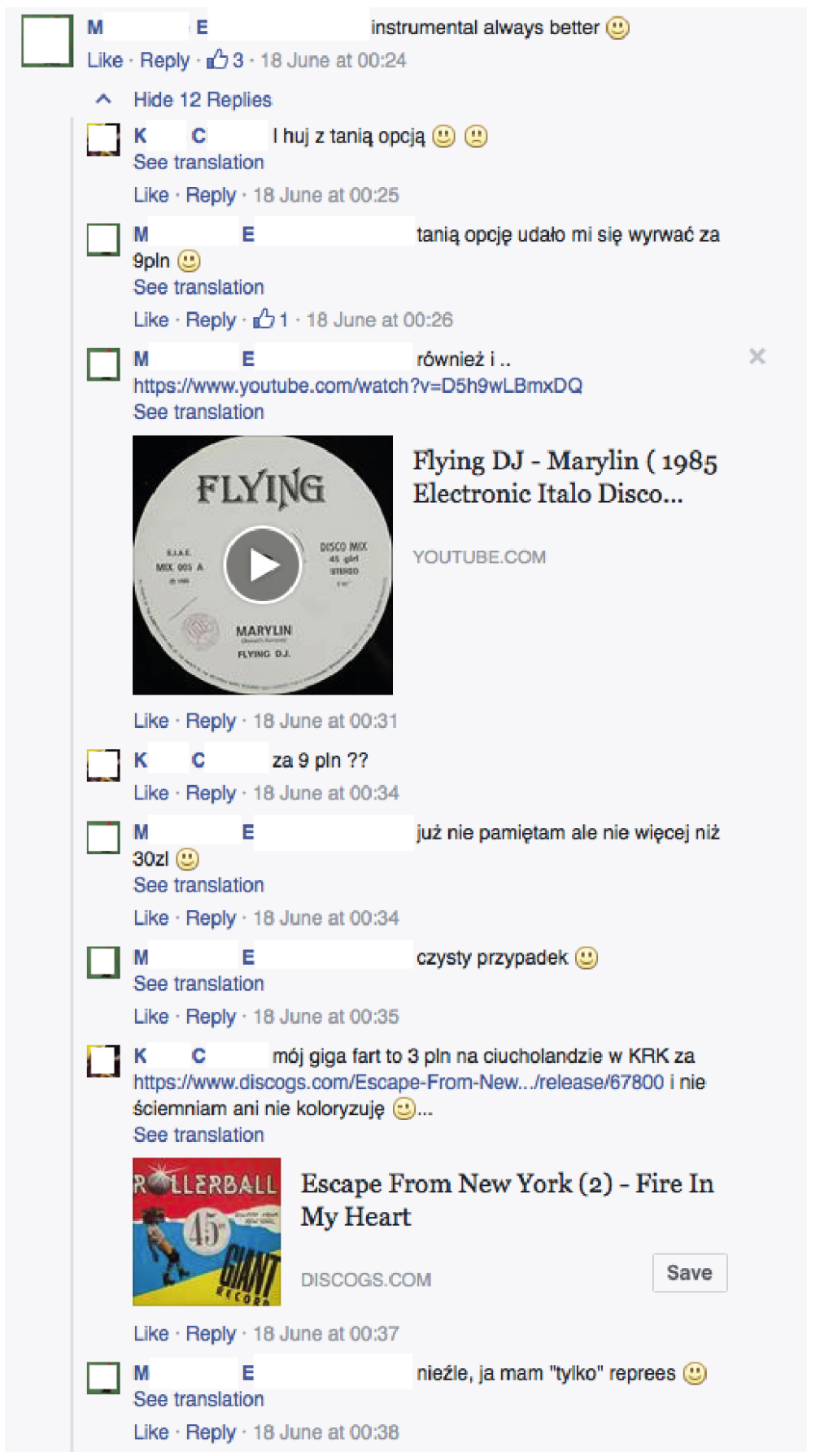


77c)

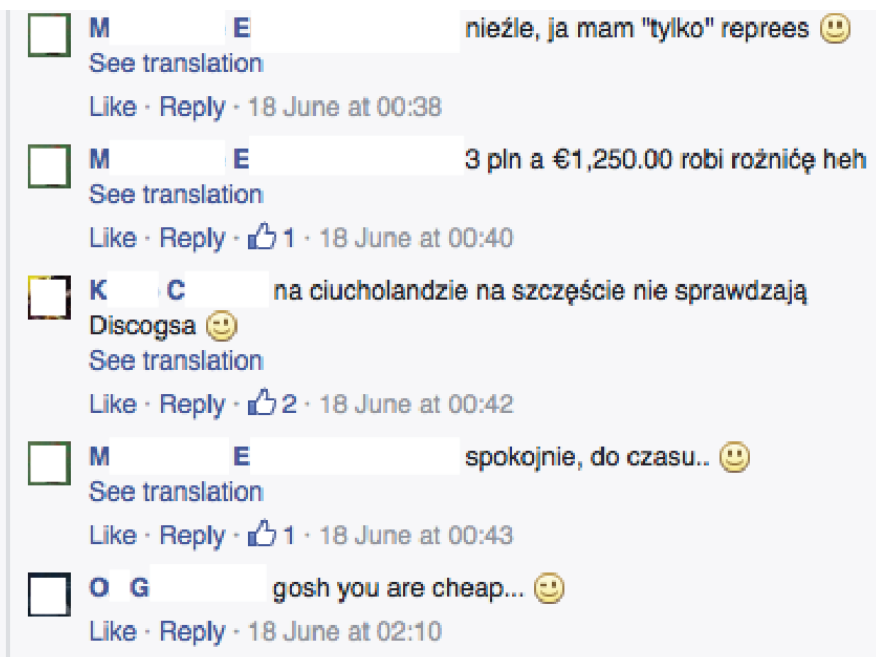


$\begin{array}{ll}\text { K } & \mathbf{C} \\ 15 & \text { June } \text { - Kraków, Poland }\end{array}$

Imagine (:) ... "Richard Benson - Animal Zoo" and "Stephen Head - Switch On Fellini" on one record vinyl and in one movie together (:) ... impossible (2) ?!

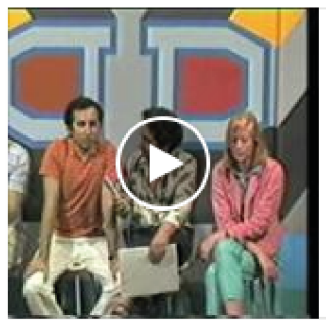

"In punta di piedi" un film di Giampiero Mele in un programma di Paolo Pecora

Giampiero Mele presenta in un vechio programma televisivo di Paolo Pecora la sua prima opera.

YOUTUBE.COM

$1+$ Like $\quad \Rightarrow$ Comment $\Rightarrow$ Share

(1) 2

7 K C I might add that both trax are extremely rare $(9)$

O G nice footage no matter the rarety.

Like - Reply + 17 June at 21:28

O G Ah there is some Dutch speaking @ $3 \mathrm{~m} 10 \mathrm{~s}(9)$ "ik vind het een hele mooi film" ${ }^{\text {" }}$ etc

See translation

Like - Reply - 31 - 17 June at 21:32 - Edited

7 K C I want watch this movie but I can't find it anywhere... last copy

0 for good price, I bought 2 copys in mint, really cheap (:)

Like - Reply - 18 June at 00:14

下 $\mathrm{C}$ https://www.discogs.com/Narious-InPunta.../release/3912514

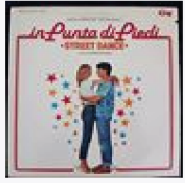

Various - In Punta Di Piedi

Label: CAM - LCM 33455 - Format: Vinyl LP,...

DISCOGS.COM

Save

Like · Reply - 132 - 18 June at 00:15

O G thanks for tipping

Like · Reply · 1 1 18 June at 21:56 
L $\quad$ P
20 June at 00:03 + Berlin

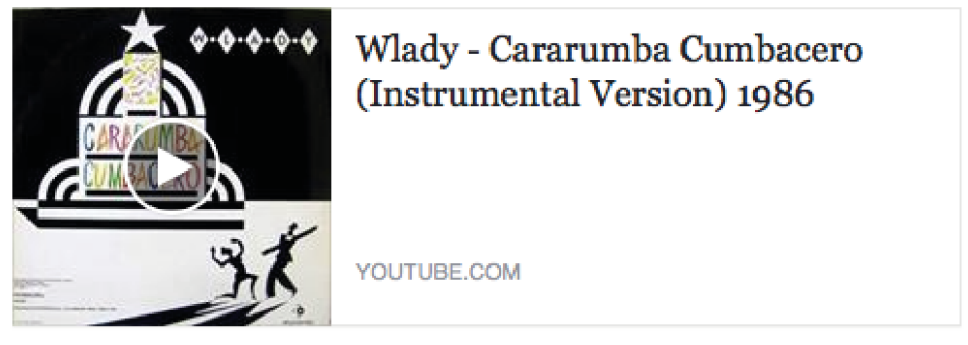

It Lilke Comment $\Rightarrow$ Share

(1) 6

$\square$ L P and of course, great vocal version too: hitps://www.youtube.com/watch?v=VYDpRI4PDac

Like - Reply - 20 June at 01:17

L $\mathrm{k}$ c c Just bought... (:)

Like - Reply - B 1 - 20 June at 01:22

1. L P i will do it soon...but a 7" !

Like - Reply - 20 June at 01:47 
K
C $\quad$ with J P P P at $09: 51$. Krakow, Poland

For all maniacs members of the best group in the world (-), for your pleasure in sunny Sunday... My Italo-Synth mix recorded two years ago, but still juicy... enjoy! (:)

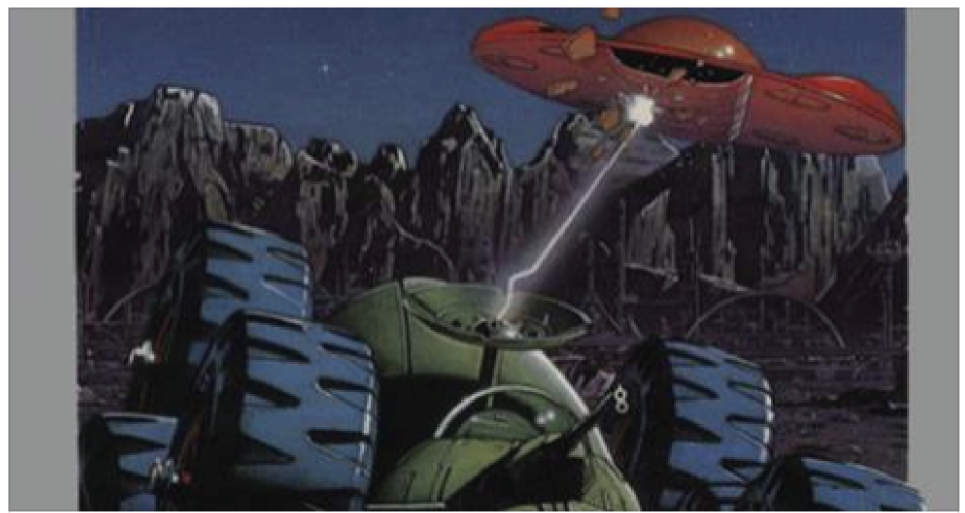

\section{Kinzo Chrome - Moon Patrol Mix}

Ścieżka dźwiękowa z codziennego patrolu na księżycu robota 5 generacji MX 218. Życzę przyjemnej kosmicznej syntezy ! Kinzo Chrome - Moon Patrol Mix 11.2014 1.Mechanical Principle - Burning Up 2.Mik

SOUNDCLOUD.COM I BY KINZO-CHROME

It Like $\quad$ Comment $\Rightarrow$ Share

(4) 14

$\square$

F $\quad \mathrm{Great}$ mixp

Like - Reply + 1 1 - 19 June at 10:10

T. Kinzo Chrome I'm glad you like it... (9) thx F

Like - Reply 19 June at 10:15

6. Write a reply...

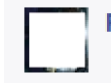

D

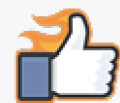

Like - Reply - 3 - 19 June at 15:30 
$\left[\begin{array}{l}\mathbf{A} \quad \mathbf{F} \\ 16 \text { June at } 17: 40\end{array}\right.$

Hello italo disco and 80s lovers! In the name of new-italo, I would like to present my last work on Sunlover Records - You can buy my digital and $12^{n}$ vinyl record here: http://faxthefox.bandcamp.com - THANKS

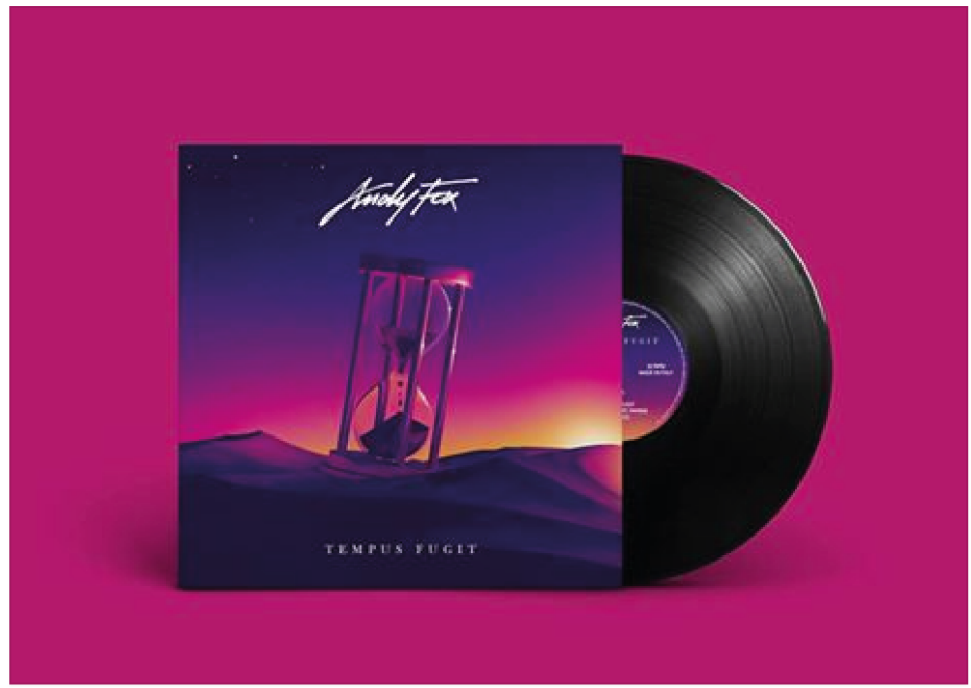

If Like $\quad$ Comment

(C) 12

F $\quad$ H I like the first and the second track* Like - Reply - 16 June at 22:02 - Edited

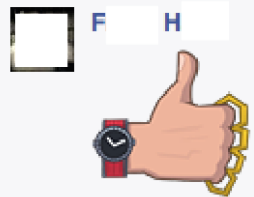

Like - Reply + 16 June at 22:08

A F Thanks! $(0)$

Like - Reply + 13 - 16 June at 22:28

F H I think I will order over discogs...is the vinyl available now ?

Like - Reply - 31 - 16 June at 22:30

D A F Yes it is!

Like - Reply - 131 - 16 June at 22:31 
81b)

H I think I will order over discogs...is the vinyl available now ?

Like - Reply + 1 + 16 June at 22:30

A $F$ Yes it is!

Like - Reply + 1 1 - 16 June at $22: 31$

K C I'm very skeptical to Italo-New Gen. but this LP is very good really! I will order for sure (:) Good job A !

Like - Reply + $132+17$ June at 01:11

F H It's also synthwave style on it...I like that.

Like - Reply + 17 June at 21:49 - Edited

L $\quad$ P $\quad$ complimentoni A F ।

Like - Reply + $131+20$ June at 01:56

A A Graziel

See translation

Like - Reply + 20 June at 12:16

82)

$\mathbf{L}$

20 June at $15: 46$

Hi,thanks for the add!

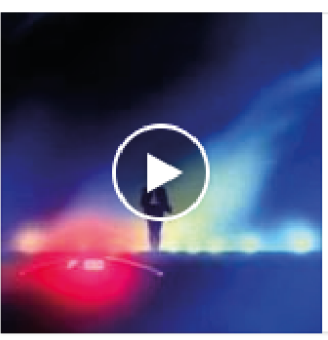

(GDo07) The Hunt - Survivor

https:/giallodiscorecords.bandcamp.com/ Edited by Jadran Huys Parisian duo The Hunt stalk the night with their armory of analog hardware. Neon, night drive...

YOUTU.BE

느 Like

Comment

$\Rightarrow$ Share

83)

W
21 June at 11:28

just love it! Italy 1982

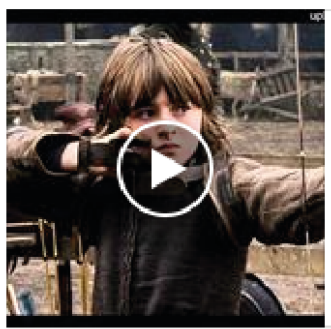

METAL MOMENTS - Young Boy

Another track from the same EP -uploaded in HD at

http:/www:TunesToTube.com

I. Like

Comment

YOUTUBE.COM

(1) 4 


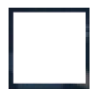

O G

21 June at $11: 47$

https://www.youtube.com/watch?v=g3WkHdQUuiU

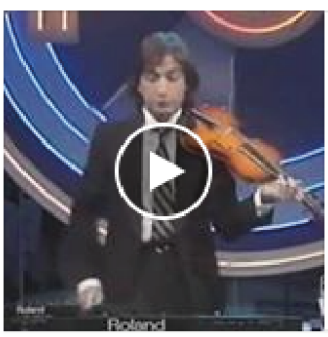

Carrara - Shine On Dance

Best Music Around

If Like

Comment

(4) 1

85)

L P S shared Automaticamore's event.
21 June at 12:13 - Berlin

For all the Berliners and neighbors this Sat 25.06! We can have a meeting (8)

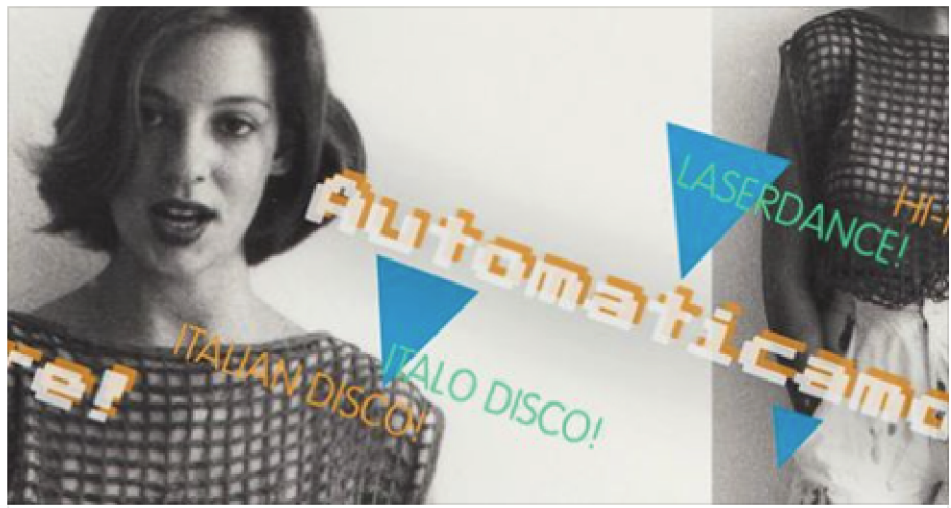

\section{Automaticamore!}

25 Sat 23:00 - Kreuzberg, Berlin

JUN 302 people interested · 84 people going

Going -

1. Like

Comment

(6) 7 
\begin{tabular}{|l|l|l|l}
\hline & P \\
21 & June at $12: 38$ & Berlin
\end{tabular}

Oh right,good morning!

Massimo Barsotti - Whole Lotta
Love (vocals)
Some quality italo-disco with some questionable if
hilarious vocals. Whole LOL la love. Label:Fuzz
Dance Format:Vinyl, 12', 33 $1 / 3$ RPM Country:Italy...
YoUTUBE.COM

87)

M M
21 June at 19:00

hey, thank you for adding ...here is 'something obvious (9)

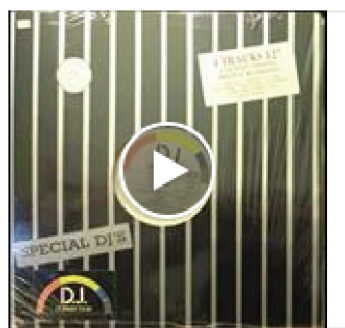

CAPRICORN-I NEED LOVE

ITALO DISCO 1982 VINYL12" 33RPM

It Like

Comment

A Share

008

88)

$\square$

O G

21 June at 22:42

https://www.youtube.com/watch?v=dBahqz Y'myc

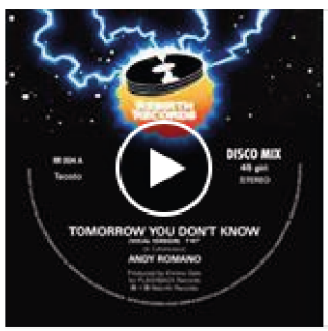

Andy Romano - Tomorrow you don't know

Tomorrow you don't know perfomed by Andy Romano with Marylinn

YOUTUBE.COM

It Like

Comment

Share

(1) 8 
89)

$\square$

o G

21 June at 23:02

it was still possible in 1990

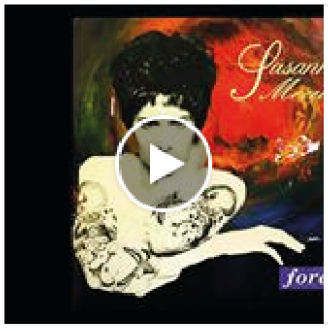

Susanne Meals - Forever

1990 - Lombardoni Publishings - Italy

It Like

Comment

YOUTUBE.COM

$102^{2}$

A4 $\mathrm{T} \quad \mathrm{S}$ I always feel like this is the "swansong" of Italo-Disco. Like $\mathrm{X}$ 1 one last beautiful reminiscence... 9

Like - Reply - 131 - 22 June at 02:57

7. 0 G "swansong of italo disco" good description

Like - Reply + 22 June at 10:50 - Edited 


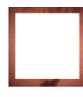

D $\quad$ M

20 June at $14: 31+$ Münster

Hey Maniacs! I need help IDing a track. I found it on the following mix by Sacha Mambo and Albion. The particular track I'm talking about begins at 19 mins 20 seconds and the lyric goes:

"guck mal ein kleiner mann ob er wohl zaubern kann, guck mal was er macht er zaubert dass ist blitzt und kracht"

Thanks in advance for taking the time to help (:)... See more

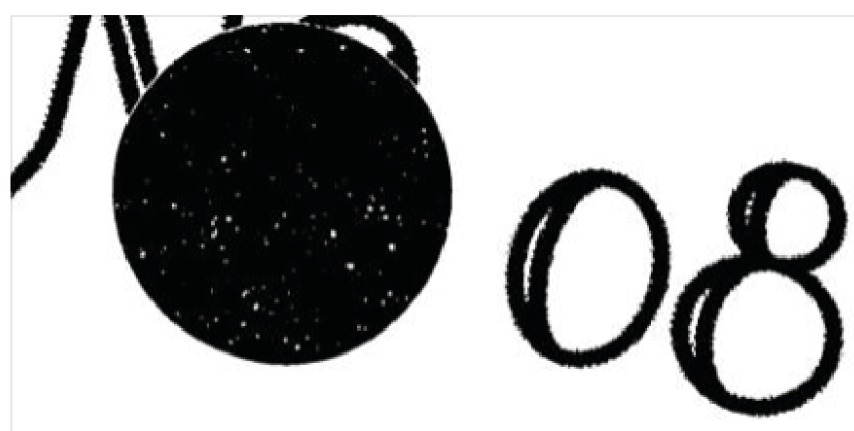

\section{Sacha (Macadam Mambo) \& Albion Venables (Frisbee)}

\section{Set}

Albion, célébrant sa sortie "Pyramids" chez Macadam Mambo; Sacha, célébrant...

SOUNDCLOUD.COM I BYLYLRADIO

Save

It Like $\quad \Rightarrow$ comment $\quad \Rightarrow$ Share

(1) 3

Hwl Noree i think it's this one: https:/Www.discogs_com/Camilla-Motor-

Der.../release/881313

Camilla Motor - Der Zauberer

A 7 zaberer L Jupiter Records - 6.13 705, Jupiter Records -...

DISCOGS.COM

Like - Reply - 12 2 20 June at $14: 38$

T. Daithi MacLlam You're my new favourite human! THANK YOU!!!

Like · Reply + 20 June at 14:40

Wh Hwi Noree hahaha! it's a great onel enjoy!

Like - Reply + 20 June at 14:50 
O G

22 June at $11: 08$

https://www.youtube. com/watch?v=8jmMOQQz1iM

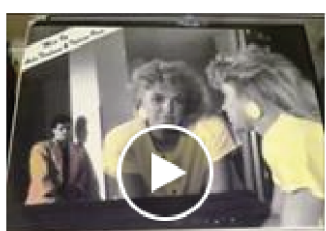

Judy And D.J. - Giving To Me

ZYX Music Italo Disco, 1987 OUT 3120

Geong torke 2aty and D? YOUTUBE.COM

It. Like $\quad \square$ Comment $\quad \Rightarrow$ Share

(1) 2

92)

$\square$ Y A 12 June at 15:00

Hello ragazzi \& paninari, discoheads \& italofreaks

See translation

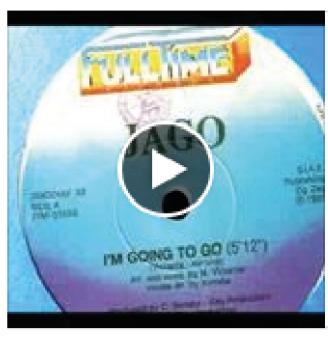

Jago - I'm Going To Go - FTM

31533

Label:Full Time Records Catalog\#: FTM 31533

Format: Vinyl, 12 ", 33 1/3 RPM Country:Italy

Released:1983 Genre: Electronic Style: Italo-Disco

YOUTUBE.COM

It) Like $\quad$ Comment $\Rightarrow$ Share

(6) 12 


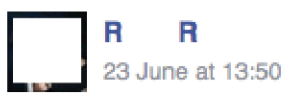

Trying my luck here - anyone know if there's a good instrumental edit or version of Future Brain out there? either MP3 or vinyl

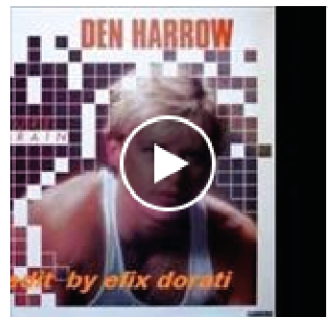

Den Harrow - Future Brain ( full instrumental version by Efix Dorati ) 1985

DEN HARROW - future brain ( full instrumental version by Efix Dorati ) versione totalmente...

YOUTUBE.COM

It Like Comment $\rightarrow$ Share

(6) 3

$\sqrt{ } \quad \sqrt{ }$ if you like this edit google youtube to $\mathrm{mp} 3$ Like - Reply - 23 June at 18:56

94)

$\square$

C

25 June at $15: 37$

Amazing!

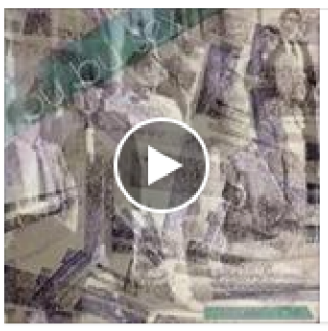

$\mathrm{Bu}$ Bu Sex - Great Expectations (1984)

Bu Bu Sex - Great Expectations Released as a EP by Best Record, Italy, in 1984 Catt: BEST 12032 Bu Bu

Sex is: Adriano Lo Giudice, Antonio Vernuccio, ....

YOUTUBE.COM

II Like

Comment

A Share

06 

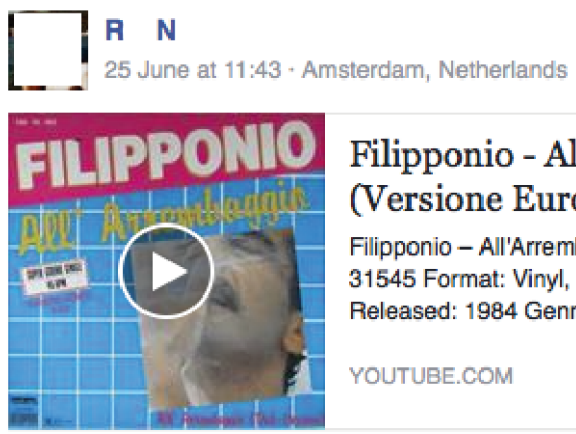

Filipponio - All' Arrembaggio (Versione Europea) 1984

Filipponio - All'Arrembaggio Label: Spice 7 - SP 31545 Format: Vinyl, 12", 45 RPM Country: Italy

Released: 1984 Genre: Electronic Style:...

YOUTUBE.COM

It Like $\quad$ comment $\Rightarrow$ Share

$0 \mathrm{O}_{2}$

O G Paolo Conte of italo disco.
See translation

Like · Reply + 25 June at 16:55

96)

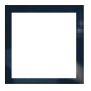

O G

22 April 2015

early disco magic

Nospy - Woilajo


O G

27 June at 00:19

https://www.youtube.com/watch?v=75EzvNdF1 is

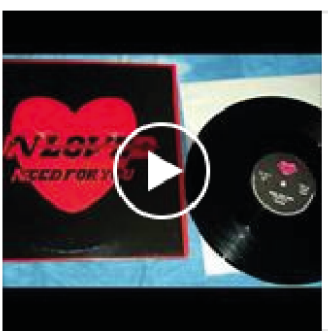

Unloved - Need For You (Midnight Mix)

Unloved - Need For You Label: Unloved - UNL 001

Format: Vinyl, 12", Maxi-Single Country: Italy

Released: Genpe: Electronic Style: Italo-Disco, New...

YOUTUBE.GOM

it Like

Comment

Share

(b) 1

98)

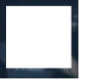

O G

27 June at $00: 25$

https://www.youtube.com/watch?v=w7jpCXznRf4

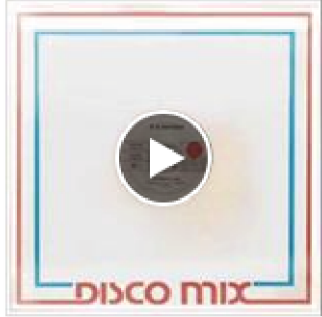

B.B. and Band - All night long (Original Mix)

buy here:

http:/www.goodymusicdownload.com/scheda.asp?

tipo=album\&id=488 Written by: M. Boncaldo-T....

It Like

Comment

YOUTUBE.COM

(1) 3 


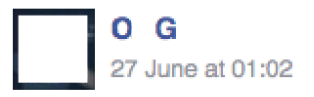

https://www.youtube.com/watch?v=zYn-2-QBpJl

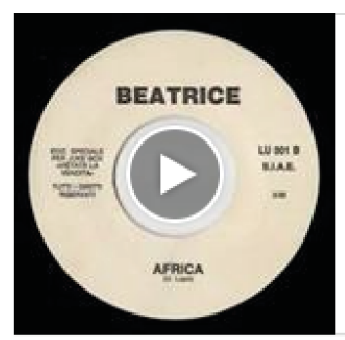

Beatrice - Africa (Italo-Disco on 7")

Label: (Not On Label) Catf: LU 001 Format: $7^{\prime \prime}$

Country: Italy Genre: Italo-Disco

It. Like

Comment

$\rightarrow$ Share

(1) 2 


\section{0a)}

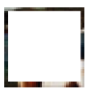

R $\mathbf{N}$

27 June at 11:17 - Amsterdam, Netherlands

Personal favourite

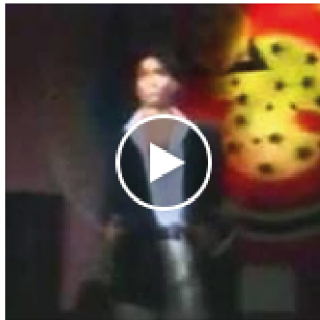

Mr Master - A Dog In The Night ( 12 Vocal ) Video Mix.

dedicado a martin albarracin que tanto le gusta este tema

YOUTUBE.COM

It Like

Comment

Share

$100_{3}$

R $\mathbf{N}$ Needs a (good) repress/reissue (9)

Like - Reply + $131+27$ June at 11:21

- G Recommended (only vocal version not on there but rest is great) https://Www.discogs.com/sel//tem/251971652

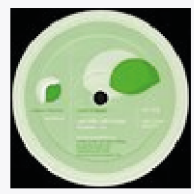

Mr. Master / Blackway - A Dog In

The Night / New Life / Follow Me

DISCOGS.COM

Like - Reply - 27 June at $11: 31$

0 o

Don't know if this is any good

https:/Www.discogs_com/Mr-Master-A-Dog.../release/6006601

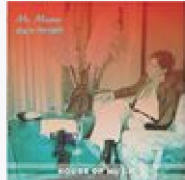

Mr. Master - A Dog In The Night

Label: Archivio Fonografico Moderno - ARFON

06 - Format: Vinyl 12

Like - Reply + 27 June at 11:32

R : N That last one I saw a lot of comments on about mastering \& physical (skipping) issues.. (:)

Like - Reply + 27 June at 11:33

R N Thanks for the Instrumental version tip! Not sure if I'm gonna order it, really prefer the vocal version (9) !

Like - Reply + 27 June at $11: 33$ 


\section{0b)}

O G Original was cheap for a while but now expensive (on discogs at least). Maybe its cheaper elsewhere... Got original for someting like 70euro and I'm stil happy with it.

Like - Reply - $131 \cdot 27$ June at 11:35 - Edited

$\square 0$

I-F used to play instrumental in his sets a lot I

remember.

Like · Reply + 27 June at 11:38

7 K C I bought orginal years ago from U.s.a from Gemm.com (30 dollars) and of corse I used many times instrumental version from Flexx records... mega classic! Love It!

Like - Reply +27 June at 12:26

100c)

R N Playing times are listed on Discogs also: https://www.discogs.com/Beppe-Loda.../release/8239248

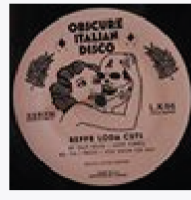

Beppe Loda - Obscure Italian Disco • Beppe Loda Cuts

DISCOGS.COM

Save

Like - Reply - 27 June at 10:41

M $\mathbf{K} \quad$ not extended

Like - Reply + 27 June at 10:42

R $\mathbf{N}$ Well, de Disgooo one seems to be 1 min longer than the youtube vid of the original I posted $\wedge$.

Like - Reply + 27 June at 10:44

$\square$ M K haha yeah well thats the edit part i guess (:) Like - Reply - 27 June at 10:45

101)

O G

27 June at 00:13

https://www.youtube.com/watch. . .

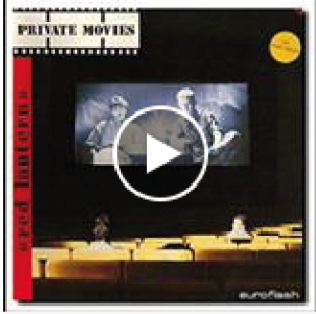

Private Movies - Red Lantern

(Extended Version)

1 Like $\square$ Comment $\Rightarrow$ Share

004

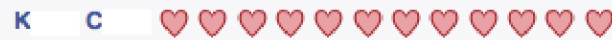

Like - Reply - 27 June at 14:10 
\ $\begin{array}{ll}\text { K } & \mathbf{C} \\ 27 & \text { June at } 13: 13\end{array}$

Kick ass Dub version!!

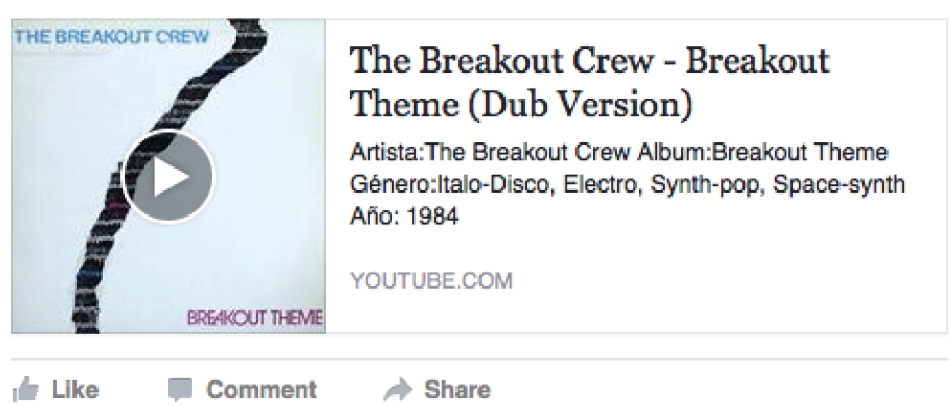

It) Lilke $\quad$ Comment $\Rightarrow$ Share

(1) 5

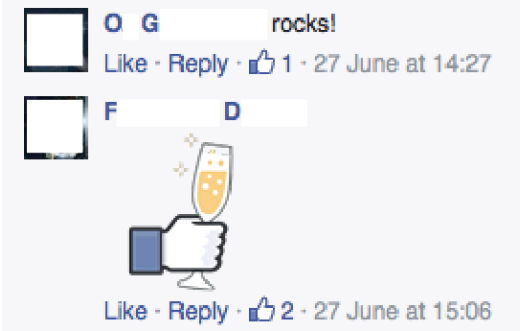




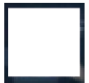

O G

27 June at 15:17

That other song by Mr. Flagio

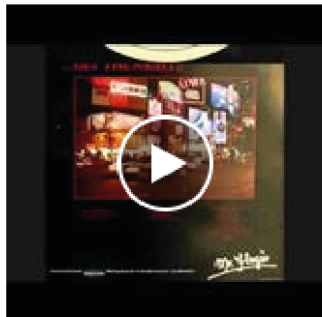

Mr. Flagio - Get The Night (1984)

This is the original version from the Italian music

label, Squish. It can be heard from the $12^{\prime \prime}$ vinyl single

release. The production information, audio and $\mathrm{g} . .$.

YOUTUBE.COM

I. Like

Comment

Share

(6) 11

O $\mathrm{G}$

https://www.youtube.com/watch?v=ker4iBtomjl

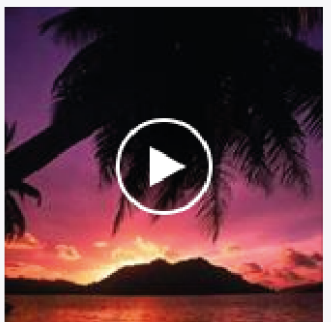

MR FLAGIO - Get The Night

(Casionova 2002 4-track Remix)

Like - Reply - 132 - 27 June at 15:20

D V echt mijn favo van hem

See translation

Like - Reply 131 - 27 June at $15: 46$ 


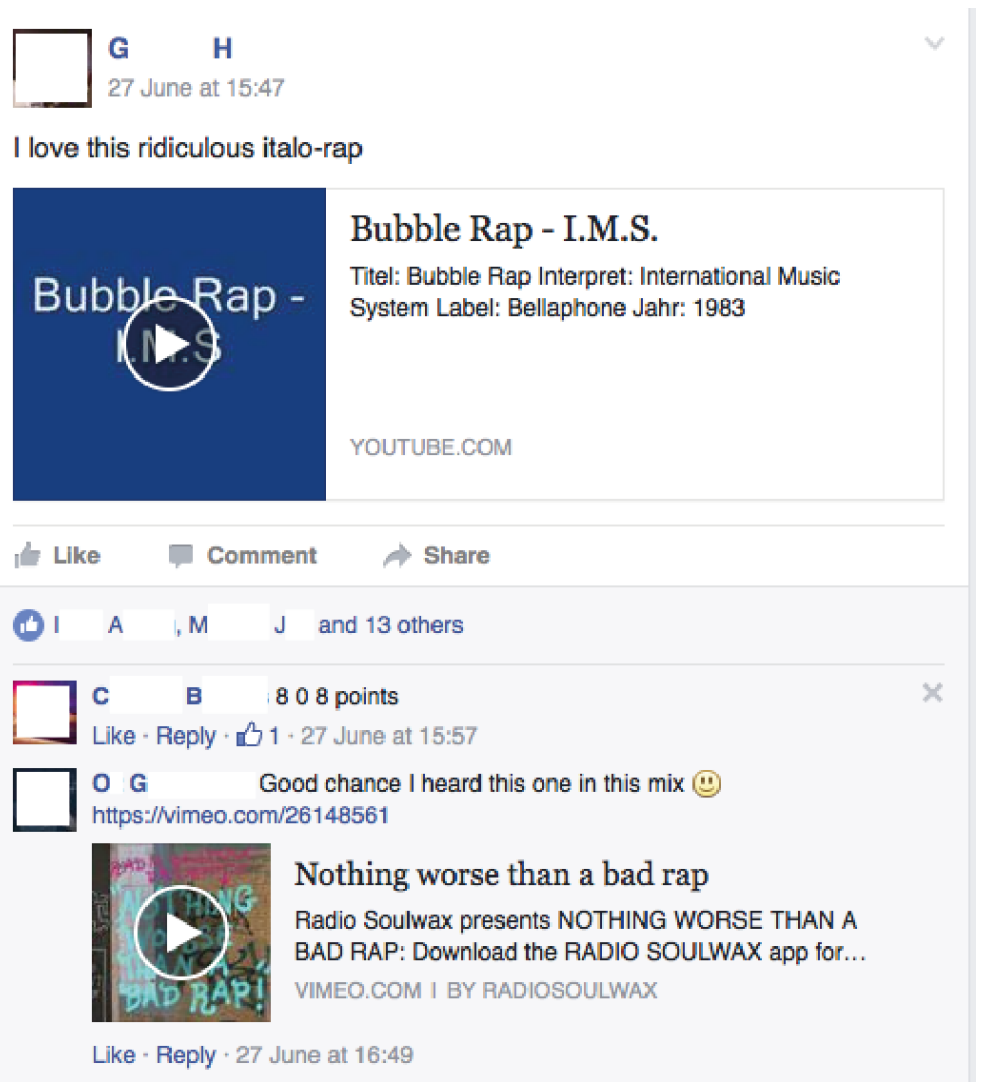

105)

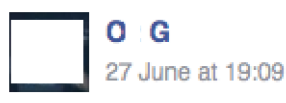

2nd half soccermatch 1/8 finale EK 2016 italo vs. spitalo at the moment 1 0 but.... who will win?

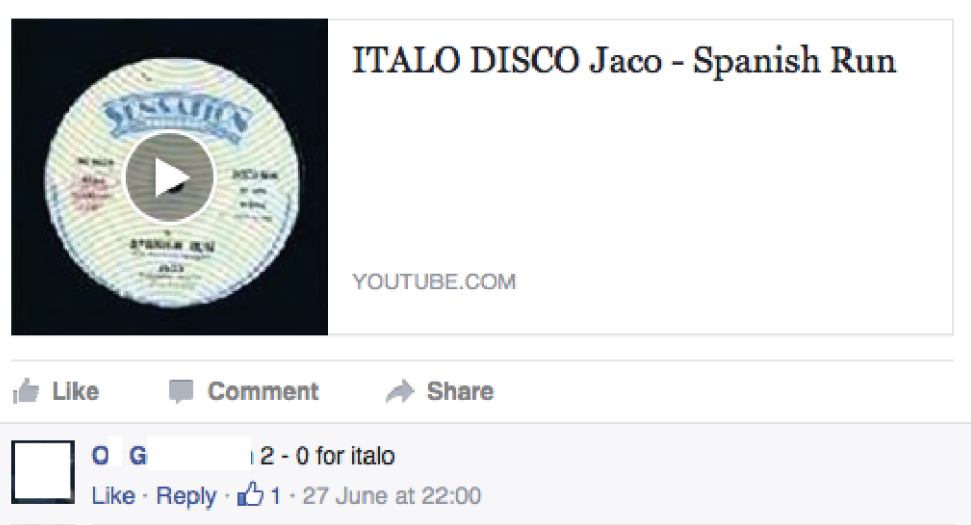


$\longrightarrow \begin{aligned} & \mathbf{K} \quad \mathbf{C} \\ & 27 \text { June at } 13: 31\end{aligned}$

So abstract, so obscure, so strange (:) that you can't not liked... so happy finally owner of this (:)

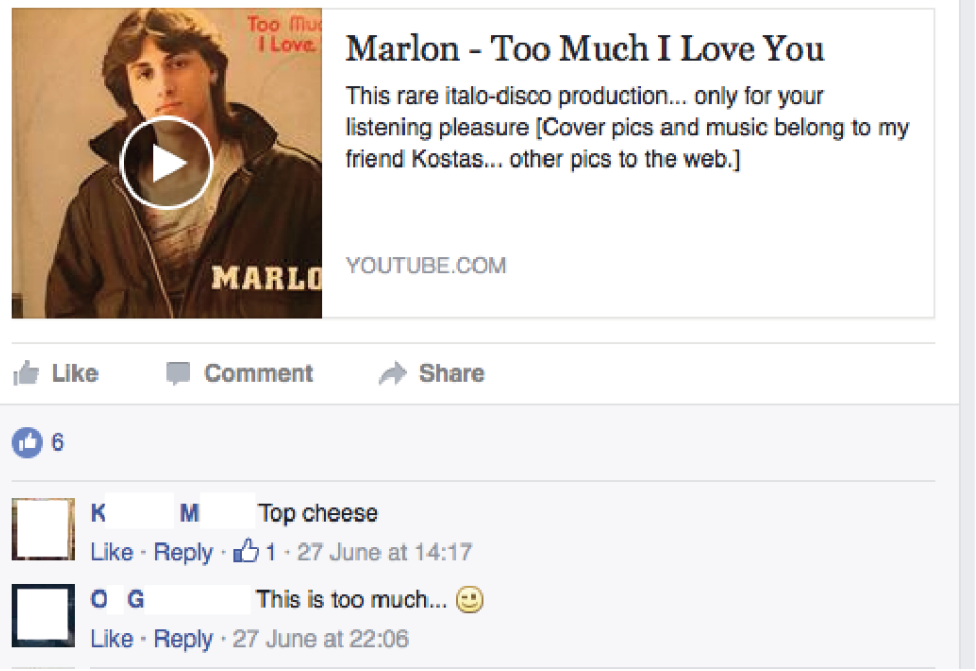

107)

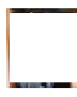

S L V

28 June at $14: 12$

https://Www.youtube.com/watch?V=Z88WdhwVKOO

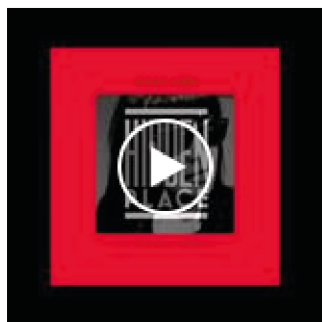

Hidden Place - Reazione (alternate version)

Alternate version by Fabio Vitelli, Antonio Losenno

Vocals by Sara Lux

https:/Www.facebook.com/hiddenplaceitalia/

YOUTUBE.COM

It Like Comment $\Rightarrow$ Share

(1) 2 
$\begin{array}{ll}\text { G } & \text { H } \\ 28 \text { June at } 16: 46\end{array}$

forever $\bigcirc$

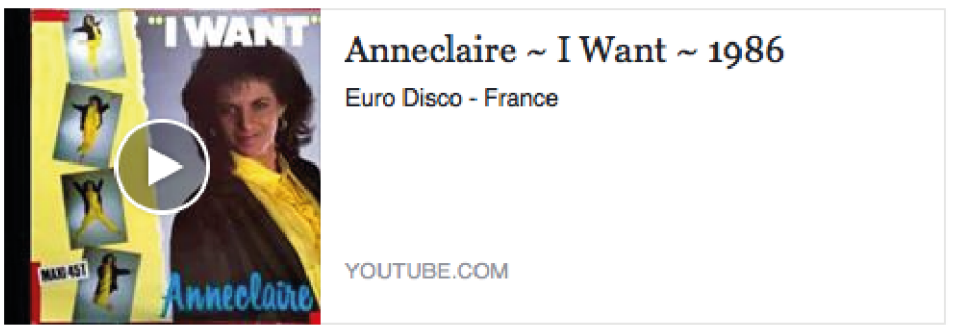

It Like $\quad$ Comment $\quad \Rightarrow$ Share

(1) I A and 14 others

109)
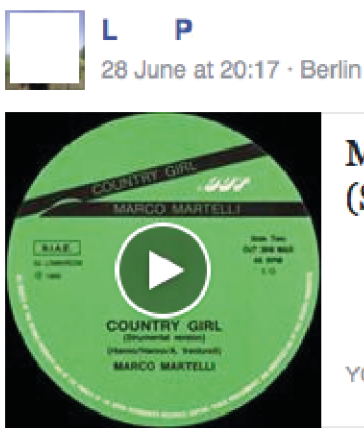

Marco Martelli D.J. - Country Girl

(Strumental Version) 1985

1. Like $\quad \square$ Comment $\quad \Rightarrow$ Share

(1) 1

M N trip down memory lane. still have the 12 ' somewhere, but with different cover.

Like - Reply - 3 1 - 29 June at 12:35 
$\square=\begin{array}{lc}\text { K } & \text { C } \\ \text { 27 June at 14:34 }\end{array}$

I know that is very obvious and big star in shity Italo FB groups (-) but I like it much (:)

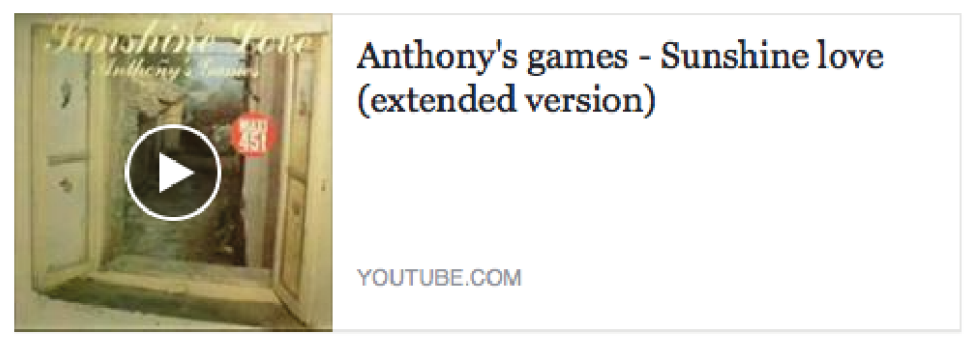

il Like $\quad \square$ Comment $\Rightarrow$ Share

904

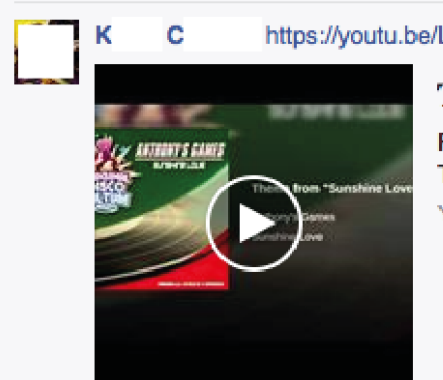

\section{Theme from "Sunshine Love"}

Provided to YouTube by Made In etaly S.r.l.

Theme from "Sunshine Love" - Anthony's...

YOUTUEE.COM

Like - Reply $: B 1+27$ June at 14:42

o G Don't see this one praised that much so I think it's underrated (?).

Like = Reply $₫ 2$ - 27 June at 15:07

4 R $T$ S replied 2 Replies

$\square$ G H Smalltown (italo) boy (:)

Like - Reply : $\triangle 3$ - 27 June at 15:08

$\square$ G $\quad$ ha indeed (9)

Like - Reply - 27 June at 15:10 
111a)

\section{O G}

28 June at $20: 00$

I say no

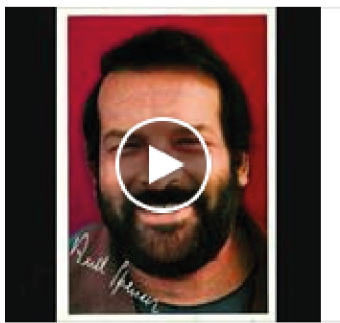

Bud Spencer - My Name Is Zulu

YOUTUBE.COM

It Like Comment $\Rightarrow$ Share

(1) $;$ James Penrose and 14 others

1 share

W B Seeing cock-a-doodle-doo has just reminded me of another amazing song: Lady Blue Star by Benny Blue, it's French so I'm not posting it here but definitely is worth listening.

Like - Reply $131+28$ June at 20:12

$\square$ o G Well it's more meant as a tribute to Bud Spencer who passed away today... Checked the song you mentioned and indeed very nice. Here another tribute song for Bud https:/Www.youtube.com/watch?v=_FFTvFqiGdo

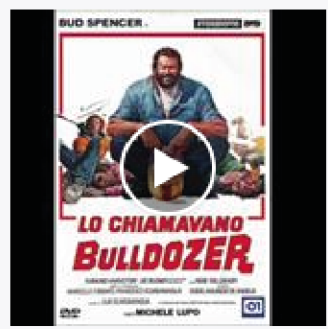

Bud Spencer-Lo

chiamavano Bulldozer -...

YOUTUBE.COM

Like - Reply + 28 June at 20:19

- W B really? oh, I didn't know anything about that...

Like - Reply - $131 \cdot 28$ June at 20:20

○ G Good childhood memories of him as moviestar. Much later I found out the music with these movies (by Oliver Onions) is mostly great too.

Like - Reply - 28 June at 20:24 
111b)

M K De Angelis, in fact this is the sing along version from a De Angelis Soundtrack from a race film

Like - Reply - 28 June at 21:10 - Edited

$\square$ O G

My Name Is Zulu is sing along version? O.k. didn't know

Like - Reply + 28 June at 20:42

7 M K this is the instr. https:/Www.youtube.com/watch? $\mathrm{v}=|\mathrm{Q}| \mathrm{cydOg} w \mathrm{t} w$

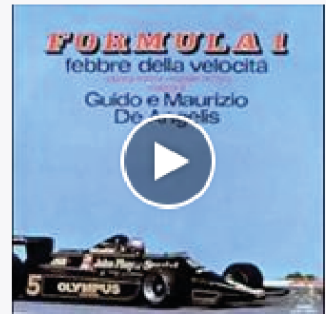

Guido De Angelis e Maurizio De Angelis -...

YOUTUBE.COM

Like : Reply : 12 2 28 June at 21:12

6. Write a reply.

K C OO00000000000000
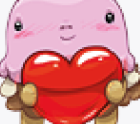

Like - Reply - 132 - 29 June at 01:19

K C Had to listen to it couple of times! AMAZING! Thanks for pasting Oz Goldenlion!!!

Like - Reply - $131 \cdot 29$ June at 01:20

o G One more for the "big man" https://www.youtube.com/watch? $\mathrm{v}=\mathrm{s} 4 \mathrm{KPyuBVbqc}$

Like · Reply - 29 June at 17:02 - Edited

O G Just listen through this account. Highly enjoyable i.m.o. https://www.youtube_com/channel/UCPC7DtBQj5Vcbsnp88rHLBw

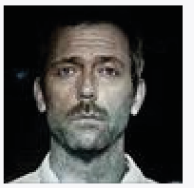

xXTerenceHillCc

Bad spencer und Terence hill lieder und vieles andere $\mathrm{m}$

YOUTUBE.COM

Like - Reply - 29 June at 17:05

111c)

G (9) https:/Www.youtube.com/watch?V=V4X2NiPOyw4

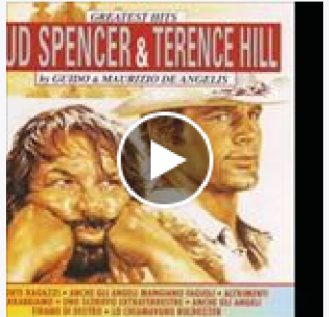

Bud Spencer \& Terence Hill

Greatest Hits Vol. 1 - 05 - Why...

Like - Reply · 29 June at 17:09 
28 June at 23:13 + Chemnitz

R.I.P. Carlo Pedersoli...Banana Joe by Olimpio

See translation

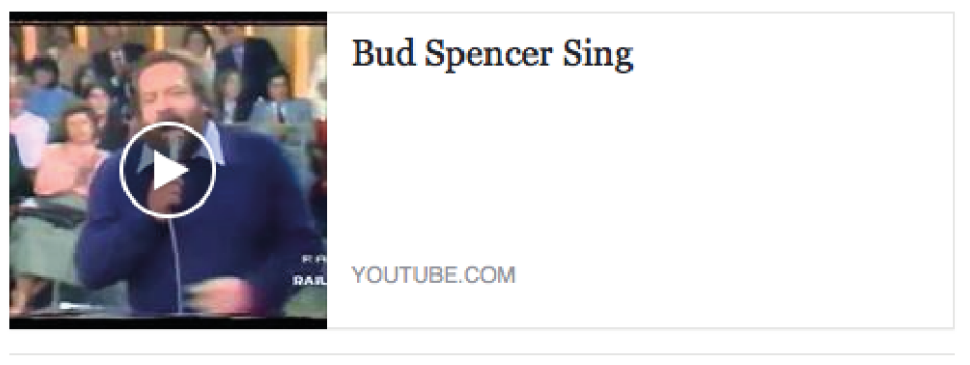

It Like $\quad \square$ Comment $\rightarrow$ Share

$00 \div 3$

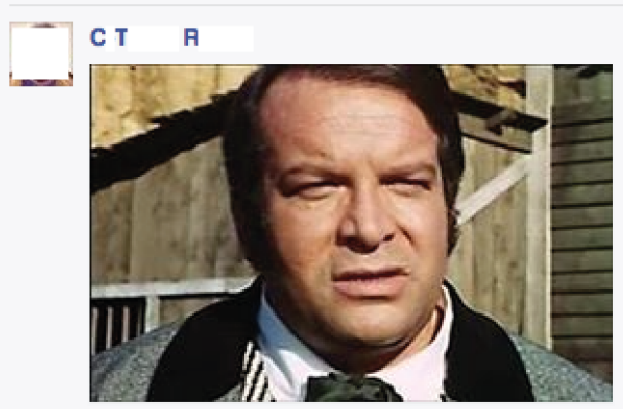

Like - Reply - 28 June at 23:14

C T $\quad$ R

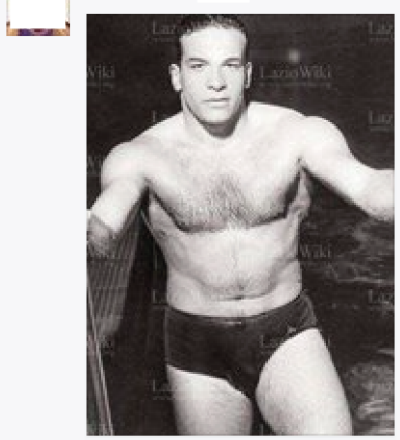

Like - Reply - 131 - 28 June at 23:14 


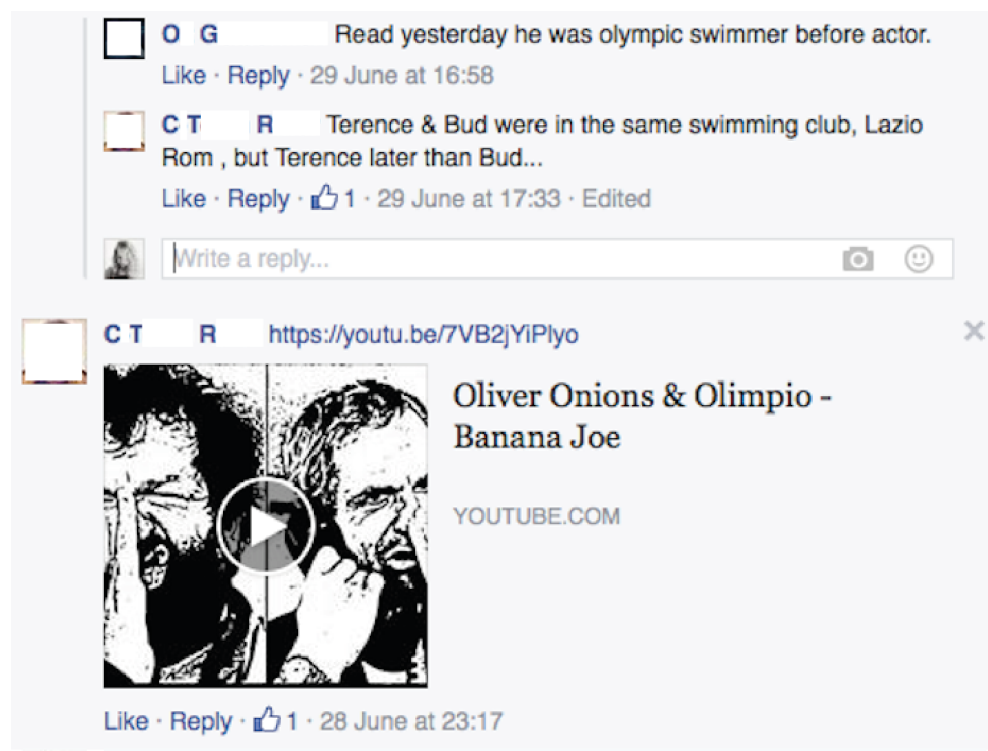

113)

O G

29 June at $18: 16$

https://www.youtube.com/watch?v=nlYoZ5vSJ6Q

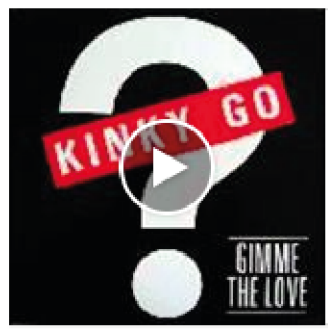

KINKY GO - Gimme the love(Razormaid Remix) - 1987

(M. Neri - R. Burchill) - Razormaid Remix - Extraido del CD"The Best of Razormaid Mixes Vol. 3" Edicion USA bajo el sello independiente GOLD IMPORT...

YOUTUBE.COM

प Comment

$\rightarrow$ Share

114)

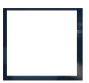

○ $G$

29 June at $118: 36$

always feel this is succeder of "topy \& roby - under the ice"

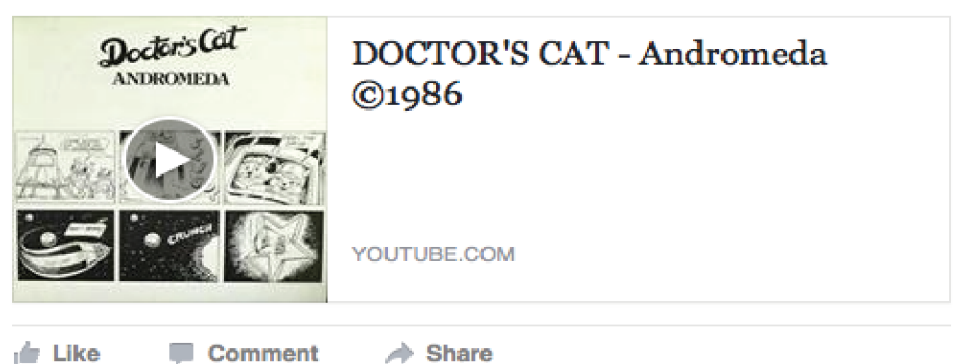
If LIke
Comment
Share

(1) 8

R $\quad$ B Both are so powerful

Like - Reply - 131 - 30 June at 07:03 
115a)

D A

28 June at 22:59 - South Bend, IN, United States

The ultimate highlight of the inimitable Angelo Segreti compilation (?)

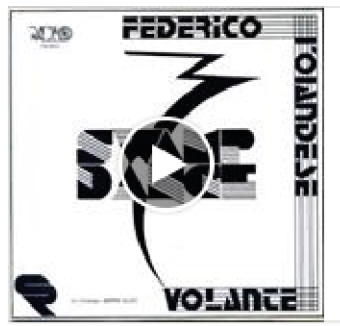

Federico l'Olandese Volante Swamp Dance (Italo-Disco)

Artist: Federico IOlandese Volante Single: Swamp

Dance Side A Label: VideoRadio Catalog \#: VR0013 Format: Vinyl, $45 \mathrm{RPM} ; 7^{\prime \prime}$ Country: Italy Released:...

YOUTUBE.COM

It. Like $\quad$ Comment

Share

(1) 10

G H I remember when PeetNeet played me this for the first time, I couldn't believe what I was hearing.... yes, it's an italo track about catching frogs.

Now that's obscure!!!

Like - Reply - 132 - 29 June at 18:25

$\square$ o G "Hey man let's go out hunting some bullfrogs tonight. And I said yeah!" (3)

Like - Reply * 131 - 29 June at 18:51 - Edited

T D A _ Basically a true-to-life account of living in Florida Like - Reply - 132 - 29 June at 19:02

Write a reply..

- G I heard it first on Lost Treasures Of Italo-Disco 3. (9)

Like - Reply - 3 3 - 29 June at 18:55 - Edited

[ F D Cheers 0 : yeah great pleasure to be the first to present it in a mix

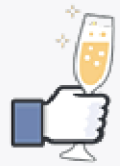

Like - Reply - 31 - 29 June at 20:18 - Edited

115b)

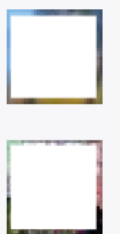

M K great track

Like - Reply $\cdot \mathbf{3} 2 \cdot 29$ June at 19:01

P N haha...yeah G ..you went crazy hearing all that Segreti tracks that evening (:) Including myself! Still the discoveries of the whole Italo era if you ask me! 3

Like - Reply + 132 - 30 June at 10:06 
. $\quad$ R $\quad$ P $\quad$ P June at 12:12

http://Www.607080.it/

Radio 607080

Radio 607080

$607080.1 \mathrm{~T}$

IN Like Comment $\Rightarrow$ Share

117)

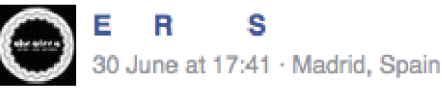

Last set of Sacha at "Discoteca":

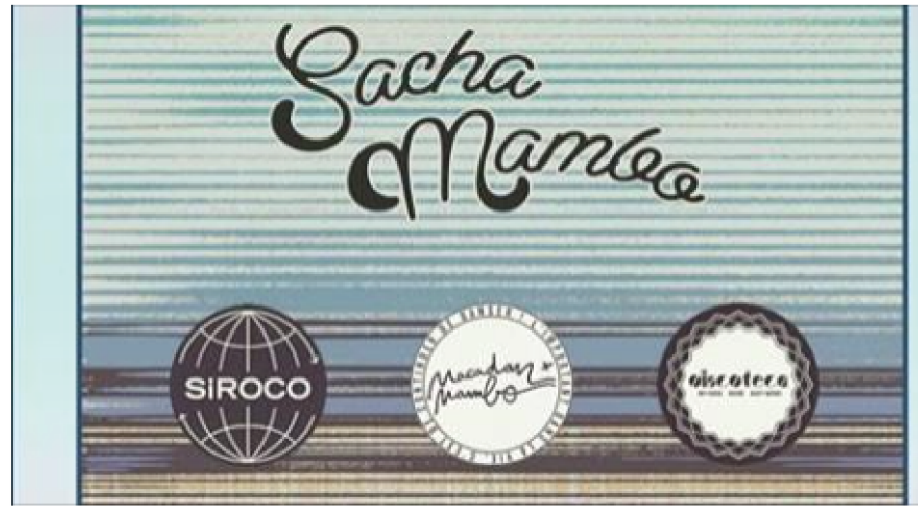

Sacha Mambo @ Discoteca 17 - 06 - 16

Sacha Mambo live at "Discoteca" Madrid 17-06-2016

SOUNDCLOUD.COM I| BY DISCOTECAGALACTICA

Save

$\begin{array}{ll}1 \text { L Like } & \Rightarrow \text { Comment } \Rightarrow \text { Share } \\ \text { (1) } \mathrm{T} & \mathrm{R}\end{array}$

118)

$\left[\begin{array}{l}\mathbf{N} \quad \mathbf{L} \\ 30 \text { June at } 17: 43 \text {, Amsterdam, Netherlands }\end{array}\right.$

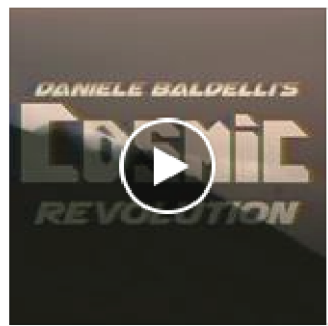

Daniele Baldelli's Cosmic

Revolution

With his new EP Volcano Extravaganza out on Friday,

we document the trailblazing Italian disc jockey.

https:/Www.vfeditions.com/product/view/330

YOUTUEE.COM

I. Like

- Comment

$\Rightarrow$ Share

$00^{8}$ 
119a)

A

30. June

https://www.youtube.com/watch?v=JmcD_38mfyA

\section{Los Angeles T.F. 1983 *Magical Body*}

Los Angeles T.F. 1983 Magical Body single Italo-Disco Franco Zasa, Tony Travagliante

YOUTUBE.COM

It Like Comment $\Rightarrow$ Share

\section{OH 55}

O G Such a strong classic. Works great on the dancefloor! Like - Reply + 30 June at 11:51

H Good as well https:/www.youtube.com/watch?v=9oerGgQeTJY

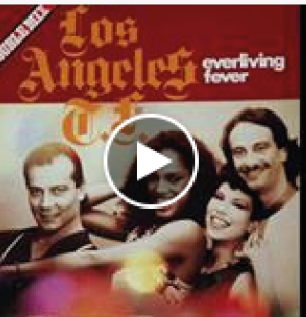

Plastic Paradise - Los Angeles T.F.

Like = Reply : 3 - 30 June at 14:28

O G Yeah so much more. Videomania, Let Your Bady Dance (and check out the b-side!l Bravo), Everlving Fever and I even like their release First Vision - Revelation Day.

Like - Reply - 30 June at 14:33 - Edited

F $\quad$ H Got the record 17 years ago

Like - Reply + 13 - 30 June at 14:33

\section{9b)}

F $\quad \mathrm{H} \quad$ Got the record 17 years ago

Like - Reply + 131 - 30 June at 14:33

O G It's one of my first when I started collection italo. Bought it

through Gemm from Kosta in Greece for a whopping 80euro's but I wanted it so bad.

Like - Reply + 30 June at 14:35

[ $\mathrm{O}$ G on sexy red vinyl

Like - Reply - 30 June at 14:37

- F H One of my first were the Plastic Paradise and Magical

Body too. I think 98 or $99 . .$.

Like - Reply : 31 - 30 June at 15:05 - Edited

[ 0 G I think round 2002

Like - Reply : 31 - 30 June at 21:56

- G next generation italo collectors (-)

Like - Reply - 30 June at 22:11 


$$
\text { O G }
$$

30 June at 22:15

posted before but as reply to original and I think this remix needs some more attention cause really nice i.m.o.

ORIENTEXPHESS

Wish Key - Orient Express (Remix '87)

Super Italodisco $1987^{\star * * * *}$

iniviarin

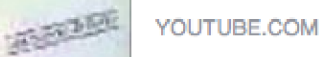

L Like Comment $\Rightarrow$ Share

(1) 2

K C Orginal... (:) 4ever

Like - Reply - 132 - 3 July at 12:06

$\square$ O G of course but that one was already posted (3) Like - Reply : $131+3$ July at 17:04 
10.4 Attachment 4: The language samples in Herring's faceted classification schame

\begin{tabular}{|c|c|c|c|c|c|c|c|c|c|c|}
\hline \multirow[b]{2}{*}{ Sample } & \multicolumn{10}{|c|}{ Medium factors } \\
\hline & M1: syncronicity & $\begin{array}{l}\text { M2: Message } \\
\text { transmission }\end{array}$ & $\begin{array}{l}\text { M3: Persistence of } \\
\text { transcript }\end{array}$ & $\begin{array}{l}\text { M4: Size of message } \\
\text { buffer }\end{array}$ & $\begin{array}{l}\text { M5: Channels of } \\
\text { communication }\end{array}$ & $\begin{array}{l}\text { M6: Anyonymous } \\
\text { messaging }\end{array}$ & $\begin{array}{l}\text { M7: Private } \\
\text { Messaging }\end{array}$ & M8: Filtering & M9: Quoting & $\begin{array}{l}\text { M10: Message } \\
\text { format }\end{array}$ \\
\hline \multicolumn{11}{|l|}{$\begin{array}{l}\text { WATMMF: thread 'Aphex } \\
\text { Twin - Syro' }\end{array}$} \\
\hline & asynchron & one-way & unlimited period of time & $\begin{array}{l}\text { no limitation, but the } \\
\text { posts are normally short }\end{array}$ & $\begin{array}{l}\text { Text; visual (static and } \\
\text { animated graphics); } \\
\text { video; audio channel; }\end{array}$ & $\begin{array}{l}\text { e-mail address is required } \\
\text { and has to be verified for } \\
\text { the registration; a } \\
\text { nickname is chosen by the } \\
\text { user }\end{array}$ & \begin{tabular}{|l} 
available: registered user. \\
can send private \\
messages to each other
\end{tabular} & $\begin{array}{l}\begin{array}{l}\text { available: registered users } \\
\text { can ignore messages from } \\
\text { rs } \\
\text { other users; they can } \\
\text { report messages to the } \\
\text { moderators }\end{array} \\
\end{array}$ & $\begin{array}{l}\text { available to reply with } \\
\text { quote }\end{array}$ & oldest message on top \\
\hline \multicolumn{11}{|l|}{$\begin{array}{l}\text { Gerslutz: thread 'Lets talk } \\
\text { samplers!' }\end{array}$} \\
\hline & asynchron & one-way & unlimited period of time & $\begin{array}{l}\text { no limitation, but the } \\
\text { posts are normally short }\end{array}$ & $\begin{array}{l}\text { Text; visual (static and } \\
\text { animated graphics); } \\
\text { video; audio channel; }\end{array}$ & $\begin{array}{l}\text { e-mail address is required } \\
\text { and has to be verified for } \\
\text { the registration; } \\
\text { inckname is chosen by the } \\
\text { user }\end{array}$ & $\begin{array}{l}\text { avaiable: registered user-. } \\
\text { anan send private } \\
\text { messages to ach other }\end{array}$ & $\begin{array}{l}\text { available: reistered users } \\
\text { can ignore messages from } \\
\text { rs other users; they can } \\
\text { oreport messages to the } \\
\text { moderators }\end{array}$ & $\begin{array}{l}\text { avaiable to reply with } \\
\text { guote }\end{array}$ & oldest message on top \\
\hline $\begin{array}{l}\text { Vintage Synth Explorer } \\
\text { (users' comments below the } \\
\text { aticles) }\end{array}$ & asynchron & one-way & unlimited period of time & \begin{tabular}{|l|}
$\begin{array}{l}\text { no limitation, but the } \\
\text { posts are normally short }\end{array}$ \\
|
\end{tabular} & Text (with hyperlinks) & $\begin{array}{l}\text { e-mail address is needed } \\
\text { and has to be verified for } \\
\text { the registration; a } \\
\text { nickname is chosen by the } \\
\text { user }\end{array}$ & not available & $\begin{array}{l}\text { not avalable, but users } \\
\text { can report abuse }\end{array}$ & not available & newest message on top \\
\hline $\begin{array}{l}\text { Resident Advisor (users' } \\
\text { comments below the } \\
\text { articles) }\end{array}$ & asynchron & one-way & unlimited period of time & \begin{tabular}{|l|} 
no limitation, but the \\
posts are normally short
\end{tabular} & Text (with hyperlinks) & $\begin{array}{l}\text { e-mail address is needed } \\
\text { and has to be verified for } \\
\text { the registration; a } \\
\text { nickname is chosen by the } \\
\text { suser }\end{array}$ & not available & $\begin{array}{l}\text { not available, but users } \\
\text { can report abuse }\end{array}$ & not available & newest message on top \\
\hline TB-303 Owners Club & asynchron & one-way & unlimited period of time & $\begin{array}{l}\text { no limitation, but the } \\
\text { posts are normally short }\end{array}$ & \begin{tabular}{|l} 
Text, visual (static and \\
animated graphics); \\
video; audio channel;
\end{tabular} & $\begin{array}{l}\text { not anonymous: a } \\
\text { Facebook registration is } \\
\text { needed with an own } \\
\text { profile }\end{array}$ & available & $\begin{array}{l}\text { available: registered users } \\
\text { can ignore messages from } \\
\text { other users; they can } \\
\text { report other users, etc. }\end{array}$ & not available & newest message on top \\
\hline ITALO DISCO MANIACS & asynchron & one-way & unlimited period of time & $\begin{array}{l}\text { no limitation, but the } \\
\text { posts are normally short }\end{array}$ & $\begin{array}{l}\text { Text; visual (static and } \\
\text { animated graphics); } \\
\text { video; audio channel; }\end{array}$ & \begin{tabular}{|l|} 
not anonymous: a \\
Facebook registration is \\
needed with an own \\
profile
\end{tabular} & available & \begin{tabular}{|l|} 
available: registered users \\
can ignore messages from \\
other users; they can \\
report other users, etc.
\end{tabular} & not avalable & newest message on top \\
\hline
\end{tabular}


Situation factors

\begin{tabular}{|c|c|c|c|c|c|c|c|}
\hline \multicolumn{8}{|c|}{ Situation factors } \\
\hline S1: Participation structure & S2: Participant characteristics & S3: Purpose & S4: Topic or Theme & S5: Tone & S6: Activity & S7: Norms & S8: Code \\
\hline 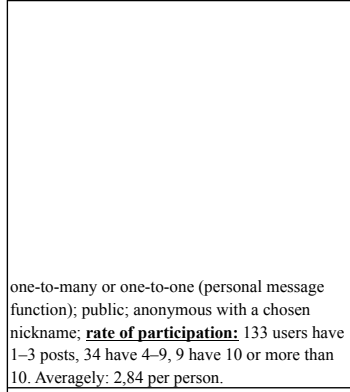 & 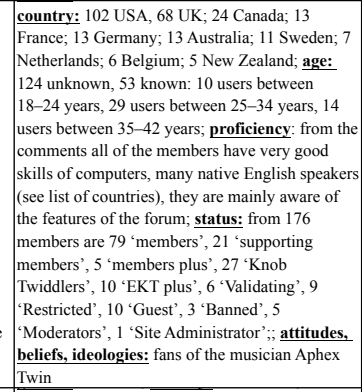 & 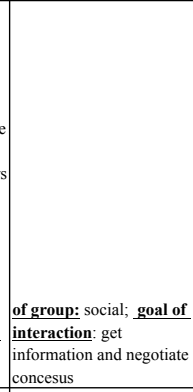 & $\begin{array}{l}\text { of group: album release } \\
\text { (music); of exchanges: } \\
\text { sharing news and ideas } \\
\text { about SRYO and Aphex } \\
\text { Twin in general }\end{array}$ & $\begin{array}{l}\begin{array}{l}\text { playful, casual, friendly, } \\
\text { cooperative, omemeites } \\
\text { sarcasticirironic and } \\
\text { critical }\end{array} \\
\end{array}$ & $\begin{array}{l}\text { information and opinion } \\
\text { exchange }\end{array}$ & 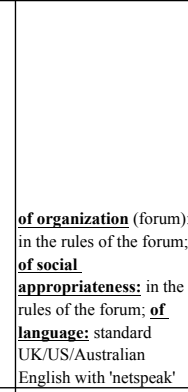 & : \\
\hline 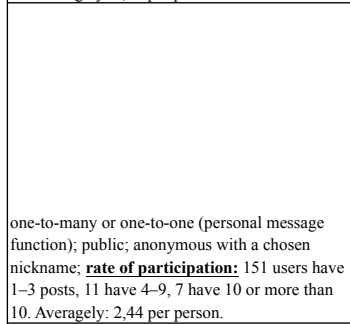 & 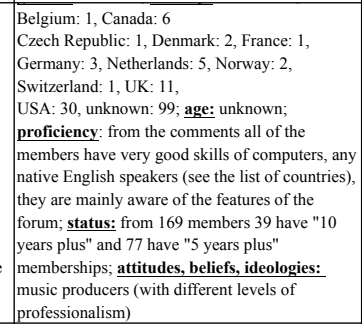 & $\begin{array}{l}\text { of group: social; goal of } \\
\begin{array}{l}\text { interaction: get } \\
\begin{array}{l}\text { information and negotiate } \\
\text { concesus }\end{array}\end{array} \\
\end{array}$ & 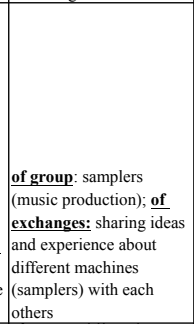 & $\begin{array}{l}\text { playful, casual, friendly, } \\
\text { cocoperative, sometimes } \\
\text { sarcastic and critical }\end{array}$ & \begin{tabular}{|l} 
information and opinion \\
exchange
\end{tabular} & 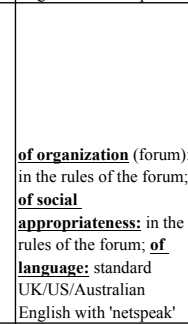 & language: abbreversions. \\
\hline $\begin{array}{l}\text { one-to-many, public; anonymous with a chosen } \\
\text { nickname (not anonnmous if one logs in with } \\
\text { her his Facebok account); rate of participation } \\
\text { for this, one should analyse all available data } \\
\text { from the website }\end{array}$ & 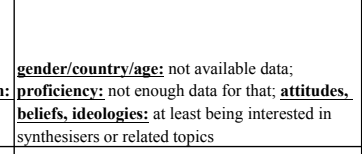 & $\begin{array}{l}\text { of group: social; goal of } \\
\text { interaction: share beliefs, } \\
\text { opinions }\end{array}$ & \begin{tabular}{|l} 
models of synthesisers; \\
exchanges: sharing ideas \\
and experience about \\
these different \\
instruments with each \\
others
\end{tabular} & $\begin{array}{l}\text { casual, friendly, } \\
\text { cooperative, sometimes } \\
\text { critical }\end{array}$ & $\begin{array}{l}\text { information and opinion } \\
\text { exchange }\end{array}$ & $\begin{array}{l}\text { of organization (Disqus } \\
\text { in terms and politics; of } \\
\text { social appropriateness: } \\
\text { in terms and conditions; } \\
\text { of language: : nglish wi } \\
\text { 'netspeak' } \\
\end{array}$ & $\begin{array}{l}\text { s): } \\
\text { ith } \\
\text { language: abbreversions, } \\
\text { mericic production } \\
\text { terminology; font: latin }\end{array}$ \\
\hline $\begin{array}{l}\text { one-to-many; public; anonymous with a chosen } \\
\text { nickname (notanonymous if one logg in with } \\
\text { her his Facebook account) rate of participation } \\
\text { for this, one should analyse all available data } \\
\text { from the website }\end{array}$ & 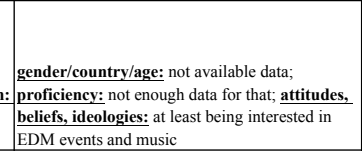 & $\begin{array}{l}\text { of group: social; goal of } \\
\begin{array}{l}\text { interaction: share } \\
\text { belifes, opinions }\end{array} \\
\end{array}$ & 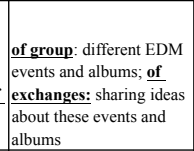 & casual friendly, & $\begin{array}{l}\text { information ar } \\
\text { exchange }\end{array}$ & 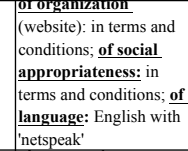 & $\begin{array}{l}\text { language: abbreversions } \\
\text { music production } \\
\text { terminology; font: latin }\end{array}$ \\
\hline $\begin{array}{l}\text { one-to-many or one-to-one (personal message } \\
\text { function); public; not anonymous; rate of } \\
\text { participation: for this, one should analyse all } \\
\text { available datat from the Facebook group (all posts } \\
\text { members data, etc.) }\end{array}$ & 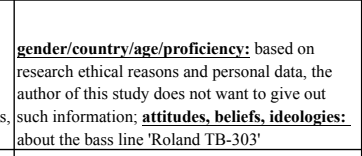 & $\begin{array}{l}\text { of groupp social; goal of } \\
\text { interaction: share } \\
\text { beliefes, opinions } \\
\end{array}$ & \begin{tabular}{|l|} 
of group: TB- 303 and \\
related topics; of \\
exchanges: sharing ideas \\
$\begin{array}{l}\text { and experience about the } \\
\text { usage of the instrument }\end{array}$ \\
\end{tabular} & 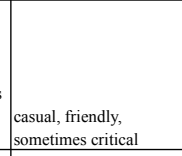 & $\begin{array}{l}\text { information and opinion } \\
\text { exchange }\end{array}$ & $\begin{array}{l}\text { (Forecobook): in terms and } \\
\text { policies; of social } \\
\text { appropriateness: also in } \\
\text { terms and conditions; of } \\
\text { language: English with } \\
\text { 'netspeak' }\end{array}$ & $\begin{array}{l}\text { d language: music } \\
\begin{array}{l}\text { production terminology; } \\
\text { font: latin }\end{array} \\
\end{array}$ \\
\hline 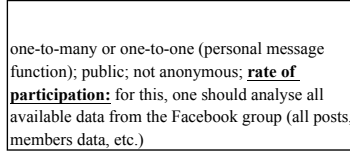 & 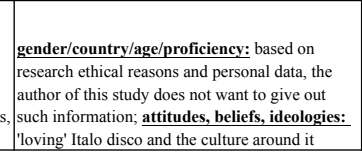 & $\begin{array}{l}\text { of group: social; goal of } \\
\text { interaction: share } \\
\text { beliefes, opinions } \\
\end{array}$ & \begin{tabular}{|l|} 
of group: Italo disco and \\
related topics; of \\
exchanges: haring ideas \\
and information about the \\
genre and the culture \\
around it
\end{tabular} & $\begin{array}{l}\text { Casual, friendly, } \\
\text { sometimes critical and } \\
\text { emotional }\end{array}$ & 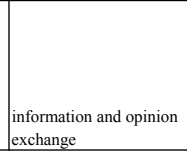 & 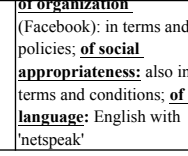 & \begin{tabular}{l|l} 
& \\
language: music \\
production terminology; \\
font: latin
\end{tabular} \\
\hline
\end{tabular}




\subsection{Attachment 5: WATMMF}

\subsubsection{Coding categories of WATMMF}

\begin{tabular}{|c|c|c|c|c|c|c|}
\hline \multirow{29}{*}{ Structure and meaning } & \begin{tabular}{|l|l} 
Phenomena type \\
\end{tabular} & \multirow[b]{2}{*}{ special adjectives related to } & Sub-subcategories & Codes/Criteria & Numbers & Analysis/Notes/Examples \\
\hline & \multirow{2}{*}{ special lexis } & & $\begin{array}{ll}\text { Aphex Twin } \\
\text { Syro }\end{array}$ & & $\frac{3}{5 \mid c}$ & \begin{tabular}{|l} 
Lord AFX, lord afx, representative is back, \\
chees, goodness, lovely, flourescent, ambient synth, aweseme
\end{tabular} \\
\hline & & related to feelings about the release & & $\begin{array}{l}\text { excited, exciting, imminent, } \\
\text { so much excitement }\end{array}$ & & $\begin{array}{l}\text { I have to invent a new word to describe the odd mix of future } \\
\text { nostalgia I've got. (\#349) I'm at a loss for words. (\#I38) I'm } \\
\text { speechless. I'm without speech. (\#142) I'm in a mild state of shock. } \\
\text { I'll punch the air later, once the shock subsides. (\#164) I don't know } \\
\text { how to react to news like this?! I can't wait for sure but I'm } \\
\text { astounded, everything building up to this has been awesome. (\#225); }\end{array}$ \\
\hline & technical terms & related to music production & & mix, bpm, track & 31 & \\
\hline & \multirow{3}{*}{$\begin{array}{l}\text { specific community reference } \\
\text { words }\end{array}$} & related to the album & & Syro, album, release & 55 & \\
\hline & & related to Aphex Twin & & $\begin{array}{l}\text { AFX, Aphex, Aphex Twin, } \\
\text { Richard, Rich, Twin, } \\
\text { Twinee, RDJ, Tuss, Phex, } \\
\text { Thrichard, }\end{array}$ & 68 & \\
\hline & & related to the community & & $\begin{array}{l}\text { lyy friend, fan, dude, } \\
\text { WaTTMMers, fellow, mate, } \\
\text { fellas, felletest, forum } \\
\text { member, man } \\
\end{array}$ & 20 & \\
\hline & \multirow{13}{*}{ personal pronouns } & \multirow{4}{*}{ first-person singular } & & I me & \begin{tabular}{r|r|}
176 & 0 \\
18 & 0
\end{tabular} & \\
\hline & & & & my & $\frac{10}{21}$ & \\
\hline & & & & mine & 1 & \\
\hline & & & & myself & 0 & are we to assume...?; we will see; we shall see; wish we had a \\
\hline & & \multirow{4}{*}{ first-person plural } & & we & 22, & release date \\
\hline & & & & us & 4 & \\
\hline & & & & our & 1 & \\
\hline & & & & $\frac{\text { ours }}{\text { ourselves }}$ & 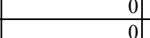 & 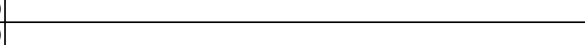 \\
\hline & & \multirow{5}{*}{ third-person plural } & & & 18 & \\
\hline & & & & them & 2 & \\
\hline & & & & their & 6 & \\
\hline & & & & theirs & & \\
\hline & & & & themselves & 0 & \\
\hline & \multirow{5}{*}{ compensatory strategies } & $\begin{array}{l}\text { emoticons, emojis } \\
\text { memes }\end{array}$ & \begin{tabular}{|l} 
different types \\
different types
\end{tabular} & & $\frac{37}{0}$ & including a specific Aphex Twin smiley (with Come to Daddy) \\
\hline & & & anterentiges & & & 2 are about Aphex Twin; 10 expression emotions or fitting to the \\
\hline & & GIFs & different types & & 12 t & topic of the discussion \\
\hline & & pictures & different types & & 221 & $\begin{array}{l}13 \text { with Aphex Twin; } 4 \text { screen shots from news or other websites; } 5 \\
\text { fitting to the topic (expressing emotions) }\end{array}$ \\
\hline & & videos & different types & & & $\begin{array}{l}4 \text { about an earlier Aphex Twin concert or music; } 3 \text { fitting to the topic } \\
\text { (e.g. a few seconds from a cartoon) }\end{array}$ \\
\hline & \multirow{4}{*}{ Concern structures } & linking & hyperlink & & & for compenasory strategies and for news about the album release \\
\hline & & quoting & other users & & & most of the time \\
\hline & & quoring & someone else & & & none \\
\hline & & using hashtag & referring to Twitter & & & 1]\#deepweb (\#143) \\
\hline
\end{tabular}




\begin{tabular}{|c|c|c|c|c|c|}
\hline \multirow{3}{*}{ Interactional management } & \multirow{3}{*}{ Participation } & number of messages per group member & & & see in the other related table \\
\hline & & participation types & through status & $\begin{array}{l}\text { EKT Plus, Knob Twiddlers, } \\
\text { Members, Supporting } \\
\text { Member, Moderator, Guest, } \\
\text { Validating; Restricted, } \\
\text { Banned, }\end{array}$ & $\begin{array}{l}79 \text { 'members', } 21 \text { 'supporting members', } 5 \text { 'members plus', } 27 \\
\text { 'Knob Twiddlers', } 10 \text { 'EKT plus', } 6 \text { 'validating', } 9 \text { 'restricted', } 10 \\
\text { 'guest', 3 'banned', } 5 \text { 'moderators', 1 'site administrator' }\end{array}$ \\
\hline & & & througt activity & & $\begin{array}{l}\text { Rate of participation: from the total } 176 \text { members, who took part in } \\
\text { the conversations, } 133 \text { have } 1-3 \text { posts, } 34 \text { have } 4-9 \text { posts, } 9 \text { have } 10 \\
\text { or more than } 10 \text { posts. Average amount of post per person: } 2,84 \text {. }\end{array}$ \\
\hline \multirow{12}{*}{ Social phenomena } & \multirow{9}{*}{ Interpersonal discourse behaviours } & agree/disagree & & & 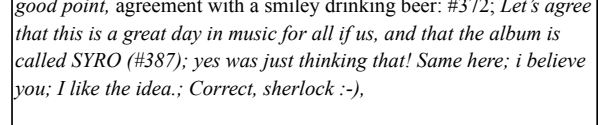 \\
\hline & & counterpoint & & & MIXL2: The 'Phex never disappoints!!! (\#187) \\
\hline & & \begin{tabular}{|l|} 
acknowledge \\
invite/give feedback \\
\end{tabular} & & & t \\
\hline & & thanking & & & $\begin{array}{l}\text { (hronical: oh. I am an idiot. thanks. (\#40) bietroast: oh! lol. thanks. } \\
\text { (\#78)THANK YOU (\#116) }\end{array}$ \\
\hline & & sympathize & & & 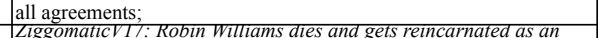 \\
\hline & & joking & & & $\begin{array}{l}\text { Aphex Twin Album. (\#72) Chalybs: So it's Jean Michelle Jarre then. } \\
\text { (\#127) auxien: I hope 180db_is really } 180 \text { decibels so my ears are } \\
\text { destroyed and Aphex is the last thing I ever hear. (\#I3I) Bechuga: I } \\
\text { wonder if this explains why Julian Assange is finally leaving the } \\
\text { Ecuadorian embassy (\#191) }\end{array}$ \\
\hline & & delegate & & & \\
\hline & & ask for infomation & & & 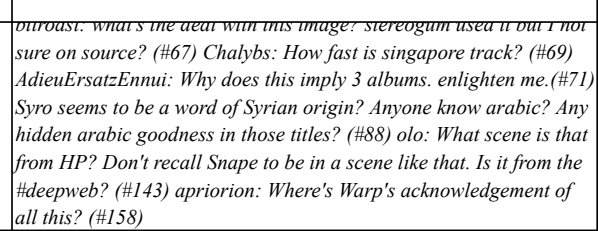 \\
\hline & & offering advice & & & | \\
\hline & \multirow[t]{3}{*}{ information exchanges } & provide knowledge & & & $\begin{array}{l}\text { (conparison with Boards of Canada's album 'Tomorrow's Harvest' } \\
\text { (\#302; \#308) Pappilon: I'm going to predict that this is the time for } \\
\text { all aphex fans to get crazy about catalogue numbers and silly detail } \\
\text { to demonstrate their knowledge and coolness. (\#395) Pappilon: } \\
\text { Actually kind of cool looking IMO reminds me of the on video for } \\
\text { some reason. (\#398); about Eric Wareheim in \#418, Monkey } \\
\text { Drummer? Rubber Johnny? (\#210) }\end{array}$ \\
\hline & & share biographical information & & & Goiter Sachez: September 8th is my Birthday so I hope so!!! (\#354) \\
\hline & & express ideas and opinions & & & $\begin{array}{l}\text { Ithink; I guess; I mean; I'm pretty sure; I was wondering; I'm } \\
\text { assuming; }\end{array}$ \\
\hline
\end{tabular}




\subsubsection{Users of WATMMF}

\begin{tabular}{|c|c|c|c|c|c|c|c|c|}
\hline \multirow{2}{*}{ User name } & \multirow{2}{*}{ Status } & \multicolumn{2}{|c|}{ Forum } & \multirow{2}{*}{\begin{tabular}{|c|} 
Thread \\
Posts
\end{tabular}} & \multirow{2}{*}{ Joined } & \multirow{2}{*}{ Gender } & \multirow{2}{*}{ Location } & \multirow{2}{*}{ Country } \\
\hline & & Posts & Topics & & & & & \\
\hline chim & EKT Plus & 5532 & 235 & 12 & 30th December 2005 & Male & $\mathrm{x}$ & Sweden \\
\hline \begin{tabular}{|l} 
AdieuErsatzEnnui \\
\end{tabular} & Knob Twiddlers & 4866 & 43 & 9 & 2nd August 2011 & Male & $\mathrm{x}$ & $\mathrm{x}$ \\
\hline MIXL2 & Members & 3311 & 62 & 24 & 8th August 2012 & Male & $\mathrm{x}$ & Sweden \\
\hline amnesiac & Supporting Member & 28 & 0 & 5 & 17th August 2014 & Male & $\mathrm{x}$ & USA \\
\hline mcbpete & Moderators & 11281 & 171 & 7 & 1st July 2001 & Female & $\mathrm{x}$ & UK \\
\hline Phoenix Manifest & Supporting Member & 2087 & 61 & 1 & 20th February 2013 & $\mathrm{x}$ & $\mathrm{x}$ & $\mathrm{x}$ \\
\hline Guest jasondonervan * & Guest & 0 & 16 & 8 & $\mathrm{x}$ & $\mathrm{x}$ & $\mathrm{x}$ & $\mathrm{x}$ \\
\hline \begin{tabular}{|l} 
Verdant Hickies \\
\end{tabular} & Members & 883 & 235 & 5 & 25 th June 2013 & Male & Osnabrück & Germany \\
\hline olo & Members & 2042 & 46 & 11 & 4th June 2013 & Male & $\mathrm{x}$ & USA \\
\hline Ivan Ooze & Members & 6457 & 4 & 17 & 23th January 2012 & Male & $\mathrm{x}$ & $\mathrm{x}$ \\
\hline \begin{tabular}{|l|} 
chronical \\
\end{tabular} & Members & 373 & 46 & 8 & 30th October 2012 & Male & $\mathrm{x}$ & Switzerland \\
\hline logakght & Members & 5156 & 43 & 10 & 7th May 2011 & Male & $\mathrm{x}$ & $\mathrm{x}$ \\
\hline triachus & Knob Twiddlers & 8399 & 46 & 6 & 12th April 2006 & Male & $\mathrm{x}$ & Belgium \\
\hline Guest_Roksen Creek_* & Guest & $\mathrm{x}$ & 7 & 9 & $\mathrm{x}$ & $\mathrm{x}$ & $\mathrm{x}$ & $\mathrm{x}$ \\
\hline jhonny & EKT Plus & 3145 & 4 & 6 & 24th September 2009 & Male & $\mathrm{x}$ & UK \\
\hline Guest_Little Lord Faulteroy_* & Guest & $\mathrm{x}$ & 55 & 2 & $\mathrm{x}$ & $\mathrm{x}$ & $\mathrm{x}$ & $\mathrm{x}$ \\
\hline funkaholic & Members & 2337 & $\mathrm{x}$ & 2 & 9th January 2006 & $\mathrm{x}$ & $\mathrm{x}$ & $\mathrm{x}$ \\
\hline Kavinsky & Members & 1774 & 90 & 6 & 5 th May 2007 & Male & Vienna & Austria \\
\hline ZiggomaticV17 & Members & 1987 & 14 & 5 & 10th November 2009 & Male & $\mathrm{x}$ & USA \\
\hline Herr Jan & Moderators & 5303 & 141 & 4 & 8 th December 2006 & Male & $\mathrm{x}$ & Netherlands \\
\hline apriorion & Members & 1130 & 121 & 5 & 6th September 2007 & Male & $\mathrm{x}$ & $\mathrm{x}$ \\
\hline Producer Snafu & Members & 1368 & 235 & 4 & 15th December 2005 & Male & Perris California & USA \\
\hline klore & Validating & 537 & 4 & 11 & 7th July 2014 & Male & $\mathrm{x}$ & France \\
\hline 747Music & Knob Twiddlers & 1465 & 14 & 1 & 13th September 2007 & Male & Ontario & Canada \\
\hline \begin{tabular}{|l} 
Atom Dowry Firth \\
\end{tabular} & Restricted & 1911 & 21 & 1 & 1st March 2013 & Male & $\mathrm{x}$ & $\mathrm{x}$ \\
\hline tec & Knob Twiddlers & 2423 & $\mathrm{x}$ & 4 & 16th June 2004 & $\mathrm{x}$ & $\mathrm{x}$ & UK \\
\hline Nil & Knob Twiddlers & 701 & $\mathrm{x}$ & 3 & 3rd June 2010 & Male & $\mathrm{x}$ & France \\
\hline bitroast & Knob Twiddlers & 8176 & 174 & 11 & 15th February 2006 & $\mathrm{x}$ & $\mathrm{x}$ & $\mathrm{x}$ \\
\hline lumines & Members & 44 & 0 & 2 & 25 th May 2008 & $\mathrm{x}$ & $\mathrm{x}$ & $\mathrm{x}$ \\
\hline Friendly Stranger & Members & 493 & 10 & 3 & 29th April 2013 & $\mathrm{x}$ & $\mathrm{x}$ & USA \\
\hline andihow & Knob Twiddlers & 691 & 31 & 5 & 30th January 2013 & Female & New York & USA \\
\hline \begin{tabular}{|l|} 
Deer \\
\end{tabular} & Supporting Member & 6422 & 55 & 1 & 14th November 2011 & $\mathrm{x}$ & $\mathrm{x}$ & $\mathrm{x}$ \\
\hline miim & Members & 609 & 171 & 2 & 8 th August 2006 & $\mathrm{x}$ & $\mathrm{x}$ & UK \\
\hline Chalybs & Members & 322 & 55 & 3 & 18th June 2013 & Male & Trehörna & Sweden \\
\hline Gocab & Knob Twiddlers & 8521 & 96 & 1 & 10th September 2009 & Male & $\mathrm{x}$ & Norway \\
\hline \begin{tabular}{|l|} 
dr lopez \\
\end{tabular} & \begin{tabular}{|l} 
Knob Twiddlers \\
\end{tabular} & 8932 & 0 & 2 & 7 th April 2008 & Male & New Haven, CT & USA \\
\hline Woozz & Members & 99 & 3 & 4 & 4th November 2013 & Male & $\mathrm{x}$ & France \\
\hline Guest_setanor_* & Guest & $\mathrm{x}$ & 27 & 13 & & $\mathrm{x}$ & $\mathrm{x}$ & $\mathrm{x}$ \\
\hline Npoess & Knob Twiddlers & 8458 & 1 & 3 & 2nd March 2009 & Male & $\mathrm{x}$ & Denmark \\
\hline Guest_digladwin_* & \begin{tabular}{|l|} 
Restricted \\
\end{tabular} & 7 & 235 & 1 & 18th January 2013 & $\mathrm{x}$ & $\mathrm{x}$ & $\mathrm{x}$ \\
\hline \begin{tabular}{|l|} 
Audioblysk \\
\end{tabular} & Members & 2132 & $\mathrm{x}$ & 1 & 1 th November 2011 & Male & $\mathrm{x}$ & USA \\
\hline Friendly Foil & Supporting Member & 6878 & $\mathrm{x}$ & 4 & 5th August 2008 & $\mathrm{x}$ & $\mathrm{x}$ & North Korea \\
\hline Franciscus & Members & 1141 & 16 & 1 & 11 th April 2006 & $\mathrm{x}$ & $\mathrm{x}$ & $\mathrm{x}$ \\
\hline ferro4prez & Restricted & 36 & 4 & 1 & 2nd May 12 & $\mathrm{x}$ & Winnipeg & Canada \\
\hline Bernard Cribbins & Members & 1167 & 36 & 3 & 14th October 2011 & Male & $\mathrm{x}$ & UK \\
\hline pizza & Members & 597 & 25 & 1 & 24th July 2013 & $\mathrm{x}$ & $\mathrm{x}$ & $\mathrm{x}$ \\
\hline PhylumZunami & Supporting Member & 890 & 61 & 1 & 12th March 2014 & $\mathrm{x}$ & $\mathrm{x}$ & $\mathrm{x}$ \\
\hline thief & Members & 1300 & 96 & 2 & 1st June 2007 & $\mathrm{x}$ & $\mathrm{x}$ & New Zealand \\
\hline Djeroek & Supporting Member & 6718 & 0 & 2 & 24th November 2005 & $\mathrm{x}$ & \begin{tabular}{|l} 
Balikpapan \\
\end{tabular} & Indonesia \\
\hline tundra & Supporting Member & 2 & 50 & 1 & 1st January 2014 & Male & $\mathrm{x}$ & $\mathrm{x}$ \\
\hline \begin{tabular}{|l|} 
Q27 \\
\end{tabular} & Members & 687 & $\mathrm{x}$ & 3 & 2nd July 2007 & Male & $\mathrm{x}$ & USA \\
\hline \begin{tabular}{|l|} 
Rbrmyofr \\
\end{tabular} & Members & $\begin{array}{ll}369 \\
\end{array}$ & 26 & 2 & 21st February 2009 & Male & $\mathrm{x}$ & Germany \\
\hline very honest & \begin{tabular}{|l} 
Knob Twiddlers \\
\end{tabular} & 2027 & 30 & 1 & 13th October 2011 & Male & $\mathrm{x}$ & $\mathrm{x}$ \\
\hline \begin{tabular}{|l} 
Barung \\
\end{tabular} & Restricted & 166 & 0 & 1 & 1st February 2013 & $\mathrm{x}$ & $\mathrm{x}$ & Italy \\
\hline auxien & Knob Twiddlers & 2341 & 42 & 5 & 10th April 2008 & Male & $\mathrm{x}$ & USA \\
\hline $000 \mathrm{o}$ & Knob Twiddlers & 6887 & 348 & 6 & 28th March 2006 & Male & $\mathrm{x}$ & $\mathrm{x}$ \\
\hline ghOsty & Members & 3797 & 99 & 3 & 3rd July 2010 & Male & St. Paul & USA \\
\hline BaggerMcGuirk & Members Plus & 363 & 1 & 1 & 1st August 2007 & $\mathrm{x}$ & $\mathrm{x}$ & USA \\
\hline \begin{tabular}{|l|} 
acid1 \\
\end{tabular} & Members & 2405 & 53 & 1 & 20th December 2005 & Male & $\mathrm{x}$ & USA \\
\hline mokz & Members & 2464 & 30 & 2 & 8 th August 2011 & Male & $\mathrm{x}$ & Finland \\
\hline saltykraut & EKT Plus & 211 & 4 & 1 & 9th December 2013 & Male & $\mathrm{x}$ & USA \\
\hline
\end{tabular}




\begin{tabular}{|c|c|c|c|c|c|c|c|}
\hline cyphersum & Restricted & 236 & 14 & \begin{tabular}{l|l|l|}
15 th October 2006
\end{tabular} & Male & $\mathrm{x}$ & USA \\
\hline \begin{tabular}{|l|} 
Iamourfou \\
\end{tabular} & Supporting Member & 122 & 8 & \begin{tabular}{|l|l|l}
1 & th November 2013 \\
\end{tabular} & Male & $\mathrm{x}$ & Canada \\
\hline \begin{tabular}{|l|} 
PolyKrome \\
\end{tabular} & Restricted & 82 & 7 & \begin{tabular}{|l|l|}
1 & 14 th March 2013 \\
\end{tabular} & $\mathrm{x}$ & $\mathrm{x}$ & $\mathrm{x}$ \\
\hline \begin{tabular}{|l|} 
doublename \\
\end{tabular} & Members & 4208 & 40 & \begin{tabular}{|l|l}
1 & 1 st June 2013 \\
\end{tabular} & Male & New York, Philadelphia & USA \\
\hline \begin{tabular}{|l|} 
Frank Poole \\
\end{tabular} & Members & 409 & 4 & \begin{tabular}{|l|l}
2 & 1at May 2008 \\
\end{tabular} & Male & New York & USA \\
\hline th555 & Members & 2346 & 89 & 1 3rd January 2010 & $\mathrm{x}$ & $\mathrm{x}$ & $\mathrm{x}$ \\
\hline Lane Visitor & Knob Twiddlers & 1979 & 75 & \begin{tabular}{l|l}
6 th May 2012 \\
\end{tabular} & Male & Phoenix, AZ & USA \\
\hline flim & Members & 671 & 4 & \begin{tabular}{l|l}
1 & 1 st September 1999 \\
\end{tabular} & Male & $\mathrm{x}$ & USA \\
\hline beerwolf & Supporting Member & 7130 & 15 & \begin{tabular}{l|l}
1 & 30 th December 2009
\end{tabular} & $\mathrm{x}$ & $x^{n}$ & UK \\
\hline pyramidpanes & Members & 566 & 55 & \begin{tabular}{l|l}
1 & 1 st June 2013 \\
\end{tabular} & Male & $\mathrm{x}$ & $\mathrm{x}$ \\
\hline Blank & \begin{tabular}{|l} 
Knob Twiddlers \\
\end{tabular} & 1435 & 15 & \begin{tabular}{|l|l|}
1 & 8 th August 2014 \\
\end{tabular} & Male & Birmingham & UK \\
\hline \begin{tabular}{|l|} 
KyonPalm \\
\end{tabular} & Members & 278 & 329 & \begin{tabular}{l|l}
27 th November 2008 \\
\end{tabular} & Male & (Florida) & USA \\
\hline delet... & Moderators & 19702 & 62 & $\begin{array}{ll} & 2 \text { nd August } 1999 \\
\end{array}$ & Male & $\mathrm{x}$ & Australia \\
\hline $\begin{array}{l}\text { Joyrex } \\
\end{array}$ & Site Administrator & 18814 & 216 & \begin{tabular}{|l|l|}
5 & 3rd June 1999 \\
\end{tabular} & Male & $\mathrm{x}$ & USA \\
\hline \begin{tabular}{|l|} 
Atop \\
\end{tabular} & EKT Plus & 8411 & 1 & \begin{tabular}{l|l|}
1 & 24th January 2006 \\
\end{tabular} & Male & (Texas) & USA \\
\hline Slacker & Members & 154 & 41 & 123 rd July 2009 & Male & $\mathrm{x}$ & UK \\
\hline noise & Members & 1366 & $\mathrm{x}$ & \begin{tabular}{l|l}
2 & 19 th November 2005
\end{tabular} & $\mathrm{x}$ & $\mathrm{x}$ & $\mathrm{x}$ \\
\hline Icct & Members & 202 & 55 & \begin{tabular}{|l|l}
25 January 2013 \\
\end{tabular} & $\mathrm{x}$ & New York & USA \\
\hline \begin{tabular}{|l|} 
Bechuga \\
\end{tabular} & Members & 1946 & 62 & \begin{tabular}{|l|l|}
4 & 16 June 2014 \\
\end{tabular} & Male & $\mathrm{x}$ & UK \\
\hline Hoarsecow & Validating & 111 & 4 & \begin{tabular}{l|l}
2 & 18 January 2014 \\
\end{tabular} & Male & $\mathrm{x}$ & USA \\
\hline \begin{tabular}{|l|} 
stripeyhat \\
\end{tabular} & \begin{tabular}{|l|} 
Restricted \\
\end{tabular} & 351 & 37 & \begin{tabular}{l|l}
1 & 16 February 2006
\end{tabular} & $\mathrm{x}$ & Manchaster & UK \\
\hline qnio & Members & 1767 & 55 & \begin{tabular}{l|l}
24 May 2007 \\
\end{tabular} & Male & $\mathrm{x}$ & $\mathrm{x}$ \\
\hline qaz & Members & 53 & 348 & 127 th April 2013 & Male & Washington & USA \\
\hline yek & EKT Plus & 14967 & $\mathrm{x}$ & \begin{tabular}{l|l}
3 & 15 th March 2002 \\
\end{tabular} & Male & $\mathrm{x}$ & Canada \\
\hline empirix & Members & 74 & 0 & \begin{tabular}{|l|l}
1 & 7 th June 2011 \\
\end{tabular} & Male & $\mathrm{x}$ & Taiwan \\
\hline MisterE & Members Plus & 2502 & 19 & \begin{tabular}{|l|l|}
1 & 8th April 2010
\end{tabular} & Male & $\mathrm{x}$ & $\mathrm{x}$ \\
\hline Guest halluciphile * & Guest & 1620 & $\mathrm{x}$ & $1 \mathrm{x}$ & $\mathrm{x}$ & $\mathrm{x}$ & $\mathrm{x}$ \\
\hline Guest HokusPoker * & Guest & 50 & $\mathrm{x}$ & $1 \mathrm{x}$ & $\mathrm{x}$ & $\mathrm{x}$ & $\mathrm{x}$ \\
\hline fletcher & \begin{tabular}{|l|} 
Knob Twiddlers \\
\end{tabular} & 7319 & 99 & 1 3rd Febraury 2010 & Male & Oxfordshire & UK \\
\hline Nebraska & Supporting Member & 4106 & 329 & 15 th December 2011 & Male & $\mathrm{x}$ & $\mathrm{x}$ \\
\hline ieatacid & \begin{tabular}{|l} 
Restricted \\
\end{tabular} & 170 & 329 & \begin{tabular}{l|l}
4 & 24 th July 2014
\end{tabular} & Male & Virginia Beach & USA \\
\hline \begin{tabular}{|l|} 
Eggs \\
\end{tabular} & \begin{tabular}{|l} 
Knob Twiddlers \\
\end{tabular} & 1113 & 10 & 1 18th November 2005 & Male & $\mathrm{x}$ & USA \\
\hline Guest couch * & Guest & 62 & $\mathrm{x}$ & $1 \mathrm{x}$ & $\mathrm{x}$ & $\mathrm{x}$ & $\mathrm{x}$ \\
\hline \begin{tabular}{|l|l|} 
bopslayer \\
\end{tabular} & \begin{tabular}{|l} 
Validating \\
\end{tabular} & 35 & $\mathrm{x}$ & \begin{tabular}{|l|l|}
1 & 8th April 2014
\end{tabular} & Male & $\mathrm{x}$ & USA \\
\hline \begin{tabular}{|l|} 
dumplings \\
\end{tabular} & Members & 354 & $\mathrm{x}$ & \begin{tabular}{|l|l|}
120 th March 2012 \\
\end{tabular} & Male & $\mathrm{x}$ & UK \\
\hline \begin{tabular}{|l|} 
varius \\
\end{tabular} & Supporting Member & 528 & 32 & \begin{tabular}{|l|l|}
24 th October 2006 \\
\end{tabular} & Male & $\mathrm{x}$ & UK \\
\hline panz0r & Members & 737 & 21 & \begin{tabular}{|l|l|}
16 th November 2005 \\
\end{tabular} & $\mathrm{x}$ & $\mathrm{x}$ & $\mathrm{x}$ \\
\hline calx & Supporting Member & 868 & 41 & \begin{tabular}{l|l}
7 & 5 th February 2011 \\
\end{tabular} & Male & $\mathrm{x}$ & UK \\
\hline \begin{tabular}{|l|} 
KingDoom \\
\end{tabular} & Supporting Member & 3 & 293 & \begin{tabular}{|l|l}
18 th August 2014 \\
\end{tabular} & Male & $\mathrm{x}$ & $\mathrm{x}$ \\
\hline \begin{tabular}{|l|} 
John Ehrlichman \\
\end{tabular} & Banned & 6466 & 1620 & \begin{tabular}{l|l}
27 th November 2005 \\
\end{tabular} & Male & Atlanta & USA \\
\hline plstik & Members & 1500 & 2 & 1 1st February 2009 & Male & $\mathrm{x}$ & Germany \\
\hline whylessness & Banned & 679 & 75 & 1 23rd February 2011 & $\mathrm{x}$ & $\mathrm{x}$ & $\mathrm{x}$ \\
\hline \begin{tabular}{|l}
$\operatorname{coax}$ \\
\end{tabular} & Members & 741 & 16 & 120 th April 2008 & $\mathrm{x}$ & $\mathrm{x}$ & $\mathrm{x}$ \\
\hline BCM & Knob Twiddlers & 16090 & 265 & 8 5th February 2006 & Male & $\mathrm{x}$ & UK \\
\hline \begin{tabular}{|l|} 
psn \\
\end{tabular} & \begin{tabular}{|l|} 
EKT Plus \\
\end{tabular} & 5552 & 4 & \begin{tabular}{l|l}
28 th July 2009 \\
\end{tabular} & Male & $\mathrm{x}$ & Norway \\
\hline oscilllik & Knob Twiddlers & 9832 & 111 & 419 th October 2006 & Male & Widnes & UK \\
\hline YELLOW & Members & 1170 & 265 & $\begin{array}{ll}14 \text { th May } 2007 \\
\end{array}$ & Male & Maine & USA \\
\hline \begin{tabular}{|l|} 
Transferrin \\
\end{tabular} & Members & 51 & 0 & \begin{tabular}{l|l}
13 th September 2010 \\
\end{tabular} & Male & $\mathrm{x}$ & USA \\
\hline \begin{tabular}{|l|} 
Jakuar \\
\end{tabular} & Members & 9 & 1 & \begin{tabular}{l|l} 
& 30 th July 2013
\end{tabular} & Male & $\mathrm{x}$ & New Zealand \\
\hline \begin{tabular}{|l|} 
diatoms \\
\end{tabular} & Members Plus & 37 & $\mathrm{x}$ & \begin{tabular}{l|l}
10 th April 2014 \\
\end{tabular} & $\mathrm{x}$ & $\mathrm{x}$ & $\mathrm{x}$ \\
\hline \begin{tabular}{|l|} 
Phonejack \\
\end{tabular} & Restricted & 157 & $\mathrm{x}$ & \begin{tabular}{l|l}
10 th May 2013 \\
\end{tabular} & Female & $\mathrm{x}$ & UK \\
\hline \begin{tabular}{|l|} 
xox \\
\end{tabular} & Members & 3185 & $\mathrm{x}$ & \begin{tabular}{|l|l}
5 & 9 th April 2008 \\
\end{tabular} & Male & $\mathrm{x}$ & Croatia \\
\hline Jobe & EKT Plus & 207 & 3 & \begin{tabular}{|l|l}
26 th August 2007 \\
\end{tabular} & Male & $\mathrm{x}$ & USA \\
\hline Bread & Members & 2350 & 92 & \begin{tabular}{|l|l}
1 & 20 th July 2006 \\
\end{tabular} & Male & $\mathrm{x}$ & $\mathrm{x}$ \\
\hline vincentvc & Supporting Member & 2919 & 62 & \begin{tabular}{|l|l|}
2 th August 2009 \\
\end{tabular} & $\mathrm{x}$ & $\mathrm{x}$ & $\mathrm{x}$ \\
\hline patternoverlap & \begin{tabular}{|l|} 
EKT Plus \\
\end{tabular} & 5133 & 36 & \begin{tabular}{l|l}
1 & 20 th November 2005
\end{tabular} & $\mathrm{x}$ & $\mathrm{x}$ & $\mathrm{x}$ \\
\hline beringelab & Supporting Member & 113 & 2 & \begin{tabular}{|l|l|}
26 th March 2014 \\
\end{tabular} & $\mathrm{x}$ & $\mathrm{x}$ & $\mathrm{x}$ \\
\hline David Bowman & Members & 109 & 235 & \begin{tabular}{l|l}
1 & 8 th October 2009
\end{tabular} & $\mathrm{x}$ & $\mathrm{x}$ & USA \\
\hline Papillon & Members & 381 & 12 & \begin{tabular}{l|l}
17 & 23 rd April 2013 \\
\end{tabular} & Male & Toronto & Canada \\
\hline \begin{tabular}{|l} 
Philipp Glass \\
\end{tabular} & Members & 2884 & 8 & \begin{tabular}{l|l}
27 th November 2005 \\
\end{tabular} & Male & Montreal & Canada \\
\hline children $\mathrm{r} r$ future & Members & 324 & 1 & \begin{tabular}{|l|l}
1 8th August 2006 \\
\end{tabular} & Male & $\mathrm{x}$ & USA \\
\hline \begin{tabular}{|l|} 
ZmillA \\
\end{tabular} & Members & 186 & 27 & 12 nd December 2011 & $\mathrm{x}$ & $\mathrm{x}$ & $\mathrm{x}$ \\
\hline \begin{tabular}{|l|} 
Cheeez \\
\end{tabular} & Members & 236 & 18 & 1) 6 th March 2008 & Male & $\mathrm{x}$ & UK \\
\hline \begin{tabular}{|l|} 
barbara planar \\
\end{tabular} & Members & 763 & 0 & 1) 14th February 2006 & Male & $\mathrm{x}$ & USA \\
\hline \begin{tabular}{|l|} 
Goiter Sanchez \\
\end{tabular} & Supporting Member & 4317 & $\mathrm{x}$ & \begin{tabular}{l|l}
30 th March 2006 \\
\end{tabular} & Male & San Francusco & USA \\
\hline \begin{tabular}{|l|} 
Parsifal \\
\end{tabular} & \begin{tabular}{|l|} 
Members Plus \\
\end{tabular} & 182 & 10 & \begin{tabular}{|l|l}
13 th December 2005 \\
\end{tabular} & Male & Gothenburg & Sweden \\
\hline impotentwhitecapitalist & Members & 4761 & 38 & \begin{tabular}{|l|l}
19 th Jnauray 2010 \\
\end{tabular} & Male & $\mathrm{x}$ & USA \\
\hline Rubin Farr & Moderators & 10777 & 1324 & 2 16th November 2005 & Male & $\mathrm{x}$ & $\mathrm{x}$ \\
\hline \begin{tabular}{|l} 
Avarik \\
\end{tabular} & Knob Twiddlers & 239 & 8 & \begin{tabular}{l|l}
5 th March 2013 \\
\end{tabular} & $\mathrm{x}$ & (California) & USA \\
\hline locustix & Members & 31 & 1 & \begin{tabular}{l|l}
24 th February 2008 \\
\end{tabular} & $\frac{1}{x}$ & $\mathrm{x}$ & \begin{tabular}{|l|l|l}
$x$ \\
$x$
\end{tabular} \\
\hline iniquity blues & Supporting Member & 26 & 0 & 1 23rd February 2014 & Male & $\mathrm{x}$ & USA \\
\hline StephenG & \begin{tabular}{|l|l|} 
EKT Plus \\
\end{tabular} & 13324 & 39 & \begin{tabular}{|l|l|}
28 th January 2012 \\
\end{tabular} & Male & $\mathrm{x}$ & Canada \\
\hline randomAmateur & Members & 427 & 37 & \begin{tabular}{|l|l|} 
6th August 2012 \\
\end{tabular} & Male & $\mathrm{x}$ & Germany \\
\hline 123 & Members & 132 & 8 & \begin{tabular}{|l|l|}
4 & 13 th June 2008 \\
\end{tabular} & $\mathrm{x}$ & $\mathrm{x}$ & $\mathrm{x}$ \\
\hline phudoshin & Members & 1964 & 179 & \begin{tabular}{|l|l}
2 & 9 th January 2006 \\
\end{tabular} & Male & $\mathrm{x}$ & Ireland \\
\hline \begin{tabular}{|l} 
sun drugs \\
\end{tabular} & Members & 313 & 7 & \begin{tabular}{l|l}
15 th July 2013 \\
\end{tabular} & Male & $\mathrm{x}$ & $\mathrm{x}$ \\
\hline lamourfou & Supporting Member & 122 & 8 & \begin{tabular}{l|l}
1 & 4th November 2013
\end{tabular} & Male & $\mathrm{x}$ & Canada \\
\hline
\end{tabular}




\begin{tabular}{|c|c|c|c|c|c|c|c|}
\hline sergeantk & Members & 1512 & 95 & \begin{tabular}{|l|l|}
13 th January 2011 \\
\end{tabular} & Male & $\mathrm{x}$ & $\mathrm{x}$ \\
\hline NorthernFusion & Knob Twiddlers & 1122 & 19 & $\begin{array}{ll}1 & 6 \text { th Apri } 2013 \\
\end{array}$ & Male & $\mathrm{x}$ & UK \\
\hline \begin{tabular}{|l|} 
datastream \\
\end{tabular} & Supporting Member & 137 & 1 & \begin{tabular}{l|l}
1 & 23 rd November 2009 \\
\end{tabular} & $\mathrm{x}$ & $\mathrm{x}$ & $\mathrm{x}$ \\
\hline Guest_tv_party_* & Guest & 73 & $\mathrm{x}$ & $1 \mathrm{x}$ & $\mathrm{x}$ & $\mathrm{x}$ & $\mathrm{x}$ \\
\hline joshuatx & Knob Twiddlers & 7739 & 0 & 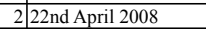 & Male & Austin & USA \\
\hline si clone & Validating & 4 & 37 & \begin{tabular}{|l|l|}
1 & 18 th August2014 \\
\end{tabular} & Male & Myron Bay & Australia \\
\hline Terpentintollwut & Members & 3045 & 12 & \begin{tabular}{l|l}
1 & 3rd March 2008 \\
\end{tabular} & Male & $\mathrm{x}$ & $\mathrm{x}$ \\
\hline \begin{tabular}{|l|} 
purlieu \\
\end{tabular} & Members & 904 & 27 & \begin{tabular}{l|l|l}
1 & 9 th February 2010 \\
\end{tabular} & $\mathrm{x}$ & $\mathrm{x}$ & UK \\
\hline Allize & Members & 658 & 16 & \begin{tabular}{|l|l|}
3 & 17 th January 2014 \\
\end{tabular} & Male & $\mathrm{x}$ & Madagascar \\
\hline cloud capture & Members & 1411 & 10 & \begin{tabular}{|l|l|}
1 & 16 th October 2011 \\
\end{tabular} & Male & Norther Wisconsin & USA \\
\hline tokn & Members & 1671 & 51 & \begin{tabular}{|l|l|}
1 & 29 th July 2009 \\
\end{tabular} & Male & Berlin & Germany \\
\hline Zorro & Validating & 303 & 10 & \begin{tabular}{l|l}
1 & 26 th May 2014 \\
\end{tabular} & Male & New Hampshire & USA \\
\hline modey & Knob Twiddlers & 10740 & 12 & \begin{tabular}{|l|l|}
7 & 9 th June 2004 \\
\end{tabular} & Male & Melbourne & Australia \\
\hline VIII & Members & 186 & 1 & \begin{tabular}{l|l}
1 & 21 st July 2012 \\
\end{tabular} & $\mathrm{x}$ & $\mathrm{x}$ & $\mathrm{x}$ \\
\hline petina & Knob Twiddlers & 1083 & 0 & \begin{tabular}{l|l|}
1 & 9 th April 2014 \\
\end{tabular} & Female & $\mathrm{x}$ & New Zealand \\
\hline forcefielder & Supporting Member & 74 & 2 & \begin{tabular}{l|l}
5 & 19 th August 2014 \\
\end{tabular} & Male & Vancouver Island & Canada \\
\hline emoji & Supporting Member & 25 & 5 & \begin{tabular}{l|l}
19 th December 2013 \\
\end{tabular} & $\mathrm{x}$ & $\mathrm{x}$ & $\mathrm{x}$ \\
\hline afxual healing & Members Plus & 303 & 430 & 1 06th April 2014 & Male & $\mathrm{x}$ & USA \\
\hline $\mathrm{xxx}$ & EKT Plus & 8318 & 74 & \begin{tabular}{l|l}
12 th July 2007 \\
\end{tabular} & Male & Kansas City & USA \\
\hline Guest_crowndicey_* & Guest & $\mathrm{x}$ & 27 & \begin{tabular}{l|l}
2 & $x$ \\
\end{tabular} & $\mathrm{x}$ & $\mathrm{x}$ & $\mathrm{x}$ \\
\hline Brisbot & \begin{tabular}{|l} 
Knob Twiddlers \\
\end{tabular} & 2040 & 246 & \begin{tabular}{|l|l|}
1 st November 2013 \\
\end{tabular} & Male & $\mathrm{x}$ & $\mathrm{x}$ \\
\hline \begin{tabular}{|l|} 
gritbox \\
\end{tabular} & Members & 160 & 46 & \begin{tabular}{l|l}
1 & 8 th July 2010 \\
\end{tabular} & $\mathrm{x}$ & $\mathrm{x}$ & $\mathrm{x}$ \\
\hline Dammy O Flannagin & Members & 1940 & 12 & \begin{tabular}{l|l}
11 th November 2011 \\
\end{tabular} & Male & (California) & USA \\
\hline webby & Members & $\mathrm{x}$ & 1037 & \begin{tabular}{l|l|}
2 & 14th February 2012 \\
\end{tabular} & Male & $\mathrm{x}$ & Australia \\
\hline \begin{tabular}{|l|} 
Candiru \\
\end{tabular} & Members & 5265 & $\mathrm{x}$ & \begin{tabular}{l|l|l} 
th August 2009 \\
\end{tabular} & Male & $\mathrm{x}$ & $\mathrm{x}$ \\
\hline bossman & Members & 264 & 17 & \begin{tabular}{l|l|l}
1 & 25 th March 2008 \\
\end{tabular} & $\mathrm{x}$ & (California) & USA \\
\hline \begin{tabular}{|l|} 
goDel \\
\end{tabular} & Members & 9233 & 29 & \begin{tabular}{|l|l|}
2 & 16 th November 2005 \\
\end{tabular} & $\mathrm{x}$ & $\mathrm{x}$ & Seychelles \\
\hline clevreuse & Knob Twiddlers & 1394 & 61 & \begin{tabular}{|l|l}
12 th August 2013 \\
\end{tabular} & Male & $\mathrm{x}$ & UK \\
\hline \begin{tabular}{|l|l|} 
cult fiction \\
\end{tabular} & Knob Twiddlers & 15555 & 30 & \begin{tabular}{l|l}
1 & 5 th August 2008 \\
\end{tabular} & Male & $\mathrm{x}$ & USA \\
\hline Guest_InternetTekevision_* & Guest & $\mathrm{x}$ & 46 & \begin{tabular}{|l|l|}
2 & $x$ \\
\end{tabular} & $\mathrm{x}$ & $\mathrm{x}$ & $\mathrm{x}$ \\
\hline rd1994 & Members & 184 & 12 & \begin{tabular}{|l|l|}
1 & 30 th March 2013 \\
\end{tabular} & $\mathrm{x}$ & $\mathrm{x}$ & Germany \\
\hline \begin{tabular}{|l|} 
Jedy Harbl \\
\end{tabular} & Moderators & 312 & 102 & \begin{tabular}{|l|l|}
1 st June 2001 \\
\end{tabular} & $\mathrm{x}$ & $\mathrm{x}$ & Argentina \\
\hline \begin{tabular}{|l} 
Berk \\
\end{tabular} & Members & 4141 & $\begin{array}{c}102 \\
44 \\
\end{array}$ & 1 24th February 2008 & Male & \begin{tabular}{|l}
$\mathrm{x}$ \\
\end{tabular} & \begin{tabular}{|l} 
Netherlands \\
\end{tabular} \\
\hline Zeffolia & Members & 2045 & 12 & 126 th October 2010 & $\mathrm{x}$ & $\mathrm{x}$ & $\mathrm{x}$ \\
\hline \begin{tabular}{|l|} 
skibby \\
\end{tabular} & Members & 2335 & 89 & \begin{tabular}{|l|l|}
2 & 13 th July 2013 \\
\end{tabular} & $\mathrm{x}$ & $\mathrm{x}$ & $\mathrm{x}$ \\
\hline Uniret & Banned & 331 & 348 & 1 22nd November 2011 & Male & $\mathrm{x}$ & $\mathrm{x}$ \\
\hline \begin{tabular}{|l|} 
Aural Unrest \\
\end{tabular} & Members & 380 & 12 & 1 3rd April 2013 & Male & Derby & UK \\
\hline \begin{tabular}{|l} 
Bordie \\
\end{tabular} & Validating & 131 & 127 & \begin{tabular}{l|l}
1 & 18 th June 2014 \\
\end{tabular} & Male & $\mathrm{x}$ & Poland \\
\hline
\end{tabular}


10.6 Attachment 6: Gearslutz

10.6.1 Coding categories of Gearslutz

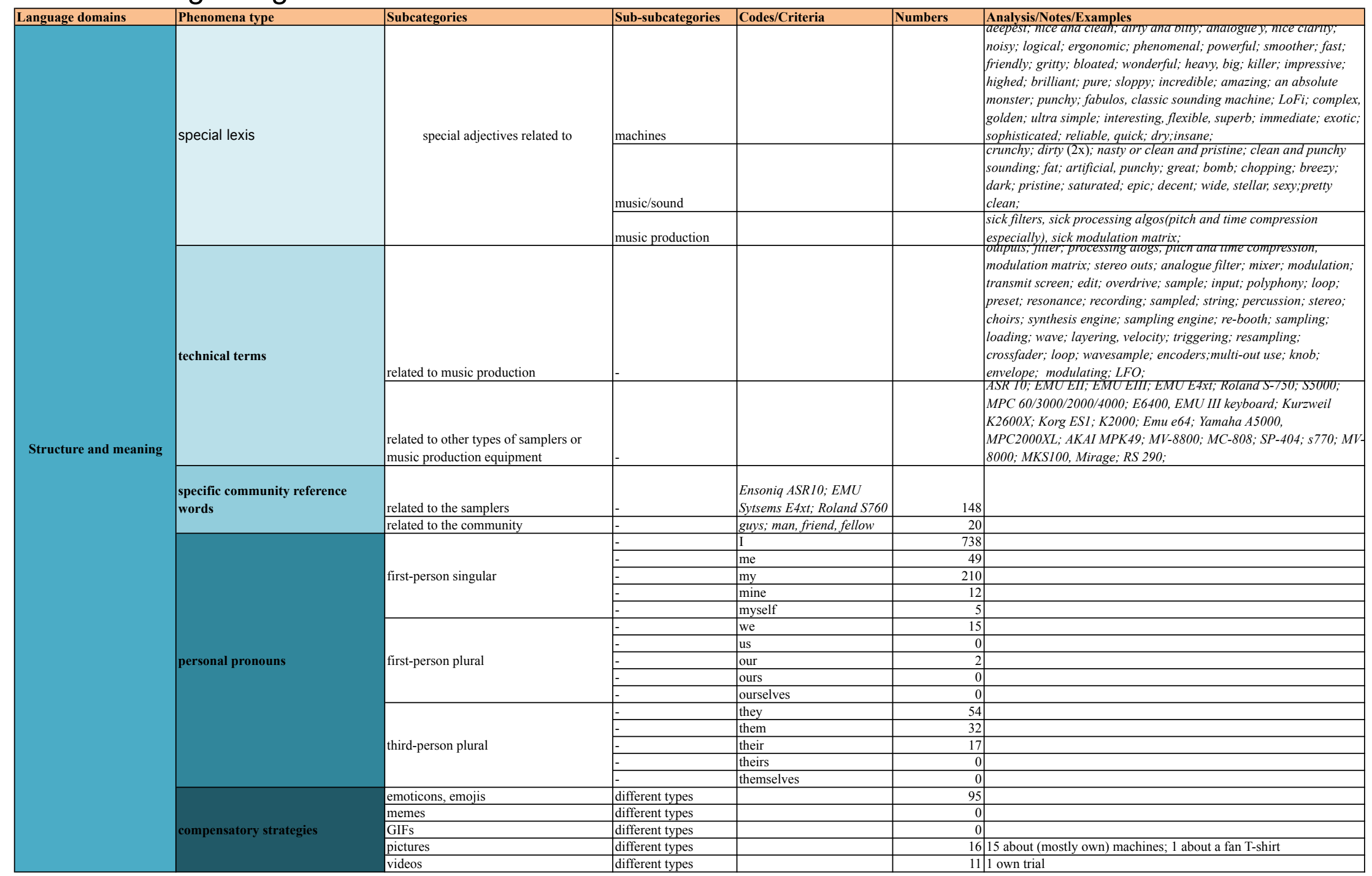




\begin{tabular}{|c|c|c|c|c|c|}
\hline \multirow{5}{*}{ Interactional management } & \multirow{3}{*}{ Concern structures } & linking & hypperlink & & 311 mostly the website's own hyperlinks - automatic \\
\hline & & quoting & $\begin{array}{l}\text { other users } \\
\text { someone else }\end{array}$ & & $\frac{181 \text { [from the total } 414}{0}$ \\
\hline & & $\begin{array}{lll}\text { tagging } \\
\text { using bastag }\end{array}$ & \begin{tabular}{|l} 
other users \\
terefrion to Twitter
\end{tabular} & & 4/aim: addressing the message \\
\hline & \multirow[b]{2}{*}{ Participation } & $\begin{array}{l}\text { using hashitag } \\
\text { number of messages per group member }\end{array}$ & referring to 1 witter & \multirow[b]{2}{*}{$\begin{array}{l}10 \text { years plus; } 5 \text { years plus } \\
\text { or none }\end{array}$} & See in the other related table \\
\hline & & participation types & through status & & See in the other related table \\
\hline & & agree/disagree & through activity & & 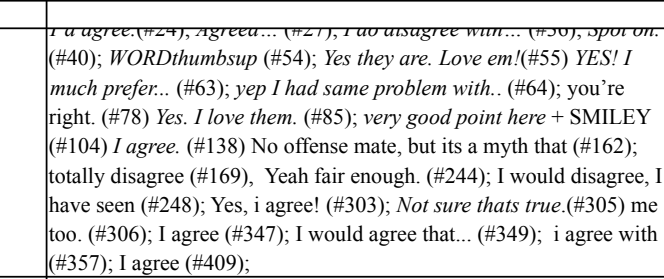 \\
\hline & & $\begin{array}{l}\text { coounterpoint } \\
\text { acknowledge }\end{array}$ & & & you are talking about something completely different here.. (\#164); \\
\hline & & invite/give feedback & & & 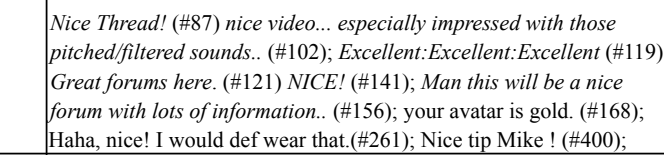 \\
\hline & & thanking & & & 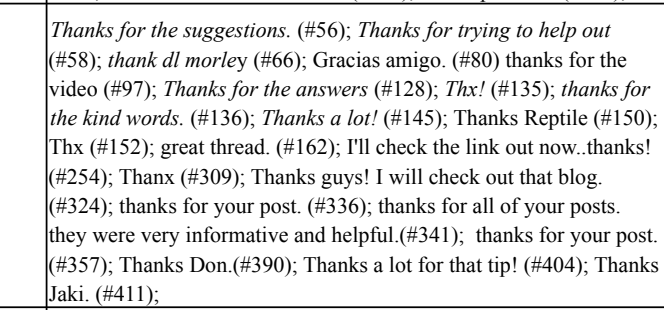 \\
\hline & & sympathise & & & \begin{tabular}{|l|l|} 
thumbsup (4x) Well, I really do appreciate it thumbsup (\#139) \\
Back in Black. (for a synth) $(\# 141)$; If you ever need a new home for
\end{tabular} \\
\hline & & joking & & & that PPG/waveterm, let me know. (\#208); \\
\hline
\end{tabular}




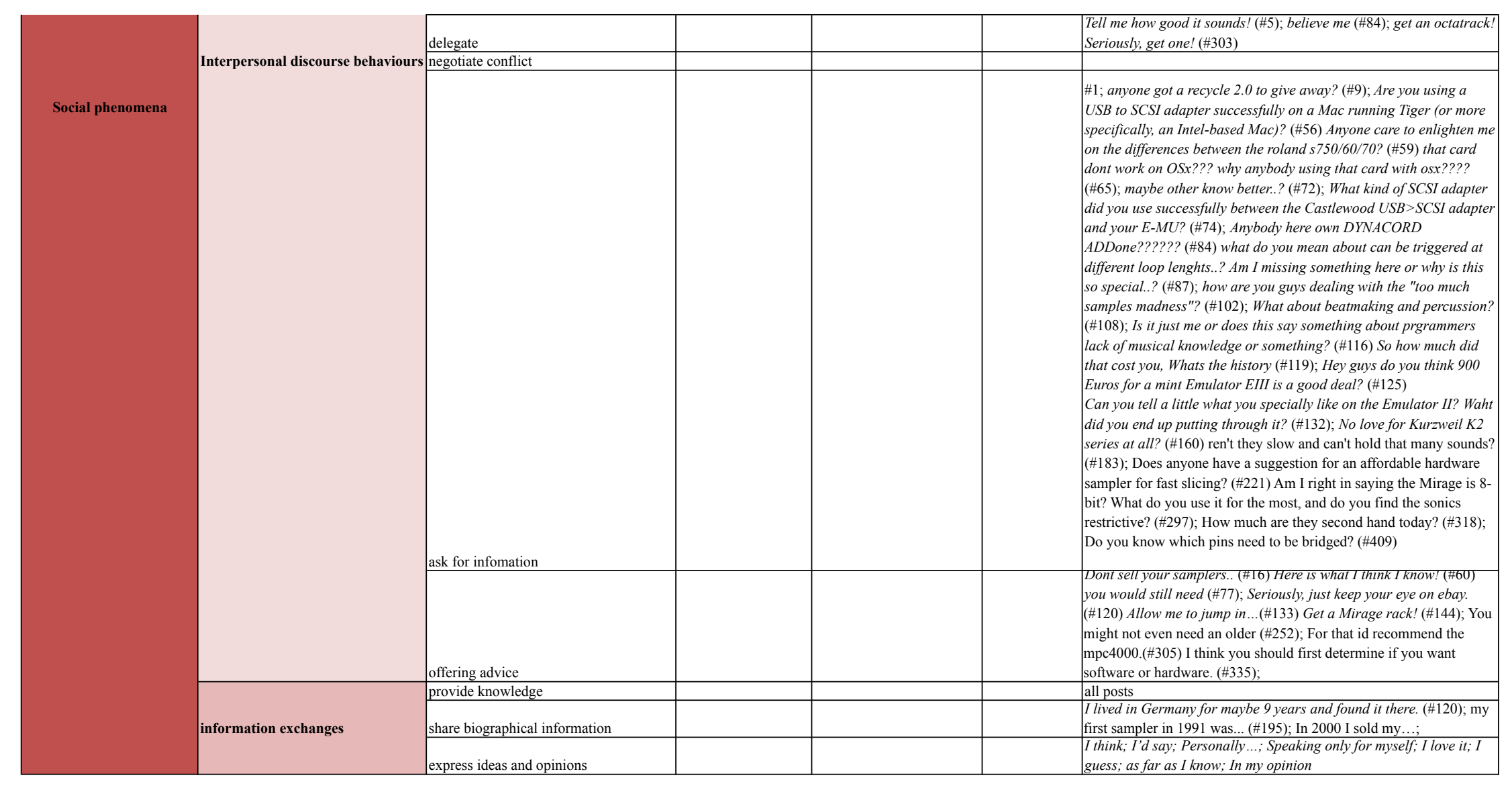


10.6.2 Users of Gearslutz

\begin{tabular}{|c|c|c|c|c|c|c|c|}
\hline \multirow{2}{*}{ User } & \multirow{2}{*}{ About } & \multirow{2}{*}{ Joined } & \multicolumn{2}{|c|}{ Posts } & \multirow{2}{*}{ Location } & \multirow{2}{*}{ Country } & \\
\hline & & & Forum & Thread & & & 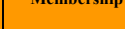 \\
\hline roginator & Lives for gear & Dec 05 & 2516 & 36 & & $\mathrm{x}$ & 10 years plus \\
\hline Doc Mixwell & $70 \%$ Coffe, $30 \%$ Beer & Dec 06 & 11453 & 1 & Quincy & UASA & 5 years plus \\
\hline nick $\mathrm{x} 0 \mathrm{x}$ & Gear nut & Sep-05 & 92 & 2 & $\mathrm{x}$ & \begin{tabular}{|l|l}
$x$ \\
\end{tabular} & 10 years plus \\
\hline H-Rezz & \begin{tabular}{|l|} 
Lives for gear \\
\end{tabular} & Feb-06 & 1948 & & $\mathrm{x}$ & $\mathrm{x}$ & 10 years plus \\
\hline rawdigits & \begin{tabular}{|l|} 
Lives for gear \\
\end{tabular} & $\begin{array}{ll}\text { May } 07 \\
\end{array}$ & 505 & 21 & \begin{tabular}{|l|l}
$x$ \\
\end{tabular} & \begin{tabular}{|l} 
Switzerland \\
\end{tabular} & 5 years plus \\
\hline rokuez & Lives for gear & $\begin{array}{ll}\text { June } 06 \\
\end{array}$ & 782 & 2 & \begin{tabular}{|l} 
Los Angeles \\
\end{tabular} & \begin{tabular}{|l|} 
USA \\
\end{tabular} & 10 years plus \\
\hline \begin{tabular}{|l|} 
alexstringer \\
\end{tabular} & \begin{tabular}{|l|} 
Lives for gear \\
\end{tabular} & March 05 & 2027 & 1 & \begin{tabular}{|l|} 
New York \\
\end{tabular} & USA & 10 years plus \\
\hline \begin{tabular}{|l} 
C Heat \\
\end{tabular} & \begin{tabular}{|l} 
Lives for gear \\
\end{tabular} & Nov- 05 & $\frac{2027}{2639}$ & $\frac{1}{1}$ & \begin{tabular}{|l|l|l|l}
$x$ \\
\end{tabular} & \begin{tabular}{|l}
$\mathrm{D}$ \\
\end{tabular} & $\begin{array}{l}10 \text { years plus } \\
\end{array}$ \\
\hline Beastie & Lives for gear & \begin{tabular}{l|l} 
Aug-06 \\
\end{tabular} & 1676 & 2 & $\mathrm{x}$ & UK & 5 years plus \\
\hline dimorley & special guest & Juni-02 & 6917 & 30 & \begin{tabular}{|l|l|}
$x$ \\
\end{tabular} & \begin{tabular}{|l|} 
Belgium \\
\end{tabular} & 10 years plus \\
\hline Halfmoon & Gear Maniac & Dec 06 & 166 & 1 & New Jersey & \begin{tabular}{|l|l} 
USA \\
\end{tabular} & 5 years plus \\
\hline MonoBrow & Lives for gear & Sep-06 & 2271 & 2 & Hamburg & Germany & 5 years plus \\
\hline \begin{tabular}{|l} 
Chrisac \\
\end{tabular} & \begin{tabular}{|l|} 
Gear Addict \\
\end{tabular} & Aug-04 & 452 & 8 & $\mathrm{x}$ & \begin{tabular}{|l}
$\mathrm{x}$ \\
\end{tabular} & \begin{tabular}{|l}
10 years plus \\
\end{tabular} \\
\hline dan p & \begin{tabular}{|l} 
Lives for gear \\
\end{tabular} & Nov-06 & 1502 & 1 & \begin{tabular}{|l|} 
San Ramon \\
\end{tabular} & Canada & 5 years plus \\
\hline sound forward & Gear nut & Nov-05 & 135 & 1 & $\mathrm{x}$ & $\mathrm{x}$ & 10 years plus \\
\hline freshmints & Gear Maniac & \begin{tabular}{l|l|} 
Feb-05 \\
\end{tabular} & 152 & & $\mathrm{x}$ & $\mathrm{x}$ & 10 years plus \\
\hline Killah Trakz & $\begin{array}{l}3+\text { infractions, forum } \\
\text { membership suspended }\end{array}$ & May 05 & 1624 & 1 & Hollywood & USA & 10 years plus \\
\hline \begin{tabular}{|l} 
Beermaster \\
Bent
\end{tabular} & \begin{tabular}{|l} 
Lives for gear \\
\end{tabular} & May 07 & $\frac{2024}{2130}$ & 1 & \begin{tabular}{|l|l|l} 
London \\
\end{tabular} & \begin{tabular}{|l|}
$U S A$ \\
$U K$ \\
\end{tabular} & \begin{tabular}{|l|l|l}
5 years plus \\
\end{tabular} \\
\hline \begin{tabular}{|l|} 
jude \\
\end{tabular} & Lives for gear & Dec 06 & 1397 & 1 & $\mathrm{x}$ & \begin{tabular}{|l|} 
Australia \\
\end{tabular} & \begin{tabular}{|l|}
5 years plus \\
\end{tabular} \\
\hline \begin{tabular}{|l} 
Stevil \\
\end{tabular} & \begin{tabular}{|l} 
Lives for gear \\
\end{tabular} & \begin{tabular}{l|l} 
June 05 \\
\end{tabular} & 3039 & 3 & \begin{tabular}{|l} 
(California) \\
\end{tabular} & USA & 10 years plus \\
\hline lord toranaga & \begin{tabular}{|l} 
Gear Addict \\
\end{tabular} & \begin{tabular}{|l|} 
May 07 \\
\end{tabular} & 350 & 15 & $\mathrm{x}$ & $\mathrm{x}$ & 5 years plus \\
\hline \begin{tabular}{|l} 
Gryten \\
\end{tabular} & \begin{tabular}{|l|} 
Gear nut \\
\end{tabular} & Apr-07 & 76 & & $\mathrm{x}$ & $\mathrm{x}$ & 5 years plus \\
\hline \begin{tabular}{|l} 
Siem \\
\end{tabular} & Gear Addict & Dec 05 & 314 & & \begin{tabular}{|l|l}
$x$ \\
\end{tabular} & Netherlands & 10 years plus \\
\hline marcceba & Here for the gear & \begin{tabular}{|l|} 
Juli-07 \\
\end{tabular} & 12 & 1 & Marsieille & $\begin{array}{l}\text { France } \\
\end{array}$ & 5 years plus \\
\hline ctms777 & Gear Addict & May 05 & 443 & 1 & Maastricht & Netherlands & \begin{tabular}{|l}
10 years plus \\
\end{tabular} \\
\hline \begin{tabular}{|l|}
$\mathrm{TZk}$ \\
\end{tabular} & Gear Maniac & Juni-06 & 276 & 1 & \begin{tabular}{|l|} 
Antwerp \\
\end{tabular} & \begin{tabular}{|l|} 
Netherlands \\
\end{tabular} & 10 years plus \\
\hline \begin{tabular}{|l}
$L \mathrm{~K}$ Silver Sonya \\
\end{tabular} & \begin{tabular}{|l|} 
Lives for gear \\
\end{tabular} & Sep-04 & 8604 & 2 & \begin{tabular}{|l|} 
Washington \\
\end{tabular} & \begin{tabular}{|l|l|} 
USA \\
\end{tabular} & \begin{tabular}{|l|}
10 years plus \\
\end{tabular} \\
\hline \begin{tabular}{|l} 
Reptil \\
\end{tabular} & Moderator & $\operatorname{Dec} 04$ & 23018 & 2 & $\mathrm{x}$ & $\mathrm{x}$ & \begin{tabular}{|l|}
10 years plus \\
\end{tabular} \\
\hline entropy & \begin{tabular}{|l} 
Lives for gear \\
\end{tabular} & Oct 02 & 1126 & & $\mathrm{x}$ & Australia & \begin{tabular}{|l|}
10 years plus \\
\end{tabular} \\
\hline ioanni & \begin{tabular}{|l} 
Lives for gear \\
\end{tabular} & Mar 07 & 554 & 1 & Athens & Greece & 5 years plus \\
\hline \begin{tabular}{|l|l|}
7161 \\
\end{tabular} & \begin{tabular}{|l|} 
Lives for gear \\
\end{tabular} & Apr-05 & 1092 & 1 & $\mathrm{x}$ & $\mathrm{x}$ & \begin{tabular}{|l|}
10 years plus \\
\end{tabular} \\
\hline \begin{tabular}{|l} 
littledoodler \\
\end{tabular} & Lives for gear & Oct 23 & 906 & & $\mathrm{x}$ & $\mathrm{x}$ & 10 years plus \\
\hline \begin{tabular}{|l|} 
crufty \\
\end{tabular} & \begin{tabular}{|l} 
Lives for gear \\
\end{tabular} & \begin{tabular}{|l|l|} 
Jan-07 \\
\end{tabular} & 5566 & & $\mathrm{x}$ & $\mathrm{x}$ & 5 years plus \\
\hline \begin{tabular}{|l|l} 
lampmeister \\
\end{tabular} & \begin{tabular}{|l} 
Gear Addict \\
\end{tabular} & Sep-06 & 462 & 1 & \begin{tabular}{|l} 
Bournemouth \\
\end{tabular} & UK & \begin{tabular}{|l|}
5 years plus \\
\end{tabular} \\
\hline jbuehler & Lives for gear & Apr-07 & 885 & 1 & $\mathrm{x}$ & $\mathrm{x}$ & 5 years plus \\
\hline \begin{tabular}{|l|l} 
Popbott \\
\end{tabular} & Lives for gear & Juni-07 & 2060 & 3 & (Texas) & USA & 5 years plus \\
\hline \begin{tabular}{|l|} 
amenbrother \\
\end{tabular} & Gear Maniac & Apr-06 & 158 & & $x$ & \begin{tabular}{|l}
$x$ \\
\end{tabular} & \begin{tabular}{|l|}
10 years plus \\
\end{tabular} \\
\hline \begin{tabular}{|l} 
teknosmoker \\
\end{tabular} & $\begin{array}{l}\text { Lives for gear } \\
\end{array}$ & Jan-06 & 980 & 9 & Baltimore & USA & 10 years plus \\
\hline \begin{tabular}{|l|} 
disturb \\
\end{tabular} & Gear Head & Aug-06 & 40 & 3 & $\mathrm{x}$ & $\mathrm{x}$ & 5 years plus \\
\hline \begin{tabular}{|l|} 
aeonlux \\
\end{tabular} & Lives for gear & Aug-07 & 719 & & $\mathrm{x}$ & $\mathrm{x}$ & 5 years plus \\
\hline \begin{tabular}{|l|} 
joshelevator \\
\end{tabular} & Lives for gear & Feb-06 & 501 & & $x$ & \begin{tabular}{|l}
$x$ \\
\end{tabular} & 10 years plus \\
\hline Syki & \begin{tabular}{|l} 
Lives for gear \\
\end{tabular} & Juni-03 & 697 & & $\mathrm{x}$ & $\mathrm{x}$ & 10 years plus \\
\hline MarkusColeman & Lives for gear & Feb-05 & 1650 & & $\mathrm{x}$ & $\mathrm{x}$ & \begin{tabular}{|l}
0 years plus \\
\end{tabular} \\
\hline \begin{tabular}{|l|} 
Diegel \\
\end{tabular} & Lives for gear & Aug-07 & 1736 & 2 & Woodmere & USA & 5 years plus \\
\hline \begin{tabular}{|l|} 
myowave \\
\end{tabular} & Gear Head & \begin{tabular}{|l|} 
Jan-07 \\
\end{tabular} & 51 & $\frac{4}{1}$ & $\mathrm{x}$ & \begin{tabular}{|l}
$x$ \\
\end{tabular} & \begin{tabular}{|l|}
5 years plus \\
\end{tabular} \\
\hline jtron5 & \begin{tabular}{|l} 
Gear interested \\
\end{tabular} & Dec 07 & 1 & & $x$ & $\mathrm{x}$ & 5 years plus \\
\hline ccl & Gear nut & Mar 05 & $\begin{array}{l}1 \\
95 \\
\end{array}$ & & $\frac{1}{x}$ & \begin{tabular}{|l}
$x$ \\
\end{tabular} & 10 years plus \\
\hline alexp & Lives for gear & $\begin{array}{ll}\text { Nov-07 } \\
\end{array}$ & 3854 & 3 & $\mathrm{x}$ & USA & 5 years plus \\
\hline \begin{tabular}{|l|l|l|l|l|l} 
Jim Stout \\
\end{tabular} & \begin{tabular}{|l} 
Lives for gear \\
\end{tabular} & Nov-07 & 896 & 2 & Denver & \begin{tabular}{|l|} 
USA \\
\end{tabular} & \begin{tabular}{|l|}
5 years plus \\
\end{tabular} \\
\hline \begin{tabular}{|l} 
jonnypowell \\
\end{tabular} & Lives for gear & Feb-07 & 1341 & 1 & Sydney & Australia & 5 years plus \\
\hline thnx1138 & Guest & $\mathrm{x}$ & 0 & & $\mathrm{x}$ & $\mathrm{x}$ & $\mathrm{x}$ \\
\hline$\# 8726$ & $\mid$ Deleted/Guest & $\mathrm{x}$ & $\mathrm{x}$ & & $\mathrm{x}$ & $\mathrm{x}$ & $\mathrm{x}$ \\
\hline nrb & Gear interested & \begin{tabular}{l|l|} 
May 05 \\
\end{tabular} & 2 & 1 & $\mathrm{x}$ & $\mathrm{x}$ & 10 years plus \\
\hline KennethA & Gear interested & \begin{tabular}{l|} 
Mar 06 \\
\end{tabular} & 6 & 2 & \begin{tabular}{|l|} 
Aarhus \\
\end{tabular} & Denmark & \begin{tabular}{|l}
0 years plus \\
\end{tabular} \\
\hline \begin{tabular}{|l|l|} 
Karloff70 \\
\end{tabular} & \begin{tabular}{|l|} 
Geariphobie \\
\end{tabular} & Oct 06 & 17970 & 13 & London & \begin{tabular}{|l|l} 
UK \\
\end{tabular} & 5 years plus \\
\hline \begin{tabular}{|l} 
clusterchord \\
\end{tabular} & Lives for gear & Sep-05 & 5391 & 1 & $\mathrm{x}$ & $\mathrm{x}$ & $\begin{array}{l}10 \text { years plus } \\
\end{array}$ \\
\hline \begin{tabular}{|l|} 
zebastian 21 \\
\end{tabular} & \begin{tabular}{|l} 
Lives for gear \\
\end{tabular} & May 07 & 787 & 2 & New York & USA & 5 years plus \\
\hline \begin{tabular}{|l|} 
Don Solaris \\
\end{tabular} & \begin{tabular}{|l} 
Moderator \\
\end{tabular} & June 07 & 8335 & $\frac{4}{7}$ & \begin{tabular}{|l}
$x$ \\
\end{tabular} & \begin{tabular}{|l}
$\mathrm{D}$ \\
\end{tabular} & \begin{tabular}{|l}
5 years plus \\
\end{tabular} \\
\hline time ago & Guest & $\mathrm{x}$ & 0 & & $\mathrm{x}$ & $\mathrm{x}$ & $\mathrm{x}$ \\
\hline \begin{tabular}{|l|} 
sleestack \\
\end{tabular} & \begin{tabular}{|l} 
Lives for gear \\
\end{tabular} & $\begin{array}{ll}\text { Juli-06 } \\
\end{array}$ & 1286 & & $x$ & $x$ & \begin{tabular}{|l|}
10 years plus \\
\end{tabular} \\
\hline \begin{tabular}{|l} 
Secret Friend \\
\end{tabular} & Gear Head & Juni-06 & 39 & & \begin{tabular}{|l|l}
$x$ \\
\end{tabular} & $\mathrm{x}$ & \begin{tabular}{|l}
10 years plus \\
\end{tabular} \\
\hline \begin{tabular}{|l|l}
$\operatorname{cdog}$ \\
\end{tabular} & Lives for gear & Dec 03 & 3994 & 2 & New York & USA & 10 years plus \\
\hline \begin{tabular}{|l|l|} 
duggabax \\
\end{tabular} & Lives for gear & Sep-09 & $\begin{array}{l}757 \\
757\end{array}$ & 1 & Vancouver & Canada & 5 years plus \\
\hline \begin{tabular}{|l|l|} 
elijahbrown \\
\end{tabular} & \begin{tabular}{|l} 
Lives for gear \\
\end{tabular} & May 11 & 625 & 1 & \begin{tabular}{|l|l} 
Atlanta \\
\end{tabular} & USA & \begin{tabular}{|l|}
5 years plus \\
\end{tabular} \\
\hline \begin{tabular}{|l} 
rockmanrock \\
\end{tabular} & Lives for gear & Feb-09 & 2511 & & $\mathrm{x}$ & $\mathrm{x}$ & 5 years plus \\
\hline \begin{tabular}{|l|} 
RobJB06 \\
\end{tabular} & Lives for gear & Sep-06 & 2615 & & $\mathrm{x}$ & $\begin{array}{ll}x \\
\end{array}$ & \begin{tabular}{|l|}
5 years plus \\
\end{tabular} \\
\hline $\begin{array}{l}\mid 000300 \\
\text { Futureman84 }\end{array}$ & Lives for gear & May 11 & $\mid 1357$ & & $\frac{x}{x}$ & \begin{tabular}{|l|} 
Australia \\
\end{tabular} & \begin{tabular}{|l}
5 years plus \\
\end{tabular} \\
\hline \begin{tabular}{|l|} 
CoolColJ \\
\end{tabular} & Lives for gear & Feb-11 & 2696 & & $\mathrm{x}$ & Australia & 5 years plus \\
\hline projectwoofer & Lives for gear & Mar 10 & 1654 & & $\mathrm{x}$ & Germany & 5 years plus \\
\hline Renge Miyauchi & Lives for gear & Oct 10 & 1682 & & $x$ & $\mathrm{x}$ & 5 years plus \\
\hline \begin{tabular}{|l} 
beingmf \\
\end{tabular} & \begin{tabular}{|l} 
Lives for gear \\
Lives
\end{tabular} & $\operatorname{Dec} 04$ & \begin{tabular}{|c|}
1557 \\
1557
\end{tabular} & & $\frac{x}{x}$ & $\frac{x}{x}$ & \begin{tabular}{|l} 
years pus \\
10 years plus \\
\end{tabular} \\
\hline \begin{tabular}{|l} 
Mr. Varaldo \\
\end{tabular} & Lives for gear & Sep-06 & 3066 & & $\mathrm{x}$ & $\mathrm{x}$ & 5 years plus \\
\hline bluegreengold & \begin{tabular}{|l} 
Lives for gear \\
\end{tabular} & Aug-11 & 3124 & & $\mathrm{x}$ & $\mathrm{x}$ & $\mathrm{x}$ \\
\hline $\begin{array}{l}\text { Juno6 } \\
\end{array}$ & Gear Maniac & Aug-10 & $\frac{177}{177}$ & & $\frac{1}{x}$ & \begin{tabular}{|l}
$x$ \\
\end{tabular} & 5 years plus \\
\hline Goa-Dubs & Lives for gear & May 10 & 4156 & 16 & \begin{tabular}{|l|l}
$x$ \\
\end{tabular} & $\mathrm{x}$ & \begin{tabular}{|l}
5 years plus \\
\end{tabular} \\
\hline \begin{tabular}{|l|l} 
Liquid360 \\
\end{tabular} & \begin{tabular}{|l} 
Registered User \\
\end{tabular} & May 10 & 1850 & 1 & \begin{tabular}{|l|l|} 
San Diego \\
\end{tabular} & USA & \begin{tabular}{|l}
5 years plus \\
\end{tabular} \\
\hline mrsound & Gear Addict & Jan-12 & 381 & 1 & $\mathrm{x}$ & $\mathrm{x}$ & $\mathrm{x}$ \\
\hline
\end{tabular}




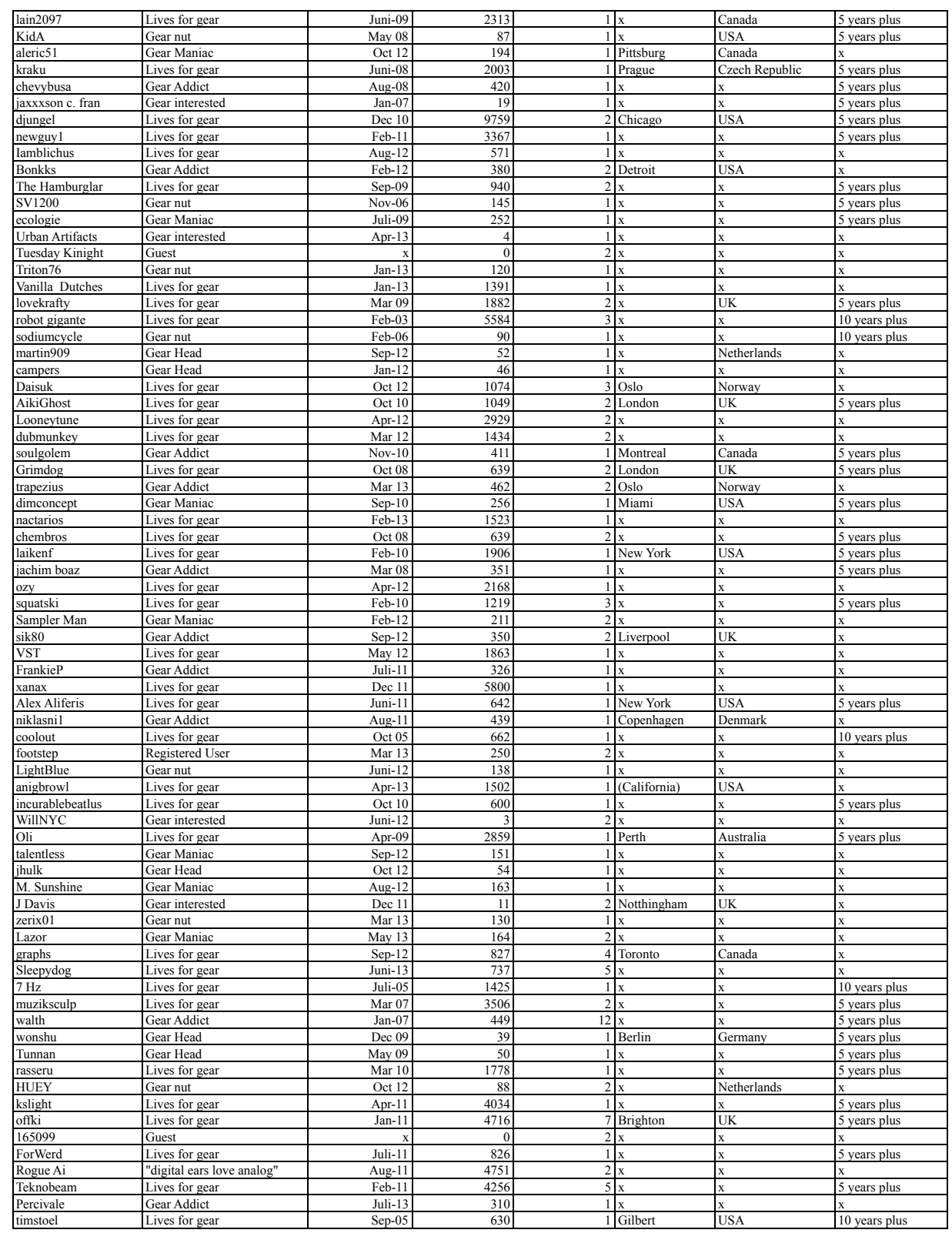




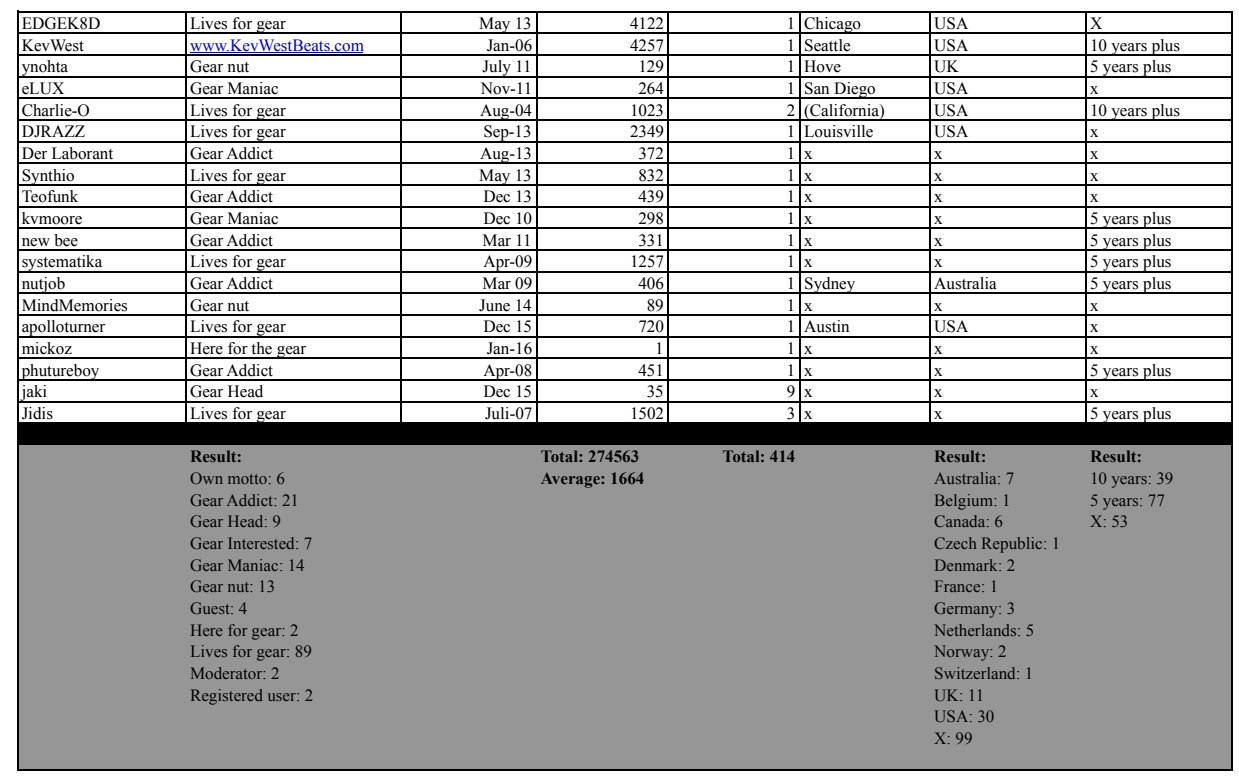


10.7 Attachment 7: Coding categories of Vintage Synth Explorer

\begin{tabular}{|c|c|c|c|c|c|c|}
\hline \multirow[t]{5}{*}{ Language domains } & \multirow[t]{5}{*}{ Phenomena type } & Subcategories & Sub-subcategories & Codes/Criteria & Numbers & \begin{tabular}{|l} 
Analysis/Notes/Examples \\
s.
\end{tabular} \\
\hline & & \multirow[b]{2}{*}{ special adjectives related to } & machines & & & $\begin{array}{l}\text { sturdy, roadworthy; hassle; wonderfully gritty; creamy; delightful;; } \\
\text { spooky; lazy; difficult; ridiculous; futuristic; smooth; killer. }\end{array}$ \\
\hline & & & music/sound & & & $\begin{array}{l}\text { wicked; dark; warm; tempting; perfect; bizarre; scary; lush; soff; } \\
\text { purre evil;; wishy, washy; noisy; warm; crazy; vivid; cartoony; } \\
\text { melodic; snappy; lead; rubbery. }\end{array}$ \\
\hline & & emotional expressions related to & machines & & & 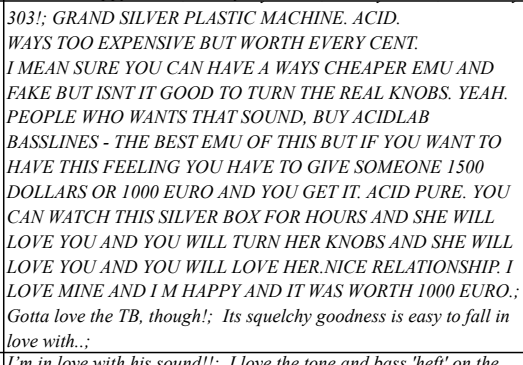 \\
\hline & & & music/sound & & & $\begin{array}{l}\text { I'm in love with his sound!!; I love the tone and bass 'heff' on the } \\
\text { DX7; the sound is fantastic i im happy!; }\end{array}$ \\
\hline \multirow{4}{*}{ Structure and meaning } & technical terms & related to music production & The & & & \\
\hline & \multirow{3}{*}{$\begin{array}{l}\text { specific community reference } \\
\text { words }\end{array}$} & $\begin{array}{l}\text { related to different music production } \\
\text { equipment }\end{array}$ & 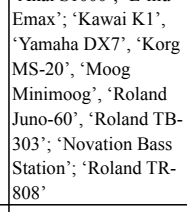 & & 230 & \\
\hline & & related to the community & & $\begin{array}{l}\text { folks; guys; man; }(m) \\
\text { firiend, people (as } \\
\text { addressing) }\end{array}$ & 16 & \\
\hline & & related to nostalgia & & & & 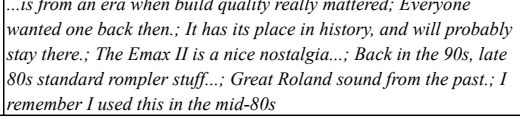 \\
\hline
\end{tabular}




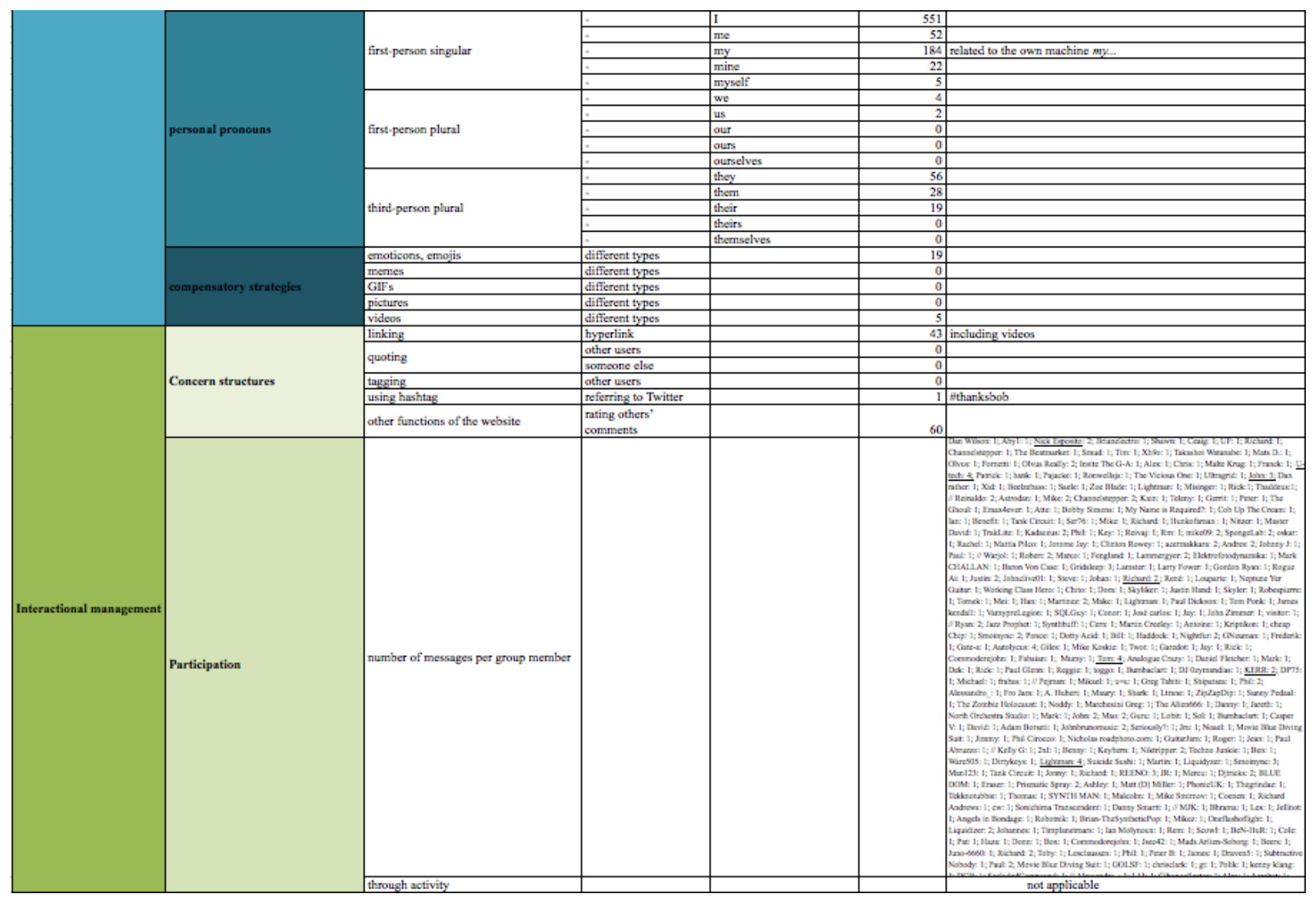




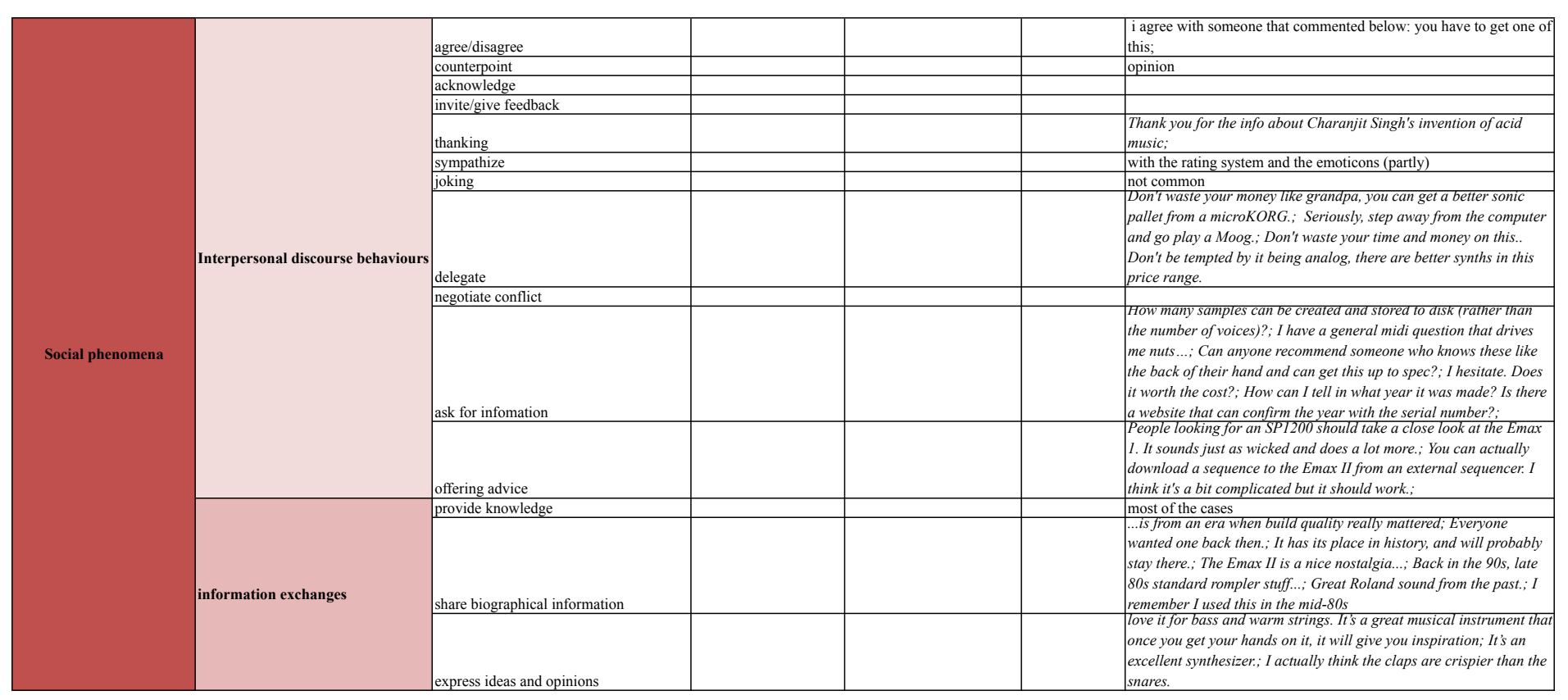


10.8 Attachment 8: Coding categories of Resident Advisor

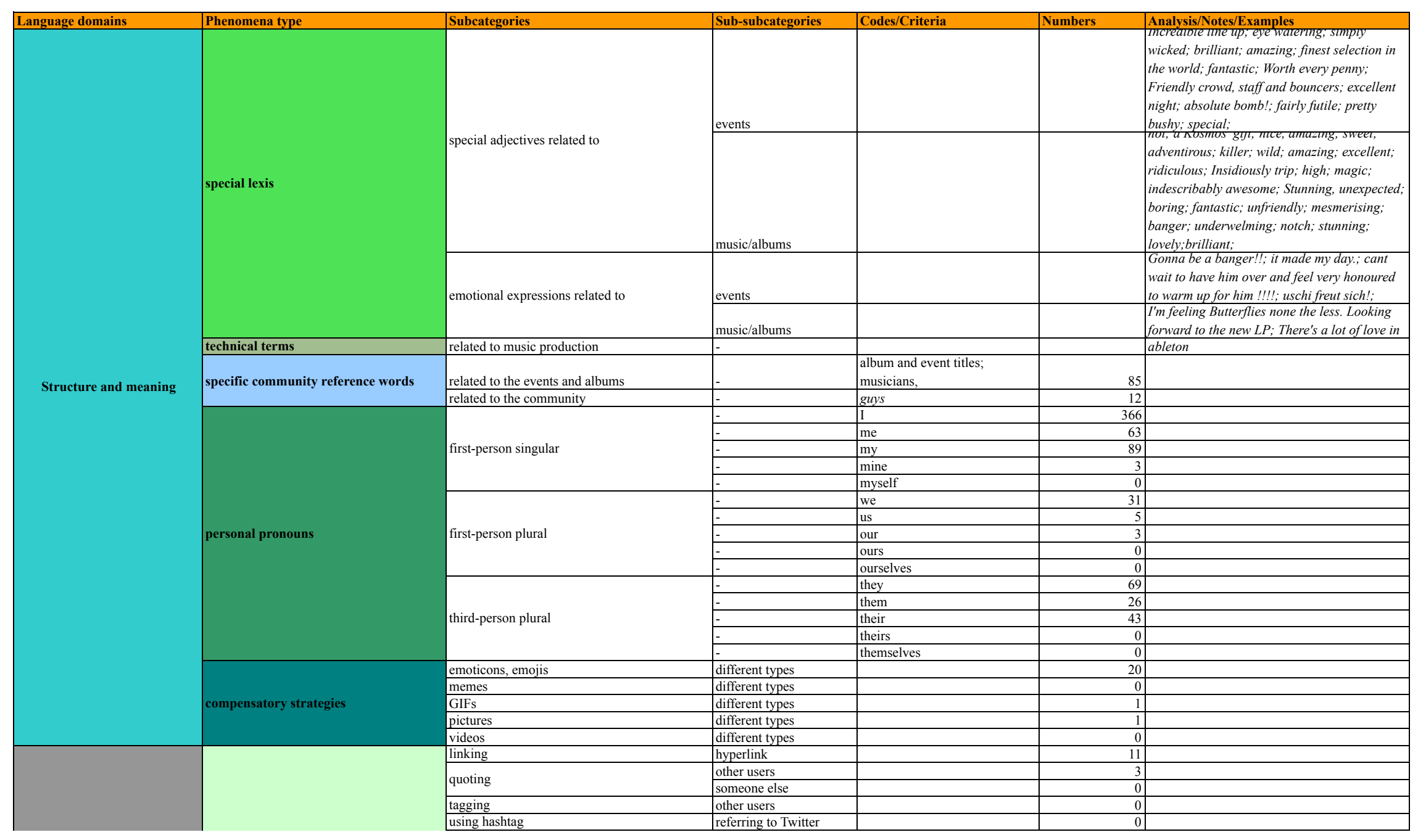




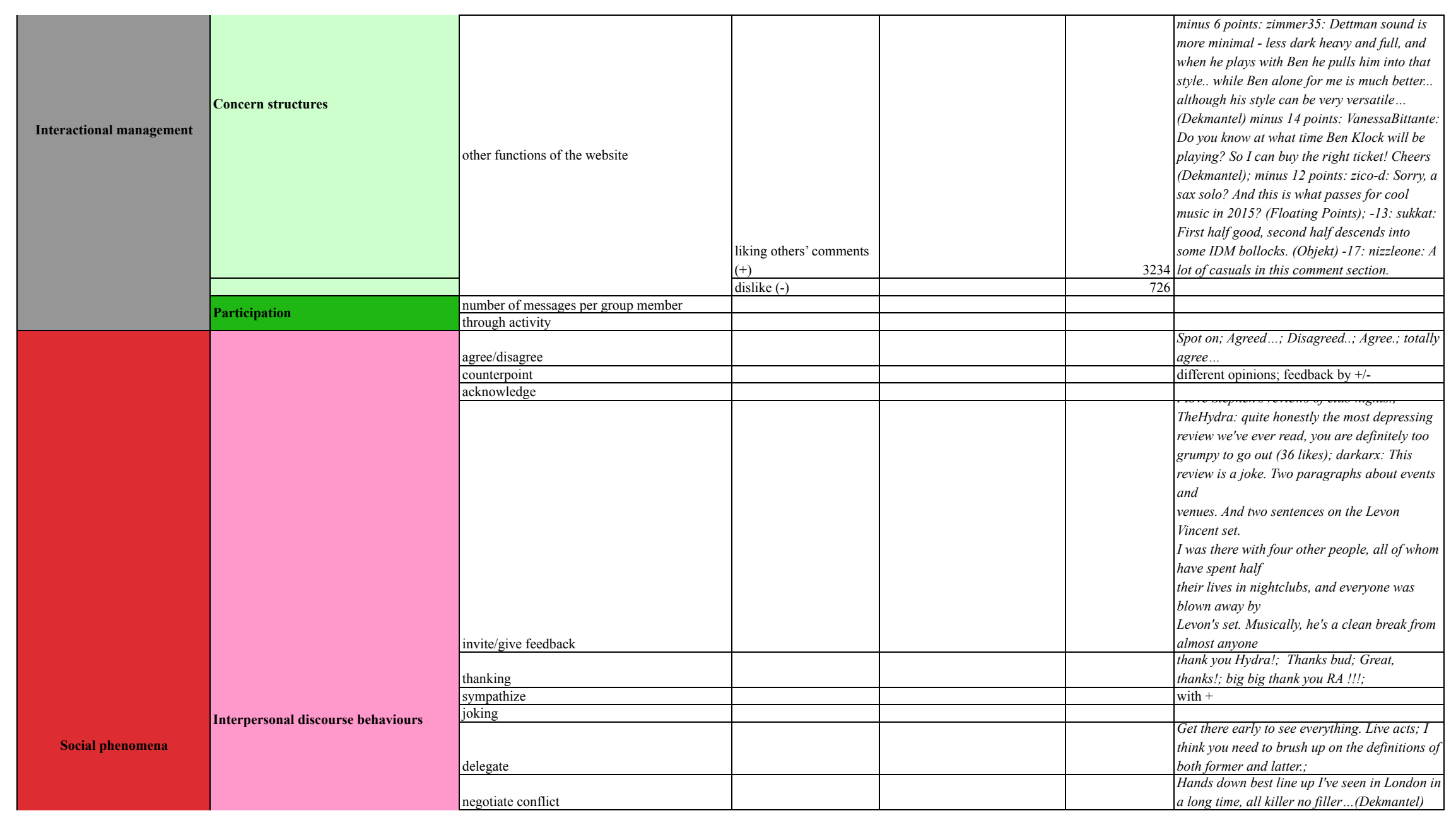




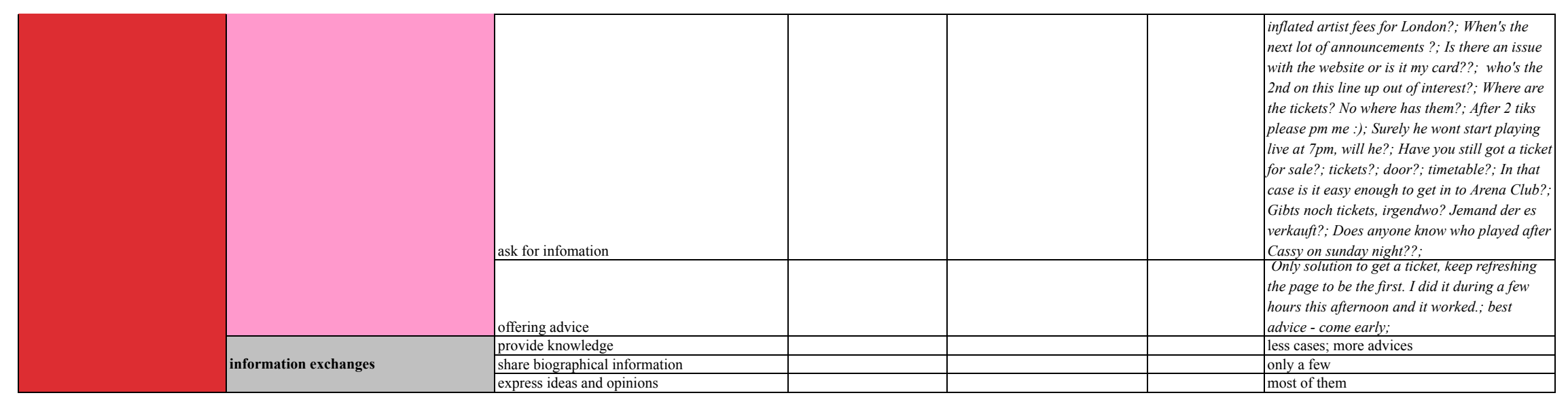




\subsection{Attachment 9: Coding categories of TB-303 Owners Club}

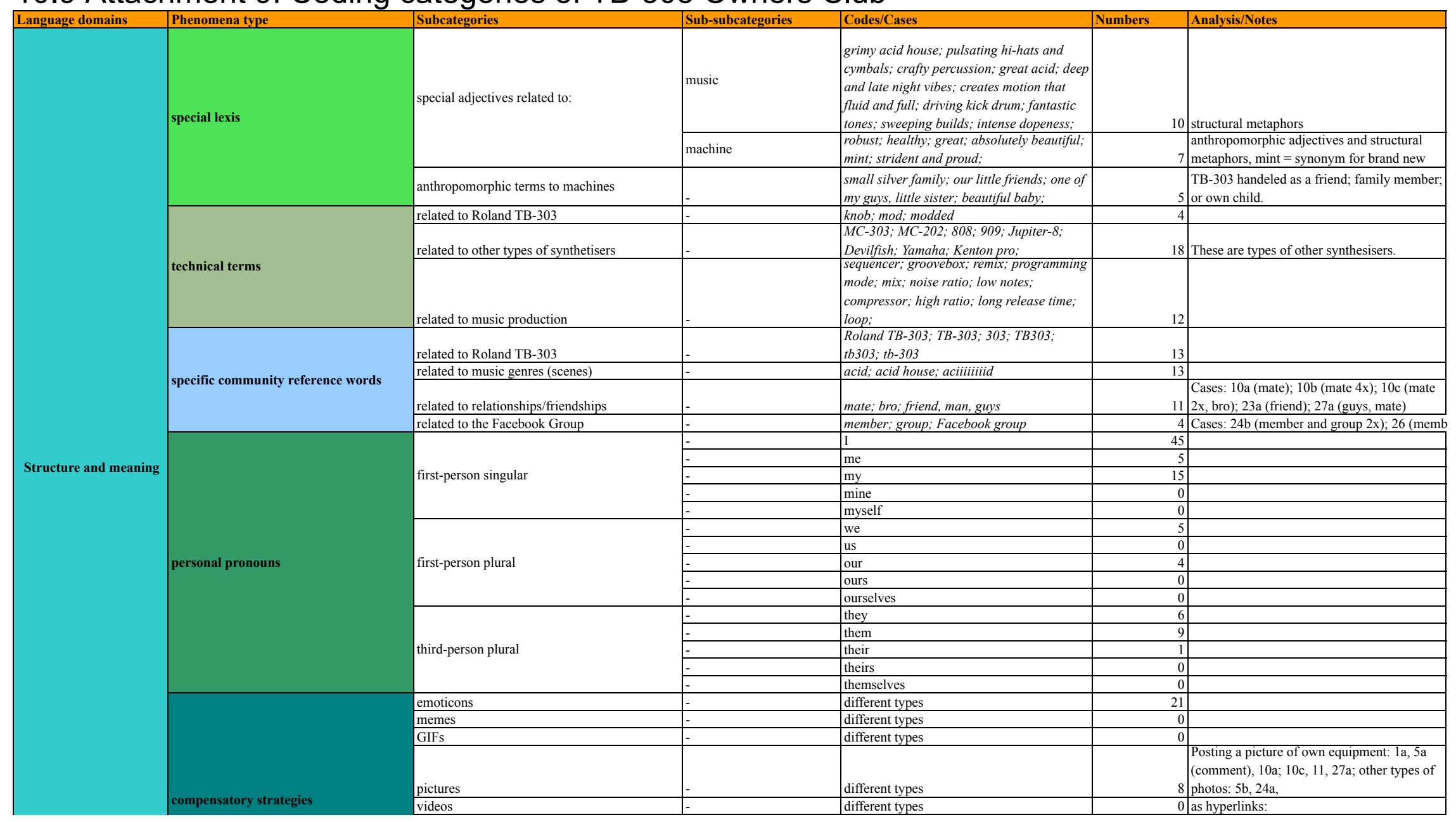




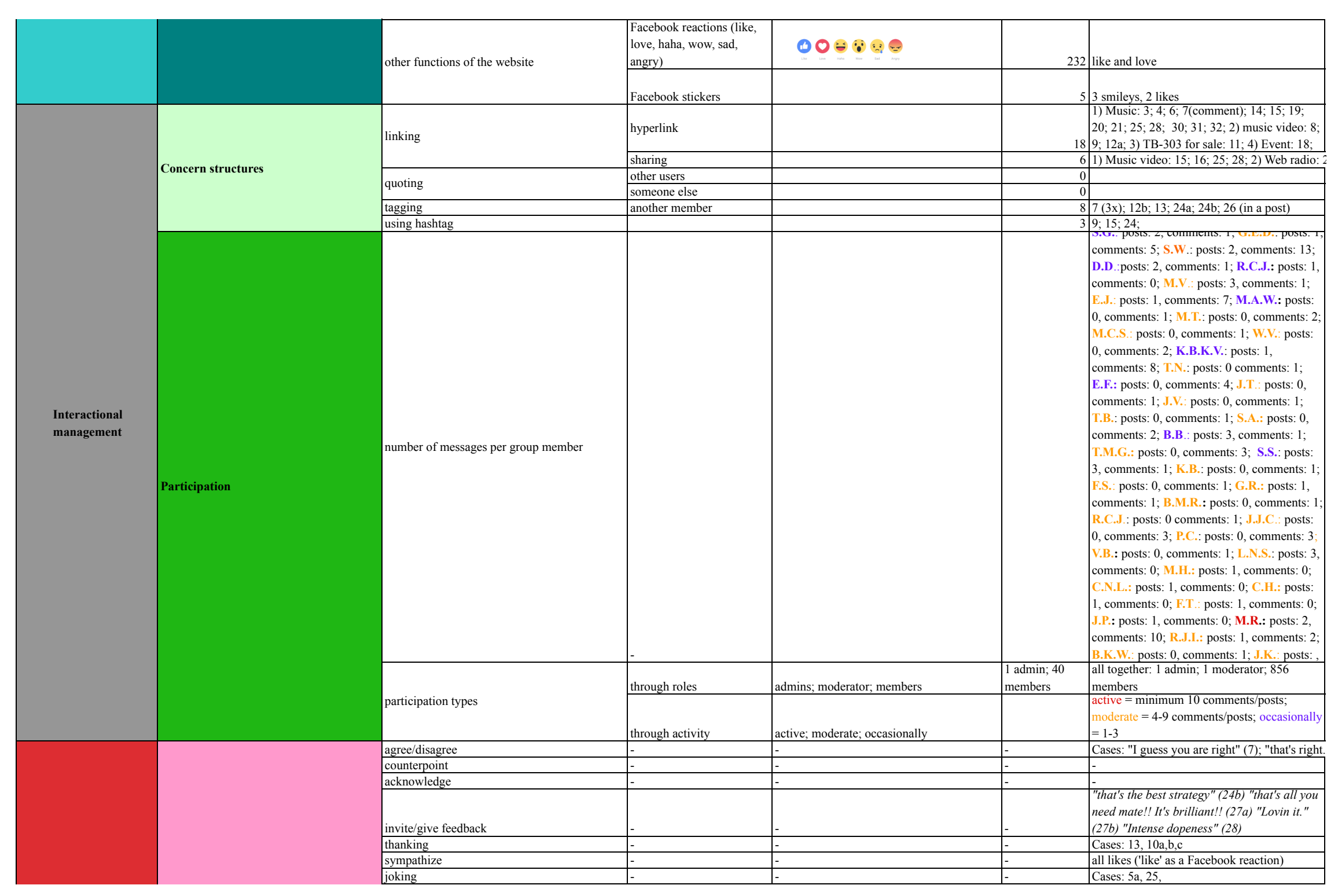




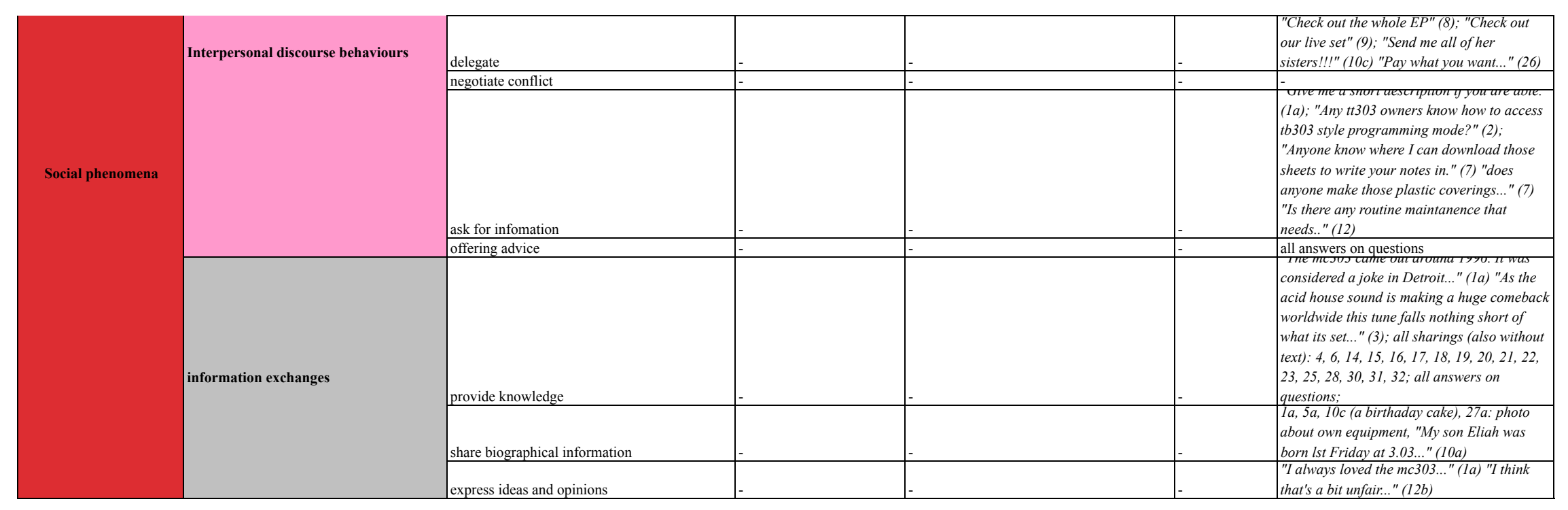




\subsection{Attachment 10: Coding categories of ITALO DISCO MANIACS}

\begin{tabular}{|c|c|c|c|c|c|c|}
\hline Language domains & Phenomena type & Subcategories & Sub-subcategories & Codes/Criteria & Numbers & Analysis/Notes/Examples \\
\hline \multirow{22}{*}{ Structure and meaning } & \multirow{4}{*}{ special lexis } & special adjectives related to music & & & & $\begin{array}{l}\text { amazing (7x), strange slowdown, bomb!, beauty instrumental, corny } \\
\text { rapping, nice one, sweet vocal, BOMB, tooo cheap ;))), Bomb, very } \\
\text { hot, very sophisticated, Obscure girl of Italo (2x), superfluous, } \\
\text { cheap, wonderful, great, hot girl of italo, such a beauty, bumped up, } \\
\text { awesome crasher, nice, lovely, extremely rare, beautiful, swansong of } \\
\text { italo discr, Hot Cosmic Italol, disco magic (2x), obscure (3x), } \\
\text { ridiculous, strange, smalltown (italo) boy, highly enjoyable, } \\
\text { powerful. }\end{array}$ \\
\hline & & Italian words, expressions & & & & $\begin{array}{l}\text { prego (18), minuto (19), bella canzone (25), un altro bella canzone } \\
(26) \text {, simpatico (27) el classico (46), (automatica)more (69), grande } \\
\text { (70) No es lo que yo Ilamaria Italo disco (76a), complimentoni ( } 81 \mathrm{~b}) \text {, } \\
\text { Grazie! ( } 81 \mathrm{~b}) \text {, ragazzi (92), }\end{array}$ \\
\hline & & realted to Italy & & & & 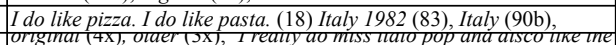 \\
\hline & & related to nostalgia & & & & 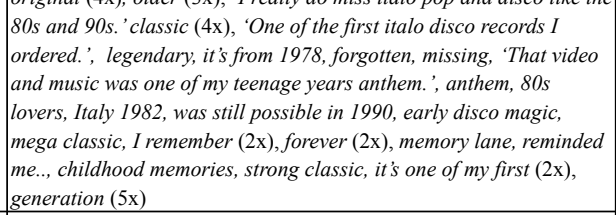 \\
\hline & \multirow[t]{2}{*}{ technical terms } & related to DJing/records & & & & 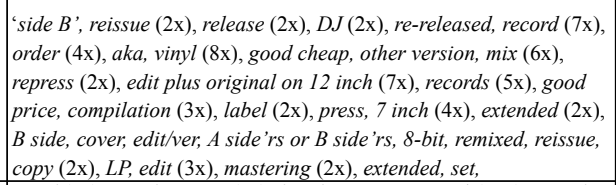 \\
\hline & & realted to the aesthetics of music & & vocoder, instrumental, vocal, & & $\begin{array}{l}\begin{array}{l}\text { vocal }(6 \mathrm{x}), \text { vocal version }(4 \mathrm{x}), \text { bassline, instrumental }(13 \mathrm{x}), \text { vocoder } \\
\text { version, funky parts, lyrics }(2 \mathrm{x}) \text {, instr: }(2 \mathrm{x}),\end{array}\end{array}$ \\
\hline & \multirow[b]{2}{*}{$\begin{array}{l}\text { specific community reference } \\
\text { words }\end{array}$} & related to the genre & & Italo, Italo disco & 37 & \\
\hline & & related to the Facebook Group & & $\begin{array}{l}\text { member; group; Facebook } \\
\text { group, maniacs }\end{array}$ & & member, maniacs, $F B$ groups \\
\hline & \multirow{14}{*}{ personal pronouns } & \multirow{4}{*}{ first-person singular } & & I & 51 & \\
\hline & & & & $\frac{\mathrm{me}}{\mathrm{my}}$ & 5 & \\
\hline & & & & mine & 0 & \\
\hline & & & & myself & & \\
\hline & & \multirow{5}{*}{ first-person plural } & & we & 2 & \\
\hline & & & & us & 0 & \\
\hline & & & - & our & 0 & \\
\hline & & & & ours & 0 & \\
\hline & & & & ourselves & 0 & \\
\hline & & \multirow{5}{*}{ third-person plural } & - & they & 1 & \\
\hline & & & & them & 1 & \\
\hline & & & & their & 0 & \\
\hline & & & & theirs & 0 & \\
\hline & & & & themselves & 0 & \\
\hline
\end{tabular}




\begin{tabular}{|c|c|c|c|c|c|c|}
\hline & \multirow{7}{*}{ compensatory strategies } & \multirow{4}{*}{\begin{tabular}{|l|} 
emoticons, emojis \\
memes \\
GIFs \\
pictures \\
\end{tabular}} & \multirow{3}{*}{\begin{tabular}{|l|} 
different types \\
different types \\
different types \\
\end{tabular}} & & \multicolumn{2}{|r|}{140 smileys, harts, like symbols, spaceship, shoe with high hills, } \\
\hline & & & & & & \\
\hline & & & & & & \begin{tabular}{c|c|}
0 & \\
\end{tabular} \\
\hline & & & different types & & & 3 as a comment in $60 \mathrm{a}$ and $114 \mathrm{a}$ \\
\hline & & videos & different types & & 11 & $\begin{array}{l}112 \text { times they share a video link from Youtube }+ \text { as a comment: } 37 \\
\text { videos }\end{array}$ \\
\hline & & \multirow[t]{2}{*}{ other functions of the website } & $\begin{array}{l}\begin{array}{l}\text { Facebook reactions } \\
\text { (like, love, haha, } \\
\text { wow, sad, angry) }\end{array} \\
\end{array}$ & $00 \Leftrightarrow 0.9$ & $465+193$ & Facebook reactions on posts: 465 ; likes on comments: 193 \\
\hline & & & Facebook stickers & different types & & 54 times a like symbol, 1 is an animal with a heart in the hand \\
\hline \multirow{8}{*}{ Interactional management } & \multirow{5}{*}{ Concern structures } & \multirow[t]{2}{*}{ linking } & hyperlink & & & $\begin{array}{l}\text { Cases: radio channel 118; soundcloud (music): } 35,40,47,80,90 \mathrm{a}, \\
\text { 119; Discogs: } 38 \mathrm{a} \text { (music) }\end{array}$ \\
\hline & & & sharing & & & Case: 74; 85 (an event) \\
\hline & & quoting & \begin{tabular}{|l|} 
other users \\
someone else
\end{tabular} & & & \begin{tabular}{c|c|c|}
0 & 2 \\
0 & -1
\end{tabular} \\
\hline & & tagging & someone else & & & $\begin{array}{l}\text { Cases: } 32 \text { (hyperlink), } 80 \text { (as a personal answer), } 81 \text { (2x, as a } \\
\text { personal answer), } 117 \text { a (as a personal answer), } 117 \mathrm{~b} \text { (as a personal } \\
6 \text { answer), }\end{array}$ \\
\hline & & using hashtag & & & & \\
\hline & Participation & number of messages per group member & & & & 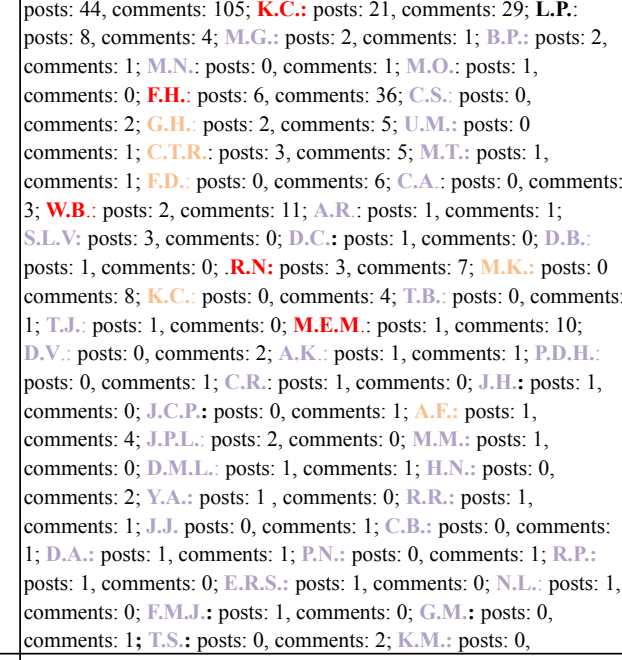 \\
\hline & & & through roles & admins; moderator; members & \begin{tabular}{|l}
1 admin, 1 \\
moderator, 52 \\
members
\end{tabular} & from the total: 1 administrator, 2 moderators and 1756 members \\
\hline & & participation types & through activity & active; moderate; occasionally & \begin{tabular}{|l}
6 active, 6 \\
moderate, 42 \\
occasionally
\end{tabular} & $\begin{array}{l}\text { active }=\text { minimum } 10 \text { comments } / \text { posts; moderate }=4-9 \\
\text { comments/posts; occasionally }=1-3\end{array}$ \\
\hline
\end{tabular}




\begin{tabular}{|c|c|c|c|}
\hline \multirow{14}{*}{ Social phenomena } & \multirow{11}{*}{ Interpersonal discourse behaviours } & agree/disagree & \begin{tabular}{|l} 
yeah me too (21) I don't believe it (23) (as a joke!) me too! (33) I \\
thought the same! (36) of course (122)
\end{tabular} \\
\hline & & counterpoint & $17 \mathrm{a}+\mathrm{b}$ \\
\hline & & \begin{tabular}{|l|l|l|l} 
acknowledge \\
\end{tabular} & \\
\hline & & invite/give feedback & to every posted message \\
\hline & & thanking & $\begin{array}{l}\text { thank you! (15) Thanks for listening! (18) as a thank you to everyone } \\
\text { (56) thank you (56), thanks (76b), thanks for tipping (78), Thanks! } \\
\text { (81a), thanks for the add (82), thank you for adding (87), THANK }\end{array}$ \\
\hline & & sympathize & comment and post likes \\
\hline & & joking & amasian (63) had to let it go (into space) (94), italo vs. Spitalo (106) \\
\hline & & delegate & enjoy!!!, Enjoy!! (80), enjoy!! (90a), \\
\hline & & negotiate conflict & i respect that of course (17b); \\
\hline & & ask for infomation & anyone know if there's a good... (93) \\
\hline & & offering advice & $\begin{array}{l}\text { I can recommend this one (38b); about buying records: 60a,b; } \\
101 \mathrm{a}, \mathrm{b}, \mathrm{c}\end{array}$ \\
\hline & \multirow{3}{*}{ information exchanges } & provide knowledge & I know Carlotto - Come With Me (39); all video shares; \\
\hline & & share biographical information & all nostalgic rememberings, \\
\hline & & express ideas and oninions & $\begin{array}{l}\text { It's only my personal opinion...; like both, love it, (always about } \\
\text { music) }\end{array}$ \\
\hline
\end{tabular}

